\title{
34435
}

\section{Lessons \\ from NAFTA \\ FOR LATIN AMERICA AND THE CARIBBEAN}

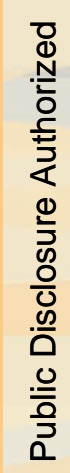

Daniel Lederman

William F. Maloney

Luis Servén 



\section{Lessons from NAFTA}





\title{
Lessons from NAFTA \\ for Latin America and the Caribbean
}

\author{
Daniel Lederman, \\ William F. Maloney, Luis Servén
}

A COPUBLICATION OF STANFORD ECONOMICS AND FINANCE, AN IMPRINT OF STANFORD UNIVERSITY PRESS, AND THE WORLD BANK 
(C) 2005 The International Bank for Reconstruction and Development / The World Bank 1818 H Street, NW

Washington, DC 20433

Telephone 202-473-1000

Internet www.worldbank.org

E-mail feedback@worldbank.org

All rights reserved.

123407060504

A copublication of Stanford Economics and Finance, an imprint of Stanford University Press, and the World Bank.
Stanford University Press
1450 Page Mill Road
The World Bank
1818 H Street, NW
Palo Alto, Calif. 94304
Washington, DC 20433

The findings, interpretations, and conclusions expressed herein are those of the author(s) and do not necessarily reflect the views of the Board of Executive Directors of the World Bank or the governments they represent.

The World Bank does not guarantee the accuracy of the data included in this work. The boundaries, colors, denominations, and other information shown on any map in this work do not imply any judgment on the part of the World Bank concerning the legal status of any territory or the endorsement or acceptance of such boundaries.

\section{Rights and Permissions}

The material in this work is copyrighted. Copying and/or transmitting portions or all of this work without permission may be a violation of applicable law. The World Bank encourages dissemination of its work and will normally grant permission promptly.

For permission to photocopy or reprint any part of this work, please send a request with complete information to the Copyright Clearance Center, Inc., 222 Rosewood Drive, Danvers, MA 01923, USA, telephone 978-750-8400, fax 978-750-4470, www.copyright.com.

All other queries on rights and licenses, including subsidiary rights, should be addressed to the Office of the Publisher, World Bank, 1818 H Street NW, Washington, DC 20433, USA, fax 202-522-2422, e-mail pubrights@worldbank.org.

ISBN 0-8213-5813-8

ISBN 0-8047-5239-7 (Hardcover)

ISBN 0-8047-5240-0 (Softcover)
(World Rights except North America)

(North America)

(North America)

Library of Congress Cataloging-in-Publication Data has been applied for. 


\section{Latin American Development Forum Series}

This series was created in 2003 to promote, debate, and disseminate information and analysis and convey the excitement and complexity of the most topical issues in economic and social development in Latin America and the Caribbean. It is sponsored by the Inter-American Development Bank, the United Nations Economic Commission for Latin America and the Caribbean, and the World Bank. The manuscripts chosen for publication represent the highest quality in each institution's research and activity output and have been selected for their relevance to the academic community, policymakers, researchers, and interested readers.

\section{Advisory Committee Members}

Inés Bustillo, Director, Washington Office, Economic Commission for Latin America and the Caribbean, United Nations

Guillermo Calvo, Chief Economist, Inter-American Development Bank José Luis Guasch, Regional Adviser, Latin America and the Caribbean Region, World Bank

Steven Haber, A. A. and Jeanne Welch Milligan Professor, Department of Political Science, Stanford University; Peter and Helen Bing Senior Fellow, the Hoover Institution

Eduardo Lora, Principal Adviser, Research Department, Inter-American Development Bank

José Luis Machinea, Executive Secretary, Economic Commission for Latin America and the Caribbean, United Nations

Guillermo E. Perry, Chief Economist, Latin America and the Caribbean Region, World Bank

Luis Servén, Lead Economist, Latin America and the Caribbean Region, World Bank 



\section{Contents}

Foreword $\quad$ Xv

Acknowledgments

1 LESSONS FROM NAFTA FOR LATIN AMERICAN AND CARIBbean COUNTRIES 1

2 NAFTA AND CONVERgENCE In NORTH AMERICA: High Expectations, Big Events, Little Time 27

3 Macroeconomic Dynamics After NAFTA: SYNCHRONIZATION, VOLATILITY, AND Macroeconomic Policy CoOrdination 77

4 NAFTA's REMAINING Trade Barriers 119

5 FACTOR MARKETS 175

6 Innovation in Mexico: NAFTA Is Not Enough 247

7 NAFTA and the Trade Flows of Nonmember Countries 289

8 The IMPACT OF NAFTA ON FOREIGN INVESTMENT IN THIRD COUNTRIES

BOXES

3.1 Macroeconomic Synchronization in the European Union $\quad 83$

3.2 Macroeconomic Synchronization at the Regional Level 
4.1 Rules of Origin and the Export of Protection

Among NAFTA Partners: The Basic Analytical

Framework

4.2 The Multiplier Effects of PROCAMPO: Evidence of Effectiveness

4.3 Mexican and U.S. Experiences with Delinked Agricultural Income Subsidies

5.1 The FDI Impact of EEC/EU Accession 178

5.2 The Investment Chapters of NAFTA 180

5.3 Corporate Governance Reform in Mexico 203

5.4 Estimating Convergence

210

6.1 Some Algebra: How Much Should Be Spent on $\mathrm{R} \& \mathrm{D}$ ?

6.2. Knowledge Flows from Public Research Centers to the Productive Sector in Mexico

7.1 Trade Creation and Diversion in the Process of Enlarging the EU

7.2 The Caribbean Basin Initiative 324

8.1 FDI Diversion in Europe 357

8.2 Disentangling Common and Idiosyncratic FDI Trends

8.3 Costa Rica vs. Mexico in the INTEL Race

FIGURES

1.1 Mexico: Real Manufacturing Wages and Poverty 5

1.2 Mexico: Estimated Impact of the Institutional Gap on the Per Capita GDP Gap

1.3 Latin America: Correlation of Annual Growth of Real GDP with that of the United States

1.4 Latin America: Imports Plus Exports over GDP

1.5 Mexico: Agricultural Production and Trade, 1990-2001

1.6 Latin America: Net FDI Inflows as a Percentage of GDP

1.7 Latin America: Wages Adjusted for Skill by Degree of Exposure to Trade

1.8 Latin America and the Caribbean Region's

Gap in Patent Counts Relative to the Average and to Patenting Overachievers

2.1 GDP Per Capita Relative to the United States, Selected Economies, 1960-2001

2.2 U.S.-Mexico GDP Per Capita Gap: Similar-Cycle Model with Quarterly PPP-adjusted Data, 1960-2002 
2.3 Gains from NAFTA: Observed and Predicted U.S.-Mexico GDP Per Capita Ratio, 1993Q4-2002Q4

2.4 Trace Tests for Cointegration Between the United States and Mexico (Log) Quarterly GDP, 1960Q4-2002Q4

2.5 Mexico Year Effect Minus Latin America and the Caribbean Year Effect, Log

2.6 Institutional Gaps in North America, 2000/01

2.7 Contribution of Institutional Gaps to the U.S.-Mexico Income Gap

2.8 Mexico Year Effects Relative to Latin America and the Caribbean Year Effects, Institutional Index

2.9 Ratio of State GDP Per Capita Relative to the Distrito Federal, 1940-2000

2.10 Relationship Between Growth (1990s) and Public Employment in Mexican States

2.11 Quarterly Data Used for Time-Series Analyses

3.1 Mexico: Trade with NAFTA Countries

3.2 Correlation of Annual GDP Growth with the United States

3.3 Correlation of Annual GDP Growth with Canada 88

3.4 Correlation of Industrial Production Growth with the United States

3.5 Correlation of Industrial Production Growth with Canada

3.6 GDP Growth Volatility in the 1980s and 1990s 99

3.7 Mexico: GDP Growth Volatility over Time 100

4.1 How NAFTA Utilization Rates Vary with Tariff Structure: The Case of the Yarn-Forward Rule for Apparel Exports

4.2 Empirical Relationship Between NAFTA Preferences Utilization Rates and Tariff Preferences, 2000: Textile and Apparel-The Obvious Outlier

4.3a-f Net Exports of Apparel and Textiles per Worker: Mexico and Central America, 1980-2001

4.4 Agricultural Production and Trade in Mexico, 1990-2001: No Apparent Devastating Effects from NAFTA

4.5 Imports and Production of Traditional Crops Before and After NAFTA: Irrigated vs. Nonirrigated Production

4.6 Land Productivity: Irrigated and Rainfed Yields, 1983-2000 
4.7 Mexico: Exports and Production of Fruits Before and After NAFTA

4.8 Mexico: Production Support Equivalent as a Share of Production: Totals and Components for Traditional Crops

4.9 Mexico AD Activity, 1987-2001

5.1 Mexico: Main Components of Capital Flows to the Private Sector

5.2 U.S. Investment Abroad by Receiving Region

5.3 Actual and Predicted Values of the Log of FDI in Mexico

5.4 Evolution of Real Mexican-U.S. Hourly Manufacturing Wages for Production Workers and Unemployment

5.5 Mexico-U.S. Wage Differentials by Industry and Proximity to U.S. Border

5.6 FDI and Net Migration by State

5.7 Wages Adjusted for Human Capital by Degree of Exposure to Foreign Competition

5.8 Impact of Minimum Wages on Wage Distribution 221

5.9 Jobs in the Maquila and Registered Rural Sector 223

5.10 Relative Formal/Informal Sector Sizes and Incomes and the Real Exchange Rate

5.11 Estimated Flexibility/Distortion in Selected Labor Markets

6.1 Growth Rates of Total Factor Productivity, 1960-99 249

6.2 Patents per Million Workers, 1960-2000 251

6.3 Innovation Outputs in Mexico 252

6.4 Mexico's Research and Development Effort Is Below the Median

6.5 Innovation Inputs in Mexico 259

6.6 Research and Development Efficiency, 1985-2000 268

6.7a-d Mexico's Comparative Advantage in Innovation: Not in the "New" Sectors

6.8 Global Competitiveness Report Survey Results: Private Sector Perceptions of Innovation-Related Factors, 1996-2001

7.1 Openness in RIA and Non-RIA Countries 294

7.2 NAFTA: Total Imports by Source 295

7.3 Total Trade in Latin America and the Caribbean's RIAs

7.4 Share of Mexico's Nonfuel Exports in NAFTA and Non-NAFTA Markets 
7.5 Destinations of Mexico's Exports 301

7.6 Destinations of Andean Group Exports 302

7.7 Destinations of CACM Exports 302

7.8 Destinations of CARICOM Exports 303

7.9 Destinations of MERCOSUR Exports 304

7.10 NAFTA: Annual Estimates of Bloc Dummy

7.11 Shares in NAFTA's Total Apparel Imports 327

7.12 U.S. Dollar Wages Relative to Mexico 328

8.1 Net FDI Inflows as a Percentage of GDP 350

8.2 Real FDI Per Capita and FDI/GDP Estimated

Country/Year Effects, 1980-2001 371

8.3 Real FDI Per Capita and FDI/GDP Estimated

Country/Year Effects, Net of Privatizations, 1980-99 372

8.4 Cumulative Country/Year Effects and

Their 10 Percent Significance Bands 375

8.5 Relative Risk and Return, All Developing

Countries, 1980-99 384

8.6 Change in Risk and Return in Latin America and the

Caribbean, 1980-93 vs. 1994-99

1.1 Mexico: Selected Indicators 5

2.1 Speed of Adjustment Between Mexico and

2.2 Cointegration Analysis for Mexico and the

2.3 Regressions of Log GDP Per Capita, $2000 \quad 44$

$2.4 \quad$ Institutional Changes in Latin America 50

2.5 Did NAFTA Accelerate Manufacturing

TFP Convergence? Arellano-Bond GMM

Regression Results

2.6 Potential Determinants of Growth of GDP

Per Capita, 1990-2000 56

2.7 List of Codes and Industries Used in

TFP Convergence Analysis

2.8 Summary Statistics of Variables and Data

Used for TFP Convergence Analysis, by

Country and Industry

2.9 Summary Statistics for Data Used in Table 2.3 67

2.10 Summary Statistics for Data Used to

Calculate Institutional Gaps and Income Gaps

Illustrated in Figures 2.5 and 2.8 
2.11 Groups of Countries Used to Calculate

GDP and Institutional Gaps Illustrated in

Figures 2.5 and 2.8

2.12 Data Used for Analysis of Convergence

Across Mexican States, 1990-2000 70

3.1 Annual Growth Rate of GDP 91

3.2 Annual Growth Rate of Industrial Production 92

3.3 Growth Correlation Between Canada, Mexico, and the United States, by

Sector of Economic Activity

3.4 Growth Correlation Between Canada, Mexico, and the United States, by Industrial Sector $\quad 97$

3.5 Correlation Between Mexico and U.S. Policy Variables 102

3.6 Trade Interdependence in Latin America, $2001 \quad 108$

3.7 Further Measures of Interdependence, 2001

4.1 Regression Results for (4.7) and (4.8) Dependent Variable: XUS

4.2 Simulation Results for (4.7) and (4.8): Effects of ROO Relaxation, Simulated

4.3 NAFTA and CBI Apparel Preferences Utilization Rates, Selected Countries

4.4 Average Annual U.S. Antidumping and

Countervailing Duty Filings, by Named

Country/Region and by Select Time Period

4.5 Negative Binomial Maximum Likelihood

Estimates of the Determinants of the Number

of U.S. AD and CVD Cases: Effects of

NAFTA Dispute Settlement Filings

4.6 CUSFTA and NAFTA Dispute Settlement Petitions and Determinations Against U.S. AD/CVD

Actions, 1989-2000

4.7 Composition of AD/CVD Filings by

Target Country, 1987-2000

4.8 Negative Binomial Maximum Likelihood

Estimates of the Determinants of the

Number of Mexican AD Cases and AD

Duties, 1990-2001

4.9 Characteristics of Agricultural Support

Programs in Mexico and the United States

5.1 Inward Flows of Foreign Direct Investment

by Receiving Region

Fixed-Effects Regressions of the Log of FDI Against Membership in a Free Trade Area and Other Variables 
5.3 Contribution of Various Factors to the

Observed Change in FDI to Mexico

5.4 Annual Averages of Selected Variables in the

Stock Exchange Data Set

5.5 Shareholder Rights, Creditor Rights, and Enforcement of Law

5.6 Change in Log Wages for Synthetic Cohorts, Males, 1990-2000

5.7 Evolution of Household Inequality

6.1 Estimates of the Rates of Return to R\&D in the United States

6.2 Determinants of R\&D/GDP

6.3 Determinants of Patenting in the United States, Presample 1963-84

6.4 R\&D in Mexico: Who Does It and Who Pays for It? Expenditures in 1999

6.5 Structure of R\&D Effort in Selected

Countries, 1995-2000

7.1 Intra-Bloc Imports 297

275

7.2 NAFTA: Changes in Import Shares 298

7.3 NAFTA: Sources of Imports

7.4 U.S. Imports: Shares by Country and

Ranking by Shares

7.5 Econometric Studies of the Trade Impact of NAFTA 308

7.6 NAFTA Dummy Estimates with Pooled Data 315

7.7 Expanded Gravity Model: Impact of NAFTA on Trade Flows from CACM, CARICOM, and Mexico

7.8 Apparel Exports to NAFTA

7.9 Shares in NAFTA's Total Apparel Imports 326

7.10 Exports from EPZs 328

7.11 PTA Membership and Key Developments 334

7.12 Trends in Tariff Rates for Developing and Industrialized Countries, 1980-99

8.1a Net FDI Inflows Per Capita in Host Country, by Period and Source

8.1b Net FDI Inflows as a Percentage of GDP, by Period and Source

8.2 Estimated Fixed Effects on Net Inflows of FDI, 1980-2001: Alternative Measures of FDI and Samples of Countries

8.3 Estimated Mexico/Year Effects on

Net Inflows of FDI (Including FDI from

Privatization): Alternative Measures of FDI and Samples of Countries 
8.4 Estimated Mexico/Year Effects on Net Inflows of FDI (Excluding Privatization): Alternative Measures of FDI and Samples of Countries

8.5 Correlation of Estimated Country/Year Effects, 1980-2001 and 1980-99: Real FDI Per Capita

8.6 Fiscal Incentives to Foreign Investors

8.7 Determinants of Net FDI Inflows to Developing

8.8 Risk and Return FDI Model: Explaining Changes in Average FDI Inflows, 1994-99 vs. 1980-93 


\title{
Foreword
}

\author{
Trade matters, but it \\ is not enough
}

TWO DIFFERENT REQUESTS MOTIVATED the research effort presented in this book. ${ }^{1}$ Several Latin American countries that were engaged in the Free Trade Area of the Americas negotiations and at that time were beginning to consider undertaking bilateral trade negotiations with the United States and the European Union approached the Bank for information. They sought evidence on the lessons developing countries could learn from the North American Free Trade Agreement (NAFTA), so far the only free trade agreement that exists among industrialized and developing countries. Simultaneously, the Mexican Government considered the treaty's 10th anniversary to be the right time to request a "neutral" (external) evaluation of its effects on Mexico, both as an input for an eventual future deepening of the agreement and as a contribution to the public debate that was likely to take place in the country on that occasion. Thus the study was marked from its inception by desires to learn from the unique experience of an economic agreement that comprises both industrialized and developing countries and to provide concrete policy advice for developing countries engaging or already engaged in such agreements. For those reasons, some of its findings and conclusions may be useful for many other countries beyond Latin America.

From an analytical point of view, the task was quite demanding. A rigorous evaluation of effects faced three major problems. First, two major events took place in Mexico before and after the agreement was negotiated and signed (1993/94): the unilateral trade liberalization from 
1985 to 1988 and the so-called Tequila macro/financial crisis in 1995. Duly separating the effects of such simultaneous events is a tall order for econometric analysis, but it is indispensable in reaching the right answers. For example, the critics of NAFTA point out that real income per capita, real wages, and income poverty have not improved much since NAFTA was signed. They disregard the fact that the Tequila crisis (mostly resulting from macroeconomic mistakes ${ }^{2}$ ) led to a dramatic fall in real incomes and wages in 1995 and that it would be a stretch of the imagination to attribute such effects to the trade agreement. Second, a similar consideration must take place with respect to the simultaneous effect of external events on the Mexican economy. In particular, although figures show a dramatic increase in exports and foreign direct investment (FDI) after NAFTA was signed, it would be wrong to attribute the full increase to the treaty because a more favorable external environment (i.e., higher growth in the U.S. economy and the generalized FDI boom to emerging markets) also contributed to such results. Finally, it might be argued that some of the effects of the treaty require a longer time span for a proper assessment, either because they may turn out to be only temporary (as preliminary results suggest for the effects on FDI flows) or because they are observable only in a longer horizon (e.g., effects on inequality).

The authors used a variety of techniques and approaches to overcome these problems, and those are explained in some detail in the text and in the background papers to this volume, which are available on the World Bank's Latin America and Caribbean Web site. In spite of such difficulties, results seem robust in general. They found large effects (actually larger than expected) on trade, FDI flows, and productivity increases, even after considering the contribution of other simultaneous external or domestic events. In contrast, they found positive but modest (perhaps more modest than expected) effects on income per capita convergence with Mexican NAFTA partners and on real wages. Thus, overall, NAFTA effects were much better than what critics acknowledge but also less impressive than what proponents expected.

From the policy stance, three main sets of conclusions emerge. The first one is directly related to the previous general conclusion and to the others that follow. Trade agreements with industrialized countries may have important positive effects but are no panacea. They create opportunities (and challenges) but do not guarantee results. In particular, the research presented in this book shows that income convergence with Northern partners is severely limited by the wide differences in the quality of domestic institutions, in the innovation dynamics of domestic firms, and in the skills of the labor force. Although the effects of the trade agreement have provided some inducement to improve in these dimensions, it is not enough to overcome divergent trends, and thus an 
exogenous effort in such areas is urgently required. Such a result is not surprising in hindsight. After all, a wide body of research has shown that the quality of institutions and human capital and the process of technological upgrading are the critical determinants of long-term income per capita differences among countries, and thus trade may at best facilitate such processes and make them more effective. Indeed, the good news is that there are important positive synergies between these types of trade agreements and those basic determinants of long-term well-being. The main policy message is thus that the negotiation of these agreements should be used in developing countries as an opportunity to create a domestic consensus to propel these other basic institutional and policy determinants of development, which appear more urgent and more profitable given the immediate opportunities and challenges provided by the agreements.

The second major policy conclusion is that effects vary widely among different types of workers, firms, and regions, and there is thus a need to complement the overall trade and development agenda with policy actions focused on those that would benefit the least or might actually be hurt. In particular, workers with higher skills and education benefited more, and thus the required educational and training effort should be focused on those workers with lower skill levels and access to formal education. Large firms benefited more than small and medium-size ones, a result that seems related to the unavailability of domestic credit after the financial crisis of 1995 (large firms were able to increase their access to international financial markets, but this option was not available for smaller ones), indicating the need to strengthen efforts in deepening domestic financial markets to reach underserved sectors. Commercial agricultural producers with access to irrigated land witnessed significant increases in productivity after NAFTA, and many of those who were in previously protected traditional sectors shifted toward activities in which they are more competitive, many in new export areas stimulated by the treaty.

Smaller producers of traditional products neither increased nor decreased their production levels, and they continued to be affected by a secular decline of the relative prices of their produce (which does not appear to have been significantly affected by NAFTA). That indicates the need to couple the income support programs à la PROCAMPO with technical assistance to either increase productivity in traditional crops or shift to different activities. Those states with higher initial levels of education, better infrastructure (especially in telecommunications), and better local institutions-in addition to locational advantages-accelerated their rate of convergence with the more prosperous North, but this did not happen for the poorer states of the South (Chiapas, Guerrero, and Oaxaca). Indeed, these poorest states show a path that diverges from the rest 
of Mexico both before and after NAFTA. What is clear is that a trade agreement like NAFTA will not alter the deleterious effects of decades of relative neglect for some areas of the country (where a large part of the indigenous population is concentrated), which underscores once more the urgent need for a more balanced territorial dimension to national policies.

Finally, the study provides some lessons for the structure of such agreements. In particular it illustrates the shortcomings of some aspects of the NAFTA treaty, specifically those related to the rules of origin, which have severely limited the capacity of Mexican firms in many sectors to take advantage of NAFTA preferences, and related to the supervision panels that do not appear to have made a major impact on the incidence of disputes and the effectiveness of their resolution either before or after NAFTA. The results mentioned above also suggest the convenience of broadening the scope of such treaties in other dimensions, such as including instruments to support laggard regions and small rural producers so that they also can benefit from the opportunities opened by the trade agreements, and of seeking to achieve a deeper financial integration that would give more financial access to small and medium-size firms. A word of caution is in order here: the study reported in this book did not attempt to evaluate the specific effects of all aspects of the NAFTA treaty (notably, the specific effect of labor, environmental, and intellectual property clauses was not examined) and thus policy recommendations about the content of such agreements included in this report are partial at best.

Guillermo Perry

Chief Economist for Latin America and the Caribbean

The World Bank

August 2004

\section{Notes}

1. This research effort is part of the Regional Studies Program coordinated by the Office of the Chief Economist for Latin America at the World Bank. The results of other studies from that program are also being published in the Latin American Development Forum series (e.g., The Limits of Stabilization: Infrastructure, Public Deficits, and Growth in Latin America by William Easterly and Luis Servén, 2003; and Keeping the Promise of Social Security in Latin America, by Indermit Gill, Truman Packard, and Juan Yermo, 2004).

2. Some claim that NAFTA may have contributed in two ways: by producing capital inflows that appreciated the currency and by creating a false sense of security that led to macroeconomic policy mistakes. The point remains that it was mostly the macroeconomic handling and not the agreement features that contributed to the problems. 


\section{Acknowledgments}

This BOOK WAS WRITTEN by DANiEl Lederman, William F. Maloney, and Luis Servén between February 2002 and February 2003. However, the authors greatly benefited from the opportunity to work closely with many colleagues and friends, whose talent and expertise enriched the manuscript substantially. Numerous colleagues wrote excellent background papers, which are available from the World Bank's Latin America and Caribbean Web site.

Chapter 2 benefited from substantial contributions by William Easterly (New York University) and Norbert Fiess (World Bank). Chapter 3 would not have been completed without help from Gerardo Esquivel (El Colegio de México). The background technical research was provided by Alfredo Cuevas (Banco de México), Miguel Messmacher (International Monetary Fund Institute), and Alejandro Werner (with the Banco de México when the research was undertaken). Chapter 4 borrows heavily from analytical reports written by Olivier Cadot (Université de Lausanne), Jaime de Melo (Université de Genève), Antoni Estevadeordal (Inter-American Development Bank [IADB]), Akiko Suwa-Eisenmann (DELTA), Bolormaa Tumurchudur (Université de Lausanne), Bruce Blonigen (University of Oregon), Gerardo Esquivel, Mario Solís (El Colegio de México), and Antonio Yúnez-Naude (El Colegio de México). Chapter 5 also benefited from analyses conducted by Cuevas, Messmacher, and Werner, as well as work by Florencio López-de-Silanes (Yale University). The discussion of labor markets was informed by analytical work done by Raymond Robertson (Macalester College) and Gordon Hanson (University of California-San Diego). Chapter 6 was informed by work from David Mayer (Centro de Investigacion y Docencia Economicas [CIDE]), Liliana Meza (Universidad Iberoamericana), 
and discussions with Carlos Bazdresch (CIDE). Chapter 7 relies on research developed by Claudio Montenegro (World Bank) and Isidro Soloaga (Universidad de las Américas-Puebla), as well as by Alex Monge-Naranjo (Northwestern University). Finally, chapter 8 borrows heavily from work by Monge-Naranjo.

The authors received invaluable guidance and support from Guillermo Perry, and benefited from input provided by colleagues from the Secretaría de Economía of the Government of Mexico, namely Angel Villalobos, María de Lourdes Dieck, and Jesús Zurita, who also offered timely comments on various preliminary drafts of the background papers.

Portions of this book were presented at various venues, and useful comments were received from participants at the May 2002 workshop held at the World Bank in Washington, D.C., and at the 2002 Annual Meeting of the Latin American and Caribbean Economic Association. In particular, Andrés Rodríguez-Clare (IADB) and Ernesto López-Córdova (IADB) frequently made themselves available to discuss various aspects of the book. Likewise, Craig Burnside (University of Virginia) and William J. Martin (World Bank) provided excellent comments at various stages.

Last but not least, the book was enhanced by comments from World Bank colleagues, including Marcelo Giugale, Ernesto May, Danny Leipziger, Mauricio Carrizosa, Marianne Fay, Vicente Fretes-Cibils, and Gillette Hall. Mariano Bosch, Patricia Macchi, and Laura Saenz provided impeccable research assistance. All remaining errors are the responsibility of the authors. 


\section{1 \\ Lessons from NAFTA for Latin American and Caribbean Countries}

THE FREE TRADE AREA OF THE AMERICAS (FTAA) is again the subject of discussion among academics and policymakers. The mainstream media and economic journals are replete with discussions of the potentially major effects of the proposed FTAA on flows of goods and capital across the Western Hemisphere. These possible effects could have consequences for growth and development in the region. In Central America, the advent of the Central America-United States Free Trade Agreement (CAFTA) was recently negotiated, and Chile already implemented its trade pact with the United States.

Mexico's performance under the North American Free Trade Agreement (NAFTA), however, provides the most directly relevant experiment from which other Latin American and Caribbean countries can learn about the likely contents and economic effects of a trade agreement with the United States. Therefore, in this book we draw lessons from the NAFTA experience. However, attempting to draw lessons from NAFTA for the FTAA poses several difficulties. First, only a short time has elapsed since implementation of the agreement, and Mexico's postNAFTA years started with the dramatic setback of the Tequila crisis in 1994/95, making it hard to disentangle the effects of the treaty on the Mexican economy. Second, an FTAA or CAFTA might differ from NAFTA, and thus their results could differ in important dimensions. Third, there is considerable diversity in the initial conditions of Latin American and Caribbean countries hoping to join the FTAA, and hence the key priorities, necessary preparatory measures, and likely effects of accession also differ considerably across countries.

In these respects the book provides a selective rather than exhaustive analysis of the impact of NAFTA on the Mexican economy. Although it 
devotes attention to a few key issues regarding possible content changes between NAFTA and the FTAA, and considers how specific characteristics of FTAA prospective members may shape its impact, it does not attempt to cover the full range of alternatives of FTAA design and/or member countries' initial conditions. Nor does it intend to identify the particular set of policies best suited for each individual country in Latin America and the Caribbean; instead, it underscores those reform areas where the experience of NAFTA suggests that policy action in preparation for, or in conjunction with, the FTAA will have the biggest payoff in terms of growth and development.

The book's main conclusion regarding NAFTA is that the treaty helped Mexico get closer to the levels of development of its NAFTA partners. The research suggests, for example, that Mexico's global exports would have been about 50 percent lower and foreign direct investment (FDI) would have been about 40 percent less without NAFTA. Also, the amount of time required for Mexican manufacturers to adopt U.S. technological innovations was cut in half. Trade can probably take some credit for moderate declines in poverty, and has likely had positive impacts on the number and quality of jobs. During 1994-2002 our estimates suggest that NAFTA made Mexico richer than it would have been without the agreement by about 4 percent of its gross domestic product (GDP) per capita. However, NAFTA is not enough to ensure economic convergence among North American countries and regions. This reflects both limitations of NAFTA's design and, more important, pending domestic reforms.

An FTAA designed along the lines of NAFTA will offer new opportunities for growth and development in Latin America and the Caribbean, particularly if improvement is achieved on some aspects of NAFTA, such as the distorting rules of origin and the antidumping and countervailing duties (AD/CVDs). However, significant policy and institutional reforms will be necessary in most countries to seize those opportunities. In particular, the reforms will need to focus on reducing macroeconomic instability, improving the investment climate and the institutional framework, and putting in place an education and innovation system capable of fostering technological advancement and productivity growth. In addition, regional trade integration will have to be accompanied by unilateral, bilateral, and multilateral actions on other trade fronts to maximize the gains from trade liberalization and reduce the possible costs from trade diversion caused by the FTAA.

These conclusions follow from careful analysis of a comprehensive, although not exhaustive, set of issues associated with the implementation of NAFTA and the upcoming FTAA. To identify the effects of NAFTA on Mexico and other countries-especially the neighboring countries of Central America and the Caribbean-the analytical work 
reviewed policies and trends prior to and after NAFTA implementation, using in many cases a broader international perspective and drawing lessons from the experience of other FTAs, notably the European Economic Community/European Union (EEC/EU).

The book consists of seven chapters. Chapter 2 examines the evidence concerning economic convergence in North America by assessing how NAFTA has affected Mexico's per capita income relative to that of the United States. Chapter 3 studies the evolution of macroeconomic synchronization across NAFTA member countries, sectors, and regions, and draws the relevant implications for macroeconomic policy design. Chapter 4 provides a critical evaluation of NAFTA's remaining trade barriers by focusing on the impact of rules of origin on trade in manufactures, especially textiles and apparel, agricultural policies, and antidumping countervailing duties (AD/CVDs). Chapter 5 focuses on the integration of factor markets, namely capital and labor. Chapter 6 provides a comprehensive diagnosis of Mexico's innovation system. Chapter 7 examines the consequences of NAFTA for the trade flows of third countries, and chapter 8 does the same with FDI flows to countries excluded from NAFTA. Both chapters pay particular attention to NAFTA's neighbors in Central America and the Caribbean. After a brief description of the contents of the agreement, the rest of this introduction comments on the book's main findings and policy recommendations.

\section{The Content of NAFTA}

NAFTA entailed substantial trade reforms by Mexico. ${ }^{1}$ Most import tariffs and other restrictions to trade among Canada, Mexico, and the United States were eliminated over the first 10 years of implementation. Consequently the average Mexican tariff fell from about 12 percent in 1993 to 1.3 percent by 2001. Likewise, U.S. tariffs on Mexican imports fell from 2.0 to 0.2 percent. However, duty-free access to the NAFTA markets depends on the fulfillment of product- or sector-specific rules of origin, which determine the criteria for products to be considered as originating in one of the three member countries. In some instances market access for Mexican exports is inhibited by these rules.

Like most trade agreements, NAFTA did not achieve completely free international trade and numerous distortions still remain. Some tariffrate quotas for sensitive agricultural products will be finally eliminated by 2008, but these quotas have not been binding and thus most agricultural imports from Canada and the United States have entered the Mexican market duty free. However, Mexico's import-competing agriculture benefited from special subsidies ranging from decoupled income transfers to producers to a variety of subsidies affecting domestic producer prices. 
Moreover, all member countries have continued to use AD/CVDs according to their own national trade laws. In addition, NAFTA allows the use of temporary safeguard duties when sudden import surges disrupt domestic production. For example, since January 2003 Mexico has imposed temporary taxes on poultry imports from the United States.

Besides trade-related measures, NAFTA includes a variety of provisions affecting investment flows, financial and other services, government procurement, and the protection of intellectual property rights. A full review of all these provisions is beyond the scope of this book. However, it is worth highlighting that the agreement did not establish a fully liberalized financial system, for example. In fact, even in banking the text provided for very limited foreign penetration of the domestic market via foreign direct investment up to a maximum of 25 percent of the banking system's aggregate capital, whereas it did establish an open capital account for cross-border financial services. ${ }^{2}$ But even regarding the latter, Mexico had already unilaterally opened its capital account prior to the implementation of NAFTA in 1994 and thus it is not obvious that the agreement had any additional impact via the liberalization of the capital account.

Finally, the agreement established various dispute settlement mechanisms dealing with foreign investment and trade-related disputes. It also established a review mechanism for the use of antidumping and countervailing duties.

In sum, NAFTA did in fact entail substantial although incomplete trade reforms. At the same time the agreement went well beyond traditional trade issues. On top of this complexity, after the implementation of NAFTA Mexico experienced economic shocks, which complicate the analysis of the agreement's impact.

\section{The Analytical Challenge- Identifying the Impact of NAFTA}

Table 1.1 and figure 1.1 contain facts about Mexican economic performance since 1980. This evidence explains why the debate over the impact of NAFTA on the Mexican economy remains controversial. On the one hand, trade and FDI as shares of GDP were higher in the postNAFTA period than in the previous years. However, these rising trends were also evident in the period of unilateral trade reforms of the late 1980s. Moreover, world trade was growing quickly and FDI was rising in many other emerging markets that did not benefit from NAFTA. On the other hand, the performance of the economy in terms of growth of GDP per capita and real wages was not that remarkable after NAFTA. Existing estimates of the national poverty rate seem to closely follow the 
Table 1.1 Mexico: Selected Indicators

\begin{tabular}{lccc}
\hline Indicator & 1980-85(\%) & 1986-93(\%) & 1994-2001(\%) \\
\hline Trade over GDP & 28.1 & 37.0 & 75.7 \\
FDI net of Privatizations & 1.1 & 1.2 & $2.9^{\mathrm{a}}$ \\
$\quad$ over GDP & 1.1 & 1.2 & 3.0 \\
FDI over GDP & -0.2 & 1.1 & 1.2 \\
Real GDP Growth per capita in & & & \\
$\quad$ local currency & -4.8 & 3.5 & -1.0 \\
Real Wages in local currency & -9.0 & 9.5 & -0.5 \\
Real Wages in dollars & - & $22.5^{\mathrm{b}}$ & $24.2^{\mathrm{c}}$ \\
Poverty Rate - SEDESOL & - & $47.8^{\mathrm{d}}$ & $41.1^{\mathrm{c}}$ \\
Poverty Rate - ECLAC & &
\end{tabular}

- Not available.

Note: ECLAC Economic Commission for Latin America and the Caribbean; SEDESOL Secretariat of Social Development.

a 1994-99.

b. Poverty line 1 for individuals; see figure 1.1.

b. 1992.

c. 2000 .

d. 1989.

Source: Author's calculations, based on data from SEDESOL, ECLAC, and the World Bank.

Figure 1.1 Mexico: Real Manufacturing Wages and Poverty

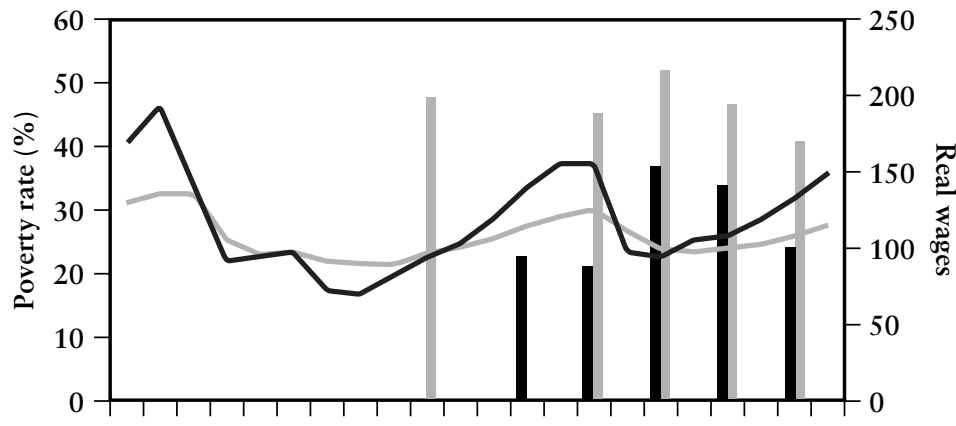

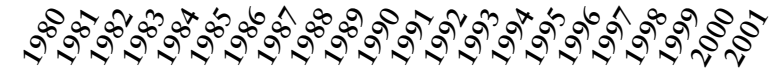

- Poverty rate, for individuals, SEDESOL $\quad$ Poverty rate, ECLAC

Real wages in local currency

Real wages in dollars

Source: Author's calculations. 
evolution of real wages, as shown in figure 1.1. Of course, an important reason why growth and wages did not perform more favorably after 1994 was the macroeconomic and financial crisis triggered by the devaluation of December 1994. Indeed, below we discuss evidence showing that trade and FDI cannot be blamed for the lackluster performance of wages. We believe that firm policy conclusions cannot be extracted from a simplistic before-and-after analysis. The reason is that there were many factors other than the implementation of NAFTA that can explain both the continuity of certain trends and the disappointment of others.

This book thus faced the analytical challenge of attempting to identify the impact of NAFTA on the Mexican economy. For this purpose we commissioned and conducted a series of analyses that applied various identification strategies. Some relied on the historical or time-series behavior of Mexican economic indicators; others used inter-sector, interregional, and international comparisons to assess the extent to which different factors affected economic outcomes. The main findings of these analyses are summarized below.

\section{The FTAA and Economic Convergence in the Light of NAFTA}

NAFTA has brought significant economic and social benefits to the Mexican economy. Trade, FDI, and growth outcomes improved as a consequence of NAFTA and of Mexico's unilateral reforms initiated in the mid-1980s. Real wages have recovered rapidly from the $1995 \mathrm{col}-$ lapse, and the poverty rate has followed a similar path.

One key conclusion from careful evaluation of the impact of NAFTA, however, is that the treaty does not suffice to ensure economic convergence in North America. Mexico still suffers from important gaps that constrain its ability to catch up with its northern neighbors. The statistical evidence (see chapter 2) shows that unilateral trade reforms and NAFTA helped Mexico enter a process of economic convergence with respect to the United States, and after 1995 the gap between its GDP per capita and that of the United States has evolved more favorably than in other Latin American and Caribbean economies.

However, the process of convergence faces significant constraints that drive a wedge between per capita GDP in Mexico and the United States even in the long run. We conclude that the key constraints result from institutional gaps (see chapter 2) and deficiencies in education and innovation policies (see chapter 6). In fact, the gap in the quality of the institutional framework is the biggest single factor behind the income gap between the two countries (figure 1.2). Although the per capita income differential is also affected by a number of other factors, taken 
Figure 1.2 Mexico: Estimated Impact of the Institutional Gap on the Per Capita GDP Gap, with respect to the United States

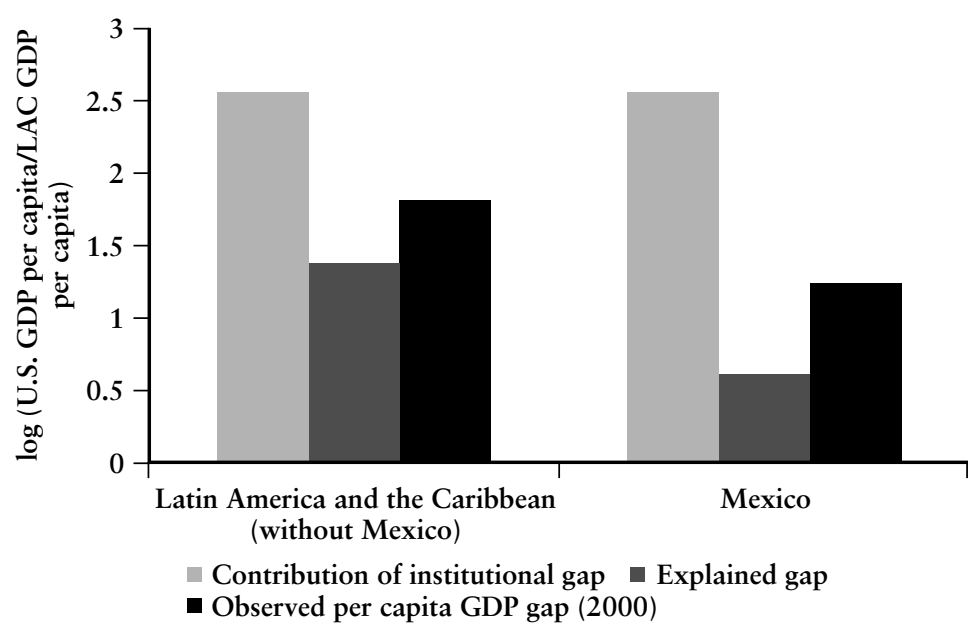

Note: LAC Latin America and the Caribbean.

Source: Author's calculations.

together they actually contribute to offset in part the large income gap attributable to Mexico's institutional weaknesses relative to its partners. Moreover, for the rest of Latin America and the Caribbean the situation is very similar: the institutional gap emerges as the biggest obstacle to the region's income convergence with the United States, a conclusion that puts in perspective the benefits to be expected from the FTAA.

Institutional reforms, especially those intended to improve the rule of law and fight corruption, are critical for the future economic development of the region. They will help narrow the current institutional gaps with respect to Canada and the United States. Those gaps for many Latin American and Caribbean countries (with Chile as the main exception) remain substantial despite the fact that in the 1990s most of the countries, including Mexico and especially Chile and Central America, did make some progress regarding the quality of their institutions (see chapter 2).

The experience of Mexico also indicates that institutional improvements should not be expected to be automatic by-products of North-South free trade agreements. Substantial unilateral efforts will be required to 
revamp Latin American and Caribbean institutions and speed up income convergence in the Americas. The role of education and innovation policies is discussed further below.

\section{Macroeconomic Synchronization and Policy Coordination}

In addition to long-run effects on per capita income and wages, trade agreements also have potentially major implications for aggregate fluctuations in member countries and, therefore, for the design of their macroeconomic policies. Through increased economic integration, the macroeconomic cycles of partner countries may become more closely synchronized-although this need not be invariably the case, especially if the countries involved are very dissimilar. A thorough review of the evidence shows that in the post-NAFTA years aggregate fluctuations in Mexico have become increasingly synchronized with those of its partners in the treaty (see chapter 3). Although the post-NAFTA period is still too brief to allow firm conclusions, this suggests that the nature of macroeconomic volatility in Mexico is changing, with developments in the United States accounting for an increasingly large fraction of the variation in Mexico's GDP growth. We may expect that the same will occur, to varying extents, in other countries after joining the FTAA.

This raises the issue of the desirability of policy coordination. There is little ground for coordination among Latin American and Caribbean countries alone, given their generally low degree of trade integration, the dominant role of idiosyncratic shocks in their macroeconomic fluctuations, and the absence of an obvious anchor country in the region whose policy credibility could enhance that of client countries. However, the prospect of an FTAA places the issue under a new light. Aggregate instability remains high in most Latin American and Caribbean countries, although it did fall in the 1990s, and it is a potential obstacle to the achievement of the full benefits of an FTAA in terms of resource reallocation and trade expansion-particularly so in the case of real exchange rate volatility. The question is therefore whether tight policy coordination with the United States-including options such as monetary unification through a currency union or unilateral dollarization-could help enhance macroeconomic stability and deepen integration.

At present, for most countries in the region the answer is likely to be negative. Their degree of trade integration with the United States is generally low, and the scope for asymmetric shocks is correspondingly large (figure 1.3). Although the latter may decline over time with deeper integration, as in the case of Mexico with NAFTA, the cost derived from the loss of policy autonomy that a monetary unification with the United 
Figure 1.3 Latin America: Correlation of Annual Growth of Real GDP with that of the United States

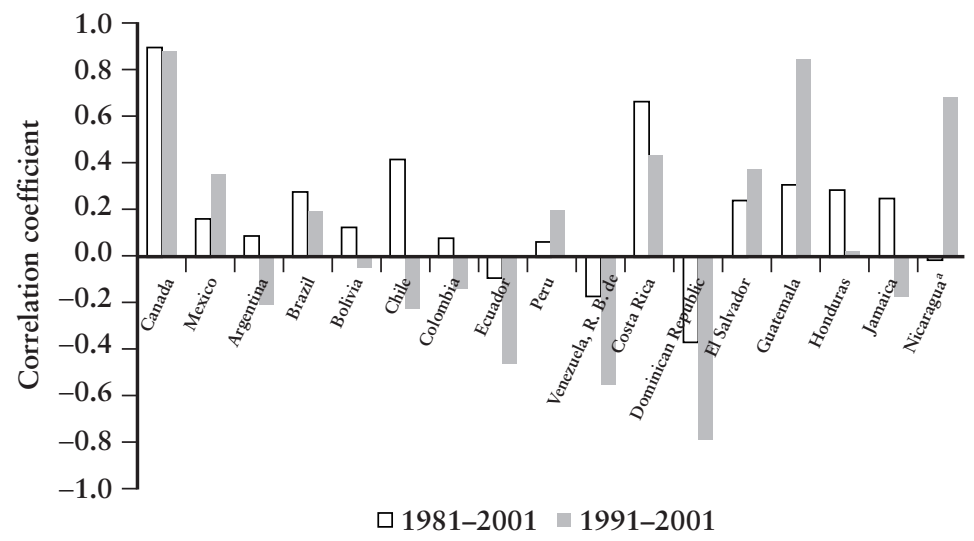

a. 1981-98

Source: Author's calculations.

States would entail likely outweighs any potential benefits in terms of increased credibility. Moreover, the prospects for a formal currency union with the United States-that is, one including arrangements for seigniorage sharing, lender-of-last-resort functions, and joint determination of monetary policy-seem remote. As a result, the only viable form of monetary unification would be unilateral dollarization, which is even less appealing because of the added cost from leaving those three issues unresolved.

Looser forms of monetary coordination short of unification, although possible, are unlikely to be credible or effective in the absence of central institutions to oversee and enforce them. The same applies to fiscal policy coordination. Whereas the external commitment imposed by common fiscal rules might help national governments push forward fiscal reform and consolidation, the absence of enforcement mechanisms and institutions is likely to render the rules largely inoperative. The very limited success of previous attempts at policy coordination in several Latin American and Caribbean subregions also points in this direction.

Central America may provide the exception to the above considerations. Most of the countries in the area are highly open and integrated 
with the United States as measured not only by trade flows but also by migrants' remittances. In addition, some of them suffer from low credibility and exhibit a high degree of de facto dollarization. On the whole, this would make them the most suitable candidates for monetary unification with the United States. El Salvador has already taken this step, although more time is needed to assess its experience with dollarization.

In contrast, most of the larger economies in South America are likely to benefit from independent monetary policy, and several of them have already made progress with the implementation of flexible exchange rate regimes guided by inflation targets. For them the challenge is to establish a track record of monetary stability and low inflation to strengthen the credibility of the inflation-targeting regime.

On the fiscal front, the ability of most Latin American and Caribbean countries to conduct countercyclical policy is severely limited by poor credibility, following from a tradition of large fiscal imbalances, and by the weak operation of automatic fiscal stabilizers, reflecting narrow tax bases and, in several cases, the large weight of volatile resource revenues in total fiscal collection. In a context of deficient fiscal institutions, the result has often been a procyclical fiscal stance, which augments aggregate volatility instead of reducing it.

A solid fiscal position will require in many countries a tax reform to expand the revenue base-and, in some countries, also to offset the income loss from declining tariff collection derived from the FTAA. Maintenance of a firm fiscal position will reinforce credibility over time. But the credibility buildup could also be aided by explicit adoption of (and adherence to) contingent fiscal targets formulated in cyclically adjusted terms. These terms entail the achievement of fiscal surpluses in periods of expansion to provide room for deficits in times of recession. The creation of strong fiscal institutions allowing policymakers to implement these rules and abide by them is an essential ingredient of this process.

\section{Trade Integration}

Mexico's trade liberalization under NAFTA followed closely the unilateral reforms begun in 1986, after the country joined the General Agreement on Tariffs and Trade (GATT). Trade negotiations among Canada, Mexico, and the United States began informally in 1990, and more formally in 1991 after the United States administration obtained "fasttrack" authority from its legislature. Thus it is difficult to separate the effects of NAFTA on Mexico's volume and composition of trade from those of the unilateral reforms, especially given that the mere announcement of NAFTA talks could have had an impact on economic outcomes. Nevertheless, it is clear that during the 1990s Mexico became one of the 
region's economies with the highest volume of trade relative to GDP. Indeed, Mexico caught up with Chile in this indicator of economic integration and is fast approaching the high trade shares typically found among smaller economies, such as Costa Rica (figure 1.4).

The rapid expansion of Mexico's trade began prior to NAFTA, approximately in 1993, and was accompanied by a marked change in its composition, through which Mexico became a net exporter of machinery in 1992-93. Thus, substantial changes happened prior to actual implementation of the free trade agreement, perhaps reflecting lagged effects of the unilateral reforms and/or their enhanced credibility resulting from anticipated passage of NAFTA. Other studies by Mexican and U.S. researchers reviewed in this book (see chapter 7) suggest that the behavior of aggregate Mexican exports and imports did not change significantly with the advent of NAFTA. Rather, this evidence indicates that the agreement ensured the continuation of these positive trends. Moreover, results from detailed statistical analyses (see chapter 7) support the argument that NAFTA did not cause significant trade diversion in the

Figure 1.4 Latin America: Imports Plus Exports over GDP

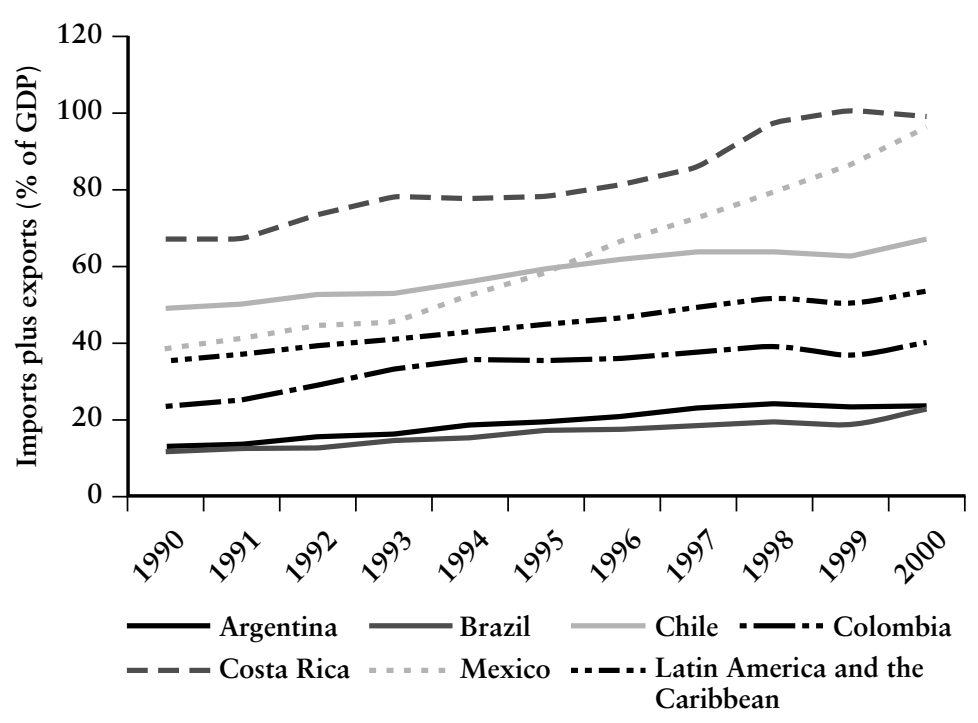

Source: Author's calculations, based on data from the World Bank. 
aggregate, but it might have diverted trade against Asian imports of textiles and apparel. In this book we also identify a few key areas where the agreement has failed to establish free trade. In particular, the main areas for future improvements are related to rules of origin (ROOs) in manufacturing trade, agriculture, and AD/CVDs.

\section{Rules of Origin}

The study shows that NAFTA's rules of origin, which as in other free trade agreements are used to identify products eligible for preferential treatment to prevent trade deflection from nonmembers, can result in countries importing the structure of protection from their partners. Rules of origin impose a cost on exporters wishing to use FTA preferences for their exports. The cost can be so high as to make it more profitable for exporters to export subject to duties, rather than to use the preferences, and thus avoid the requirements imposed by the rules.

An extreme case is that of the textile and apparel industries, where Mexico probably has imported the U.S. structure of protection. This occurred because the United States seems to be NAFTA's low-cost source of textiles used in the manufacture of apparel. Because NAFTA offered substantial preferential treatment to Mexican exports of apparel that use textiles and yarns from NAFTA countries (mainly the United States), the decision whether to export to the U.S. apparel market depends only on the U.S. apparel and textile prices as determined by its import barriers. The evidence shows that Mexico has become a net exporter of apparel to the United States but not to the rest of the world, and a major importer of U.S. textiles.

But a large share of Mexican apparel exports does not enter the United States taking advantage of NAFTA preferences. In fact, the use of those preferences by Mexican exporters is similar to the use of the Caribbean Basin Initiative/Caribbean Basin Economic Recovery Act (CBI/CBERA) preferences by exporters in Central America and the Caribbean, even though the latter impose stricter rules of origin demanding that the textiles used in apparel manufacture be entirely from the United States (see chapter 4). The recently approved Andean Trade Promotion and Drug Eradication Act (ATPDEA) imposes similarly strict rules of origin on apparel exports to the United States from the beneficiary countries.

Thus, for other Latin American and Caribbean countries expecting their apparel and textile industries to benefit from a NAFTA-type deal, it is important to keep in mind that the relevant rules of origin might limit the magnitude of the desirable market access effect. For countries possessing a competitive textile industry, moving from CBERA (or ATPDEA) to NAFTA rules of origin might make a big difference. Using estimates of net exports of textiles and apparel, we argue here that this 
will be the case for countries such as Colombia or El Salvador. But for other countries that will not be the source of low-cost textile and yarn inputs used in apparel, the change might not be very beneficial. Hence, for most countries in the region it may be preferable to amend NAFTA's rules of origin in this sector. One alternative would be to use regional value content rules, rather than the existing change of chapter rule, which would in effect imply that all of the textile and yarn inputs in apparel need to be of regional origin. For countries that use low-cost inputs from other regions, however, NAFTA rules of origin might be more harmful than what was observed for Mexico.

\section{Agriculture}

Contrary to some predictions, NAFTA has not had a devastating effect on Mexico's agriculture. In fact, both domestic production and trade in agricultural goods rose during the NAFTA years (see chapter 3) (figure 1.5). The more challenging question is why NAFTA did not have the expected negative consequences. We offer three arguments. First, aggregate demand in Mexico and the United States grew in the latter half of the 1990s, thus allowing for simultaneous increases in Mexican production and imports. Second, some segments of Mexican agriculture

Figure 1.5 Mexico: Agricultural Production and Trade, 1990-2001

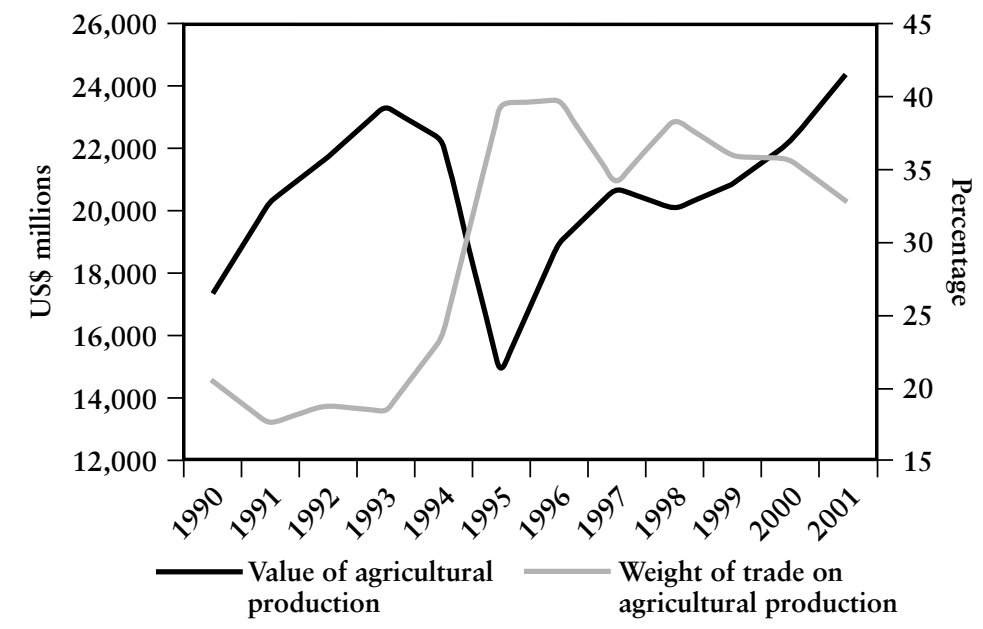


experienced increases in land productivity. This was the case for irrigated lands, but not for rain-fed lands. Third, whereas the total amount of subsidies and income support for traditional agriculture did not rise during the NAFTA period, Mexico's unilateral reforms did entail an improvement in the efficiency of such subsidies. In particular, Programa para el Campo (PROCAMPO), which delinked the amount of public support from current and future production decisions, became the main source of income support provided by the government for farmers who had historically produced traditional crops such as maize and other grains.

In this book we briefly discuss some key program design issues that should be considered when implementing delinked agricultural support programs, based on the Mexican and U.S. experiences. In particular, the efficiency gains from the PROCAMPO program suggest that other countries liberalizing trade should also consider agricultural support programs that provide incentives for productive transformation of the sector rather than maintain incentives similar to those provided by protectionist policies that inhibit agriculture's transformation.

\section{Antidumping and Countervailing Duties}

Regarding AD/CVD activity, the analysis in chapter 4 of this book finds two contrasting results. On the one hand, NAFTA's Chapter 19, which provides a panel review mechanism for assessing whether $A D / C V D$ decisions by the competent national agencies have been properly applied, has had no significant impact on U.S. AD/CVD activity against Canada or Mexico. The post-NAFTA period has conformed to tradition in that U.S. AD/CVD actions against Canada and Mexico have continued to be infrequent.

On the other hand, there is some evidence suggesting that Mexico's $\mathrm{AD}$ activity against Canada and the United States has been significantly lower after the implementation of NAFTA. However, the United States has traditionally been a major focus of Mexican AD cases. It is also notable that Chile rejected the U.S.-proposed language on $\mathrm{AD} / \mathrm{CVDs}$ in its recently finalized FTA.

For the upcoming FTAA, AD/CVD activity poses a key policy challenge. One option is to harmonize the antitrust regime among Latin American and Caribbean countries and the United States. Given the fact that $\mathrm{AD} / \mathrm{CVD}$ laws in each country were designed with the explicit purpose of protecting domestic producers from "unfair" foreign competition, however, it is unlikely that such a process of regulatory convergence can be achieved in the forthcoming trade negotiations with the United States. Another alternative is for each country to use its own $\mathrm{AD} / \mathrm{CVD}$ laws to retaliate against any abuses by the United States or other countries-at the risk of trade wars and more rather than less 
protectionism. The third (preferred) alternative would be to reach an agreement with the United States that would allow the use of safeguards for regional trade relief rather than $\mathrm{AD} / \mathrm{CVD}$ procedures. This would entail a regional negotiation of a new safeguards chapter stating clearly that regional import surges should be dealt with primarily through this mechanism. This alternative is attractive in the short run because safeguard duties are temporary and require the action of the executive branch, in contrast with duties lacking sunset clauses supported by a supposedly technical and independent, but often unfair, trade machinery.

\section{Trade Diversion from NAFTA}

When NAFTA was being negotiated in the early 1990s, many third countries voiced concern that their exports to the United States (and, to a lesser extent, to Canada and Mexico) would be displaced by NAFTA exports, even though in many products and industries those countries could be more competitive than NAFTA producers. From the viewpoint of Mexico, this trade diversion is also important because it would entail a loss of fiscal revenues from replacing imports from third countries subject to tariffs with duty-free imports from Canada or the United States.

From a thorough analysis of trends in aggregate trade flows, controlling for their basic determinants, we find little evidence of trade diversion at the aggregate level, a conclusion that agrees with previous studies of NAFTA (see chapter 7). Indeed, such a result is also suggested by the fact that Mexico's export share in non-NAFTA markets rose as much as, or even more than, its share in NAFTA markets.

We also examine the trends in apparel trade to assess if NAFTA's neighboring countries were hurt by trade diversion in this sector, as some studies have suggested. On the whole, there is no solid evidence that neighboring countries lost apparel market share because of NAFTA preferences. Although all countries in Central America and the Caribbean faced the same change in U.S. preferences relative to those enjoyed by Mexico, their post-NAFTA performances showed considerable diversity. Most Central American countries managed to raise their export share in NAFTA markets; Caribbean economies fared less well. This suggests that factors other than NAFTA preferences are responsible for much of this diverse post-NAFTA performance.

Among such factors, export incentives granted by a number of countries in the context of export processing zones (EPZs) may have played an important role. It is thus possible-although hard to verify-that the upward trend in the region's apparel export shares might have been achieved at significant costs derived from EPZ concessions, such as forgone fiscal revenues and other potential distortions. Looking to the future, World Trade Organization (WTO) rules imply that EPZ incentives in their 
current form will have to be phased out and a new export- and investmentfriendly framework will have to be developed by the countries involved.

\section{Future Trade Negotiations for Latin American and Caribbean Countries: Multiple Fronts}

For Latin American and Caribbean countries the likely benefits of an FTA with Canada and the United States go beyond the reduction of barriers to their mutual trade. On the one hand, an FTA implies a firm guarantee of market access, in contrast with preferences granted unilaterally by the United States (such as those under the CBI/CBEPA and ATPDEA), which are offered on a temporary basis and are subject to unilateral revocation at any time. Furthermore, unilateral concessions typically leave the resolution of trade disputes to the discretion of U.S. authorities.

On the other hand, an FTA can help "lock in" progress made on unilateral trade liberalization, making it immune to protectionist pressures that might arise in the future. It may also have a broader positive impact on credibility by offering domestic and foreign investors a more stable and predictable framework that prevents backtracking not only in the rules governing international trade but possibly also in the reforms on other fronts. These lock-in and credibility effects, however, may vary considerably across FTAA prospective members. They are likely to be most important for countries at an early stage of trade opening whose reforms still suffer from poor credibility. For other countries that already possess low barriers to trade and a strong constituency in favor of trade openness, the credibility dividend will largely depend on the extent to which FTAA accession prompts improvement and strengthening of policies and institutions.

An FTA also entails costs and policy challenges, however-negotiation costs, especially significant for small countries; fiscal costs derived from the elimination of tariffs against other FTA members, which for some countries will imply a sizable shock requiring fiscal reform; and hidden costs such as the distortions imposed by ROOs under NAFTA, which can detract substantially from FTAA benefits if not properly tackled in the negotiation process.

Moreover, the anticipation of gains to be made from an FTA does not reduce the need for continued progress with unilateral trade reforms and multilateral negotiations under the aegis of the WTO. Some key issues, such as those surrounding agricultural trade, are unlikely to be resolved in the context of the FTAA, as experience has shown that the United States is not prepared to deal with its own agricultural supports in the context of FTAs. The same is true for AD/CVD activity, although it is unclear whether the United States would be able to change its relevant laws even under a WTO-brokered deal. Finally, for some countries, 
especially in South America, trade agreements with Europe and the Doha trade round are likely to be quite important for market access, perhaps to a greater extent in some areas than the proposed FTAA.

Latin American and Caribbean countries should remain actively engaged in the Doha trade round. Argentina and Brazil are likely to be important players in the agricultural debate as 2 of the 17 members of the Cairns Group of agricultural exporters, which also includes Australia and Canada, to push for important reforms in agricultural policies around the world. In this area, success of the WTO round in providing incentives for all countries to delink their subsidies from production decisions-as previously attempted by the European Union and implemented by Mexico and the United States-would be a significant improvement over the current situation, where only 5 percent of the average Organisation for Economic Co-operation and Development (OECD) agricultural support is based on historical harvests. If one excludes the United States ( 20 percent) and Canada (9 percent), the average of the rest of the OECD is even lower. Because the process of EU enlargement is already bringing to the fore the sustainability of Europe's Common Agricultural Policy (CAP), it is likely that there will be room for compromise on agricultural subsidies in the future.

Regarding unilateral liberalization, the analysis in the book suggests that much of the gain in export market share achieved by Mexico in recent years reflects its unilateral trade liberalization since the late 1980s. The implication for third countries is that trade-friendly policies, even if unilateral, can yield large dividends in terms of export market expansion. Moreover, there is no convincing evidence that higher initial tariffs can help developing countries attain better market access to industrialized countries in trade negotiations, as some have suggested. On the contrary, developing countries with weak credibility may need to lower tariffs to signal their willingness to implement further trade reforms as mandated by potential trade agreements. It is not a coincidence that the United States negotiated NAFTA after Mexico had unilaterally reformed, and that Chile was the next country in line, closely followed by Central America, which as a whole is among the most open economies of the region. Thus, Latin American and Caribbean countries should pursue unilateral and multilateral reforms while negotiating FTAs with the United States and other countries. In fact, this has been the Chilean model for some time.

\section{Factor Markets}

Whereas by definition FTAs are about trade, they also have potentially major consequences for both the allocation of labor and capital across industries and for the distribution of income across households for several 
reasons. First, theory suggests that trade should lead to greater convergence of the returns to capital and wages among the trading partners, reflecting increased efficiency in the allocation of factors. Second, FTAs may include explicit provisions removing barriers to international movements of capital (as in NAFTA) and/or labor (as in the EU). Last, but no less important, FTAs may reduce the perceived risk from investing in member countries by guaranteeing access to the extended market defined by the agreement and by locking in the trade and other policies of participating countries.

\section{Capital}

Through the above channels an FTA may deepen the degree of financial integration - in addition to trade integration-of its member countries. In particular it may prompt a substantial rise in foreign investment inflows to FTA newcomers. Indeed, the anticipation of higher FDI is probably one of the main benefits that prospective members expect from the upcoming FTAA. The experience with NAFTA appears to validate these expectations: aggregate FDI flows to Mexico did rise significantly in the period following NAFTA, and econometric analysis suggests that the trade agreement played an instrumental role in the rise (see chapter 5). On the whole, however, Mexico's FDI performance in the post-NAFTA period was not significantly above the Latin American norm, except in the years immediately following passage of the treaty (figure 1.6). Nor is there much evidence that increased investment in Mexico came at the expense of other countries in the region-that is, that NAFTA led to investment diversion. The neighboring countries of Central America and the Caribbean, which stood to lose the most from a redirection of FDI flows to Mexico, did not show a generally worsened performance as investment hosts after NAFTA (see chapter 8).

Taken together, this evidence indicates that although the FTAA is likely to encourage FDI to Latin American and Caribbean member countries, it is neither necessary nor sufficient for such a result. Chile has experienced persistently large FDI in the absence of an FTA, whereas Greece derived no immediate FDI benefits at the time of its EEC accession. In other words, an FTA is a complement to rather than a substitute for an investment-friendly policy and institutional environment, and it cannot make up for macroeconomic instability and weak institutions. Thus, countries hoping to benefit from FTA-induced investment creation need to push forward with reforms aimed at improving investment fundamentals: economic and policy stability, productivity, institutions, and governance. There is considerable diversity in the region, but along most of these dimensions Latin American and Caribbean countries still lag behind other developing regions such as East Asia. 


\section{Figure 1.6 Latin America: Net FDI Inflows as a Percentage of GDP}

(annual averages by period)

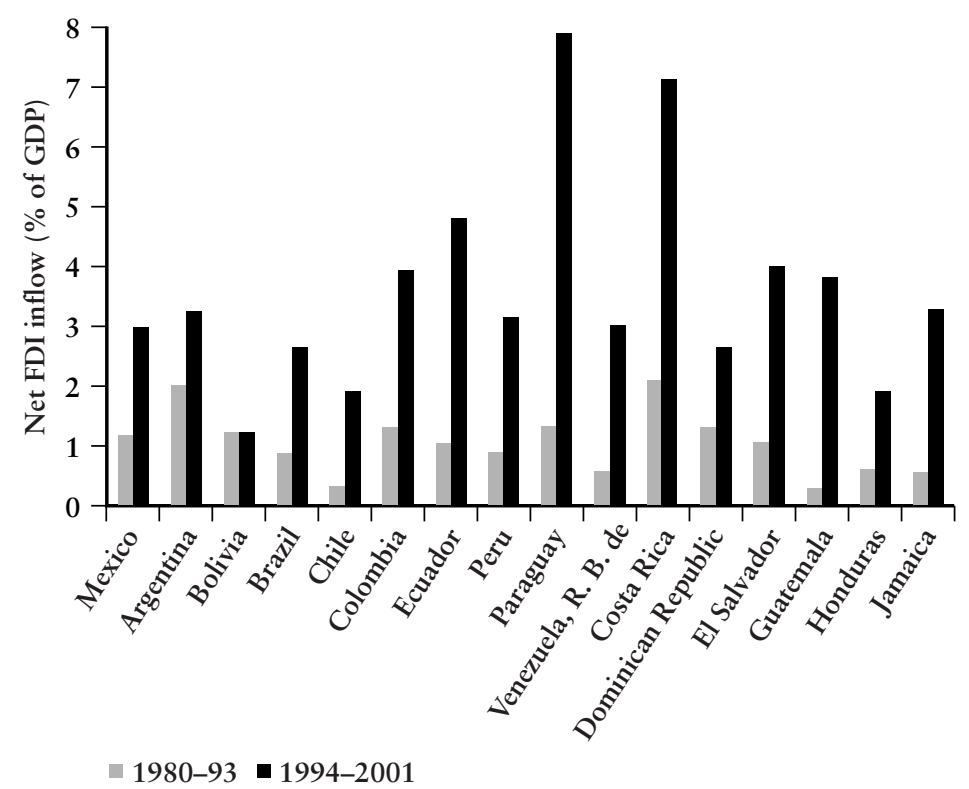

Source: Author's calculations, based on data from the World Bank.

This strategy that is centered on improving the investment climate for both domestic and foreign investors should replace the export-based FDI incentives that have been at the core of FDI-attracting efforts in a number of countries, notably Central America and the Caribbean. As already noted, such incentives will soon cease to be feasible under WTO rules. Tax concessions and other incentives are less important than FDI fundamentals for investment location decisions, although they do have some impact when the choice is among hosts with similar fundamentals. However, incentives can also be distorting and wasteful if the investments they attract do not involve significant positive externalities. To minimize their costs, incentives should be rules based, and available on equal terms to all investors irrespective of nationality.

The key concern for host countries is not the volume of FDI they may receive but rather the benefits that it brings to the economy. Reforms in 
anticipation of an FTAA have to focus also on the key determinants of those benefits, even if they do not directly affect the volume of FDI inflows. In particular, for the domestic economy to absorb any technological spillovers arising from FDI, sufficient levels of human capital and an adequate knowledge and innovation system need to be in place (see chapter 6).

Increased FDI and international financial integration do not guarantee that firms will be able to take full advantage of the new opportunities offered by the FTAA and speed up income convergence in the Americas. The vast majority of firms in Latin America and the Caribbeanespecially smaller and new ones-cannot resort to foreign financial markets and their access to domestic finance is constrained by the deficiencies of local financial markets. To a large extent, the small size and illiquidity of these markets reflect legal and institutional shortcomings regarding the protection of creditor and shareholder rights, which in most Latin American countries is far weaker than in industrialized countries and East Asia (see chapter 5). Thus, legal and regulatory measures to strengthen investor protection should rank high in the reform agenda.

\section{Labor}

Regarding labor, the lessons emerging from Mexico for other countries contemplating the FTAA are necessarily tentative, but the overall evidence warrants cautious optimism. There is some evidence of convergence toward U.S. wage levels, but inference is made very difficult by the collapse of Mexican real wages following the Tequila crisis. Although manufacturing wages rose after unilateral liberalization and sharply so in the years following NAFTA, there is no strong evidence that this was particularly the result of convergence through trade. On the one hand, wages are higher and have grown faster in states with more trade, FDI, and the presence of maquila. On the other hand, the apparently tighter integration of wages along the border, in traded and nontraded industries alike, suggests an important role for migration in driving the limited convergence seen so far. Perhaps a longer-run view is offered by Chile. After its very similar version of the Tequila crisis following unilateral liberalization in the early 1980s, Chile generated real wage growth of an impressive 3.2 percent a year from 1986 to the present, with large declines in rates of poverty.

Despite popular perception, there is little ground for concerns that NAFTA, or FTAs more generally, are likely to have a detrimental effect on the availability and/or quality of jobs. Consistent with the regionwide evidence, there is little indication of higher unemployment, increased volatility of the labor market after the initial adjustments, or increased 
informalization associated with trade liberalization. As is true of firms of the region generally, Mexican firms that are more exposed to trade tend to pay higher wages adjusted for skills (figure 1.7), are more formal, and invest more in training. The probably temporary widening of the wage gap between skilled and unskilled workers observed throughout the region can be seen as reflecting a welcome increase in the demand for skilled workers by new and upgrading firms. ${ }^{3}$ It does imply, however, that the FTAA will require a more vigorous effort in raising the level of human capital.

It is more difficult to identify the labor market regulations and policies best suited to complement the FTAA. At the time of NAFTA's signing, the Mexican labor market showed few nominal rigidities and this is partly responsible for the low levels of unemployment during periods of necessary sectoral reallocations, and the 20-year low reached within five years of the agreement's signing. Even during the crisis, Mexico engineered sharp falls in real wages by allowing inflation to erode pactguided wages and kept unemployment low. Arguably, this is the critical difference with countries such as Argentina and Colombia, whose macroeconomic crises during the 1990s in a context of relatively rigid

Figure 1.7 Latin America: Wages Adjusted for Skill by Degree of Exposure to Trade

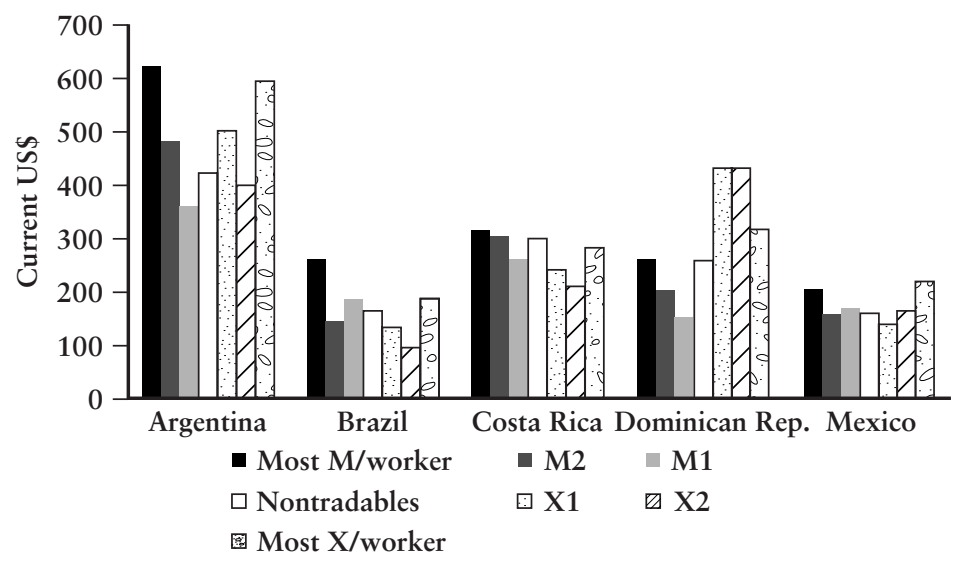

Note: M1 and M2 are progressively the terciles of industry most exposed to imports. X1 and $\mathrm{X} 2$ are progressively the terciles with the most exports.

Source: Author's calculations. 
real wages have led to high and sustained unemployment. What Mexico's experience suggests, as does that of the industrialized countries, is that neither prolonged spells of unemployment nor degradation of job quality are necessary or even likely results of increased openness or an FTA, and adjustments to trade- or nontrade-related shocks can be facilitated by higher degrees of nominal wage flexibility.

A greater concern for all countries considering FTAs are the inability of firms to make adjustments to their labor force at moderate and predictable cost and the lack of safety nets for workers where such adjustments are possible. In the short run an FTA may lead to significant reallocation of jobs from sectors not in a country's comparative advantage to those sectors that are, and such reallocation is essential to take advantage of the gains from trade. Over the longer run, more dynamic economies are likely to require higher turnover of workers as new technologies are adopted and as new firms and sectors are created, expand, and die. Labor legislation needs to facilitate the transition of workers from dying to expanding industries while it protects their livelihoods.

Mexico is very representative of South and Central America (although not of the Caribbean region) in prohibiting worker layoffs for economic reasons and in imposing costs for dismissals that are roughly double the advanced-country average. In this sense labor legislation is far more protective than in Canada or the United States. Brazil, with the lowest separation costs in Latin America, is only slightly above the advanced-country average whereas Bolivia at the high end shows costs that almost triple those of industrialized countries. The lack of an orderly system of separations for economic reasons leads to highly litigious dismissals that raise transaction costs for firms and create uncertainty for both workers and employers about final compensation. The system discourages the ongoing reallocation of workers to better job matches, impeding the gains in labor productivity that are a desired by-product of the FTAA. It also represents a very poor form of protection for workers. Without individual accounts such as those implemented in Chile or Colombia, or unemployment insurance programs such as that of Brazil, workers' only source of income is supposedly the ailing firm itselfexactly the wrong agent to bear the risk. In sum, Mexico's labor code, like many of those in countries considering the FTAA, probably serves neither workers nor employers well and is likely to become more of an impediment in the context of more open, competitive economies following regional trade liberalization.

The discussion above raises two questions about side agreements on labor issues. First, given that in key dimensions Latin American labor legislation is excessively rigid by industrialized country standards, would it not be better for agreements to facilitate the transition to systems that both protect workers better and promote dynamic growth, 
rather than to insist on the enforcement of archaic structures? Second, and more fundamental, given increasing evidence that foreign and more trade-oriented firms offer higher wages and better working conditions, should not the effort to improve labor standards focus on all sectors of the economy and be freestanding (perhaps coordinated by an organization like the International Labour Organization) rather than linked to particular trade agreements? In light of the potential for protectionist abuse of side agreements, both questions merit careful debate as FTAA discussions go forward.

\section{Innovation}

The deficiencies in the educational and innovation systems of most Latin American and Caribbean countries pose a critical constraint on their ability to catch up with the United States. The literature and Mexican experience suggest that a passive approach will not ensure that greater trade and FDI will lead to rapid transfer of technology and gains in total factor productivity. As a complement, countries need to develop a national innovative or learning capacity to fully exploit the possibilities of an FTAA. As described in the recent World Bank Latin America and the Caribbean Region's flagship report on "Closing the Gaps in Education and Technology in Latin America and the Caribbean" (2002), virtually every country in the region lags in the key ingredients of such capacity.

The main educational gaps in Latin America and the Caribbean are those related to the coverage of secondary enrollment and the poor quality of the education provided to its citizens. Attainment along these dimensions in Mexico, as well as in most of the countries in the region, is below the international norm for countries with similar levels of income. The region as a whole also lags the international norm in both the level and efficiency of innovative effort. As admittedly imperfect proxies, total research and development $(\mathrm{R} \& D)$ spending and patenting activity fall short of the levels typically found in countries with similar characteristics. The international evidence suggests that the region's R\&D investment effort should be about 2.5 times its current level, which during the late 1990s was approximately 0.4 percent of GDP in Argentina, 0.6 percent in Mexico, and 0.8 percent in Brazil, compared with greater than 2.5 percent in Korea and the United States. NAFTA's main contribution to Mexico's innovation effort might have been its Chapter 17 on intellectual property rights because our analysis suggests that stronger protection is associated with higher levels of $R \& D$ spending relative to GDP.

The lack of innovative effort is reflected in the fact that the number of U.S. patents granted to regional researchers is significantly below what 
Figure 1.8 Latin America and the Caribbean Region's Gap in Patent Counts Relative to the Average and to Patenting Overachievers

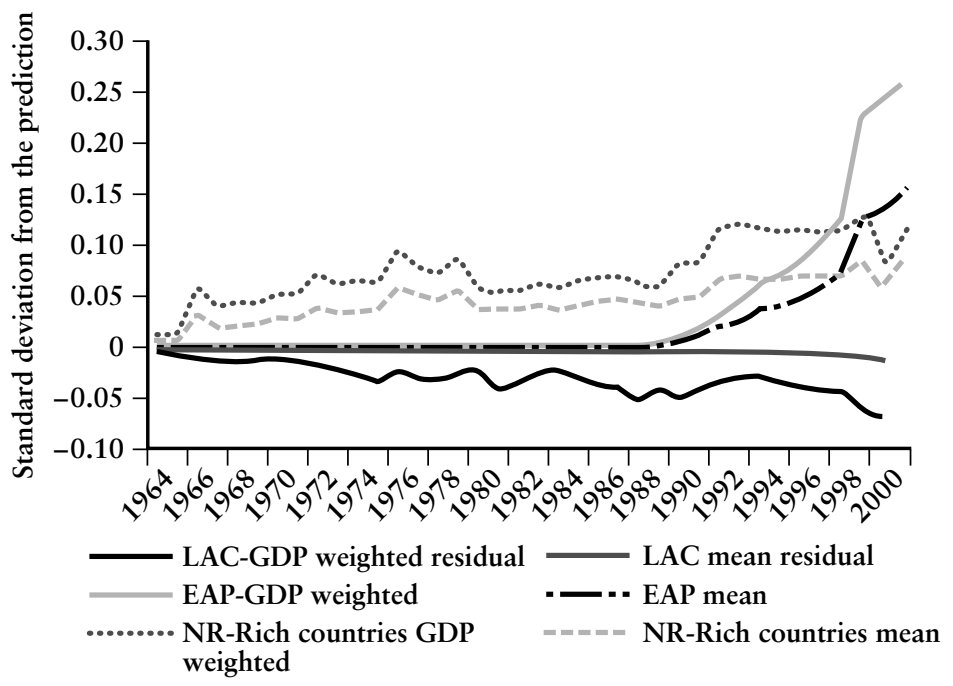

Note $: \mathrm{EAP}=$ East Asia and the Pacific; LAC = Latin America and the Caribbean; NR = natural resource.

Source: Author's calculations.

should be expected on the basis of GDP, labor force, and exports to the United States (figure 1.8). This common regional pattern is not a result of a comparative advantage in resource-intensive products: resource-abundant countries like Australia, Canada, Finland, New Zealand, Norway, and Sweden along with manufacturing-intensive East Asian countries do much better than the international norm. But the region's underperformance also results from the inefficiency of its innovation systems as reflected in the rate of conversion of R\&D spending into patents. Again, this is below the OECD average, which itself is substantially below the averages of Finland, Korea, Sweden, and Taiwan (China). Both the low level of effort and the inefficiency seem to be associated with the poor quality of research and weak linkages between the productive sector and the universities and public think tanks, which are partially the results of poorly designed incentives with the respective institutions. 
An adequate innovative capacity is essential to fully exploit the potential of NAFTA and the upcoming FTAA. To develop such a capacity, the region needs to intensify its progress in education, in terms of both coverage and quality, and to make a strong effort in innovation spending. This can be accomplished by reviewing the public incentives to $\mathrm{R} \& \mathrm{D}$ and overhauling what is, for the most part, a dysfunctional national innovation system.

\section{Notes}

1. For a more detailed description of the contents of NAFTA, see U.S. International Trade Commission (1997).

2. Annexes VII(B) and 1413.6 of NAFTA limited the scope of foreign penetration in Mexico's banking system to a maximum of 25 percent of the aggregate capital of all commercial banks. NAFTA's restrictions on foreign insurance companies were even more severe. Mexico removed the limitations on foreign entry into the domestic commercial banking system unilaterally during the financial crisis of 1995 .

3. The regionwide trends in the quality and availability of jobs, as well as the skill premium and its determinants, are amply documented in the World Bank Latin America and the Caribbean Region's flagship reports titled "From Natural Resources to the Knowledge Economy" (2001) and "Closing the Gap in Education and Technology in Latin America and the Caribbean” (2002).

\section{References}

U.S. International Trade Commission. 1997. The Impact of the North American Free Trade Agreement on the U.S. Economy and Industries: A Three-Year Review. Publication 3045. Washington, DC.

World Bank. 2001. From Natural Resources to the Knowledge Economy. World Bank Latin American and Caribbean Studies, Washington, DC. Processed. 2002. Closing the Gap in Education and Technology. World Bank Latin American and Caribbean Studies, Washington, DC. Processed. 



\section{2 \\ NAFTA and Convergence in North America: High Expectations, Big Events, Little Time}

\section{Introduction and Related Literature}

The North American Free Trade Agreement (NAFTA) was formally implemented on January 1, 1994, by Canada, Mexico, and the United States. This treaty instantly gained global notoriety when the formal negotiations started in 1991 mainly because the initiative would become one of the most comprehensive trade agreements in history and because it seemed to be a breakthrough that would lead to free trade in goods and services among industrialized countries and a developing country. The high expectations were that trade liberalization would help Mexico catch up with its northern neighbors. As shown in figure 2.1, the ratio of Mexican GDP per capita to the United States did increase somewhat after unilateral trade reforms were implemented in 1986 and after the implementation of NAFTA in the aftermath of the so-called Tequila crisis. However, it is noteworthy that other Latin American economies also have grown faster than the U.S. economy since the mid-1980s, especially Chile and to a lesser extent Costa Rica. Thus it is not obvious that NAFTA was particularly important in helping Mexico catch up with the United States. The experience of Puerto Rico is also interesting, given that it is an economy that started with a level of development similar to that of Mexico in the late 1950s but achieved an unprecedented level of economic and institutional integration with the United States in 1952, and subsequently experienced the fastest rates of economic growth in the 
Figure 2.1 GDP Per Capita Relative to the United States, Selected Economies, 1960-2001

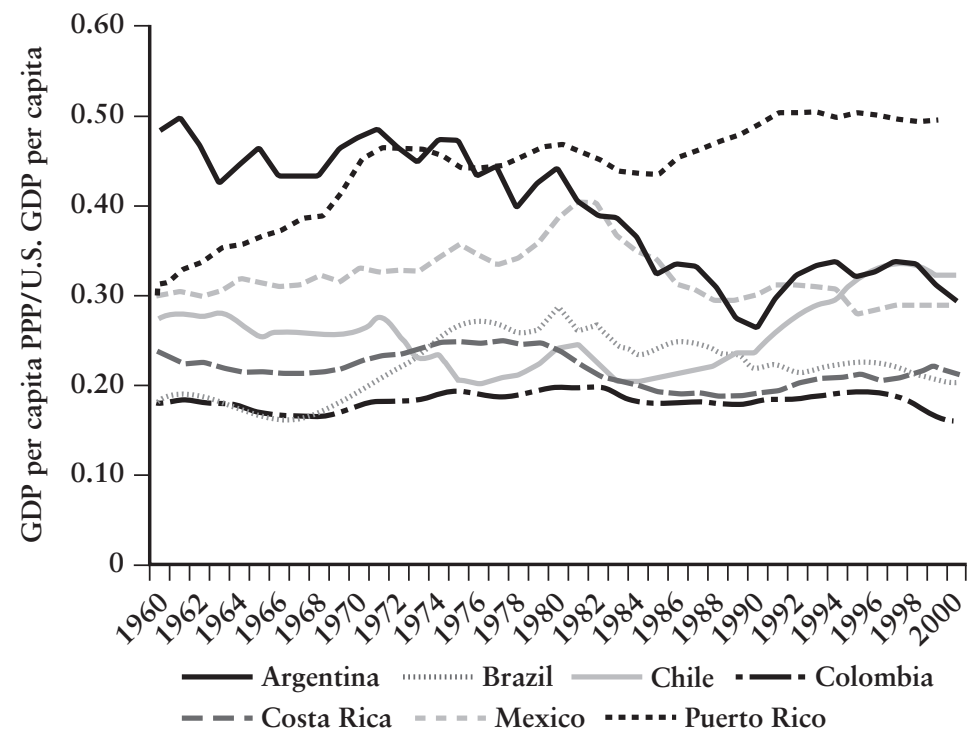

Source: Loayza et al. 2002.

developing Latin American economies. In this chapter we attempt to assess the extent to which the high expectations of economic convergence among NAFTA members seem to be materializing. We examine trends and determinants of income and productivity gaps observed in North America, both across countries and within Mexico.

\section{High Expectations}

The high expectations for NAFTA were supported by neoclassical growth and trade theories. The seminal work of Solow (1956) stated that capital-poor countries grow faster than rich countries because of the law of diminishing returns, as long as production technologies, population growth, and preferences are the same across countries. Likewise, the neoclassical Heckscher-Ohlin trade models predict that as the prices of goods and services converge, so will factor prices, including real wages. Hence income levels across borders will also tend to converge as prices 
converge. A key simplifying assumption of neoclassical economics is that all countries use the same production technologies exhibiting either constant or diminishing returns to scale.

There is a lively debate about the evidence concerning the impact of trade liberalization on income convergence across countries (Ben-David 1996, 2001; Slaughter 2001). There is also an extensive body of literature about economic convergence within countries, including Barro and Sala-I-Martin (1995) and Sala-I-Martin (1996). At least since the publication of Barro (1991), the economics profession has been aware that convergence might be conditioned by convergence in certain fundamentals that are believed to cause economic growth. Although there is admittedly much uncertainty about what these fundamentals are (Doppelhofer, Mille, and Sala-I-Martin 2000), the evidence of conditional convergence can be interpreted as evidence in favor of the neoclassical growth model or as evidence that there are fundamental differences that prevent income convergence.

\section{Technology and Divergence: The "Big” Story}

For Easterly and Levine (2001) and Pritchett (1997), the "big story" in international income comparisons is that the rich have gotten richer while the poor got poorer. Some studies focusing on cross-country differences in the levels of income per capita (or gross domestic product [GDP] per worker) have argued that these differences are largely explained by institutional factors (Acemoglu, Johnson, and Robinson 2001; Hall and Jones 1999). However, there are other factors besides different institutions that might impede economic convergence among geographic areas even if there is free trade.

More recent theories of growth with increasing returns and/or technological differences across regions, such as the pioneering work of Grossman and Helpman (1991), Lucas (1988), and Romer (1986, 1990), have predicted divergence in income levels and growth rates across regions. Trade flows might help international technology diffusion when technical knowledge is embodied in goods and services, and theories of technology diffusion via trade have been the subject of a fastgrowing body of literature (Eaton and Kortum 1999; Keller 2001). A related body of literature focuses on the barriers that impede technological adoption, explaining differences in the levels of income per capita (Parente and Prescott 2000). Thus, even when production technologies are different across countries, convergence can be aided through the liberalization of trade. But this would tend to be detected in convergence (divergence) of total factor productivity (TFP) levels within industries across countries (Bernard and Jones 1996). But even when trade liberalization allows poor countries to import production technologies from 
advanced countries, if the factor endowments are different, productivity levels might not converge because of the mismatch between labor skills available in poor countries and the sophisticated technologies imported from rich countries. Productivity gaps within industries across countries therefore might persist even if trade facilitates technological convergence (Acemoglu and Zilibotti 2001).

\section{Geography and Divergence: The "Big” Story}

The recently resurgent literature on economic geography, transport costs, economies of scale, and knowledge spillovers is less optimistic about the impact of trade liberalization on economic convergence (Fujita, Krugman, and Venables 1999; Krugman 1991). For example, transport costs will remain as barriers to trade and economic integration even if all policy distortions are removed (Eaton and Kortum 2002). In addition, if learning and innovation depend on trade then geography will also be an impediment to convergence via technological diffusion (Eaton and Kortum 2002; Keller 2002). These factors might hamper income convergence across countries (Redding and Venables 2001). Moreover, economies of scale and knowledge spillovers might make some geographic regions more prosperous than others simply because of the cumulative effects of initial conditions such as the density of economic activity (Ciccone and Hall 1996).

\section{Life After NAFTA: Big Events, Little Time}

On the day of NAFTA's implementation the Zapatista rebels took up arms in Mexico's southern state of Chiapas. Later that year, in December 1994, Mexico was forced to float the peso, which was followed by a deep banking crisis and severe recession. After a sharp deterioration and subsequent recovery of domestic investment, the Mexican economy was recovering by 1996 (Lederman et al. 2003). These were big events that coincided with the implementation of NAFTA. Moreover, from a long-run perspective, the post-NAFTA period is still short. These big events combined with little time after NAFTA increase the difficulty of empirically identifying the impact of the agreement on income and productivity gaps in North America. Nevertheless, we have tried various methodologies to assess how income and productivity differences were affected by NAFTA.

The rest of this chapter is organized as follows. The second section uses time-series techniques to identify the impact of NAFTA on the income gap between the United States and Mexico. To deal with the bigevents/little-time problem we apply various time-series methods. First, we follow Harvey (2002) and conduct a structural time-series exercise 
that might be able to separate transitory effects (e.g., the Tequila crisis) from the long-term effects expected from NAFTA. Second, we provide estimates of the impact of NAFTA on the rate of convergence between Mexico's GDP per capita and that of the United States. Third, we follow Fuss (1999) in applying cointegration analysis to see whether there is an observable process of income convergence between the United States and Mexico. We do this recursively to test whether there was a structural change in the equilibrium condition between U.S. and Mexican GDP using quarterly data from 1960 to 2001 . We find that the debt crisis in the early 1980s and the Tequila crisis temporarily interrupted a process of economic convergence (perhaps toward absolute convergence), which resumed after 1995. Convergence after Mexico's trade liberalization in the late 1980s and after NAFTA might have been faster than it was prior to the debt crisis. Given that other Latin American economies also seem to have grown quickly during this time period, however, we also provide econometric annual estimates of the differences between Mexico-specific and Latin American income effects. These results indicate that Mexico's performance between 1986 and 1993 was not that different from the average Latin American economy, but it was significantly more positive after NAFTA, with the obvious exception of 1995. The estimates of the rate of convergence suggest that by the end of 2002 Mexico's GDP per capita would have been about 4 percent lower without NAFTA.

The third section of this chapter looks at the income per capita differentials across countries in 2000 and estimates the extent to which institutional differences explain observed income differences. This exercise follows Acemoglu, Johnson, and Robinson (2001) in using settlers' mortality rates from colonial times as instruments for currently observed differences in institutional quality, based on data from Kaufmann and Kraay (2002a). We find that the income gap between the United States and Mexico largely can be explained by the institutional gap plus geographic variables. In addition, we examine the evolution of Mexico's institutional gap with respect to the United States by again comparing annual estimates of Mexico's effects with the average Latin American effect, and we conclude that there is no evidence that Mexico's institutions improved more than others from Latin America in the postNAFTA period. Thus, to accelerate convergence a major effort will be required to improve Mexico's institutions. NAFTA is not enough.

In the fourth section of the chapter we study the impact of NAFTA on TFP differentials within manufacturing industries across the United States and Mexico. Based on a panel estimation of the rate of convergence across 28 manufacturing industries, we find that the post-NAFTA period was characterized by a substantially faster rate of productivity convergence than in previous years. However, at this time we cannot say 
whether the productivity convergence resulted from increased imports of intermediate goods from the United States (as argued by Schiff and Wang 2002); from competitive pressures and preferential access to the U.S. market (as argued by López-Córdova 2002); or from increased Mexican innovation that might have been caused by a variety of factors, including increased domestic research and development (R\&D) efforts and patenting aided by the enhanced protection of intellectual property rights contained in NAFTA (Lederman and Maloney 2003a).

In the fifth section of the chapter we look at the impact of NAFTA on economic convergence across Mexican states. This issue is of particular interest to many Latin American economies looking forward to the proposed Free Trade Area of the Americas (FTAA). This hemispheric economic integration would theoretically lead to the establishment of free trade, and, in such cases as Central America and perhaps MERCOSUR (Common Market of the South), to deeper forms of economic integration among countries-integration that would resemble a single economic entity. Thus different economic performances of Mexican states under NAFTA might be a prelude to differential effects produced by the FTAA or other proposed arrangements, such as the Central AmericaUnited States Free Trade Agreement (CAFTA). We test the conditional convergence hypothesis across Mexican states, but focus exclusively on initial conditions that might explain why some Mexican states grew faster than others during 1990-2000. We find suggestive evidence that the initial level of skills of the population and the telephone density played an important role. We interpret these results as evidence that trade liberalization might indirectly induce divergence within countries, even if it induces convergence across countries. In the sixth section we summarize the main findings and propose a research agenda focusing mainly on the questions raised by our findings related to TFP convergence in manufacturing.

\section{Time-Series Evidence}

To identify the impact of NAFTA on the income gap between the United States and Mexico, we apply structural time-series modeling followed by recursive cointegration analysis. We then compare Mexico's experience to other regional economies.

\section{Structural Time-Series Modeling}

A simple way to gain insight into the convergence process is to separate trends and cycles from the relative output gap between the United States and Mexico, whereby a decreasing trend in the output gap indicates 
convergence. The Hodrick-Prescott (1997) filter can create serious distortions, however, as can the Baxter-King band-pass filter. ${ }^{1}$ We therefore follow Harvey and Trimbur (2001) and, in a later work, Harvey (2002), who argued that trends and cycles are best estimated by structural time-series models. We estimate a bivariate structural time-series model in which convergence between two economies is captured through a similar-cycle model that allows the disturbances driving the cycles to be correlated across countries (Harvey and Koopman 1997). Harvey (2002) provided a direct link among cointegration, common factors, and balanced growth models. He also showed that the balanced growth model results as a special case of the similar-cycle model when a common trend restriction is imposed (Harvey and Carvalho 2002).

The analysis in this section is based on quarterly data on real GDP per capita for the United States and Mexico over the period 1961Q4-2002Q4. To create a quarterly data series adjusted for purchasing power parity (PPP), we applied the following procedure. Quarterly GDP data were obtained from the Organisation for Economic Co-operation and Development (OECD) and the population series were constructed as quarterly moving averages of annual figures (from the World Bank's World Development Indicators) spread across four quarters. U.S. GDP data were seasonally adjusted by the provider; Mexican GDP data were seasonally adjusted using X-12-ARIMA. We first converted Mexican data into U.S. dollars using quarterly average nominal exchange rates. Both series were then deflated by the U.S. consumer price index to 1996 U.S. dollars. Because PPP-adjusted figures are only available on an annual frequency, we follow Summers and Ahmad (1974) and apply a two-step procedure for the PPP adjustment of our quarterly series. In the first step we estimate the exchange rate bias by regressing the annual PPP-adjusted GDP figures from Penn World Tables 6.1 on an annual exchange rate-adjusted GDP series. In the second step we apply the predicted exchange rate bias to our series of quarterly exchange rate-adjusted per capita GDP figures. ${ }^{2}$

We then fit a similar-cycle bivariate model to the logarithms of quarterly per capita GDP in the United States and Mexico (following Harvey 2002). The individual trends and cycles from these bivariate structural time-series models are displayed in figure 2.11 in the appendix to this chapter. A model with two cycles appears to describe the data well, and the second cycle appears to capture large movements in Mexico around the 1980s.

Figure 2.2 shows that the PPP-adjusted gap exhibits convergence until the setback of the 1980s associated with the debt crisis. Convergence resumed around 1987, coinciding with the unilateral liberalization that the Mexican economy implemented in 1986. However, this trend might also reflect the recovery from the recession of 1982-84. The Tequila crisis also was a temporary setback. Abstracting from the adverse impact 
Figure 2.2 U.S.-Mexico GDP Per Capita Gap: Similar-Cycle Model with Quarterly PPP-Adjusted Data, 1960-2002

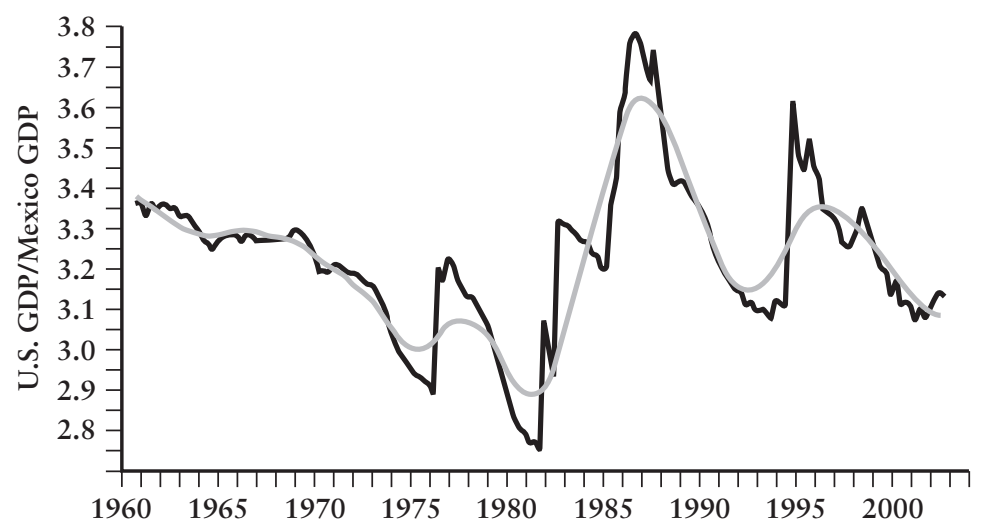

Note: Dotted line is the ratio of the U.S.-Mexico trend components of GDP per capita. Solid line is the observed ratio.

Source: Author's calculations.

of the last crisis, the downward slope of the income gap is steeper after 1987 than prior to the 1980s-a finding that supports the hypothesis that convergence between Mexico and the United States occurred at a faster rate after trade liberalization. ${ }^{3}$

To investigate the speed of convergence further, we estimated the following model:

$$
\begin{aligned}
g_{t}= & \alpha_{0}+\alpha_{L i b}+\alpha_{N a f t a}+\beta_{0} g_{t-1}+\beta_{L i b} g_{t-1} * L i b+\beta_{N a f t a} g_{t-1} \\
& * \text { Nafta }+ \text { tequila }+\beta_{\text {tequila }} g_{t-1} * \text { tequila }+ \text { dum } 82,
\end{aligned}
$$

where $g_{t}$ is the $\log$ of the U.S.-Mexico income gap, tequila is a dummy for the 1994/95 Tequila crisis (1994Q4-1995Q1), and Lib* $g_{t-1}$, Nafta $* g_{t-1}$, and tequila $* g_{t-1}$ are dummies for Mexico's unilateral trade liberalization (1986Q1-2002Q4), NAFTA (1994Q1-2002Q4), and the Tequila crisis, interacted with the lagged income gap. Dum82 is a dummy for 1982Q1. The regression results from various specifications of this model are presented in table 2.1.

Lagrange multiplier tests for first- and fourth-order error-serial correlation appear in the bottom rows of table 2.1. These tests suggest that 
Table 2.1 Speed of Adjustment Between Mexico and the United States

\begin{tabular}{|c|c|c|c|c|c|c|}
\hline & $\begin{array}{c}\text { Model } \\
\text { (1) }\end{array}$ & $\begin{array}{c}\text { Model } \\
\text { (2) }\end{array}$ & $\begin{array}{c}\text { Model } \\
\text { (3) }\end{array}$ & $\begin{array}{c}\text { Model } \\
\text { (4) }\end{array}$ & $\begin{array}{c}\text { Model } \\
(5)\end{array}$ & $\begin{array}{c}\text { Model } \\
\text { (6) }\end{array}$ \\
\hline$\alpha_{0}$ & $\begin{array}{c}0.092 * \\
(0.046)\end{array}$ & $\begin{array}{c}0.092 * \\
(0.042)\end{array}$ & $\begin{array}{c}0.028 \\
(0.039)\end{array}$ & $\begin{array}{c}0.092 * \\
(0.041)\end{array}$ & $\begin{array}{c}0.028 \\
(0.039)\end{array}$ & $\begin{array}{c}0.021 \\
(0.028)\end{array}$ \\
\hline$\alpha_{L i b}$ & $\begin{array}{c}-0.102 \\
(0.082)\end{array}$ & $\begin{array}{c}-0.102 \\
(0.075)\end{array}$ & $\begin{array}{c}-0.038 \\
(0.069)\end{array}$ & $\begin{array}{c}-0.102 \\
(0.075)\end{array}$ & $\begin{array}{c}-0.038 \\
(0.068)\end{array}$ & - \\
\hline$\alpha_{N a f t a}$ & $\begin{array}{c}0.192 * \\
(0.116)\end{array}$ & $\begin{array}{c}0.210 * \\
(0.105)\end{array}$ & $\begin{array}{c}0.210 * \\
(0.095)\end{array}$ & $\begin{array}{c}0.169 * \\
(0.108)\end{array}$ & $\begin{array}{c}0.169 * \\
(0.097)\end{array}$ & $\begin{array}{c}0.138 * \\
(0.084)\end{array}$ \\
\hline$\beta_{0}$ & $\begin{array}{c}0.920 * \\
(0.040)\end{array}$ & $\begin{array}{c}0.920 * \\
(0.036)\end{array}$ & $\begin{array}{c}0.975 \% \\
(0.034)\end{array}$ & $\begin{array}{c}0.920 * \\
(0.036)\end{array}$ & $\begin{array}{c}0.975 * \\
(0.034)\end{array}$ & $\begin{array}{c}0.980 * \\
(0.024)\end{array}$ \\
\hline$\beta_{L i b}$ & $\begin{array}{c}0.086 \\
(0.069)\end{array}$ & $\begin{array}{c}0.086 \\
(0.063)\end{array}$ & $\begin{array}{c}0.030 \\
(0.058)\end{array}$ & $\begin{array}{c}0.086 \\
(0.063)\end{array}$ & $\begin{array}{c}0.030 \\
(0.057)\end{array}$ & - \\
\hline$\beta_{\text {Nafta }}$ & $\begin{array}{c}-0.160 * \\
(0.097)\end{array}$ & $\begin{array}{c}-0.179 * \\
(0.089)\end{array}$ & $\begin{array}{c}-0.179 * \\
(0.080)\end{array}$ & $\begin{array}{c}-0.145^{*} \\
(0.091)\end{array}$ & $\begin{array}{c}-0.145^{*} \\
(0.082)\end{array}$ & $\begin{array}{c}-0.120 * \\
(0.072)\end{array}$ \\
\hline Tequila & - & $\begin{array}{c}0.085 * \\
(0.015)\end{array}$ & $\begin{array}{c}0.085 * \\
(0.013)\end{array}$ & $\begin{array}{c}0.593 * \\
(0.312)\end{array}$ & $\begin{array}{c}0.593 * \\
(0.282)\end{array}$ & $\begin{array}{c}0.593 * \\
(0.280)\end{array}$ \\
\hline$\beta_{\text {Tequila }}$ & - & - & - & $\begin{array}{c}-0.430 \\
(0.264)\end{array}$ & $\begin{array}{c}-0.430 \% \\
(0.238)\end{array}$ & $\begin{array}{c}-0.430 \% \\
(0.237)\end{array}$ \\
\hline Dum82 & - & - & $\begin{array}{c}0.114 * \\
(0.019)\end{array}$ & - & $\begin{array}{c}0.114 * \\
(0.019)\end{array}$ & $\begin{array}{c}0.115 * \\
(0.018)\end{array}$ \\
\hline $\begin{array}{l}\mathrm{LM}(1) \\
(p \text {-value })\end{array}$ & 0.56 & 0.85 & 0.85 & 0.82 & 0.88 & 0.87 \\
\hline $\begin{array}{l}\mathrm{LM}(4) \\
(p \text {-value })\end{array}$ & 0.01 & 0.01 & 0.43 & 0.01 & 0.34 & 0.38 \\
\hline$R^{2}$ & 0.87 & 0.92 & 0.92 & 0.89 & 0.92 & 0.92 \\
\hline
\end{tabular}

-Not available.

* Significant at the 10 percent level.

Source: Author's calculations.

the dum 82 variable is required to produce white-noise regression errors. The estimated coefficients of the well-behaved specifications are thus listed under columns three, five, and six.

The results from the well-specified models suggest that NAFTA, but not unilateral trade liberalization, had a significant positive impact on the speed of convergence. With NAFTA, the half-life of a unit shock to the income gap appears to have fallen from about 8.5 to 1.2 years. The fact that unilateral liberalization does not appear to be significant for income convergence is interesting. We find a similar result later in the chapter when analyzing the impact of unilateral liberalization and NAFTA on productivity growth.

The NAFTA period was also characterized by a significant increase in the average development gap, which is reflected in a statistically significant 
Figure 2.3 Gains from NAFTA: Observed and Predicted U.S.-Mexico GDP Per Capita Ratio, 1993Q42002Q4
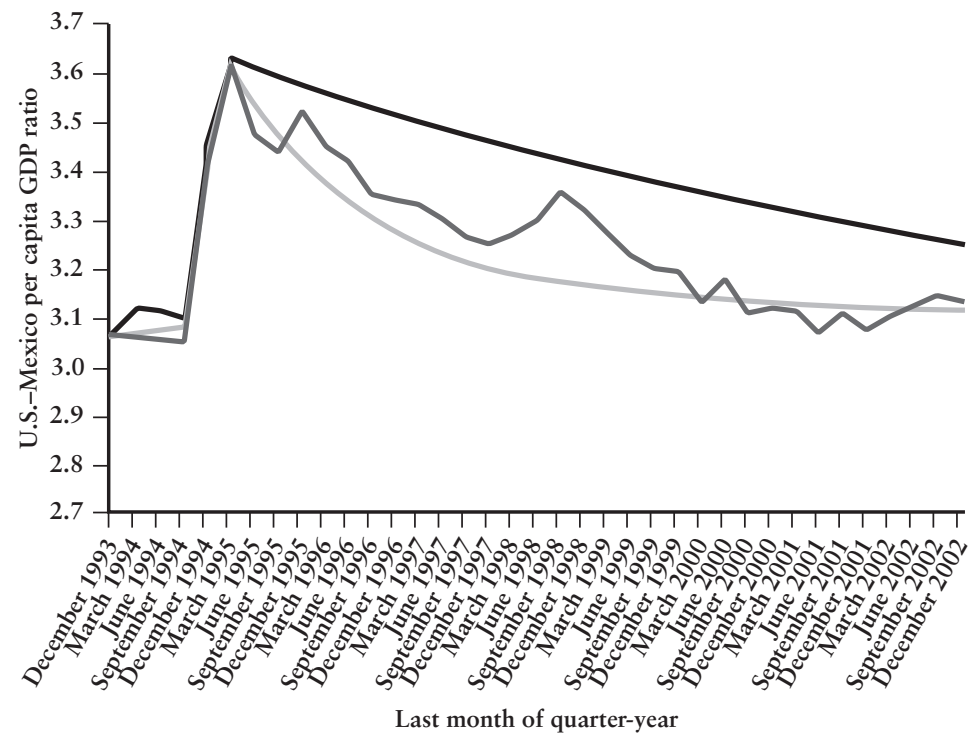

- Actual U.S.-Mexico gap SH6 Gap without NAFTA Gap with NAFTA

Source: Author's calculations.

coefficient of the NAFTA dummy variable. Thus, to get a clear view of the overall impact of NAFTA we need to consider both the acceleration of the speed of convergence during the NAFTA years as well as the increase in the average development gap. Also, the two quarters of the Tequila crisis (1994Q4-1995Q1) were associated with both a significantly faster speed of convergence and a temporary increase in the U.S.-Mexico development gap, both of which could not have been the result of NAFTA because these effects were so short-lived whereas NAFTA is here to stay for the long run.

Figure 2.3 illustrates the gains from NAFTA. It shows the evolution of the observed U.S.-Mexico development gap, the gap predicted by model (6) in table 2.1, which considers both effects of NAFTA, and the predicted gap if the NAFTA period had been characterized by the same 
data-generation process that existed prior to 1994 plus the short-lived impact of the eruption of the Tequila crisis. The overall accumulated effect of NAFTA as of 2002Q4 can thus be calculated by the difference between the inverse of the U.S.-Mexico gap predicted by the model with NAFTA's effects on the speed of convergence and the shift in the mean (which is virtually identical to the observed gap in 2002Q4) and prediction that assumes that NAFTA's effect was zero. This calculation leads us to conclude that NAFTA had an overall positive effect on Mexico's development. Its GDP per capita at the end of 2002 would have been about 4 percent lower without NAFTA.

\section{Cointegration Analysis}

According to Bernard and Durlauf $(1995,1996)$ long-run convergence between two or more countries exists if the long-run forecasts of output differences approach zero. In other words, two economies are said to have converged if the difference between them, $y_{t}$, is stable. Abstracting from initial conditions, stability implies that the difference between two series is stationary. Absolute convergence requires that the mean of $y_{t}$ is zero, whereas relative or conditional convergence requires that the difference between the two series has a constant mean. If two series are cointegrated, but with a vector different from $[1,-1]$, the economies are co-moving (i.e. driven by a common trend) but not necessarily converging to identical levels of output. Cointegration between economies alone is therefore a necessary but not a sufficient condition for absolute convergence. If a constant is introduced into the cointegration space, it is possible to test for absolute and relative convergence by restricting the constant to zero. A zero constant supports absolute convergence. ${ }^{4}$ Following Fuss (1999) we intend to interpret evidence of a cointegration vector of the form of $[1,-1]$ at the end of the sample together with a rejection of this vector parameterization in subsamples as evidence of an ongoing process of convergence. ${ }^{5}$

A cointegration analysis between U.S. and Mexican GDP with a constant and four lags in the cointegration space over the full sample from 1960 to 2002 reveals one significant cointegration vector (see table 2.2). Because a restriction of the cointegration space according to $[1,-1]$ cannot be rejected $\left(\chi^{2}(1)=2.86, p=0.09\right)$ over the full sample, this provides evidence in favor of convergence during $1960-2002^{6}$ :

$$
\mathrm{GDP}_{\mathrm{us}}-\mathrm{GDP}_{\mathrm{mx}}=0.835
$$

(standard error: 0.060).

The estimate of the constant in the cointegration vector is greater than zero and the standard error for the constant is relatively small. We interpret this as evidence of incomplete convergence in the sense that Mexico 
Table 2.2 Cointegration Analysis for Mexico and the United States, 1960Q4 to 2002Q4

\begin{tabular}{lcccccc}
\hline Eigen value & $L$-max & Trace & $H 0: r$ & $P-r$ & $L$-max90 & Trace90 \\
\hline 0.1671 & $30.17^{* *}$ & $32.91 * *$ & 0 & 2 & 10.29 & 17.79 \\
0.0165 & 2.74 & 2.74 & 1 & 1 & 7.50 & 7.50 \\
\hline
\end{tabular}

* Significant at the 5 percent level.

Source: Author's calculations.

is converging toward the U.S. level of income up to a point. That is, the observed process of convergence is unlikely to lead to absolute convergence but rather to a constant income differential. The estimated constant suggests that Mexico reaches about 40 to 50 percent of the U.S. per capita GDP. Whereas this evidence applies to the whole period, it is possible that this process of conditional convergence holds only for certain years.

Recursive cointegration analysis reveals that the $[1,-1]$ restriction does not hold in all subsamples (see figure 2.4). The graph in figure 2.4 is scaled in such a way that unity represents the 5 percent level of signif-

Figure 2.4 Trace Tests for Cointegration Between the United States and Mexico (Log) Quarterly GDP, 1960Q4-2002Q4

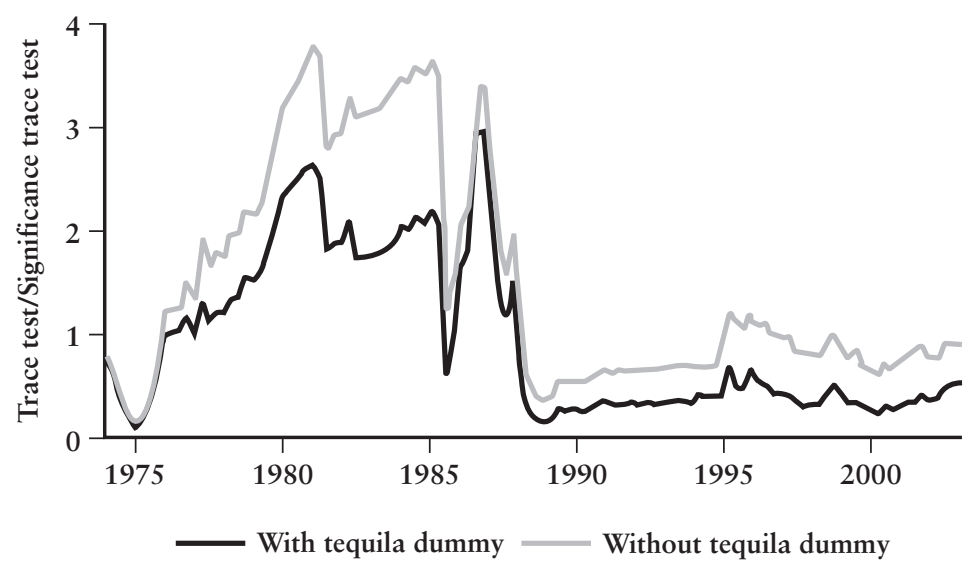

Note: Recursive estimates.

Source: Author's calculations-see text. 
icance. As such, a test statistic below one indicates that the hypothesis of convergence cannot be rejected. In particular, we find strong evidence for divergence during the 1980s (debt crisis), despite the fact that we estimated the cointegration vector with dummies that properly identify the key first and fourth quarters of $1982 .^{7}$

To assess the impact of the 1994/95 Tequila crisis on the convergence process, we perform a recursive cointegration analysis with and without a dummy for the Tequila crisis. As can be seen in figure 2.3, which plots the cointegration trace test over time, the Tequila crisis had an impact on the convergence process. When we include a crisis dummy, we find evidence of a resumed convergence process from 1987/88 onward. Without the Tequila dummy, the convergence hypothesis is rejected around the time of the crisis. This suggests that the Tequila crisis temporarily interrupted an ongoing convergence process that started at the beginning of the 1990s.

The evidence from time-series analyses can be summarized as follows. Structural time-series modeling and recursive cointegration analysis both identify periods of convergence and divergence between Mexico and the United States during 1960-2002. Both econometric techniques find evidence that the Tequila crisis only temporarily interrupted a convergence process that started in the late 1980s. But this process seems to have a limit. The time-series perspective on convergence has allowed us to recover interesting stylized facts about the underlying dynamics of the U.S.-Mexican convergence process, but as highlighted by figure 2.1, it is possible that other economies grew just as fast or even faster than Mexico relative to the United States since the late 1980s. Therefore, to better identify the Mexico-specific process of convergence toward the U.S. level of development we now examine Mexico's performance relative to other regional economies.

\section{Mexico's Performance Relative to Other Latin American Countries}

To know how Mexico performed in closing the per capita income gap relative to the United States in comparison with other Latin American countries that did not enjoy the benefits of NAFTA but did reform their economic policies, we tested whether there was a significant statistical difference between the year effects for a group of Latin American countries and the year effects specific to Mexico. The dependent variable was the $(\log )$ ratio of GDP per capita of the countries relative to the United States, and it is summarized in table 2.10 in the appendix to this chapter. The test was conducted with two samples of Latin American countries that include Mexico, one that consisted of 23 countries and another of 9 countries. The list of countries appears in table 2.11 in the appendix. 


\section{Figure 2.5 Mexico Year Effect Minus Latin America and the Caribbean Year Effect, Log}

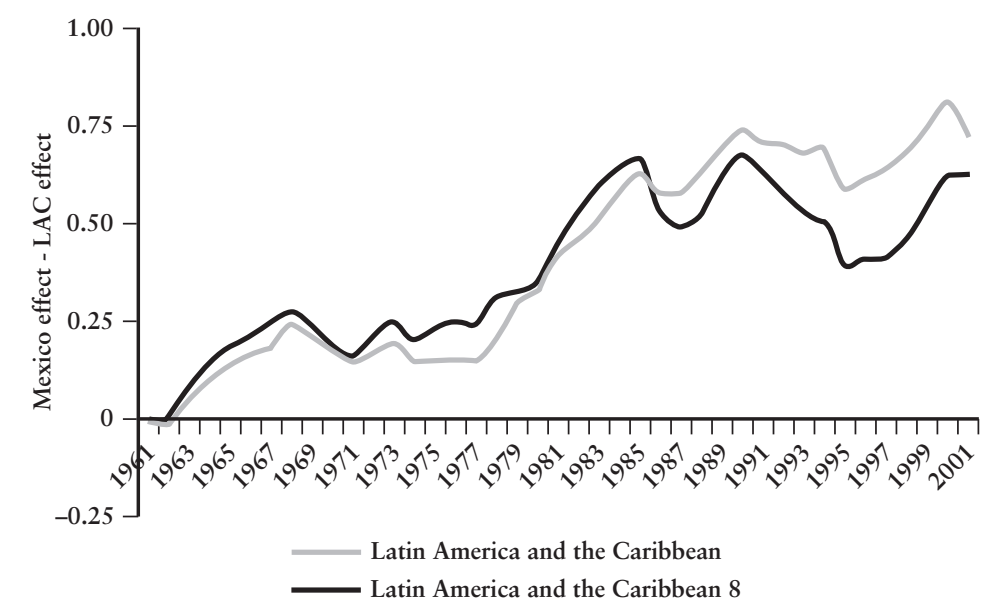

Note: GDP per capita/U.S. GDP per capita, PPP. The excluded year is 1960. The Latin America and the Caribbean 8 refer to the eight countries other than Mexico that make up group 2 in table 2.11.

Source: Author's calculations.

The results are shown in figure $2.5{ }^{8}$ Mexico's year effects are statistically significantly different from the group of 21 other countries at a level of 10 percent of confidence since 1982. In other words, the annual observations shown in figure 2.4 are significantly different from zero only after 1982 . With respect to the smaller comparator group, Mexico's annual effects are also different during 1982-94 and 1999-2001.9 However, these differences simply reflect that Mexico tended to be significantly richer than other regional economies during these years. The real question is whether Mexico grew significantly richer than other Latin economies during these years, which should be reflected in upward movements of the country-effects differentials shown in figure 2.5. This only occurred after 1995 with respect to both comparator groups. For the larger group of Latin American and Caribbean economies, this might have also occurred during 1986-93.

The fact that Mexico did not catch up to the United States significantly faster than other middle-income countries (the eight included in the small 
comparator group) creates some doubts about the possibility that Mexico's unilateral reforms spurred convergence with respect to the United States to a greater extent than reforms in countries such as Chile or Costa Rica. In contrast, the post-NAFTA period is characterized by a declining U.S.-Mexico income gap, which declined faster than for the average Latin economies included in both samples. Following the analysis of the dynamics of convergence process, the next sections in this chapter try to identify the underlying constraints of the U.S.-Mexico convergence process.

\section{Income Gaps and Institutional Gaps}

As discussed in the introduction, there is a substantial body of literature that highlights the role of institutional differences in producing crosscountry differences in income per capita (Acemoglu, Johnson, and Robinson 2001; Hall and Jones 1999). Despite trade liberalization and

Figure 2.6 Institutional Gaps in North America, 2000/01

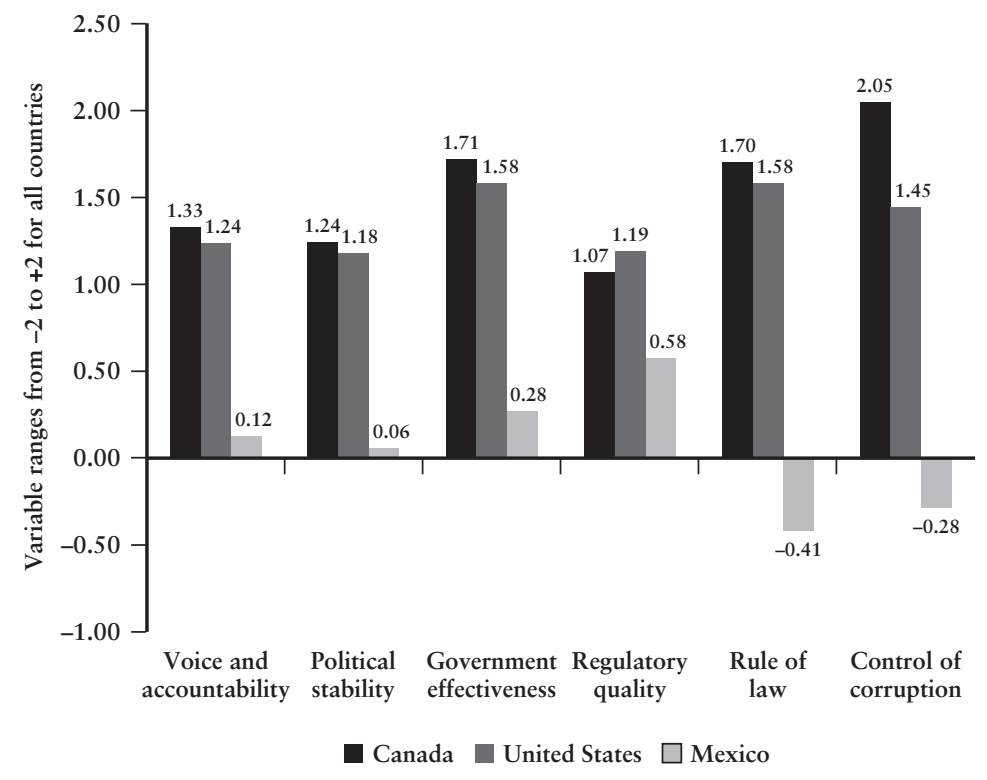

Source: Kaufmann and Kraay 2002a. 
the institutional harmonization requirements imposed by NAFTA (e.g., intellectual property rights, investor protection, and environmental standards), there are obvious remaining institutional gaps between the United States and Mexico. Based on data from Kaufmann and Kraay (2002a), figure 2.6 shows the gaps along six dimensions. It is clear that in 2000/01 Mexico lagged behind its North American partners in all institutional dimensions, especially in corruption and rule of law. If these institutional differences persist, it is likely that absolute income convergence, as predicted by neoclassical economics, will never materialize even if trade is completely liberalized. These types of impediments to convergence are difficult to identify with time-series analyses, such as those presented in the previous section, mainly because institutional gaps can be rooted in history and tend to vary little over time.

The experience of Puerto Rico (recall figure 2.1) can provide a useful medium-term perspective on how institutional convergence might affect convergence. Since Puerto Rico became a commonwealth territory of the United States in 1952, it gained not only free trade in goods and factors of production, but in practice also gained some of the political and regulatory institutions available in the United States. In addition, firms gained tax incentives for setting up operations on the island. Hence it is not surprising that the income gap between Puerto Rico and mainland United States narrowed significantly in the last 50 years, especially when compared to the income gaps with respect to Mexico and other Latin American countries. In what follows we attempt to estimate the role of institutional gaps in maintaining long-run income gaps.

\section{Data and Methodology}

To investigate the impact of institutional gaps we follow the methodology of Acemoglu, Johnson, and Robinson (2001). Briefly put, we use a set of exogenous variables related to geographic characteristics (regional dummy variables, landlocked-country dummy, latitude, and dummies for oil and commodity exporters), a constructed trade share indicator that takes into consideration countries' size and geographic factors (from Frankel and Romer 1999), an indicator of ethnolinguistic fractionalization, and a composite index of the Kaufmann-Kraay indicators of institutional quality from 2000/01 as explanatory variables of income per capita (U.S. dollars on a PPP basis) as of the year 2000. ${ }^{10}$ Table 2.9 in the appendix contains the summary statistics for our data set. Our methodology is two-stage least squares (TSLS).

Because the indicators of institutions and the corresponding composite index can be endogenous to the level of development, we need to find instruments for this variable. Also, the institutional variables are measured with error, as explained by Acemoglu, Johnson, and Robinson 
(2001) and by Kaufmann and Kraay (2002a). A priori, it is difficult to say which effect will predominate because the endogeneity problem could bias the estimates upwards if income improves institutions, whereas the measurement error problem could produce an attenuation bias.

Acemoglu and his coauthors showed that the $(\log )$ mortality rates of settlers can be a good instrument for current institutions. These authors relied on a long historical body of literature linking the importation of political and economic institutions to the extent to which colonies were settled by their European colonizers, as opposed to becoming sources for the extraction of high-priced commodities. Where Europeans settled they imported "good" institutions. However, Europeans had incentives not to settle in places where the climate and other historical factors reduced life expectancy. Consequently it seems logical to use settler mortality rates in the 18th and 19th centuries as instruments for institutions in the present.

\section{Results}

Table 2.3 contains a set of results. Panel A contains the estimated effects of the key variables on the $(\log )$ income per capita on a PPP basis as of 2000. Panel B shows the first stage regressions, where the composite index of institutional quality is the dependent variable. Panel C shows the corresponding ordinary least squares (OLS) regressions, which depend on the assumption that institutions are exogenous.

In the five specifications shown in table 2.3, the instrumented composite index of institutions is positively and significantly correlated with income. In fact, across the five models the relevant coefficient is quite stable, ranging from 1.35 to 1.94 . The only other "robust" explanatory variable is the dummy for oil exporters, which appears consistently with positive and significant coefficients. It is interesting that the FrankelRomer trade openness indicator is not a significant determinant of income per capita. Virtually identical results were obtained when we used the Sachs-Warner (Sachs and Warner 1995) policy openness index average for 1965-90 instead of the Frankel-Romer constructed trade share. These results can be interpreted as an indication that the long-run level of development of countries is mainly determined by the quality of domestic institutions, or that the correlation between the instruments used by Frankel and Romer to estimate the exogenous portion of the tradeto-GDP ratios (the so-called geographic gravity variables) and the settlers' mortality rates is so high that it is quite difficult to identify the marginal effects of institutions and trade separately (Dollar and Kraay 2003).

The results for the first-stage OLS regressions show that the $(\log )$ settlers' mortality rates are good predictors of institutional quality in 2000. The mortality variable is always statistically significant and with the expected negative sign. The comparison of the OLS and TSLS estimates of 


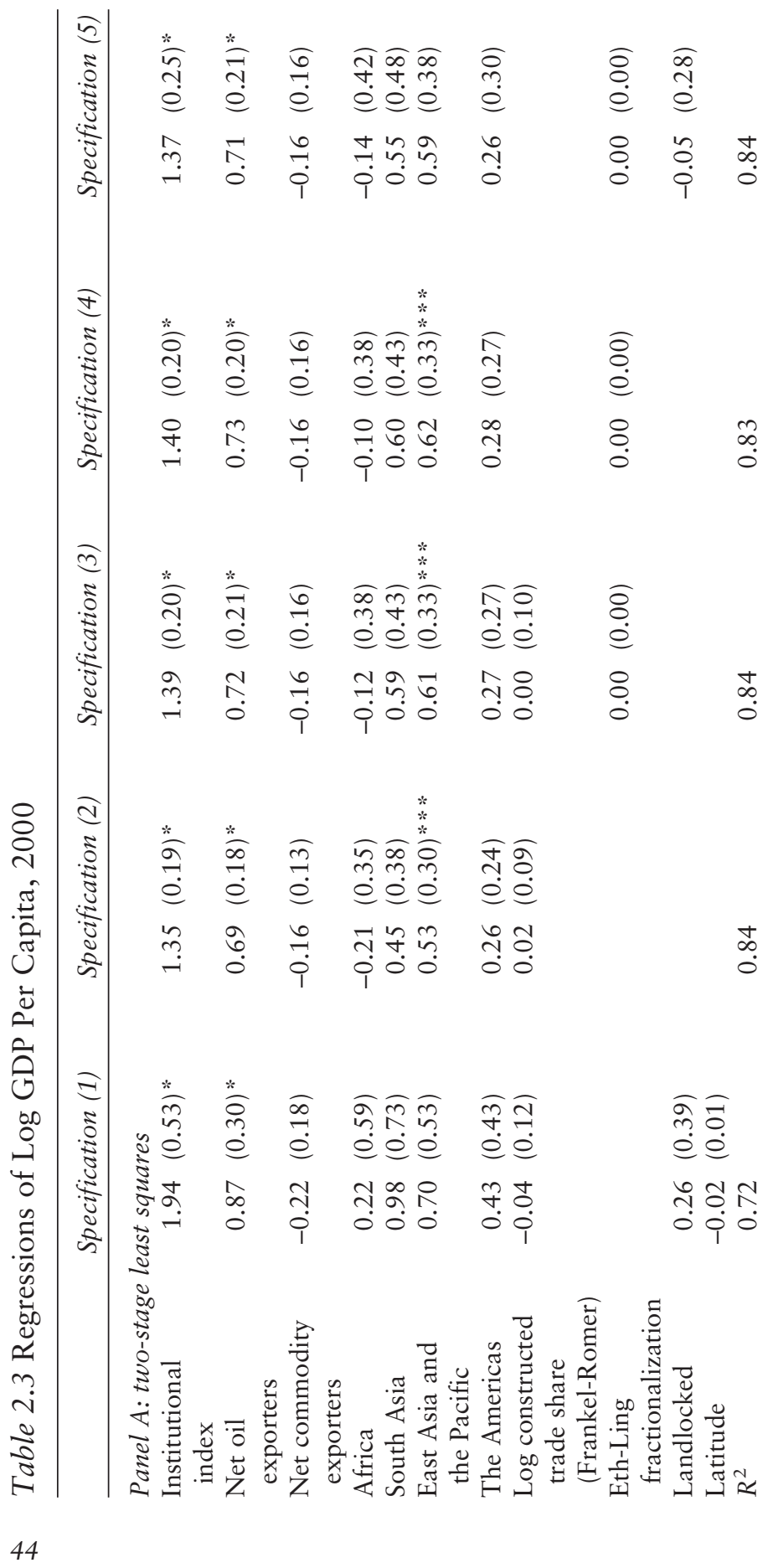




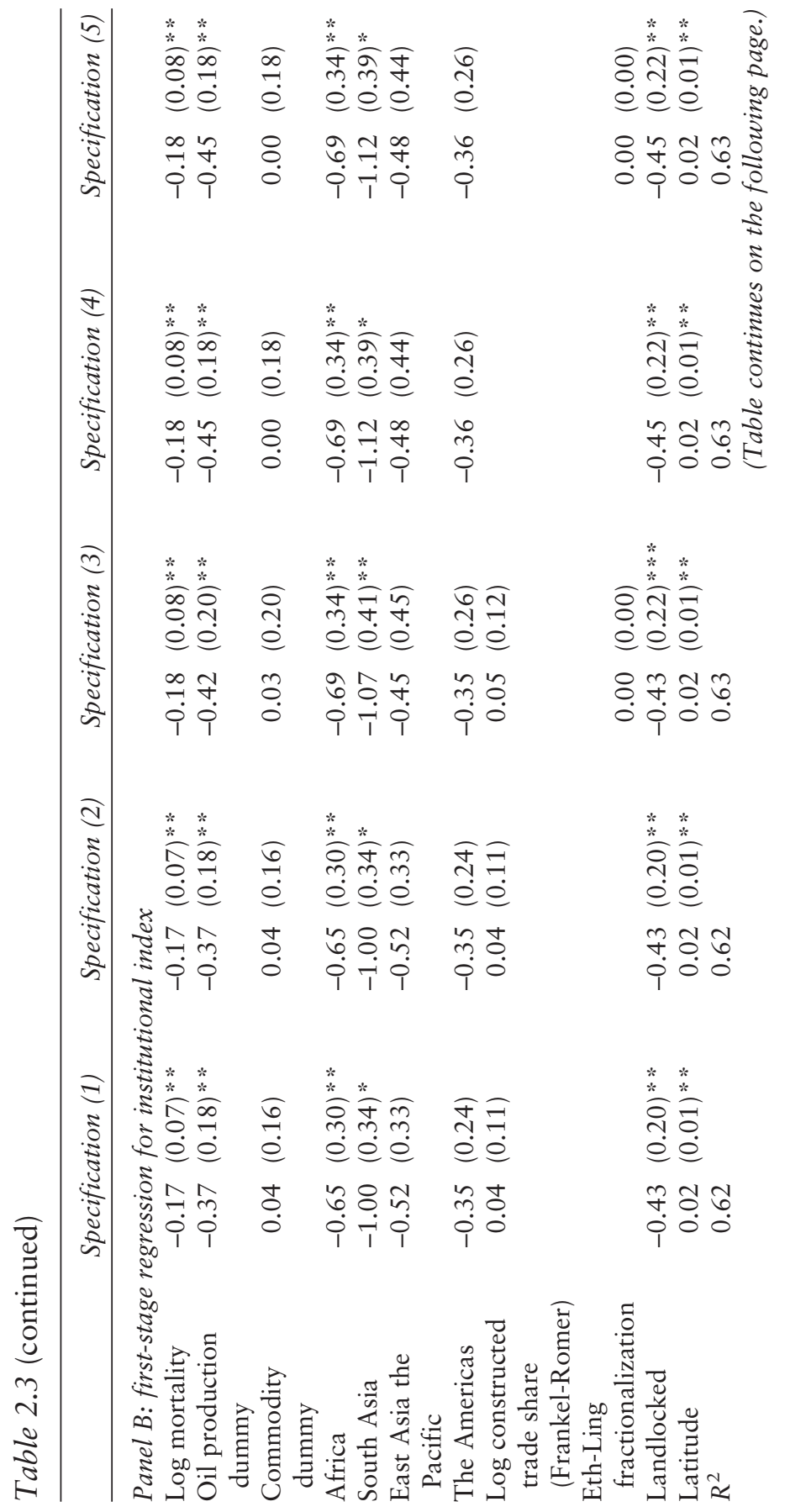




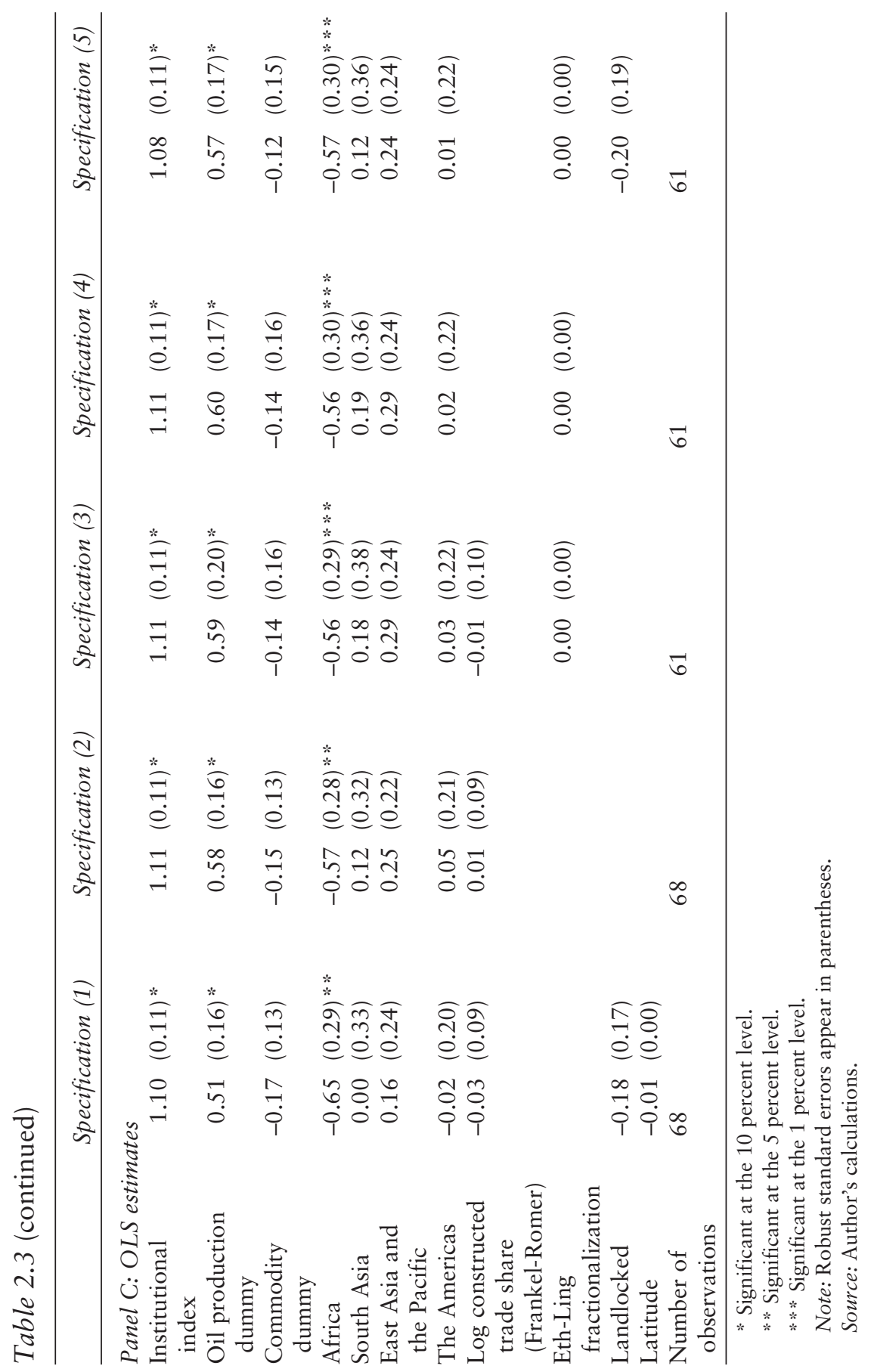


the institutional coefficient shows that the OLS estimates are significantly lower. These results suggest that OLS estimates suffer from attenuation bias as a result of measurement errors afflicting the institutional variable.

Figure 2.7 illustrates how these econometric results shed light on the income gap observed between the United States and Mexico. The last bar on the right is the income gap (the difference in the log of GDP per capita on a PPP basis) as of 2000, which is approximately 1.2. The penultimate bar shows the model's (column [1] of table 2.3) estimated income gap. The other bars show the marginal effects of the statistically significant variables on the (log of) of the U.S.-Mexico income gap. Mexico's status of a net exporter of oil tends to reduce the income gap by about 0.88 . In contrast, the first six bars on the left of figure 2.7 show the contribution of each institutional dimension. The sum of the individual institutional contributions is about 2.5 , but gaps in rule of law and corruption seem to be a bit more important than the other institutions, although the measurement errors in each category probably make this last observation less meaningful because we cannot be sure that these institutional gaps are significantly different from the others. In any case, the large income gap observed between the United States and

Figure 2.7 Contribution of Institutional Gaps to the U.S.-Mexico Income Gap

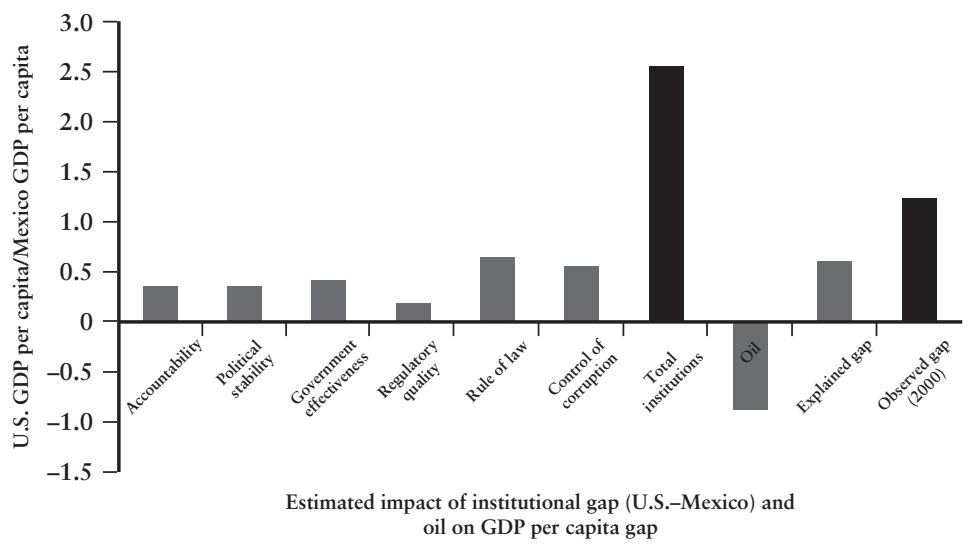

Source: Author's calculations. 
Mexico is readily explained by institutional features. Moreover, if Mexico were not an oil exporter it would probably be poorer than it actually is. Finally, the full model predicts a log ratio of U.S. over Mexican GDP per capita of about 0.62 , which translates into a 0.54 ratio of Mexican GDP per capita over the U.S. GDP per capita. It is perhaps a coincidence that this is more or less the limit to the convergence process estimated with the cointegration analysis discussed above.

So institutional gaps might hamper convergence in North America. However, this does not mean that trade reforms and NAFTA in particular did not have an effect on institutional convergence. We have already seen that time-series analyses suggest that convergence was in fact present after NAFTA. Was this the result of institutional convergence?

\section{Institutional Performance in Mexico vs. the Rest of Latin America and the Caribbean}

Since NAFTA was implemented it was expected that the agreement would put direct and indirect pressures on Mexico to improve its institutions. The direct pressures came from specific elements of the trade agreement, including those related to investor protection, intellectual property rights, and the labor and environmental trade side-agreements, which explicitly focus on Mexico's enforcement of its own laws. The indirect pressure could have emanated from the political debate in the United States regarding Mexico's ability to implement its commitments.

To test whether this has happened we estimated regressions similar to those concerning the income gaps presented in figure 2.4. The dependent variable was the difference between the country's composite institutional indicator comprising three indexes of institutional quality provided by the International Country Risk Guide (ICRG) and the U.S. value of this index. The index was constructed using factor analysis of ICRG's absence of corruption, law and order, and bureaucratic quality variables, and is summarized in table 2.10 in the appendix to this chapter. These data cover 1984-2001. Again, for the comparisons we used two samples consisting of 23 and 9 comparator countries (see table 2.11 in the appendix). Figure 2.8 shows the results. With respect to the first group of Latin American countries, Mexico's year effects were not statistically different, but they were statistically different from the average for the group of other 22 countries since 1994. Mexico seems to have underperformed relative to the regional average during this period, which is reflected in a declining or stable negative difference between Mexico and the average Latin American and Caribbean effects.

Even though Mexico has improved its institutions relative to the United States in the post-NAFTA period, the results in figure 2.8 arise from the fact that other countries from the region also improved their 
Figure 2.8 Mexico Year Effects relative to Latin America and the Caribbean Year Effects, Institutional Index

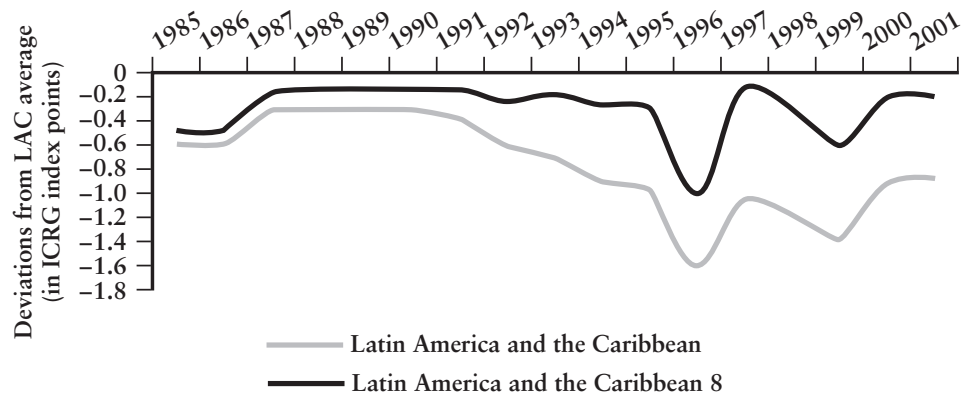

Note: The excluded year is 1984. LAC = Latin America and the Caribbean. Source: Author's calculations.

institutions without benefiting from NAFTA. Table 2.4 shows the changes in the gap of the composite institutional index before and after 1994 with respect to the United States. The countries that improved their institutional gap the most after 1994 were Chile and Central America, whereas Mexico's improvement was rather the norm for the whole region. Moreover, Mexico's big improvement took place after 1999 and thus it was probably related to the political transition, as was the case in Chile and Central America. These data are consistent with the findings of Lederman, Loayza, and Soares (2002) who found that political democratization has a positive effect in terms of reducing corruption in a large sample of countries. Thus NAFTA alone is unlikely to contribute to the institutional development of Mexico outside the specific areas covered by the agreement. Consequently, Mexico's policy efforts to combat corruption and improve general institutions need to be pursued further.

\section{Productivity Gaps Within Industries Across the United States and Mexico}

We have already mentioned that if NAFTA trade liberalization helped technological adoption and modernization in Mexico we should observe an acceleration in the rate of TFP convergence within industries between the United States and Mexico. To examine this channel of convergence we 
Table 2.4 Institutional Changes in Latin America

\begin{tabular}{lccr}
\hline & $\begin{array}{c}\text { ICRG Index } \\
\text { Points } \\
\text { Pre-NAFTA } \\
\text { Country/Group }\end{array}$ & $\begin{array}{c}\text { ICRG Index } \\
\text { Points } \\
\text { Post-NAFTA }\end{array}$ & \\
\hline Argentina & $1984-93$ & $1984-2001$ & Change \\
Andean countries & -1.98 & -1.60 & 0.39 \\
Brazil & -1.49 & -1.05 & 0.43 \\
Central America & -1.00 & -1.57 & -0.57 \\
Chile & -2.51 & -1.61 & 0.90 \\
Colombia & -1.55 & -0.73 & 0.82 \\
Latin American & -1.80 & -1.91 & -0.11 \\
$\quad$ countries & -1.83 & -1.53 & 0.30 \\
Mexico & & & \\
South America & -1.80 & -1.46 & 0.34 \\
\hline
\end{tabular}

Note: These are the gaps relative to the United States in terms of the International Country Risk Guide (ICRG) composite index. Index points specifically refer to U.S. index minus country/region index points.

Source: Author's calculations based on data from the ICRG.

calculated TFP differentials in manufacturing sectors between the two countries. The following paragraphs discuss the data, methodologies, and econometric results concerning the impact of NAFTA on TFP convergence.

\section{Data and Estimates of Total Factor Productivity}

To measure differences in TFP we followed the approach suggested by Caves, Christensen, and Diewert (1982), which has been used in the cross-country context by Keller (2002). They calculated a multilateral (bilateral in our present case) and flexible TFP index of the following form:

$$
\begin{aligned}
\ln T F P_{c i t}= & \left(\ln Y_{c i t}-\overline{\ln }_{i t}\right)-\overline{\sigma_{c i t}}\left(\ln L_{c i t}-\overline{\ln L}_{i t}\right) \\
& -\left(1-\bar{\sigma}_{c i t}\right)\left(\ln K_{c i t}-\overline{\ln K}_{i t}\right)
\end{aligned}
$$

where $c$ is the country index (Mexico and the United States), $i$ represents industries, and $t$ is time. $Y$ is total output, $L$ is labor, and $K$ is capital stock. $\sigma$ is the cost-based labor share of output. The Caves et al. approach entails de-meaning of the log output, labor and capital series, using the geometric averages of both countries. The resulting TFP index in each country and industry is based on a vector of outputs and inputs that are common to both countries. Intuitively, this index tells us the productivity level in each country and industry if each had the same outputs and inputs. 
Data on production and factor shares come from the OECD and the United Nations Industrial Development Organization and cover 28 manufacturing industries at the three-digit International Standard Industrial Classification code (see table 2.7 in the appendix for the industry codes). ${ }^{11}$ The output data were deflated using the U.S. industry deflators from Bartelsman. Becker, and Gray (2000) because there are no existing series of PPP-adjusted sectoral output data for Mexico. The capital stock data were constructed using the permanent inventory method, assuming a 5 percent depreciation rate per year, based on fixed investment, and were deflated using the PPP investment price levels from the Penn World Tables 6.0. ${ }^{12}$ Table 2.8 in the appendix to this chapter contains summary statistics on the industry-level data for the United States and Mexico.

\section{Estimation Strategy}

To assess how the rate of $(\log )$ TFP convergence changed after the implementation of NAFTA we estimated an autoregressive model with structural change in the autoregressive coefficient with industry fixed effects:

$$
\begin{aligned}
y_{i, t} & =\alpha_{i}+\beta y_{i, t-1}+\lambda D_{F T A} y_{i, t-1}+\delta D_{F T A}+\varepsilon_{i, t}, \\
i & =1,2, \ldots, N ; t=1,2, \ldots, T .
\end{aligned}
$$

As mentioned, the number of industries is $N=28$ and the maximum number of years is $T=25$. In the context of the fixed-effects estimator, designed to control for industry-specific effects, $\alpha_{i}$, by de-meaning both the left- and righthand side variables, the estimated coefficients could be biased as a result of the correlation between the lagged mean of $y$ and the contemporaneous error, $\varepsilon_{i, t}$. The bias is inversely proportional to $T$ (Anderson and Hsiao 1981). Also as mentioned, there are no good data on Mexico's PPP-adjusted unit prices for industry-level output so the use of the U.S. deflator might have introduced a measurement error that is endogenous to (i.e., affected by) the trade liberalization efforts. This is a concern because trade reforms reduced the output price differences between the United States and Mexico and thus the TFP estimates for Mexico could be systematically biased after liberalization. Finally, it is possible that trade reforms themselves (including the sector-specific tariff phase-out periods) were implemented when industrial productivity was rising, thus producing another source of biases in our proposed exercise. For these reasons we used the Arellano-Bond (1991) differences estimator to estimate model 2.2. This estimator helps reduce the influence of the endogeneity biases discussed above by using lagged levels of the TFP differentials to instrument for the changes in these differentials. Hence we also control for unobserved industry-specific effects. 
In (2.2), the autoregressive coefficient, $\beta$, provides an indication of the speed of convergence. When this coefficient is less than 1 it can be interpreted as evidence of convergence in TFP levels between the United States and Mexico. If NAFTA was associated with an acceleration of TFP convergence then the estimated coefficient of the corresponding interactive variable should be negative, which entails an increase in the speed with which productivity improvements in the United States are diffused into Mexican manufacturing.

\section{Results}

Table 2.5 reports the results from the Arellano-Bond differences estimator applied to the model suggested by equation 2.2 plus additional controls for the potential effect that Mexico's unilateral liberalization (from 1985) might have had on TFP convergence. The second model focuses on the gap in labor productivity for comparisons because these data are not affected by the lack of a Mexican fixed investment deflator for the 28 manufacturing industries. In both cases the models pass the specification tests, which indicates that the instrument set is adequate and there is no serial correlation. This suggests that the coefficients are not biased owing to measurement error in the output series. Also in

Table 2.5 Did NAFTA Accelerate Manufacturing TFP Convergence? Arellano-Bond GMM Regression Results

\begin{tabular}{lcc}
\hline & $\begin{array}{c}\text { Log TFP } \\
\text { Differential } \\
\text { (Mexico-U.S.) } \\
(2.1)\end{array}$ & $\begin{array}{c}\text { Log Output per } \\
\text { Worker Differential } \\
\text { (Mexico-U.S.) }\end{array}$ \\
$\begin{array}{l}\text { Explanatory Variable } \\
\text { Log productivity }\end{array}$ & $\begin{array}{c}(2.2) \\
\text { differential }(t-1)\end{array}$ & $0.76 * * *$ \\
NAFTA $\times \log$ productivity & $-0.28 * * *$ & $-0.09 * * *$ \\
differential $(t-1)$ & & \\
Lib $\times \log$ productivity & -0.03 & 0.04 \\
differential $(t-1)$ & & \\
Observations/industries & $462 / 28$ & $482 / 28$ \\
Sargan over-id test $(p$-value $)$ & 0.25 & 0.39 \\
Second-order serial & 0.32 & 0.87 \\
correlation test $(p$-value $)$ & & \\
\hline
\end{tabular}

$* *$ Significant at the 1 percent level.

Note: These are the first-step estimates. Year dummies are not reported.

Source: Author's calculations. 
both cases NAFTA was associated with a faster rate of manufacturing productivity convergence, as indicated by the highly significant and negative coefficients of the NAFTA dummy variable interacted with the lagged productivity differential. The TFP results (column 1, table 2.5) imply that the half-life of a unit shock to the TFP gap fell from 1.6 prior to NAFTA to 0.7 years after its implementation. The corresponding change for labor productivity (column 2, table 2.5) was from 2.5 to 1.7 years. These results are consistent with the estimates of the change in the degree of persistence of the U.S.-Mexico income gap discussed above.

In sum the econometric results strongly suggest that the NAFTA period was associated with a significantly faster convergence in manufacturing TFP levels. Hence we are tempted to postulate that the trade agreement had an important positive effect on Mexican manufacturing TFP. These results are consistent with firm-level evidence provided by López-Córdova (2002) and industry-level data presented by Schiff and Wang (2002). However, the former study argued that this effect was related to preferential market access to the United States and import competition but was not the result of imports of intermediate goods. In contrast, the study by Schiff and Wang argued that Mexico benefited from imported intermediate goods from the United States, depending on the extent of R\&D effort in the United States. Our results seem to indicate that NAFTA brought something to the table that was not necessarily accomplished by unilateral liberalization, but we have not speculated about the exact channels of influence. In our view this issue remains an open question for future research.

Having reviewed the times-series evidence concerning income convergence and the panel evidence concerning TFP convergence between the United States and Mexico, we now turn to the impact of NAFTA within Mexico. If geography and initial conditions play an important role in economic convergence then NAFTA might have had a notable impact on income differentials across Mexican states.

\section{Initial Conditions and Divergence Within Mexico}

It is standard practice in analytical work on economic growth to examine potential determinants of growth in a set of geographic entities using econometric techniques (see the textbook by Barro and Sala-I-Martin 1995). This approach was previously applied to the case of Mexico by Esquivel (1999) and Messmacher (2000). Here we use the same standard approach but we attempt to focus on a small set of policy-related variables that determined initial conditions in each Mexican state. In the following paragraphs we describe the data and methods used to address these questions. ${ }^{13}$ 


\section{Data and Methodologies}

We want to explain the rate of growth of state GDP per capita during 1990-2000 (at constant prices of 1993). ${ }^{14}$ As mentioned, this is the period when trade liberalization and NAFTA must have been felt. It is also a period that is sufficiently long so that the cumulative growth rate during this whole period could reflect medium-term phenomena rather than merely short-lived conditions such as the economic crisis of 1995. Figure 2.9 shows the evolution since 1940 of the ratio of GDP per capita in a selection of northern and southern states relative to the Distrito Federal (D.F.), the capital of the Republic. The big story is, again, that the D.F. was richer and stayed richer for the last 60 years or so. In fact it is difficult to argue that any of these states managed to significantly catch up in absolute terms, despite the fact that free trade within Mexico has existed

Figure 2.9 Ratio of State GDP Per Capita Relative to the Distrito Federal, 1940-2000

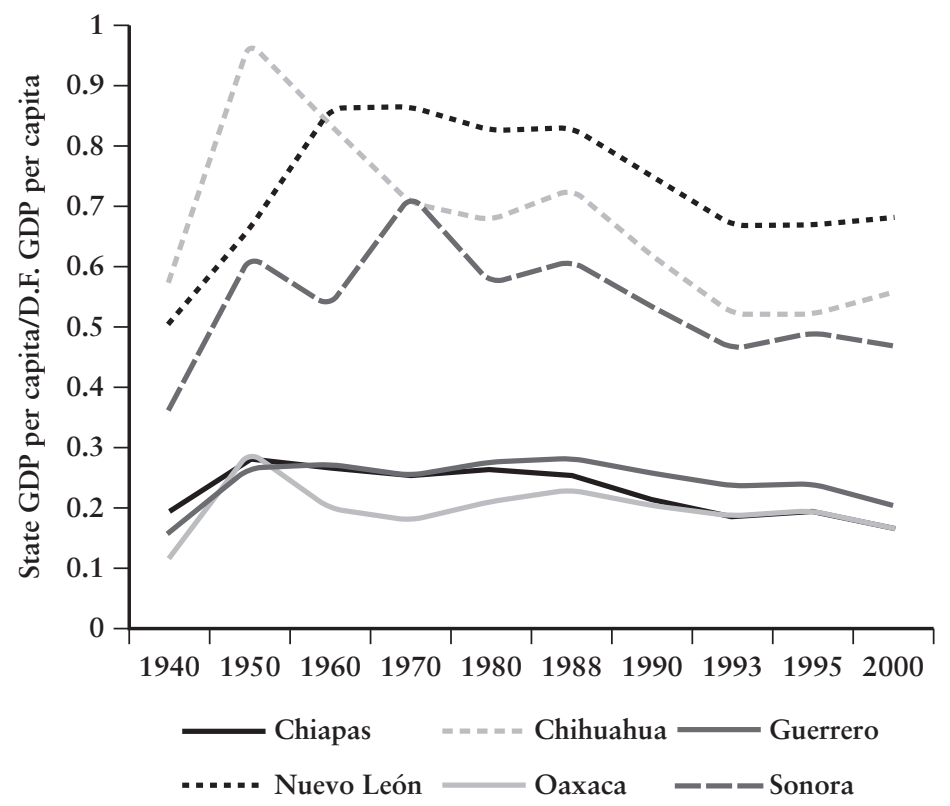

Source: Author's calculations. 
for a long time. Also it looks like the 1990s were characterized by a slight catch-up in the northern states and by continuing divergence of the southern states relative to the D.F.

What are some factors that might help explain why some states grew more than others? Given the issues raised by the literature concerning the role of geography and transportation or coordination costs in hampering convergence, one set of key explanatory variables are indicators of transportation and communications infrastructure, which we measured by the kilometers of paved highways per worker and by telephone density. ${ }^{15}$ We also used the distance from the U.S. border as an additional explanation of economic growth to assess the argument that being far from the United States was an impediment to growth. ${ }^{16}$

It is conventional wisdom that the level of education of the adult population might be related to the rate of growth. Hence we also examined the impact of educational attainment in the year 1990 as an explanation of growth rates during the subsequent period 1990-2000. In this way we can be sure that growth did not cause the level of education. We also experimented with literacy rates of the adult population instead of the years of schooling.

It is often argued that poor states grow slower because they receive insufficient public resources to finance their growth. It could be argued, for example, that private capital markets do not provide sufficient financing for the development of lagging regions because of various types of obstacles to private financing related to insufficient information about the capacity to pay back loans by firms operating in those areas. However, it is also possible that large public sectors can be a drain on economic growth by distorting the local labor markets (e.g., raising wages above what private enterprises can pay) or by raising the costs of capital that would otherwise have gone to the private sector (i.e., the socalled crowding-out effect of public expenditures). To assess these alternative arguments we looked at the impact of the size of the public sector, measured as the share of public employment in total employment, on the growth rates of Mexican states.

To assess whether the really poor states-Chiapas, Guerrero, and Oaxaca-had other characteristics that hampered their prospects for development, we also included a dummy variable that identifies these states. Finally we included the initial level of GDP per capita to test the conditional convergence hypothesis. The data used in this analysis are provided in table 2.12 in the appendix.

\section{Results}

Table 2.6 reports some of our results based on standard statistical techniques. The first two columns report results based on OLS, and the third 


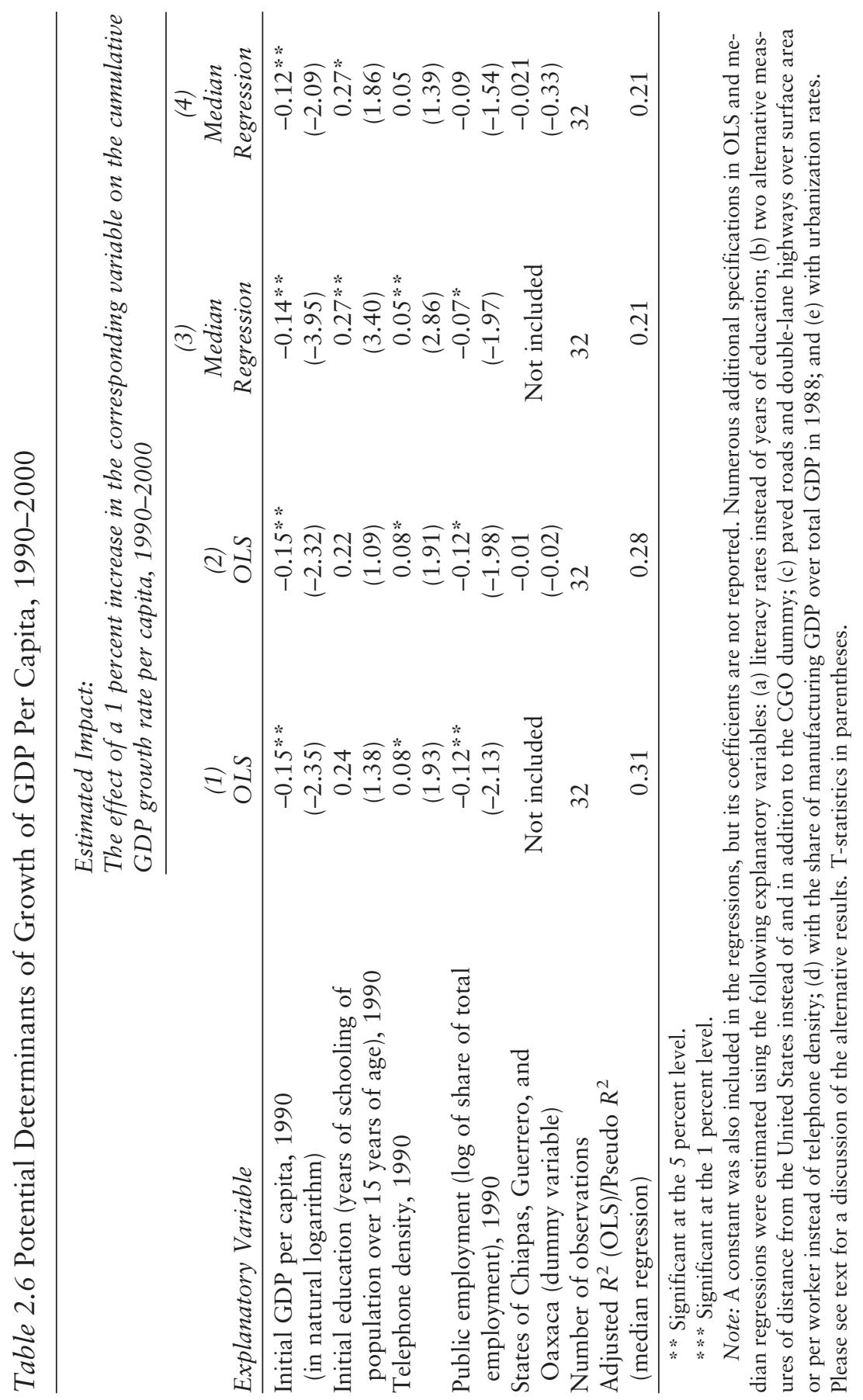


and fourth columns report results from an alternative technique, median regressions, which are less sensitive to outliers. It shows evidence of conditional convergence; the initial GDP per capita has a negative and statistically significant coefficient in the four exercises. Hence it seems that poor states do grow faster if they have policies that are similar to those of rich states.

The other explanatory variables, except the variable that identifies the southern states (Chiapas, Guerrero, and Oaxaca), also seem to be important for growth and are generally statistically significant. As expected, telephone density has a positive effect on growth. However, estimates using paved roads and paved roads with two lanes per worker (or over surface area) revealed that these variables were negatively correlated with growth during the period. ${ }^{17}$ Hence there is no evidence suggesting that building more roads will lead to higher growth in the future. This result might be caused by the existence of economically unnecessary infrastructure that does not serve a useful purpose for existing economic activity.

The results concerning the role of distance from the U.S. border (not reported here) indicate that this variable was not a statistically significant impediment to economic growth in most exercises, although the coefficient is always negative. ${ }^{18}$ When the distance variables were introduced, however, the statistical significance (but not the direction of the estimated effects) of the other explanatory variables was driven down. This evidence indicates that the states located farther from the United States also suffer from low levels of education and telephone density that hamper their growth prospects.

The level of education at the beginning of the period has no statistically important impact on growth in the OLS estimates. This result might be caused by the fact that human capital can migrate to dynamic regions, and thus this variable does not have any discernable impact on the state in which the estimates were calculated in 1990. When literacy rates were used instead of educational attainment, the estimated coefficient was positive and statistically significant. Moreover, the estimates based on median regressions forcefully show that educational attainment does matter. It is also possible that the correlation among telephone density, initial GDP per capita, and initial education makes it rather difficult to identify the impact of education.

An interesting result is that the share of public employment had a negative effect on economic activity. Figure 2.10 shows the simple correlation between these two variables-it is negative. It seems that this negative correlation might result from some observations that appear at the lower right of the chart. However, the median regression estimates, which are less likely to be disproportionately influenced by strange observations, also show that this variable had a negative effect on economic growth, although it was not statistically significant in the fourth column of 
Figure 2.10 Relationship Between Growth (1990s) and Public Employment in Mexican States

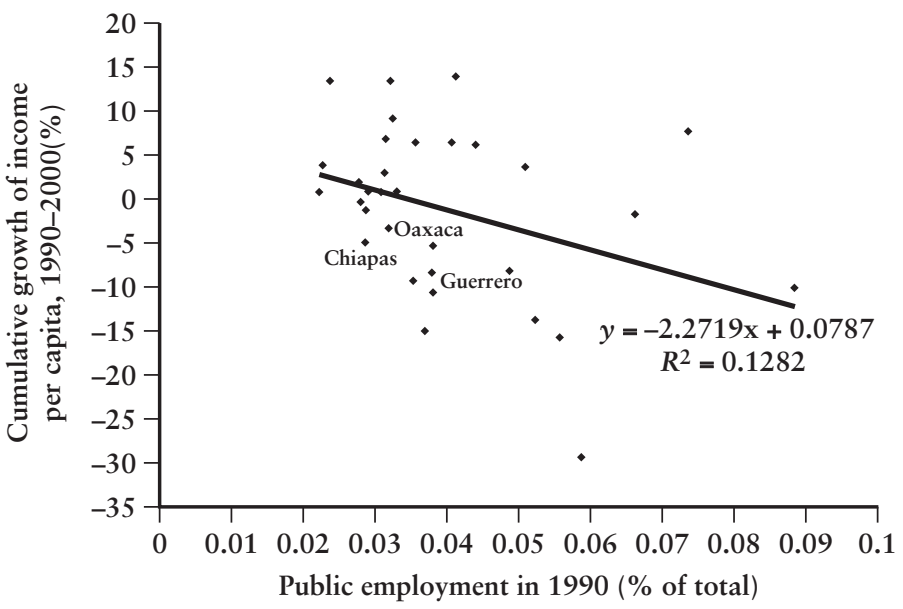

Source: Author's calculations.

table 2.4 after controlling for other unobserved characteristics of the southern states.

To be sure that the aforementioned explanations of the observed differences of growth rates across Mexican states are not misleading, we conducted additional exercises in which we controlled for the share of manufacturing production over total state GDP in 1990. As discussed in Esquivel et al. (2002), the southern states have never had a high share of manufacturing production, and for the country as a whole some manufacturing industries (and some services) grew quite rapidly during the 1990s. The performance of manufacturing relative to natural resource or agricultural industries could have resulted from changes in relative prices (e.g., the decline of international coffee prices began in the late 1980s). In any case, our statistical analyses indicated that the qualitative nature of the OLS results presented in table 2.6 are not affected by including the manufacturing share of production. In the relevant median regressions, however, including the share of manufacturing production affected the sign of the education and public employment variables, although none of them were statistically significant. This influence of manufacturing 
production on the estimated effect of education and public employment could be the result of a positive correlation between education and manufacturing production (which is 0.5 ) and a negative correlation with the share of public employment (which is, coincidentally, -0.5 ). In other words, manufacturing production seems to be concentrated in states with high levels of education and/or low levels of public employment. It is likely that the high mobility of new capital combined with the relative irreversibility of past investment make capital-intensive activities particularly sensitive to the initial economic environment in a state, and thus manufacturing is implicitly capturing things such as the rule of law, instability, crime, or excessive intervention by the state.

Thus far we have presented suggestive evidence indicating that hope for the southern states is not lost; there is some evidence of conditional convergence and some key policy-sensitive variables help explain the patterns of economic growth observed across Mexican states from 1990 to 2000. In particular, communications infrastructure (measured by telephone density) is more likely to have been positively associated with economic activity than are paved roads or highways. Also, there is no evidence to support the idea that increasing the size of the public sector can be a force for economic convergence. However, the big story remains that initial conditions seem to have had important effects on economic growth within Mexico during the 1990s, and thus states that were initially better prepared to reap the benefits of NAFTA grew faster during this period while the poor states of the south fell further behind.

\section{Conclusion}

In this chapter we analyzed the dynamics and sources of convergence between Mexico and the United States. Time-series analyses of the convergence process produced interesting stylized facts about the U.S.-Mexican convergence process and identified periods of convergence and divergence. Although convergence suffered a major setback in the 1980s because of the debt crisis, we find that the Tequila crisis only temporarily interrupted a convergence process that started in the late 1980s when Mexico opened its economy. However, we found evidence of only incomplete convergence in the sense that the constant in the cointegration space was greater than zero, which indicated that Mexico is converging toward a constant income differential of about 50 percent of the U.S. GDP per capita. In contrast, the comparison between annual Mexican relative income effects and average Latin American effects indicated that Mexico's convergence toward the United States was especially important after 1995. Finally, our estimates of the change in the autoregressive coefficient of the U.S.-Mexico income per capita gap suggest that 
Mexico's GDP per capita would have been about 4-5 percent lower by the end of 2002 if NAFTA had not been implemented.

The cross-country evidence showed that differences in institutional features inherited from history play an important role in producing income gaps. Consistent with previous studies (Acemoglu, Johnson, and Robinson 2001; Kaufmann and Kraay 2002b), the TSLS estimates produced much larger estimated effects of institutions on incomes than the OLS estimates, thus indicating that measurement error is an important source of attenuation bias in these relationships. The use of historical instruments for current institutional quality is also interesting on its own because it reflects that institutions tend to persist over time and thus might remain a source of income divergence for a long time. Future research could yield additional practical insights, however, if it focuses on the determinants of institutional quality. In particular, further understanding about the role of political institutions in determining the quality of governance and economic policy could help us understand what types of reforms may help overcome the weight of history. Recent research along these lines has already proved fruitful (Lederman, Loayza, and Soares 2002; Persson 2002). Still our understanding remains quite thin regarding how accountability mechanisms can help improve national institutions. In the case of North America, international economic convergence in the long run might depend on Mexico's capacity to catch up to the standards of its neighbors. In fact, the econometric analyses indicated that the model with institutions, geography, and trade predict about a 54 percent income gap in the U.S.-Mexico GDP per capita ratio, which is coincidentally similar to the incomplete convergence estimated using cointegration analysis. Furthermore, the quality of Mexican institutions did not improve significantly more than in other Latin American countries during the post-NAFTA period.

The analysis of TFP convergence within manufacturing industries produced more optimistic results concerning the impact of NAFTA. The evidence indicates that the agreement was associated with improvements in the rate of TFP convergence between the United States and Mexico. Although these results are broadly consistent with other studies (LópezCórdova 2002; Schiff and Wang 2002), those studies contradict each other in terms of the channels through which NAFTA is thought to have improved Mexican manufacturing TFP. Namely, López-Córdova argued that it was preferential access to the U.S. market (e.g., the tariffs faced by Mexican exporters to the United States) and import penetration, but not imports of inputs from the United States. Schiff and Wang argued that TFP improvements resulted from the R\&D content of imported inputs. In addition, we can think of other alternative hypotheses.

One possibility is that NAFTA, through its demand for improved protection of intellectual property rights and/or through increased 
international competition (for import-competing and exporting industries) provided incentives for improvements in private R\&D effort and patenting. As reported by Meza and Mora (2002) as well as in chapter 6 of this book, the post-NAFTA period was characterized by significant increases in $\mathrm{R} \& \mathrm{D}$ expenditures. The existing literature however, remains silent about this particular force toward convergence. An examination of these issues would require empirical work addressing the determinants of patenting across countries, with a special focus on the impact of trade policies and innovation policies. Much work remains to be done in this area, although there is an emerging body of literature (Furman, Porter, and Stern 2002). Lederman and Maloney (2003b) have shown that protection of intellectual property rights tends to increase R\&D effort relative to GDP in a broad panel of countries and that these expenditures are cyclical in the sense that they tend to rise with improvements in short-term growth (see chapter 6). Thus it is very likely that NAFTA helped Mexico improve its innovation through its intellectual property rights regime and by helping Mexico recover after the Tequila crisis. On the other hand, chapter 6 shows that the emerging manufacturing sectors under NAFTA (road vehicles, telecommunications equipment, and appliances) are not yet characterized by significant improvements in patenting activity, thus suggesting that there are significant efficiency problems related to the lack of linkages between R\&D performed by the public and higher-education sectors and the productive sector.

The study of growth patterns within Mexico during 1990-2000 showed that initial conditions determined which Mexican states grew faster. We interpret this evidence as showing that trade liberalization might be associated with economic divergence within countries because of differences in initial conditions. In the Mexican case, it seems that telecommunications infrastructure and human capital were especially important. In addition, it is commonly understood that the poor states suffer from poor public institutions and political instability (Esquivel et al. 2002). If the poor states had been adequately prepared to reap the benefits of free trade, they might have grown faster during this period. Thus economic convergence in North America might not materialize under free trade or under any trade regime as long as fundamental differences in initial conditions persist over time. It is fortunate that some of these fundamentals should be sensitive to policy changes.

\section{Appendix}

This appendix contains graphs and tables that describe the data used in the empirical analyses discussed in this chapter. 
Figure 2.11 Quarterly Data Used for Time-Series Analyses
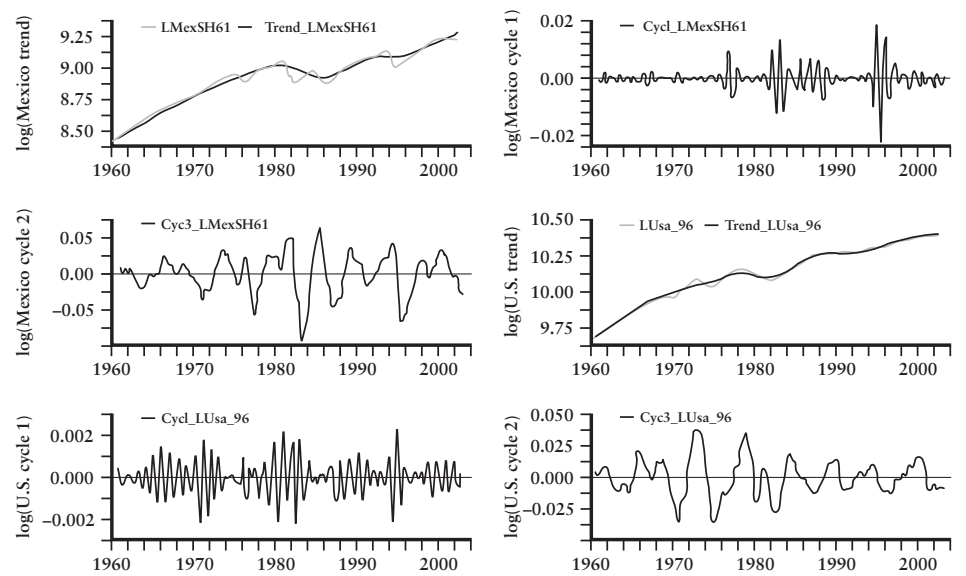

Source: Author's calculations. 
Table 2.7 List of Codes and Industries Used in TFP Convergence Analysis

\begin{tabular}{|c|c|}
\hline ISIC Code & Industry \\
\hline 311 & Food products \\
\hline 313 & Beverages \\
\hline 314 & Tobacco \\
\hline 321 & Textiles \\
\hline 322 & Wearing apparel, except footwear \\
\hline 323 & Leather products \\
\hline 324 & Footwear, except rubber or plastic \\
\hline 331 & Wood products, except furniture \\
\hline 332 & Furniture, except metal \\
\hline 341 & Paper and products \\
\hline 342 & Printing and publishing \\
\hline 351 & Industrial chemicals \\
\hline 352 & Other chemicals \\
\hline 353 & Petroleum refineries \\
\hline 354 & Miscellaneous petroleum and coal products \\
\hline 355 & Rubber products \\
\hline 356 & Plastic products \\
\hline 361 & Pottery, china, earthenware \\
\hline 362 & Glass and products \\
\hline 369 & Other nonmetallic mineral products \\
\hline 371 & Iron and steel \\
\hline 372 & Nonferrous metals \\
\hline 381 & Fabricated metal products \\
\hline 382 & Machinery, except electrical \\
\hline 383 & Machinery, electric \\
\hline 384 & Transport equipment \\
\hline 385 & Professional and scientific equipment \\
\hline 390 & Other manufactured products \\
\hline
\end{tabular}

Note: ISIC International Standard Industrial Classification. 


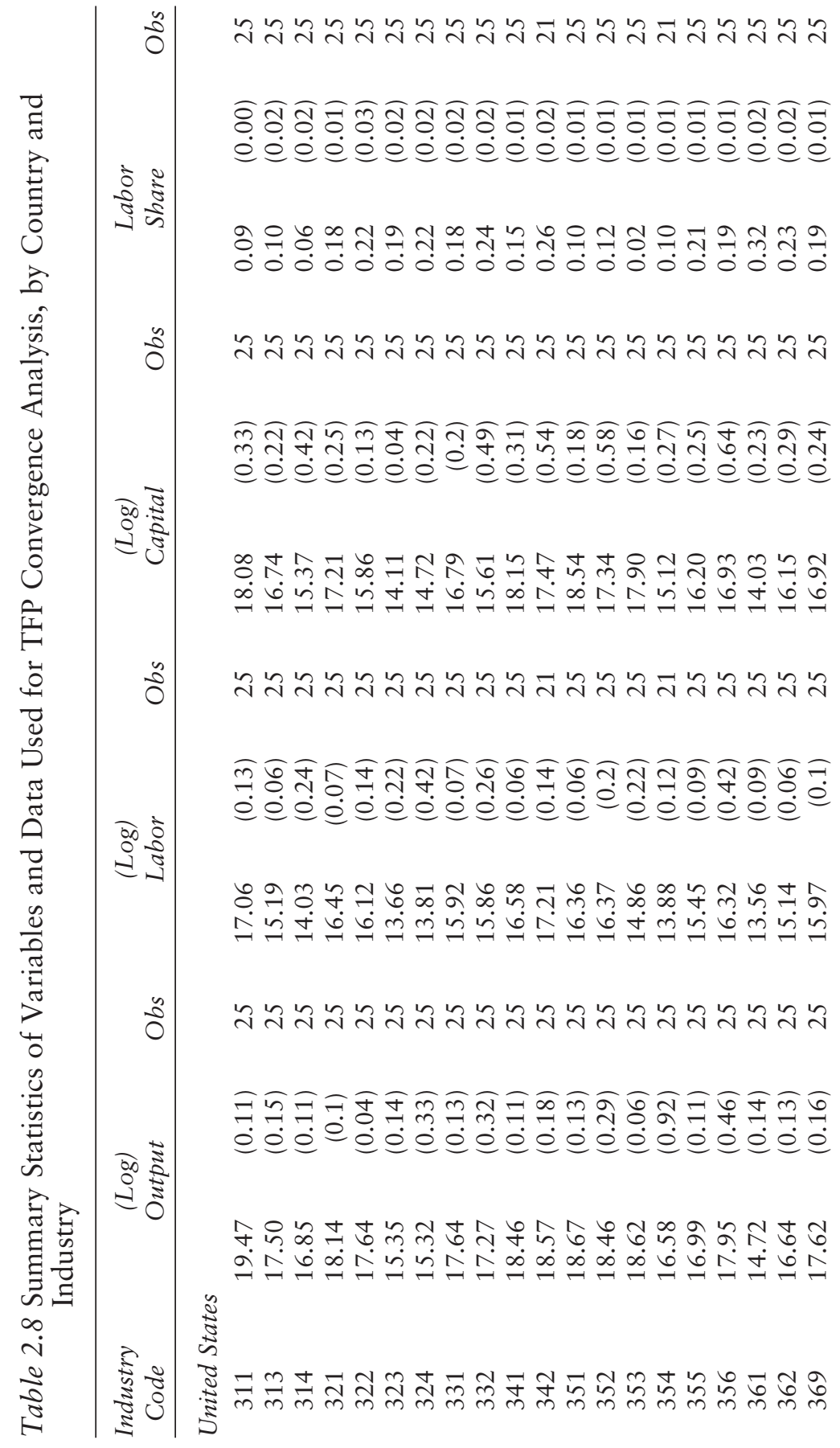




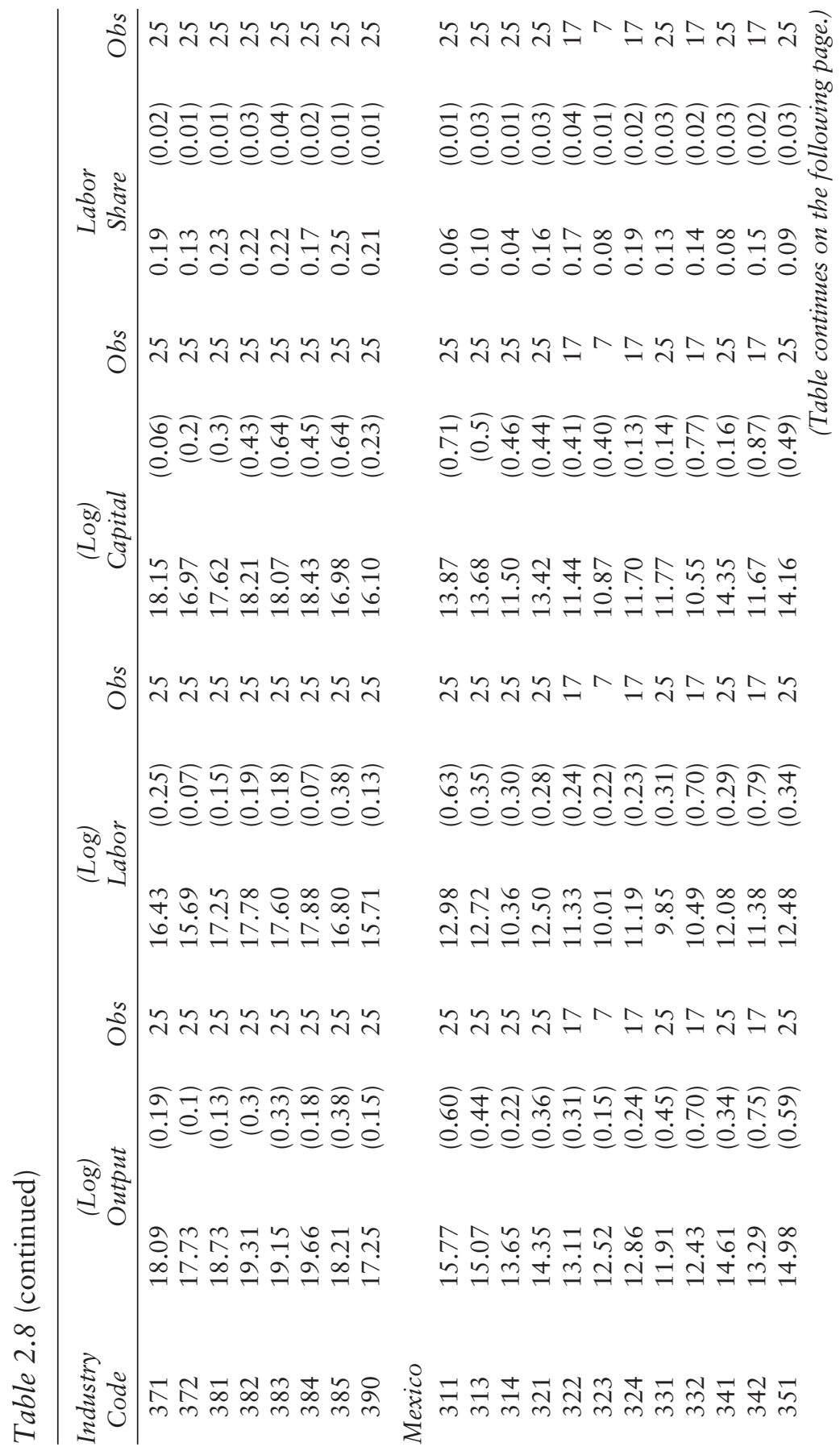




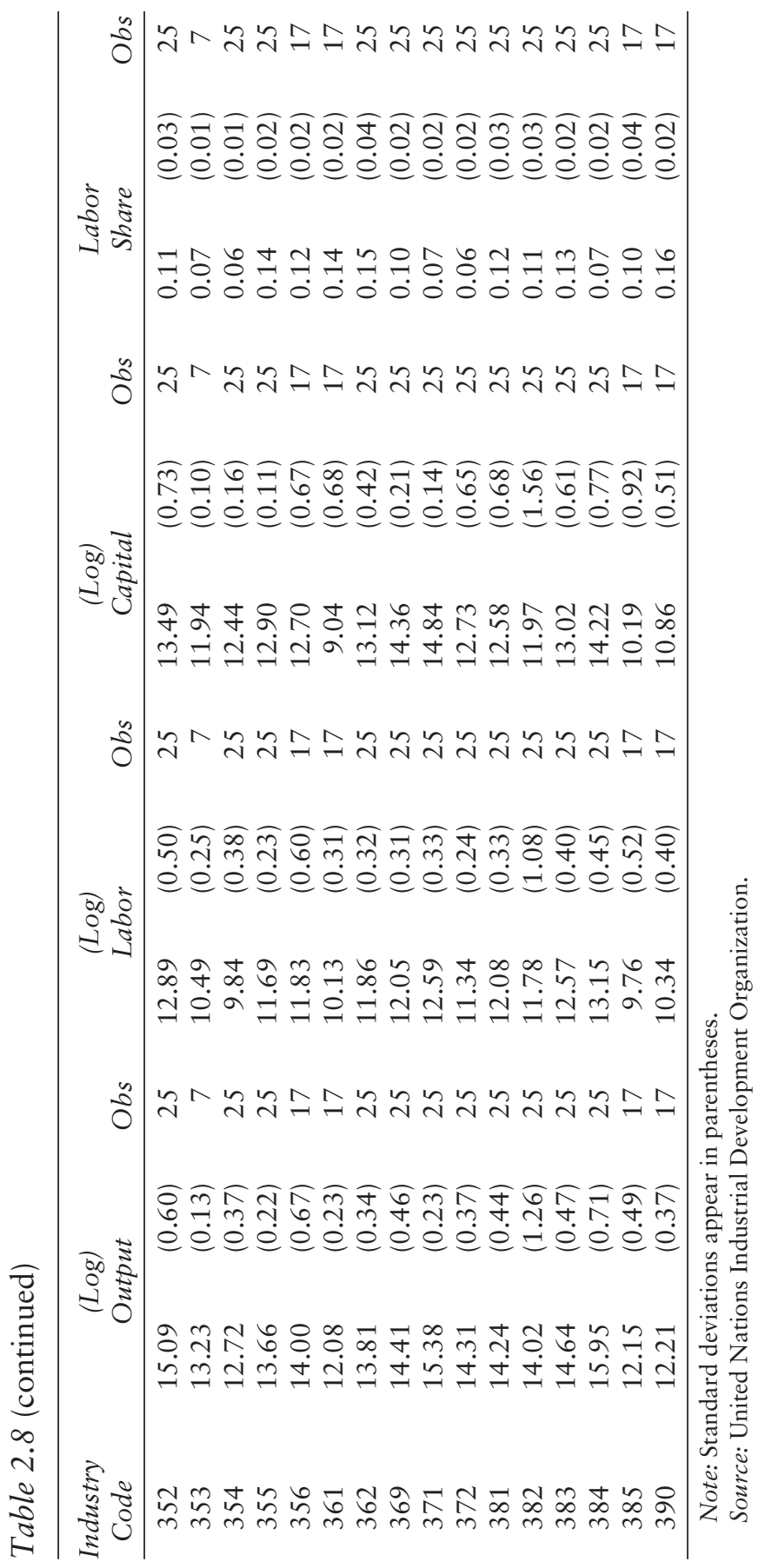


Table 2.9 Summary Statistics for Data Used in Table 2.3

\begin{tabular}{|c|c|c|c|c|c|}
\hline Variable & Obs & Mean & $\begin{array}{l}\text { Standard } \\
\text { Deviation }\end{array}$ & Minimum & Maximum \\
\hline Landlocked & 68 & 0.1323529 & 0.3413936 & 0 & 1 \\
\hline $\begin{array}{l}\text { Openness } \\
\text { (Sachs and } \\
\text { Warner 1995) }\end{array}$ & 63 & 0.2252768 & 0.3423797 & 0 & 1 \\
\hline $\begin{array}{l}\text { Log constructed } \\
\text { trade share } \\
\text { (Frankel-Romer) }\end{array}$ & 68 & 2.721456 & 0.7672238 & 0.94 & 4.586 \\
\hline Latitude & 68 & 6.318064 & 19.69103 & -41.81407 & 61.06258 \\
\hline $\begin{array}{l}\text { Eth-Ling } \\
\text { fractionalization }\end{array}$ & 61 & 46.37705 & 29.43024 & 1 & 90 \\
\hline Africa & 68 & 0.3382353 & 0.4766266 & 0 & 1 \\
\hline South Asia & 68 & 0.0588235 & 0.2370435 & 0 & 1 \\
\hline $\begin{array}{c}\text { East Asia and } \\
\text { the Pacific }\end{array}$ & 68 & 0.0735294 & 0.2629441 & 0 & 1 \\
\hline The Americas & 68 & 0.3970588 & 0.4929263 & 0 & 1 \\
\hline $\begin{array}{l}\text { Oil production } \\
\text { dummy }\end{array}$ & 68 & 0.2647059 & 0.4444566 & 0 & 1 \\
\hline $\begin{array}{l}\text { Commodity } \\
\text { dummy }\end{array}$ & 68 & 0.6764706 & 0.471301 & 0 & 1 \\
\hline $\begin{array}{l}\text { Institutional } \\
\text { index }\end{array}$ & 68 & -0.1134657 & 0.7704978 & -1.978333 & 1.585833 \\
\hline Log mortality & 68 & 4.588946 & 1.255075 & 2.145931 & 7.986165 \\
\hline $\begin{array}{l}\text { Log GDP per } \\
\text { capita }\end{array}$ & 68 & 7.794468 & 1.109153 & 5.252923 & 10.0311 \\
\hline
\end{tabular}

Source: Author's calculations. 


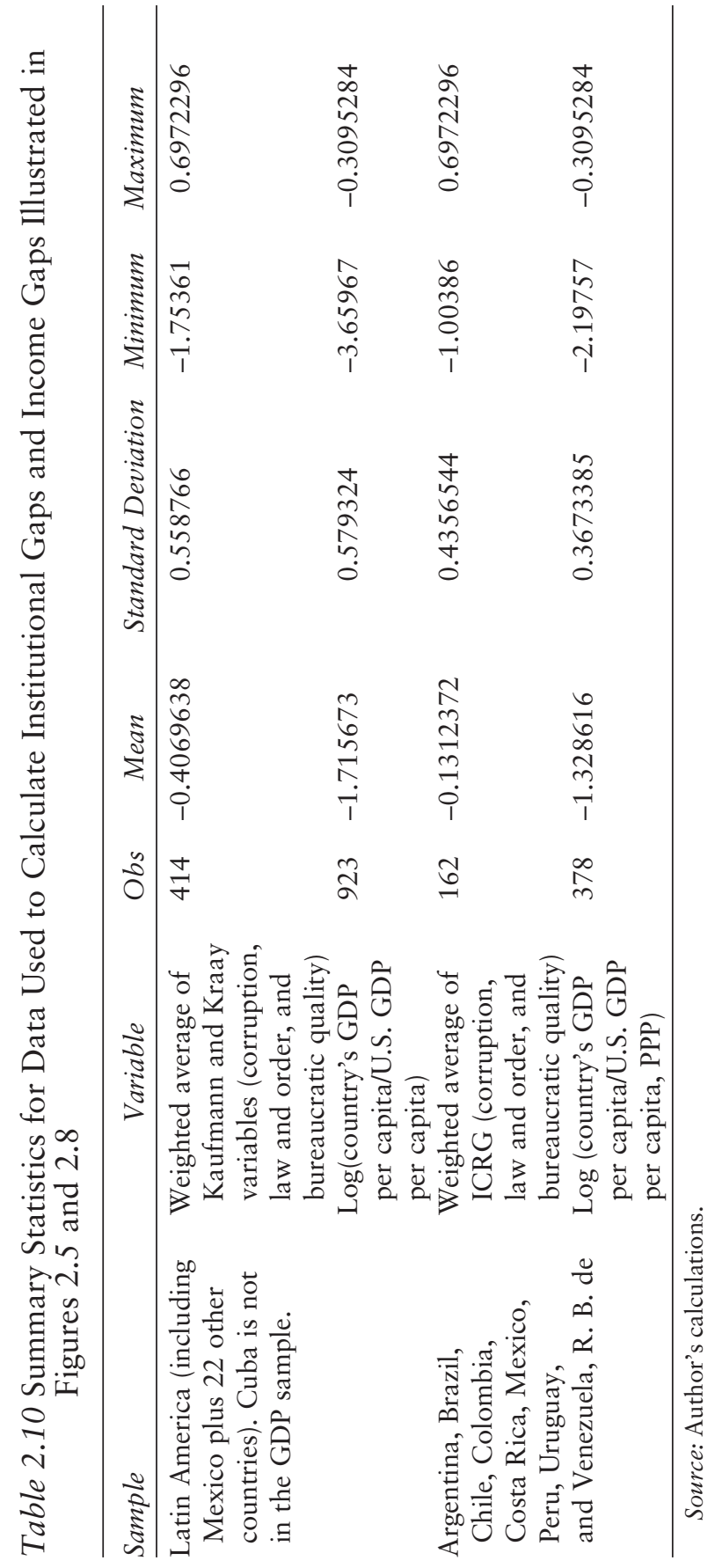


Table 2.11 Groups of Countries Used to Calculate GDP and Institutional Gaps Illustrated in Figures 2.5 and 2.8

\begin{tabular}{lll}
\hline Group 1 & & \multicolumn{1}{c}{ Group 2 } \\
\hline Argentina & Haiti & Argentina \\
Bolivia & Honduras & Brazil \\
Brazil & Jamaica & Chile \\
Chile & Mexico & Colombia \\
Colombia & Nicaragua & Costa Rica \\
Costa Rica & Panama & Mexico \\
Cuba & Paraguay & Peru \\
Dominican Republic & Peru & Uruguay \\
Ecuador & Trinidad and Tobago & Venezuela, R. B. de \\
El Salvador & Uruguay & \\
Guatemala & Venezuela, R. B. de & \\
Guyana & & \\
\hline
\end{tabular}

${ }^{a}$ Cuba was not included in the sample used to calculate log of GDP differentials with respect to the United States. 


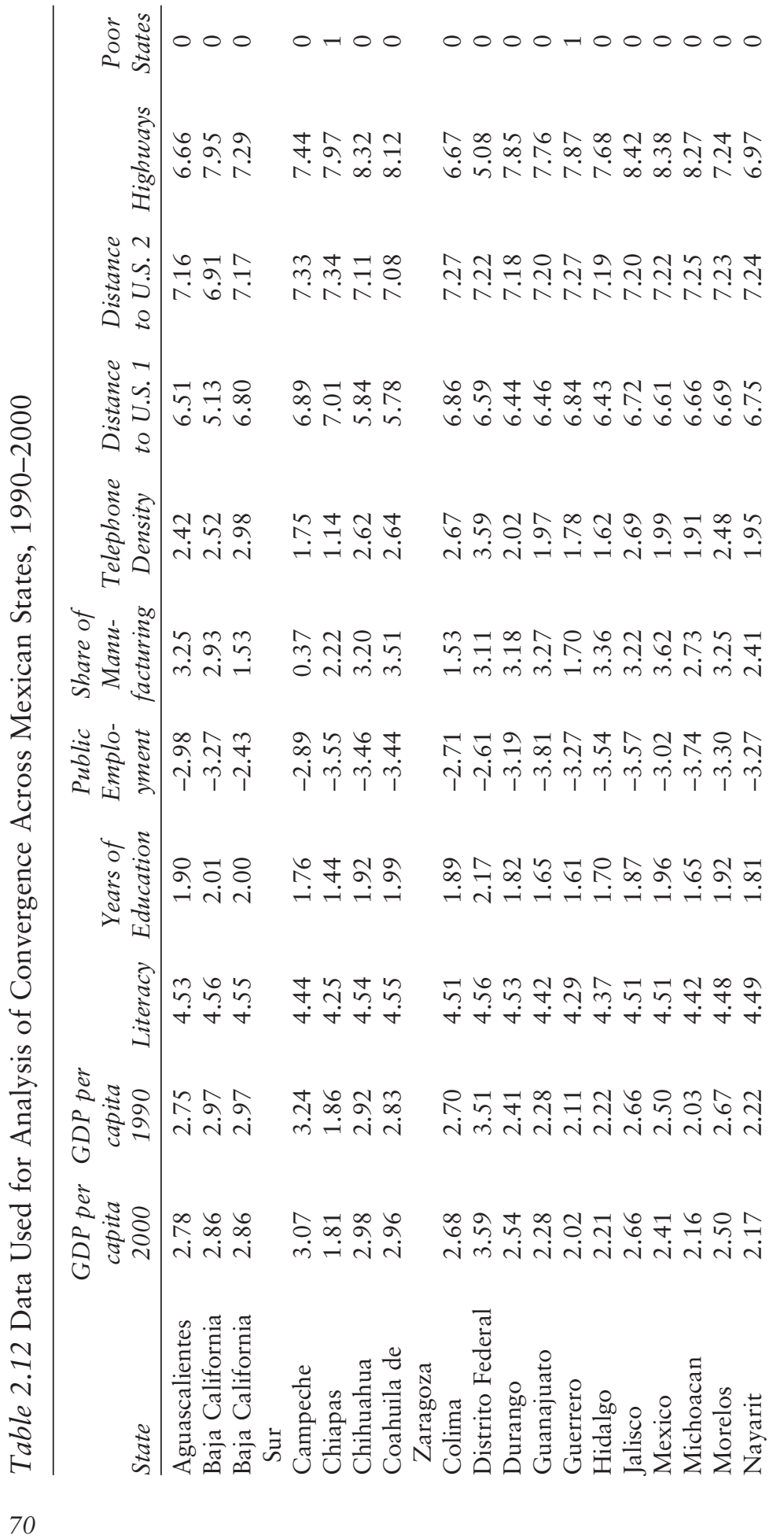




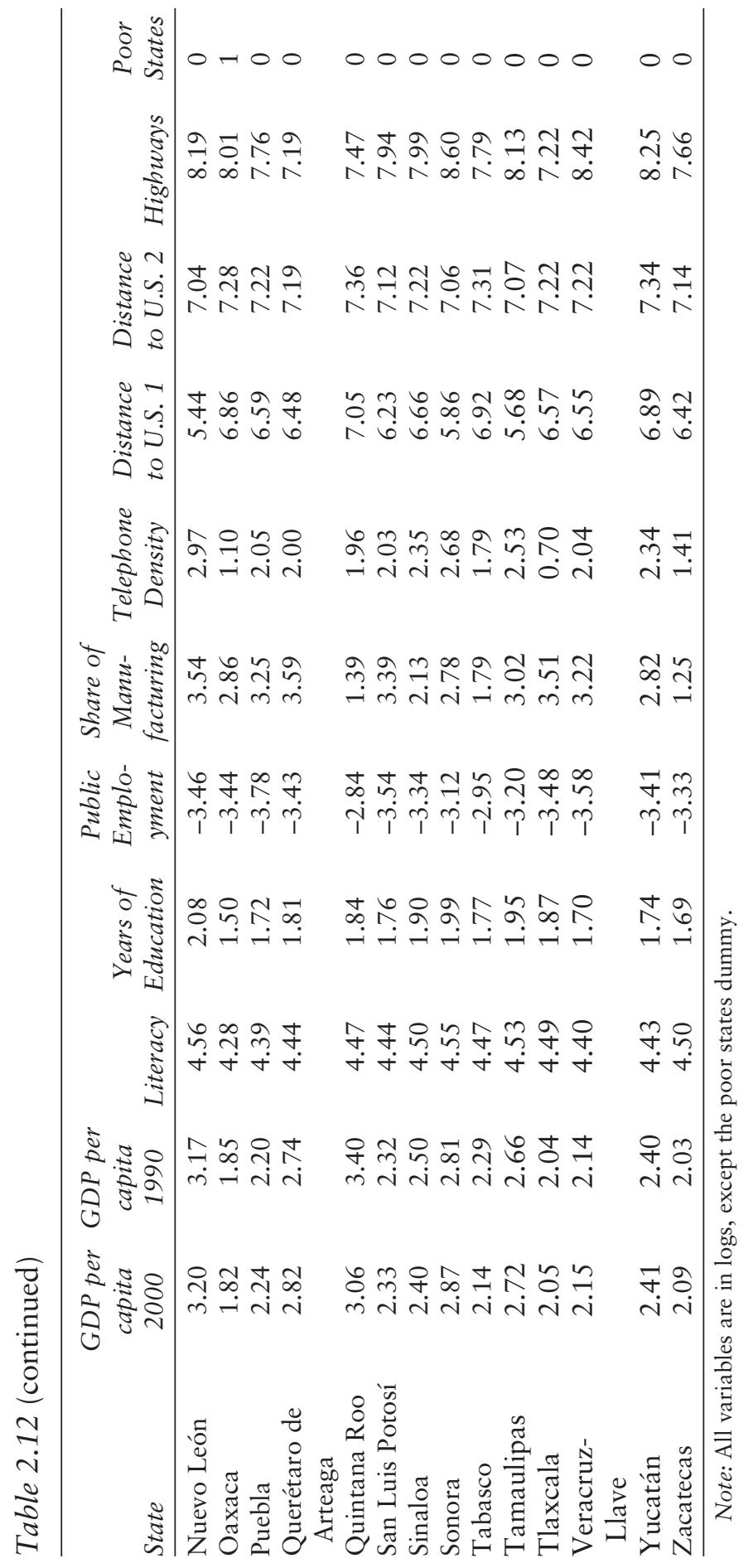




\section{Notes}

1. On the distortions associated with the Hodrick-Prescott (1997) filter and the Baxter-King (1999) band-pass filter, see references in Harvey (2002).

2. To estimate the exchange rate bias we regressed log-transformed PPPadjusted U.S.-Mexican income gap $\left(g_{P P P}\right)$ on log-transformed exchange rateadjusted U.S.-Mexican income gap $\left(g_{e}\right)$. We found that our results are robust to different methods of adjustments (standard errors are in parentheses):

$g_{P P P}=0.6991+0.2484 * g_{e}, R^{2}=0.25,(0.099)(0.053)$.

3. Because the STAMP (Koopman et al. 2000) algorithm provides only root mean square error (RMSE) for the final state vector, we estimated for our quarterly series a structural time-series model with three different sample endpoints: 1987Q1, 1994Q4 and 2001Q3. The resulting final state vectors allow us to gain insight if the different gap estimates are statistically different. This is indeed the case. The respective gaps are as follows: 1987Q1: 4.067 (0.226), 1994Q4: 3.055 (0.205), and 2001Q3: 1.951 (0.156) (RMSEs are in parentheses).

4. Further, by introducing a trend into the cointegration space it is possible to distinguish between stochastic and deterministic convergence (see Ericsson and Halket 2002), where a homogeneity $[1,-1]$ restriction on the GDP coefficients with a trend corresponds to stochastic convergence and homogeneity $[1,-1]$ without a trend to deterministic convergence. Because we reject stochastic convergence in favor of deterministic convergence in our data, we only report the findings based on a constant in the cointegration space, which we view as a test of deterministic conditional convergence.

5. Fuss (1999) postulated that if $y$ and $x$ are cointegrated at the end of the period with: $y=a+b x+u$, then evidence of

$a=0$ and $b=1$ indicates that the series are converging,

$a \neq 0$ and $b=1$ indicates that the two series are converging up to a constant,

$a>0$ and $b<1$ implies that $x$ converges toward $y$,

$a<0$ and $b>1$ implies that $y$ converges toward $x$,

$a>0$ and $b>1$ implies divergence ( $x$ falls behind $y$ ), and

$a<0$ and $b<1$ implies divergence ( $y$ falls behind $z$ ).

6. A similar result is obtained for annual data: $G D P_{u s}-G D P_{m x}=0.881$ (standard error 0.044).

7. The relevant model specification tests showed that other dummy variables for the debt crisis tended to bias the estimates of the cointegration rank and coefficient restrictions.

8. The estimated model was $y_{c, t}=c+\beta_{t} \bullet D_{t}+\beta_{t, M e x} D_{t} \bullet D_{M e x}$, where $y$ is the $\log$ of the GDP per capita ratio with respect to the United States, $D_{t}$ is a year dummy, and $D_{M e x}$ is a Mexico dummy. Figure 2.4 plots $\beta_{t, M e x}-\beta_{t}$.

9. Wald tests for significance of the difference between Mexico and average Latin American and Caribbean area effects are not reported.

10. The composite index is the average of the six individual components.

11. We got our data from the United Nations Industrial Development Organization but they received the Mexico and U.S. data directly from the OECD.

12. Output and capital inputs were expressed in constant prices of 1987 . The investment PPP deflator series from the Penn World Tables and the industry deflators from Bartelsman, Becker, and Gray (2000) end in 1996. We applied the average growth rate of the investment PPP deflator for the available years to the rest of our sample ending in 2000 .

13. This section is based on Esquivel et al. (2002). 
14. The data were graciously provided by Gerardo Esquivel from El Colegio de México, Mexico City. The GDP series were adjusted for the allocation of oil revenues, which in the original series (from INEGI, the national statistical agency) had been periodically allocated to different states, although in practice they are probably allocated according to population shares.

15. The coverage of paved roads could be measured with respect to the surface area of each state. However, this measure might also be imprecise because we would need to know the surface area of economically meaningful territory. In any case, when we used the ratio of paved roads or highways over surface area of each state, the results were virtually identical to the ones discussed here.

16. The distance from the U.S. border was measured in two alternative ways: first, by the distance from the major city in each state to the closest major city near the border, plus the distance of the latter to the border itself; and. second, by the geographic distance from the capital city of each state to the closest major U.S. city.

17. These OLS results did not change when the Distrito Federal, which has low paved roads per worker because of the high population density and had relatively high rates of growth, was removed from the sample.

18. We estimated four models with the two distance variables discussed above in note 4. Two regressions were estimated via OLS and two via median regressions. In only one of these four models was the distance variable significant at the 10 percent level. However, several of the other explanatory variables were also not significant in these specifications. These results arise from the correlation between the distance variables and the other explanatory variables.

\section{References}

The word "processed" describes informally produced works that may not be commonly available through libraries.

Acemoglu, Daron, Simon Johnson, and James A. Robinson. 2001. The Colonial Origins of Comparative Development: An Empirical Investigation. American Economic Review 91 (5): 1369-1401.

Acemoglu, Daron, and Fabrizio Zilibotti. 2001. Productivity Differences. Quarterly Journal of Economics 116 (2): 563-606.

Anderson, T. W., and Cheng Hsiao. 1981. Estimation of Dynamic Models with Error Components. Journal of the American Statistical Association 76 (375): 47-82.

Arellano, Manuel, and Stephen Bond. 1991. Some Tests of Specification for Panel Data: Monte Carlo Evidence and an Application to Employment Equations. Review of Economic Studies 58 (2): 277-97.

Barro, Robert J. 1991. Economic Growth in a Cross Section of Countries. Quarterly Journal of Economics 106: 407-44.

Barro, Robert J., and Xavier Sala-I-Martin. 1995. Economic Growth. New York: McGraw-Hill.

Bartelsman, Eric J., Randy A. Becker, and Wayne B. Gray. 2000. NBER-CES Manufacturing Industry Database. Cambridge, MA: National Bureau of Economic Research. Processed.

Baxter, M., R. G. King. 1999. Measuring Business Cycles: Approximate Band-Pass Filters for Economic Time Series. Review of Economics and Statistics 81: 575-93. 
Ben-David, Dan. 1996. Trade and Convergence Among Countries. Journal of International Economics 40: 279-98.

- 2001. Trade Liberalization and Income Convergence: A Comment. Journal of International Economics 55: 229-34.

Bernard, Andrew B., and Steven N. Durlauf. 1995. Convergence in International Output. Journal of Applied Econometrics 10: 97-108.

—_ 1996. Interpreting Tests of the Convergence Hypothesis. Journal of Econometrics 71: 161-73.

Bernard, Andrew B., and Charles I. Jones. 1996. Technology and Convergence. Economic Journal 106: 1037-44.

Caves, Douglas W., Laurits R. Christensen, and W. Erwin Diewert. 1982. Multilateral Comparisons of Output, Input, and Productivity Using Superlative Index Numbers. Economic Journal 92: 73-86.

Ciccone, Antonio, and Robert E. Hall. 1996. Productivity and the Density of Economic Activity. American Economic Review 86 (1): 54-70.

Dollar, David, and Aart Kraay. 2003. Institutions, Trade, and Growth: Revisiting the Evidence. Policy Research Working Paper 3004, World Bank, Washington, DC.

Doppelhofer, Gernot, Ronald I. Mille, and Xavier Sala-I-Martin. 2000. Determinants of Long-Term Growth: A Bayesian Averaging of Classical Estimates Approach (BACE). Working Paper 7750, National Bureau of Economic Research, Cambridge, MA.

Easterly, William, and Ross Levine. 2001. It's Not Factor Accumulation: Stylized Facts and Growth Models. World Bank Economic Review 15 (2): 177-220.

Eaton, Jonathan, and Samuel Kortum. 1999. International Technology Diffusion: Theory and Measurement. International Economic Review 40 (3): 537-70.

- 2002. Technology, Geography, and Trade. Econometrica 70 (5): 1741-80.

Ericsson, Neil R., and Jonathan R. Halket. 2002. Convergence of Output in the G7 Countries. Working Paper, Board of Governors of the Federal Reserve System, Division of International Finance. Processed.

Esquivel, Gerardo. 1999. Convergencia regional en México, 1940-1995. El Trimestre Económico 66 (264): 725-61.

Esquivel, Gerardo, Daniel Lederman, Miguel Messmacher, and Renata Villoro. 2002. Why NAFTA Did Not Reach the South. Office of the Chief Economist for Latin America and the Caribbean, World Bank, Washington, DC. Processed.

Frankel, Jeffrey, and David Romer. 1999. Does Trade Cause Growth? American Economic Review. 89 (3): 379-99.

Fujita, Masahisa, Paul R. Krugman, and Anthony J. Venables. 1999. The Spatial Economy, Cities, Regions and International Trade. Cambridge, MA: MIT Press.

Furman, Jeffrey L., Michael E. Porter, and Scott Stern. 2002. The Determinants of National Innovative Capacity. Research Policy 31: 899-933.

Fuss, Catherine. 1999. Convergence among Industrialized Countries: A Time Series Investigation. Cahiers Economiques de Bruxelles 158: 177-202.

Grossman, Gene M., and Elhanan Helpman. 1991. Innovation and Growth in the Global Economy. Cambridge: MIT Press.

Hall, Robert, and Charles I. Jones. 1999. Why Do Some Countries Produce So Much More Output per Worker Than Others? Quarterly Journal of Economics 114 (1): 83-116. 
Harvey, A. C. 2002. Trends, Cycles and Convergence. Central Bank of Chile Working Papers 155, Santiago, Chile.

Harvey, A. C., and V. Carvalho. 2002. Models for Converging Economies. Department of Applied Economics, University of Cambridge, UK. Processed.

Harvey, Andrew C., and Siam J. Koopman. 1997. Multivariate Structural Time Series Models. In System Dynamics in Economic and Financial Models, eds. C. Heij et al., 269-98. Chichester, UK: Wiley and Sons.

Harvey, A. C., and T. Trimbur. 2001. General Model-based Filters for Extracting Cycles and Trends in Economic Time Series. Discussion Paper 0113, Department of Applied Economics, University of Cambridge, UK.

Hodrick, P. J., and E. C. Prescott.1997. Postwar U.S. Business Cycles: An Empirical Investigation. Journal of Money, Credit and Banking 24, 1-16.

Kaufmann, Daniel, and Aart Kraay. 2002a. Governance Matters II: Updated Indicators for 2000-01. Policy Research Working Paper 2772, World Bank, Washington, DC.

-2002b. Growth Without Governance. World Bank Institute, Washington, DC. Processed.

Keller, Wolfgang. 2001. International Technology Diffusion. Working Paper 8573, National Bureau of Economic Research, Cambridge, MA.

- 2002. Geographic Localization of International Technology Diffusion. American Economic Review 92 (1): 120-42.

Koopman, S. J., A. C. Harvey, J. A. Doornik, and N. Shepard. 2000. STAMP 6.0 Structural Time Series Analysis Modeller and Predictor. London: Timberlake Consultants.

Krugman, Paul R. 1991. Geography and Trade. Cambridge, MA: MIT Press.

Lederman, Daniel, and William F. Maloney. 2003a. Innovation in Mexico: NAFTA Is Not Enough. Office of the Chief Economist for LCR, World Bank, Washington, DC. Processed.

- 2003b. R\&D and Development. Office of the Chief Economist for LCR, World Bank, Washington, DC. Processed.

Lederman, Daniel, Norman Loayza, and Rodrigo Soares. 2002. Accountability and Corruption: Political Institutions Matter. Office of the Chief Economist for Latin America and the Caribbean, World Bank, Washington, DC. Processed.

Lederman, Daniel, Ana María Menéndez, Guillermo Perry, and Joseph Stiglitz. 2003. The Recovery of Mexican Investment after the Tequila Crisis: Basic Economics, Confidence Effects or Market Imperfections? Journal of International Money and Finance 22: 131-51.

Loayza, Norman, Pablo Fajnzylber, and César Calderón. 2002. Economic Growth in Latin America and the Caribbean: Stylized Facts, Explanations, and Forecasts. Office of the Chief Economist for Latin America and the Caribbean, World Bank, Washington, DC. Processed.

López-Córdova, and J. Ernesto. 2002. NAFTA and Mexico's Manufacturing Productivity: An Empirical Investigation Using Micro-Level Data. Inter-American Development Bank, Washington, DC. Processed.

Lucas, Robert M. 1988. On the Mechanics of Economic Development. Journal of Monetary Economics 22: 342.

Messmacher, Miguel. 2000. Desigualdad Regional en Mexico. El Efecto del TLCAN y Otras Reformas Estructurales. Working Paper 2000-4, Banco de México, Mexico D.F. 
Meza, Liliana, and Ana Belén Mora. 2002. Why Mexican Firms Invest in R\&D. Office of the Chief Economist for Latin America and the Caribbean, The World Bank, Washington, DC. Processed.

Parente, Stephen L., and Edward C. Prescott. 2000. Barriers to Riches. Cambridge: MIT Press.

Persson, Torsten. 2002. Do Political Institutions Shape Economic Policy? Econometrica 70 (3): 883-906.

Pritchett, Lant. 1997. Divergence, Big Time. Journal of Economic Perspectives 11 (3): 3-17.

Redding, Stephen, and Anthony J. Venables. 2001. Economic Geography and International Inequality. Discussion Paper, Centre for Economic Performance, London School of Economics. Processed.

Romer, Paul. 1986. Increasing Returns and Long-Run Growth. Journal of Political Economy 94: 1002-37.

- 1990. Endogenous Technological Change. Journal of Political Economy 98 (5): S71-102.

Sachs, Jeffrey D., and Andrew Warner. 1995. Economic Reform and the Process of Global Integration. Brookings Papers on Economic Activity 1: 1-95.

Sala-I-Martin, Xavier. 1996. The Classical Approach to Convergence Analysis. Economic Journal 106 (July): 1019-36.

Schiff, Maurice, and Yanling Wang. 2002. Regional Integration and Trade-Related Technology Diffusion: The Case of NAFTA. Office of the Chief Economist for Latin America and the Caribbean, World Bank, Washington, DC. Processed.

Slaughter, Matthew J. 2001. Trade Liberalization and Per Capita Income Convergence: A Difference-in-Differences Analysis. Journal of International Economics 55: 203-28.

Solow, Robert M. 1956. A Contribution to the Theory of Economic Growth. Quarterly Journal of Economics 70: 65-94.

Summers, Robert, and Sultan Ahmad. 1974. Better Estimates of Dollar Gross Domestic Product for 101 Countries: Exchange Rate Bias Eliminated. Discussion Paper 297, University of Pennsylvania, Philadelphia. 


\section{3 \\ Macroeconomic Dynamics After NAFTA: Synchronization, Volatility, and Macroeconomic Policy Coordination}

WHAT ARE THE CONSEQUENCES OF NAFTA for the conduct of macroeconomic policy in Mexico? The agreement contained no explicit provisions in this regard, but its implementation may have had a significant effect on Mexico's macroeconomic dynamics. This is so because Mexico's trade (as well as financial) integration with its NAFTA partners could have led to an increased similarity among their respective business cycles, and this in turn could have changed the desirability of alternative fiscal and monetary policies for Mexico.

Figure 3.1 illustrates the high degree of trade integration with NAFTA partners that Mexico has reached in recent years. By the end of the 1990s, total trade with the United States and Canada represented almost 50 percent of Mexico's gross domestic product (GDP), and more than 80 percent of its total trade. Exports to NAFTA partners accounted for more than one fourth of its GDP and 90 percent of total exports. One would expect that this rising degree of trade intensity would lead to Mexico's economy marching in step with those of its NAFTA partners. But trade is not the only factor affecting macroeconomic synchronization, and other ingredients matter-ingredients such as the similarity of production structure, financial integration, and policy coordination. Moreover, synchronization is not an automatic by-product of trade integration. Indeed, there are theoretical arguments that trade integration, financial integration, or both among dissimilar countries could result in reduced, not increased, macroeconomic synchronization, through specialization of the countries involved that would leave them more exposed to asymmetric shocks. 


\section{Figure 3.1 Mexico: Trade with NAFTA Countries}

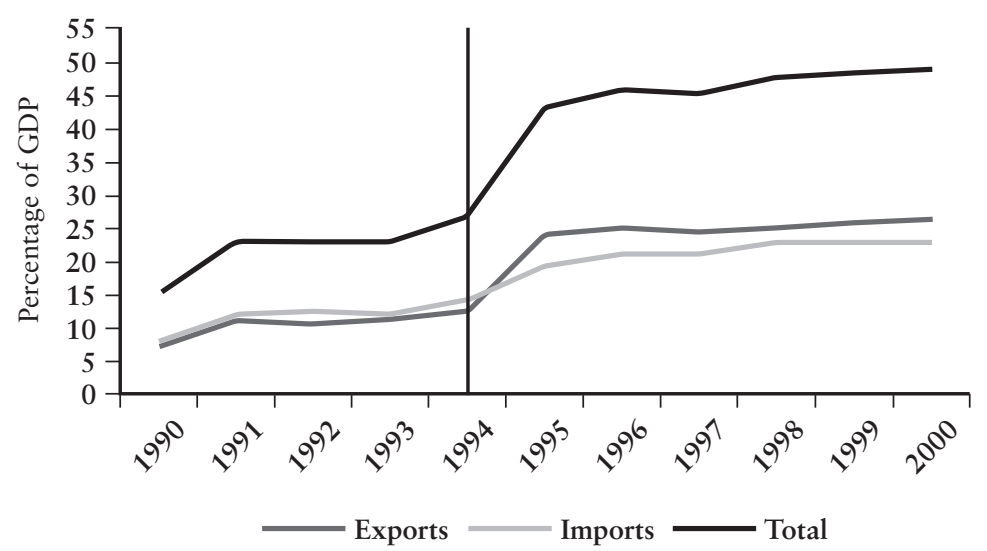

Source: World Bank data.

Macroeconomic synchronization is important because it provides an indicator of the necessity of independent fiscal and monetary policies. If Mexico's business cycles become more similar to those of Canada and the United States, and its macroeconomic variability is dominated by shocks common with its free trade agreement (FTA) partners, then Mexico would benefit from the stabilization policies followed by those partners and, indeed, its own desired policy adjustments would be similar to those desired by the other two countries. In the extreme case of very high macroeconomic synchronization, Mexico could benefit from a common macroeconomic policy with NAFTA members-perhaps even in terms of a currency union. The theory of optimal currency areas (OCA) implies that the benefits from a currency union rise with the volume of trade among member countries, whereas the costs increase with the degree of asymmetry in their business cycles (see McKinnon 1963 and Mundell 1961). ${ }^{1}$

On the contrary, if business cycles in NAFTA countries are not becoming more synchronized, and Mexico's macroeconomic variability is dictated primarily by idiosyncratic shocks, then policy synchronization and coordination would be less likely to help reduce macroeconomic volatility. Instead, reducing the volatility would require the authorities to implement policies potentially very different from those followed by the United States and Canada. 
The proper design of Mexico's policies to reduce its macroeconomic volatility is an important issue in the post-NAFTA context. Macroeconomic volatility is a potential obstacle to the country's reaping the full benefits from trade integration, because those benefits accrue primarily through trade and investment flows, and volatility-traditionally high in Mexico as in the rest of Latin America-is a powerful deterrent to both trade and investment.

It is also useful to assess the degree to which synchronization is changing because that can shed light on the likelihood of a further deepening of the economic integration process. If business cycles are becoming highly symmetric, FTA members will be more likely than otherwise to consider further steps to enhance economic integration, including measures such as policy coordination.

In this chapter we assess the changes in macroeconomic synchronization between Mexico and its partners, the United States and Canada, following NAFTA, and we draw their implications for macroeconomic policy. ${ }^{2}$ The chapter examines different (but mutually related) aspects of synchronization: the degree of co-movement between Mexico and the other NAFTA economies, the sensitivity of the Mexican economy to developments in partner countries, and the portion of Mexico's overall growth volatility attributable to shocks emanating from partner countries. The analysis proceeds at several levels of disaggregation-the overall economy, major productive sectors, and individual manufacturing industries.

Given the short time elapsed since the implementation of NAFTA, the findings from this analysis must be tentative. Most importantly, they are conditional on the pattern of shocks actually observed in the postNAFTA years, and there is no assurance that such a pattern-specifically the relative frequency and magnitude of common versus idiosyncratic shocks observed in those years-will persist in the future.

With this important limitation, the chapter finds that the period after the free trade agreement has been characterized by a higher degree of synchronization between Mexico and its NAFTA partners. This suggests that their respective optimal countercyclical policies will likely be qualitatively more similar in the future. However, a number of factors underscore the need for Mexico to retain macroeconomic policy independence rather than adopt the fiscal and monetary policies of its partners (notably those of the United States): idiosyncratic volatility in Mexico remains high, total volatility is on the decline but still exceeds that of the United States and Canada, and policy effectiveness is likely to differ significantly between Mexico and its NAFTA partners. Mexico's immediate policy challenge is to build a solid fiscal position and strengthen monetary and fiscal institutions to enlarge the scope for countercyclical macroeconomic policy. 
For other countries intending to enter free trade agreements with North America, the key concern is to reduce macroeconomic volatility in order to reap the benefits from trade integration. However, the means to achieve this reduction in volatility depend considerably on the economic and institutional characteristics of each country, and no single policy regime can fit all of those countries.

\section{Trade Integration and Macroeconomic Synchronization}

We next review briefly the links between trade integration and macroeconomic synchronization. First we summarize the main theoretical arguments and then discuss some recent empirical studies of the issue.

\section{Theory}

On theoretical grounds, the impact of trade integration on macroeconomic co-movement may go either way, depending on several ingredients: the relative importance of sector-specific vs. global shocks in macroeconomic dynamics, the similarity among countries' production patterns, and the degree of commonality of aggregate shocks.

If business cycles are driven mostly by sector-specific shocks, the impact of greater economic integration on business cycle synchronization depends on the trade and specialization patterns of the countries under consideration. The more similar their specialization patterns, the more likely that increased trade will result in increased synchronization.

Thus, business cycle synchronization could actually fall following a free trade agreement if the latter leads to higher specialization of the countries involved. This is more likely to happen if they engage mostly in horizontal inter-industry trade (see Eichengreen 1992, Kenen 1969, and Krugman 1993). If instead the pattern of trade among participating countries is mainly of intra-industry type, then greater economic integration is likely to lead to a higher synchronization of their business cycles. This result is also likely to arise if total trade involves significant vertical inter-industry trade; that is, if the economies specialize in different stages of a common production process (e.g., through outsourcing), in which case trade integration effectively links the various stages of production across countries (see Feenstra and Hanson 1996 and Kose and Yi 2001).

This means that the effects of trade agreements on business cycle correlation depend on the intrinsic characteristics of participating countries and on the nature of their trade relationships. For example, among industrialized countries-whose trade is mainly of intra-industry type-trade 
intensity and business cycle correlation are positively related. But such result could be driven by the similarity of their factor endowments and the limited scope for further specialization from trade. On these grounds one would expect to find integration having less of a positive effect on synchronization in a trade agreement such as NAFTA (involving both industrialized and developing economies) because member countries differ substantially in terms of factor endowments-unless trade among them is mostly intra-industry (or vertical inter-industry) in character. ${ }^{3}$

On the other hand, if business cycles are dominated instead by aggregate shocks, the key factor is the impact of trade integration on the correlation of shocks across countries. In most scenarios the impact is likely to be positive, as increased trade will facilitate the transmission of aggregate disturbances across economies, and thus we would expect to observe a more synchronized business cycle as a result of greater economic integration (see Frankel and Rose 1998). Assume, for example, that aggregate disturbances reflect mostly demand shocks. In such a case, a positive (negative) shock in one country will increase (decrease) demand for goods produced in other countries, so the shock will spill over to other countries. The magnitude of such spillover obviously will depend on the intensity of trade among the participating countries.

In addition to demand spillovers, there are other possible channels through which greater economic integration may increase business cycle correlation. For example, the process of trade integration could lead to faster diffusion and transmission of productivity, knowledge, and technological shocks, as well as to stronger foreign direct investment links across countries. ${ }^{4}$ All of these elements should enhance business cycle synchronization among the countries involved in the process of integration.

These factors contribute to raise synchronization by reducing the idiosyncratic component of shocks. Thus, other forces that likewise increase the commonality of shocks across countries tend to have the same effect. For example, policy shocks are a significant source of cyclical fluctuations, and therefore the increase in synchronization will be even larger if the process of trade integration is accompanied by a greater degree of macroeconomic policy coordination among countries.

So far we have focused on trade integration, but financial integration also matters for business cycle co-movement. As with trade integration, however, its effects are not clear-cut and they depend on the role of idiosyncratic vs. common shocks. On the one hand, in theory, capital market integration should facilitate risk sharing and hence encourage higher specialization across countries by insuring them against asymmetric shocks (Kalemi-Ozcan, Sorensen, and Yosha 2000). A higher degree of specialization would in turn leave countries more exposed to 
idiosyncratic shocks and reduce the co-movement of production across economies-but would increase that of income and consumption as countries would tend to hold similarly diversified asset portfolios.

On the other hand, financial integration facilitates international transmission of aggregate financial shocks. Increased openness to capital flows makes local interest rates and financial asset prices more responsive to world financial conditions, as the extensive literature on "contagion" has argued. The likely consequence is an increase in aggregate co-movement across countries.

\section{International Evidence}

The empirical literature on the impact of trade integration on macroeconomic synchronization includes both studies of the relationship between trade intensity and business cycle correlation and case studies that analyze the effect of specific trade agreements or economic integration processes on business cycle synchronization. The evidence from industrialized countries is mostly supportive of a positive effect of integration on macroeconomic synchronization. For example, using a sample of 20 industrialized countries over 30 years, Frankel and Rose (1998) found strong evidence that greater trade links increase business cycle correlation. A number of other studies using a similar methodology found mostly similar results, in some cases highlighting the contribution of intra-industry trade to the positive integration-synchronization link. ${ }^{5}$ However, Imbs $(1999,2000)$ found that cycle synchronization is more responsive to similarities in the structure of production than to trade intensity, thus suggesting that sector-specific shocks are an important part of the story.

Another group of studies sheds light on the experiences of Ireland, Portugal, and Spain from accession to the European Economic Community/European Union (EEC/EU) (see box 3.1). They suggest that the main force behind the observed increase in the correlation of the business cycles of these countries with the rest of the EU was deeper trade integration rather than common policies such as the ERM. Synchronization increased first in the tradable goods sector and only later in the rest of the economy.

As already noted, however, these findings from industrialized countries do not carry over automatically to developing countries for a variety of reasons. Among industrialized countries, intra-industry trade accounts for a larger fraction of total trade than among developing countries, production structures are more similar, and common and/or global shocks likely play a bigger role. In fact, the empirical evidence on the effects of trade integration between industrialized and developing countries, or among the latter, points to smaller effects on business cycle correlation. 


\section{Box 3.1 Macroeconomic Synchronization in the European Union}

Ireland, Portugal, and Spain, like Mexico, were relatively small open economies that joined a larger and richer area, the EEC/EU. It is important to keep in mind that integration has been gradually increasing in the EU and has reached a much higher level than in the case of NAFTA. That is because it has involved not only free trade but also labor migration agreements and a common monetary policy (as well as fiscal policy rules) for European Monetary Union (EMU) members. Furthermore, the difference in levels of development between these three countries and the rest of the EU was smaller than that between Mexico and its NAFTA partners.

A number of studies have examined the evolution of macroeconomic synchronization between these three countries and the rest of the FTA. Artis and Zhang $(1995,1997)$ assessed the effect on synchronization of monetary and exchange rate policy, particularly the establishment of the European monetary system and the exchange rate mechanism in 1979. They found a very sharp increase in the correlation of Portuguese and Spanish business cycles with those of Germany, although they observed no increase with respect to U.S. fluctuations. However, much of this increase is likely the result of these countries' entry into the European Union in 1986 rather than the result of policy convergence.

Several other studies have followed the research by Artis and Zhang using longer time periods and different methodologies. Angeloni and Dedola (1999), for example, looked at the correlation between the GDP and industrial production of Ireland, Portugal, and Spain and that of the EU, breaking the sample into four different subperiods (pre-ERM, soft ERM, hard ERM, and pre-EMU; the total time period covered is 1965-97). They found that for both variables the correlation was higher for Portugal and Spain since the hard ERM period. In contrast, there seems to be no such increase in correlation for Ireland. They also found that the increase in output correlation was more gradual than that of industrial production, which suggested that the rising correlation reflects in part cycles in tradable goods and not only common policies.

In another study, Belo (2001) calculated industrial production correlations and cyclical coherence for several countries and the Euro zone in the period 1960-99, splitting the sample in 1979 coinciding with the ERM. The results are similar to those found in the other studies, although in the case of Ireland the initial association is weaker and therefore is found to have risen over time. Nonetheless, such increase is still the smallest across countries in the sample. ${ }^{1}$

Boone (1997) used a vector auto regression analysis to identify demand and supply shocks for the countries in the EU (and some other countries as controls), employing a methodology similar to that of Bayoumi and (Box continues on the following page.) 


\section{Box 3.1 (continued)}

Eichengreen (1993). He analyzed the degree of correlation between demand and supply shocks of each country with Germany. In the case of supply shocks, he found that their correlation is fairly constant for Ireland and Spain in the period 1974-90, but it increases in the 1991-94 period. In the case of Portugal the correlation of supply shocks is already quite high in the period 1980-90 but becomes higher as well in 1991-94. As for demand shocks the correlation in the three countries either remains constant or diminishes in the period 1991-94. As with previous studies, this evidence seems more consistent with gradually increasing trade integration than with common policies. Indeed, the increase in correlation of supply shocks is precisely what could be expected from greater trade integration.

Finally, a recent study by Ramos, Clar, and Suriñat (2003) examined the role of aggregate and sector-specific shocks in the observed performance of manufacturing industries across European countries. They found that aggregate shocks have become a less important source of variability in recent years, especially in the EU's peripheral countries as well as among EMU members. They viewed this finding as reflective of the increased coordination of macroeconomic policies, although they did not examine the role that increased trade integration may have played in achieving this result.

Thus, with some exceptions, most of the empirical studies on business cycle synchronization in Ireland, Portugal, and Spain with the rest of the EU suggest that the main force behind the increasing synchronization was deeper trade integration rather than common policies such as the ERM. The evidence also suggests that synchronization increases first in the tradable goods sector and only later in the rest of the economy.

Note

1. Borodo, González, and Rodríguez (1998) found similar results looking at fiveyear moving correlations.

The most comprehensive study is that of Calderón, Chong, and Stein (2002), who explored the issue in a sample of 147 countries during the period 1960-99. For the case of trade relationships between developing and industrialized countries, they found that higher trade intensity is associated with higher business cycle correlation, although the magnitude of the effect is about one third of that found in the case of industrialized countries. The effect of trade intensity on business cycle correlation among developing countries is even smaller. ${ }^{6}$

As for the effects of financial integration on macroeconomic synchronization, there is evidence that GDP co-movement rises significantly 
with financial integration, although the channels through which the effect occurs are not yet well understood (Imbs 2004).

\section{NAFTA and Macroeconomic Synchronization}

We turn to assessing the changes in the degree of macroeconomic synchronization between Mexico and its NAFTA partners. ${ }^{7}$ We consider three different aspects of synchronization. The first concerns the contemporaneous correlation of key macroeconomic variables among NAFTA countries. The second is the sensitivity of the Mexican economy to developments in its NAFTA partners-that is, the magnitude of its response to business cycle fluctuations in Canada or the United States. The third aspect is the contribution to Mexico's overall aggregate volatility of shocks to growth in Canada or the United States, relative to the contribution of Mexico's idiosyncratic shocks, such as terms of trade fluctuations, financial contagion from other emerging markets, or domestic aggregate demand disturbances. ${ }^{8}$

To conclude with some confidence that greater economic integration between Mexico and its partners has contributed to greater macroeconomic synchronization in the region, we should find that (a) there has been an increase in the degree of business cycle co-movement among the NAFTA countries in recent years; (b) the sensitivity of the Mexican economy to developments in the United States and Canada has increased; and (c) shocks to growth in the United States and Canada have become a larger source of growth volatility in Mexico.

\section{Methodological Approach}

Throughout this section we work with annual growth rates of the variables of interest (derived from quarterly or monthly frequency data) at various levels of aggregation (national, sector, and regional). We use two basic methods. First, we compare the contemporaneous cross-country correlations of the different variables, computed over the longest possible time period as dictated by data availability, with those computed over a shorter time period meant to capture the effect of NAFTA. This enables us to check if the correlation between the Mexican and U.S. variables has increased more than that between other countries and the United States. When using sectorwise (or regional) information, we can likewise see if the correlation between Mexican and U.S. sectors (regions) has increased more in those cases where we would expect a larger effect from NAFTA. ${ }^{9}$

The second method involves basic regression analysis. We regress the annual growth rate of the Mexican variable of interest against its lagged 
value and current and lagged values of its U.S. counterpart. The general form of the regressions is

$$
\begin{aligned}
\Delta x_{i t}= & \alpha_{i}+\beta_{i} \Delta x_{i t-1}+\gamma_{i} \Delta x_{U S t}+\mu_{i} d T+\lambda_{i} d T \cdot \Delta x_{i t-1} \\
& +\delta_{i} d T \cdot \Delta x_{U S t}+\varepsilon_{i t}
\end{aligned}
$$

where $\Delta x_{i t}$ is the annual growth rate of variable $x$ in country, region, or sector $i$; $\Delta x_{U S t}$ is the annual growth rate of the same variable in the United States (or the partner country under consideration); and $d T$ is a time dummy to capture changes in the sensitivity of the variable to developments in the United States after year $T .{ }^{10}$ Although the equation as written allows only for one lag of the dependent variable, we also explored a number of longer lag structures. However, unlike the first lag of the dependent variable, which was virtually always highly significant, additional lags of the dependent and independent variables proved generally insignificant.

There are two options for the dummy variable $d T$. The first option sets it equal to 1 from 1994 to the end of the sample, and 0 for previous periods. The second sets it at 0 from 1997 on. The logic of the latter specification is that, although NAFTA was implemented in 1994, the large balance of payments crisis that took place in Mexico in 1995 and the fast subsequent recovery in 1996 are large shocks unrelated to NAFTA that tend to obscure the effects of the trade agreement. Below we will report results using both specifications. ${ }^{11}$

From these simple regressions we can assess two facts. The first is how sensitive the dependent variable is to developments in the United States (as given by $\gamma$ ). The second is how this sensitivity has changed after time $T$ (when it is given by $\gamma+\delta$ ), and if such change is statistically significant.

In addition, however, we need a measure of the contribution of U.S. (or partner-country) shocks to the variation in the dependent variable. This is of interest because even if the responsiveness of the latter to developments in the United States (i.e., $\gamma$ ) is large, if shocks from the United States are sufficiently small their contribution to the total variation could be just marginal. ${ }^{12}$ In this regard, neither the simple correlation coefficient between the dependent and the U.S. variable nor the $R^{2}$ of a dynamic regression such as equation 3.1 offer the right measure. The simple correlation only captures the contribution of changes in the independent variable to contemporaneous changes in the dependent variable, ${ }^{13}$ whereas the $R^{2}$ from equation 3.1 is likely to be dominated by the explanatory power of the lagged dependent variable.

If we are interested in the contribution of current and past changes in the U.S. variable to the variation in the dependent variable, then a better measure is obtained by solving the dynamic equation 3.1 to express the current value of the dependent variable in terms of current and past 
random errors and the entire history of the explanatory variable. The fraction of the variation in the dependent variable attributable to such history is what we take as our measure of the total contribution of U.S. shocks to the observed variation of the lefthand-side variable. We gauge the change in this contribution over time by comparing such a measure as calculated in a regression covering the pre-NAFTA years with that obtained from another regression estimated on the postNAFTA sample. ${ }^{14}$

\section{Aggregate Output}

We first measure the degree of output synchronization between Canada and/or the United States, on the one hand, and Mexico and other countries in Europe and Latin America on the other. ${ }^{15}$ Figure 3.2 shows the correlation of annual GDP growth of various countries with that of the United States during the periods 1981Q1-2001Q2 and 1994Q1-2001Q2. In the

Figure 3.2 Correlation of Annual GDP Growth with the United States

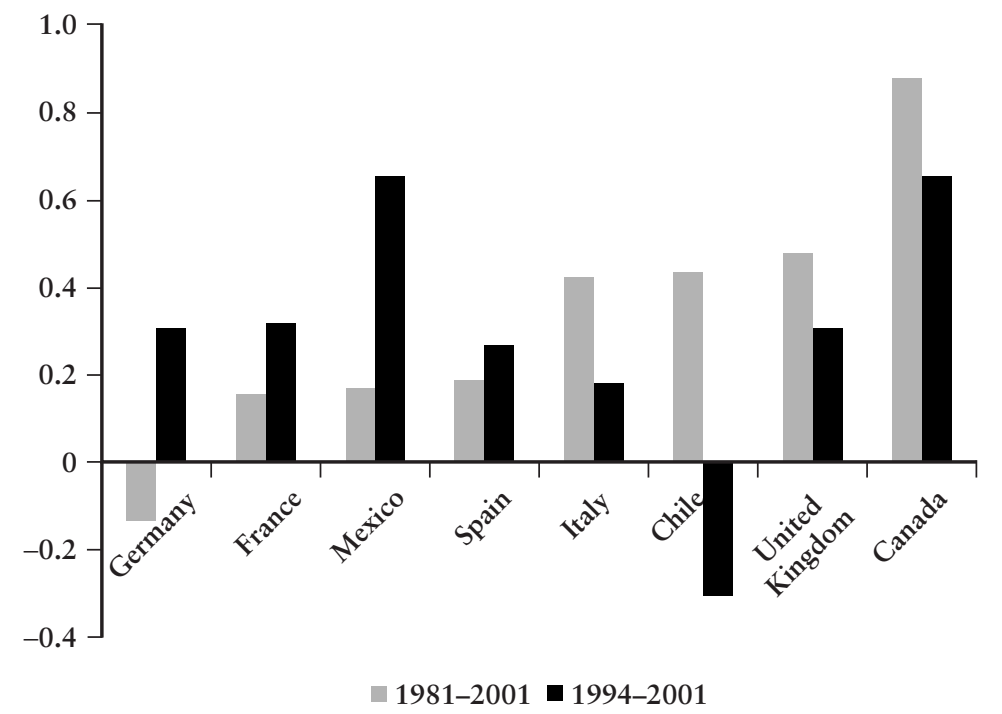

Source: Cuevas, Messmacher, and Werner 2002. 
longer sample, the correlation coefficient between Canada and the United States is by far the highest, followed by those of the United Kingdom, Chile, and Italy. Mexico's correlation is positive but much lower. In the shorter, more recent time period, however, Canada and Mexico share the top spot, with a correlation coefficient with the United States of $0.66,{ }^{16}$ much higher than the values for the other industrialized countries shown in the figure.

It is also interesting to note that the correlation between Canada and Mexico in the shorter period is substantially higher than for the whole sample (figure 3.3). However, Canada's correlation with several European countries is higher than that with Mexico. Other results (not shown in the figure) also reveal an increase in the correlation of Mexico's output with most European economies in the sample, although the increase is much smaller than for the correlation with the United States. This phenomenon is consistent with Mexico's opening up to trade since the mid-1980s.

Results using industrial production growth broadly confirm those based on GDP growth. Figure 3.4 shows the correlation coefficients of industrial production growth in various countries with that of the United States during the periods 1987-2001, 1995-2001, and 1997-2001.

Figure 3.3 Correlation of Annual GDP Growth with Canada

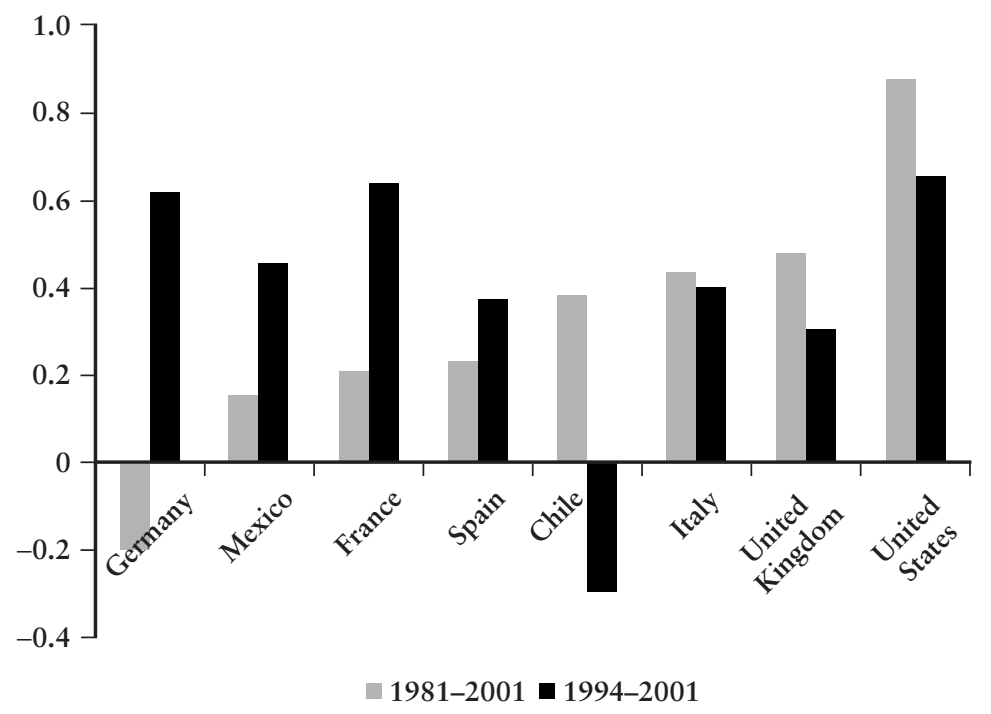

Source: Cuevas, Messmacher, and Werner 2002. 
Figure 3.4 Correlation of Industrial Production Growth with the United States

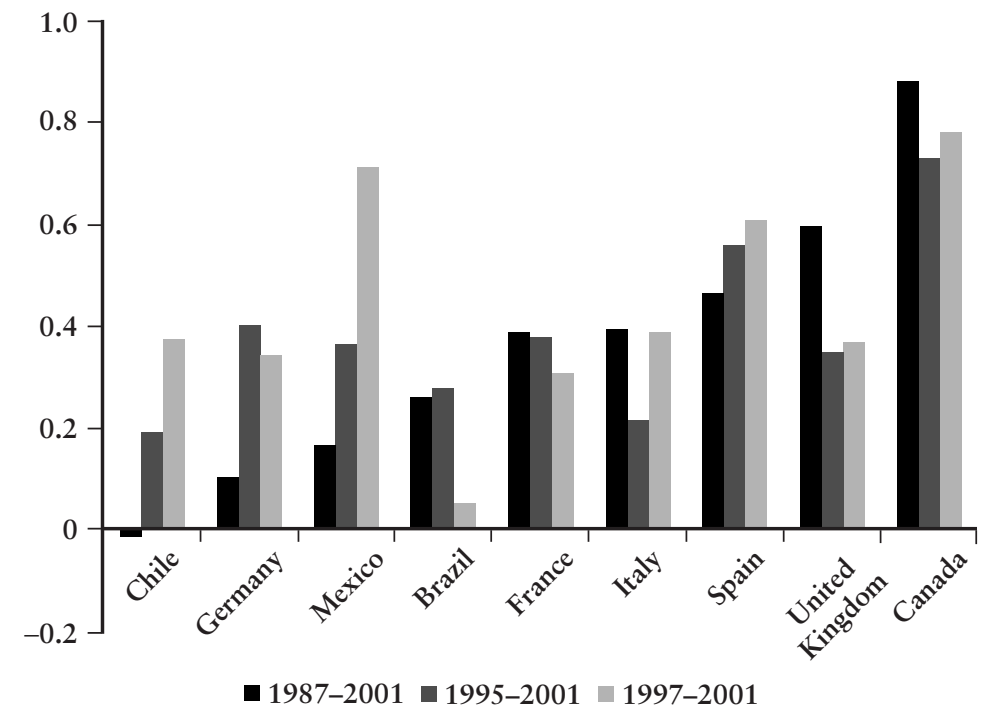

Source: Cuevas, Messmacher, and Werner 2002.

The countries showing the largest correlation with the United States during the longer sample period are Canada and the United Kingdom. At the other extreme are Chile, Mexico, and Germany, all with correlation coefficients below 0.2. The differences between these results and those for the period 1995-2001 are generally small, with the correlation falling for some countries and increasing for others but in most cases by a relatively small magnitude. However, the differences between the full-sample results and those for the 1997-2001 sample are more striking. Most important, Mexico's industrial output correlation with the United States increases to a level similar to Canada's. As with GDP, the correlation with the United States rises for several countries, but Mexico's increase is clearly the largest. Further, figure 3.5 shows that Mexico's industrial production has also become much more tightly correlated with that of Canada in the recent period, a phenomenon unique among the countries shown in the figure.

So far these results indicate that in the post-NAFTA period output growth rates in Mexico and its NAFTA partners have tended to move in the same direction and at the same time to a greater extent than in the 


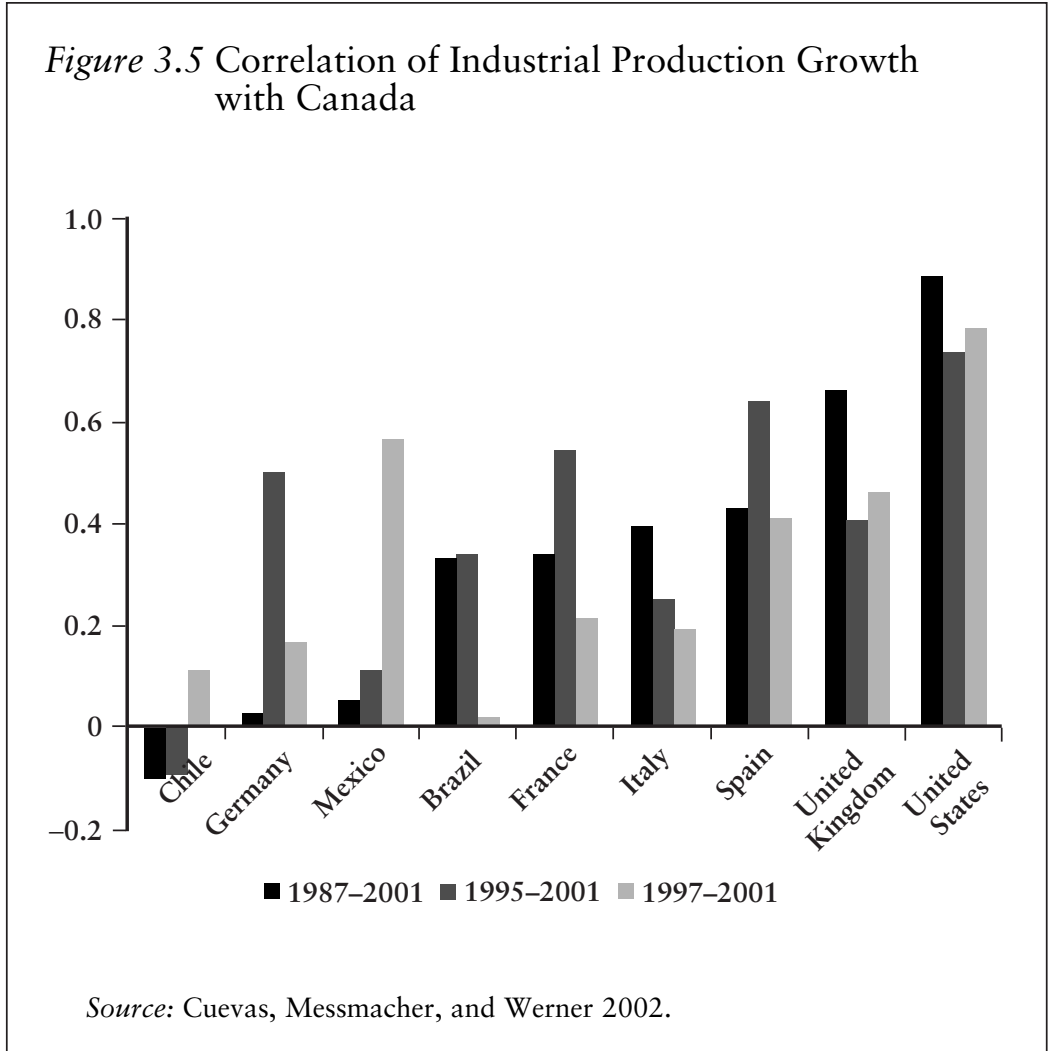

pre-NAFTA years. In principle this could reflect the occurrence of larger common shocks relative to idiosyncratic shocks to these countries, without any increase in Mexico's sensitivity to developments in its NAFTA partners, or an increased sensitivity without changes in the structure of shocks, or both at the same time.

To assess the changes in the sensitivity of Mexican variables to developments in the United States we turn to the simple regressions described in equation 3.1 above. ${ }^{17}$ Table 3.1 shows estimates of the sensitivity parameters $\gamma$ and $\delta$ from equation 3.1 using GDP growth data, for the two choices of post-NAFTA period (starting in 1994 and 1997, respectively). As explained above, $\gamma$ indicates the sensitivity to changes in the U.S. variable before the break date, whereas $\gamma+\delta$ represents the sensitivity after that date.

The coefficient estimates in the table show considerable diversity across countries. In both specifications shown, all countries except Canada and Chile exhibit increases in their sensitivity coefficients, 
Table 3.1 Annual Growth Rate of GDP

Sensitivity Coefficients Before and After NAFTA

a. Dummy 1994

\begin{tabular}{|c|c|c|c|c|c|c|c|}
\hline \multirow[b]{2}{*}{ Country } & \multirow[b]{2}{*}{$\gamma$} & \multirow[b]{2}{*}{$\delta$} & \multirow[b]{2}{*}{$\gamma+\delta$} & \multirow[b]{2}{*}{$\operatorname{Adj} R^{2}$} & \multicolumn{3}{|c|}{$\begin{array}{l}\text { Fraction explained } \\
\text { by U.S. shocks }\end{array}$} \\
\hline & & & & & $\begin{array}{c}\text { Before } \\
1994\end{array}$ & $\begin{array}{l}\text { After } \\
1994\end{array}$ & Difference \\
\hline Canada & 0.65 & -0.13 & 0.52 & 0.89 & 0.85 & 0.72 & -0.13 \\
\hline Mexico & 0.28 & 1.35 & 1.63 & 0.66 & -0.03 & 0.48 & 0.50 \\
\hline Brazil & -1.03 & 1.63 & 0.60 & 0.32 & 0.01 & -0.10 & -0.11 \\
\hline Chile & 0.56 & -0.63 & -0.07 & 0.75 & 0.39 & -0.05 & -0.44 \\
\hline France & 0.04 & 0.24 & 0.29 & 0.75 & 0.13 & 0.16 & 0.03 \\
\hline Germany & -0.04 & 0.37 & 0.33 & 0.71 & -0.01 & 0.05 & 0.05 \\
\hline Italy & 0.10 & 0.23 & 0.32 & 0.64 & 0.37 & -0.23 & -0.59 \\
\hline Spain & -0.02 & 0.34 & 0.31 & 0.81 & -0.06 & 0.01 & 0.06 \\
\hline UK & 0.05 & 0.13 & 0.17 & 0.80 & 0.47 & 0.06 & -0.42 \\
\hline \multicolumn{8}{|c|}{ b. Dummy 1997} \\
\hline
\end{tabular}

\begin{tabular}{|c|c|c|c|c|c|c|c|}
\hline \multirow[b]{2}{*}{ Country } & \multirow[b]{2}{*}{$\gamma$} & \multirow[b]{2}{*}{$\delta$} & \multirow[b]{2}{*}{$\gamma+\delta$} & \multirow[b]{2}{*}{$\operatorname{Adj} R^{2}$} & \multicolumn{3}{|c|}{$\begin{array}{c}\text { Fraction explained } \\
\text { by U.S. shocks }\end{array}$} \\
\hline & & & & & $\begin{array}{c}\text { Before } \\
1997\end{array}$ & $\begin{array}{l}\text { After } \\
1997\end{array}$ & Difference \\
\hline Canada & 0.63 & -0.19 & 0.44 & 0.89 & 0.84 & 0.74 & -0.10 \\
\hline Mexico & 0.31 & 0.71 & 1.03 & 0.64 & -0.01 & 0.36 & 0.37 \\
\hline Brazil & -0.09 & 0.19 & 0.09 & 0.09 & -0.08 & -0.11 & -0.03 \\
\hline Chile & 0.53 & -0.37 & 0.16 & 0.75 & 0.37 & -0.15 & -0.52 \\
\hline France & 0.07 & 0.06 & 0.13 & 0.73 & 0.18 & 0.47 & 0.30 \\
\hline Germany & -0.03 & 0.44 & 0.41 & 0.71 & 0.03 & -0.26 & -0.29 \\
\hline Italy & 0.10 & 0.33 & 0.43 & 0.65 & 0.33 & 0.08 & -0.25 \\
\hline Spain & -0.01 & 0.08 & 0.07 & 0.85 & 0.29 & -0.14 & -0.44 \\
\hline UK & 0.06 & 0.09 & 0.14 & 0.81 & 0.49 & 0.01 & -0.48 \\
\hline
\end{tabular}

Note: The parameter estimates correspond to the empirical specification given by equation 3.1 in the text. Coefficients in italics are significantly different from 0 at the 10 percent level or better. The parameter $\gamma$ represents the sensitivity coefficient to developments in the United States before period T (either 1994 or 1997) and the sum of $\gamma$ plus $\delta$ indicates the sensitivity coefficient after period $T$. The measures of the contribution of U.S. shocks are described in the text. They are obtained from separate regressions on the subsamples before and after $T$, and are adjusted for degrees of freedom.

Source: Cuevas, Messmacher, and Werner 2002.

although few of them are statistically significant. Mexico's coefficient rises substantially in the post-NAFTA period, although the increase is significant only when 1994 is taken as the break year. Mexico is also the country exhibiting the largest post-NAFTA sensitivity coefficient, 
Table 3.2 Annual Growth Rate of Industrial Production

Sensitivity Coefficients Before and After NAFTA

a. Dummy 1994

\begin{tabular}{|c|c|c|c|c|c|c|c|}
\hline \multirow[b]{2}{*}{ Country } & \multirow[b]{2}{*}{$\gamma$} & \multirow[b]{2}{*}{$\delta$} & \multirow[b]{2}{*}{$\gamma+\delta$} & \multirow[b]{2}{*}{$\operatorname{Adj} R^{2}$} & \multicolumn{3}{|c|}{$\begin{array}{l}\text { Fraction explained } \\
\text { by U.S. shocks }\end{array}$} \\
\hline & & & & & $\begin{array}{c}\text { Before } \\
1994\end{array}$ & $\begin{array}{l}\text { After } \\
1994\end{array}$ & Difference \\
\hline Canada & 0.37 & 0.04 & 0.41 & 0.91 & 0.93 & 0.68 & -0.25 \\
\hline Mexico & 0.00 & 0.15 & 0.14 & 0.59 & -0.01 & 0.08 & 0.09 \\
\hline Brazil & 0.08 & 0.28 & 0.36 & 0.42 & -0.02 & 0.09 & 0.12 \\
\hline Chile & 0.02 & 0.08 & 0.10 & 0.71 & -0.01 & 0.05 & 0.06 \\
\hline France & 0.07 & 0.10 & 0.17 & 0.73 & 0.04 & 0.22 & 0.19 \\
\hline Germany & 0.02 & 0.36 & 0.38 & 0.69 & -0.03 & 0.21 & 0.24 \\
\hline Italy & 0.27 & 0.17 & 0.45 & 0.49 & 0.14 & 0.19 & 0.05 \\
\hline Spain & 0.06 & 0.12 & 0.19 & 0.81 & 0.01 & 0.30 & 0.29 \\
\hline UK & 0.41 & -0.33 & 0.08 & 0.77 & 0.64 & 0.33 & -0.31 \\
\hline \multicolumn{8}{|c|}{ b. Dummy 1997} \\
\hline
\end{tabular}

\begin{tabular}{|c|c|c|c|c|c|c|c|}
\hline \multirow[b]{2}{*}{ Country } & \multirow[b]{2}{*}{$\gamma$} & \multirow[b]{2}{*}{$\delta$} & \multirow[b]{2}{*}{$\gamma+\delta$} & \multirow[b]{2}{*}{$A d j R^{2}$} & \multicolumn{3}{|c|}{$\begin{array}{l}\text { Fraction explained } \\
\text { by U.S. shocks }\end{array}$} \\
\hline & & & & & $\begin{array}{c}\text { Before } \\
1997\end{array}$ & $\begin{array}{l}\text { After } \\
1997\end{array}$ & Difference \\
\hline Canada & 0.32 & 0.24 & 0.56 & 0.91 & 0.82 & 0.76 & -0.06 \\
\hline Mexico & -0.01 & 1.15 & 1.14 & 0.59 & -0.01 & 0.61 & 0.61 \\
\hline Brazil & 0.37 & -0.24 & 0.13 & 0.41 & 0.05 & -0.02 & -0.07 \\
\hline Chile & 0.03 & 0.03 & 0.06 & 0.72 & -0.01 & 0.07 & 0.07 \\
\hline France & 0.11 & -0.01 & 0.10 & 0.73 & 0.13 & 0.20 & 0.07 \\
\hline Germany & 0.03 & 0.31 & 0.34 & 0.69 & -0.01 & 0.12 & 0.13 \\
\hline Italy & 0.23 & 0.24 & 0.47 & 0.48 & 0.12 & 0.25 & 0.13 \\
\hline Spain & 0.09 & 0.20 & 0.29 & 0.81 & 0.16 & 0.37 & 0.20 \\
\hline UK & 0.27 & -0.08 & 0.19 & 0.76 & 0.57 & 0.51 & -0.06 \\
\hline
\end{tabular}

Note: The parameter estimates correspond to the empirical specification given by equation 3.1 in the text. Coefficients in italics are significantly different from 0 at the 10 percent level or better. The parameter $\gamma$ represents the sensitivity coefficient to developments in the United States before period T (either 1994 or 1997) and the sum of $\gamma$ plus $\delta$ indicates the sensitivity coefficient after period T. The measures of the contribution of U.S. shocks are described in the text. They are obtained from separate regressions on the sub samples before and after $T$, and are adjusted for degrees of freedom.

Source: Cuevas, Messmacher, and Werner 2002.

which in both specifications is greater than 1. Canada's coefficient, the second largest, is less than half that of Mexico. Thus, not only is Mexico's GDP becoming more sensitive to variations in U.S. output, but it also responds more than proportionately to changes in the latter. 
The $R^{2}$ results from these regressions are in general quite high, with the exception of Brazil's. But to a large extent they reflect the action of lagged growth, and to gauge the contribution of U.S. growth to the observed variation in growth in the other countries we turn to the last three columns of the table. These report the estimated contribution of U.S. growth over the pre- and post-break sample periods, as measured by the $R^{2}$-like statistic described earlier.

By this measure both specifications yield fairly similar conclusions regarding the role of U.S. shocks. These account for the bulk of the variation in growth in Canada, and for a fair share of the variation in growth in Chile and the United Kingdom in the early part of the sample. In these two countries, however, the contribution of U.S. shocks declines sharply in the later years. In contrast, U.S. shocks appear wholly unimportant for Brazil and Germany in all samples and specifications. Mexico is the country exhibiting the largest increase in the role of U.S. shocks under both specifications shown. In the later sample, U.S. growth accounts for between one third and one half of the variance of Mexico's growth. Only Canada (as well as France when the sample is broken in 1997) shows a larger figure.

Table 3.2 shows similar regressions of the annual growth rate of industrial production, using monthly data for 1987-2001. As with GDP, most countries exhibit increasing sensitivity coefficients, but few of the changes are significant. Mexico shows a large jump when the break year is 1997; in such a specification, it again exhibits the largest post-NAFTA sensitivity coefficient-as before exceeding 1 . The last three columns in the table show that the explanatory power of U.S. industrial production rises in all countries except Canada and the United Kingdom. As before, the explanatory power is greatest for Canada. In the early samples U.S. shocks appear to play a very marginal role in the observed variation in Mexico's growth, but in the post-1997 sample they become a major factor-they account for 61 percent of the variation, a figure that exceeds even that of the United Kingdom, and is second only to Canada's.

\section{NAFTA and Output Synchronization: The Disaggregated View}

There are two potentially important dimensions of synchronization that may be masked in the aggregate data. The first one is geographic. Have all regions of Mexico experienced a similar increase in the importance of U.S. developments as a source of growth variation? To answer this question, we explored regional employment growth data. The results from this analysis, summarized in box 3.2, show that the Southern states of Mexico have been a clear exception to the trend of increasing co-movement with the United States. 


\section{Box 3.2 Macroeconomic Synchronization at the Regional Level}

Has NAFTA had different effects across Mexico's regions on the degree of macroeconomic synchronization with the United States? In principle we would expect to see higher synchronization with the United States in the northern states of Mexico, given their lower transport costs to access the U.S. market, and in those regions producing tradable goods. But the northern regions were already relatively integrated with the United States and for them the marginal change may be modest. In that case we could find a larger increase for other regions that were less integrated but produce tradable goods. To explore this question we used monthly employment data by region. ${ }^{1}$ The table here shows the correlation of employment growth between Mexican regions and the United States (both at the national level and for the Pacific region) over 1992-2001 and 1997-2001. Over the longer period, the north and the Gulf regions of Mexico exhibited the largest correlation ( 0.37 and 0.28 , respectively) with U.S. employment growth. However, most of Mexico's regions were highly synchronized in terms of employment growth with the U.S. Pacific region. The correlation coefficients are between 0.53 and 0.82 . The last two columns in table B2.1 show that for 1997-2001 the correlation coefficients rose for all Mexican regions, with the exception of those in the south. ${ }^{2}$ The change in the correlation coefficients across periods is depicted in the figure here.

Correlation Coefficients Between Annual Employment Growth Rates in Mexico and the United States, by Region

\begin{tabular}{|c|c|c|c|c|}
\hline \multirow[b]{2}{*}{ Region } & \multicolumn{2}{|c|}{ 1992-2001 } & \multicolumn{2}{|c|}{ 1997-2001 } \\
\hline & $\begin{array}{c}\text { Total } \\
\text { United States }\end{array}$ & $\begin{array}{c}\text { Pacific } \\
\text { United States }\end{array}$ & $\begin{array}{c}\text { Total } \\
\text { United States }\end{array}$ & $\begin{array}{c}\text { Pacific } \\
\text { United States }\end{array}$ \\
\hline Total Mexico & 0.22 & 0.80 & 0.63 & 0.93 \\
\hline North & 0.37 & 0.82 & 0.55 & 0.88 \\
\hline Pacific & 0.14 & 0.69 & 0.69 & 0.86 \\
\hline North Central & 0.21 & 0.70 & 0.63 & 0.89 \\
\hline Central & 0.07 & 0.53 & 0.59 & 0.91 \\
\hline Capital & 0.12 & 0.70 & 0.68 & 0.86 \\
\hline Gulf & 0.28 & 0.76 & 0.46 & 0.79 \\
\hline South & 0.12 & 0.55 & 0.02 & 0.52 \\
\hline
\end{tabular}

Source: Cuevas, Messmacher, and Werner 2002.

Regression estimates, as well as factor analysis, of regional employment growth confirm that most Mexican regions have become more sensitive to U.S. developments in the post-NAFTA period. The exception is again the southern region. Thus, in addition to the well-documented 


\section{Box 3.2 (continued) \\ Change in the Correlation of Employment Growth Between Mexican and U.S. Regions}

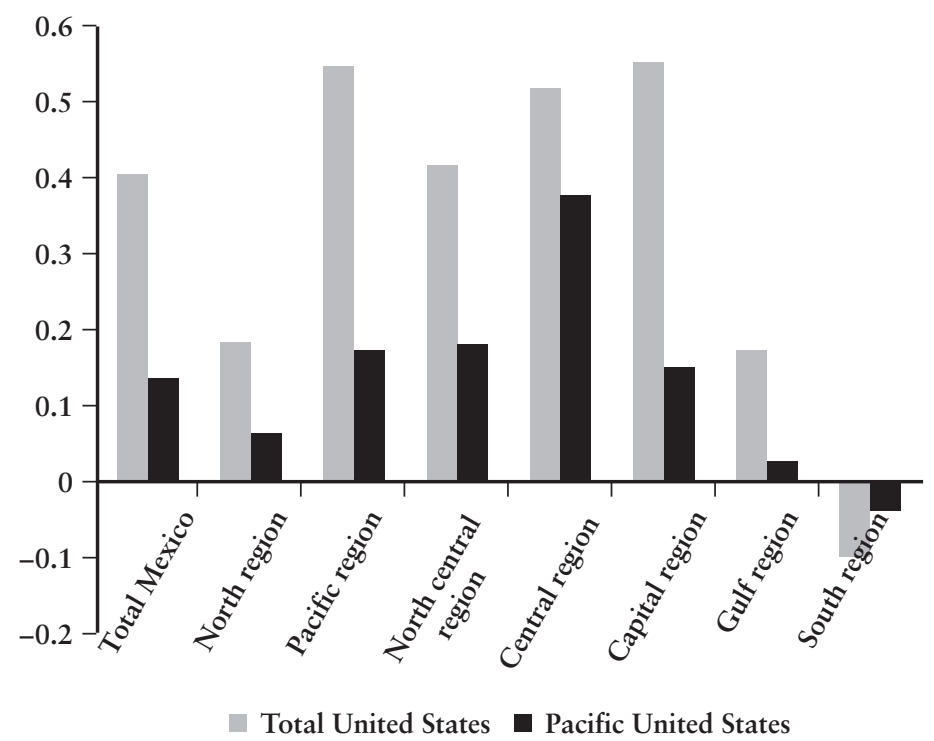

Source: Cuevas, Messmacher, and Werner 2002.

income gap, another gap appears to have opened between the south and the rest of Mexico in terms of macroeconomic synchronization with the United States.

\section{Notes}

1. The required production data are not available. The employment data come from the Mexican Social Security Institute and the U.S. Bureau of Labor Statistics.

2. This latter result is not surprising because this region also has the lowest correlation with any other Mexican region.

The other dimension refers to the economic sector level. If increased synchronization is indeed a result of deepening trade integration, we should expect a more marked increase in the degree of synchronization of tradable goods sectors than in other sectors. We investigate this hypothesis using quarterly GDP measures for Canada and Mexico and national gross income data for the United States, at the one-digit sector 
Table 3.3 Growth correlation between Canada, Mexico, and the United States, by Sector of Economic Activity

\begin{tabular}{|c|c|c|c|c|c|c|}
\hline & \multicolumn{2}{|c|}{$1988-2001$} & \multicolumn{2}{|c|}{ 1994-2001 } & \multicolumn{2}{|c|}{ 1997-2001 } \\
\hline & Canada & Mexico & Canada & Mexico & Canada & Mexico \\
\hline Agriculture & 0.135 & -0.005 & 0.167 & 0.086 & 0.409 & 0.265 \\
\hline Mining & 0.589 & 0.392 & 0.645 & 0.451 & 0.753 & 0.489 \\
\hline Manufactures & 0.657 & 0.112 & 0.779 & 0.169 & 0.890 & 0.867 \\
\hline construction & 0.604 & 0.031 & 0.125 & 0.489 & -0.542 & 0.137 \\
\hline $\begin{array}{l}\text { Transportation and } \\
\text { communications }\end{array}$ & -0.031 & 0.240 & 0.296 & 0.399 & 0.150 & 0.619 \\
\hline $\begin{array}{l}\text { Electricity, gas, and } \\
\text { water }\end{array}$ & 0.241 & 0.024 & 0.575 & 0.184 & 0.705 & 0.387 \\
\hline Financial services & -0.155 & -0.189 & -0.120 & -0.118 & 0.332 & 0.186 \\
\hline $\begin{array}{l}\text { Social, communal, and } \\
\text { personal services }\end{array}$ & 0.322 & -0.056 & 0.513 & 0.423 & 0.145 & 0.635 \\
\hline
\end{tabular}

Sources: Cuevas, Messmacher, and Werner 2002.

level, as well as monthly industrial production at the two-digit level for Mexico and the United States. ${ }^{18}$

Table 3.3 shows correlation coefficients of sectorwise growth rates in Canada and Mexico with the corresponding U.S. sector for the periods 1988-2001, 1994-2001, and 1997-2001. Over the full 14-year period, the correlation between Canadian and U.S. sectors is generally larger than that between Mexican and U.S. sectors, with transport and communications the only exception. In the post-NAFTA years, however, and especially after the 1995-96 balance-of-payments crisis, the correlation between Mexican and U.S. sectors increased significantly in several cases-manufacturing, transport and communications, and general services. In contrast, it remains low for agriculture, construction, and financial services.

Comparing the full-sample correlation coefficients between Mexican and U.S. sectors with those obtained in the more recent periods it can be seen that the latter are larger than the former in every instance, and in all cases but one they are larger in the most recent years (1997-2001). In contrast, Canada-U.S. correlation coefficients fall in some cases during the latter part of the sample.

We can dig one level deeper by examining the patterns of growth correlation by industrial sector. This is done in table 3.4, which shows the correlation of industrial production growth and its components between Mexico and the United States for the whole sample period 1981-2001 and for the subperiods 1994-2001 and 1997-2001. The table shows a significant increase in the correlation of total industrial production, 
Table 3.4 Growth Correlation Between Canada, Mexico, and the United States, by Industrial Sector

\begin{tabular}{lccc}
\hline \multicolumn{4}{c}{ Correlation between Mexico and United States of America } \\
\hline Total & $1981-2001$ & $1994-2001$ & $1997-2001$ \\
Mining & 0.316 & 0.519 & 0.968 \\
Electricity, gas, and water & 0.366 & 0.368 & 0.432 \\
Manufacturing & -0.141 & -0.179 & 0.054 \\
Food and beverages & 0.284 & 0.619 & 0.970 \\
Textiles & 0.014 & 0.100 & 0.328 \\
Wood industries & -0.039 & 0.371 & 0.790 \\
Paper and printing & 0.020 & 0.316 & 0.344 \\
Chemical products & 0.083 & 0.511 & 0.748 \\
Minerals & 0.098 & 0.572 & 0.691 \\
Basic metals & 0.071 & 0.499 & 0.636 \\
Machinery & 0.561 & 0.520 & 0.766 \\
Other manufacturing industries & 0.396 & 0.501 & 0.832 \\
\hline
\end{tabular}

Source: Cuevas, Messmacher, and Werner 2002.

driven mostly by manufacturing. Within manufacturing the increase in correlation is particularly large for paper and printing, chemical products, mineral-based products, textiles, and machinery. However, except for the latter sector (plus perhaps textiles), none of these was particularly export-oriented in the pre-NAFTA years.

As with the aggregate data, the correlation analysis was complemented with simple regressions of sectorwise GDP growth in Mexico against the corresponding U.S. variable using a variety of specifications. The results from this exercise ${ }^{19}$ show that the sensitivity of Mexico's growth at the one-digit level to growth in the same sector in the United States has increased substantially in the past few years, in some cases to exceed the corresponding sensitivity estimates for Canada. As in the correlation analysis, the sectors exhibiting the highest sensitivity in recent years are manufacturing, transport and communications, and social services. However, the contribution of U.S. shocks to the variance of growth remains modest even in these sectors, again suggesting that idiosyncratic shocks have continued to play a significant role in Mexico in recent years.

Similar regression exercises were performed for industrial production growth at the two-digit level of disaggregation. The coefficients capturing the post-NAFTA change in sensitivity were positive in most cases, and in every one when the break year is 1997. In a number of cases the change was statistically significant-total industrial production, total manufacturing, textiles, wood products, paper and printing, chemical 
products, and minerals. Several of the post-NAFTA sensitivity coefficients were larger than 1 , which suggested that industrial output in Mexico reacts more than proportionately to changes in the same subsector in the United States.

In most sectors the regressions also show an increase in the explanatory power of U.S. growth; indeed, this is the case for every sector in the post-1996 sample. In the latter case, the United States accounts for the bulk (more than 90 percent) of the growth variation in total industry and total manufacturing. In textiles, machinery, paper, and chemicals, U.S. shocks account for around one half of the total variation. In contrast, U.S. factors remain marginal for mining, utilities, food and beverages, and wood products.

Finally, the role of common U.S.-Mexico factors in the variation of industrial output was also explored using factor analysis. Specifically, we compared the patterns of factor loadings between 1988-2001 and 1997-2001. The results were in broad agreement with those reported above: in the former period, there was virtually no instance in which matching industrial sectors in Mexico and the United States shared a common factor. In contrast, in the latter period there is strong evidence that most manufacturing sectors in both countries are significantly driven by common shocks.

\section{NAFTA and Macroeconomic Volatility}

Related to macroeconomic synchronization, another important dimension in which NAFTA has potentially major implications for Mexico is that of macroeconomic volatility. On the one hand, the nature and extent of volatility in Mexico may change as a result of NAFTA-as suggested by the preceding analysis. On the other hand, macroeconomic volatility itself acquires renewed importance because it may detract from the benefits of economic integration by holding back the rise in foreign trade and investment flows through which the gains should accrue. This underscores the need for macroeconomic policies that foster macroeconomic stability.

Like most other Latin American economies, Mexico has long been characterized by high macroeconomic volatility, much above the levels observed in industrialized countries and successful East Asian economies. Figure 3.6 presents a comparative perspective on macroeconomic volatility as measured by the standard deviation of real GDP growth over the 1980s and 1990s. Three facts emerge from the graph. ${ }^{20}$ First, there is a great degree of diversity across countries, but as a rule industrialized economies are much less volatile than most developing countries. Second, in the 1990s growth volatility declined in many 
Figure 3.6 GDP Growth Volatility in the 1980s and 1990s

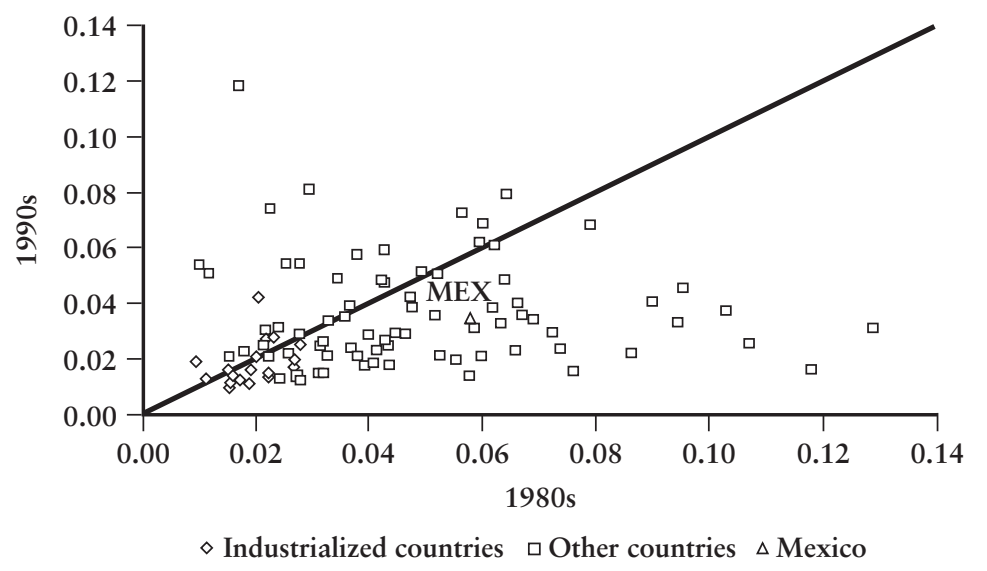

Note: Standard deviation of GDP growth, period average.

Source: Authors' elaboration from World Bank data.

developing countries relative to the (exceedingly high) levels of the 1980s-most of the data points are located below the 45-degree line. Third, Mexico has shown an improvement too: its growth volatility has declined almost by half relative to the previous decade, although it still remains higher than in industrialized and East Asian countries.

The decline in macroeconomic instability in Mexico is further illustrated in figure 3.7. ${ }^{21}$ The figure shows that growth volatility rose sharply in the early 1980 s, at the time of the debt crisis, and then declined until 1994-96, when the Tequila crisis hit. After 1996 volatility has remained low, but still above the levels of the early 1970s.

In broad terms, macroeconomic volatility reflects both the action of external shocks—real and financial—and the poor functioning of key shock absorbers, namely inadequate macroeconomic policies and weak financial systems. Terms-of-trade shocks are more severe for economies whose external trade is heavily concentrated on a few commodities (typically natural resources), and affect more strongly economies that are very open. Weak financial systems are unable to fulfill their risk-diversification role, and instead tend to amplify shocks, or even generate them. ${ }^{22}$ Finally, macroeconomic policy has often played a destabilizing role in Latin America, with monetary policy devoted in 


\section{Figure 3.7 Mexico: GDP Growth Volatility over Time}

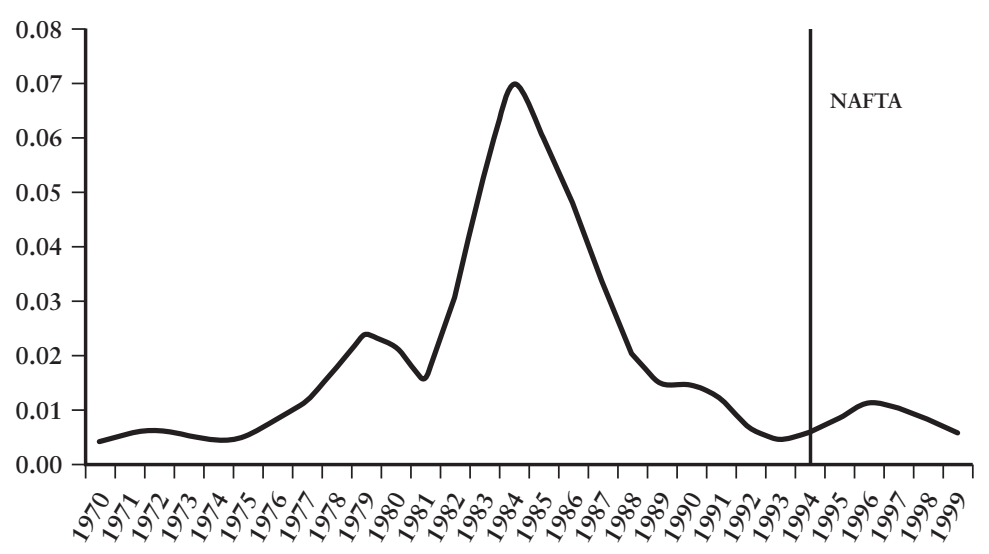

Note: Five-year interquartile range, moving average.

Source: Authors' elaboration from World Bank data.

many countries to inflationary finance of unsustainable fiscal deficits, and fiscal policy following a procyclical stance of expansion in booms and contraction in recessions. ${ }^{23}$ Indeed, the decline in volatility in Mexico after 1996 surely reflects, among other factors, improved fiscal and monetary policies in recent years.

There is ample evidence that volatility deters economic growth by discouraging both investment and productivity. ${ }^{24}$ In the presence of higher macroeconomic volatility, economic agents face greater uncertainty, and this deters them from undertaking fixed investment decisions because in many cases those decisions cannot be reversed (at least without major costs). Volatility also hampers agents' ability to allocate economic resources in an efficient manner, as the informative content of relative price and profitability signals may be drowned by aggregate instability.

For Mexico the process of trade opening and the passage of NAFTA also may have direct consequences for macroeconomic volatility. Although in principle increased openness could have raised the country's exposure to terms of trade changes, in practice it has been accompanied by an impressive increase in export diversification, which probably has led to reduced terms-of-trade risk. ${ }^{25}$ Much of this diversification has been the result of the trade liberalization process initiated in the late 1980s and the passage of NAFTA in the 1990s. As for the implications for volatility of the increased degree of cyclical synchronization between 
Mexico and its NAFTA partners described earlier, they are not entirely clear. In principle, greater synchronization with FTA partners does not necessarily imply reduced amplitude of Mexico's cyclical fluctuations. Indeed, some of the empirical results reported earlier appear to suggest that Mexico shows "excess sensitivity" to contemporaneous developments in the United States. Finally, although volatility has declined in Mexico in recent years, it still remains above that of its NAFTA partners.

Over the medium term, deeper integration with two large, stable economies should be expected to lead to reduced instability for Mexico. In fact, it may be argued that the prospect of declining instability as a result of FTA accession is precisely one of the primary reasons why countries join them in the first place-in the hope of locking in policy reforms in trade and other areas, securing market access, and generally offering a more stable environment for investors. ${ }^{26}$

Do FTAs fulfill these expectations of enhanced stability? The international evidence suggests that they might. A simple comparison of volatility measures in a large time-series cross-country sample, ${ }^{27}$ controlling for unobservable country-specific effects, shows that annual GDP growth volatility is more than 1 percent lower for those observations (country-years) corresponding to FTA membership than for the rest, and the difference is significant at the 1 percent level. But whether this reflects causation from FTA membership to stability is debatable. Causation could go the other way if, for example, FTAs tend to happen more often after countries have achieved relatively stable macroeconomic conditions.

Regardless of whether volatility can be expected to decline in the long run as a result of NAFTA, the treaty makes it an especially pressing concern for Mexico. Much of the gain that the country can achieve from trade integration relies on new investment taking place and on the expansion of external trade. However, macroeconomic volatility may prevent NAFTA from delivering its full benefits-or may delay themthrough trade and investment. Indeed, there is compelling international evidence that high volatility discourages foreign investment (and external financing in general) as the appeal of profitable investment opportunities is weakened by high risk derived from the possibility of large swings in relative prices, real exchange rates, and other major macroeconomic variables. ${ }^{28}$ Likewise, macroeconomic volatility, and specifically real exchange rate variability, deter foreign trade as a number of empirical studies have confirmed. ${ }^{29}$ Higher real exchange rate uncertainty increases the riskiness of foreign transactions, leading traders to demand higher profits in order to undertake such transactions and thus reducing the volume of trade (Brodsky 1984). ${ }^{30}$ Real exchange rate uncertainty also affects the political economy of the integration process because abrupt swings in real exchange rates may trigger protectionist pressures. ${ }^{31}$ 
In summary, to enhance the speed and scope of the gains from NAFTA, Mexico's macroeconomic stability is of paramount importance and macroeconomic policies need to ensure that the declining volatility trend of the late 1990s is maintained. Against this background the next section turns to the role of policy coordination.

\section{The Role of Policy Coordination}

The increased macroeconomic synchronization among Mexico and its NAFTA partners in recent years raises two policy questions. First, is rising synchronization simply a result of the fact that the Mexican authorities have been following policies similar to those of Mexico's NAFTA partners rather than (or in addition to) an increased incidence of common (nonpolicy) shocks? Second, looking forward does Mexico stand to gain from increased policy coordination with its NAFTA partners?

Have Mexico's fiscal and monetary policies become more similar to those of the United States? Table 3.5 reports the correlation between key fiscal and monetary policy indicators of Mexico and the United States. In the case of the fiscal and primary balances, the correlation turns from positive in the whole period to negative in the post-NAFTA sample. In

Table 3.5 Correlation Between Mexico and U.S. Policy Variables

\begin{tabular}{lrrr}
\hline & $\begin{array}{c}\text { Financial } \\
\text { Balance }\end{array}$ & $\begin{array}{c}\text { Primary } \\
\text { Balance }\end{array}$ & $\begin{array}{c}\text { Government } \\
\text { Current } \\
\text { Expenditure }\end{array}$ \\
\hline 1980Q1-2001Q4 & 0.282 & 0.038 & -0.044 \\
1994Q1-2001Q4 & -0.514 & -0.274 & 0.005 \\
1997Q1-2001Q4 & -0.497 & -0.287 & -0.087 \\
\hline
\end{tabular}

Note: Fiscal variables.

\begin{tabular}{|c|c|c|c|c|}
\hline & $\begin{array}{c}\text { Growth } \\
\text { in Real } \\
\text { Money } \\
\text { Balances }^{a}\end{array}$ & $\begin{array}{c}\text { Real } \\
\text { Interest Rate } \\
\text { (accurate }^{a} \\
\text { expectations) }\end{array}$ & $\begin{array}{c}\text { Monetary } \\
\text { Base }\end{array}$ & $\begin{array}{c}\text { Short-term } \\
\text { Nominal } \\
\text { Interest } \\
\text { Rate }\end{array}$ \\
\hline Whole & 0.066 & 0.174 & 0.168 & 0.522 \\
\hline 1994M1-2001M12 & 0.328 & 0.034 & 0.136 & 0.413 \\
\hline 1997M1-2001M12 & 0.401 & -0.110 & 0.230 & 0.324 \\
\hline
\end{tabular}

Note: Monetary variables.

${ }^{\mathrm{a}}$ The whole period is $1986 \mathrm{M} 12-2001 \mathrm{M} 12$ for real money balances and monetary base, 1984M12-2001M12 for the real interest rate, and 1987M12-2001M12 for the short-term nominal interest rate.

Source: Cuevas. Messmacher, and Werner 2002. 
terms of government current expenditures to GDP, the correlation is close to 0 for any of the periods.

Regarding the monetary indicators, the real growth rate of M2 shows a 0 correlation for the whole period, which becomes modestly positive in the post-NAFTA subsample. However, to the extent that real money balances are driven by money demand, this could turn out to be just a reflection of the increasing output correlation between the two countries. As for real interest rates, their cross-country correlation is slightly positive for the whole period and negative after 1997. In any case the magnitude of the coefficient is very low. In the case of the nominal growth rate of the monetary base, the correlation is positive but of small magnitude and shows little change over time. Finally, nominal interest rates display a positive correlation-which is somewhat surprising given the relatively high volatility of inflation in Mexico-that declines over time.

On the whole, this provides little indication that policy synchronization has risen, which is hardly surprising. Regarding, for example, monetary policy in the post-NAFTA years, in the United States it was dictated by local growth forecasts, whereas in Mexico it was conditioned by the disinflation processes, the 1995 balance-of-payments crisis, and external financial shocks associated with the Brazilian and Russian crises. Thus, the conclusion is that synchronization has risen despite dissimilar policies.

Does Mexico need to coordinate its policies with those of NAFTA partners? The question arises in view of the increasing role of developments in Canada and the United States for Mexico's macroeconomic performance. Here "policy coordination" is taken to mean formal adoption of a set of common policies, or policy rules, to be followed by all the countries involved-such as a common currency, fiscal redistribution agreements, and/or fiscal rules like those established in the European Union's Stability Pact. Looser or informal coordination, which countries would obey in their own interest, is of course possible but its desirability is not directly related to the degree of macroeconomic synchronization. ${ }^{32}$ Besides, loose coordination without binding agreements to which the authorities can be held accountable-and without institutions to enforce them-is unlikely to be credible or effective (Eichengreen 2002).

The case for coordination is predicated on two types of arguments, mutually related but conceptually distinct. The first type is economic: when cyclical fluctuations are transmitted across economies, uncoordinated policies may result in insufficient or excessive stabilization. In such conditions, coordinated stabilization policies can deliver higher welfare (see Andersen and Spange 2002). Furthermore, coordination with an anchor country enjoying a strong reputation may enhance the credibility of domestic policies.

An extreme form of coordination that has attracted considerable attention is monetary unification between the countries involved, be it in 
the form of a currency union as in the European Monetary Union (EMU), or through unilateral adoption by one country of the other country's currency, with the U.S. dollar as the obvious candidate in the case of NAFTA. Of course unification is only one possible form of monetary coordination. Other alternatives, such as exchange rate target zones, harmonized inflation, or money targets, are also possible but they are subject to the enforcement problems already mentioned. The gains from monetary unification stem from the reduction in transaction costs involved in goods and assets trade with the anchor country (and other countries using the same currency) and from its potential role as an expeditious shortcut through which countries with poor policy credibility can acquire the higher credibility of the anchor country.

Against these benefits, the loss of monetary independence also involves costs. Their magnitude is determined by two main factors highlighted in the OCA literature. The first one is the degree of similarity between the business cycles of the anchor and client countries. The second is the extent to which, in the absence of independent monetary policy, the client country can adjust to asymmetric shocks through alternative mechanisms, such as wage and price flexibility, international labor mobility, and/or redistributive fiscal policy agreements with the anchor.

What matters are the degree of business cycle asymmetry and the functioning of the alternative mechanisms after unification, which may differ from that prevailing prior to it. For example, monetary unification itself may raise macroeconomic synchronization by encouraging trade. Also, if asymmetry is largely a result of divergent policies, unification will obviously reduce asymmetry. In other words, OCA criteria are partly endogenous-although the precise extent of this endogeneity remains controversial. ${ }^{33}$

In addition, unilateral monetary unification entails other costs, such as the loss of seigniorage revenues and lender-of-last-resort functions, and the lack of voice of the client countries in the choice of monetary policy by the anchor. These additional costs make it a clearly inferior strategy vis-à-vis a symmetric currency union (Buiter 1999).

So far we have focused on the economic argument for policy coordination. The second argument for policy coordination is political: tighter coordination of policies helps further the cause of integration. The adoption of common policies makes sense as part of a long-run process of deepening integration, such as that followed by the EU. Policy convergence among its members (as imposed by the Maastricht Treaty) was a logical step on the way to a monetary union, itself another step in the European process of political and institutional integration, which was primarily driven by noneconomic factors. In contrast, from a political perspective the need for common policies is much less clear if the process of integration is not expected to advance much beyond an FTA. 


\section{Policy Coordination in Mexico}

How do these considerations apply to Mexico? In principle the increased macroeconomic synchronization with NAFTA partners could make a common policy more likely to fit Mexico. But in practice the absence of institutional mechanisms for joint design and enforcement of policies and the sheer disparities in economic size among partners offer little room for true coordination, short of Mexico adopting the monetary and/or fiscal policies of the United States.

Would Mexico benefit from adopting the U.S. monetary policy? Although developments in the United States account for an increasing fraction of the fluctuations of Mexican macroeconomic variables, the scope for asymmetric shocks remains considerable. They still account for more than half of Mexico's growth variability. Nominal price and wage flexibility are lacking in Mexico, and NAFTA does not provide unrestricted labor mobility or mechanisms of fiscal redistribution to facilitate Mexico's adjustment to shocks in the absence of independent stabilization policy. ${ }^{34}$

Likewise, the high sensitivity of Mexican variables to their U.S. counterparts in recent years-which, according to the empirical estimates reported earlier, tend to make the magnitude of the response larger than that of the shock-poses another obstacle. Common policies would not be able to deal properly with Mexico's output and employment fluctuations, even those triggered by common shocks. Instead, common shocks would demand policies of the same sign as but different intensity than those of the partner countries. ${ }^{35}$

Furthermore, there are good reasons to expect the impact of policies to differ across NAFTA economies. Regarding monetary policy, Mexico's lower level of financial development and domestic credit to the private sector implies that the interest rate and credit channels are likely to be weaker than in Canada and the United States. In turn, because foreign trade as a ratio to GDP is much higher in Canada and Mexico than in the United States, the exchange rate channel is likely to be more important for the first two countries. Finally, although we do not have direct evidence on the channels through which fiscal policy works in the three countries, the fact that liquidity constraints are more likely to bind in Mexico than in its NAFTA partners suggests that the effect of countercyclical fiscal policies could be much stronger in the former than in the latter economies because Ricardian offsetting of public deficits by private surpluses is less likely to occur in the Mexican case.

The above arguments suggest that common NAFTA policies are unlikely to be better for Mexico than are independent policies. But an issue is whether Mexico can effectively carry out independent countercyclical policies. Regarding monetary policy, it has been argued that emerging market floating exchange rate regimes such as Mexico's 
do not really grant monetary independence, and local interest rates end up closely tracking international rates (up to a risk premium) because of a fear of floating on the part of the authorities in the face of lack of credibility and/or significant currency mismatches in the balance sheets of bank and nonbank private agents (Calvo and Reinhart 2002). In this view there would be little loss of policy autonomy from monetary unification. However, recent empirical studies show that, at least in the short term, floating exchange rate regimes do allow a degree of monetary autonomy significantly greater than that of pegged regimes. ${ }^{36}$ In this regard, the adoption of a flexible exchange rate anchored by inflation targets has increased Mexico's ability to carry out an independent monetary policy, as has clearly been the case during the current disinflationary episode. Such ability will presumably grow over time as the credibility of the inflation targeting regime is strengthened and a track record of monetary stability and low inflation is established.

In turn, the scope for countercyclical fiscal policies is also limited by weak credibility. Mexico's past tradition of large fiscal deficits and balance-of-payments crises has led financial markets to regard with suspicion the use of fiscal stabilizers in recessions because they could signal permanent deficit increases and a deterioration of the public sector's solvency rather than just a temporary countercyclical adjustment.

Credibility can be reinforced over time by the maintenance of prudent fiscal policies. A solid fiscal position will create more scope for countercyclical fiscal policy, which could be guided by the explicit adoption of (and adherence to) contingent fiscal targets formulated in cyclically adjusted terms. These would entail the achievement of fiscal surpluses in periods of expansion to provide room for deficits in times of recession. The creation of suitable fiscal institutions allowing policymakers to implement these or similar rules and abide by them could be a major step forward.

The room for fiscal maneuver is further constrained by the large weight of oil-related income in Mexico's total fiscal revenues-and, correspondingly, the small size of nonoil tax collection-that makes government income highly sensitive to volatile oil prices and weakens its automatic stabilizer properties. Hence, strengthening Mexico's ability to carry out countercyclical fiscal policy also requires a fiscal reform that reduces the vulnerability of fiscal revenues to fluctuations in the price of oil.

In summary, the evidence of higher macroeconomic synchronization suggests that Mexico's optimal macroeconomic policies are likely to become more similar than in the past to those followed by its NAFTA partners. But Mexico is still subject to significant idiosyncratic shocks, and its economy responds to policy shocks in different fashion than do the economies of its NAFTA partners. Hence there is a continuing need to 
conduct independent monetary and fiscal policies to reduce macroeconomic volatility. The immediate challenge is to strengthen monetary and fiscal institutions in order to build up credibility and enhance the ability of the authorities to pursue countercyclical policies.

\section{Policy Coordination of Other Latin American and Caribbean Countries}

What about policy coordination in the case of other Latin American countries? On the whole they stand to gain little from coordination among themselves. With few exceptions-such as Nicaragua and Paraguay-their degree of trade integration is low (table 3.6) and their macroeconomic fluctuations are dominated by idiosyncratic shocks. ${ }^{37}$ Moreover, there is no obvious anchor country in the region whose policy credibility could enhance that of client countries.

As for coordination with the United States, table 3.6 reveals a contrast between Central American countries on the one hand and South America on the other. In general, the former are much more open than the latter, and trade intensity with the United States is considerably higher among Central American and Caribbean countries than South American ones. In Central America the degree of trade integration of the group as a whole with the United States is also quite high: in three Central American economies (Costa Rica, Honduras, and Nicaragua) the combined GDP share of trade with the United States and intragroup trade equals or exceeds the comparable figure for Mexico, placing them as a group at the top of the list of potential candidates for monetary unification with the United States. Two economies in this region, El Salvador and Panama, have already adopted the U.S. dollar as their currency. ${ }^{38}$

Aside from goods trade, two other ingredients deserve mention regarding the issue of monetary unification with the United States. The first one is the flow of workers' remittances. Table 3.7 shows that for several Central American and Caribbean economies (notably El Salvador, Jamaica, and Nicaragua) remittance inflows, the bulk of which originate in the United States, are quite considerable. In El Salvador their magnitude relative to GDP even exceeds that of trade with NAFTA. In contrast, the figures are much smaller for Mexico and South America, with Ecuador as the only exception. Remittances matter just like goods trade from the viewpoint of international integration, but for the purposes of monetary unification they assume a key role: remittances from the anchor country work in a way similar to that of international fiscal transfers, facilitating adjustment to asymmetric shocks in the client countries.

The other ingredient is de facto financial dollarization, which is generally high in Central American economies, as well as in Andean and 
Table 3.6 Trade Interdependence in Latin America, 2001

\begin{tabular}{|c|c|c|c|c|c|}
\hline & \multicolumn{5}{|c|}{ Imports plus exports (percent of GDP) with: } \\
\hline & \multirow{2}{*}{$\begin{array}{l}\text { Rest of } \\
\text { Trading } \\
\text { Group }^{a}\end{array}$} & \multicolumn{2}{|c|}{ NAFTA } & \multirow[b]{2}{*}{$\begin{array}{c}\text { European } \\
\text { Union }\end{array}$} & \multirow[b]{2}{*}{ World } \\
\hline & & $\begin{array}{l}\text { United } \\
\text { States }\end{array}$ & Total & & \\
\hline \multicolumn{6}{|l|}{ Andean Community } \\
\hline Bolivia & 6.85 & 5.91 & 6.42 & 3.77 & 38.43 \\
\hline Colombia & 4.98 & 11.72 & 12.30 & 4.69 & 30.09 \\
\hline Ecuador & 9.67 & 20.40 & 21.40 & 9.07 & 61.66 \\
\hline Peru & 2.61 & 7.66 & 8.13 & 6.37 & 27.26 \\
\hline Venezuela & 2.43 & 14.89 & 15.64 & 3.70 & 33.13 \\
\hline \multicolumn{6}{|l|}{ Central America } \\
\hline Costa Rica & 7.06 & 34.39 & 38.86 & 15.82 & 82.69 \\
\hline El Salvaldor & 10.22 & 11.12 & 13.84 & 2.98 & 36.38 \\
\hline Guatemala & 7.06 & 22.11 & 26.39 & 4.01 & 51.24 \\
\hline Honduras & 9.83 & 88.23 & 93.04 & 7.68 & 139.89 \\
\hline Nicaragua & 26.92 & 27.21 & 37.74 & 8.02 & 98.59 \\
\hline Panama & 3.10 & 13.54 & 15.16 & 4.07 & 37.10 \\
\hline Dominican Republic & 1.82 & 48.42 & 50.89 & 5.80 & 70.70 \\
\hline Jamaica & 1.07 & 25.68 & 30.54 & 11.49 & 60.89 \\
\hline \multicolumn{6}{|l|}{ MERCOSUR } \\
\hline Argentina & 4.97 & 2.49 & 2.99 & 3.44 & 17.46 \\
\hline Brazil & 2.80 & 5.72 & 6.55 & 6.21 & 23.75 \\
\hline Paraguay & 29.32 & 6.77 & 7.09 & 6.53 & 55.42 \\
\hline Uruguay & 13.20 & 3.66 & 5.32 & 6.07 & 33.67 \\
\hline \multicolumn{6}{|l|}{ NAFTA } \\
\hline Canada & 58.85 & 57.34 & 58.85 & 5.77 & 75.36 \\
\hline Mexico & 44.22 & 42.96 & 44.22 & 3.74 & 55.63 \\
\hline United States & 6.08 & & 6.08 & 3.79 & 18.79 \\
\hline \multicolumn{6}{|l|}{ Memorandum item: } \\
\hline Chile & 9.75 & 9.91 & 13.12 & 11.95 & 57.26 \\
\hline
\end{tabular}

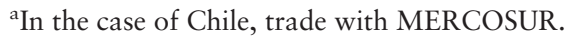

Source: Direction of Trade Statistics, United Nations.

MERCOSUR (Common Market of the South) countries-but not in Mexico or Chile (table 3.7). ${ }^{39}$ Extensive financial dollarization hampers the conduct of independent monetary policy. De facto dollarization itself often reflects a lack of confidence in monetary policy.

In summary, when all factors (real and financial) are taken together, Central America seemingly tops the list of potential candidates for 
Table 3.7 Further Measures of Interdependence, 2001

\begin{tabular}{|c|c|c|}
\hline & $\begin{array}{c}\text { Workers' } \\
\text { Remittances to } \\
\text { GDP Ratio }\end{array}$ & $\begin{array}{c}\text { Financial } \\
\text { Dollarization }^{a}\end{array}$ \\
\hline \multicolumn{3}{|l|}{ Andean Community } \\
\hline Bolivia & 1.34 & 91.50 \\
\hline Colombia & 2.13 & .. \\
\hline Ecuador & 7.87 & 53.70 \\
\hline Peru & 1.32 & 66.00 \\
\hline Venezuela & 0.11 & 0.30 \\
\hline \multicolumn{3}{|l|}{ Central America } \\
\hline Costa Rica & 1.03 & 43.80 \\
\hline El Salvador & 13.91 & $81.40^{\mathrm{b}}$ \\
\hline Guatemala & 2.93 & 5.10 \\
\hline Honduras & 8.36 & 33.10 \\
\hline Nicaragua & 13.13 & 71.00 \\
\hline Dominican Republic & 8.52 & $17.30^{\mathrm{b}}$ \\
\hline Jamaica & 12.07 & 23.30 \\
\hline \multicolumn{3}{|l|}{ MERCOSUR } \\
\hline Argentina & .. & 73.60 \\
\hline Brazil & 0.23 & .. \\
\hline Paraguay & 1.94 & 66.90 \\
\hline Uruguay &.. & 84.60 \\
\hline \multicolumn{3}{|l|}{ NAFTA } \\
\hline Mexico & 1.44 & 10.40 \\
\hline \multicolumn{3}{|l|}{ Memorandum item: } \\
\hline Chile &.. & 10.70 \\
\hline
\end{tabular}

.. Zero or insignificant.

${ }^{\mathrm{a}}$ Rate of dollarization is the ratio of foreign currency deposits to total deposits.

${ }^{\mathrm{b}}$ Share of foreign currency-denominated quasimoney in M2.

Source: World Development Indicators, World Bank; International Financial Statistics, International Monetary Fund; Consejo Monetario Centroamericano.

monetary unification with the United States in the long run. ${ }^{40}$ Indeed, El Salvador recently followed Panama in taking this step, although more time is needed to assess its experience with dollarization.

In contrast, lower real integration with the United States and a potentially large scope for asymmetric shocks (partly on account of the key role of commodities such as oil or copper) make most South American countries much less suitable candidates for monetary unification with the United States. Some of them (e.g., MERCOSUR) trade more with the EU than with the United States. The cost of losing policy autonomy seems much larger for these economies. They are likely to benefit from 
retaining monetary independence, and several of them (Brazil, Chile, Colombia, and Peru) have already made progress with the implementation of flexible exchange rate regimes guided by inflation targets. As with Mexico, for them the challenge is to establish a track record of monetary stability and low inflation to strengthen the credibility of the inflation-targeting regime.

On the fiscal front, to varying degrees most Latin American and Caribbean countries face the same problems as Mexico. Poor credibility and inadequate tax collection (which in some cases is dominated by volatile resource revenues) limit their ability to conduct countercyclical policy. In a context of deficient fiscal institutions, the result has often been a procyclical fiscal stance that augments aggregate volatility instead of reducing it. Achievement of a solid fiscal position will require in many countries a tax reform to expand the revenue base and to offset the income loss from declining tariff collection derived from the FTAA, likely to be significant for countries trading intensely with the United States. As with Mexico, a substantial strengthening of fiscal institutions will be needed to create room for countercyclical policy.

\section{Concluding Remarks}

In this chapter we have shown that despite the important differences between Mexico and its NAFTA partners, the period after the free trade agreement has been characterized by higher business cycle synchronization, the same result that has been observed in the case of trade agreements among industrialized countries. This has potentially important implications for future trade agreements between high-income and developing countries because it indicates that even with the significant differences in factor endowments that characterize Mexico and its NAFTA partners higher synchronization is likely to follow from closer trade.

Mexico had important links with the United States before NAFTA, as can be inferred from the fact that some sectors of manufacturing and a few Mexican regions exhibited a high sensitivity to developments in the United States even then. NAFTA seems to have reinforced the relationship by extending the link to other economic sectors and regions by way of a stronger trade bond through which shocks are also transmitted.

Macroeconomic volatility is a potential obstacle to Mexico's reaping the full benefits of trade integration. The increased synchronization between Mexico and the United States raises new questions on the appropriate design of macroeconomic policies to deal with volatility, and specifically whether Mexico would benefit from sharing a common monetary and/or fiscal policy with its partners. A substantial amount of idiosyncratic volatility still remains in Mexico, and overall volatility 
remains higher in Mexico than in Canada and the United States, although it has declined in recent years. Finally, the effectiveness of policies is also likely to differ between Mexico and its partners. Thus, although deepening integration might open the door to deep forms of coordination in the long run-even monetary unification—over the near future management of macroeconomic volatility in Mexico may continue to require fiscal and monetary policy stances that differ from those followed in Canada and the United States.

The immediate challenge ahead is to build a solid fiscal position and strengthen monetary and fiscal institutions to enlarge the scope for countercyclical macroeconomic policy. Adopting a set of contingent rules for fiscal policy could be a major step in this direction.

For other countries intending to join the upcoming free trade agreements the key concern is to reduce macroeconomic volatility. As noted earlier, economic volatility can severely curtail the benefits from trade integration. However, the fiscal and monetary regimes most adequate to achieve this end may differ considerably from one country to another. Central American economies seem closer than South American ones to meeting the conditions for an OCA with the United States. ${ }^{41}$ Progress in the development of fiscal and monetary institutions allowing countercyclical policy also varies greatly across countries. Thus, although there is a common objective of reducing volatility, the means to achieve it will depend considerably on the economic and institutional characteristics of each country.

One final point worth stressing, which applies to Mexico as well as to other Latin American economies, is that there is no conflict between the long-term strategies that lead to strong national currencies and those that lead to a monetary union. To a large extent, the preconditions are similar: a solid fiscal position, flexible labor markets, and strong prudential regulation and supervision of the financial system. Thus, irrespective of the final decision regarding the degree of policy coordination and monetary unification, the main lines of the policy agenda are very much the same. ${ }^{42}$

\section{Notes}

1. In a stylized model, Alesina and Barro (2002) showed that the key issue is the variance of asymmetric shocks, both nominal and real. See also Alesina, Barro, and Tenreyro (2002) for a recent empirical application to a large country sample, including Mexico.

2. This chapter draws from the background paper by Cuevas, Messmacher, and Werner (2002).

3. This was apparently the case for trade between Mexico and the United States even before NAFTA (see Esquivel 1992).

4. Some of these aspects have been emphasized by Coe and Helpman (1995), among others. 
5. Artis and Zhang (1995) found that European economies were highly correlated with the United States during the period 1961-79, but they co-moved more closely with Germany since joining the Exchange Rate Mechanism (ERM). Fidrmuc (2001) used a sample that included Central and Eastern European countries, and added the level of intra-industry trade as an explanatory variable, finding that it has a positive and significant effect on the correlation of business cycles. Fontagné and Freudenberg (1999) found the same results as Frankel and Rose (1998) looking at more disaggregated trade data for the European Union. Anderson, Kwark, and Vahid (1999) found similar results using more sophisticated measures of co-movement. Finally, Gruben, Koo, and Mills (2002), who separated out effects of specialization and intra-industry trade, also found similar results, although the positive effect of trade intensity on business cycle correlation was slightly lower than previous estimates.

6. Evidence from case studies is even more mixed. For example, Achy and Milgram (2001) argued that a free trade agreement between Morocco and the European Union is very likely to lead to higher specialization in Morocco and, therefore, to a lesssynchronized business cycle between them. Ahumada and Martirena-Mantel (2001) replicated the Frankel-Rose analysis for a sample of MERCOSUR countries plus Chile. They found suggestive evidence that higher trade has led to higher co-movement, but their results are largely driven by the change in correlation between Argentina and Brazil from 1987-92 to 1993-99. The correlations Argentina-Uruguay, Brazil-Uruguay, Argentina-Chile, Brazil-Chile, and Chile-Uruguay change little between both periods and in some cases fall in the second period.

7. We just summarize the main results of Cuevas, Messmacher, and Werner (2002), who reported many additional experiments.

8. Note that these three dimensions are related but distinct. For example, a rise in the observed sensitivity of the Mexican economy to contemporaneous developments in its NAFTA partners could reflect either increased co-movement or higher volatility in Mexico with an unchanged degree of co-movement. In the latter case, the contribution of idiosyncratic shocks to Mexico's overall volatility would not necessarily have declined.

9. In addition, time-varying contemporaneous correlations were computed, along with cross-correlations at various leads and lags to verify that the timing of comovement between the variables of interest has changed (see Cuevas, Messmacher, and Werner 2002). Finally, factor analysis was also used to tackle the same questions. Because the methodology is slightly more complex, and because the results are consistent with those obtained with the other two methodologies, we omit the presentation of this analysis. However, the factor analysis results tend to support the conclusions based on the correlations and basic regression analyses.

10. Note that we also allow for changes in the constant and the degree of inertia of the dependent variable so that the dummy really allows for general structural change in the equation. This methodology is very similar to that used by Frankel, Schmukler, and Servén (2003) to assess the response of local to foreign interest rates under different currency regimes.

11. Many other specifications were used and the results obtained were qualitatively similar. Seasonal time dummies were also included, but they were seldom significant and their inclusion did not affect the estimated values of the parameters or their significance.

12. To be specific, let $\Delta x_{i t}=\alpha_{i}+\gamma_{i} \Delta x_{U S t}+\epsilon_{i}$, and let $\sigma_{U S}^{2}$ and $\sigma_{\varepsilon}^{2}$ denote, respectively, the variance of the U.S. variable and the residual error term. Define $\theta=\sigma_{\epsilon}$ $/ \sigma_{\text {US }}$, which captures the relative importance of idiosyncratic shocks relative to U.S. shocks. Then it follows that $R^{2}=\gamma^{2} / \gamma^{2}+\theta^{2}$, and therefore the variance ratio $\theta$ and the sensitivity coefficient $\beta$ affect $R^{2}$ in opposite directions.

13. Note that the contemporaneous correlation coefficient equals the square root of the unadjusted $R^{2}$ from a simple static regression with no dummies, such as that in the preceding note. 
14. Formally, let $L$ denote the lag operator and, assuming $d T=0$ for simplicity, rewrite equation 3.1 as $\Delta x_{i t}\left(1-\beta_{i} L\right)=\alpha_{i}+\gamma_{i} \Delta x_{U S t}+\epsilon_{t}$. Then we can use the final form of the equation to compute $\operatorname{Var}\left[\Delta x_{i t}\right]=\gamma_{i}^{2} \operatorname{Var}\left[\left(1-\beta_{i} L\right)^{-1} \Delta x_{U S t}\right]+$ $\left(1-\beta_{i}{ }^{2}\right)^{-1} \sigma_{\epsilon}^{2}$, and the measure proposed in the text is just given by $1-\left(1-\beta_{i}^{2}\right)^{-1}$ Var $\left[\Delta x_{i t}\right]^{-1} \sigma_{\epsilon}^{2}$. Note that if the past histories of the independent variable and the disturbances are not orthogonal, in effect we are attributing their correlation to the former. Note also that if there is no persistence at all (so that $\beta=0$ and $\Delta x_{U S}$ is serially uncorrelated), this expression reduces to the square of the contemporaneous correlation coefficient. Except in this case, however, the two statistics differ. Finally, to adjust for varying sample sizes between the pre- and post-NAFTA years, we apply to this measure the standard degrees-of-freedom correction used to compute adjusted $R^{2}$.

15. The data employed are annual rates of growth of GDP (at quarterly frequency) and of industrial production (at monthly frequency). The source of the data for all countries is the International Monetary Fund (IMF), with the exception of the industrial production of Chile, which is taken from domestic sources.

16. These turn out to be also the highest correlation coefficients of these two countries with any other country in the sample. In turn, the somewhat surprising negative correlation between Chile and the United States in the recent sample is discussed by Morandé and Schmidt-Hebbel (2000).

17. The regressions were estimated using annual growth rates of GDP and industrial production for each country. For those countries where the data allow it, the regressions cover the period 1981-2001 in the case of GDP and 1987-2001 for industrial production. For countries with shorter data series the sample starts with the first available observation. A variety of lag specifications were tried and seasonal dummies were included with little change in the qualitative results.

18. Comparable industrial production data were unavailable for Canada. The sources for the data are CANSIM, INEGI, and BEA for Canada, Mexico, and the United States, respectively. The sample period used for the quarterly data is 1988Q1-2001Q2, whereas that for the monthly data is 1980M1-2001M11. Both sample periods are determined by the availability of data.

19. The details are not reported here to save space but are available in Cuevas, Messmacher, and Werner (2002).

20. The stylized facts regarding macroeconomic volatility are discussed at length in De Ferranti et al. (2000).

21. To limit the effect of extreme annual observations, which lead to large jumps in conventional volatility measures, the figure depicts a three-period centered moving average of the interquartile range computed over five years.

22. De Ferranti et al. (2000) found that external shocks, poor policies, and weak financial systems roughly account for one third each of Latin America's "excess volatility" vis-à-vis industrial and East Asian economies over the last quarter century. See also Caballero (2000) for an analysis attributing much of Latin America's macroeconomic instability to weak domestic and foreign financial links.

23. The procyclicality of fiscal policy in most developing countries is documented by Talvi and Vega (2000).

24. On the negative impact of volatility on growth, see Ramey and Ramey (1995) and Fatás (2000). The adverse impact on investment is amply documented in Servén (1998). Lederman, Menéndez, and Stiglitz (2003) provided evidence of this negative effect for the case of Mexico.

25. De Ferranti et al. (2002) showed that by the late 1990s Mexico had achieved one of the most diversified export baskets in Latin America.

26. Indeed, NAFTA has very likely changed investors' perceptions about the risk of investing in Mexico, prompting increased investment flows even for a given degree of observed macroeconomic instability. We will return to this issue in chapter 5 . 
27. The sample includes 44 countries and 880 observations. The data and the FTAs included are described in detail in chapter 5 .

28. This was confirmed empirically by Calderón, Loayza, and Servén (2003) for the case of overall capital flows and by Albuquerque, Loayza, and Servén (2003) for FDI. These studies include as measures of volatility the variability of GDP growth, the real exchange rate, the terms of trade, and the inflation rate.

29. For example, Caballero and Corbo (1989) showed that higher volatility of the real exchange rate reduces exports in a large group of developing countries. More recent empirical studies by Arize et al. (2000) and Dell'Ariccia (1999) found strong evidence of a negative impact of exchange rate volatility on trade flows. These recent studies specifically took into account the endogeneity problems that afflict most earlier literature. Esquivel and Larraín B (2002) showed that thirdparty exchange rate volatility, as represented by the volatility of the Group of Three (Colombia, Mexico, and Venezuela, R. B. de) currencies, also reduces trade flows of developing countries.

30. Real exchange rate volatility is also a major deterrent for investment, both in Mexico (Lederman, Menéndez, and Stiglitz 2003) and in developing countries in general (Servén 2003).

31. Recall, for example, the protectionist pressures that arose in MERCOSUR following Brazil's 1999 devaluation.

32. An example of looser coordination would be implicit or explicit agreements between economic authorities about their separate responses to specific shocks, with the respective responses defined only by domestic considerations and hence dictated only by self-interest. Even in the absence of any agreement, policymakers could simply take into account the effects of their actions on other countries-for example, the United States could relax monetary policy not because of a deceleration of growth in its own economy but because of a strong negative idiosyncratic shock to Mexico.

33. Frankel and Rose (1998) found a positive impact of currency unions on trade among members, but its magnitude appears implausibly large. See Artis (2002) for a discussion of the endogeneity of OCA criteria.

34. Oil price and international financial shocks (such as the East Asia and Russia crises) are examples of disturbances having a clearly asymmetric effect on Mexico and the United States, and thus pointing toward the need for stabilization policies of different sign in the two countries. The scope for asymmetric shocks has also been offered as an argument against a monetary union between Canada and the United States (Murray 1999). In the case of Mexico, formal empirical tests have shown that Mexico and the United States (or Mexico and its two NAFTA partners) do not constitute an optimal currency area, mainly because their cyclical comovement is not sufficiently high. See Del Negro and Ponce (1999) and Alesina, Barro, and Tenreyro (2002).

35. Alesina and Barro (2002) also underscored this point in the context of currency unions.

36. See Frankel, Schmukler, and Servén (2003), who estimated that the mean lag of local interest rate adjustment to foreign rates lies in the four- to eight-month range for floating regimes and barely more than two weeks in hard pegs.

37. Loayza, Lopéz, and Ubide (2001) reported a detailed analysis of comovement using an error components model that compared the results from three blocks of countries: East Asia, Europe, and Latin America. They found that common shocks explain a substantial part of the variation in growth rates in East Asia and Europe, but idiosyncratic shocks are clearly dominant for Latin America. Karras (2000) used a similar methodology when considering if the Americas are an optimal currency area and he found similar results. Hall, Monge, and Robles (1999) found a similar preponderance of idiosyncratic shocks in an analysis of Central American countries and Mexico. 
38. Guatemala also allows use of the U.S. dollar as legal tender.

39. The figures for the Dominican Republic and Guatemala are underestimated because of the unavailability of information on offshore deposits, which are quite large for these countries. The table thus refers only to onshore deposits. Also, the figures for Argentina and Uruguay reflect the situation prior to the collapse of Argentina's convertibility system.

40. This conclusion is reinforced by the weak credibility of monetary institutions in several of these economies. See Perry, Lederman, and Suescún (2002) and Berg, Borensztein, and Mauro (2002).

41. Indeed, the analysis of Alesina, Barro, and Tenreyro (2002) suggested that Central American countries are much closer than Mexico to meeting the conditions for an OCA with the United States.

42. Hochreiter, Schmidt-Hebbel, and Winckler (2002) underscored this point.

\section{References}

The word "processed" describes informally produced works that may not be commonly available through libraries.

Achy, Lahcen, and Juliette Milgram. 2001. Does a Free Trade Area Favor an Optimum Currency Area? The Case of Morocco and the European Union. Libre University of Brussels. Processed.

Ahumada, Hildegart, and Ana Martirena-Mantel. 2001. Towards a Potential Monetary Union in Latin America: Testing the Endogeneity Criteria for Mercosur. Torcuato Di Tella University and Torcuato Di Tella Institute, Buenos Aires. Processed.

Albuquerque, Rui, Norman Loayza, and Luis Servén. 2002. World Market Integration Through the Lens of Foreign Direct Investors. Working Paper 3060, World Bank, Washington, DC.

Alesina, Alberto, and Robert Barro. 2002. Currency Unions. Quarterly Journal of Economics 117 (2): 409-36.

Alesina, Alberto, Robert Barro, and Silvana Tenreyro. 2002. Optimal Currency Areas. Discussion Paper 1958, Harvard Institute of Economic Research, Cambridge, MA.

Andersen, Torben, and Morten Spange. 2002. International Interdependencies in Fiscal Stabilization Policies. Discussion Paper 3580, Centre for Economic Policy Research, London.

Anderson, Heather, Noh-Sun Kwark, and Farshid Vahid, 1999. Does International Trade Synchronize Business Cycles? Working Paper 8/99, Department of Econometrics and Business Statistics, Monash University, Australia.

Angeloni I., and L. Dedola. 1999. From the ERM to the Euro: New Evidence on Economic and Policy Convergence Among EU Countries. Working Paper 4, European Central Bank, Frankfurt, Germany.

Arize, Augustine, Thomas Osang, and Daniel Slottje. 2000. Exchange-Rate Volatility and Foreign Trade: Evidence from Thirteen LDCs. Journal of Business and Economic Statistics 18 (1): 10-17.

Artis, Michael J. 2002. Reflections on the Optimal Currency Area (OCA) Criteria in the Light of EMU. Working Paper 193, Central Bank of Chile, Santiago. 
Artis, Michael J., and Wenda Zhang. 1995. International Business Cycles and the ERM: Is There a European Business Cycle? Discussion Paper 1191, Centre for Economic Policy Research, London.

- 1997. International Business Cycles and the ERM: Is There a European Business Cycle? International Journal of Finance Economics 2: 1-16.

Bayoumi, Tamim, and Barry Eichengreen. 1993. Shocking Aspects of European Monetary Unification. In Adjustment and Growth in the European Monetary Union, eds. F. Torres and F. Giavazzi. Cambridge, UK: Cambridge University Press.

Belo, Federico. 2001. Some Facts About the Cyclical Convergence in the Euro Zone. Working Paper 7-01, Bank of Portugal, Portugal.

Berg, A., E. Borensztein, and P. Mauro. 2002. An Evaluation of Monetary Regime Options for Latin America. Working Paper 67, Oesterreichische Nationalbank, Vienna, Austria.

Boone, Laurence. 1997. Symmetry and Asymmetry of Supply and Demand Shocks in the European Union: A Dynamic Analysis, CEPII Working Paper 97-03, Centre d'Etudes Prospectives et d'Informations Internationales, Paris.

Borodo, C., Y. González, and B. Rodríguez. 1998. Cyclical Convergence Inside the EU: The Case of Spain. Working Paper 98-10, FAE Business School, Curitiba, Brazil.

Brodsky, David. 1984. Fixed versus Flexible Exchange Rates and the Measurement of Exchange Rate Instability. Journal of International Economics 16 (3-4): 295-306.

Buiter, Willem H. 1999. The EMU and the NAMU: What Is the Case for a North American Monetary Union? Discussion Paper 2181, Centre for Economic Research, London.

Caballero, Ricardo. 2000. Macroeconomic Volatility in Latin America: A View and Three Case Studies. Economía 1 (1): 31-108.

Caballero, Ricardo, and Vittorio Corbo. 1989. The Effect of Real Exchange Rate Uncertainty on Exports: Empirical Evidence. World Bank Economic Review 3 (2): 263-78.

Calderón, Cesar, Alberto Chong, and Ernesto Stein. 2002. Trade Intensity and Business Cycle Synchronization: Are Developing Countries Any Different? Inter-American Development Bank, Washington, DC. Processed.

Calderón, Cesar, Norman Loayza, and Luis Servén. 2003. Do Capital Flows Respond to Risk and Return? Working Paper 3059, World Bank, Washington, DC.

Calvo, Guillermo, and Carmen Reinhart. 2002. Fear of Floating. Quarterly Journal of Economics 117 (2): 379-408.

Coe, David T., and Elhanan Helpman. 1995. International R\&D Spillovers. European Economic Review 39 (5): 859-87.

Cuevas, Alfredo, Miguel Messmacher, and Alejandro Werner. 2002. Macroeconomic Synchronization Between Mexico and Its NAFTA Partners. Office of the Chief Economist for Latin America and the Caribbean, World Bank, Washington, DC. Processed.

De Ferranti, David, Guillermo Perry, Indermit Gill, and Luis Servén. 2000. Securing Our Future in a Global Economy. Washington, DC: World Bank.

Dell'Ariccia, Giovanni. 1999. Exchange Rate Fluctuations and Trade Flows: Evidence from the European Union. IMF Staff Papers 46 (3): 315-34.

Del Negro, Marco, and Alejandro Ponce. 1999. Is North America an Optimal Currency Area? Regional vs. National Shocks in the U.S., Canada and Mexico. Unpublished manuscript. 
Eichengreen, Barry. 1992. Should the Maastricht Treaty Be Saved? Princeton Studies in International Finance 74, International Finance Section, Princeton University.

- 2002. What Macroeconomic Measures Are Needed for Free Trade to Flourish in the Western Hemisphere? Unpublished manuscript.

Esquivel, Gerardo. 1992. Una Nota sobre el Comercio Intra-industrial MéxicoEstaods Unidos. Estudios Económicos 7: 119-37.

Esquivel, Gerardo, and Felipe Larraín B. 2002. The Impact of G-3 Exchange Rate Volatility on Developing Countries. G-24 Discussion Paper 16, United Nations, New York.

Fatas, Antonio. 2000. The Effects of Business Cycles on Growth. In Economic Growth: Sources, Trends, and Cycles, eds. Norman Loayza and Raimundo Soto, 191-220. Santiago, Chile: Central Bank of Chile.

Feenstra, Robert C., and Gordon Hanson. 1996. Foreign Investment, Outsourcing and Relative Wages. in The Political Economy of Trade Policy: Papers in Honor of Jagdish Bhagwati, eds. R. C. Feenstra, G. M. Grossman, and D. A. Irwin, 89-127. Cambridge: MIT Press.

Fidrmuc, Jarko. 2001, The Endogeneity of the Optimum Currency Area Criteria, Intraindustry Trade, and EMU Enlargement. Oesterreichische Nationalbank, Austria. Processed.

Fontagné, Lionel, and Michael Freudenberg. 1999. Endogenous Symmetry of Shocks in a Monetary Union. Open Economies Review 10: 263-87.

Frankel, Jeffrey, and Andrew Rose. 1998. The Endogeneity of the Optimum Currency Area Criteria, Economic Journal 108 (July): 753-60.

Frankel, Jeffrey, Sergio Schmukler, and Luis Servén. 2003. Global Transmission of Interest Rates: Monetary Independence and Currency Regime. Journal of International Money and Finance 23 (5): 70-133.

Gruben, William C., Jahyeong Koo, and Eric Mills. 2002. How Much Does International Trade Affect Business Cycle Synchronization? Federal Reserve Bank of Dallas. Processed.

Hall, Luis, Alexander Monge, and Edgar Robles. 1999. Fluctuations, CoMovements and Trends in Central America, Mexico and USA. In Fluctuations, Trends, and Transmission of Shocks in Central America, Mexico, and USA, eds. Luis Hall, Alexander Hoffmaister, Alexander Monge, and Edgar Robles, Washington, DC: Regional Studies Committee, Latin America and the Caribbean Region, World Bank.

Hochreiter, E., K. Schmidt-Hebbel, and G. Winckler. 2002. Monetary Union: European Lessons, Latin American Prospects. Working Paper 68, Osterreichische Nationalbank, Austria.

Imbs, Jean. 1999. Co-fluctuations. Discussion Paper 2267, Centre for Economic Policy Research, London.

- 2000. Sectors and the OECD Business Cycle. Discussion Paper 2473, Centre for Economic Policy Research, London.

- 2004. The Real Effects of Financial Integration. Unpublished manuscript.

Kalemi-Ozcan, Sebnem, Bent Sorensen, and Oved Yosha. 2000. Risk Sharing and Industrial Specialization: Regional and International Evidence. Research Working Paper 00-06, Federal Reserve Bank of Kansas City.

Karras, Georgios. 2000. The Prospect of Dollarization: Are the Americas an Optimum Currency Area? University of Illinois at Chicago. Processed. 
Kenen, Peter. 1969. The Theory of Optimum Currency Areas: An Eclectic View. In Monetary Problems in the International Economy, eds. R. Mundell and A. Swoboda, 41-60. Chicago: University of Chicago Press.

Kose, M. Ayhan, and Kei-Mu Yi. 2001. International Trade and Business Cycles: Is Vertical Specialization the Missing Link? American Economic Review 91 (2): 371-75.

Krugman, Paul. 1993. Lessons of Massachusetts for EMU. In The Transition to Economic and Monetary Union in Europe, eds. F. Giavazzi and F. Torres, 241-56. New York: Cambridge University Press.

Lederman, Daniel, Ana María Menéndez, Guillermo Perry, and Joseph Stiglitz. 2003. Mexican Investment After the Tequila Crisis: Basic Economics, "Confidence" Effects or Market Imperfections. Journal of International Money and Finance 22: 131-51.

Loayza, Norman, Humberto López, and Angel Ubide. 2001. Co-movements and Sectoral Interdependence: Evidence for Latin America, East Asia and Europe. IMF Staff Papers 48 (2): 367-96.

McKinnon, Ronald I. 1963. Optimum Currency Areas. American Economic Review 53: 717-24.

Morandé, Felipe, and Klaus Schmidt-Hebbel. 2000. Chile's Peso: Better Than (Just) Living with the Dollar. Working Paper 68, Central Bank of Chile, Santiago.

Mundell, Robert. 1961. A Theory of Optimum Currency Areas. American Economic Review 51: 509-17.

Murray, John. 1999. Why Canada Needs a Flexible Exchange Rate. Working Paper 99-12, Bank of Canada, Ottawa.

Perry, Guillermo, Daniel Lederman, and Rodrigo Suescún. 2002. Trade Structure, Trade Policy and Economic Policy Options in Central America. World Bank, Washington, DC. Processed.

Ramey, Garey, and Valerie Ramey. 1995. Cross-Country Evidence on the Link Between Volatility and Growth. American Economic Review 85 (5): 1138-51.

Ramos, R., M. Clar, and J. Suriñat. 2003. National Versus Sectoral Shocks: New Evidence for the Manufacturing Sector in European Countries. Economics Letters 78: 241-45.

Servén, Luis. 1998. Macroeconomic Uncertainty and Private Investment in Developing Countries: An Empirical Investigation. Working Paper 2035, World Bank, Washington, DC.

- 2003. Real Exchange Rate Uncertainty and Private Investment in LDCs. Review of Economics and Statistics 75: 212-17.

Talvi, Ernesto, and Carlos Vega. 2000. A Tax Base Variability and Procyclical Fiscal Policy. Working Paper 7499, National Bureau of Economic Research, Cambridge, MA. 


\section{4 \\ NAFTA's Remaining Trade Barriers}

WHEN THE NORTH AMERICAN FREE TRADE Agreement (NAFTA) was being negotiated in the early 1990s it created controversy because of the expected liberalization of commerce among its member countries. To some extent the positive effects that NAFTA has had on the Mexican economy, which are discussed in chapters 2-4 of this report, resulted from the substantial liberalization of trade. In fact, the extent of liberalization probably helped Mexico catch up with the level of income and wages observed in the United States by increasing the efficiency of its allocation of factors of production across and within industries.

Although the previous chapters and chapter 6 stress that the national and international policy agenda needed to complement and deepen NAFTA so that Mexico (and its partners) can prosper at an accelerated pace is substantial, an important liberalization agenda still remains. Removal of the remaining trade barriers can improve the efficiency of resource allocation within the Mexican economy, improve the efficiency of its innovation system (see chapter 6), and thus raise aggregate productivity. This liberalization agenda is the subject of this chapter.

More specifically, in the following sections we cover market access issues that might require further negotiations among the NAFTA partners and selected complementary policies to support additional adjustments of certain sectors. In the case of manufactures, one of the key issues that was raised in the early 1990s when NAFTA was negotiated is the impact of rules of origin (ROOs), which determine the criteria for exporting Mexican products to the United States under the preferential NAFTA treatment. We analyze this topic in the second section of the chapter. We conclude that ROOs have been particularly burdensome in the textile and apparel sector; they have inhibited Mexican exports from taking full advantage of the NAFTA preferences. However, these preferences will become less important over time because of the phasing out of the 
Multi-fiber Agreement under the rules negotiated in the Uruguay Round of global trade talks in 1995. Hence the challenge for Mexico in the future will not be to renegotiate less-restrictive ROOs for its apparel exports, but to develop innovation capacity that enables its firms to compete in the U.S. market by upgrading its technological capacity. Thus, in addition to focusing on ROOs, the policy discussions on innovation in chapter 6 are important as well.

In the third section of this chapter we deal with the impact of NAFTA on Mexico's agricultural sector and examine the extent to which this sector has been liberalized since the early 1990s. The main findings are that NAFTA-related liberalization of agricultural trade has been notable despite the barriers that have not yet been phased out. However, substantial subsidies are offered to farmers in all three NAFTA countries. In terms of economic performance of the sector, Mexican crop agriculture has not been devastated by this liberalization, as was expected prior to NAFTA implementation. This positive sectoral result probably arose from a combination of factors, including the growth of the U.S. and Mexican economies during 1996-2000, the productivity improvements in Mexican agriculture based on irrigated land, and possibly because of the existing income support subsidies under PROCAMPO (Programa Nacional de Modernizacion del Campo) and the Alianza para el Campo (Alliance for the Countryside) programs. Moreover, the poorest farmers have not been negatively affected by NAFTA primarily because these small farmers produce maize and other crops for subsistence and thus do not sell their products in the market. In fact, they might have benefited from falling prices of food staples because these poor farmers are net consumers of food.

In the fourth section of the chapter we analyze how NAFTA affected the use of antidumping (AD) and countervailing duties (CVD) by the United States against its NAFTA partners. The statistical evidence discussed herein is somewhat pessimistic: it shows that NAFTA's panel review mechanism has had an insignificant effect in terms of shielding Mexico from U.S. AD/CVD activity. But there is some evidence that Canada has been a bit more successful against the United States, partly because it has a longer history in terms of reviewing U.S. AC/CVD decisions under the previously negotiated U.S.-Canada Free Trade Agreement (CUSFTA) of 1988. However, this is an area that remains a concern for Mexico and for any other country wishing to implement free trade agreements with the United States. In the future the only real solution to this problem is to harmonize competition policies across the NAFTA countries and allow competition policy to regulate firms' anticompetitive behavior. If this is not a viable short-term solution, then Mexican negotiators should first evaluate why the panel review mechanism under NAFTA is functioning particularly slowly for Mexican cases. On the 
other hand, Mexico itself seems to have used $\mathrm{AD} / \mathrm{CVD}$ investigations in a highly discretionary fashion. Thus a negotiated solution to this problem of barriers imposed by these administrative mechanisms is one that should aim to restrict its use by all three NAFTA members, perhaps by agreeing to rely more on safeguard duties when sectors experience sudden surges of imports.

\section{Trade Barriers and Rules of Origin Under NAFTA}

Even prior to the formal implementation of NAFTA, Krueger (1993) had already noted that ROOs play an important role in free trade agreements (FTAs) that is not present in customs unions. Under FTAs each partner is allowed to maintain its own import restrictions affecting the rest of the world, and thus ROOs are criteria for identifying products that are eligible for preferential treatment within the member countries. The main objective of these ROOs is to prevent trade "deflection" whereby imports from nonmember countries could be introduced into the FTA region through the country with the lowest import barriers, then re-exported to the country with the highest levels of import protection.

An economic challenge posed by these ROOs is that they can become a vehicle for exporting protectionism from the most protectionist FTA member to the more open members. For example, if tariffs and nontariff barriers to the importation of textiles are more restrictive in the United States than in Mexico, then the NAFTA rule of origin for apparel and clothing can indirectly impose U.S. textile barriers on Mexican producers of clothing who wish to export apparel to the U.S. market.

ROOs' protectionist effects have been widely studied in the scientific literature (see, among others, Ju and Krishna 1998; Krishna and Krueger 1995; Krueger 1993, 1997; Rodríguez 2001) and are not disputed. To illustrate how ROOs can transfer the protectionist structure from the United States to Mexico, box 4.1 presents Krueger's (1993) explanation of how profits of a Mexican firm that wishes to export clothing to the U.S. market is affected by U.S. trade policies. The basic setup presented in box 4.1 indicates that if the United States is NAFTA's low-cost producer of textiles, the main input in apparel manufacturing, then the hypothetical Mexican apparel firm will decide whether to export to the United States based on the yarn-forward ROO specified in the NAFTA text, and the only relevant variables will be the tariffs on imports of apparel and textiles in the United States.

The framework in box 4.1 can also be used to assess the extent to which a reduction of import tariffs for textiles in the United States or a relaxation of the ROOs will affect Mexican incentives to export apparel to the U.S. market. Elementary calculations show that apparel firms in 


\section{Box 4.1 Rules of Origin and the Export of Protection Among NAFTA Partners: The Basic Analytical Framework}

The text presented here aims to clarify how rules of origin can act as protectionist devices whereby the structure of production of one of the NAFTA partners determines the profitability of exporting firms.

Consider a Mexican firm deciding whether to export apparel products to the United States under the NAFTA preferences. Its expected profits can be formally written as follows:

$$
\pi_{A}^{M e x}=P_{T}^{U S}-P_{T}^{U S} \bullet \alpha \bullet q-P_{T}^{W}(1-\alpha) \bullet q
$$

where $\pi$ represents the expected profits for this firm. If it sells the product in the U.S. market, it will receive revenues per unit of apparel equal to the U.S. price $\left(P_{A}^{U S}\right)$ for that article. On the cost side, the firm will have to pay the U.S. price for the necessary textile inputs. This cost has three components: (a) the unit price of textiles in the United States $\left(P_{T}^{U S}\right)$ if the firm decides to use U.S. components (which is likely because of the low-cost textile source within NAFTA); (b) the resulting unit cost, which is the product of this price times the cost share of U.S. textile inputs $(\alpha)$ times the textile cost share relative to the value of apparel that is determined by the production technology $(q)$; (c) minus the cost of using textile inputs from other sources that might be cheaper than U.S. parts $\left(P_{T}^{W}(1-\alpha) \bullet q\right)$.

The relevant U.S. prices, world prices, and the technological parameter can be defined as follows:

$$
\begin{gathered}
P_{A}^{U S}=\left(1+t_{A}^{U S}\right) P_{A}^{W} \\
P_{T}^{U S}=\left(1+t_{T}^{U S}\right) P_{T}^{W} \\
q<1
\end{gathered}
$$

where $t_{A}^{U S}$ is the ad valorem U.S. import tariff (equivalent) on apparel and $t_{T}^{U S}$ is the corresponding U.S. tax on textile imports. To simplify, let world prices of apparel and textile inputs be equal to unity:

$$
P_{T}^{W}=1 ; P_{A}^{W}=1
$$

Then,

$$
\pi_{A}^{M e x}=\left(1+t_{A}^{U S}\right)-q\left[\left(1+t_{T}^{U S}\right) \alpha+(1-\alpha)\right] .
$$

The ROO determines $\alpha$, which is the share of textile inputs that must come from regional sources in order for the export of apparel to be eligible 


\section{Box 4.1 (continued)}

for NAFTA preferential treatment. In the specific case of textile and apparel products, the NAFTA ROO implies $\alpha=1$ because of the yarnforward rule, which says that apparel must be made from yarn originating in NAFTA countries. Thus, the profits for Mexican firms wishing to penetrate the U.S. market under the NAFTA preferences can be rewritten as follows:

$$
\pi_{A}^{M e x}=\left(1+t_{A}^{U S}\right)-q \bullet\left(1+t_{T}^{U S}\right) .
$$

This formula shows that for exports under NAFTA preferences, Mexican firms' profits will be determined exclusively by U.S. tariffs on apparel and textiles and the technological parameter, which we can safely assume is constant in this case because it is unlikely that technological change in the apparel industry can reduce the amount of cloth used per unit of apparel. The fact that Mexican apparel profits are determined by U.S. tariff structure is the key result from Krueger (1993).

Alternatively, firms can choose not to use the NAFTA preferences. In this case, firms face the following profit condition:

$$
\pi_{A}^{M e x}=1-q \cdot\left(1+t_{T}^{M e x}\right) .
$$

That is, the firm that decides not to use the NAFTA preferences for apparel exports will receive the world price minus the costs of textile inputs, which in this case depend solely on Mexico's textile import tariffs (and implicitly on the world price of textiles, which we have set equal to 1). Hence the decision to actually use the NAFTA preferences will depend on whether profits from using the preferences as defined in equation 4.4 are greater or at least equal to the profits from not relying on the preferences as defined in equation 4.5 .

Thus it is easy to show that the apparel preferential margin, which equals the U.S. tariff when all intra-NAFTA trade enters duty free, needs to be greater or equal to the product of the textile cost share in production times the difference between the U.S. and Mexican textile tariffs:

$$
t_{A}^{U S}>=q \bullet\left(t_{T}^{U S}-t_{T}^{M e x}\right)
$$

The analysis presented in the main text of this chapter discusses possible explanations for why the utilization of the NAFTA preferences in apparel exports from Mexico to the United States is relatively low, given that the extent of the preferential treatment under NAFTA has been quite high. The framework presented here indicates that there are three key parameters, which are those in equation 4.6.

Source: The framework is from Krueger (1993). 
Mexico would be indifferent between a unilateral move by the United States to eliminate its import restrictions (tariffs) on textiles by driving $t_{T}^{U S}$ to zero and the renegotiation of the ROOs so that Mexico can use textiles from the rest of the world for the production of apparel for export to the United States. But this framework can be used to understand why certain Mexican exports to the United States have not made full use of the preferences offered by the agreement. This is the topic of the next section.

\section{NAFTA Preferences, Utilization Rates, and Rules of Origin}

Box 4.1 showed that there are some specific conditions under which Mexican exporters will voluntarily decide to export to the United States without using the NAFTA preferences. This occurs when the profits from exporting without preferences are greater than those from using them. This is more common in industries where tariff preference is smaller than the cost differential from exporting to the United States by satisfying the rule of origin minus the costs from importing inputs of production from other sources. This is stated in equation 4.6 in box 4.1 for the case of apparel exports.

To illustrate how ROOs and the structure of protection in FTA members can affect the extent to which exporters use the FTA preferences, figure 4.1 shows profit schedules for firms wishing to use FTA preferences. We continue to use the example of textile and apparel goods. The downward-sloping lines correspond to the expected profit schedules for three different hypothetical apparel products. The expected profits of exporting to the United States under FTA preferences decline with the textile tariff differential (or tariff equivalent rate of protection). The graph shows three different products: the top dotted line shows the expected profits for a firm that produces apparel with a rather low share of textile inputs $(\mathrm{q}=0.2)$ and facing a mostfavored-nation (MFN) nonpreferential tariff of 40 percent. The corresponding expected profit from not using the preference is portrayed by the horizontal line, which simply shows that the profits for nonpreferential exports do not depend on differences between U.S. and Mexican textile tariffs. Exporters facing these conditions would probably choose to make full use of the FTA preferences because the FTA profit line is above the nonpreferential profits for a reasonable range of textile tariff differentials. In contrast, the two other downwardsloping profit lines cross their corresponding nonpreferential profit lines, which we set equal to zero, at different points of the horizontal axis (or at two different levels of textile tariffs in the United States relative to the Mexican tariff of 18.9 percent as of 2001). ${ }^{1}$ This implies that for products on which the U.S. apparel tariff is close to 12 percent 
Figure 4.1 How NAFTA Utilization Rates Vary with Tariff Structure: The Case of the Yarn-Forward Rule for Apparel Exports

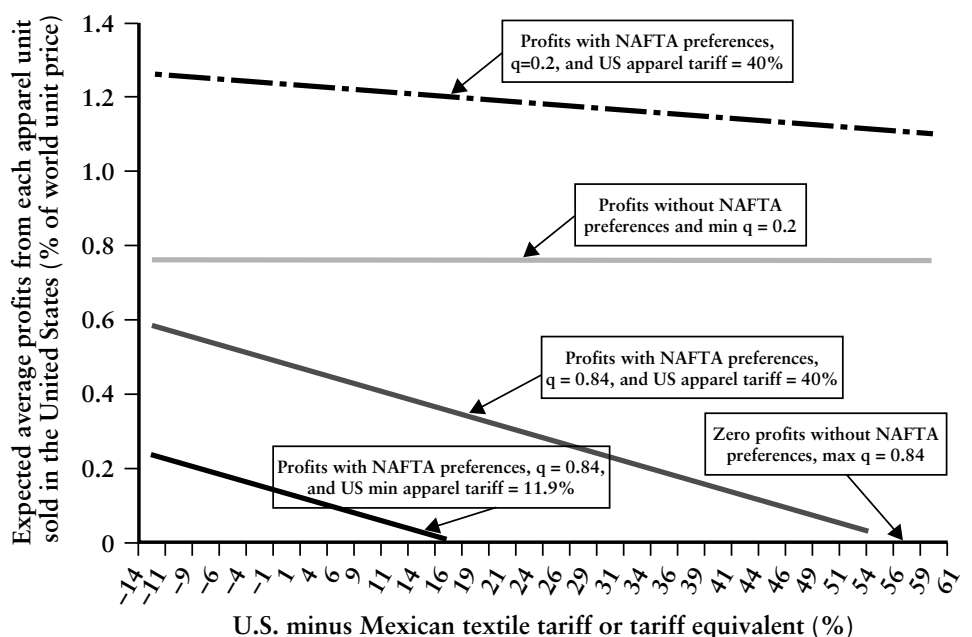

Source: Author's calculations (see box 4.1 and text for details).

(the U.S. MFN average tariff without considering the impact of quotas) and a maximum textile cost share of 84 percent $(\mathrm{q}=0.84)$, using NAFTA preferences becomes unprofitable at low levels of U.S. textile tariffs. In fact, this would occur when the U.S. textile tariff is about 14 percent higher than Mexico's 19 percent tariff. This breakeven point occurs at higher levels of the U.S. textile tariff when the U.S. apparel tariff is 40 percent, which makes selling that apparel product in the U.S. market more profitable. Thus it is clear that the decision to take advantage of NAFTA preferences will vary across firms and products, depending on some key parameters, namely, U.S. apparel and textile tariffs and the cost share of textile inputs in the production of apparel goods. This statement is generally applicable to any product and ROO.

An important empirical question is which Mexican exports are using NAFTA preferences and which ones are not. Figure 4.2, provided by Cadot et al. (2002), shows the relationship between NAFTA utilization rates in various sectors (measured along the vertical axis) and the tariff preferential margin offered by the agreement (measured along the 


\section{Figure 4.2 Empirical Relationship Between NAFTA Preferences Utilization Rates and Tariff Preferences, 2000: Textile and Apparel- The Obvious Outlier}

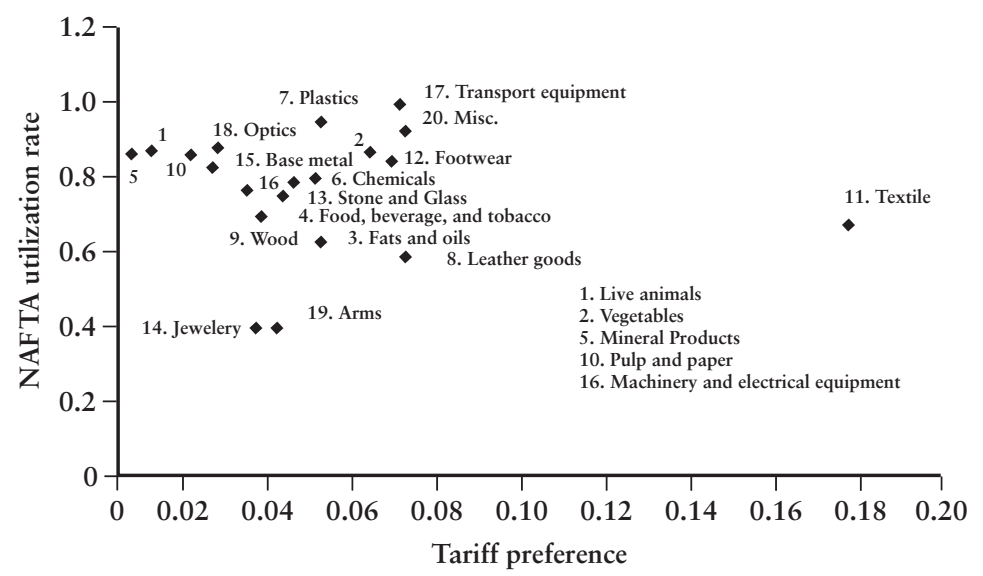

Source: Cadot et al. (2002), based on data from the U.S. International Trade Commission.

horizontal axis). ${ }^{2}$ The textile and apparel sector is a clear outlier: it enjoys the highest preferential treatment, although the utilization rate was quite low in 2000. The evidence indicates that only about 62 percent of Mexican exports of textile and apparel enter under the NAFTA preferences. Hence it seems that there is something peculiar about this sector in terms of how the ROOs affect decisions by Mexican firms. We now turn to a more detailed empirical analysis of the impact of tariff preferences and ROOs on Mexican exports to the United States.

Given that there is substantial variation in NAFTA's tariff preference across industries, in the absence of offsetting administrative or ROO costs one would expect Mexico's trade flows to be affected by NAFTA's rate of preference. As discussed in box 4.1 and illustrated in figure 4.1, items with larger preferential treatment under NAFTA (e.g., higher U.S. MFN tariffs) should be associated with a higher percentage of Mexican firms choosing to export to the United States under NAFTA preferences. Hence, higher tariff preferences should be positively correlated with higher utilization rates (the percentage of exports entering the U.S. market 
with NAFTA preferential treatment). However, if the cost of complying with NAFTA's ROOs and other administrative hassles offset the benefit of the preferences, one would expect the composition of Mexico's trade flows to be less affected by NAFTA preferences. That is, under the latter hypothesis and provided that the pattern of U.S. MFN tariffs does not differ too strongly from the pattern of MFN tariffs applied by Mexico's other trading partners, one should not be able to trace large differences between the pattern of Mexican exports to the United States and the pattern of exports to the rest of the world. Thus, comparing Mexico's exports to the United States and to the world provides a further check on the hypothesis that NAFTA involved a switch of protection instrument from tariffs or quotas to ROOs rather than an overall reduction in the level of protection.

Cadot et al. (2002) explored this question by estimating the following model using a weighted least squares regression with Mexican exports as weights at the six-digit level of industry disaggregation in the Harmonized Tariff Schedule (HTS) for the year 2000:

$$
\begin{aligned}
X U S_{i}= & \alpha_{0}+\alpha_{1} * X R O W_{i}+\alpha_{2} * \ln P_{R E F_{i}} \\
& +\alpha_{3} * \ln \mathrm{ROO}_{i}+\Sigma_{\mathrm{k}} \alpha_{\mathrm{k}} * D_{k i} .
\end{aligned}
$$

$X U S_{i}$ stands for Mexico's exports to the United States in tariff line $i$, $X R O W_{i}$ is Mexico's exports to the rest of the world, $P R E F_{i}$ stands for the rate of tariff preference under NAFTA, $R O O_{i}$ is Estevadeordal's (2000) ROO-restriction index, and $D_{k i}$ is a vector of dummy variables by HTS chapters.

Cadot et al. (2002) estimated a variant of (4.7) in which Estevadeordal's (2000) ROO-restriction index was replaced by a vector of dummies for specific types of ROOs used in NAFTA. More specifically these analysts used the following set of dummy variables to identify products subject to the following types of ROOs:

- CHAP $=1$ when the $\mathrm{ROO}$ requires a change in tariff chapter (as in the case of apparel)

- $H E A D=1$ when the $\mathrm{ROO}$ requires a change in tariff heading

- $S U B H E A D=1$ when it requires a change in tariff subheading

- ITEM $=1$ when it requires a change in tariff item

- $E X C=1$ when one or more exceptions exist

- $R V C=1$ when the $\mathrm{ROO}$ specifies a minimum regional value content.

In addition, the analysis included an interaction between the CHAP variable and the dummies identifying food and textiles (where most ROOs take the form of a change of chapter). The estimated equation was: 


$$
\begin{aligned}
\mathrm{XUS}_{i}= & \alpha_{0}+\alpha_{1} * \mathrm{XROW}_{i}+\alpha_{2} * \mathrm{PREF}_{i} \\
& +\alpha_{3} * R_{i}+\alpha_{4} * \text { CHAP } * \text { FOOD } \\
& +\alpha_{5} * \text { CHAP } * \text { TEXTILE }+\Sigma_{k} \alpha_{k} * D_{k i}
\end{aligned}
$$

where $\alpha_{2}$ is the vector of coefficients on the various types of ROOs mentioned above.

As explained by Cadot et al. (2002) there are two potential technical complications in estimating models 4.7 and 4.8 that merit some attention. First, if PREF and ROO are substitutes, there may be collinearity (in a weak sense) between the two. However regressing ROO on PREF gives a positive and significant parameter estimate (consistent with substitutability) but an $R^{2}$ of only 10 percent, which suggests that the association is not close enough to be a problem in the estimation of (4.7). Second, it can be argued that ROO and PREF are endogenous to Mexican exports if tariff and ROO protection are used to restrict Mexican access to the U.S. market. However ROOs determined in the course of negotiations held in the early 1990s and finalized in 1992 can hardly be endogenous to Mexico's 2000 export pattern. ${ }^{3}$ As for PREF, Article XXIV of the General Agreement on Tariffs and Trade (GATT) implies that intra-bloc tariffs have to go to zero, so steady-state tariff preferences are equal to MFN tariffs, which are also predetermined (see endnote 3). Estimation results are shown in table 4.1.

\begin{tabular}{|c|c|c|c|c|}
\hline & \multicolumn{2}{|c|}{ (4.7) } & \multicolumn{2}{|c|}{ (4.8) } \\
\hline & Estimate & $\overline{t \text {-statistic }}$ & Estimate & $t$-statistic \\
\hline Constant & 1882.19 & 3.01 & 785.43 & 1.42 \\
\hline XROW & 3.99 & 103.70 & 3.63 & 97.60 \\
\hline Ln PREF & 25.04 & 15.01 & 26.09 & 15.31 \\
\hline Ln ROO & -628.48 & -12.34 & & \\
\hline ITEM & & & -2197.41 & -3.04 \\
\hline SUBHEAD & & & -308.36 & -2.18 \\
\hline HEAD & & & -658.84 & -6.00 \\
\hline $\mathrm{CHAP} * \mathrm{FOOD}$ & & & -387.68 & -1.05 \\
\hline CHAP * TEXTILE & & & -533.09 & -1.02 \\
\hline $\mathrm{EXC}$ & & & 230.67 & 3.84 \\
\hline RVC & & & -985.41 & -19.70 \\
\hline$R^{2}$ adjusted & \multicolumn{2}{|c|}{0.94} & \multicolumn{2}{|c|}{0.95} \\
\hline $\begin{array}{l}\text { Number of } \\
\text { observations }\end{array}$ & \multicolumn{2}{|c|}{3616} & \multicolumn{2}{|c|}{3389} \\
\hline
\end{tabular}

Table 4.1 Regression Results for (4.7) and (4.8) Dependent Variable: Mexican Exports to the United Sates (XUS)

Source: Cadot et al. 2002, table 3. 
The results from (4.7) are as expected. The relationship between exports to the United States and exports to the rest of the world is proportional with a factor between three and four, but tariff preferences have a positive influence on Mexico's exports to the United States. ROOs have the opposite effect, and both are highly significant.

The results of (4.8), in which Estevadeordal's (2000) ROO-restriction index is decomposed into dummy variables for various types of ROOs, are also interesting. Changes of tariff classification have negative and significant effects, whereas exceptions have positive effects. This finding suggests that the bulk of exceptions to ROOs make them less rather than more constraining, unlike the often-cited restriction on tomato paste, according to which ketchup is deemed originating if it results from a transformation of ingredients satisfying a change-of-chapter rule, but not if it results from the transformation of tomato paste (see Krueger 1999). Regional value content rules appear particularly significant and have large marginal effects.

To estimate the quantitative effects of each instrument on the direction of Mexican trade flows, Cadot et al. (2002) performed the following exercise. On the basis of the parameter estimates in (4.7) and (4.8), they compared the predicted values of Mexican exports to the United States in three cases: (a) with actual values of the PREF and ROO variables (NAFTA as it is, i.e., the benchmark case); (b) with no tariff preferences and no rules of origin, ${ }^{4}$ which we interpret as "no NAFTA"; and (c) with NAFTA tariff preferences but no ROOs (a hypothetical NAFTA without rules of origin). The difference between case (a) and case (b) gives an estimate of the direct effect of NAFTA's package (tariff preference and ROOs) on Mexican trade flows. Results are presented as percentage deviations from the relevant baseline predicted value for Mexico's exports to the United States, namely, US\$152.3 billion using the results for (4.7) and US\$133.4 billion with (4.8). The results are shown in table 4.2.

Consider the first part of table 4.2, based on (4.7). If "No NAFTA" is interpreted as setting ROOs at their lowest level, then the combined effect of tariff preferences and ROOs (NAFTA's package) raises Mexican exports, on average, by only 3.1 percent. Because "No NAFTA" is interpreted as tariff preferences eliminated but ROOs set at higher levels, NAFTA's effect appears more favorable. With this caveat in mind, it is fair to say that the marginal effects of tariff preferences and ROOs as they are in NAFTA's present form seem to produce limited positive net effects $(+11.7$ percent with $R O O=2$ taken as the "No NAFTA" value). The second column shows that if tariff preferences were maintained but ROOs eliminated the positive effects on Mexico's exports would be considerable $(+35.3$ percent if ROOs were set across the board at a level corresponding to $R O O=2$ ). This finding has important policy implications because it shows that loosening NAFTA ROOs could bring substantial gains in terms of Mexico's ability to take advantage of the preferences offered by NAFTA. 
Table 4.2 Simulation Results for (4.7) and (4.8): Effects of ROO Relaxation, Simulated (percentage deviation from baseline)

\begin{tabular}{|c|c|c|}
\hline Constrained ROO values & No NAFTA & $\begin{array}{c}\text { NAFTA } \\
\text { without } R O O\end{array}$ \\
\hline \multicolumn{3}{|l|}{ Using Estevadeordal's index (equation 4.7) } \\
\hline $\mathrm{ROO}=1$ & -3.1 & 76.6 \\
\hline $\mathrm{ROO}=2$ & -11.7 & 35.3 \\
\hline $\mathrm{ROO}=3$ & -22.6 & 17.8 \\
\hline \multicolumn{3}{|l|}{ Using dummies (equation 4.8) } \\
\hline $\mathrm{RVC}=0$ & & 15.8 \\
\hline $\mathrm{ITEM}=0$ & & 1.5 \\
\hline SUBHEAD $=0$ & & 9.0 \\
\hline $\mathrm{HEAD}=0$ & & 63.2 \\
\hline $\mathrm{CHAP}=0$ & & 35.3 \\
\hline $\mathrm{RVC}=0$ and $\mathrm{EXC}=0$ & & 4.5 \\
\hline $\mathrm{RVC}=0, \mathrm{ITEM}=0$, and $\mathrm{EXC}=0$ & & 5.3 \\
\hline $\begin{aligned} \mathrm{RVC}= & 0, \mathrm{ITEM}=0, \mathrm{SUBHEAD}=0, \\
& \text { and } \mathrm{EXC}=0\end{aligned}$ & & 11.3 \\
\hline $\begin{aligned} \text { RVC }= & 0, \text { ITEM }=0, \text { SUBHEAD }=0, \\
& \text { HEAD }=0, \text { and } E X C=0\end{aligned}$ & & 85.0 \\
\hline All dummies at zero (no ROO) & -9.0 & 108.3 \\
\hline
\end{tabular}

Source: Cadot et al. 2002, table 4.

The second part of the table provides some guidance about which ROOs could have the biggest impacts if they were to be relaxed. Regarding required changes of tariff classification (the most common type of ROOs), note that relaxing ITEM (changes of tariff item), which has the largest marginal effects in (4.7), produces only a minor effect on trade flows because this type of ROO affects only low-volume tariff lines. Conversely, relaxing CHAP, which has a low and imprecisely estimated marginal effect, produces a large change on textile and food exports. Relaxing HEAD (change of tariff heading) also produces a dramatic effect on Mexican trade flows.

Several caveats are important. First, the exercise cannot measure nontrade effects of NAFTA (e.g., effects on the credibility of reforms) and should therefore be taken as a lower bound on NAFTA's real-world effect. Second, these results are based on effects measured on a crosssectional data set and cannot give a full picture of NAFTA's effects because effects that cut across all sectors are subsumed in the constant. Thus, at least one important question remains unanswered: is the recent expansion of Mexico's exports to the United States attributable to NAFTA but to effects that are only indirectly related to tariff preferences, 
or is it attributable instead to exchange rate or macroeconomic and credibility effects discussed elsewhere in this volume?

With these caveats in mind the provisional conclusion here is that, at least at first sight, Mexico's export pattern seems to have been affected positively but in a quantitatively small way by the combined effect of NAFTA's tariff preferences and ROOs because the negative effect of the latter partly offsets the positive effect of the former. This conclusion has two policy implications. First, it supports the view that the gains from tariff liberalization under FTAs can be offset by nontariff compliance costs related to ROOs. In this case FTAs involve a substitution of instruments rather than the simple elimination of one of them. Second, the extent of the substitutability between tariff and ROO protection varies across industries, depending on the type of ROO. Although the point estimates of the impact of the chapter-change ROO requirement, such as the rules that apply to textile and apparel trade under NAFTA, were imprecise, the magnitude of the negative effect is economically large. The imprecision probably arises because the same rule literally applies to textiles and apparel, although we suspect that in Mexico's case the yarnforward rule has hampered mainly the profitability of Mexican apparel exports because the country is a net importer of textiles from the United States. The following section takes a closer look at these and other issues related to the apparel industry.

\section{NAFTA and Textile and Apparel Trade in North America}

As shown in figure 4.2, textile and apparel trade under NAFTA is characterized by two features: very high preferential treatment for Mexican exporters relative to the MFN tariffs and a rather low level of utilization of these preferences by Mexican exporters. We have already explained and demonstrated that relaxing the relevant ROOs might have economically important consequences for Mexican exporters of apparel. However, here we aim to consider additional factors affecting this sector: NAFTA preferences for Mexico have been diluted by unilateral actions taken by the United States. First, the Caribbean Basin Economic Recovery Act (CBERA) in 2000 allowed exports of apparel from Caribbean and Central American countries to enter duty free into the U.S. market as long as the yarn used for these manufactures originates in the United States. As of late 2002, this is also true for apparel exports from Colombia and other Andean countries, because in September 2002 the U.S Congress approved the Andean Trade Promotion and Drug Eradication Act, which offered preferential treatment to apparel made with U.S. yarns and textiles. Hence, to some extent the NAFTA preferential margin in apparel became less important. ${ }^{5}$ Furthermore, the implementation of the recently negotiated Central America-United States Free 
Trade Agreement (CAFTA) will level the playing field in terms of the ROOs affecting apparel exports from these countries relative to Mexico.

We can use these facts to compare the Caribbean Basin Initiative (CBI) and NAFTA utilization rates to better understand how the textileapparel ROOs affect different types of countries. In principle, the move from the CBI ROO to a NAFTA ROO (which allows apparel to enter the United States with preferential treatment even when the yarn is produced domestically rather than exclusively in the United States) should be more beneficial for countries that have a domestic textile industry that is internationally competitive.

To assess the extent to which various CBI and NAFTA countries have a comparative advantage in textiles, the main input for producing apparel, we look at the pattern of net exports per worker relative to the United States for CBI countries, relative to NAFTA for Mexico, and relative to the rest of the world for both sets of countries. We also examine the latest data concerning the CBI and NAFTA utilization rates in apparel.

Figure 4.3a-f shows the net exports of textiles for Mexico and the five Central American countries, both relative to the United States (United States plus Canada for Mexico). Only El Salvador seems to have a comparative advantage in textiles because it is the only country that has systematically had positive net exports of textiles to the whole world since the early 1980s. Hence, this country is likely to benefit substantially from shifting from the CBERA apparel ROOs to the NAFTA-type ROOs. Mexico, on the other hand, has become a large net importer of textiles, most of them coming from its NAFTA partners. This finding is consistent with our previous point that the NAFTA ROOs have resulted in the export of U.S. protectionism to Mexico in this sector. That is, the large decline in the net exports of textiles in Mexico has been related to rising imports of textiles from the United States, which are required for its apparel producers to export to the United States under NAFTA preferences. This fact also explains why the econometric estimates of the ROOs' impact on textiles and apparel are imprecise: the same rule affects textiles, for which Mexico is not the low-cost producer in North America (the United States is) and apparel, for which Mexico is the NAFTA low-cost producer. ${ }^{6}$

Table 4.3 shows the latest available data concerning NAFTA and CBI utilization rates in 2001 and most of 2002. El Salvador and Mexico have similar utilization rates. We interpret this as evidence that El Salvador has not benefited as much as other CBI beneficiaries in this sector partly because the United States is not its low-cost source of textile and yarn inputs used to manufacture apparel. This is also the case for Mexico. The difference, however, is that El Salvador's own textile industry might be the potential source of textile inputs (because it has a revealed 
Figures 4.3a-f Net Exports of Apparel and Textiles per Worker: Mexico and Central America, 1980-2001

a.

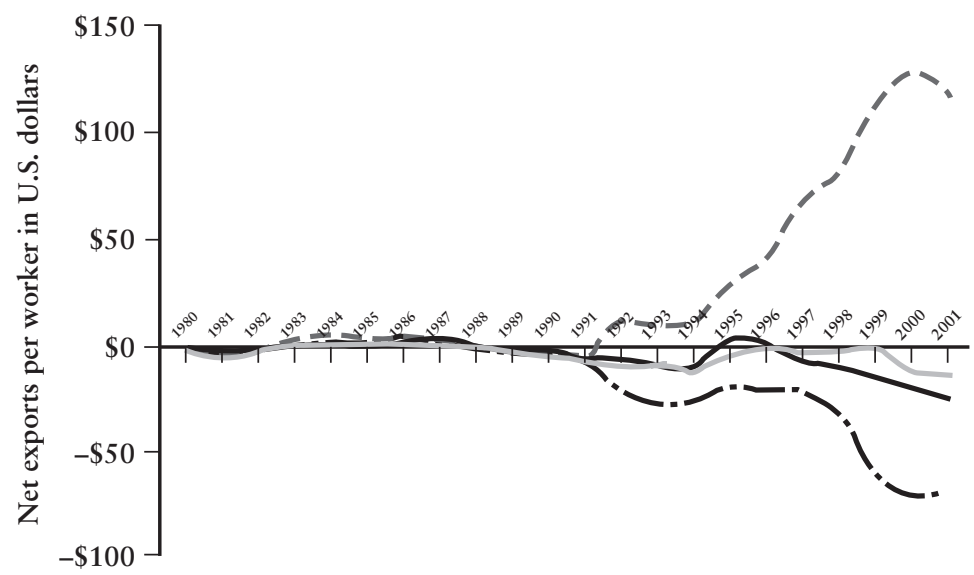

Mex apparel rest of world - - - Mex apparel U.S. and Canada Mex textiles rest of world - - - - Mex textiles U.S. and Canada

b.

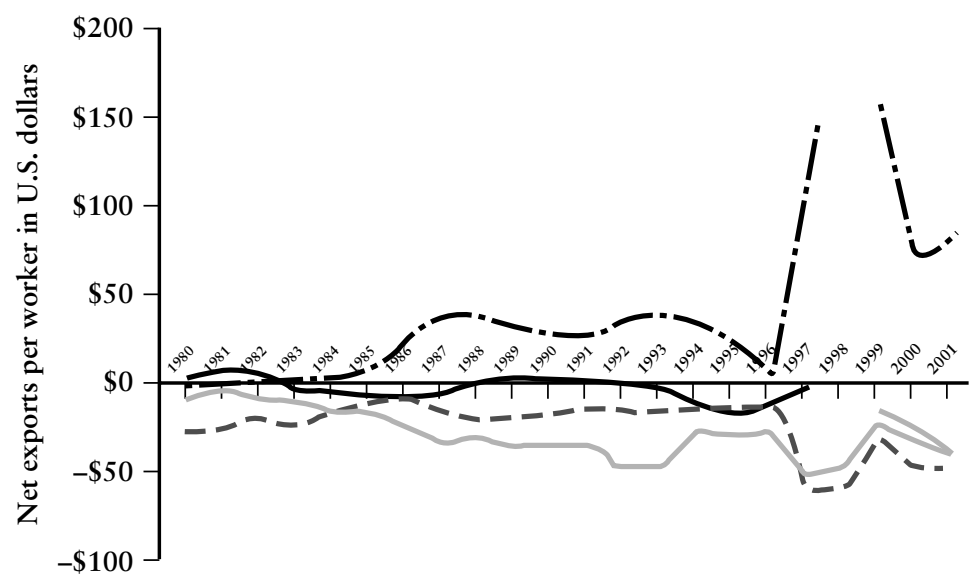

C. Rica textiles rest of world - - C. Rica textiles U.S.

C. Rica apparel rest of world - - - C. Rica apparel U.S. 
c.

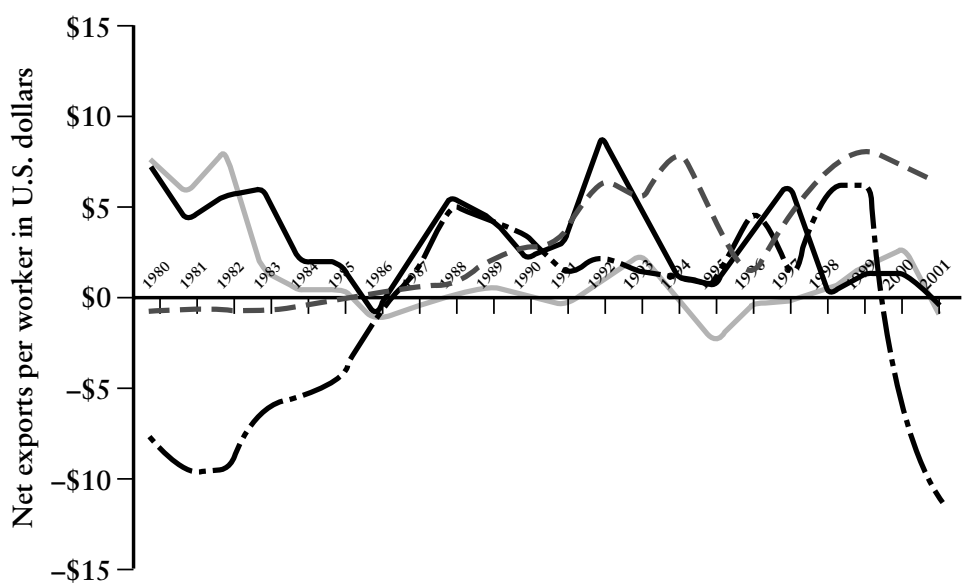

El Salv. textiles rest of world - - - El Salv. textiles U.S.

El Salv. apparel rest of world - - El Salv. apparel U.S.

d.

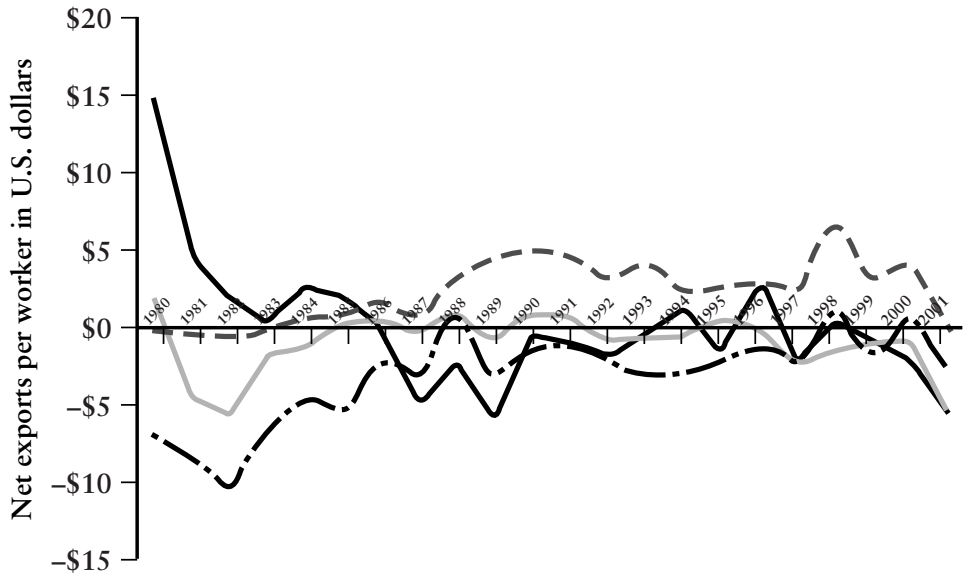

- Guat. textiles rest of world - - - Guat. textiles U.S.

Guat. apparel rest of world - - - Guat. apparel U.S. 


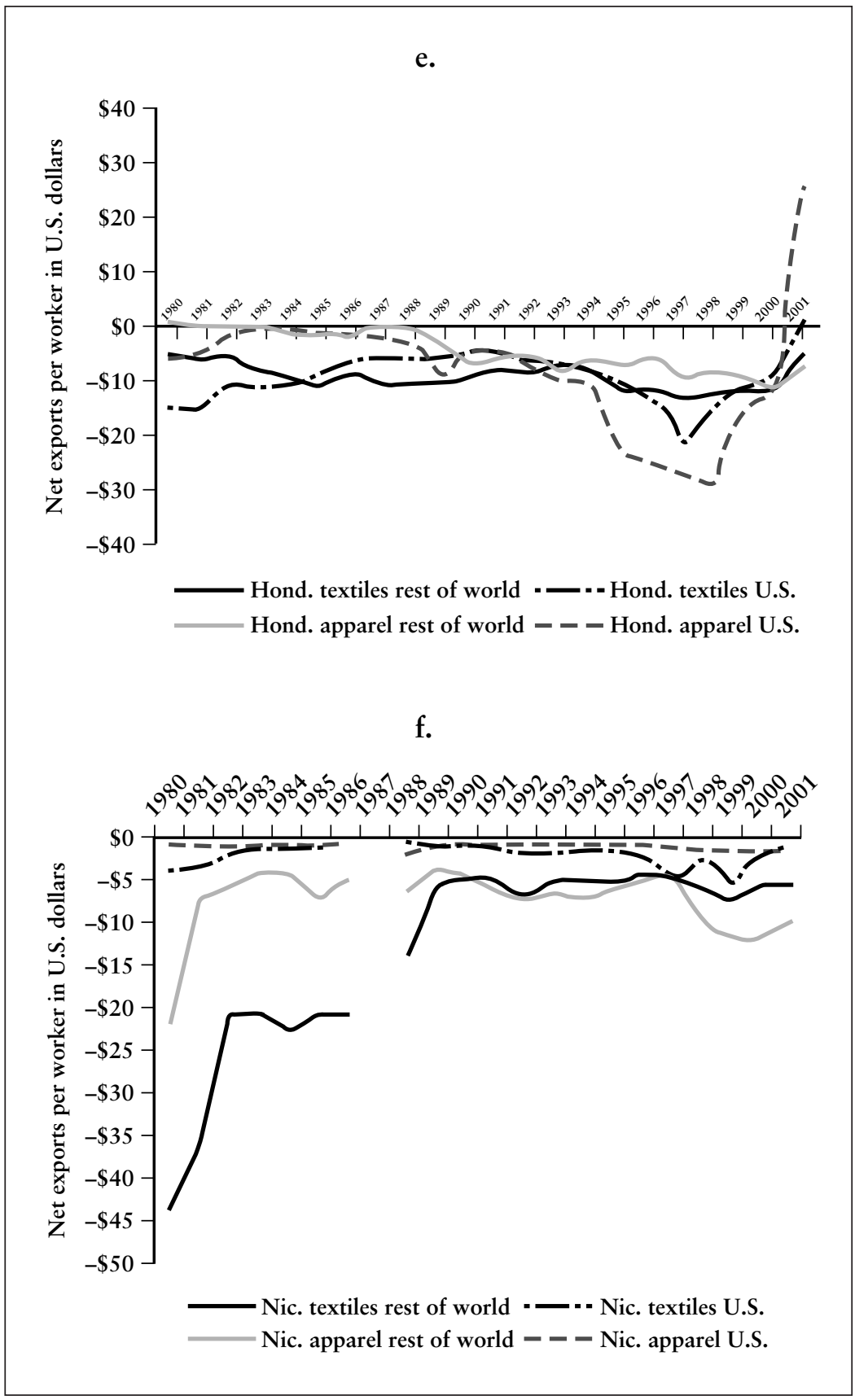


Table 4.3 NAFTA and CBI Apparel Preferences Utilization Rates, Selected Countries

\begin{tabular}{lcc}
\hline Country & $2001(\%)$ & January-November 2002 (\%) \\
\hline Mexico (NAFTA) & 68 & 74 \\
Costa Rica (CBI) & 53 & 65 \\
El Salvador (CBI) & 57 & 63 \\
Honduras (CBI) & 62 & 73 \\
Nicaragua (CBI) & 21 & 29 \\
Dominican Rep (CBI) & 68 & 83 \\
Jamaica (CBI) & 59 & 88 \\
\hline
\end{tabular}

Source: Author's calculations, based on data from the U.S. International Trade Commission.

comparative advantage for textiles relative to the whole world), and thus for this country NAFTA-type ROOs might be more beneficial than they were for Mexico or could be for Costa Rica, for example, under a NAFTA-type agreement. Although we have not shown the corresponding graphs for Colombia, a country that is also beginning to consider an FTA with the United States, Colombia is similar to El Salvador in that it has a significant domestic textile industry and thus could benefit more than Mexico from NAFTA-type ROOs. ${ }^{7}$

From Mexico's viewpoint we have already suggested that an important policy implication of this analysis is that it could benefit from negotiating a relaxation of the ROOs, especially those affecting apparel exports. However, there is one additional important consideration for the future. In January 2005, the United States will eliminate its textile and apparel quotas as a result of its commitments under the Uruguay Round agreement signed in 1995. Consequently, the NAFTA preferential margins will be further diluted at that time. Whereas it is unlikely that the United States will fully liberalize its import tariffs on textile and apparel imports from the rest of the world, it is likely that the resulting preferential margins will be lower after 2005. This has two important policy implications. First, the renegotiation of the ROOs should be done very soon so that the new rules can be implemented prior to 2005 . Second, in the medium to long run, the profitability of Mexico's apparel industry will depend less on NAFTA preferences and more on its capacity to innovate and take advantage of Mexico's enviable geographic location. To accomplish this successfully, domestic complementary policies are required. The innovation issues are discussed in chapter 6 of this volume, whereas the other policies concern domestic and border infrastructure and customs procedures, which go beyond the scope of this report. 


\section{Agriculture}

The impact of NAFTA on Mexican agriculture received a lot of rather pessimistic attention prior to the implementation of the agreement (Baffes 1998; Burfisher, Robinson, and Thierfelder 1992; and Levy and van Wijnbergen 1994). It has also become the subject of recent political controversy as a consequence of the liberalization of certain sensitive products for Mexico implemented in January 2003. In part, this attention results from the perception that poor farmers dedicated to traditional crops, such as maize, have been hurt by the liberalization in agricultural trade mandated by NAFTA. In this section we examine the economic trends of Mexico's crop agriculture before and after NAFTA and analyze the extent to which liberalization has actually taken place. ${ }^{8}$ Our main conclusion is that liberalization of agricultural trade under NAFTA has been substantial, but domestic distortions supporting producer prices of maize and other sensitive crops have been maintained. Thus it is noteworthy that NAFTA-related liberalization did not devastate Mexican agriculture as a whole and has not had negative effects on poor subsistence farmers in particular. The challenging questions are, first, why did NAFTA not have a negative effect on Mexican farms, and second, what are the main policy challenges for the Mexican government in the medium term? These questions are addressed in the subsequent paragraphs. Given the sensitive nature of the subject matter, we pay detailed attention to both the policies pursued by Mexico before and after NAFTA and the economic effects of these policies. We begin with a brief historical review of Mexico's agricultural policies.

\section{Agricultural Policy Reforms in Mexico Without NAFTA}

Although Mexico became a full member of GATT in 1986, the government did not reform agricultural protection until 1990. Until that time, all products in whose markets CONASUPO (Compania Nacional de Subsistencia Populares) intervened through producers' price supports were also subject to import licenses. It was not until the beginning of the 1990s that domestic reforms and trade liberalization began to include the most important Mexican agricultural crops. Between 1990 and 1991 import controls and government direct price supports to producers of 9 of the 11 traditional crops were abolished, ${ }^{9}$ and subsidies granted to agricultural inputs, credit, and insurance were drastically reduced.

The most important agricultural reform was the elimination of producer price supports for traditional crops and the elimination of CONASUPO. In 1990 CONASUPO limited its market interventions to maize 
and beans, and producers' price supports were abolished for all of the remaining basic crops. In 1991 the Agricultural Marketing Board (ASERCA) was created to replace CONASUPO's interventions in sorghum and wheat markets. ${ }^{10}$ Since its creation, ASERCA has followed a plan of "indifference prices" for these two crops. The plan is regionspecific and entails fixing a "concentrated price" for the crop in question before the cropping season, taking as a reference international prices plus transportation costs. Producers sell their crops to processors at the international price, and the government transfers to the farmers the difference between that price and the concentrated price. ${ }^{11}$

Until 1994 the Agricultural Council fixed the prices of maize and beans, which were administered by CONASUPO. In 1995 the government changed CONASUPO into a "last-instance buyer" of these crops, thus eliminating domestic price supports. Because of the declining international price of maize, in 1996 Mexico followed an intermediate price-setting plan, whereby the domestic price was fixed for each state (or region) at levels between the guaranteed price and the international price (ASERCA, May 1997, pp. 10, 13-14). During 1996-97 the price supports for maize changed again. Maize and beans were bought by CONASUPO at "indifference prices." The prices were region-specific and determined by the average of international prices listed on the Chicago Commodity Exchange plus international transportation and logistics costs (SAGAR, July 1997, p. 22). Under this plan, abolished in late 1999 , CONASUPO became a lastinstance buyer because maize growers were allowed to sell at higher prices.

Direct Income Transfers: PROCAMPO. Three years after the creation of ASERCA a major transitional program called PROCAMPO was initiated in the winter season of 1993-94, a few months before the beginning of NAFTA. PROCAMPO is a decoupled program that substituted for previous direct price supports. It consists of income transfers to farmers who produce barley, beans, maize, cotton, rice, sorghum, soy, sunflower, and wheat. The main purposes of PROCAMPO are to support domestic producers of basic staples who face competition from Canadian and U.S. farmers introduced by NAFTA, and to help Mexican producers switch to crops that are more competitive in a liberalized context. PROCAMPO is planned to last until 2008 when full trade liberalization under NAFTA will be attained, and its beneficiaries have been those producers who cultivated (or continue to cultivate) the above-mentioned crops during the three years before NAFTA implementation. The transferred amount is per hectare and is the same for all farmers, regardless of their level of productivity, and it is granted even if the beneficiaries switch to producing other crops. Box 4.2 reviews recent evidence concerning the income effects of PROCAMPO on its beneficiaries. 


\section{Box 4.2 The Multiplier Effects of PROCAMPO: Evidence of Effectiveness}

Evaluations of income support programs, such as PROCAMPO, should consider, among other factors, how such transfers affect total incomes of the beneficiaries. Effective programs should in principle create additional income from other sources so that each dollar spent by the public sector results in more than one dollar of additional income. The study by Sadoulet, de Janvry, and Davis (2001) found that PROCAMPO created large indirect effects. The multiplier for all households is in the range of 1.5 to 2.6. Multipliers are higher for households with medium and large farms, with low numbers of adults in the household, with nonindigenous backgrounds, and ones that are located in the Central and Gulf regions. Large multipliers reflect uncaptured marginal income opportunities because of the liquidity constraints that are relaxed by the transfers. Liquidity constraints can be caused by incomplete property rights in the ejido sector and by the disarray of financial institutions servicing agriculture following the scaling down of the agricultural development bank. Large multipliers thus reflect sizable gaps between opportunities and constraints. Households with migrants sending remittances and with higher levels of education may thus have lower multipliers because they were able to work around the liquidity constraints more effectively than were other households. Households with little land and with ethnic backgrounds may have lower access to liquidity, but also have lower opportunities to invest additional cash received, again resulting in lower multipliers.

Source: Sadoulet, de Janvry, and Davis 2001.

Alliance for the Countryside. In addition to ASERCA and PROCAMPO the government launched the Alliance for the Countryside in 1993. The program's main objective is to increase agricultural productivity and capitalize farmers by contributing funds for investment and sanitary projects that integrate farmers into the commercial food-processing industry. A major purpose is to promote farming efficiency through crop substitution (mainly from traditional crops to fruits and vegetables) for farmers who have a potential comparative advantage in producing such crops in the context of an open economy. Other important features of the Alliance include its decentralized character with state-level control of its programs and contribution to the funding by participating farmers.

The Alliance for the Countryside includes PROCAMPO as well as other programs. The most important among these programs is PRODUCE, which focuses on three main activities: (a) the use of irrigation 
canals to deliver liquid fertilizer, (b) mechanization, and (c) the improvement of pasture quality for livestock producers. The Alliance also includes a phytosanitary program.

Other Reforms. Less government intervention in agriculture was accompanied by the abolition of state enterprises involved in the sector. Along with the disappearance of CONASUPO, government companies producing fertilizers, seeds, and other inputs and those involved in the marketing of coffee, sugar, and tobacco were eliminated or privatized.

Credit subsidies and official credit coverage for working capital given to farmers by public financial institutions for rural development (the most important being BANRURAL) declined sharply during the 1990s. There are several reasons for the reduction of government participation in rural credit, ranging from public budget restrictions to a very high default rate among beneficiaries. The gap caused by the decline in governmental rural credit was expected to be filled by private commercial banking. The current government passed the Ley de Capitalización del Campo (Agrarian Capitalization Law), which simplified and improved the system for granting credit subsidies through FIRA (Fideicomiso Institudo en Relación con la Agricultura; the Agricultural Trust Institute)—in this case for potentially profitable agricultural activities for the beneficiaries of PROCAMPO. This instrument clearly aims to help the productive transformation of traditional agriculture (a PROCAMPO criterion) in favor of other activities.

Another major reform was the amendment of the Mexican Constitution in 1991 that liberalized property rights in the ejidal sector. Until that year peasants who benefited from land distribution (a result of the Mexican Revolution called ejidatarios) were, by law, not allowed to associate, rent, or sell their land. With the reform this mandate disappeared and land redistribution ended. The ejidal reform was expected to help develop the land market and to capitalize agricultural activities by allowing farmers to participate in the private credit market and by promoting direct private investment.

The administration of Carlos Salinas de Gortari (1988-94) created the Ministry of Social Development, and, with it, a social program designed specifically to assist the rural poor (called Progresa during the Zedillo government). The concern with the development of poor rural areas has been maintained by the current government under its comprehensive Plan for Rural Development.

\section{Liberalization Under NAFTA}

Under NAFTA, the structure of border protection for Mexico's agricultural sector was transformed and Mexico gained access to Canadian and U.S. markets—a benefit not obtained through its previous liberalization 
efforts. Two separate agreements between Mexico and Canada and between Mexico and the United States were actually negotiated. ${ }^{12}$

Market Access Granted by Mexico Under NAFTA. Some traditional crops were liberalized immediately after the implementation of NAFTA. From January 1994 onward, sorghum, sesame seeds, and sunflower from Canada and the United States entered duty free. Free trade also applies to seeds for barley, beans, maize, cotton, and sunflower, and since January 1998 all types of soy also enter duty free to Mexico from its two North American partners.

NAFTA became the first free trade agreement using tariff rate quotas (TRQs) as a transition mechanism to eliminate quantitative restrictions and move toward free trade. TRQs were applied to those products that the governments of the three North American countries considered very sensitive. Under NAFTA no tariffs for those agricultural products that are under in-quota imports are charged. A phase-out period of 15 years of above-quota tariff reductions and quota increases was defined for the imports of maize and dry beans. ${ }^{13}$ TRQs were also established for grain and malt barley (for which free trade was reached in 2003).

Quota levels were established using trade flows between Mexico and its two North American partners from 1989 to 1991. In 1994 the quota for maize was set at 2,500,000 metric tons for the United States and 1,000 metric tons for Canada, and the above-quota base or consolidated tariff for both countries was fixed at 215 percent (or US $\$ 206.40 /$ metric ton). In January of 1994 the quota for beans was 50,000 metric tons for the United States and 1,500 for Canada, and the above-quota tariff was 139 percent (US $\$ 480 /$ metric ton). For both grain and malt barley the quota was set in 1994 to 120,000 metric tons for imports from the United States and 30,000 metric tons for imports from Canada, and the above-quota ad valorem tariff for grain barley was 128 percent and for malt barley 175 percent.

Beginning in 1995 the quotas for barley, beans, and maize grew each year and their above-quota tariffs were subjected to a yearly process of reductions. This liberalization was designed under NAFTA for beans and maize to reach duty free treatment by Mexico in December 2007. Full liberalization for barley was achieved in January 2003.

Until the end of 2000 quota assignments were set by a committee formed by the Ministry of Commerce (SECOFI; la Secretaría de Comercio y Fomento Industrial) and the Ministry of Agriculture (SAGAR; la Secretaría de Agricultura, Ganadería, y Desarrollo Rural) and by representatives of the private sector. The Mexican government has followed four allocation mechanisms for TRQs: direct assignment, auction, government monopoly, and "first come-first served" processes. Maize and barley have been subject to direct allocations and dry beans to auctions. 
Until 1999 CONASUPO participated indirectly in the allocation of maize quotas and, with the Ministry of Agriculture, it defined the amount of the crop to be allocated so as to accomplish what were the company's reduced functions (mainly stockpiling and sales to tortilla producers to sustain the tortilla subsidy program). The rest of the maize quota has been allocated to private cattle feeders (Shagam and Plunkett 1997). In practice, however, from the beginning of NAFTA implementation until 2000 Mexico did not charge above-quota tariffs on any of the crops subject to TRQs. This was the result of either quotas that went unfilled or unilateral actions taken by the Mexican government. Mexico's imports of beans have been lower than the quota, whereas above-quota maize imports were allowed without applying the high over-quota tariff. ${ }^{14}$

In January 1995 Mexico restructured its protection measures for World Trade Organization (WTO) members following the Uruguay Round Accord. The main differences between Mexico's commitments under NAFTA and those under the WTO are twofold: (a) greater quota access and lower off-quota tariffs for Canada and the United States than the rest of the world, and (b) Mexican abolition of all border protection of imports from Canada and the United States by 2003 or 2008. Mexico, however, will maintain the 1995 quota levels and off-quota tariffs for other WTO members and it has reduced MFN tariffs by an average of 24 percent between 1995 and 2000.

In NAFTA Mexico included a safeguard clause for several agricultural products, which can be used as a "countervailing mechanism" when an increase of imports represents a "considerable menace" or a "serious damage" to the sector in question. In this case the measure to be taken is either to suspend the tariff reduction process or to use (to "snap back" to) the base tariff of 1994. In the WTO the Mexican government is allowed to set additional import taxes when "imports rise due to low import prices." Mexico used this clause to limit imports of poultry parts in January 2003 after its import tariffs of 45 percent were eliminated and in response to social pressures from farmers' organizations.

Market Access for Mexican Exports Granted by the United States Under NAFTA. NAFTA enhanced access for Mexico's competitive cropsmainly fruits and vegetables - to the United States markets. However, trade liberalization was not immediate for those products considered sensitive by the United States. For these commodities the process of negotiations with Mexico to phase out trade restrictions was based on the complementary or substitutive character of Mexican exports, meaning that the agreed liberalization of these products was based on the productive annual cycles of vegetables and fruits in both countries. Thus, trade restrictions on some products exported by Mexico to the United States were eliminated in 1994 (e.g., grapes, mangoes, and pineapples), 
but for most vegetables and fruits tariffs will be charged for some periods of the year until their elimination in 2008. For some of these commodities TRQs are also applied. ${ }^{15}$

\section{Trade and Production Outcomes}

The above discussion indicated that at least on paper agricultural trade within NAFTA and, most important, between Mexico and the United States was substantially liberalized. We now focus on the evolution of trade and production outcomes for Mexico.

Figure 4.4 shows total agricultural production in Mexico as well as the ratio of imports plus exports over the value of domestic production during the period 1990-2001. The dip in production in 1995 as well as the rise of the importance of trade in that year resulted from the Tequila crisis, which was generally associated with rising exports, less-thanproportional declines in imports (and thus the trade to GDP ratio rose), and declining domestic value added (see Lederman et al. 2001, 2003).

Figure 4.4 Agricultural Production and Trade in Mexico, 1990-2001: No Apparent Devastating Effects from NAFTA

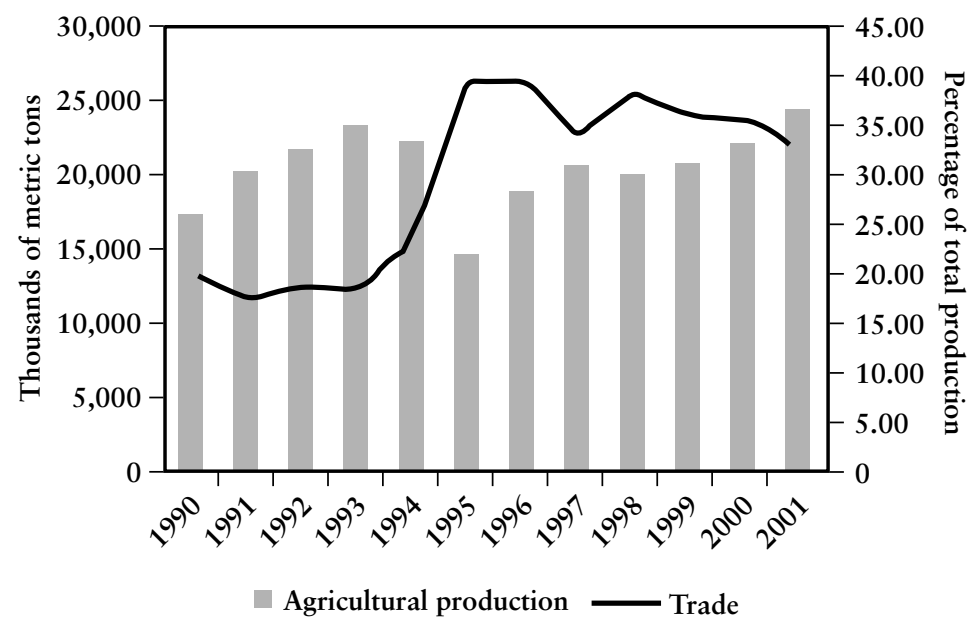

Source: Yúnez-Naude (2002), based on data from Secretaría de Aqricultura, Ganadería, Desarrollo Rural, Pesca, Y Alimentación (SAGARPA). 
But after the recovery from the crisis domestic agricultural production rose quickly while trade remained at higher levels than prior to the implementation of NAFTA. Thus it is difficult to argue that NAFTA had a devastating effect on Mexican agriculture despite the fact that trade increased as a consequence of the liberalization plan implemented under the agreement.

Regarding the sensitive products from traditional agricultural activities, such as maize, beans, and other commodities, figure 4.5 shows total production by irrigated and nonirrigated lands. The distinction between irrigated and nonirrigated land is interesting because nonirrigated land encompasses the small ejidatario farmers who are thought to be poor subsistence farmers, and about whom there are no other systematic data. The evidence indicates that despite the rise in imports during the years after NAFTA (1994-2000), total production was significantly higher than before (1983-93). This result is driven by a notable increase in the production of maize and is especially true for nonirrigated farming, whereas production of the other traditional crops declined during this period. In fact, the irrigated traditional agriculture had a comparatively lackluster performance relative to nonirrigated farms. These data, however, arise from the fact that irrigation farming was more dynamic in nontraditional agriculture because many farmers managed to substitute nontraditional crops, such as fruits, for the traditional ones. These conclusions seems to be robust to comparisons across various subperiods, as shown in figure 4.5.

Figure 4.6 shows the evolution of land productivity for the whole of irrigated and nonirrigated agriculture. The main conclusion is that irrigated agriculture experienced a substantial productivity improvement after NAFTA, whereas productivity of nonirrigated agriculture stagnated.

Figure 4.7 shows trends in exports and production of fruits as an example of nontraditional agricultural performance. In the post-NAFTA years both exports and production surged relative to the earlier years. This surge resulted in part from the transformation of irrigated traditional agriculture into nontraditional production as well as the aforementioned improvements in land yields. Given the high profile of the state of agriculture in Mexico at this time, it is worth discussing potential explanations for why NAFTA did not result in the expected devastation of traditional and nontraditional agriculture (see below).

A word of caution is required for making conclusions about the income effects of NAFTA based on the aforementioned evidence concerning volumes of production. This is so because the relative prices for producers of import-sensitive commodities fell in Mexico during the 1990s. These declines in relative prices imply that agricultural incomes fell for some farmers during this period. However, the relative prices of 
Figure 4.5 Imports and Production of Traditional Crops

Before and After NAFTA: Irrigated vs.

Nonirrigated Production

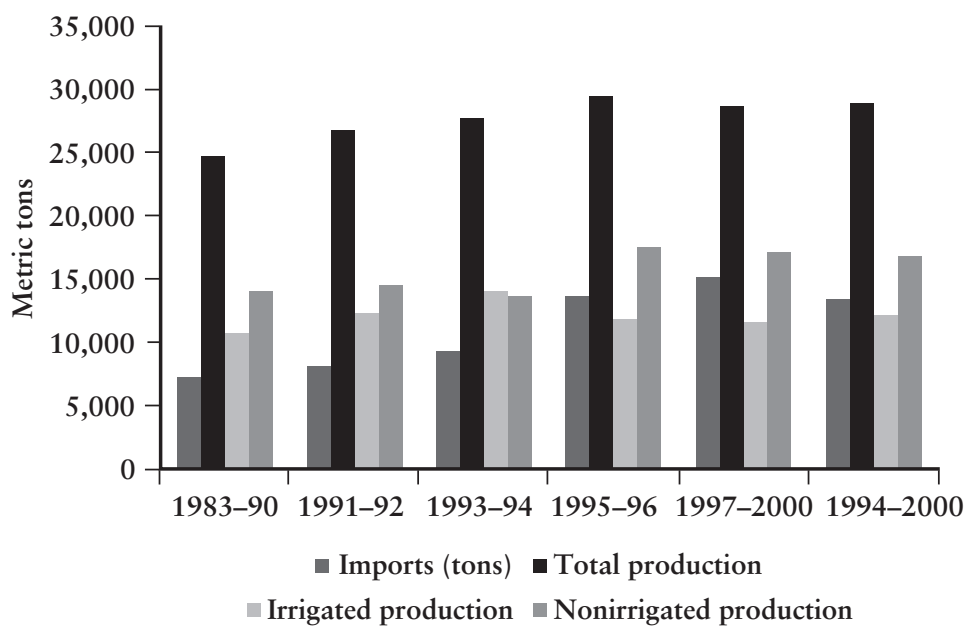

Source: Yúnez-Naude (2002), based on data from SAGARPA.

agricultural commodities in Mexico were falling well before NAFTAas early as the 1980s. For example, between 1987 and 1994, the relative price of maize for Mexican producers fell by almost 50 percent according to data provided by Yúnez-Naude and Barceinas (2003). In turn, in the equivalent seven-year period after NAFTA implementation, between 1994 and 2001, this relative price fell by about 43 percent. Thus, incomes derived from maize production fell during NAFTA, primarily because of the relative price decline. But this decline began well before 1994, and Yúnez-Naude and Barceinas (2003) reported econometric results indicating that the behavior of Mexican agricultural prices did not change significantly after 1994. Moreover, Yúnez-Naude (2002, table 5) also reported that the portion of the variation in the relative price of maize resulting from policy interventions was actually positive, whereas the decline after 1993 resulted from the movement in international prices. Thus it is difficult to blame NAFTA for any income losses arising from the behavior of the relative price of maize. ${ }^{16}$ In chapter 5 we discuss the evolution of agricultural employment, which also experienced a secular decline dating back at least to 1980. Finally, it is worth noting 


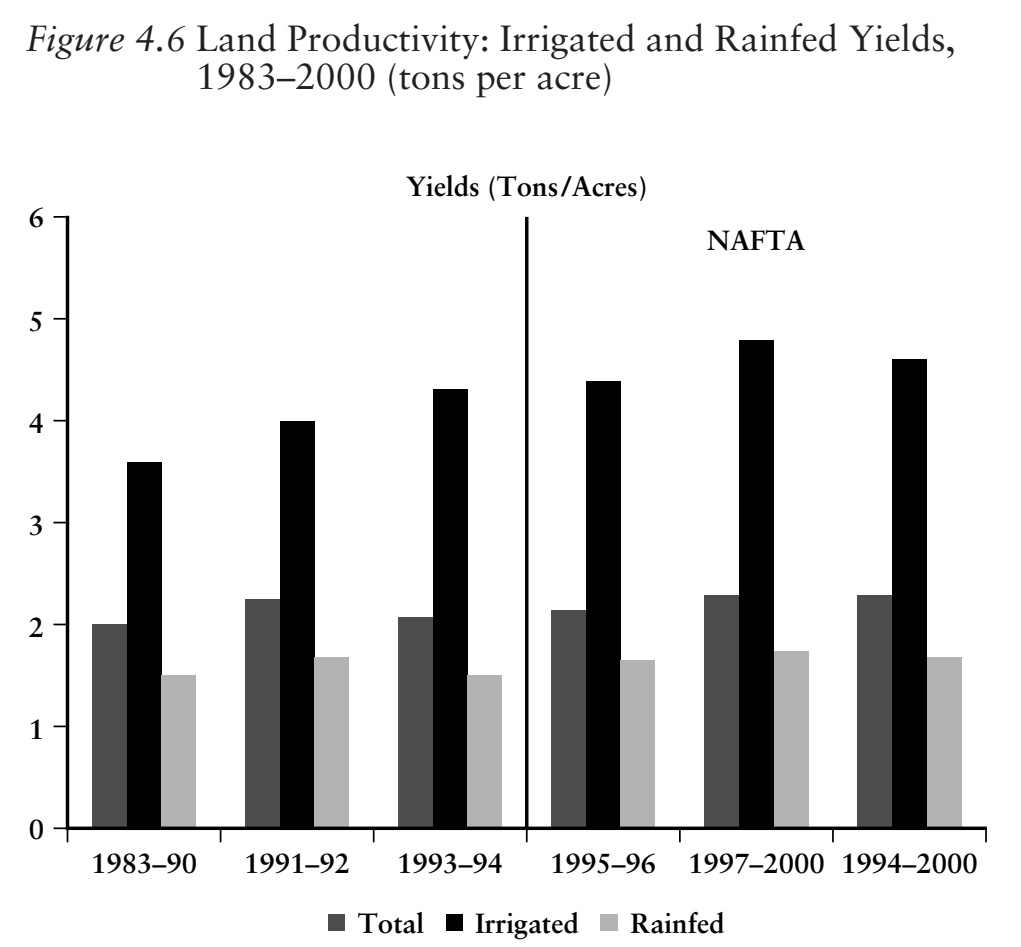

Source: Yúnez-Naude (2002), based on data from SAGARPA.

that the Mexican government implemented a series of agricultural support policies during this time period, some of which insulated producers from the price fluctuations. The following section examines this and other potential explanations for the surprising resiliency of Mexican agriculture.

\section{Three Plausible Explanations for the Resilience of Mexican Agriculture}

The growth of demand in the late 1990s in both Mexico and the United States is a well-known fact (see Lederman et al. 2001, 2003). It is quite possible that Mexican agriculture performed remarkably well during the late 1990s precisely because these economies were growing and thus Mexican production could rise despite the increase in imports of 
Figure 4.7 Mexico: Exports and Production of Fruits Before and After NAFTA

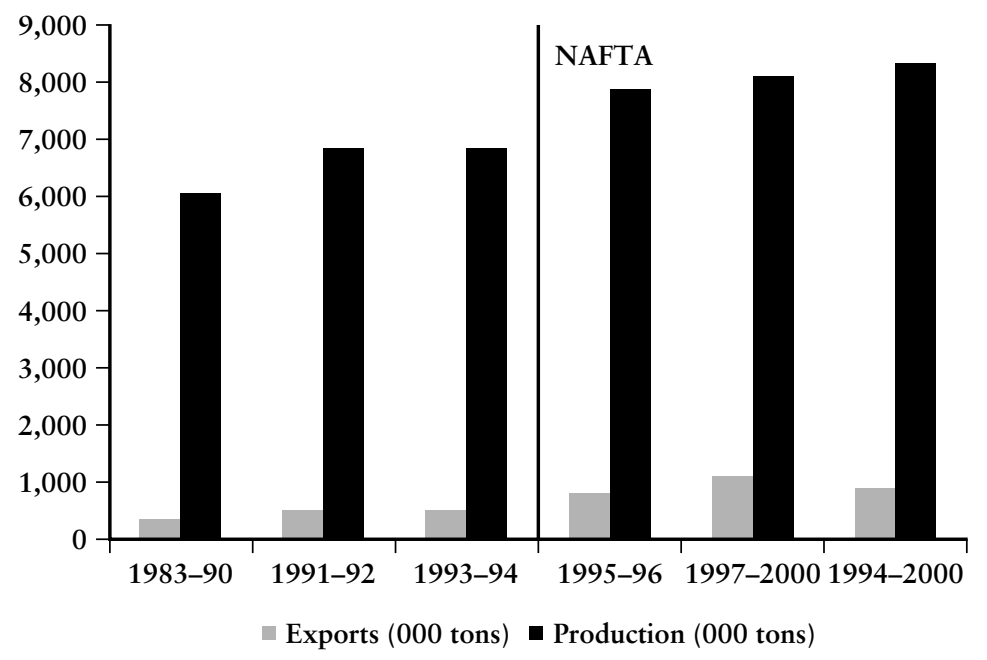

Source: Yúnez-Naude (2002), based on data from SAGARPA.

traditional agricultural products. Productivity gains concentrated in the irrigated farm sector also contributed to this resilience, as demonstrated above. Last but not least, the income support and subsidy programs maintained by Mexico after 1994 might have helped sustain agricultural dynamism during this period.

The domestic support policies merit further attention. As described earlier, agriculture in Mexico historically had enjoyed ample public support, although the programs were quite inefficient in economic terms. With the advent of the agricultural reforms, the quantity and quality of the support programs changed. Figure 4.8 shows the evolution of the total support for traditional agriculture and its corresponding components relative to gross farm receipts, as reported by the Organisation for Economic Co-operation and Development (OECD 2000). On the one hand, it is clear that total support was not higher after NAFTA than in the average year prior to the implementation of the agreement. Hence the resilience of the traditional sector did not result from an increase in total support. On the other hand, the composition of this support was changed with the advent of PROCAMPO. Beginning in 1994, about 50 


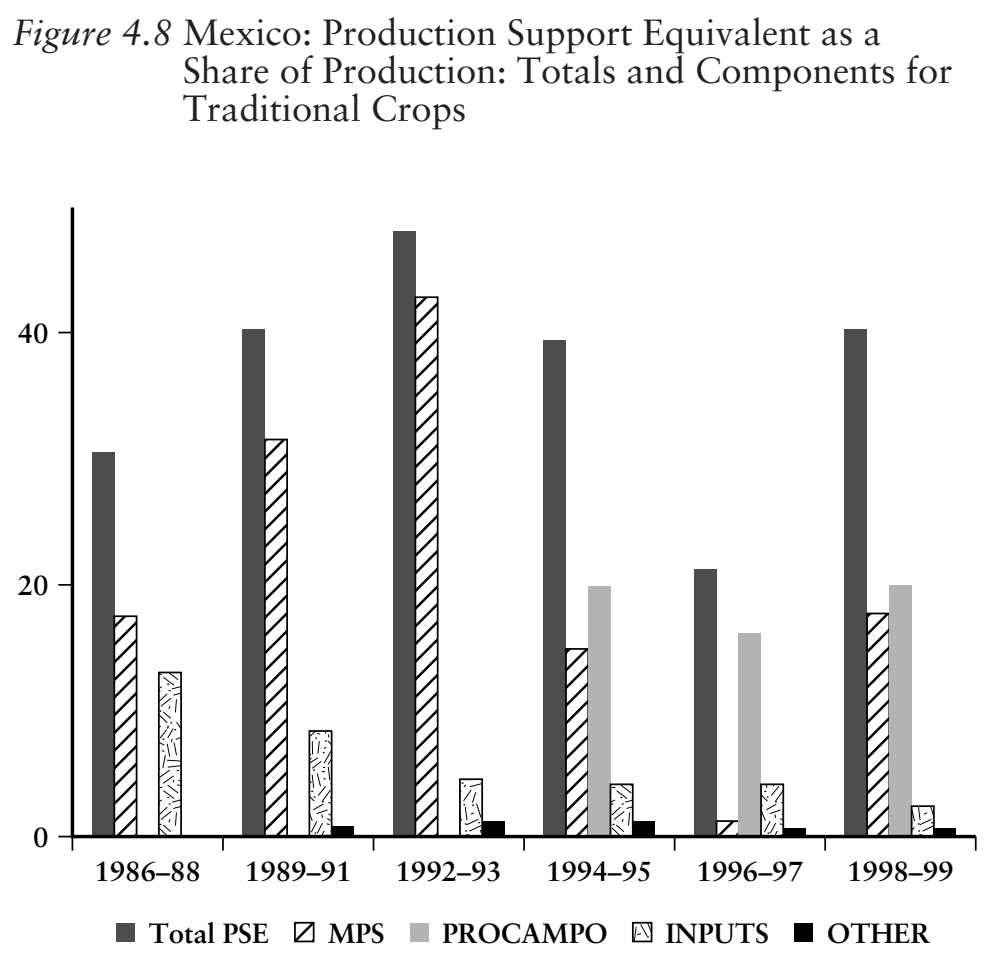

Note: Traditional crops are barley, maize, rice, sorghum, soybean, and wheat.

Source: OECD 2000.

percent of total support was administered through PROCAMPO, the income subsidies of which are delinked from existing and future production decisions. This contrasts notably with the situation prior to 1994 when most domestic support was concentrated in so-called market-price supports that compensate farmers for low commodity prices and thus tend to distort production decisions.

When comparing the annual averages of total producer support estimates as a whole during 1999-2001 in Canada (18 percent), Mexico (18 percent), and the United States (23 percent), we find that Mexico has converged with the levels of its NAFTA partners. These shares are still smaller than those benefiting the traditional crops, which reached 40 percent of production in the late 1990s. The OECD agricultural database also reported similar shares of the total producer support estimates 
that are assigned on the basis of historical entitlements (20 percent). Canada's historical entitlements share is only 9 percent, which is still higher than the OECD average of 5 percent. This high share of historical entitlements represents an advantage in the sense that it reflects assistance that might be less likely to affect production decisions. In the case of the United States, however, it is worrisome that the Farm Bill of 2002 allowed for updating the historical criterion (i.e., planted acreage in the past). This type of updating should not be imitated because it raises expectations that future support will rise if planted areas rise before the next "update." A more detailed discussion of issues related to the design of delinked agricultural support programs in the United States and Mexico is presented in box 4.3.

In summary, the resilience of Mexican agriculture was partly the result of the efficiency improvement achieved through the country's unilateral agricultural reforms. However, there are significant challenges ahead for Mexican agricultural development.

\section{The Challenges Ahead: Toward the Productive Transformation of Mexican Agriculture}

We have already noted that PROCAMPO entailed a substantial improvement over the pre-NAFTA agricultural support policies. The main reason for this conclusion is that the subsidies are now delinked from current and future production decisions and thus do not necessarily provide incentives for farmers to continue producing traditional agricultural crops. In addition, this program is supposed to end in 2008. Hence, the challenge is what can be done to aid the productive transformation of Mexican agriculture toward nontraditional crops. The recently implemented agrarian capitalization program mentioned earlier is a step in the right direction because it offers credit subsidies to PROCAMPOeligible farmers who present potentially profitable investment projects. The program, administered by FIRA, also demands cost sharing on the part of the farmers so that their proposals are efficient and carefully thought out. However, this may not be enough.

There is an important role for macroeconomic stability. Yúnez-Naude (2002) showed that in Mexico a substantial share of the variations of domestic agricultural prices during 1980-99 resulted from exchange rate fluctuations. This was generally the case for most Latin American countries during this period, as reported by Foster and Valdés (2001). Consequently, macroeconomic stability should be a key ingredient in any economic program intended to support the long-term investments necessary for the productive transformation of Mexican agriculture.

In the recent social upheaval associated with the next-to-last phase of agricultural trade liberalization under NAFTA, the Mexican government 


\section{Box 4.3 Mexican and U.S. Experiences with Delinked Agricultural Income Subsidies}

\section{Mexico: The 1994 PROCAMPO Program}

In 1994 Mexico introduced a new farm program, PROCAMPO, to provide income support to grain and oilseed producers-about 90 percent of all Mexican farmers. Under this regime prices of the nine crops in the program have become market driven or autonomous. Thus production and trade are less distorted. Moreover, PROCAMPO is distributionally more attractive than the earlier guaranteed price support because poor subsistence farmers are eligible for payments and there is a ceiling of 100 hectares on the amount of land that any single farmer can claim to justify payments (see table 4.9, page 165).

\section{United States: The 1996 FAIR Act}

On April 4, 1996 the Federal Agricultural Improvement and Reform Act (FAIR) became law, after the longest debate on a farm bill in U.S. congressional history (USDA 1996). FAIR removed the link between income support payments and farm prices by providing "production flexibility contract payments" for several crops. Participant producers receive these payments as a function of the amount of land registered for government support payments in earlier years. The payments are independent of current production, and farmers therefore have a more flexible incentive structure regarding planting decisions. The payments are fixed annually at a declining rate but were revised by the U.S. Farm Bill of 2002 (see table 4.9).

\section{Room for Improvement: Efficiency, Equity, and Risk}

Both of these programs are less than ideal in that the use of land is not delinked from them. This requirement probably reflects political considerations because the payments must be seen to be going to "true" farmers. PROCAMPO holds land in agricultural production but permits a variety of crops to be cultivated. FAIR requires that land be kept in general agricultural use, but cannot be switched to fruits and vegetables.

These programs may promote equity when there is a correlation between poverty and subsistence production. Poor subsistence farmers with land are better off because they can consume the previously subsidized commodities and receive cash payments. In Mexico farmers who owned less than two hectares of land received more than 8 percent of PROCAMPO payments, although they have historically marketed very little and therefore received little support under the old program because the price guarantees applied only to the traded commodities.

Replacing stable support prices or guaranteed prices with direct income transfers exposes producers to the risk of price volatility. Short- 


\section{Box 4.3 (continued)}

term volatility can be alleviated with devices that mitigate market-based risk, either through private initiative or with public assistance. Forward and futures markets are effective tools that can offer both price discovery and hedging not only to producers but also to merchants or other concerned parties. Government-assisted risk-mitigation devices are another option. In 1997 the United States introduced revenue insurance against both crop failure and falling prices. Similarly, Mexico offers a guaranteed minimum price to cotton farmers for a predetermined fee through a government organization, ASERCA. Generally speaking, there are many ways to reduce risk in addition to formal measures. Farmers can grow a variety of crops with different market and climatic risks, but this requires that the income support program be completely decoupled from cropping decisions.

Ideally programs should not restrict land uses, should not cost more than the subsidization programs they replace, and should be transitory. To realize the full benefits of an income support system, the programs should include all crops and substitute for all existing price support programs so that farmers do not face production incentives driven by the relative benefits from the various programs. Other supporting factors, such as government credibility, favorable macroeconomic conditions, and property rights are key. Credibility was a problem in Mexico where the amount of land in crops was first underreported in many areas (because of fear of government taxation) and then overreported. Clearly the macroeconomic environment, and particularly the exchange rate, should be adequate and stable to maintain domestic price stability. In some cases eliminating currency overvaluation may make it possible to eliminate protection without fiscal compensation. Another set of problems stems from uncertain land tenure rights because it becomes difficult to allocate subsidies.

Source: Baffes and Meerman 1998.

has reacted in part by seeking temporary safeguards for poultry imports. This is also a recommendable action in light of the political economy considerations that need to be addressed in the short run. The government also responded by providing further subsidies for agricultural inputs, such as electricity and diesel fuel. Again these actions are undoubtedly short-term solutions to a mainly political situation. But in the medium and long run these responses are not solutions for the competitiveness of Mexican agriculture. The long-term profitability of Mexican producers depends on their capacity to plant new crops, produce processed foods, or both. To support these efforts the government can take a closer look at its agricultural research and extension support services, which are 
related to the national innovation system (discussed in chapter 6 of this volume). The public sector also needs to evaluate the current infrastructure demands of the agricultural sector, including its roads, ports, and irrigation infrastructure. All of these are and should be an integral part of the country's rural development strategy in the context of an open North American economy that supplies one of the most competitive and dynamic agricultural production and consumption centers in the worldthe U.S. economy. This means that regional (encompassing the United States, Canada, and Mexico) cooperative efforts to support agricultural research and extension services funded by the public sector, as well as infrastructure investments, could be an integral part of Mexico's rural development agenda in the years prior to the 2008 disappearance of PROCAMPO. The hope is that by that time PROCAMPO could be replaced by an even more efficient regional system of agricultural transformation policies in which temporary protection plays only a very limited role.

\section{NAFTA's Antidumping and Countervailing Duties}

With the success of GATT/WTO rounds in reducing traditional forms of trade protection, such as tariffs and quotas, recent focus by economists and policymakers has been on the use of AD/CVD laws by WTO-member countries. There is concern that the growing adoption and use of these laws by countries may threaten to roll back the free trade gains negotiated in GATT/WTO rounds since the end of World War II. ${ }^{17,18}$ In recent WTO meetings it has become apparent that traditional users of AD/CVD laws, particularly the United States, have been extremely reluctant even to allow these practices to be subject to future WTO negotiations. (See this chapter's section concerning Mexico's AD/CVD system before and after NAFTA for a review of technical criteria used for deciding to impose AD/CVDs. These are quite similar across countries.)

Likewise, treatment of $\mathrm{AD} / \mathrm{CVD}$ practices has been a contentious issue for recent preferential trade agreements (PTAs) negotiated by the United States. In negotiations for the Canada-U.S. Free Trade Agreement (CUSFTA) implemented in 1989, Canada originally proposed exempting both countries from each other's AD/CVD actions. Given strong U.S. objections to this, a compromise was eventually reached to establish binational panels to review $\mathrm{AD} / \mathrm{CVD}$ actions between the two countries when requested by an involved party (Gantz 1998). This compromise was codified in Chapter 19 of the CUSFTA. ${ }^{19}$ The role of these binational panels is limited to determining whether a country appropriately follows its own national $\mathrm{AD} / \mathrm{CVD}$ laws in making a particular determination. Thus, national AD/CVD laws were not changed and cannot be questioned by the review panels (a crucial issue for the United 
States). On the other hand, the process provides an alternative to having national courts handle appeals of $\mathrm{AD} / \mathrm{CVD}$ decisions, thus providing the possibility for greater impartiality in the review. ${ }^{20}$

An almost identical Chapter 19 was ultimately adopted in NAFTA as well, but not before the United States rejected calls by Canada for NAFTA countries to exempt each other from their AD/CVD actions. In addition, there was substantial concern from both Canada and the United States over Mexico's AD/CVD laws and their application, which led to agreements by Mexico to make major procedural changes in their $\mathrm{AD} / \mathrm{CVD}$ laws before implementation of NAFTA. ${ }^{21}$ Likewise, treatment of $\mathrm{AD} / \mathrm{CVD}$ laws is a major concern in negotiations for a Free Trade Area of the Americas, with the United States unlikely to accept any concessions that would restrict its ability to apply U.S. AD/CVD laws.

The role of $\mathrm{AD} / \mathrm{CVD}$ laws is already an important issue for future trade negotiations over PTAs and in the multilateral arena under the aegis of the WTO. Studying the impact of change in the appeals process afforded through Chapter 19 of CUSFTA and NAFTA depends on a key policy question: did this change alter incentives sufficiently to affect $\mathrm{AD} / \mathrm{CVD}$ activity? To date, very little literature has examined these issues. ${ }^{22}$ The main exception is Jones (2000), which pointed out that the creation of Chapter 19 binational review panels has the potential to create many more successful appeals by parties becoming subject to AD/CVDs. This, in turn, would limit the success of domestic groups that file such actions and could lead to diminished $\mathrm{AD} / \mathrm{CVD}$ activity toward other NAFTA countries. It is important to note that the level of activity in the NAFTA dispute settlement process for $\mathrm{AD} / \mathrm{CVD}$ cases has been substantial, with approximately 75 reviews occurring since CUSFTA began in 1989.

On the other hand, PTAs obviously reduce trade barriers in general and lead to increased trade flows. AD/CVD decisions are supposedly based on whether imports are injuring domestic industries so increased import activity from a region may make this injury determination more likely and then lead to a greater probability of affirmative decisions. This in turn gives domestic industries greater incentives to file $\mathrm{AD} / \mathrm{CVD}$ cases, raising the level of AD/CVD filing activity. In summary, the effect of CUSFTA and NAFTA on U.S. AD/CVD activity against NAFTA countries is an open question because of these opposing effects of increased trade and a new binational dispute settlement process.

The following sections empirically examine U.S. AD/CVD actions from 1980 through 2000 to determine the effects, if any, of CUSFTA and NAFTA on U.S. AD/CVD activity with respect to Canada and Mexico, and Mexican cases against the other two countries. ${ }^{23,24}$ Jones (2000), in the only report to empirically examine this issue, found that both U.S. AD filings against Canada and Canada's AD filings against the United States significantly dropped after the CUSFTA agreement. This is 
Table 4.4 Average Annual U.S. Antidumping and Countervailing Duty Filings, by Named Country/Region and by Select Time Period

\begin{tabular}{lccc}
\hline & $\begin{array}{c}\text { Pre-CUSFTA, } \\
\text { Pre-NAFTA, } \\
1980-88\end{array}$ & $\begin{array}{c}\text { Post-CUSFTA, } \\
\text { Pre-NAFTA, } \\
1989-93\end{array}$ & $\begin{array}{c}\text { Post-CUSFTA, } \\
\text { Post-NAFTA, } \\
1994-2000\end{array}$ \\
\hline $\begin{array}{l}\text { NAFTA partners } \\
\text { Canada }\end{array}$ & 3.9 & 4.3 & 1.6 \\
Mexico & 1.1 & 3.8 & 1.7 \\
Other countries/regions & & & \\
Japan & 7.6 & 6.3 & 3.3 \\
Asia & 13.8 & 22.3 & 14.6 \\
European Union & 32.7 & 20.3 & 8.3 \\
Latin America & 10.8 & 11.3 & 4.0 \\
Rest of the World & 14.1 & 11.5 & 9.1 \\
\hline
\end{tabular}

Source: U.S. Antidumping Database available from the National Bureau of Economic Research Web site (http://www.nber.org/antidump/), and official sources of the U.S. Department of Commerce and U.S. International Trade Commission.

attributed by Jones to the new binational dispute settlement process put into place by CUSFTA and NAFTA. However, this is true for all regions of the world, as shown in table 4.4. Understanding the impact of NAFTA's Chapter 19 on Canada's and Mexico's vulnerability to U.S. $\mathrm{AD} / \mathrm{CVD}$ activity requires more careful analysis, which we present in the following section. We will examine the geographic and other trends of Mexican AD/CVD activity later in this chapter.

\section{U.S. AD/CVD Activity Toward NAFTA Partners: Did Chapter 19 Help?}

The United States' and Mexico's AD/CVD activities are likely to be affected not only by NAFTA but also by macroeconomic (Feinberg 1989; Knetter and Prusa 2000), industrial, and microeconomic conditions (Blonigen and Prusa 2002; Feinberg and Hirsch 1989; Finger, Hall, and Nelson 1982) that are known to explain AD/CVD activity in various countries. To examine the impact of NAFTA's Chapter 19, Blonigen (2002) estimated various econometric models of such activity in the United States where NAFTA case fillings are only part of the explanation. The results are presented in table 4.5. The most notable finding is that neither Canadian nor Mexican Chapter 19 filings against U.S. decisions are significant determinants of U.S. AD/CVD activity. Blonigen (2002) conducted further exercises to test for the robustness of these 
Table 4.5 Negative Binomial Maximum Likelihood Estimates of the Determinants of the Number of U.S. AD and CVD Cases: Effects of NAFTA Dispute Settlement Filings

\begin{tabular}{|c|c|c|c|c|}
\hline \multirow[b]{2}{*}{ Explanatory Variables } & \multicolumn{2}{|c|}{ Total Filings } & \multicolumn{2}{|c|}{ Affirmative Decisions } \\
\hline & $\begin{array}{c}A D \text { and } \\
C V D\end{array}$ & $A D$ Only & $\begin{array}{c}A D \text { and } \\
C V D\end{array}$ & $A D$ Only \\
\hline \multicolumn{5}{|l|}{ NAFTA variables } \\
\hline \multicolumn{5}{|l|}{ Canadian NAFTA } \\
\hline dispute settlement filings & $\begin{array}{l}-0.073 \\
(-1.29)\end{array}$ & $\begin{array}{l}-0.081 \\
(-0.97)\end{array}$ & $\begin{array}{l}-0.163 \\
(-1.23)\end{array}$ & $\begin{array}{l}-0.154 \\
(-1.18)\end{array}$ \\
\hline \multicolumn{5}{|l|}{ Mexican NAFTA } \\
\hline dispute settlement filings & $\begin{array}{c}0.140 \\
(1.26)\end{array}$ & $\begin{array}{l}0.195^{*} \\
(1.73)\end{array}$ & $\begin{array}{c}0.018 \\
(0.10)\end{array}$ & $\begin{array}{c}0.087 \\
(0.54)\end{array}$ \\
\hline \multicolumn{5}{|l|}{ Control variables } \\
\hline Import penetration & $\begin{array}{l}4.165 \\
(0.24)\end{array}$ & $\begin{array}{c}0.160 \\
(0.01)\end{array}$ & $\begin{array}{r}19.809 \\
0.77)\end{array}$ & $\begin{array}{l}-2.925 \\
(-0.12)\end{array}$ \\
\hline Exchange rate & $\begin{array}{c}0.198 \\
(0.42)\end{array}$ & $\begin{array}{l}0.860 * * \\
(2.14)\end{array}$ & $\begin{array}{c}0.341 \\
(0.71)\end{array}$ & $\begin{array}{r}0.789 \\
(1.64)\end{array}$ \\
\hline Real GDP growth & $\begin{array}{l}0.045 \\
(1.26)\end{array}$ & $\begin{array}{c}0.038 \\
(1.08)\end{array}$ & $\begin{array}{c}0.026 \\
(0.61)\end{array}$ & $\begin{array}{c}0.004 \\
(0.08)\end{array}$ \\
\hline Unemployment rate & $\begin{array}{c}0.073 \\
(1.26)\end{array}$ & $\begin{array}{l}-0.024 \\
(-0.45)\end{array}$ & $\begin{array}{l}-0.031 \\
(-0.44)\end{array}$ & $\begin{array}{l}-0.130^{*} \\
(-1.69)\end{array}$ \\
\hline Corporate profitability & $\begin{array}{l}-0.114 \\
(-1.60)\end{array}$ & $\begin{array}{l}-0.198 * * * \\
(-3.21)\end{array}$ & $\begin{array}{l}-0.158 * * \\
(-2.19)\end{array}$ & $\begin{array}{l}-0.179 * * * \\
(-2.82)\end{array}$ \\
\hline \multicolumn{5}{|l|}{ Regional fixed effects } \\
\hline Canada & $\begin{array}{l}-1.175^{* * * *} \\
(-5.17)\end{array}$ & $\begin{array}{l}-1.311^{* * * *} \\
(-5.14)\end{array}$ & $\begin{array}{l}-1.269 * * * \\
(-3.20)\end{array}$ & $\begin{array}{l}-1.325^{* * *} \\
(-3.47)\end{array}$ \\
\hline Mexico & $\begin{array}{l}-1.939 * * * \\
(-5.53)\end{array}$ & $\begin{array}{l}-1.921^{* * *} \\
(-5.81)\end{array}$ & $\begin{array}{l}-1.946^{* * * *} \\
(-4.46)\end{array}$ & $\begin{array}{l}-2.018 * * * \\
(-4.77)\end{array}$ \\
\hline Japan & $\begin{array}{l}-0.700 * * * \\
(-3.57)\end{array}$ & $\begin{array}{l}-0.373^{*} \\
(-1.82)\end{array}$ & $\begin{array}{l}-0.255 \\
(-0.99)\end{array}$ & $\begin{array}{c}0.160 \\
(0.62)\end{array}$ \\
\hline Asia & $\begin{array}{c}0.286 \\
(1.29)\end{array}$ & $\begin{array}{l}0.455^{*} \\
(1.83)\end{array}$ & $\begin{array}{l}0.561^{*} \\
(1.65)\end{array}$ & $\begin{array}{l}0.914 * * * \\
(2.59)\end{array}$ \\
\hline European Union & $\begin{array}{l}0.639 * \\
(1.90)\end{array}$ & $\begin{array}{c}0.435 \\
(1.50)\end{array}$ & $\begin{array}{r}0.109 \\
(0.34)\end{array}$ & $\begin{array}{c}0.239 \\
(0.76)\end{array}$ \\
\hline Latin America & $\begin{array}{l}-0.345 \\
(-1.37)\end{array}$ & $\begin{array}{l}-0.524 * * \\
(-2.12)\end{array}$ & $\begin{array}{l}-0.167 \\
(-0.62)\end{array}$ & $\begin{array}{l}-0.469 \\
(-1.62)\end{array}$ \\
\hline Number of observations & 147 & 147 & 147 & 147 \\
\hline Pseudo- $R^{2}$ & 0.11 & 0.12 & 0.12 & 0.15 \\
\hline
\end{tabular}

* Significant at the 10 percent level.

* Significant at the 5 percent level.

$\because *$ Significant at the 1 percent level.

Note: Regressor set also includes a constant term (not reported). Omitted regional fixed effect is "Rest of the World" to avoid perfect multicollinearity with the constant. The $t$-statistics are in parentheses.

Source: Blonigen 2002. 
results. In one set of econometric experiments, Blonigen tested the importance of other aspects of the NAFTA review mechanism. He found that, in the case of Mexico, the number of remands per year (i.e., the number of cases determined to be wrongfully assessed against Mexico by the NAFTA panel of experts), the number of accumulated remands, and the accumulated number of filings by Mexico are all not significant determinants of U.S. AD/CVD activity. In contrast, Canadian cumulative filings and cumulative remands do seem to reduce that country's vulnerability to U.S. AD/CVD investigations. The aforementioned results were unchanged when Blonigen examined only steel-related cases filed by the United States. (Table 4.6 contains a statistical summary of CUSFTA and NAFTA filings against U.S. AD/CVD cases.)

\section{Mexico's AD/CVD System Before and After NAFTA}

Having reviewed the performance of the CUSFTA and NAFTA review mechanism with respect to U.S. AD/CVD activity, we now turn to Mexico's AD/CVD system. ${ }^{25}$ We start with a brief historical description of the relevant institutions.

Table 4.6 CUSFTA and NAFTA Dispute Settlement Petitions and Determinations Against U.S. AD/CVD Actions, 1989-2000

\begin{tabular}{|c|c|c|c|c|c|c|c|c|}
\hline \multirow[b]{2}{*}{ Year } & \multicolumn{4}{|c|}{$\begin{array}{c}\text { Canadian Filings } \\
\text { Against United States }\end{array}$} & \multicolumn{4}{|c|}{$\begin{array}{c}\text { Mexican Filings } \\
\text { Against United States }\end{array}$} \\
\hline & Filings & Affirm & Remand & Terminate & Filings & Affirm & Remand & Terminate \\
\hline 1989 & 11 & 6 & 4 & 1 & n.a. & n.a. & n.a. & n.a. \\
\hline 1990 & 3 & 0 & 1 & 2 & n.a. & n.a. & n.a. & n.a. \\
\hline 1991 & 5 & 0 & 2 & 3 & n.a. & n.a. & n.a. & n.a. \\
\hline 1992 & 6 & 1 & 5 & 0 & n.a. & n.a. & n.a. & n.a. \\
\hline 1993 & 5 & 2 & 1 & 2 & n.a. & n.a. & n.a. & n.a. \\
\hline 1994 & 1 & 0 & 1 & 0 & 1 & 1 & 0 & 0 \\
\hline 1995 & 1 & 1 & 0 & 0 & 4 & 2 & 2 & 0 \\
\hline 1996 & 0 & 0 & 0 & 0 & 1 & 0 & 0 & 1 \\
\hline 1997 & 3 & 0 & 1 & 2 & 5 & 1 & 1 & 2 \\
\hline 1998 & 2 & 1 & 1 & 0 & 3 & 0 & 0 & 0 \\
\hline 1999 & 5 & 0 & 0 & 5 & 2 & 0 & 0 & 0 \\
\hline 2000 & 6 & 0 & 0 & 3 & 4 & 0 & 0 & 0 \\
\hline
\end{tabular}

n.a. Not applicable.

Note: The nine Mexican filings from 1998 to 2000 and three Canadian filings in 2000 are still active investigations.

Source: Blonigen (2002) based on data from NAFTA Secretariat Web site (http://www.nafta-sec-alena.org/english/ index.htm?decisions/decisions.htm). 
Mexico's trade liberalization resulted in a surge in imports. Considering that fact, along with the "right thing to do" derived from the political economy of trade integration, creating a system that protected the domestic industry through $\mathrm{AD} / \mathrm{CVD}$ s was thought to be necessary. ${ }^{26}$ In 1985 and 1986 two preliminary laws were created, ${ }^{27}$ but it was not until 1987 that the system was fully operational, by means of the approval of the GATT Antidumping Code. In that same year Mexico's first AD/CVD case was filed. Between 1987 and 1990 the average number of $\mathrm{AD} / \mathrm{CVD}$ investigations was 12 cases a year. However, the import surge that followed between 1991 and 1994 tripled this average to 36 cases a year.

In 1993 Mexico's AD/CVD legislation underwent another change through the approval of the Foreign Trade Law (Ley de Comercio Exterior, LCE). The law proposed a more specific framework for AD/CVD procedures. Finally, in 1994 the Antidumping Code changed as a result of the Uruguay Round and it embodied the WTO criteria. ${ }^{28}$ The key organizational innovation of this law was the creation of the International Trade Practices Unit (Unidad de Practicas Comerciales Internacionales, UPCI).

The UPCI is Mexico's government agency accountable for the filing and investigation of $\mathrm{AD} / \mathrm{CVD}$ practices. The UPCI is responsible for the following activities:

- advising the minister of economy about the application and size of $\mathrm{AD} / \mathrm{CVDs}$

- serving as the general adviser to the federal government on $\mathrm{AD} / \mathrm{CVD}$ and escape clause issues

- providing assistance in formulating reforms to the Foreign Trade Law regarding $\mathrm{AD} / \mathrm{CVD}$ and escape clause issues

- explaining and defending the ministry's AD/CVD resolutions to international agencies and local authorities

- offering technical and legal assistance to Mexican firms involved in $\mathrm{AD} / \mathrm{CVD}$ investigations by other countries.

To understand further the types of technical responsibilities held by the UPCI we must first review the legal definitions of "dumping" and other relevant terms because they explain to a significant extent why AD/CVDs in Mexico, the United States, and around the world can easily become sources for the reversal of trade reforms. Indeed, given the lax criteria used for identifying dumping and foreign subsidies of private firms, some analysts have concluded that, at least in the case of the United States, the real puzzle is not why AD/CVD actions are so popular among private firms and governments, but why they are not used more often (Prusa 1992). 
Dumping. The case for dumping or price discrimination is justified whenever a firm that exports a particular good does it at a price that is less than the prevailing one at the exporter's market. It is important to note that dumping per se is not forbidden by law; unfair competition holds when the imports cause material damage (or potential damage) to the importing country's industry. There are two key elements in the analysis of an $\mathrm{AD}$ investigation. The first is the export price of the good. The second is the price of a similar good on the exporting country's market. The comparison between the prices leads to the dumping margin. Some of the potential motivations for a firm to engage in dumping activities are

- a wish to improve its competitive position through an increased market share (generally in countries where it has a low participation ratio)

- an effort to sell excess production

- its benefit maximization process (price discrimination on the basis of demand elasticities)

- market predation, through the elimination of rival firms.

Countervailing Duties. The exporting firm may not always be directly responsible for the low prices. In some cases the government of the exporting firm's country provides subsidies to its companies, thereby reducing the effective export price. In a CVD analysis there are three basic elements: (a) the amount of the subsidy; (b) the export price, considering the subsidy; and (c) the export price that would have prevailed had there been no subsidy. The comparison between both prices results in the CVD margin. Similar to the AD case, the granting of subsidies is a necessary but not sufficient condition for an affirmative duty resolution. CVDs can only be applied when the subsidies are responsible for damage (or potential damage) to the domestic industry. ${ }^{29}$

Damage Assessment Criteria. Mexico's legislation does not allow duty imposition under the sole excuse of dumping or government subsidies; these conditions are a necessary but not sufficient condition. In addition to these conditions, it must be proved that these actions have caused material damage (or are a potential threat) to the domestic industry, and a cause-effect relationship must exist between the AD/CVD activities and the industry's injury. The same is true in Canada and the United States.

The methodology designed to test for injury to a domestic industry is composed of five steps. First, the authorities have to ensure that the domestic product under investigation is identical (or similar) to the imported one. The latter obeys the fact that AD/CVDs can only be applied when both products have similar characteristics, serve the same purposes and functions, and can be commercially interchanged. 
The second step requires an assessment of the size of the filing firm, relative to the industry. Because the firm can be either a major participant or a small fraction of the entire market, the fact that a firm is being affected by imports does not necessarily mean that the industry as a whole is being damaged. This analysis allows authorities to determine if the investigation must be undertaken (considering the injuries done to the industry) and to identify which firms must be excluded from the process either because they are importers of the good or because they are linked to importers or exporters.

The third step requires study and evaluation of the importing country's market, both relative to national consumers and to the distribution channels (in the filing country) of the merchandise, given the fact that the structure and channels of the product's distribution are important parts of the injury analysis.

The fourth requirement, the causality test, is probably the most important step in determining injury against a certain industry. First it is necessary to determine if the surge on imports has caused the national (as well as any foreign competitor's) good to be displaced from the market. Also, it must be verified that the imports were sold through the same distribution channels and market niches and to the same clients. The authorities next need to analyze if the imported goods affected domestic prices and if the market share of these imports is related to their price level. Then a cause-effect relationship must be discovered, relating imports with the main variables of the affected industry.

In the fifth and final step, the effect of exogenous variables on the performance of the industry must be isolated, thus giving a clear picture of the causality between imports and industry behavior. Although these criteria (and the previous ones concerning the margin of dumping and subsidies) seem reasonable, they can easily be satisfied when trading partners experience macroeconomic fluctuations such as exchange rate changes.

Generally but not always, the size of the AD/CVD is equivalent to the dumping or CVD margin. The UPCI can impose a lesser duty ${ }^{30}$ so as to minimize the impact of this action over related productive chains that can be affected because of the price increase. That is, the UPCI can consider the potential impact of such duties on consuming industries. Mexican as well as Canadian and U.S. laws do not consider the impact of these duties on noncorporate consumers, which might result in rather large welfare losses (Gallaway, Blonigen, and Flynn 1999).

As in the United States, AD/CVDs imposed by a final resolution in Mexico are not necessarily permanent; they can be reviewed to determine if the conditions that originally led to their imposition have changed, thereby allowing the duty to be reduced, revoked, or confirmed. The LCE states that the revisions can be requested on the 
anniversary of the resolution; however, the UPCI can start an official revision at any time if it considers that the general circumstances that originated the duties have changed. The new duties will be considered final and therefore will be subject to new revisions in further years. In Mexico, if the duties have not been reviewed in the past five years, they will automatically expire. This practice differs from the laws in the United States where AD/CVDs do not automatically expire.

To clarify particular situations that may arise from the interpretation of both the LCE's and UPCI's rulings, the following special procedures have been designed: ${ }^{31}$

- Product reach: duties are imposed over tariff lines. However, the same tariff line can include products that are not related to the AD/CVD investigation; in these cases, a special procedure is used to exempt (or confirm) duties for the specific good (generally at the four- or five-digit Standard Industry Classification level).

- Benefit extension: Mexican legislation states that UPCI's rulings always extend to other firms, given that the interested party demands the special procedure and proves that it has the same legal situation as the original firm.

- Isolated market determination: in cases where AD/CVD injury is determined, the damage may not be nationwide. For some special industries the injured firms can be located in a defined area (for example, in a particular state or region). Using this special procedure, duties are only paid for the imported products that are destined for that specific area.

The mechanisms designed to appeal $\mathrm{AD} / \mathrm{CVD}$ decisions made by the UPCI and the equivalent authorities worldwide are diverse. Broadly speaking, disputes about the final resolutions dictated by the UPCI can be solved using a variety of channels (considering that the specific procedure will depend on the conditions of the FTA between Mexico and the affected country; if no FTA exists, higher authorities must be consulted, such as the WTO). Of particular importance to the analysis are the Mexican review system and the aforementioned NAFTA Chapter 19 bilateral panels, both designed to provide an alternative review procedure to the national appeals processes. ${ }^{32}$

According to the LCE, interested parties can request a review of the UPCI's decision through administrative and judicial procedures. The administrative review process requires that the interested party present the case to the UPCI within 45 days of the (original) final resolution. The LCE states that the UPCI is required to present a new resolution within four months. This new resolution can revoke, modify, or confirm the original decision. When the UPCI states its new resolution, if the interested party is not satisfied with the result a judicial review process can 
be requested. In this case the decision corresponds to the Federal Fiscal Tribunal (Tribunal Fiscal de la Federación, TFF). The TFF can dictate five possible resolutions: (a) take the UPCI's decision as valid; (b) nullify (totally or partially) the UPCI's decision; (c) send back the decision to the UPCI, stating the specific terms for compliance; (d) order the UPCI to renew the administrative review; or (e) reject and discard the review. As a last (and extraordinary) review process, a juicio de amparo (an appeal) can be requested. In this judicial procedure-used often in Mexican law-the interested parties can ask for an amendment of the TFF's resolutions. Under the juicio de amparo two types of violations can be presented: procedural errors and legal errors in the procedure. It is noteworthy that the reviewing authority is limited to an examination of legal topics, determining if the TFF did apply the appropriate legislation.

\section{Mexico's AD/CVD Activity and NAFTA}

We have already reviewed the evidence concerning U.S. AD/CVD activity and concluded that Mexico has not yet benefited from NAFTA's Chapter 19 review mechanism. We have also reviewed Mexico's AD/CVD institutions, which share many features with those of its NAFTA partners. However, given that the scientific literature accepts the finding that $\mathrm{AD} / \mathrm{CVDs}$ are often imposed for political reasons pertaining to macro- and microeconomic circumstances that are not necessarily related to firm or government economic practices, it is an empirical question whether Mexico's AD/CVD activity was affected by NAFTA. Esquivel and Solis (2002) provided an empirical exploration of the determinants of Mexico's AD/CVD activity that is methodologically similar to the exercises presented above and in Blonigen (2002) for the U.S. case.

The evolution of Mexican AD activity is shown in figure 4.9. Mexico's filings followed a similar pattern as U.S. AD filings (shown in the figure for comparative purposes). Between 1987 and 1994 investigations in Mexico increased from 18 to 83, and fell back to 5 by 2000 . The final resolutions from Mexican authorities follow the total filings trend with a one-year lag. From the graph it is clear that both Mexican and U.S. filings fell after NAFTA, whereas the world total followed an increasing trend after $1995 .{ }^{33}$

A great deal of information can be obtained with an analysis of the composition of $\mathrm{AD} / \mathrm{CVD}$ actions by the target country. Considering all 234 investigations, table 4.7 shows that 60 percent concentrated on the top five countries (United States, China, Brazil, the República Bolivariana de Venezuela, and the Republic of Korea), that 55 percent focused on the top three, and that the United States is solely responsible for nearly 30 percent of the AD/CVD petitions. Nevertheless, the United States only accounted 
Figure 4.9 Mexico AD Activity, 1987-2001

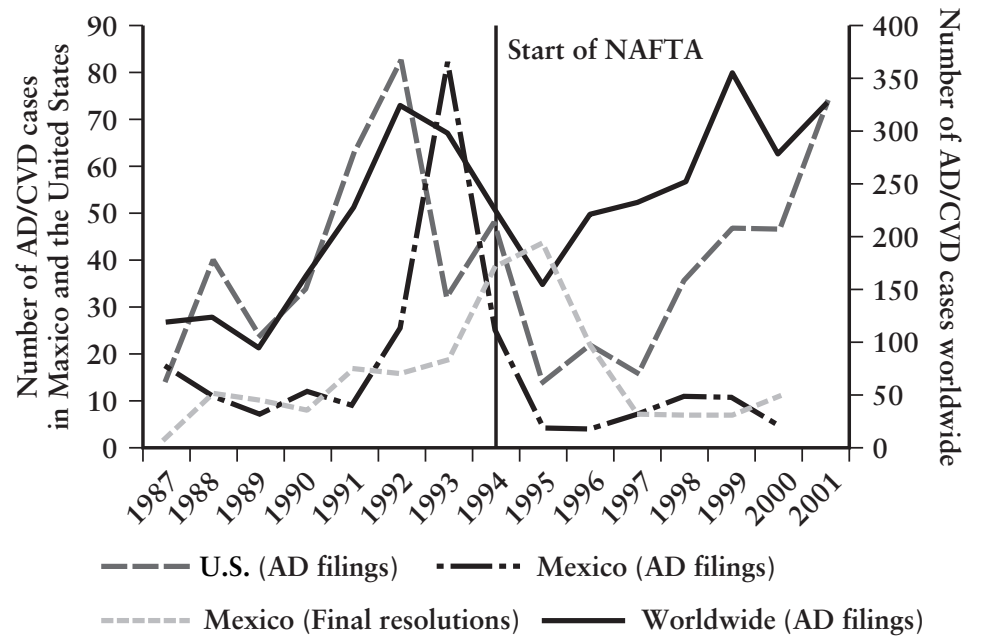

Source: Esquivel and Solis (2002), based on data from Prusa (2001) and UPCI (2001).

for 19 percent of the duties imposed. In contrast, China, having 17 percent of the $\mathrm{AD} / \mathrm{CVD}$ requests, accounts for almost 36 percent of the total duties imposed. The United States and Brazil come in second and third, respectively. Also, the last column of table 4.7 calculates the "success rate" (defined as the percentage of filings where a duty is imposed) of cases for $\mathrm{AD} / \mathrm{CVD}$ investigations. In this regard, China is the most punished country, with a ratio of 87.2 percent (that is, for every $10 \mathrm{AD} / \mathrm{CVD}$ filings, almost 9 end up with a duty). Considering only those countries with more than five claims, China is followed by the República Bolivariana de Venezuela (70 percent), Russia (66.7 percent), Taiwan (China) (60 percent), and Brazil (52.2 percent). The average success rate is 41 percent.

The main econometric results from Esquivel and Solis (2002) about the macro- and microeconomic determinants of Mexican AD filings are presented in table 4.8. ${ }^{34}$ The basic model considered various explanatory variables as determinants of $\mathrm{AD}$ filings by Mexico that might lead private firms to petition the UPCI for AD protection or that might affect the decisions of this organization because of the political consequences of industry-specific economic conditions. The chosen variables were the 
Table 4.7 Composition of AD/CVD Filings by Target Country, $1987-2000$

\begin{tabular}{|c|c|c|c|c|c|}
\hline Economy & Investigations & $\begin{array}{c}\text { Percentage } \\
\text { of } \\
\text { Investigations }\end{array}$ & $\begin{array}{c}\text { Duties } \\
\text { (Still on } \\
\text { Operation) }\end{array}$ & $\begin{array}{c}\text { Percentage } \\
\text { of } \\
\text { Duties }\end{array}$ & $\begin{array}{c}\text { Success } \\
\text { Rate }\end{array}$ \\
\hline Belarus & 2 & 0.85 & 0 & 0 & 0.0 \\
\hline Belgium & 2 & 0.85 & 0 & 0 & 0.0 \\
\hline Brazil & 23 & 9.82 & 12 & 11.58 & 52.2 \\
\hline Canada & 5 & 2.14 & 1 & 1.05 & 20.0 \\
\hline Chile & 2 & 0.85 & 0 & 0 & 0.0 \\
\hline China & 39 & 16.66 & 34 & 35.79 & 87.2 \\
\hline Colombia & 3 & 1.29 & 0 & 0 & 0.0 \\
\hline Denmark & 2 & 0.85 & 1 & 1.05 & 50.0 \\
\hline Estonia & 2 & 0.85 & 0 & 0 & 0.0 \\
\hline \multicolumn{6}{|l|}{ European } \\
\hline Union & 4 & 1.70 & 2 & 2.11 & 50.0 \\
\hline Germany & 7 & 3.00 & 1 & 1.05 & 14.3 \\
\hline Greece & 2 & 0.85 & 0 & 0 & 0.0 \\
\hline \multicolumn{6}{|l|}{ Hong Kong } \\
\hline (China) & 2 & 0.85 & 1 & 1.05 & 50.0 \\
\hline India & 2 & 0.85 & 1 & 1.05 & 50.0 \\
\hline Japan & 3 & 1.29 & 2 & 2.11 & 66.7 \\
\hline Kazakhstan & 2 & 0.85 & 1 & 1.05 & 50.0 \\
\hline Lithuania & 2 & 0.85 & 0 & 0 & 0.0 \\
\hline Netherlands & 2 & 0.85 & 2 & 2.11 & 100.0 \\
\hline \multicolumn{6}{|l|}{ Republic of } \\
\hline Korea & 9 & 3.84 & 1 & 1.05 & 11.1 \\
\hline Russia & 6 & 2.66 & 4 & 4.21 & 66.7 \\
\hline Spain & 6 & 2.66 & 3 & 3.16 & 50.0 \\
\hline Taiwan (China) & 5 & 2.14 & 3 & 3.16 & 60.0 \\
\hline Tajikistan & 2 & 0.85 & 0 & 0 & 0.0 \\
\hline Ukraine & 5 & 2.14 & 0 & 0 & 0.0 \\
\hline United States & 66 & 28.20 & 18 & 18.95 & 27.3 \\
\hline Uzbekistan & 2 & 0.85 & 0 & 0 & 0.0 \\
\hline Venezuela, R. B. de & 10 & 4.27 & 7 & 7.37 & 70.0 \\
\hline Others $^{\mathrm{a}}$ & 17 & 7.26 & 2 & 2.11 & 11.8 \\
\hline Total & 234 & 100 & 96 & 100 & 31.7 \\
\hline
\end{tabular}

Note: Success rate indicates the percentage of filings for which a duty is imposed.

ancludes Argentina, Armenia, Australia, Azerbaijan, Bulgaria," France, ${ }^{*}$ Georgia, Indonesia, Kyrgyz Republic, Lethonia, Malaysia, Moldova, Pakistan, Peru, South Africa, Turkey, and Turkmenistan (* indicates duty imposed).

Source: Esquivel and Solis (2002), based on data from UPCI (2001). 


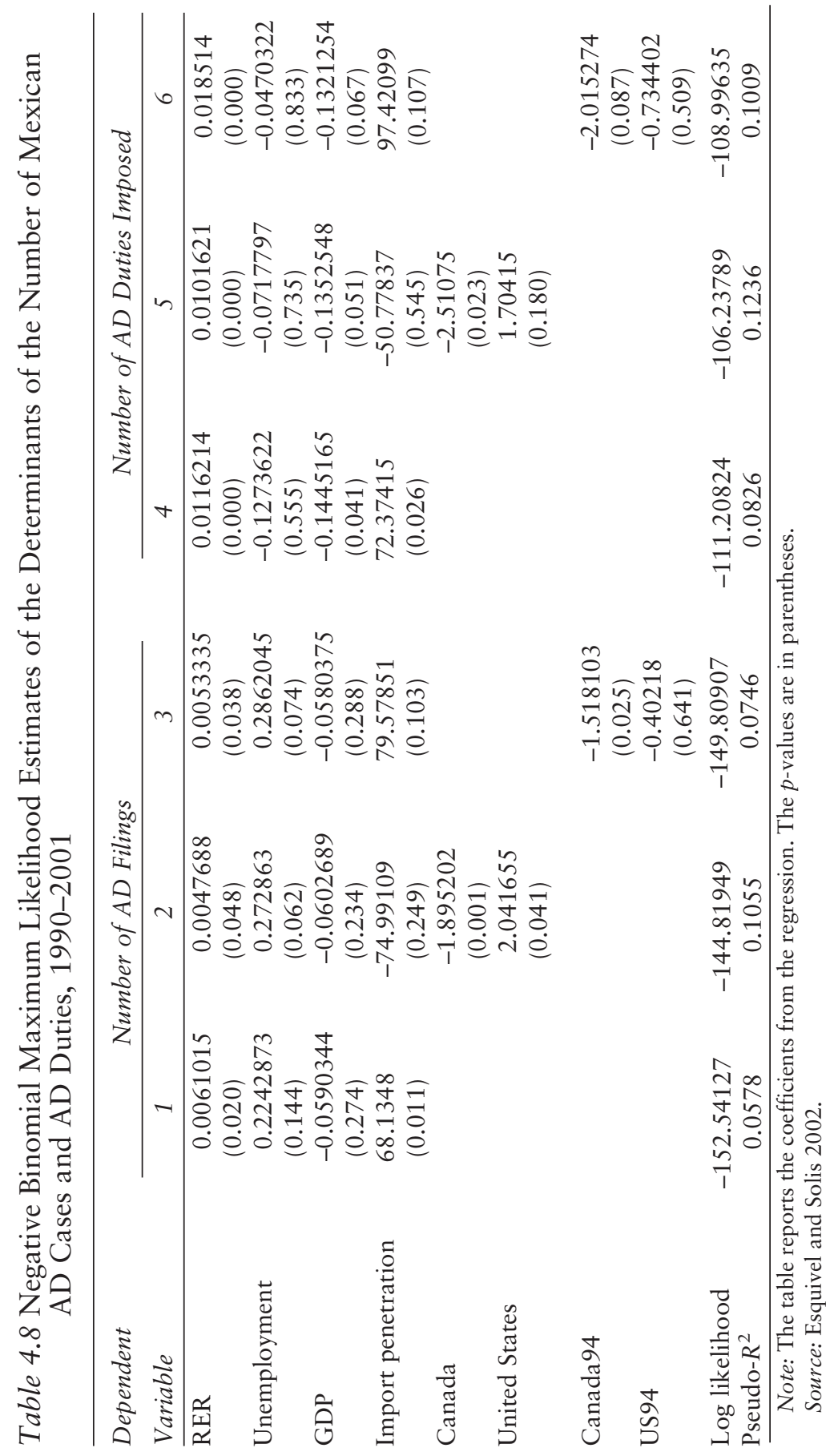


Table 4.9 Characteristics of Agricultural Support Programs in Mexico and the United States

\begin{tabular}{|c|c|c|}
\hline Characteristic & $\begin{array}{c}\text { Mexico: } \\
\text { PROCAMPO } \\
1994 \\
\end{array}$ & $\begin{array}{c}\text { United States: } \\
\text { FAIR implemented } \\
1996\end{array}$ \\
\hline Objective & $\begin{array}{l}\text { To compensate producers } \\
\text { for the elimination of } \\
\text { guarantee prices on } \\
\text { support crops }\end{array}$ & $\begin{array}{l}\text { To compensate producers } \\
\text { for the elimination of } \\
\text { deficiency payments }\end{array}$ \\
\hline Payment basis & $\begin{array}{l}\text { Average acreage in } \\
\text { support crops during } \\
1991-93\end{array}$ & $\begin{array}{l}\text { Acreage for which } \\
\text { deficiency payments were } \\
\text { received in any of the } \\
\text { past five years. Base } \\
\text { years were updated in } \\
2002 \text { extension. }\end{array}$ \\
\hline Supported products & $\begin{array}{l}\text { Wheat, maize, sorghum, } \\
\text { barley, rice, cotton, } \\
\text { beans, soybean, safflower }\end{array}$ & $\begin{array}{l}\text { Wheat, maize, sorghum, } \\
\text { barley, rice, cotton, oats }\end{array}$ \\
\hline Time profile & $\begin{array}{l}\text { Total of } 15 \text { years: first } 10 \\
\text { years fixed in real terms; } \\
\text { declining in final } 5 \text { years }\end{array}$ & $\begin{array}{l}\text { Program lapsed after } \\
\text { seven years but was } \\
\text { extended in } 2002 \text {. }\end{array}$ \\
\hline Payment limits & US $\$ 6,700$ per farm & US $\$ 40,000$ per farm \\
\hline $\begin{array}{l}\text { Restrictions on the } \\
\text { use of support- } \\
\text { crop land }\end{array}$ & $\begin{array}{l}\text { Land should be allocated } \\
\text { to support crops, but } \\
\text { since } 1996 \text { land can be } \\
\text { allocated to other } \\
\text { agricultural uses }\end{array}$ & $\begin{array}{l}\text { Land should be kept in } \\
\text { agricultural use (exclud- } \\
\text { ing fruits and vegeta- } \\
\text { bles); use must be in } \\
\text { compliance with existing } \\
\text { conservation plans }\end{array}$ \\
\hline Other features & $\begin{array}{l}\text { "Negotiated" prices in } \\
\text { effect for the first two } \\
\text { transition years of the } \\
\text { program; floor prices are } \\
\text { retained for maize and } \\
\text { beans }\end{array}$ & $\begin{array}{l}\text { Nonrecourse government- } \\
\text { guaranteed commodity } \\
\text { loans are retained in } \\
\text { modified form }\end{array}$ \\
\hline
\end{tabular}

Note: The upper limit for PROCAMPO payments is 100 hectares and the perhectare payment is currently 484 Mexican pesos, or approximately US\$6,700 (at 7.2 pesos/US\$). Following the 1994 devaluation, PROCAMPO payments were not fully adjusted to inflation.

Source: USDA 1996; SAGAR 1997.

relevant bilateral real exchange rates and imports over gross domestic product (GDP) or import penetration (lagged one year), which might lead domestic firms to file AD petitions with the UPCI and might lead the UPCI to find AD margins. Second, the authors considered variables 
that might have had additional direct effects on the UPCI decisions because of their political effects. Among these, the authors included the unemployment rate, value-added or GDP performance at the industry level, and other unobserved country effects (including dummies for Canada and the United States, as well as effects affecting those two countries in or after 1994).

Real exchange rate and import penetration are important determinants of both the number of filings and the number of positive findings by the UPCI, as shown across the six columns of table 4.8. In contrast, GDP performance and the unemployment rate alternate in significance, depending on the variable under analysis. In the case of $\mathrm{AD}$ filings, the relevant variable is the unemployment rate and GDP is never significant. For the case of $\mathrm{AD}$ duties, GDP performance is the key variable. In any case, the inclusion of dummy variables in the model shows a differentiated effect for Canada and the United States, depending on the period under analysis. Canada's effect is negative, whereas the United States' effect is positive for the entire period (1990-2000) but zero when considering the NAFTA years (1994-2000). We interpret these results as suggesting that NAFTA had a notable effect in reducing the U.S. vulnerability to Mexican AD actions, although the United States tends to be more vulnerable than other countries to such actions. As mentioned earlier, this is true only for the number of $\mathrm{AD}$ filings, and not for the number of positive findings, where countries such as China are significantly more vulnerable.

These results are interestingly different from those concerning Mexico's vulnerability with respect to U.S. action, which show that NAFTA has not had a significant impact on Mexico's vulnerability, although Mexico has always been less vulnerable than other countries. Thus these are exactly opposite to the results concerning U.S. vulnerability to Mexican AD actions.

\section{Policy Implications Regarding AD/CVD Activity Under NAFTA}

The findings discussed in the previous sections have important implications not only for Mexico but also for other countries from Latin America and the Caribbean that are implementing (Chile), will implement (Central America and the Dominican Republic), or will sign (Colombia, Ecuador, and Peru) FTAs with the United States. The results have implications for future FTA and WTO round negotiations because the Chapter 19 dispute settlement process was likely intended to reign in abuse of these laws by the United States. In both CUSFTA and NAFTA, the United States clearly tried to thwart any attempt by the partner countries to affect their application of AD/CVD laws. These intentions are 
now explicitly stated in the 2002 Trade Promotion Authority granted by the U.S. Congress to the Executive branch of government. The compromise solution of Chapter 19 binational dispute settlement procedures for $\mathrm{AD} / \mathrm{CVD}$ cases had the potential to affect $\mathrm{AD} / \mathrm{CVD}$ activity because it allowed for timely dispute settlements by panels representing both countries involved in the case to supercede appeals to national courts. A critical holdover, however, was limiting the Chapter 19 panels (as with the national appeals courts) to only rule on whether a country has appropriately applied its own AD/CVD laws and practices. Given sufficiently ambiguous laws about the practice of determining dumping, subsidization, and injury, a whole range of practices can be ruled consistent.

In addition, the panels have no ability to enforce judgments. Although government agencies from all three countries have mainly complied with remands from the panel, this process did not resolve the largest trade dispute it has faced, namely, the softwood lumber case with Canada that led to direct governmental negotiations. Some remands connected with U.S. cases against Canada have led to significant changes in judgments in a handful of cases, which may explain why there is some evidence of the effect of cumulative remands with respect to Canada. There are no such "successful" remands concerning initial U.S. AD/CVD cases against Mexico to date. In fact, a worry with the Mexican experience is the long delays in the dispute settlement process, which make it very unlikely it will affect U.S. behavior in the near future. Thus, although it may make government agencies more vigilant in maintaining consistency in how they apply their laws, Chapter 19 has little power to affect real change in AD/CVD laws and practices. This realization led Chilean negotiators to reject language similar to NAFTA's Chapter 19 in its recent FTA negotiations with the United States.

This begs the question of possible avenues that current and future partner countries may have to persuade the United States to reform or eliminate its $\mathrm{AD} / \mathrm{CVD}$ laws. One option is more aggressive retaliatory AD/CVD activity against the United States. Both Canada and Mexico have substantial enough trade volumes to be able to create effective retaliation. There are a number of reasons why this is not a good strategy. First, estimates reported by Blonigen (2002) showed that U.S. AD/CVD actions do not seem to be affected by AD/CVD activity in Canada and Mexico against the United States. Second, such strategies could just as easily lead to a trade war rather than an agreement to "disarm."

A second option is to make efforts to harmonize competition policies and push for folding antidumping policies into a common competition policy. Were $\mathrm{AD} / \mathrm{CVD}$ practices subject to the same strong criteria for action as current competition policy (at least in the United States), we would likely see almost the complete elimination of successful AD/CVD cases. However, this is exactly the problem. AD/CVD laws are explicitly 
devised to benefit only domestic producers, even at the expense of competitive markets and the welfare of consumers, which directly contradicts competition policy. Thus, limiting AD/CVD use through harmonization with competition policy is likely a very long and difficult road.

A final alternative may be to negotiate a new safeguards agreement with Canada and the United States and to agree to use safeguard actions rather than $\mathrm{AD} / \mathrm{CVD}$ laws. Safeguard protection allows for governments to impose temporary protection for a domestic industry, provided that imports are a significant cause of injury to the domestic industry. The explicit condition that safeguard actions are temporary is a definite improvement over $\mathrm{AD} / \mathrm{CVD}$ cases, because the United States currently assesses $\mathrm{AD} / \mathrm{CVD}$ from cases occurring as far back as the 1970s. In Mexico the only applicable "sunset" clause is the one that states that $\mathrm{AD} / \mathrm{CVDs}$ can be removed after five years if there has been no review of the case during that time span. In addition, safeguard actions require a more stringent test to determine that imports are a significant cause of injury, not just a nontrivial one. There is no required finding of dumping or subsidization for safeguard actions, but this criterion is virtually always passed anyway in AD/CVD cases. Not calculating dumping/subsidization also makes it more transparent that the action is political, rather than allowing it to fall under the guise of promoting "fair trade practices," despite having no economic basis. Finally, because safeguard actions must involve presidential action, they ensure that only nontrivial trade actions take place. This feature also forces leaders to consider the overall political implications of imposing taxes that hurt voters and other interested parties.

\section{Notes}

1. This zero-profit condition can be readily calculated from equation 4.5 in box 4.1 by setting Mexico's MFN textile tariff equal to its actual reported tariff of 18.84 percent and setting the cost share of textile inputs at the maximum possible ratio so that profits equal zero. This is the tariff reported by the Free Trade Area of the Americas (FTAA) Hemispheric Database maintained by the Tripartite Commission composed by the Inter-American Development Bank (IDB), the Organization of American States, and the Economic Commission for Latin America and the Caribbean.

2. This section borrows heavily from Cadot et al. (2002).

3. Technically, the ROO variable can be considered as predetermined, which implies that there is no correlation between the regressors and the equation's error term, hence ordinary least squares and weighted least squares estimates are unbiased. An equation determining ROOs on the basis of contemporaneous variables can be found in Estevadeordal 2000, but simultaneous estimation of these two in a recursive system would not alter the point estimates of (4.7).

4. The exercise we performed is as follows. In case (a), we used actual values of the PREF and ROO variables to predict the value of Mexico's exports to the 
United States. In case (b), we set PREF equal to $10 \mathrm{E}-13$ across the board and $R O O$ to a "low" value across the board. The first part of table 4.2 reports results for three values of $R O O: 1,2$, or 3 . The reason for not setting the $R O O$ variable to zero is that under NAFTA there is no tariff line with $R O O$ equal to zero, so that predicting the value of XUS (the dependent variable) so far out of the sample with nonlinear forms gives unreasonable results. Results based on setting $R O O$ equal to a higher value are more conservative but arguably less prone to prediction error. If anything, the bias that this introduces reinforces the point we are making because setting ROOs at a lower level would generate larger negative effects.

5. The Africa Growth and Opportunity Act also offered preferential treatment in the United States for textile and apparel imports from African countries. This is another reason why NAFTA textile and apparel preferences have been diluted.

6. It should be noted that the United States is a net exporter of textiles within NAFTA but not for the rest of the world.

7. Historically, Colombia has been a net exporter of textiles to the world. This situation changed slightly in the mid-1990s, but it was not a significant net importer of textiles by the late 1990s. In other words, Colombia is on the fringe between a net exporter and net importer of textiles. Shifting from the Andean Trade Promotion and Drug Eradication Act to NAFTA-type ROOs in the textile sector might make this economy recover its relative position in textile and apparel exports.

8. This section borrows heavily from Yúnez-Naude (2002).

9. The crops were copra, cotton seed, grain barley, rice, soy, sorghum, sunflower, and wheat (guaranteed prices for sesame seed were eliminated before this time). The exceptions were maize and beans.

10. Cotton, rice, and soy producers in selected regions were included in ASERCA's programs during some years, and from 1997 to 2000 marketing support for maize producers was added to the subsidy mix. For example, although the price of rice was fully liberalized in 1990, supports for rice producers were granted in 1996 because of a drop in its real price (ASERCA 1996).

11. A program of price coverage in the international markets for these crops plus cotton and maize was added to the indifference pricing plan. For example, during 1996 coverage for 91,920 metric tons of wheat and 1.7 million metric tons of maize was placed in the commodity exchanges of Chicago and New York (Zedillo 1996).

12. The following discussion emphasizes the agricultural agreement between Mexico and the United States because in the short and medium run major impacts of NAFTA have been concentrated in Mexico-U.S. trade.

13. In the agreement between Mexico and the United States, Mexico also included powdered milk.

14. Imports of beans are low because Mexico has been self-sufficient in the type of beans preferred by its population. This crop was included in the TRQ plan mainly because the farmers who produce beans have marketing problems and because beans are a major component of the Mexican diet.

15. An example is fresh tomatoes. From January 1994 to December 1998 there was a tariff of 3.3 U.S. cents per kilogram on fresh tomatoes entering the United States between July 15 and September 14. (This tariff was eliminated in January 1999.) The tariff charged by the United States on Mexican tomato imports from March 1 to July 14 and from September 15 to the end of February was eliminated in December 2003. In addition, Mexico's exports of tomatoes to the United States have a TRQ of 172,300 metric tons from November 15 to the end of February and of 165,500 metric tons from March 1 to June 14. Over-quota imports in the United States are charged the lower of the MFN tariffs in effect before NAFTA and the MFN rate in effect at the time of the over-quota trade. (Details are in SECOFI 1994.) Mexico's exports of avocados to the United States are a special case because 
they are subject to phytosanitary restrictions. Partial easing of avocado imports to some regions of the United States was implemented in 1997 and amplified in 2001 (Order 2002).

16. The relative prices of Mexican agricultural commodities fluctuated dramatically during this period because of wild fluctuations in the real exchange rate and because of international market conditions, such as the severe Asian financial crises of 1997-98.

17. See Prusa (2001) for analysis of the recent spread of AD/CVD laws and their use across WTO-member countries. Blonigen and Prusa (2003) provided an extensive survey of the academic literature on the economics of $\mathrm{AD}$ activity.

18. Although AD/CVD activity often involves narrowly specified import products, the high duties often imposed and other features of the administration of these programs can lead to quite significant welfare impacts. Gallaway, Blonigen, and Flynn (1999) estimated that U.S. AD/CVD programs cost the United States \$4 billion annually using 1993 data. This placed AD/CVD programs as second only to the Multi-fiber Agreement in terms of welfare costs to the United States.

19. This Chapter 19 review process of $\mathrm{AD} / \mathrm{CVD}$ actions by binational panels was separate from a more general dispute settlement mechanism for all NAFTArelated issues stipulated in Chapter 20 of CUSFTA and NAFTA.

20. The national courts of appeals for unfair trade cases are the U.S. Court of International Trade, the Federal Court of Canada, and the Federal Fiscal Tribunal for the U.S., Canada and Mexico.

21. See Giesze (1994) for more details on the historical evolution of Mexican $\mathrm{AD} / \mathrm{CVD}$ laws.

22. A small set of law journal articles and U.S. Government Accounting Office $(\mathrm{GAO})$ reports have observed a number of developments with respect to the operation of the binational review panels stipulated under Chapter 19. Gantz (1998), GAO (1997), Pippin (1999), and Vega-Canovas (1997) provided descriptive assessments of how well the binational panel system of Chapter 19 reviews has worked in fulfilling its stipulated goals. These issues will be discussed in more depth later in this chapter.

23. This section draws heavily from Blonigen (2002).

24. The primary focus on U.S. AD/CVD activity is because of data accessibility issues, as well as the fact that the United States is the largest market in NAFTA and the largest user of $\mathrm{AD} / \mathrm{CVD}$ laws.

25. This section borrows heavily from Esquivel and Solis (2002).

26. It is important to note that the alternatives were limited-or perhaps nonexistent. The use of tariffs and quotas is regulated by the WTO, whereas such other alternatives as escape clauses represent a high cost in terms of the lobbying and political power involved.

27. The Ley Reglamentaria del Artículo 131 de la Constitución Política de los Estados Unidos Mexicanos en Materia de Comercio Exterior (Article 131 of the political constitution of Mexico in matters of foreign trade) and the Reglamento contra Prácticas Desleales de Comercio Internacional (anticompetitive international trade law), respectively.

28. It should be noted that each country establishes its own AD/CVD policies according to general GATT/WTO principles. Such guidelines, however, are generally vague and thus leave each country's legislators to interpret them. However, a key criterion is that AD/CVD laws should allow some legal appeals or review mechanism.

29. International legislation classifies such subsidies into three groups: (a) nonactionable (subsidies that have no effect on international trade, such as health or education transfers-no duty is applied); (b) actionable (subsidies that are specific and either injure the domestic industry of another member [defined the same way as with antidumping duties], nullify, or impair benefits under GATT, or 
cause serious prejudice to the interests of another member-a duty may be applied); and (c) prohibited (direct transfers granted to increase exports-duties applied).

30. This practice is known as the lesser duty rule.

31. The following is not an exhaustive listing. For more details, see Unidad de Prácticas Comerciales Internacionales (1997).

32. For a more detailed description, see Leycegui (1997).

33. Although not included in the graph, Canada's filings also decreased after their peak in 1992.

34. Esquivel and Solis (2002) focused on Mexico's AD activity because AD cases completely predominate over CVD and even safeguards cases in Mexico. AD cases accounted for more than 90 percent of total cases during the period under study.

\section{References}

The word "processed" describes informally produced works that may not be commonly available through libraries.

ASERCA (Apoos y Servicios a la Comercialización Agropecuaria). 1994-2001. Claridades Agropecuarias. Mexico, D.F.

Baffes, John, and Jacob Meerman. 1998. From Prices to Incomes: Agricultural Subsidization without Protection? World Bank Research Observer 13 (2): 191-211.

Blonigen, Bruce. 2002. The Effects of CUSFTA and NAFTA on Antidumping and Countervailing Duty Activity. Office of the Chief Economist for Latin America and the Caribbean, World Bank, Washington, DC. Processed.

Blonigen, Bruce A., and Thomas J. Prusa. 2002. Antidumping. In Handbook of International Trade, eds. J. Harrigan and E. K. Choi. Oxford, UK: Blackwell Publishers.

Burfisher, M., Sherman Robinson, and K. Thierfelder. 1992. Agricultural and Food Policies in a United States-Mexico Free Trade Agreement. North American Journal of Economics and Finance 3: 117-39.

Cadot, Olivier, Jaime de Melo, Antoni Estevadeordal, Akiko Suwa-Eisenmann, and Bolormaa Tumurchudur. 2002. Assessing the Effect of NAFTA's Rules of Origin. Office of the Chief Economist for Latin America and the Caribbean, World Bank, Washington, DC. Processed.

Cadot, Olivier, J. de Melo, and M. Olarreaga. 2000. The Protectionist Bias of Duty Drawbacks. Journal of International Economics 59 (1): 161-82.

ERS (Economic Research Service of the U.S. Department of Agriculture). 1999. ERS NAFTA Report. WRS-99-1. Washington, DC. http://www.econ.ag.gov.

Esquivel, Gerardo, and Mario Solis. 2002. Antidumping Practices in Mexico. Office of the Chief Economist for Latin America and the Caribbean. World Bank, Washington, DC. Processed.

Estevadeordal, Antoni. 2000. Negotiating Preferential Market Access: The Case of the North American Free Trade Agreement. Journal of World Trade 34: 141-66.

Feinberg, Robert M. 1989. Exchange Rates and Unfair Trade. Review of Economics and Statistics 71 (4): 704-07.

Feinberg, Robert M., and Barry T. Hirsch. 1989. Industry Rent-Seeking and the Filing of "Unfair Trade" Complaints. International Journal of Industrial Organization 7 (3): 325-40. 
Finger, J. M., H. Keith Hall, and Douglas R. Nelson. 1982. The Political Economy of Administered Protection. American Economic Review 72 (3): 452-66.

Foster, William, and Alberto Valdés. 2001. Has Reform Failed Latin American Agriculture? A Review of Argentina, Chile, and Colombia. World Bank, Washington, DC. Processed.

Gallaway, Michael P., Bruce A. Blonigen, and Joseph E. Flynn. 1999. Welfare Costs of the U.S. Antidumping and Countervailing Duty Laws. Journal of International Economics 49 (3/4): 211-44.

Gantz, David. 1998. Resolution of Trade Disputes Under NAFTA'S Chapter 19: The Lessons of Extending the Binational Panel Process to Mexico. Law and Policy in International Business 29 (3): 297.

GAO (U.S. General Accounting Office). 1997. North American Free Trade Agreement: Impacts and Implementation (Testimony before the Subcommittee on Trade, Committee on Ways and Means, House of Representatives.) Washington, DC: U.S. Government Printing Office.

Giesze, Craig R. 1994. Mexico's New Antidumping and Countervailing Duty System: Policy and Legal Implications, as Well as Practical Business Risks and Realities, for United States Exporters to Mexico in the Era of the North American Free Trade Agreement. St. Mary's Law Journal 25: 885.

Jones, Kent. 2000. Does NAFTA Chapter 19 Make a Difference? Dispute Settlement and the Incentive Structure of U.S./Canada Unfair Trade Petitions. Contemporary Economic Policy 18 (2): 145-58.

Ju, Jiandong, and Kala Krishna. 1998. Firm Behavior and Market Access in a Free Trade Area with Rules of Origin. Working Paper 6857, National Bureau of Economic Research, Cambridge, MA.

Knetter, Michael M., and Thomas J. Prusa. 2000. Macroeconomic Factors and Antidumping Filings: Evidence from Four Countries. Working Paper 8010, National Bureau of Economic Research, Cambridge, MA.

Krishna, Kala, and A. Krueger. 1995. Implementing Free Trade Areas: Rules of Origin and Hidden Protection. Working Paper 4983, National Bureau of Economic Research, Cambridge, MA.

Krueger, Anne O. 1993. Free Trade Agreements as Protectionist Devices: Rules of Origin. Working Paper 4352, National Bureau of Economic Research, Cambridge, MA.

- 1997. Free Trade Agreements versus Customs Unions. Journal of Development Economics 54: 169-87.

- 1999. Trade Creation and Trade Diversion Under NAFTA. Working Paper 7429, National Bureau of Economic Research, Cambridge, MA.

Lederman, Daniel, Ana María Menéndez, Guillermo Perry, and Joseph Stiglitz. 2001. Mexico-Five Years After the Crisis. Paper presented at the Annual World Bank Conference on Development Economics 2000. World Bank, Washington DC.

- 2003. Mexican Investment after the Tequila Crisis: Basic Economics, Confidence Effects or Market Imperfections? Journal of International Money and Finance 22: 131-51.

Levy, Santiago, and Sven van Wijnbergen. 1994. Labor Markets, Migration, and Welfare: Agriculture in the North American Free Trade Agreement. Journal of Development Economics 43: 263-78. 
OECD (Organisation for Economic Co-operation and Development). 2000. Agriculture and Food: Producer and Consumer Support Estimates. OECD database: 1986-1999. Paris.

Orden, David. 2002. Partial Easing of U.S. Avocado Restrictions Through a Systems Approach to Pest. Paper presented at the Eighth Agricultural and Food Policy Information Workshop, Puerto Vallarta, Mexico, March.

Pippin, Kenneth J. 1999. An Examination of the Developments in Chapter 19 Antidumping Decisions Under the North American Free Trade Agreement (NAFTA): The Implications and Suggestions for Reform for the Next Century Based on the Experience of NAFTA After the First Five Years. Michigan Journal of International Law 21 (1): 101-30.

Porrúa, Miguel A. 1994. Fracciones arancelarias y plazos de desgravación. Secretaría de Comercio y Fomento Industrial (SECOFI), Mexico, D.F.

Prusa, Thomas J. 1992. Why Are So Many Antidumping Petitions Withdrawn? Journal of International Economics 33 (1/2): 1-20.

- 2001. On the Spread and Impact of Anti-dumping. Canadian Journal of Economics 34 (3): 591-611.

Rodríguez, Peter L. 2001. Rule of Origin with Multistage Production. World Economy 2: 201-20.

Sadoulet, Elisabeth, Alain de Janvry, and Benjamin Davis. 2001. Cash Transfer Programs with Income Multipliers: PROCAMPO in Mexico. FCND Discussion Paper 99, International Food Policy Research Institute, Washington, DC.

SAGAR (Secretaría de Agricultura, Ganadería y Desarrollo Rural). 1997. Programas y Proyectos en Apoyo al Campo. Mexico, D.F., July 1996.

Shagam, S., and D. Plunkett. 1997. Tariff Rate Quotas Administration in Mexico: 1994-97. Paper presented at the Annual Meeting of the International Agricultural Trade Research Consortium, San Diego, CA, December.

UPCI (Unidad de Prácticas Comerciales Internacionales). 1997. Apéndixe Estadístico, Secretaría de Economía, Mexico, D.F.

— 2001. Apéndixe Estadístico, Secretaría de Economía, Mexico, D.F.

USDA (United States Department of Agriculture). 1996. 1996 FAIR Act Frames Farm Policy for 7 Years. Agricultural Outlook Supplement (April).

Vega-Canovas, Gustavo. 1997. Disciplining Anti-dumping in North America: Is NAFTA Chapter Nineteen Serving Its Purpose? Arizona Journal of International and Comparative Law, 14: 479.

Yúnez-Naude, A. 2002. Lessons from NAFTA: The Case of Mexico's Agricultural Sector. Office of the Chief Economist for Latin America and the Caribbean, World Bank, Washington, DC. Processed

Yúnez-Naude, Antonio, and Fernando Barceinas. 2003. Los Impactos del TLCAN (NAFTA) en el sector agrícola de México. Department of Economics, Colegio de Mexico, Mexico City. Processed.

Zedillo, Ernesto. 1996. Governmental Reports by the President of the Republic, Mexico, D.F. 



\section{5 \\ Factor Markets}

ViRTUALly BY DEFINITION, THE North American Free Trade Agreement (NAFTA) would seem to be about trade, evoking images of changes in the patterns and volumes of merchandise exchange among countries. But both the motivations for the treaty and much of the heated debate over its possible effects have focused not on the goods that are traded but on the factors that produce them, particularly capital and labor.

Theoretical discussions of trade liberalization typically treat the two factors similarly as two internationally immobile algebraic arguments in a production function. The key prediction of the Heckscher-Ohlin framework is that liberalizing trade should cause a degree of convergence of the returns to capital and wages in the two countries and, if the countries are not too distinct, their complete equalization-although the conditions required for such a result are admittedly stringent. This reflects a more efficient use of factors in both countries. Hence, the degree of integration not only of product markets but of factor markets as well, as measured by returns to capital or wages, is of interest in understanding the impact of the treaty.

Beyond such basic tests of integration, however, the intrinsic differences in the two factors demand individual approaches that require stepping away from basic trade theory. To begin, part of the motivation for NAFTA was to boost the confidence of foreigners investing in plant and equipment in Mexico-that is, to promote the flow of foreign direct investment (FDI). This was motivated in part by the desire to decrease the movement of the other factor, labor, across the borders into the United States. Thus, from the beginning the goal of increased flows of goods was inextricably bound up with that of altering the flows of factors, although in opposite ways.

A second and arguably more critical distinction between the two factors lies in the simple truth that labor is human. Convergence of wages toward U.S. levels not only represents greater efficiency but also implies a higher standard of living for Mexican workers. Alternatively, those people who 
are less optimistic about the impact of free trade are concerned that NAFTA, or globalization more generally, may have a detrimental effect on the quality of jobs and hence the quality of life that workers enjoy.

Dealing thoroughly with both topics in all their particulars is beyond the scope of one chapter. What we offer here is a selective overview of the evidence available to date, what it suggests we may expect over the near future, and what complementary policies may be required to ensure that NAFTA attains its potential. The first half of the chapter examines the evidence of greater financial integration and the determinants of capital flows, with a particular focus on FDI. The second section explores the impact on labor market integration and trends in the quality of work. We then sketch some aspects of how labor market legislation might be revisited to better serve both workers and employers in a more competitive global environment.

\section{Financial Integration: What Was or Should Have Been Expected from NAFTA?}

Changes in trade patterns resulting from a free trade agreement (FTA) should be expected to be associated with modifications in the forms, sources, cost, and levels of financing. There is a variety of reasons for this. As already noted, conventional trade theory predicts that unrestricted goods mobility should lead to the equalization of the return on capital across countries. At a more mundane level, foreign corporations may want to use countries belonging to trade agreements as export platforms, domestic firms may find external financing a more appropriate hedge against foreign exchange risk when their exporting activity increases, foreign banks may be more willing to supply such external financing to local firms as their earnings become less dependent on domestic activity, and so on. Furthermore, in the case of NAFTA there are specific reasons to expect changes in external financing patterns, given that the agreement also contained specific provisions for liberalizing the rules that govern international investment within the region in addition to trade.

On both accounts NAFTA should be expected to increase Mexico's financial integration with its partners in the trade agreement and the world economy in general. By "financial integration" here we mean the process through which a country's financial markets become more tightly linked with those abroad. It typically involves the elimination of legal and regulatory barriers to capital flows and foreign participation in domestic firms and financial markets. Its result is an increased volume of cross-border financial flows and financial services and eventually the 
equalization of the prices of assets of similar risk and return characteristics located at home and abroad.

Ideally we would like to measure the degree of financial integration by the yardstick of price equalization. However, the information necessary to do so is largely unavailable, in part because the bulk of assets is often not traded in organized markets (e.g., the equity of most firms in Mexico) and because it is difficult to find significant volumes of assets with similar characteristics to perform comparisons of their prices at home and abroad. The main exception is that of short-term assets such as money market funds and demand deposits, but these are not very informative about the return on long-term assets such as productive capital, which from the perspective of income convergence should be our main concern. ${ }^{1}$ For these reasons, in this chapter we shall focus instead on the observed changes in Mexico's external financing flows after NAFTA, paying particular attention to foreign investment.

For many analysts the "dynamic effects" of FTAs through their impact on international investment flows are as important as (or even more important than) the static effects on trade of goods and services. Indeed, in the case of Mexico many observers view such impact on investment flows as the main purpose of NAFTA. In this view the objective of NAFTA was not so much further liberalizing trade ${ }^{2}$ as it was boosting private sector confidence in Mexico and creating a legal and economic environment hospitable to foreign investors. ${ }^{3}$

How big an impact on FDI should result from NAFTA? The European Economic Community/European Union (EEC/EU) experience offers some lessons in this regard. The EU accessions of Portugal and Spain in 1986 were accompanied by an FDI boom. Between 1980-85 and 1986-92 investment inflows rose by a factor of eight in Spain and a factor of six in Portugal (Kehoe and Kehoe 1994). However, the boom was largely temporary: by the mid-1990s the ratio of FDI to gross domestic product (GDP) was roughly the same as in the years prior to accession. This time pattern of FDI flows probably reflects a once-and-for-all reallocation of foreign investors' portfolios toward Spain and Portugal. It is important to note, however, that such reallocation was not an automatic result of EU accession. This is shown by the experience of Greece, whose entry into the EU in 1981 was not accompanied by any significant changes in FDI inflows-a fact that has been widely attributed to its poor policy framework in those years (see box 5.1).

The lesson from southern Europe, therefore, was that as long as sound policies prevailed Mexico could expect a boom in foreign investment following its entry into NAFTA, at least for a period of several years. But there are reasons why the FDI rise could be more modest than those witnessed in the Iberian countries (see Berzosa 2000 and Oyarzún de la Iglesia 2000). First and foremost, as a free trade area NAFTA was 


\section{Box 5.1 The FDI Impact of EEC/EU Accession}

The experience of southern Europe is suggestive of the potential of an FTA to produce increased capital inflows. In the cases of Portugal and Spain, entry into the EU in 1986 was accompanied by an FDI boom. Over 1980-85 Spain's FDI inflows averaged around 1.5 percent of GDP; by 1990 the figure was 3.0 percent. Similarly, FDI to Portugal rose to more than 4.0 percent of GDP (figure below). More than two thirds of this capital originated in other EU countries.

\section{EEC Accession and FDI in Greece, Portugal, and Spain}

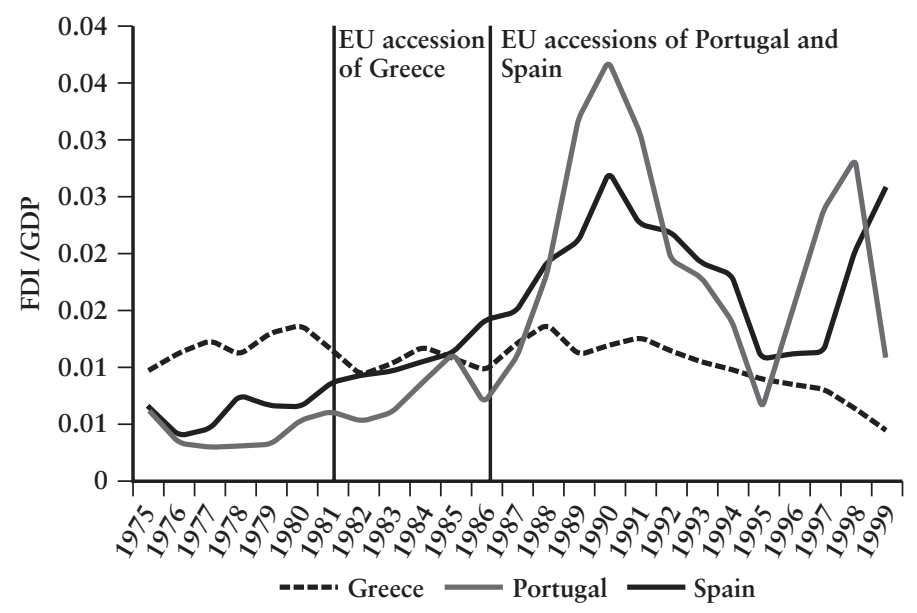

Source: World Development Indicators.

As the figure shows, however, the boom was not permanent: by the mid-1990s, the ratio of FDI to GDP had returned roughly to the levels it occupied prior to accession. Furthermore, this pattern of rise and fall is not the result of global trends in worldwide FDI; indeed, the same pattern is observed if one looks instead at the share of Portugal and Spain in world FDI inflows. This suggests that a stock adjustment took place after these countries joined the EU, with world investors rebalancing their portfolios in favor of Portugal and Spain in a process that lasted several years.

The figure also presents the case of Greece, which joined the EU in 1981. Unlike the situations in Portugal and Spain, FDI inflows showed 


\section{Box 5.1 (continued)}

little change in Greece, a fact that has been attributed to Greece's distorted policy environment in the 1980s (Baldwin and Seghezza 1998). This serves as a reminder that membership in a regional integration initiative is no guarantee of increased FDI.

more limited in scope than was the European Community, which in 1986 already involved a closer integration as a customs union and has continued to evolve toward an even deeper integration, including through the unification of labor markets, the coordination of macroeconomic policies, and the adoption of a common currency. In addition, the European Community also had a series of compensatory policies in favor of its poorest members, and these policies (such as those targeting infrastructure) were complementary to private investment.

Moreover, NAFTA contained specific provisions for the liberalization of international investment within the region. The rules governing foreign investment in Mexico, as stipulated in the Foreign Investment Law of 1973, were quite restrictive, with a number of productive sectors closed to foreign investors and strict limits on foreign participation in most others. The new legislation approved in 1993 adopted some key principles for the treatment of foreign investment, including in particular national treatment and most-favored-nation privileges for any investor residing in North America, which were expected to encourage the decision to establish production facilities in Mexico by firms headquartered in Canada and the United States. The Foreign Investment Law of 1993 effectively opened to foreign investors the majority of economic sectors, with a few significant exceptions (see box 5.2).

The next sections review the changes in Mexico's pattern of external financing after NAFTA, with particular attention to FDI. ${ }^{4}$ Changes in financing can be examined both from an aggregate perspective and from the viewpoint of individual firms. We first document the changes in the broad patterns of aggregate capital flows that coincided with the incorporation of Mexico into the free trade area. Because some of these changes are not particular to the case of Mexico, we present the results of the statistical analysis of an international data set suggesting that free trade agreements have promoted foreign investments elsewhere too. We then shift the focus to the individual firm level to examine the new financing opportunities that may have become available to firms following NAFTA. This work is of a more tentative nature because of the scarcity of appropriate firm-level data.

In chapter 2 we noted the difficulty in identifying the impact of NAFTA on Mexico's economic performance in recent years, partly as a result of the 


\section{Box 5.2 The Investment Chapters of NAFTA}

Foreign investment in Mexico had been significantly restricted under the law of 1973, which was written when Mexico was still under the framework of the import substitution doctrine of the postwar period. The law prohibited or limited foreign investment in a number of key sectors of the economy, which in some cases were reserved for the state (oil, electricity, railroads, and telegraph) and in others for Mexican citizens (air transportation, distribution of gas, forestry, and radio and TV). For the remaining sectors the 1973 law gave the government broad discretionary powers to limit foreign ownership to 49 percent of the capital.

In December 1993 a new foreign investment law was passed that took into account the investment framework laid out by NAFTA. The free trade agreement was respectful of the state monopolies established in the Mexican Constitution-emphatically, state control of the oil and electricity industries-but improved significantly the relative standing of foreign investors in Mexico and expanded the areas where they could participate. The key principles incorporated in the free trade agreement (Serra Puche 1992) were the following:

1. The most-favored-nation principle, which ensured that no investor from outside North America would be granted benefits exceeding those available to North American investors.

2. The national treatment principle, which guaranteed that there would be no discrimination among investors from each one of the three members of NAFTA. Combined with the above principle, this means that NAFTA residents are entitled to the best treatment available in each one of the NAFTA countries.

3. The absence of trade-related performance requirements for foreign investors.

4. The freedom to buy foreign exchange and to transfer funds across countries (royalties, profits, and dividends).

There were exceptions (in some cases temporary) to these principles. For example, for a period of 10 years the automobile industry in Mexico would continue to be subject to net export performance requirements. Also, for a period of 6 years, there would be a limit on foreign ownership of firms producing auto parts and components. ${ }^{1}$ The banking sector was also to remain subject to rules imposing narrow limits on foreign ownership of individual banks and on foreign participation in the banking industry as a whole for 6 years. Even after that period, safeguards could be invoked to impose new limits on foreign ownership. The original liberalization schedule for this sector, however, had to be accelerated to facilitate the recapitalization of banks after the crisis of 1995. During the following years a series of legal changes finally resulted in the full liberalization of foreign ownership in the commercial banking system. As a 


\section{Box 5.2 (continued)}

result, entry by international banks injected significant capital into the financial system, culminating with the US $\$ 12.5$ billion (more than 2 percent of GDP) sale of Banamex in 2001. By the late 1990s foreign banks held a substantial fraction (some 25 percent) of overall banking system assets, greater than five times more than they held in 1994.

The new foreign investment law of 1993, although preserving limits on foreign ownership, was more liberal than the 1973 law. It adopted the logic that, unless otherwise determined in the law, foreign investors could participate in any proportion in the ownership of Mexican corporations. As of 2002 the exceptions, other than those corresponding to state monopolies, concern mainly the retail sale of gasoline, passenger land transportation, credit unions, development banking, and radio and TV other than by cable, which are reserved for Mexicans. The law also limits to 49 percent or less the foreign stake in firms operating in the areas of insurance, air transportation, explosives, fishing, and telephony. In other areas, such as private education, sea shipping, and the operation of railroads, airports, and maritime ports, foreign investment is allowed to exceed 49 percent with approval by the National Commission for Foreign Investments. To allow a measure of compromise in some of these areas, the 1993 law created the figure of "neutral investment." Neutral investment is foreign investment in nonvoting shares and it does not count in the computation of the proportion of a firm owned by foreign investors. ${ }^{2}$

\section{Notes}

1. Car makers had to generate 80 percent of the foreign exchange they required for their imports.

2. Dussel et al. (2002) observed that information on neutral investment is difficult to obtain because it is not reported in official statistics as foreign investment. This has given rise to some pressure to eliminate this form of investment by foreigners.

short time elapsed since the passage of the treaty and its coincidence in time with the Tequila crisis. In the case of Mexico's financing patterns, the task is even more challenging. In the 1990s there were significant events and structural changes in the economies of Mexico and the world, with important implications for capital flows. A number of key developments with major financial repercussions took place in Mexico: the restructuring of Mexican sovereign debt under the Brady deal in 1990, the government's privatization program (including the sale of commercial banks), the process of financial liberalization started in the early 1990s, the exchange rate collapse of 1994 and the adoption of a floating exchange rate regime, and the banking crisis of 1995 with its aftermath, which likely prompted Mexican agents to look for alternative financing sources abroad. At the same time a global trend toward intensified international financial flows 
was at work, including a generalized movement toward more investmentfriendly policies and more open markets in a large number of countries, which must have helped channel foreign funds into countries such as Mexico. In the analysis below we attempt to control for these changing domestic and global factors by taking into consideration the domestic and international contexts and by using a comparative international perspective.

\section{Trends in Mexico's Aggregate External Financing in the 1990s}

Mexico's capital account and stock market had already been significantly liberalized by the early 1990s. Cross-country studies rank Mexico in the early 1990s among the emerging markets with lower capital account barriers, and liberalization of the stock market had taken place in 1989 (see Bekaert and Harvey 1998; Kaminsky and Schmukler 2000). As noted earlier, however, significant barriers to foreign direct investment remained prior to 1993.

In the 1990s there were major changes in the pattern of capital flows to Mexico. The volume of net inflows rose significantly relative to the 1980s, especially in the case of flows accruing to the private sector. Furthermore, their composition also changed markedly, with FDI becoming by far the leading source of external financing.

Figure 5.1 shows the time pattern of major components of private capital flows to Mexico. Total private capital flows rose significantly in the 1990s, and especially in 1991-93, reflecting the record-high current account deficit of those years. After dropping sharply at the height of the Tequila crisis of 1995 (during which they nevertheless remained positive), net private flows resumed an upward trend in $1996 .{ }^{5}$

The changing composition of private capital flows is also apparent from figure 5.1. The pre-NAFTA years of the 1990s were characterized by booming portfolio equity and FDI flows and by significant borrowing by both bank and nonbank agents. In contrast, the late 1990s saw a collapse of portfolio equity and bank borrowing, while FDI continued to boom and, to a more modest extent, so did other loans. ${ }^{6}$

How do these changes in the patterns of capital flows relate to the anticipation and/or the passage of NAFTA? It is important to observe that similar trends were at work globally. ${ }^{7}$ Prior to 1989 no developing country received significant amounts of foreign portfolio investment. But in the first part of the 1990s portfolio investment into many developing economies, particularly in Latin America, grew dramatically, with Mexico as one of the leading host countries. ${ }^{8}$ As in Mexico, however, portfolio equity flows to developing countries then declined sharply in the second half of the 1990s. In turn, loan flows showed a similar pattern of rise and decline over the decade. 
Figure 5.1 Mexico: Main Components of Capital Flows to the Private Sector

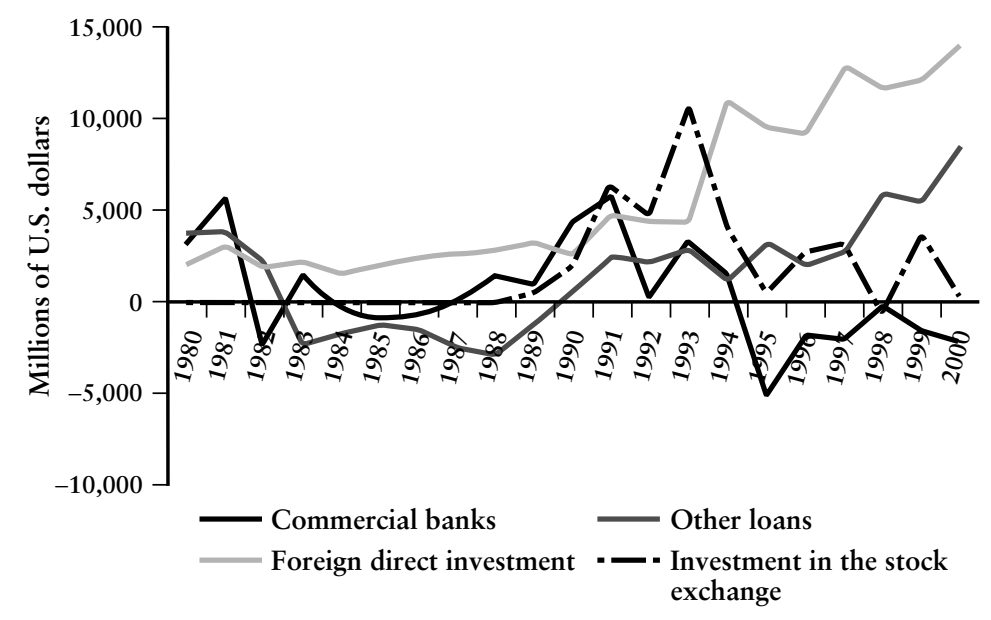

Source: Banco de México.

Likewise, the steady increase in FDI to Mexico was part of the global rise in FDI flows to developing countries during the 1990s, which again was particularly significant in the case of Latin America. ${ }^{9}$ FDI flows to Latin American countries rose from an average of less than US\$10 billion in the late 1980 s to nearly US $\$ 100$ billion in the late 1990 s. Although Mexico was one of the prime FDI destinations in Latin America in the 1990s, other countries in the region, such as Argentina and Brazil, attracted similarly large or even larger absolute and/or relative volumes of FDI (table 5.1).

However, Mexico appears to have been running ahead of other emerging markets because its FDI inflows showed a steep increase already in 1994, in contrast with the more gradual increase seen in FDI flows going elsewhere in Latin America. Indeed, Mexico's share of global FDI flows to developing countries peaked in the early 1990s and then fell in the late 1990s (see the middle block of table 5.1). This reflects in part the different timing and scope of privatization across the region, which attracted considerable volumes of foreign investment. By 1994 Mexico had completed its main privatization transactions. ${ }^{10}$ In contrast, privatization activity remained important in Argentina and Brazil long after that. Furthermore, the scale of the Mexican privatization program, large as it was, was far smaller than those of Argentina and Brazil. 


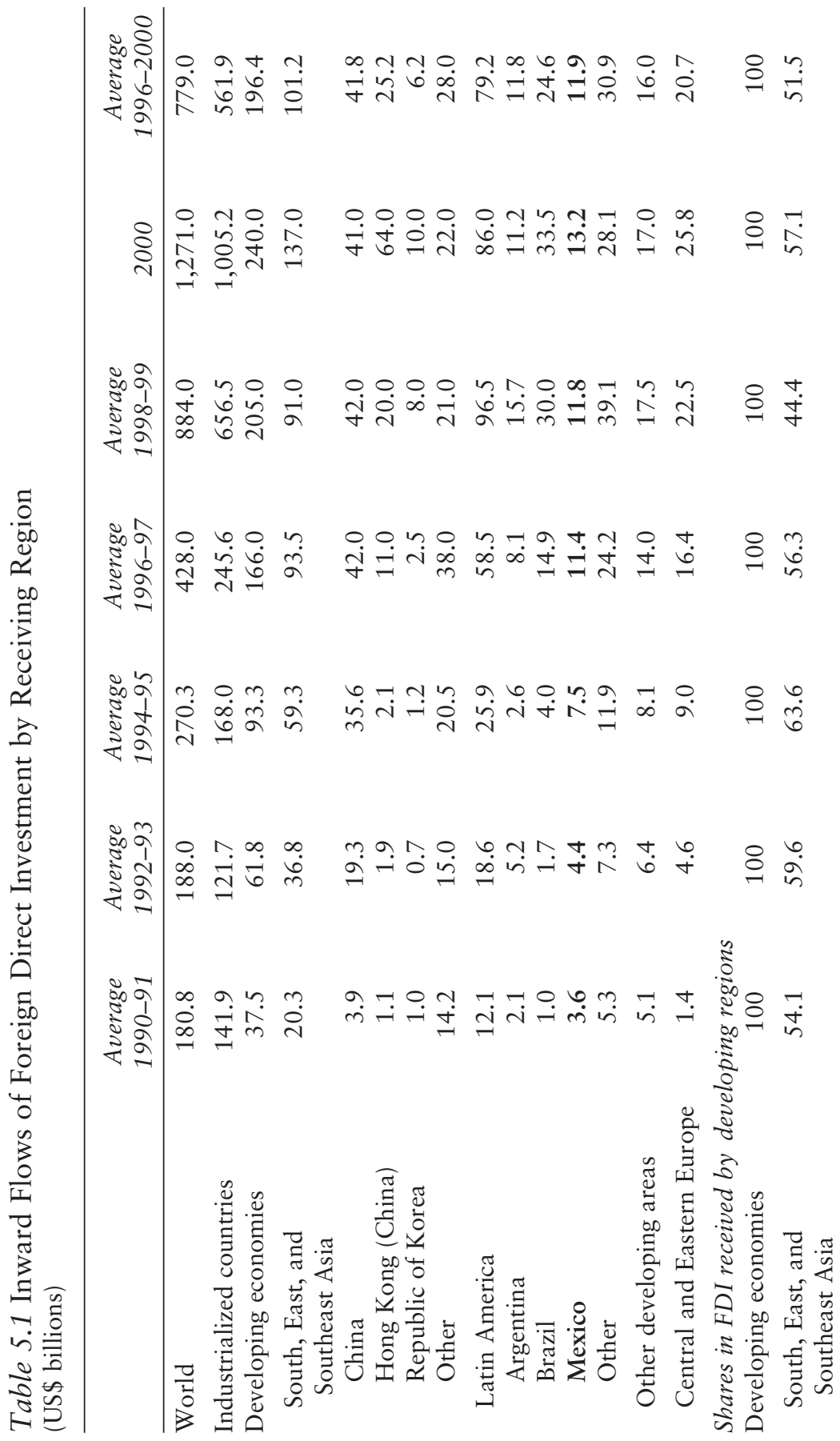




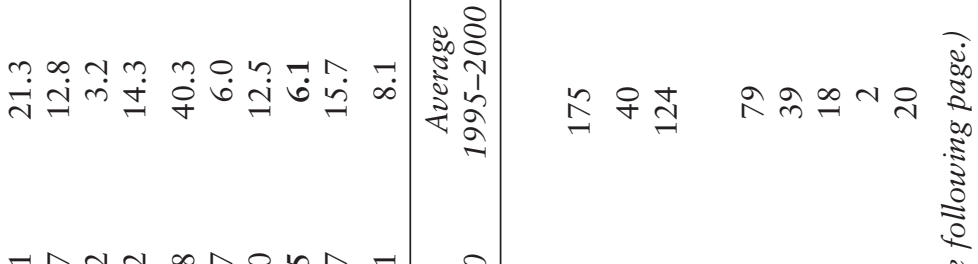

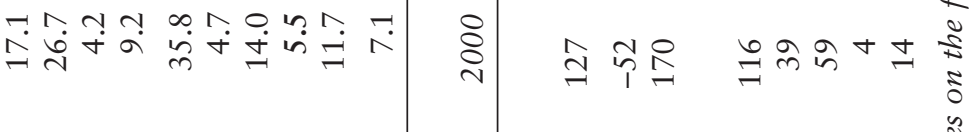

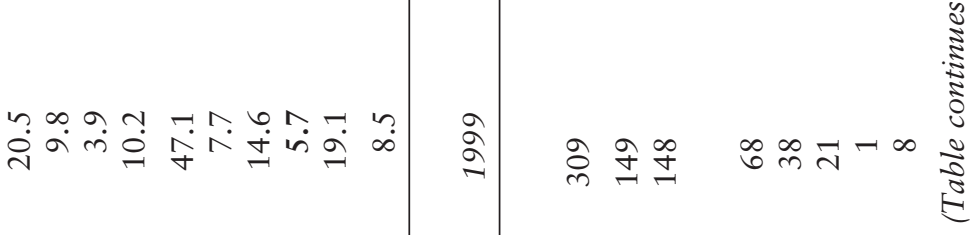

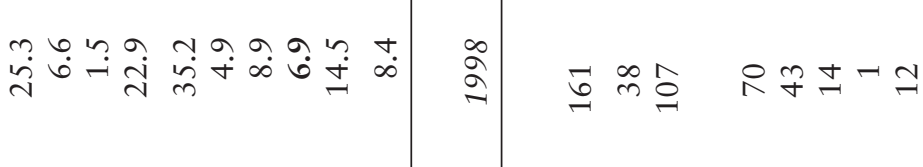

$$
\begin{aligned}
& \text { ming }
\end{aligned}
$$

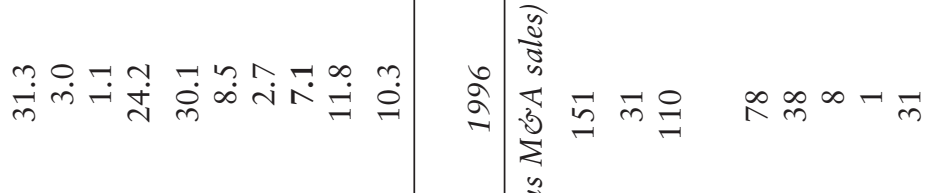

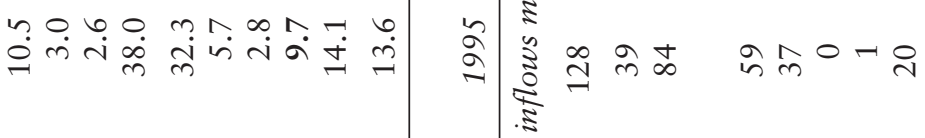

$$
\begin{aligned}
& \text { 裹总 }
\end{aligned}
$$

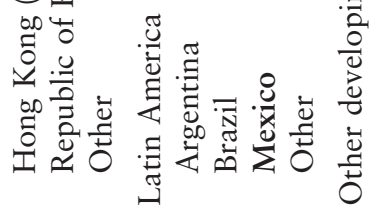




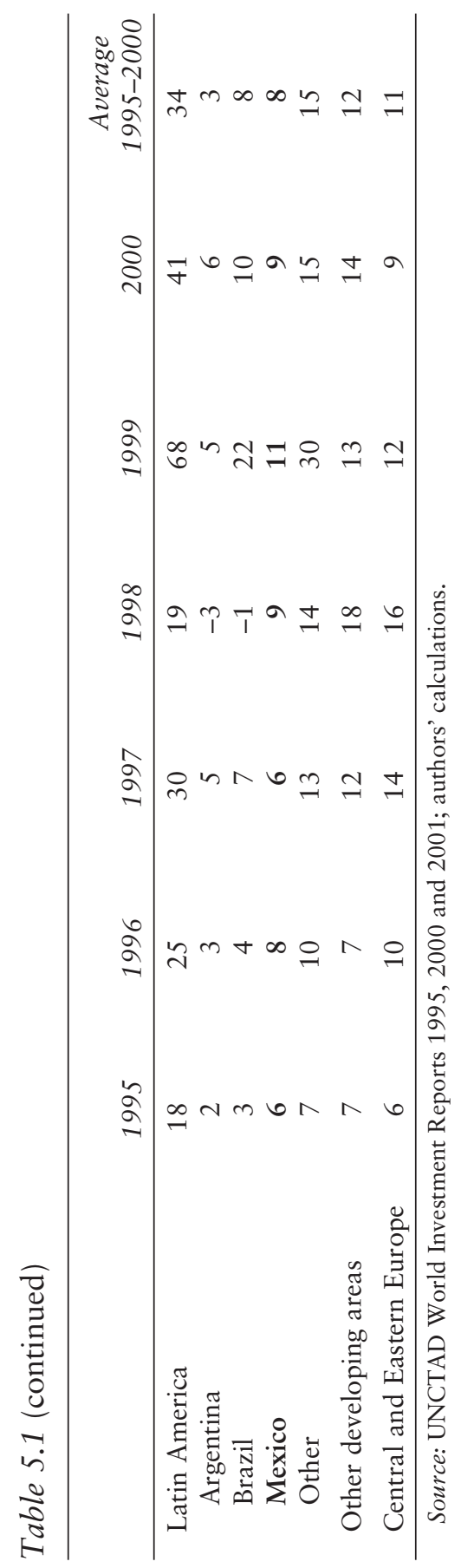


The relatively limited role of privatization transactions in Mexico's total FDI inflows reflects a more general phenomenon, namely that cross-border mergers and acquisitions (M\&As) —one of whose components is privatization FDI-played a much more modest role in Mexico than in the rest of Latin America. Cross-border M\&A flows to Latin American countries, which were virtually negligible in the 1980s, experienced a spectacular increase in the 1990 s, to exceed 50 percent of total FDI inflows in the late 1990s. ${ }^{11}$ In the case of Mexico, cross-border M\&As accounted for less than one fourth of FDI inflows. Indeed, if we look at the "greenfield" (that is, non-M\&A) component of FDI, Mexico's flows were on par with or even above those received by other major Latin American economies (see the bottom portion of table 5.1).

The increase in FDI to Mexico after the passage of NAFTA included a major rise in flows from North American sources. However, the rise in FDI from North America did not involve an enhanced role of Mexico as host for investors based in Canada and the United States. As figure 5.2 shows, Mexico's share in U.S.-based investment remained remarkably constant, over the 1990s, at around 5 percent of the total. ${ }^{12}$ In contrast, the share of the rest of Latin America declined sharply. In

Figure 5.2 U.S. Investment Abroad by Receiving Region

\section{Percent}

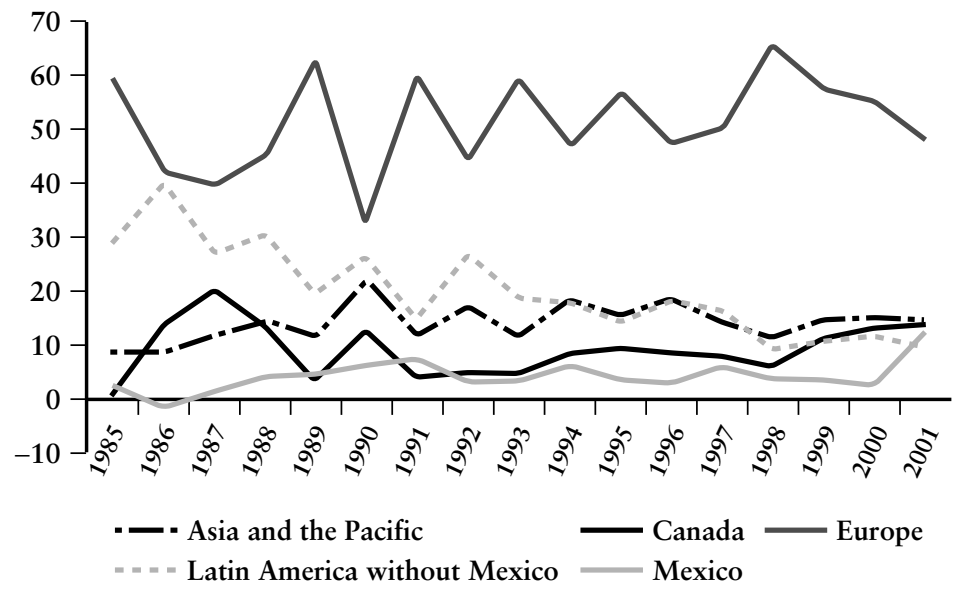

Source: U.S. Department of Commerce. 
this regard NAFTA might have prevented Mexico from joining this downward trend.

If global trends contribute to explain much of the observed pattern of capital flows to Mexico in the 1990s, local factors played no small role. The most prominent one was the liberalization and eventual collapse of the banking system, which was largely responsible for the changing nature of external borrowing over the decade. As figure 5.1 shows, the early 1990s were characterized by large volumes of external borrowing by banks-trends that were reversed in the late 1990s and replaced by an increasing recourse to external loans by nonbank agents.

This pattern is easy to understand in the light of the main events that affected the banking system in the 1990s. The liberalization of the banking industry in the early $1990 \mathrm{~s}^{13}$ enhanced the role of domestic banks in the private credit market. As part of the process, banks borrowed heavily abroad to lend to the private nonbank sector, including large amounts of dollar-denominated loans to domestic firms with no significant sources of foreign-currency income. Whereas banks' foreign currency liabilities were hedged on paper, they were not hedged in reality, and the collapse of the peso at the end of 1994 generated a major banking crisis as debtors and then their banks became insolvent.

Bank credit to the private sector has yet to recover from the crisis. ${ }^{14}$ Commercial banks' assets fell drastically, and credit to the private sector shrank from 25.0 percent of GDP in 1996 to 6.6 percent in 2000. By mid-2001 virtually half the bank loans in good standing were owed by the public sector, including the government and the deposit insurance agency (see González-Anaya and Marrufo 2001 and Serrano 2001). Furthermore, the collapse of bank credit prompted private agents to look for new sources of financing, including direct external borrowing and suppliers' loans. Hence, the result was an increase in the demand for external credit by Mexican residents, which undoubtedly contributed to the behavior of external capital flows (especially direct external borrowing) described above. However, it is very difficult to quantify the influence of these demand factors on the evolution of capital inflows.

On the whole, therefore, the changing patterns of capital inflows to Mexico appear to agree fairly well with global trends and major local developments unrelated to NAFTA. This, of course, does not mean that the treaty had no impact. Indeed, the timing of some major changes in capital flows suggests that they may have been affected by the anticipation and passage of NAFTA. This is especially so in the case of FDI, which shows an early increase in 1991 likely related to expectations of passage of the treaty, and an even larger jump in 1994 coinciding with the actual implementation of the agreement. ${ }^{15}$ 


\section{The Impact of NAFTA on Foreign Direct Investment}

What was the contribution of NAFTA to the FDI boom of the 1990s? From an analytical perspective an FTA affects both the profitability and the risk from investing in member countries. However, the relative profitability of alternative investment locations within the FTA is also affected in a way that depends to a large extent on whether investment flows are horizontally or vertically motivated. Horizontal FDI is aimed at serving the local market of the host country and is often motivated by trade costs such as transportation and tariffs. Vertical FDI is typically aimed at exporting the production to third countries or back to the source country and seeks to exploit a cost advantage of the host country. In the case of horizontal ("tariff-jumping") FDI, an FTA tends to discourage investment because the (tariff-inclusive) cost of serving the local market from other locations within the FTA declines. For the same reasons FTAs encourage vertically motivated FDI. In the case of Mexico there is evidence that a major fraction of FDI is vertically motivated (Venables and Winters 2002).

A specific aspect of NAFTA relevant to investment location decisions was the adoption of rules of origin for determining which goods could benefit from the preferences established by the treaty. These rules, which vary across goods (see chapter 4), provided new incentives for the location of investments in the NAFTA region in general and Mexico in particular, in those industries where existing levels of regional integration were below the threshold levels determined by the rules.

But the effect of FTAs on the perceived riskiness of investment-the so-called credibility effect-can be even greater than the profitability effect. Although the term "credibility" is somewhat vague, in the present context it encompasses three different things: ${ }^{16}$

1. the FTA's locking-in effect of trade policies

2. the locking-in effect of broader reforms (ranging from regulation and competition policies to property rights, contract enforcement, and macroeconomic stability)

3. the guarantee of access to partners' markets. ${ }^{17}$

Different preferential trade arrangements entail different combinations of the three elements. For example, EU accession is viewed by a majority of observers as having significant effects in all three dimensions, and particularly in the broader area (2), because the single market entails a common regulatory framework for all members (leaving aside even broader issues of political unification). In the case of a regional integration agreement such as NAFTA, the main effects should in principle accrue through the "secured access" channel and the locking-in of Mexico's commitment to 
trade opening initiated in the late $1980 \mathrm{~s}^{18}$ because the treaty entails fewer automatic repercussions than does the EU in the broader policy environment. Nevertheless, many analysts have expressed the view that NAFTA's risk-reducing effect could also be very large (see, e.g., Leamer et al. 1995).

To gauge the effect of NAFTA on FDI flows and disentangle it from that of other factors affecting FDI, we turn to an econometric analysis of the influence of FTA membership on direct investment flows. We then use the empirical estimates to quantify the relative contributions of regional integration, globalization, and other factors to the evolution of FDI in Mexico. ${ }^{19}$

The approach is described in detail in Cuevas, Messmacher, and Werner (2002) so here we provide only a brief summary. The analysis focuses on aggregate FDI flows to 45 countries over $1980-2000 .^{20}$ This sample includes the same FTAs studied by Frankel and Wei (1998). ${ }^{21}$ It is important to note that the framework assumes implicitly that North-North, North-South, and South-South FTAs are all the same in terms of FDI effects. This is worth noting because NAFTA is the only North-South FTA in existence so far. Rather than testing a structural relationship, the empirical model attempts to capture the main empirical regularities in the data. It relates FDI to the following four sets of variables:

1. FTA-related variables consist of one dummy indicating FTA membership of the host country (FTAMEMBR) and another capturing the anticipation of future membership (EXPFTA). ${ }^{22}$ In addition, we include a measure of the extended market size of the FTAs to which the host country belongs, given by members' total GDP (GDPFTA). These variables should be expected to carry positive signs if FTAs encourage FDI to member countries. Finally, to explore FTAs' potential investment diversion effects, a measure of the degree of trade integration of other countries (GLOINT) is used; this is basically a weighted sum of the GDP of all the sample countries participating in FTAs, with the weight of each country's GDP given by the fraction of worldwide GDP covered by its FTA arrangements. ${ }^{23}$

2. Global trends are captured by three variables: world GDP growth (WRLDGRWT), international interest rates (US1YTBILL), and worldwide FDI (FDIWRLD). The third variable serves to control for the increasingly important globalization forces.

3. Local factors characterizing the host country include its market size (GDP), outward orientation (EXPORTS), level of per capita income relative to the United States (RELGNIPH), rate of GDP growth (GDPGRWTH), inflation, and the current account balance (CURRACCT). Among these, market size, outward orientation, and GDP growth should have a positive effect, whereas inflation, as a symptom of macroeconomic instability, is expected to carry a negative effect. In turn, to the extent that relative GDP per capita captures real wage differentials, it should carry a negative sign. Last, the sign of the current account bal- 
ance is uncertain, depending on whether it is viewed as a reflection of macroeconomic instability or overall external financing need.

4. Institutional variables were added in some specifications to capture the effects of governance on FDI flows. Because of data limitations this shortens the sample period by four years. The three variables used are indicators of government stability (GOVSTAB), rule of law (LAWORDER), and quality of bureaucracy (BUREAU). They are all expected to carry positive signs.

Table 5.2 reports empirical estimates of the determinants of FDI obtained from this specification. ${ }^{24}$ Four variants are reported, with different combinations of the FTA-related variables and the institutional variables. On the whole the explanatory power of the empirical equations is quite satisfactory given the samples employed.

The results concerning the variables capturing FTA membership support the notion that joining a trade block leads to higher FDI inflows. The expectation of joining a free trade area (EXPFTA) has a positive impact on foreign investment. The coefficient consistently exceeds one third, indicating that announcement of an imminent entry into a larger regional market raises FDI in that proportion. The fact that the free

Table 5.2 Fixed-Effects Regressions of the Log of FDI Against Membership in a Free Trade Area and Other Variables

\begin{tabular}{lcccc}
\hline Variable/Model & 1 & 2 & 3 & 4 \\
\hline FTAMEMBER & -0.211 & & -0.149 \\
& 0.219 & & 0.249 \\
EXPFTA & $0.377 * * *$ & $0.437 * *$ & $0.341 * * *$ & $0.389 * *$ \\
& 0.199 & 0.188 & 0.202 & 0.185 \\
LNGLOINT & 0.158 & 0.162 & 0.256 & 0.253 \\
& 0.141 & 0.141 & 0.166 & 0.166 \\
LNGDPFTA & $0.158 * *$ & $0.110 * *$ & $0.146 * *$ & $0.114 * *$ \\
& 0.072 & 0.053 & 0.079 & 0.059 \\
WRIDGRWT & $-0.072 * *$ & $-0.070 * *$ & -0.100 & -0.099 \\
& 0.041 & 0.041 & 0.062 & 0.062 \\
US1TBILL & 0.006 & 0.007 & 0.045 & 0.045 \\
& 0.020 & 0.020 & 0.039 & 0.039 \\
LNFDIWRL & $0.747 * *$ & $0.744 * *$ & $0.617 * *$ & $0.614 * *$ \\
GDPGRWTH & 0.116 & 0.116 & 0.139 & 0.139 \\
& $0.034 * *$ & $0.033 * *$ & $0.036 * *$ & $0.036 *$ \\
INFLATIO & 0.012 & 0.011 & 0.013 & 0.013 \\
& $-1.31 \mathrm{E}-04$ & $-1.47 \mathrm{E}-04$ & $-3.45 \mathrm{E}-05$ & $-4.31 \mathrm{E}-05$ \\
& $1.22 \mathrm{E}-04$ & $1.21 \mathrm{E}-04$ & $1.22 \mathrm{E}-04$ & $1.21 \mathrm{E}-04$ \\
& & $($ Table continues on the following page.)
\end{tabular}


Table 5.2 (continued)

\begin{tabular}{|c|c|c|c|c|}
\hline Variable/Model & 1 & 2 & 3 & 4 \\
\hline \multirow[t]{2}{*}{ CURRACCT } & $-0.040 *$ & $-0.041 * *$ & $-0.033 *$ & $-0.033 *$ \\
\hline & 0.011 & 0.011 & 0.013 & 0.013 \\
\hline \multirow[t]{2}{*}{ RELGNIPH } & $-2.491 *$ & $-2.297 * *$ & $-5.493 * *$ & $-5.397 * *$ \\
\hline & 1.179 & 1.161 & 1.394 & 1.384 \\
\hline \multirow[t]{2}{*}{ LNEXPORT } & $0.748 * *$ & $0.719 * *$ & $0.638 * *$ & $0.620 * *$ \\
\hline & 0.219 & 0.217 & 0.270 & 0.268 \\
\hline \multirow[t]{2}{*}{ LNGDP } & 0.170 & 0.204 & -0.036 & -0.006 \\
\hline & 0.240 & 0.237 & 0.300 & 0.296 \\
\hline \multirow[t]{2}{*}{ GOVSTAB } & & & $0.137 * *$ & $0.139 * *$ \\
\hline & & & 0.048 & 0.048 \\
\hline \multirow[t]{2}{*}{ LAWORDER } & & & $0.293 * *$ & $0.298 * *$ \\
\hline & & & 0.066 & 0.065 \\
\hline \multirow[t]{2}{*}{ BUREAU } & & & 0.064 & 0.061 \\
\hline & & & 0.080 & 0.079 \\
\hline \multirow[t]{2}{*}{ CONSTANT } & $-14.806 * *$ & $-14.498 * *$ & $-11.724 * *$ & $-11.518 * *$ \\
\hline & 1.796 & 1.767 & 2.142 & 2.113 \\
\hline \multirow{2}{*}{$\begin{array}{l}R^{2}: \text { within } \\
\text { total }\end{array}$} & 0.4703 & 0.4696 & 0.4937 & 0.4934 \\
\hline & 0.8071 & 0.8068 & 0.8250 & 0.8249 \\
\hline $\begin{array}{l}\text { Number of } \\
\text { observations }\end{array}$ & 787 & 787 & 645 & 645 \\
\hline $\begin{array}{c}\text { Number of } \\
\text { countries }\end{array}$ & 45 & 45 & 45 & 45 \\
\hline
\end{tabular}

$\because *$ Significant at the 5 percent level.

$* * *$ Significant at the 1 percent level.

Note: Standard errors appear in italics below the corresponding coefficient estimate. Source: Authors' calculations.

trade area dummy has a statistically insignificant coefficient reflects the inclusion in the equations of a more direct measure of integration, extended market size (FTAGDP), which is always significant. The elasticity of FDI with respect to this variable is between one tenth and one seventh, implying that if a country joins a free trade area five times as large as the country itself, it should expect FDI inflows to rise by 50 percent or more. In contrast we find no significant effects of the variable capturing investment diversion (GLOINT), perhaps because of the rudimentary nature of this measure.

As for the global variables, world growth carries in all cases a negative coefficient, close to 10 percent significance. This is in agreement with the findings reported by Albuquerque, Loayza, and Servén (2003) on the role of global factors in FDI flows: other things being equal, faster growth in the rest of the world, given the growth rate of the host coun- 
try, reduces the latter's appeal to international investors. In turn the international interest rate is generally insignificant. Finally, world FDI flows are strongly significant and positive, as should be expected. ${ }^{25}$

Among the local factors, the elasticity of FDI inflows with respect to exports is about 0.7 and significant in all models, which suggests that openness is a major attractant for FDI. ${ }^{26}$ Host country growth is also consistently positive and significant, likely reflecting the positive impact of profitability on FDI, and again consistent with Albuquerque, Loayza, and Servén (2003). Inflation has a generally negative effect on FDI, as expected, but the effect is not statistically significant. Likewise, local market size, as measured by GDP, carries a consistently positive but insignificant coefficient. In turn, the negative coefficient on the current account balance in all regressions seems to reflect financing need (likely driven by domestic investment) rather than an unstable macroeconomic environment. Finally, the measure of relative per capita income (RELGNIPH) always carries a significant negative coefficient. If, as already argued, per capita income differentials proxy for relative wages, the result implies that if all other factors remain unaltered, countries with lower labor costs attract larger FDI inflows. ${ }^{27}$

The last two columns in table 5.2 add the institutional quality variables. They carry significantly positive signs, as one should expect, with the exception of the quality of the bureaucracy indicator, which fails to be significant. On the whole, the coefficients on the other regressors show only modest changes relative to the previous specifications.

The key result from this analysis is the positive effect of FTAs on FDI inflows to member countries. This agrees with earlier empirical studies of the impact of FTAs based on a variety of methodological frameworks ranging from structural model simulations (e.g., Baldwin, François, and Portes 1997) to gravity-based studies of bilateral FDI (Levy-Yeyati, Stein, and Daude 2002).

How well does this empirical model account for the trends in FDI to Mexico? Figure 5.3 presents the actual and fitted values, as well as the implied residuals, from the regressions in columns (2) and (4) of table 5.2. The tracking is fairly good, given the cross-country dimension of the model: the correlation between the actual and fitted values exceeds 0.85 in both cases. However, there is a clear pattern of overprediction from 1996 on as the FDI volume predicted by the statistical model exceeds the actually observed values by an increasingly large margin. ${ }^{28}$ The pattern is similar for both specifications, although the prediction error is somewhat smaller when the institutional quality indicators are included.

What was the role of NAFTA in the observed increase of FDI to Mexico throughout the 1990s? If NAFTA is just like any other FTA in the sample we can use the estimates reported in table 5.2 for a rough assessment of its impact. Table 5.3 shows the estimated contribution of the 
Figure 5.3 Actual and Predicted Values of the Log of FDI in Mexico

(U.S. dollars)

Natural log of FDI inflows

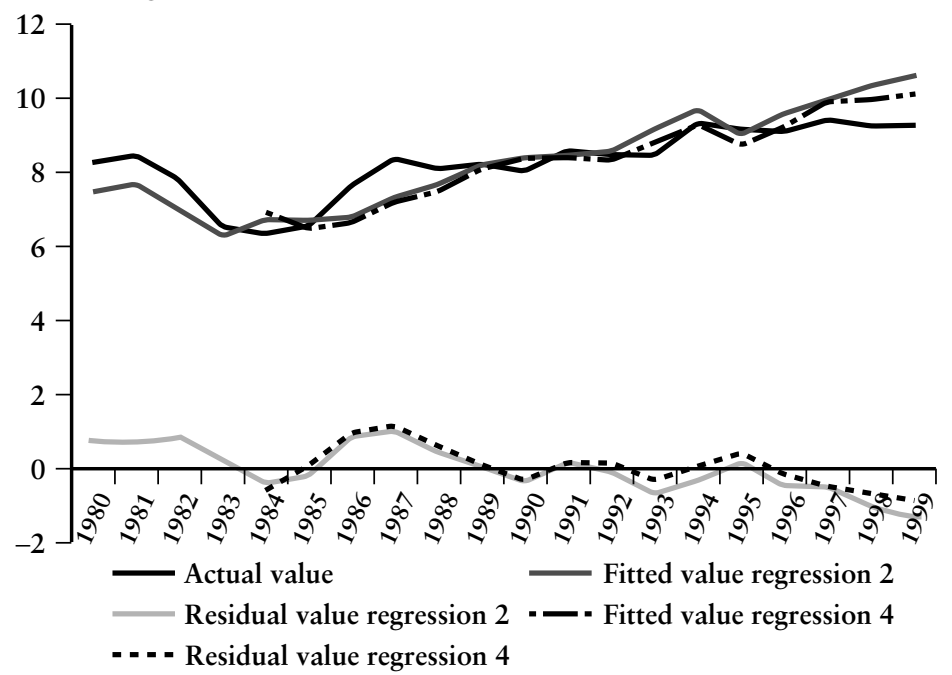

Source: Authors' calculations

FTA-related variables to the change in Mexico's annual FDI inflows between 1984-93 and 1994-99. The change in FDI predicted by the model is broken down into the portions due to each of the four groups of variables included in the regression in column 4 of table 5.2-FTA-related, global and local factors, and institutional quality indicators.

It can be seen from table 5.3 that the combined changes in the variables included in each of the first three groups contributed positively to the rise in FDI by roughly similar amounts whereas the fourth had, if anything, a slightly negative contribution resulting from a modest deterioration in the institutional quality indicators across the two subperiods considered. A deeper look reveals that among the FTA-related variables the bulk of the positive contribution to FDI was the result of the growth in Mexico's extended market, as measured by NAFTA's overall GDP. In turn, the positive effect of the global factors reflects basically the growth in worldwide FDI flows between the two periods. Finally, the positive 


\section{Table 5.3 Contribution of Various Factors to the Observed Change in FDI to Mexico \\ (FDI in constant U.S dollars, 1994-99 vs. 1984-93) ${ }^{\mathrm{a}}$}

\begin{tabular}{lc}
\hline Observed change in log FDI & 1.38 \\
\hline Explained by: & \\
FTA-related variables & 0.65 \\
Global Factors & 0.56 \\
Local factors & 0.67 \\
Institutional variables & -0.01 \\
Total predicted change & 1.86 \\
\hline Residual (actual - predicted) & -0.48 \\
\hline
\end{tabular}

a. Projected DI changes using the coefficients of column (4) of table 5.2.

Source: Authors' calculations.

impact of the local factors primarily resulted from expanding exports. However, the substantial overestimation shown in the table, reflected by the large positive residual amounting to one third of the observed change in FDI, indicates that these calculations should be viewed with great caution and considered mainly illustrative.

Because the estimated equation is expressed in logs, the effects of the various groups of variables are multiplicative, not additive, and hence it is not straightforward to translate these figures into the implied changes in the level of FDI. However, a rough approximation indicates that, had the other factors remained unchanged, the FTA-related variables would imply that Mexico's entry into NAFTA led to about a 40 percent increase in annual FDI (see Cuevas, Messmacher, and Werner 2002).

However, the contribution of NAFTA may be understated in the above calculations. Mexico's openness was presumably also increased by the treaty (see chapter 6), and the regression estimates imply that this in turn had an additional, albeit indirect, favorable impact on FDI inflows. Although it is difficult to quantify such impact, a back-of-the-envelope calculation suggests that taking it into account could raise the estimated effect of NAFTA on constant-dollar FDI quite significantly, ${ }^{29}$ to levels closer to those reported by Waldkirch (2001), who used bilateral FDI data to conclude that NAFTA led to a 72 percent increase in FDI from Canada and the United States. ${ }^{30}$

The time pattern of observed and predicted FDI flows to Mexico shown in figure 5.3 deserves consideration. At the time of NAFTA accession, FDI rose even beyond the model's predictions. But in the late 1990s FDI has consistently fallen short of the international norm as given by the empirical model, implying that Mexico became relatively 
less attractive to foreign investors despite the growing intensity of global capital flows, Mexico's closer integration with its NAFTA partners, and its rebound in GDP and export growth.

What lies behind this lagging FDI performance vis-à-vis the international norm in the late 1990s? Several factors may be at work. First, there was an overall decline in the proportion of FDI going to developing countries during the second half of the 1990s so that Mexico's relatively low levels of FDI might partly reflect this general trend. ${ }^{31}$ Second, it might be argued that the relatively limited scope and early conclusion of the Mexican privatization program could also lie behind its underperformance as FDI host in the late 1990s. However, this only tells us which form of FDI Mexico failed to receive rather than the reasons why FDI did not materialize. Third, consistent with the experiences of Portugal and Spain described in box 5.1, it is also possible that NAFTA led mainly to a stock adjustment that was completed around 1994-95, so that FDI is now settling toward more "normal" levels. Finally, contrary to the assumption underlying the empirical model, it is also possible that North-South FTAs have different FDI implications than do North-North and South-South FTAs because of the greater dissimilarity among their partner economies. ${ }^{32}$ Because NAFTA is the only North-South FTA in our sample there is no simple way to assess this hypothesis.

In addition to these arguments, however, another candidate explanation is that after the initial impulse given by NAFTA, other FDI hosts have outpaced Mexico in terms of investment-friendly reforms-for example, the Czech Republic, Hungary, Poland, the Slovak Republic, and Turkey were all working to upgrade their institutional and policy frameworks with a view to joining the European Union. Indeed, these improving trends abroad contrast with the fact that the institutional quality variables in table 5.3 exhibit, if anything, a slight deterioration in the case of Mexico and thus made a negative contribution to Mexico's FDI performance in the late 1990s.

\section{Firm Financing After NAFTA}

Against the background of these aggregate trends in external financing we next examine the effects of NAFTA on financing opportunities from the point of view of individual firms. The presumptive expectation is that the free trade agreement will open new doors to the private sector, especially to exporters, and that firms will try (and find it easier) to obtain foreign financing to match their increasing openness.

Table 5.4 presents some basic indicators of financial structure and openness for a sample of firms listed on the Mexican stock exchange. Although the sample is not representative, it is the only relatively large firm sample 


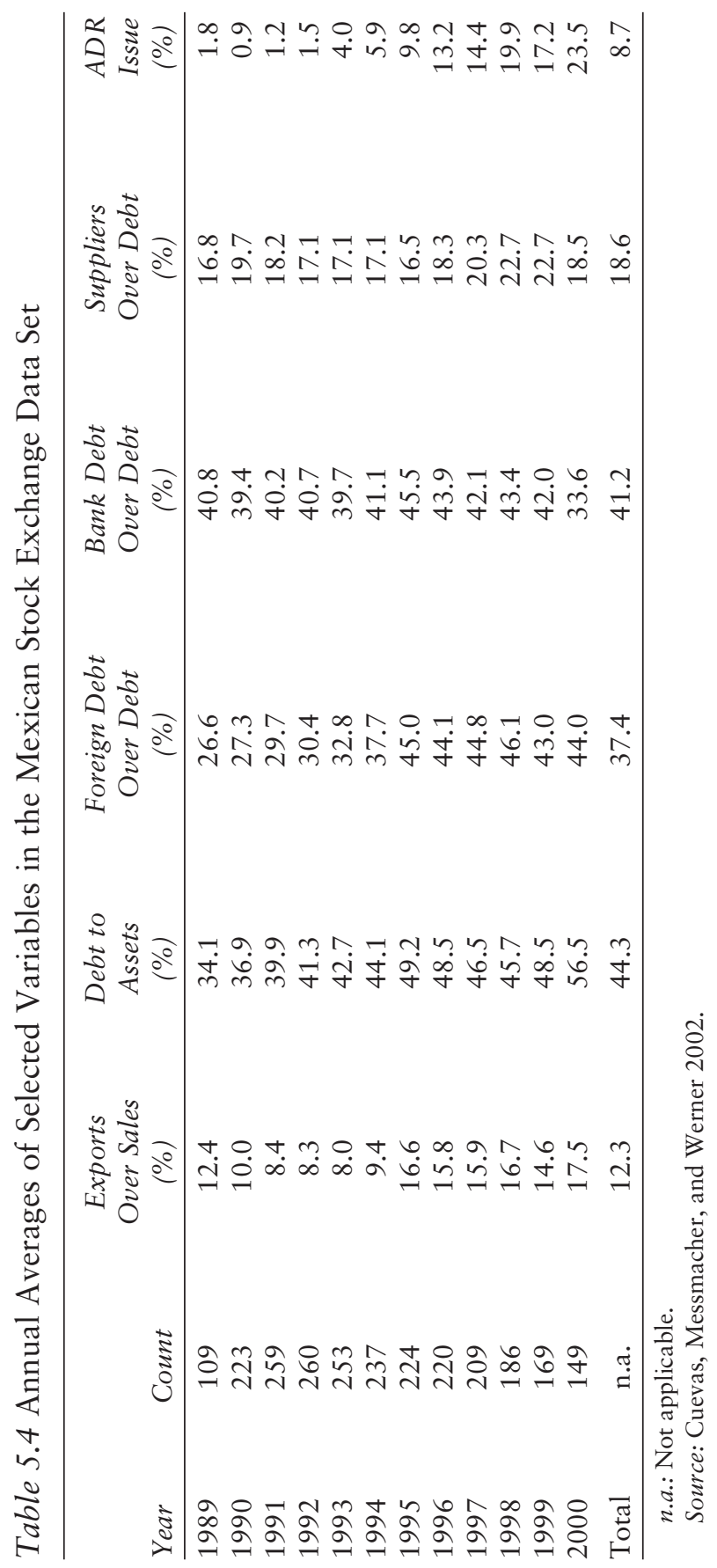


for which comprehensive financial data are available. ${ }^{33}$ As can be seen in the table the average proportion of these firms' sales accounted for by exports went from single to double digits starting in 1995-likely reflecting both the free trade agreement and the real depreciation of the peso. Overall indebtedness reached a peak in 1995, doubtless influenced in part by the capital losses resulting from the depreciation of the peso, but in recent years it has not shown any tendency to return to the pre-1995 levels.

Regarding the composition of firms' liabilities, the two most remarkable developments were the increase in the proportion of foreign debt ${ }^{34}$ in the total after 1995, and the increasing proportion of firms that resorted to issuing American Depositary Receipts (ADRs) after 1995, as shown in the last column of table 5.4.

The factors behind these changes in the financial structure of Mexican firms are explored empirically by Cuevas, Messmacher, and Werner (2002) in regressions using firm-level data and including as controls the export ratio, tariff levels, and a number of other control variables (including a dummy for the post-NAFTA period). Although these regressions cannot be given a strictly causal interpretation-because simultaneity among the different variables considered is a likely issue-they do highlight the key stylized facts.

Those empirical experiments confirm that after controlling for other factors, there is a significant positive association between the foreign debt ratio and the export ratio, ${ }^{35}$ which implies that the increased outward orientations of sales and financing are two aspects of the same phenomenon. Furthermore, the results show that firms' foreign debt ratio not only rose after NAFTA but also is negatively associated with the level of Mexican tariffs, which brings out the link between trade opening and external financing. However, the same results show that the role of export orientation as predictor of external indebtedness declined in the postNAFTA era. On the one hand, this suggests that even producers of nontraded goods are taking advantage of more integrated capital markets to borrow abroad, be it from their suppliers or from financial intermediaries. On the other hand, foreign debt ratios are found to be positively associated (after controlling for other factors) with ADR issuance, implying that the two forms of external finance are mutually reinforcing. ${ }^{36}$ Finally, foreign debt ratios are also positively associated with firm size.

This leads us to the factors behind the remarkable increase in the resort of Mexican firms to ADR issuance shown in table 5.4, a trend similar to that found in other emerging markets (see Claessens, Klingebiel, and Schmukler 2002 and Moel 2001). Regressions of ADR issuance reported by Cuevas, Messmacher, and Werner (2002) found results broadly similar to those described above for external debt ratios. ADR issuance is positively related to export ratios and firm size, and negatively to tariff levels. As with debt, however, the magnitude of the impact of export orientation 
is found to have declined in the post-NAFTA period. Again this suggests not only that outward orientation and trade liberalization affect ADR issuance positively but also that even less outward-oriented firms have increased resort to ADRs in the post-NAFTA years.

In contrast with the association between export orientation and external financing, export ratios are negatively related to suppliers' credit ratios. Combined with the preceding results on foreign debt ratios, this seems to suggest a taxonomy of firms' responses to the banking crisis: outward-oriented firms reacted in part by increasing their recourse to foreign finance and inward-oriented ones relied more on domestic supplier financing. It is worth noting also that when other factors are taken into consideration, firms' resort to suppliers' financing declined in the post-NAFTA period.

\section{The Road Ahead: Institutional Reform for Financial Development}

To summarize the analysis in the preceding sections, we find that the changes in capital flows to Mexico over the 1990s, and specifically the steep rise in FDI, reflected in part global trends and perhaps also the effects of the banking crisis. However, an econometric analysis of the FDI impact of free trade agreements, using a large cross-country time-series data set, suggests that trade opening and NAFTA accession also helped raise Mexico's FDI, although the foreign investment performance in the late 1990s suggests that this effect may have been only temporary. ${ }^{37}$

The available firm-level evidence is broadly consistent with this aggregate picture. The post-NAFTA period is characterized by increased resort to foreign financing in the forms of both equity and debt, especially among export-oriented firms that were better positioned to take advantage of the new environment. The evidence is tentative, however, because it is confined to relatively large firms listed on the Mexican stock exchange.

On the whole, therefore, both macro- and microeconomic data suggest that NAFTA has represented a significant step toward Mexico's financial integration in the world economy. However, for the vast majority of Mexican firms (especially smaller and new ones) ADR issuance and external borrowing do not represent viable options to secure outside financing. Indeed, their access to financing remains woefully inadequate, posing a major obstacle for Mexico's real convergence toward its NAFTA partners. This reflects the deficiencies of financial markets in Mexico. As already noted, the domestic banking system has yet to fully recover from the 1995 crisis. In turn, the small size, illiquidity, and high degree of concentration of Mexico's capital market relative to the markets of successful emerging economies-such as those in East Asiahave been amply documented. ${ }^{38}$ Of course, these ills also affect other 
Latin American economies, but in many critical areas (e.g., the ability of new firms to raise capital) Mexico falls significantly short of the Latin American norm as well (López-de-Silanes 2002).

The consequences of this situation are well understood. A large body of research has shown that financial underdevelopment hampers investment, economic efficiency, and technological progress. It also amplifies the economy's vulnerability to shocks. As a result it imposes a major cost in terms of income growth and economic development. ${ }^{39}$

Mexico's inadequate legal and regulatory framework deserves much of the blame for the country's financial underdevelopment. ${ }^{40}$ Indeed, international comparisons reveal that Mexico ranks among the countries with weakest protection of creditor and shareholder rights, well below international and even Latin American standards. Table 5.5 presents synthetic measures of creditor and investor rights, as embedded in the laws, across various groups of countries. The former measure captures the protection offered to creditors by the legal system in situations of reorganization and bankruptcy, and the latter reflects primarily the protection granted to noncontrolling shareholders. ${ }^{41}$ It can be seen that Mexico lags behind along both dimensions, even relative to other major Latin American economies.

Legal rules are only one of the factors at play; their enforcement is equally or even more important. Two summary indicators of the quality of enforcement of laws, along with a measure of corruption, appear also in table 5.5. ${ }^{42}$ In all three dimensions Mexico ranks below the world average. Thus, on balance the evidence indicates that creditors and investors are poorly protected by Mexico's inadequate laws and weak enforcement.

The international experience shows that the law and its enforcement are very good predictors of financial development, and hence it is difficult to overemphasize the adverse consequences of this situation for Mexico's financial markets. Inadequate protection of shareholder rights leads to small and shallow capital markets with highly concentrated ownership and few new firms entering the market. Likewise, without essential creditor rights debt markets are bound to remain small and the cost of credit high. And even if all firms could access foreign financial markets, they would not be able to avoid the consequences of the weak regulatory framework. ADRs may offer firms an escape from poor securities laws because the regulations that apply are those of the market where the securities are issued. But in the case of credit the ultimate law is the bankruptcy law of the country where the assets are located. ${ }^{43}$ This means that it is virtually impossible to escape a poor bankruptcy law and a poor court enforcement of such law.

What can Mexican policymakers do to foster better investor protection? There are several types of corporate governance reforms at work in many countries, and the evidence shows that some of them have had major 


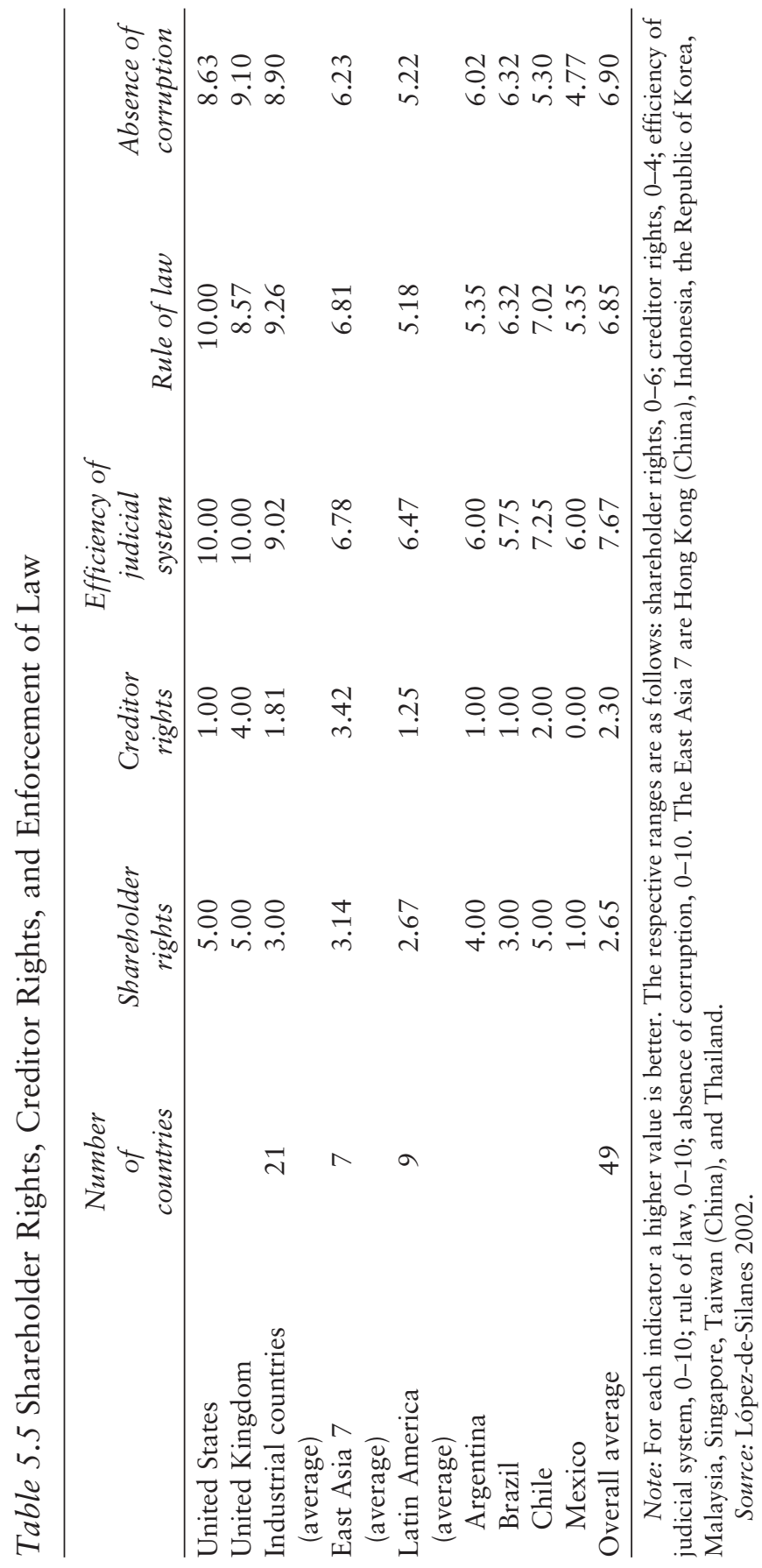


positive effects on investor protection and the financing of firms. Some mechanisms found in other countries might be appropriate for Mexico, although others might not work given the current enforcement environment.

There is no universal checklist of what needs to be done, but the available evidence indicates that reforms to foster financial markets in Mexico should follow a two-track approach. Because legal reform is slow and complicated, complementary market-based mechanisms should be adopted to temporarily substitute for or complement the reform of laws and regulations. As box 5.3 details, these mechanisms could include an improved Code of Best Practices, the possible creation of an alternative market with higher standards for new entrants, enforcement of corporate governance standards for institutional investors, and an exemplary role for public enterprises. These mechanisms should help facilitate competition and allow investors to discriminate among firms according to their corporate governance practices, thus making it possible for the firms that better protect investors to access capital at lower cost. At the same time, adopting such measures would help to develop a culture of investor protection and build momentum for legal reforms to take place.

Although these market-based mechanisms can help, ultimately they should be complemented with legal reforms whose effects can reach all firms and can be more easily enforced as the standard in the country. However, effective enforcement of legal rules is deeply connected with the rules themselves, and the design of successful legal reforms in Mexico needs to take into account the weakness of the legal system. The proper strategy for reform is not to create an ideal set of rules and then see how they can be enforced, but rather to enact the rules that can be enforced with the existing enforcement structure. With this general perspective, box 5.3 outlines some principles for enhancing securities, corporate, and bankruptcy laws.

In some of these dimensions Mexico has already made significant progress in the right direction. However, major issues still remain to be addressed in order to achieve a more satisfactory protection of investor and creditor rights. A decided push on this front can be instrumental in helping Mexico realize the full growth potential of the new opportunities created by NAFTA.

\section{NAFTA and the Evolution of Mexican Labor Markets}

This section focuses on two broad themes. First, what has been the impact of product and factor market integration discussed in earlier chapters on integration of the Mexican and U.S. labor markets? In particular, our workhorse trade models suggest that the integration of product markets should cause pressures toward convergence of wage levels even in the 


\section{Box 5.3 Corporate Governance Reform in Mexico}

What can policymakers do to foster better investor protection in Mexico? In a background paper for this report, López-de-Silanes (2002) outlined a set of reforms aimed at deepening Mexico's financial markets. Because legal reforms are typically slow and complicated this proposed agenda combines them with complementary market-based mechanisms that would constitute a useful first step to foster a culture of respect for investor protection and set the basis for the eventual legal reform.

\section{Market-Based Mechanisms}

\section{Committee on Best Corporate Governance Practices}

Mexico's Committee on Corporate Governance, created in January 2000, follows the example of Australia, England, and New Zealand, which established commissions formed by members of the private sector and government to review corporate practices and investor protection. These committees compiled best practice codes detailing rules of good corporate governance mechanisms. The underlying principle is that firms' disclosure of information about their corporate practices will allow shareholders to single out those firms that adhere to investor protection, making investors more willing to fund them. Firms with better practices should find it easier to access capital at lower cost because they provide a more certain environment for the investor. Adherence to the Code of Best Practices is voluntary but disclosure by listed firms is compulsory. Although it is a step forward, the Code also has clear limitations: it is only a guideline for publicly traded firms, and concern with its initial deficiencies (i.e., the generality of some principles and the vague definition of directors' responsibilities) has risen in the wake of corporate scandals in the United States. Thus, the code needs to be revised and a permanent committee should be created to oversee its improvement and adaptation to the changing corporate environment.

\section{Alternative Markets with Higher Standards}

In Mexico and many European countries stock markets attract few initial public offerings. The absence of competition from new entrants allows established firms to raise capital on favorable terms but slows the development of new firms. The successful experience of Germany since 1997 with the Neuer Markt, a sub-exchange of the Frankfurt Stock Exchange for new firms wishing to go public, shows one way to overcome the resistance of existing firms to changes in the rules. Companies wishing to (Box continues on the following page.) 


\section{Box 5.3 (continued)}

list on the Neuer Markt must comply with U.S. Generally Accepted Accounting Principles or the International Accounting Standards, including more stringent disclosure requirements than those applicable to already-listed firms. This has allowed new firms easier access to the market: more than 200 firms have gone public in the past three years, which is more than in the previous 50 years. The Republic of Korea, despite a relatively weak legal system, has recently started implementing a similar approach. In Mexico, a new listing venue-with U.S.-style rules and greater restrictions on entrepreneurs-could accelerate the pace of initial public offerings. Leaving incumbent firms unaffected could offer one possible strategy for overcoming political opposition to reform.

\section{Prudential Measures for Institutional Investors}

Enhanced disclosure requirements may not be sufficient in countries like Mexico with weak legal institutions or where investors have very few rights and are thereby prevented from demanding changes. In such instances it may be desirable to restrict institutional investors to investments in companies that meet minimum corporate-governance standards as determined by the Code of Best Practices or by independent best-practice commissions. This is advisable not only on prudential grounds but also to encourage firms to improve investor protection. An approach along these lines has been implemented in Chile.

\section{State-Controlled Enterprises}

Despite significant privatization in Mexico, there are still close to 150 state-controlled enterprises. These firms could set the example for private firms by adopting better investor protections. Most of the state-run firms are large public utilities for which external funding has become equally or more important than it is for private firms. Adoption of the Code of Best Practices outlined above can provide a quick and easy way for these statecontrolled firms to substantially transform themselves and secure access to funds at better rates, thereby also alleviating their pressure on the government budget.

\section{Legal Reforms}

\section{Securities Regulation}

The new Securities Law tries to refocus regulation so that supervision is concentrated on intermediaries rather than issuers, with the idea that well-supervised intermediaries (i.e., brokers, accounting firms, investment 


\section{Box 5.3 (continued)}

advisors) will in turn force issuers and traders to comply with regulatory requirements. This approach was pioneered by the United States and later successfully applied by other countries. In Poland, for example, stringent and toughly enforced regulations of this kind have stimulated rapid development of securities markets. Thus, smart regulations, particularly in countries with relatively weak legal systems such as Mexico, can improve the protection of investors and this will help firms obtain external financing. Mexico's recent takeover regulations represent the newest impetus in this area. The new rules, among the most stringent in the world, try to prevent differential treatment of investors through acquisitions of control and they protect minority shareholders to a far greater degree than was previously the case. Overall, these rules level the playing field between majority and minority shareholders in change-of-control situations and thus should boost the value of minority stock. Although enforceability is always an issue, the movement is clearly on the positive side.

\section{Corporate Law}

Securities regulations requiring disclosure need to be complemented with changes in corporate law to give shareholders the rights to act on the information they receive. Because Mexican shareholders' rights are among the worst in the world, the Ley de Sociedades Anónimas must be revamped. The reforms do not need to follow U.S.-type mechanisms that rely heavily on the judicial system through derivative or class-action lawsuits. Instead, given the state of Mexico's legal system, the application of more "automatic" principles, as was done in Chile, may be a better answer. Specifically, the reform of Mexico's corporate law should enforce (a) better information and simplified attendance procedures for shareholders' meetings; (b) easier participation and voting procedures for dissenting shareholders; (c) mechanisms for qualified minorities to submit proposals; (d) proportional board representation for qualified minorities; (e) nondiscriminatory treatment of minorities, including a semiautomatic procedure for their compensation if controlling shareholders act in detriment of the corporation (as in the case of Chile); (f) definition of fiduciary obligations and responsibilities of officers and board members; (g) regulation of conflicts of interest; and (h) strengthened internal auditing procedures and committees for material transactions.

\section{Bankruptcy Law}

Improving bankruptcy procedures is more difficult than improving shareholder rights because different types of creditors, unlike different (Box continues on the following page.) 


\section{Box 5.3 (continued)}

noncontrolling shareholders, have different objectives. Reform typically involves the whole mechanism, not just a few principles or articles of the law. In addition, bankruptcy procedures tend to rely on adjudication by the courts, which leaves the process vulnerable to political pressures and weak judiciaries, particularly in countries with poor enforcement and high corruption. Procedures leaving most of the discretion in the hands of creditors rather than judges (as is done in the United Kingdom) may be much better. In this light, Mexico's new bankruptcy law, adopted in May 2000, still falls short in key areas. Most significantly, the discretion and decision powers remain in the hands of judges and a new breed of regulators. These shortcomings are reflected in the fact that there are almost no cases brought to court because people are simply not using the law. In terms of basic creditor rights, Mexico scores equally poorly before and after the reform. But an efficient bankruptcy procedure is essential to expand credit access and restore the stability of the banking sector. The key objectives of the pending reform should be (a) minimizing transaction costs as well as the discretionary ability of third parties, such as the judiciary; (b) facilitating firms' access to credit; (c) ensuring that the assets of the firm are used efficiently, either through reorganization or liquidation; (d) preserving the absolute priority of creditors; (e) allowing creditors holding collateral to repossess it in due course and before other creditors benefit from it; and (f) maximizing the payments to all those investors who provided financing to the firm.

absence of labor market integration. Relevant to this discussion is the evolution of the relative wages of skilled and unskilled workers. Second, what can be said about the impact on the quality of jobs workers face? The vastness of this topic restricts us to focusing on a couple of particularly visible sectors and selected indicators.

Approaching these issues is difficult for three reasons. First, only a decade has passed since NAFTA was implemented. Second, this decade was interrupted by the Tequila crisis, which caused real wages to fall by 25 percent and from which the country has only recently recovered. Both factors lead us toward relying heavily on inference from the unilateral liberalization of 1986 when Mexico joined the General Agreement on Tariffs and Trade. In spirit they are part of the same process but such inference is limited in telling us about the impact of NAFTA per se. Third and last, Mexico is unique in sharing a long border with the United States that has exhibited varying degrees of porousness during the period. Among males 25-34 years old, the 1990 number of Mexican immigrants in the United States was equivalent to a very significant 
12 percent of that age cohort (Chiquiar and Hanson 2002). Hence, it is often difficult to isolate what is a function of demand shifts resulting from trade reform and what is a result of migration flows.

The next section approaches the question of whether there has been a greater integration of Mexican wage levels across the period of liberalization. The third section looks more carefully at a phenomenon found throughout the region-increased returns to skilled workers that are the opposite of what theory suggests should have happened. Section four broadens our view of job quality to include labor protections, and particularly the evolution of the uncovered or "informal" sector.

We conclude with a discussion of labor policies for a more open Mexico.

\section{Convergence of Wages}

Standard neoclassical trade theory, and especially the Stolper-Samuelson theorem of the Heckscher-Ohlin framework, suggests that converging of product prices will also cause convergence in factor prices. A fall in the cost of capital-intensive goods relative to the price of labor-intensive goods should cause a rise in the relative return of the factor in which Mexico appears to be most abundant, labor. Despite relatively straightforward underlying logic, there are many reasons why we might not see the expected effects: Mexico is not especially labor abundant compared with China, for instance; trade in intermediate goods such as would also be expected to increase with NAFTA can lead to reverse predictions (Jones 2000); and production technologies may differ importantly across countries and change across the course of liberalization. On the other hand, other elements of NAFTA not captured by the standard Stolper-Samuelson framework-greater flows of FDI and of technology - may generate the hoped-for effects. In particular, FDI is seen as bringing jobs at good wages for poorer workers that would reduce the incentive to search for work in the United States.

Figure 5.4 graphs two possible measures of wages in Mexico relative to those in the United States. The "dollar-based" ratio converts peso wages into dollars through the exchange rate and then forms a ratio with relatively comparable U.S. wages. It has the advantage of measuring worker incomes in a globally comparable basket of goods or unit of purchasing power. It has the disadvantage of being heavily affected by the evolution of the real exchange rate that, over the medium term, is largely a function of macroeconomic balance and not economic integration. The "home currency-based" measure deflates each series by its home consumer price index (CPI) and then forms a ratio. This measure is less affected by exchange rate movements and uses the basket of goods most relevant to the workers, and hence the local labor market as captured by 
Figure 5.4 Evolution of Real Mexican-U.S. Hourly Manufacturing Wages for Production Workers and Unemployment

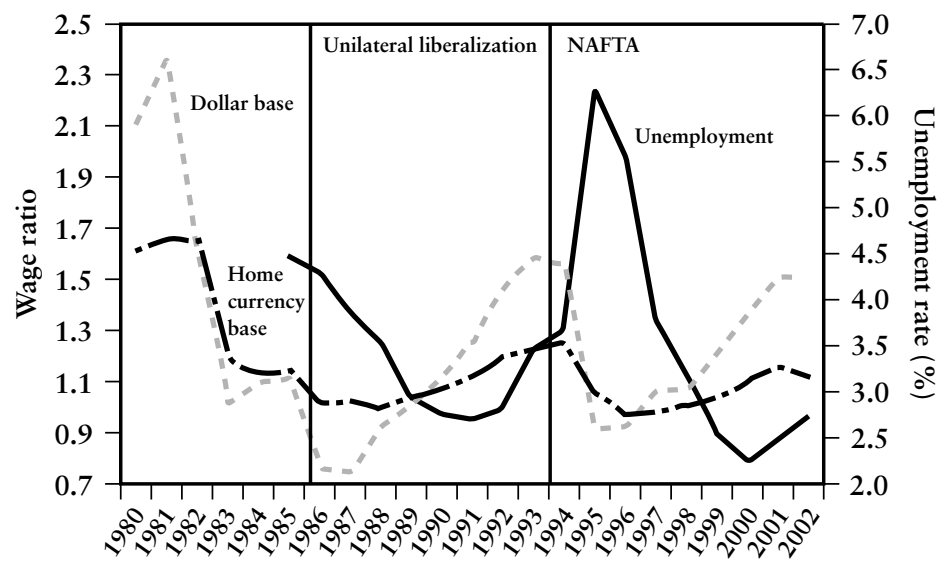

Source: INEGI and U.S. Bureau of Labor Statistics.

the local CPIs. Neither is an ideal measure of convergence of wages, but both tell a similar story. ${ }^{44}$

It is unfortunate that the period across which we would want to test for convergence of wages among the NAFTA partners is one characterized by extraordinary macroeconomic fluctuations unrelated to trade liberalization that have taken Mexican workers and their families on a brutal ride since 1980 . The difficulty of comparing levels is immediately obvious: both measures suggest that Mexican and U.S. wages were closest two decades ago in 1980, during the oil bonanza and before the debt crisis. The lost decade of the 1980s led to a sharp divergence where wages were roughly halved relative to those in the United States. This probably does not represent a process of disintegration of factor markets through lower trade and investment flows; rather, the overheated economy probably pushed wages above the level compatible with sustainable macroeconomic policy and a sharp downward adjustment was inevitable.

Similarly, the unsustainable appreciation of the peso in the early 1990s exaggerates the workers' purchasing power in 1993-94 and the blow to Mexican households during the following crisis represents an extreme overcorrection of wages on the order of 25 percent in real terms 
in the opposite direction. The period from 1996 to 2000 represents a rapid recovery relative, say, to the crisis in Argentina or Colombia where unemployment rates have remained in double digits for a decade. By 2000 open unemployment rates had reached their lowest levels since 1980 and real wages measured in Mexico or relative to U.S. wages (dollar-base) had largely recovered, with maquila wages exceeding their previous high. This is particularly striking given a very sharp increase in female labor market participation over the same period. The strong rise in U.S. productivity and wages in the 1990s keeps the home currencybased measure substantially below 1993 levels.

The crisis contaminates inference of the impact of NAFTA and makes any casual conclusions unreliable. Trade liberalization cannot be held responsible for the dramatic fall in wages. Nor can we attribute to NAFTA the rapid wage growth and employment creation although NAFTA did help by stimulating FDI and exports, the sharp devaluation of the peso is likely to have had a much larger effect. In summary, we cannot know what might have been the outcome if the peso crisis had not occurred, and simply looking at figure 5.4 we cannot come to any conclusion about NAFTA's positive or negative impact on the labor market. For this reason the next sections attempt less direct measures that may shed some light.

Estimating Synchronization and Convergence Effects. One approach is to employ time-series regression techniques that specifically attempt to measure convergence and control to the limited degree possible for crisis-related effects. Robertson (2000a, b; 2002) constructed a panel of synthetic cohorts from household survey data in both countries over the period 1987-97 and then updated them for this study. ${ }^{45}$ Both his and other work takes an approach similar to that discussed in chapter 2: convergence implies that cohorts with larger wage gaps vis-à-vis similar cohorts in the United States should catch up faster and hence show larger wage gains. In addition, as integration increases, overall wage growth in the United States should presumably be communicated more rapidly (see box 5.4 for more details). Robertson found wage changes in Mexico to be negatively correlated with the U.S.-Mexico wage difference, which suggests that over time wages in the two economies tend to converge. $\mathrm{He}$ also found wages to be strongly positively correlated with wage changes in the United States: a 10.0 percent rise in U.S. wages is correlated with a 1.8 percent rise of wages in Mexican interior cities and a 2.5 percent rise in wages in Mexican border cities, suggesting that the border is more integrated with the U.S. economy. The implied rate of wage convergence was faster in those cities sharing a border with the United States, having high rates of migration to the United States, and having a large number of maquiladoras. ${ }^{46}$ It is somewhat puzzling, however, that regardless of 


\section{Box 5.4 Estimating Convergence}

The equation describes the relationship between the change in the Mexican log wage for group $j$ (defined here as an age-education group) at time $t$, the change in the log wage in the United States, and the difference between the U.S. log wage levels (the error correction term). In this approach, the $\beta_{1}$ term captures the effect of the U.S. wage shock on Mexican wages, and $\beta_{2}$ measures the rate of convergence back to the equilibrium differential. Larger differences between the two suggest a faster rate of return to the equilibrium differential. These two coefficients are measures of integration. More integrated labor markets should have larger coefficients (in absolute value). The effects of NAFTA are estimated by modifying the basic equation by including a dummy variable equal to 1 for the post-NAFTA years (1994 and on). In addition to the main effect this dummy variable is interacted with the shock and convergence terms. A possible objection to this approach is that it assumes that the wages will always converge to a fixed Mexico-U.S. gap, which seems unlikely given Mexico's history and seems inconsistent with long-run convergence of wage levels among the two countries. On the other hand, Robertson (1999) argued that U.S. border policy in fact targets a constant differential to some degree.

In a similar spirit and using similar data, Hanson (2002) simply uses ordinary least squares to estimate the determinants of wage growth of the cohorts between the points 1990 and 2000 including, to begin, the difference term and a measure of the gap between comparable U.S.Mexican cohorts in 1990.

Robertson (2002) estimated an error correction model

$$
\Delta w_{j t}^{\text {mex }}=\beta_{0}+\beta_{1} \Delta w_{j t}^{u s}+\beta_{2}\left(w^{\text {mex }}-w^{u s}\right)_{j t-1}+e_{t} .
$$

the degree of tradedness of the sector (transportation equipment most traded and services and construction least traded), the impact of the Tequila crisis was far more moderate and shorter in duration on the border in Tijuana than in central Mexico (see figure 5.5). This is perhaps more consistent with migration integrating the markets than with trade integrating them.

Equally surprising is the limited impact of NAFTA on convergence, except for educated workers. ${ }^{47}$ Excluding 1987 and 1995 from estimation to compensate for the devaluations in those years, Robertson found stronger impacts of U.S. wages and regional effects and a slightly stronger although statistically significant increase only for educated workers in the rate of convergence after 1994. More disturbingly, at the industry level he found no impact of U.S. wage changes on Mexican changes and strong convergence effects emerged only for the construction 
Figure 5.5 Mexico-U.S. Wage Differentials by Industry and Proximity to U.S. Border
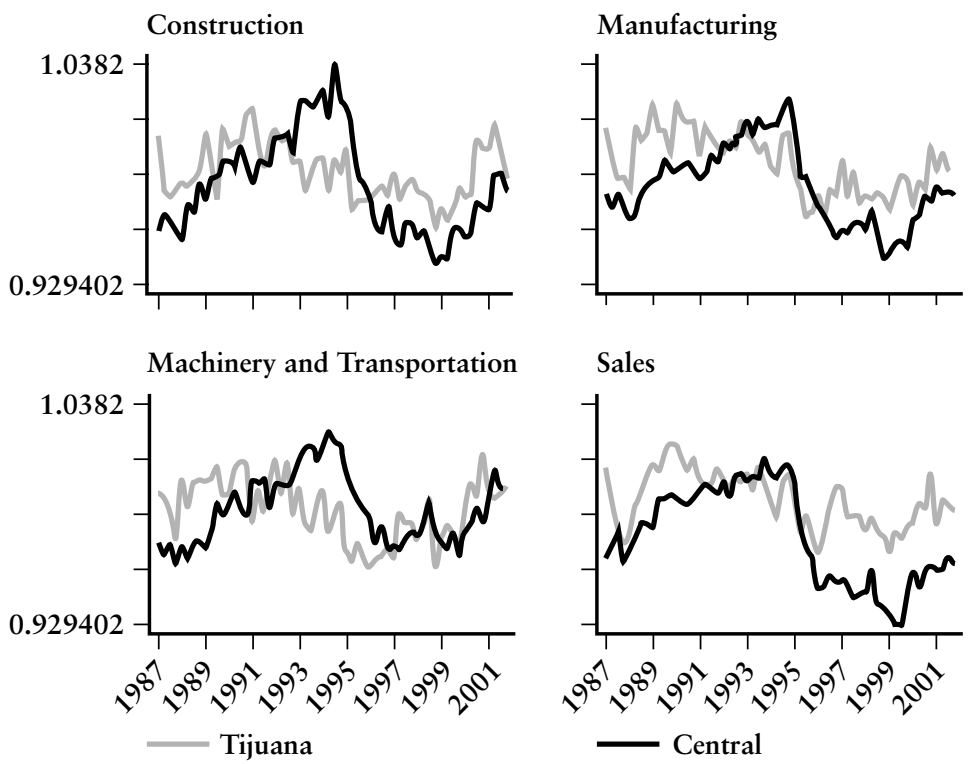

Source: Robertson 2002.

industries. ${ }^{48}$ Again, because this is generally considered a nontradable sector, the appearance of high linkages lends some support to the idea that migration is the largest integrating force. So also does Robertson's related finding that between 1987 and 1993 inter-industry wage differentials in Mexico became less similar to inter-industry wage differentials in the United States (which are very stable over time).

A similar exercise by Hanson (2002) further muddies the initial convergence findings. Focusing only on the determinants of Mexican wage growth between the two points 1990 and 2000 for a similar set of synthetic cohorts, there is no robust impact of the gap between Mexican and U.S. wages that would be expected for convergence (see table 5.6). In fact, during the 1990s interior regions had higher wage growth for cohorts with higher initial wages (evidence for wage divergence), an effect diminishing near the border (column [b]). Although there is still evidence that changes in U.S. wages are communicated to Mexican wages, the evidence for convergence is fragile. This may partly be the result of the 


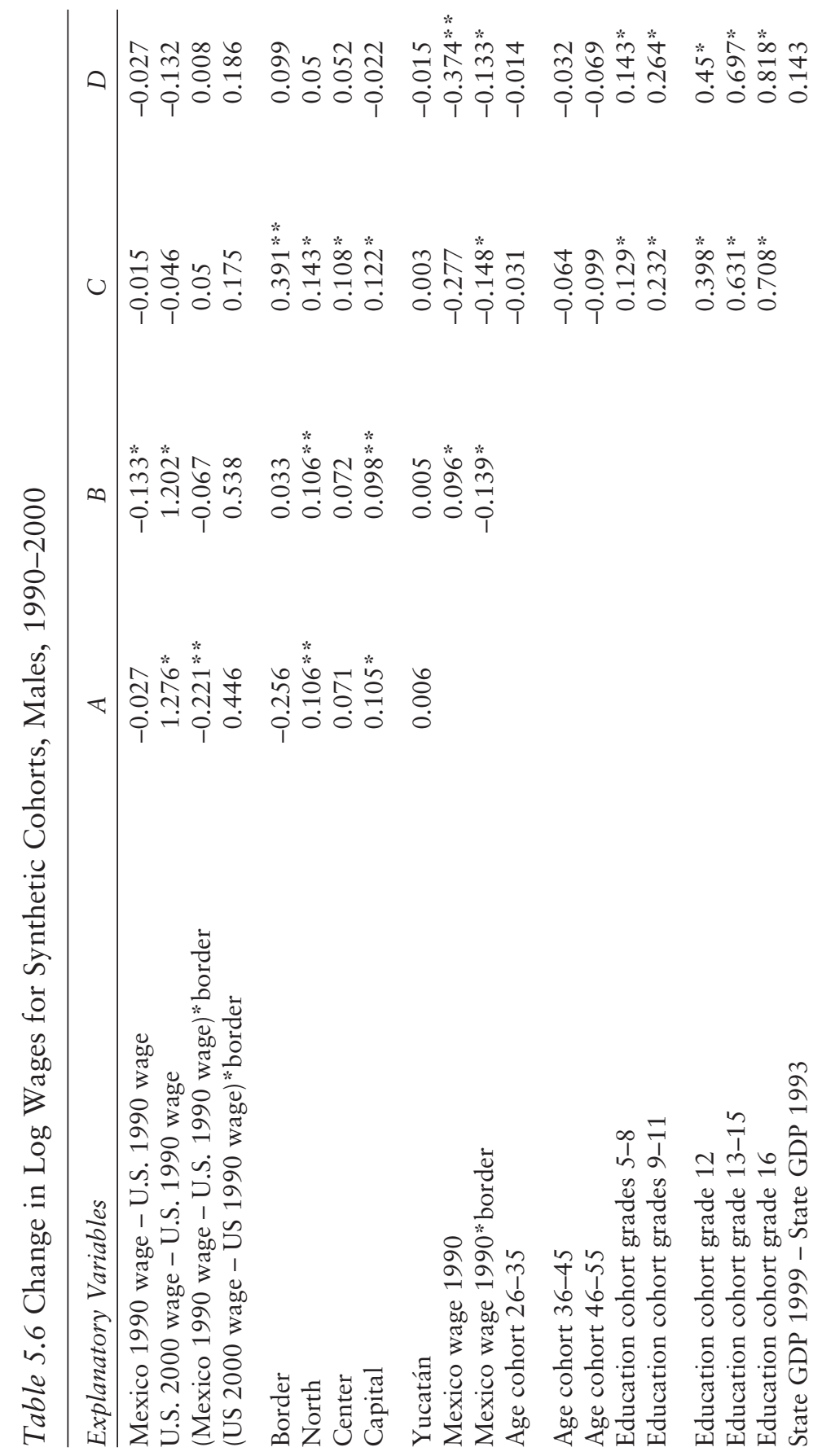




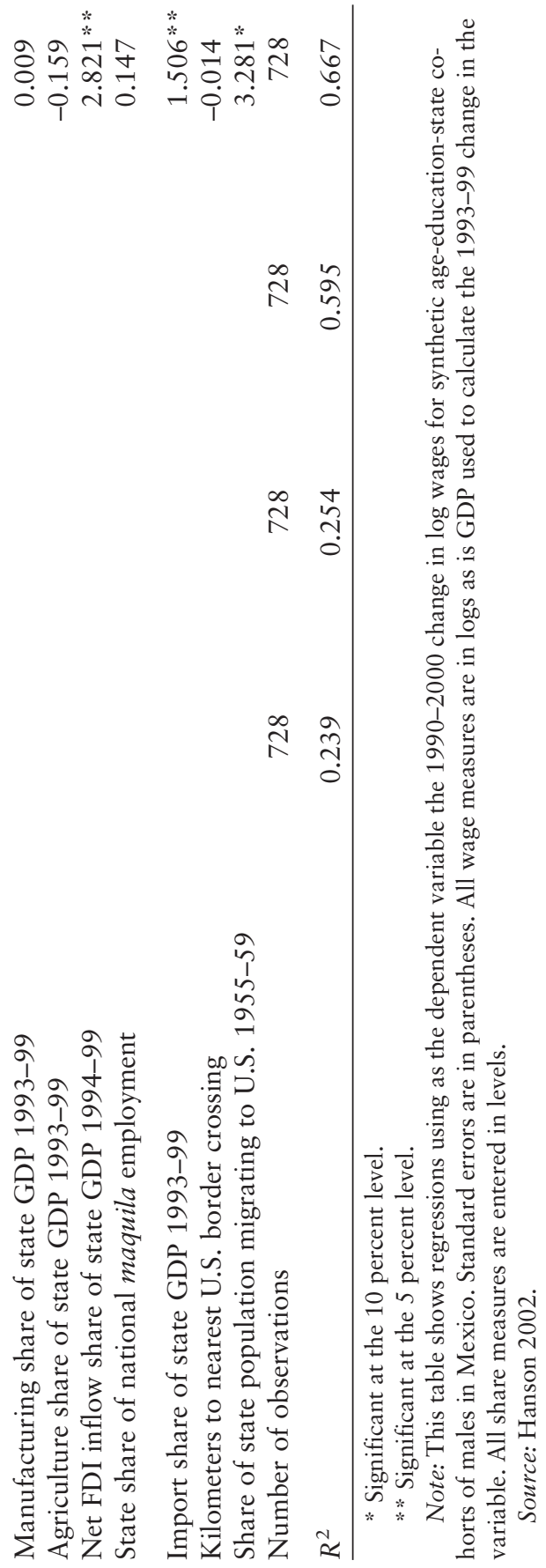


span of time between observations. Robertson's work suggests that most adjustment occurs in just over a year, which implies that a 10 -year period would miss the adjustment process. However, the evidence of growing wage dispersion is not surprising given the rising returns to skill that we will discuss later. In fact, as table column (c) suggests, including education cohorts virtually eliminates the impact of U.S. wages growth on Mexican wage growth. This suggests that a common rise in the skill premium in both countries accounts for the apparent co-movement in wages.

Geographic and Direct Trade/Foreign Direct Investment/Migration Effects. Column (a) in table 5.6 does suggest strong regional effects on wage growth rates with the North and Capital regions growing especially fast, and these seem to be linked to liberalization-related phenomena. These effects almost completely disappear when a set of "globalization" variables is included in column (d). The share of manufacturing in state GDP and agriculture does not enter significantly, consistent with recent evidence that there is no particular productivity growth advantage to manufactures over natural resources. What does enter significantly is the share of FDI in state GDP, and greater exposure to foreign trade suggesting that regions better integrated with foreign markets have experienced greater labor demand growth. The share of employment in maquilas enters positively but insignificantly as would be the case if there were no special effect of assembly operations (and no deleterious effect either) beyond the fact that they represent FDI. States with traditionally high migration rates also had especially high wage growth rates, which reflects the greater integration of the labor markets or the role of migratory remittances in starting businesses. ${ }^{49}$

These findings are consistent with work showing that high levels of FDI, imports, and maquila value added in an individual Mexican state increase migration to and deter migration away from that state (see figure 5.6 and Aroca and Maloney 2004). The principal channel through which these variables work is increased labor demand manifested in reduced unemployment and higher wages. ${ }^{50}$ In principal, then, the idea that NAFTA would reduce migration by creating jobs enjoys some support. Although the poor quality of illegal migration data makes it difficult to directly calculate the impact on cross-border flows, a crude calculation holding fixed the total migration from any state to any destination including the United States generates an elasticity of reduction of migration to the United States in response to a 10 percent rise in investment averages at roughly $0.15-0.2$ percent.

The high shares of imports, FDI, and maquila operations in the North are all part of a larger process of industrial reallocation that appears to have partially driven the spatial distribution of wages (Hanson 1996, 1967). ${ }^{51}$ In 1980, five years before trade reform began, 46.4 percent of Mexico's manufacturing labor force was located in Mexico City and 21.0 percent was located in states along the U.S. border. In 1993, after 
Figure 5.6 FDI and Net Migration by State
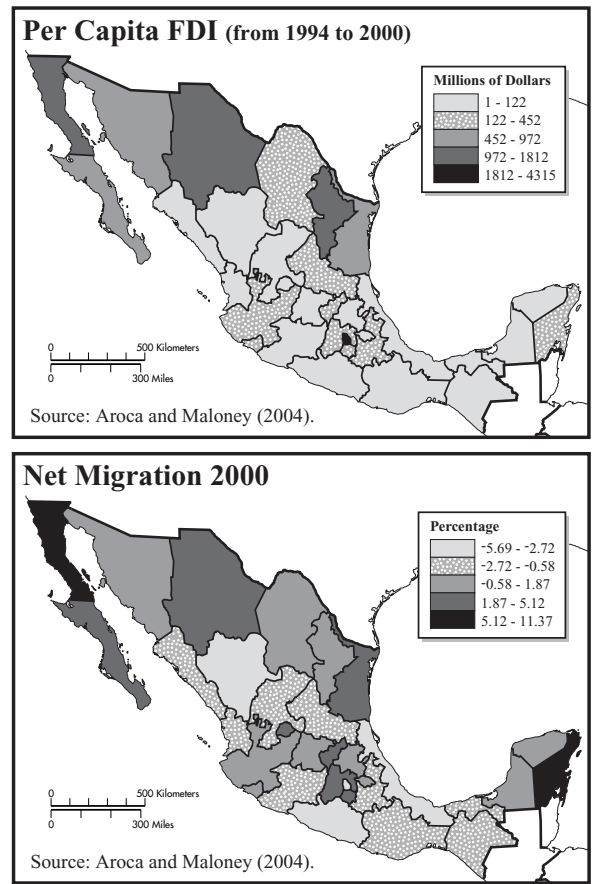

eight years of trade reform, the share of manufacturing activity in Mexico City had fallen to 28.7 percent and the share at the border had risen to 29.8 percent. By 1998, four years after NAFTA, Mexico City's employment share had fallen further to 23.0 percent and the border's employment share had risen to 34.0 percent. This had a striking impact on the shape of the wage gradient within Mexico. Generally speaking, regional relative wages decrease with the distance from Mexico City and from the Mexico-U.S. border. Prior to trade reform a 10.0 percent increase in distance from Mexico City and the border was associated with a 1.9 percent and 1.3 percent decrease in the relative state nominal wage, respectively. After trade reform, however, the effect of distance from Mexico City on state manufacturing wages weakens and the effect of distance from the United States strengthens. Because this tilting of gradient happened during a time of greater U.S. restrictions on migration from Mexico it is more likely to be the result of trade and investment liberalization. ${ }^{52}$

The apparent tilt in wage gradient is also broadly consistent with work analyzing spatial patterns of Mexican growth using state-level 
GDP that found a cluster of states with high per capita GDP income among the border states, and a low income cluster in Chiapas, Guerrero, and Oaxaca in the south, far from either the capital city or the border (Aroca, Bosch, and Maloney 2002; also see chapter 3). However, in this case there is little evidence for a smooth gradient flowing from the border south. The row of states behind the front line (Durango, San Luis Potosí, Tamaulipas, and Zacatecas are not rich and do not appear to form a "convergence club" with the border states. Whether this same pattern will emerge for wages remains to be tested.

In summary, the mechanisms through which convergence is thought to work are confirmed in much of the empirical work to date. FDI, trade, and maquila presence all increase labor demand in an individual state, raising its wages, lowering unemployment, and reducing outmigration. Therefore, given the extremely noisy macroeconomic evolution over the last decade, the fact that aggregate measures of convergence are ambiguous perhaps should not be too distressing. However, it is also true that there have been striking movements in the distribution of wages across skill groups-movements whose roots are not known with confidence, but which add additional noise to the aggregate convergence regressions. We turn now to this phenomenon.

\section{Increasing Wage Dispersion and the Skill Premium}

The same Stolper-Samuelson logic that predicts that trade liberalization should lead to a convergence of wages and returns to capital with those of the trading partners also applies to subcategories of the labor force. Mexico has an abundance of unskilled labor and relatively scarce supplies of physical and human capital. The expectation would be then that liberalization of trade with Canada and the United States would lead to an increased demand for unskilled labor-intensive goods relative to skilled labor-intensive goods and therefore to a fall in the premium for skills and an improvement in the distribution of wages. Even if levels of wages are too muddied by crises to tell clear stories, the distribution of wages may be less so.

Since the mid-1980s, however, the reverse of the predicted evolution has occurred, a phenomenon found throughout the region as well as in Europe and the United States. ${ }^{53}$ After the trade liberalizations of the 1980s wages of skilled workers rose sharply relative to those of unskilled workers. ${ }^{54}$ Cragg and Epelbaum (1996) showed that between 1987 and 1993, relative to the wages of workers with a primary school education (grade 6 completed), wages of workers with secondary education (grade 9 completed) rose by 15 percent and the wages of urban workers with post-secondary education rose by 60 percent. The rise did not continue throughout the 
1990s, however. Esquivel and Rodríguez-Lopez (2003) documented the same rise in the ratio of the wages of nonproduction to production workers until 1996 before the series levels off or even declines, a pattern repeated if we simply look at the ratio of the 10 percent best-paid workers to the bottom 10 percent (De Ferranti et al. 2002).

Despite this levelling off after NAFTA, the issue is still critical for several reasons. First, we are interested in the impact of NAFTA in the context of overall integration with the United States, including previous reforms, so the pre-NAFTA period remains of interest. Second, the earlier dynamic may still be present during NAFTA but masked by the crisis. Finally, as noted in table 5.6, common co-movement in skill premium seems to explain any overall co-movement of U.S. and Mexican wages, and identifying the factors driving this increasing premium is important to the issue of overall integration of wages in levels.

That said, there is as yet no consensus on those factors beyond the fact that they are relative demand phenomena rather than supply phenomena. ${ }^{55}$ Staying within the Stolper-Samuelson theorem, several factors suggest themselves as possible explanations. First, prior to liberalization, labor-intensive sectors had the highest tariff and nontariff barriers and hence experienced falls in their prices. Initial tariff reductions in Mexico as a result of NAFTA have been larger in more skill-intensive sectors. That raises the possibility that in the late 1990s trade reform may have halted the increase in skill premiums, as crude comparisons have suggested (see Hanson and Harrison 1999, Robertson 2001, and De Ferranti et al. 2002). It is also true that whereas Mexico has abundant unskilled labor relative to Canada and the United States, emerging competition in the far east does not have that abundance. Hence, Stolper-Samuelson may be predicting correctly given the new trade patterns.

Skill-Biased Technical Change. However, the widening skill gap is so widespread that such specific trade policies are unlikely to be capturing all relevant effects. Skill-biased technical change unrelated to trade is the dominant explanation for the rising differential in Argentina, Brazil, Colombia, Europe, and the United States ${ }^{56}$ and there is some support for this view in Mexico. Firms that invest in research and development or training of workers tend to have wider spreads between skilled and unskilled workers than do firms that do not so invest, and consistent with studies by the Organisation for Economic Co-operation and Development, firms with greater access to technology have, overall, a higher demand for skilled workers (Tan and Batra 1997, Lopez-Acevedo 2001, and Esquivel and Rodríguez-Lopez 2003).

These phenomena may, in fact, be more related to trade liberalization in the developing countries than in the industrialized countries, although the evidence is far from certain. Figure 5.7 suggests that exposure to 


\section{Figure 5.7 Wages Adjusted for Human Capital by Degree of Exposure to Foreign Competition}

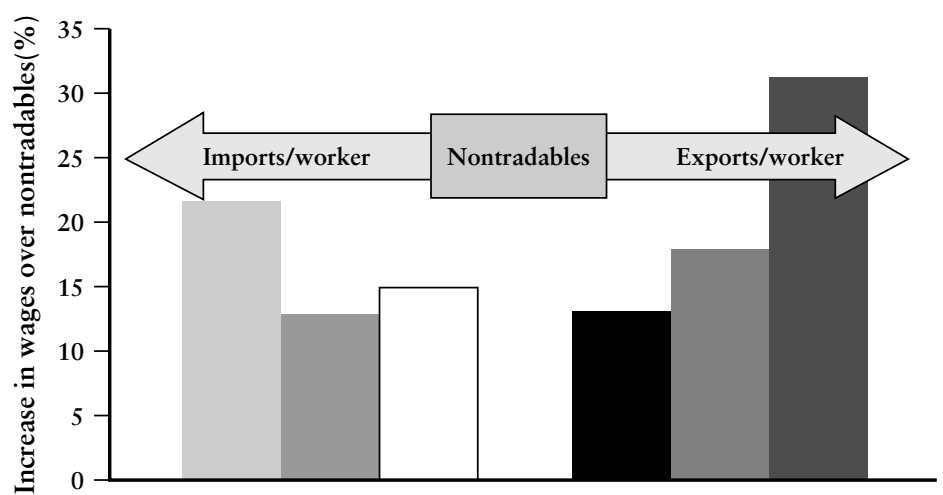

Note: Nonagricultural workers. Conditional on human capital.

Source: De Ferranti et al. 2001.

global competition is associated with higher wages after adjusting for education, and hence demand for unobserved skills. The bar at the extreme left represents the third of workers in import-competing industries that are most exposed, measured as the dollar value of imports per worker, and exposure decreases moving toward the middle section that represents nontradables such as services or commerce. The three bars on the right capture increasing exports per worker moving right. What jumps out immediately is a $U$ pattern where those industries most exposed to competition pay higher wages, a finding consistent with the extensive literature from other countries. ${ }^{57}$

In firm-level studies, external competition is associated with the adoption of new technologies and these, in turn, require training and skill upgrading. The tripling of manufacturing exports observed during the 1990s has been associated with increased rates of adoption of modern production technologies, an acceleration of productivity growth, and a relative increase in the demand for skilled labor. Between 1992 and 1999 the rates of adoption of modern manufacturing technologies were not only higher among exporters than nonexporters, but they also increased more rapidly. Firms also show higher rates of both human capital and skill building prior to entering export markets, and there is an association between plant-level efficiency (total factor productivity) and exporting. 
To the degree that these additional skills are not captured by the fairly standard and imprecise human capital variables, more open industries will appear to pay higher wages, as suggested in figure 5.7 (Audretsch and Lopez-Acevedo 2001; Hallberg, Tan, and Koryukin 2000; and Lopez-Acevedo 2001). Furthermore, these industries may also pay higher than market clearing or "efficiency" wages to hold onto workers they have trained. The inability of these microeconomic studies to establish causality (i.e., whether more technologically able firms are taking advantage of new trade opportunities or whether more trade caused technological upgrading) means there may be no necessary contradiction with the findings noted above from Argentina, Brazil, Colombia, Europe, and the United States that trade did not drive the skill premium.

Finally, studies using household data have found a correlation between the wage premium with technology embodied in trade measured by Keller's measure of trade-weighted technology imports correlated with the skill premium (Schady and Sánchez-Páramo 2000). This measure does have the odd property that the technological transfer effect appears counterintuitively to decline with distance- that is, European-embodied technology has a lower impact than does U.S. technology (see chapter 6). It may not be trade per se but the relationships among firms or individuals that is responsible for technology transfer and is simply being proxied for by trade variables. This does not imply that the widening skill differential is unrelated to liberalization or NAFTA; only that the impact may be through encouraging firms to look outward more generally than trade itself.

Foreign Direct Investment and Outsourcing. Increased outsourcing to Mexico by foreign firms may also partially explain the skill premium (see Feenstra and Hanson 1996, 1997). A large fraction of U.S.-Mexico trade in manufactured products is the result of U.S. multinational firms establishing maquiladoras in Mexico. In 1995 exports by maquiladoras accounted for 40.2 percent of all Mexican exports to the United States and grew to account for 25.1 percent of manufacturing employment in 1997. Although U.S. firms have relocated the low-skilled aspects of the production process below the border, these processes in fact are relatively skill intensive by Mexican standards. In regions where maquiladoras are concentrated, maquiladora growth can account for more than 50 percent of the increase in the skilled labor wage share that occurred during the late 1980s. More generally, FDI is likely to have an impact on the differential through similar channels, although the empirical studies to date are inconclusive. ${ }^{58}$

Migration. A substantial body of literature on the labor market consequences of immigration in the United States suggests that immigration has at most put slight downward pressure on the wages of low-skilled U.S. native workers. ${ }^{59}$ However, the effects may have been larger on the 
Mexican side. Mexican immigrants, although much less educated than U.S. natives, are on average more educated than residents of Mexico. The most likely group to migrate are individuals with 12 to 15 years of schooling, and removing this relatively large number of individuals from the middle of Mexico's wage distribution may contribute to raising wage dispersion in the country (Chiquiar and Hanson 2002). ${ }^{60}$

Labor Market Institutions. Changes in the influence of labor market regulations and institutions may also have affected the wage distribution as well as the rate of convergence to U.S. wages. For instance, the process of privatizing and deregulating state-owned enterprises and in general exposing firms to greater external competition may have altered the bargaining power of workers. The same may have occurred in the various pactos and policies implemented by the government that urged firms to exercise restraint in raising wages and prices during Mexico's inflationary period in the late 1980s and early 1990s.

One by-product of these incomes policies was a 45 percent decline in the real minimum wage during the $1980 \mathrm{~s} .{ }^{61}$ The first panel of figure 5.8 offers kernel estimates of the density function with a vertical line to mark the location of the minimum wage (Maloney and Nuñez forthcoming). The second panel is the cumulative distribution of wages. The formal and informal wage distributions are plotted in light and dark lines, respectively. ${ }^{62}$ In each graph, a "piling up" of the probability mass around the minimum wage suggests that the policy has, in effect, forced a change in the distribution. Both graphs suggest that in the formal sector the minimum wage is not strongly binding although it is in the informal sector. This may reflect a "lighthouse" effect where what informal workers consider to be the "fair" wage is indexed off the minimum wage. This effect, along with what might be called the "numeraire effect" of minimum wage gains being used as references higher up in the wage distribution were also recently verified by Castellanos, García Verdú, and Kaplan (2003) suggesting that the minimum wage may be more binding than first appears in figure 5.8. Nonetheless, they still found fewer nominal rigidities than in the United States, and Bell's (1997) finding that even in 1990 plant-level employment seemed unaffected by the minimum wage suggests that, although declining since, it is unlikely to be a major driver of the overall wage distribution.

Whether unions have become less powerful and whether their power was previously exercised in seeking higher wages for less-educated workers is not clear. Quantile analysis on manufacturing surveys from the early 1990s suggests that Mexican unions used their power more to affect levels of employment than to affect wages, except to put a floor under the wages of each skill class. This would be reasonable if, given the limited reach of unemployment support programs, employment is more valued than are wage gains. ${ }^{63}$ On the other hand, Fairris (2003) argued that the substantial decline in union coverage and bargaining 
Figure 5.8 Impact of Minimum Wages on Wage Distribution

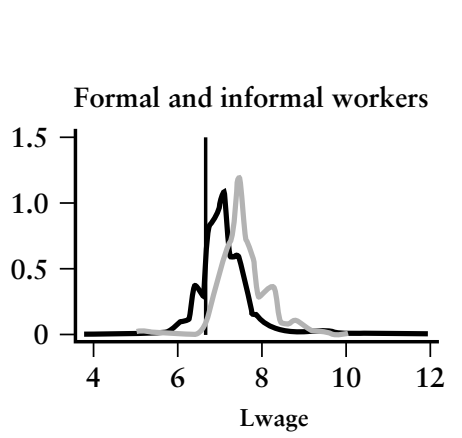

Mexico, 1999:1
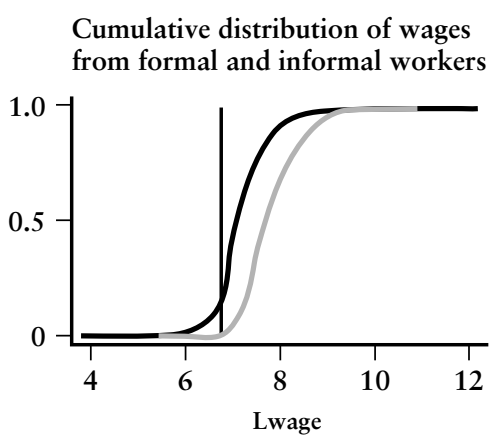

Mexico, 1999:1

- Informal workers

- Formal workers

Source: Maloney and Nuñez (forthcoming).

power from 1984 to 1996, the time span including the first period of liberalization, increased the rise in inequality by roughly 10 percent. Although explaining relatively little of the increase, this would be consistent with the fact that both production and nonproduction workers in manufacturing plants experienced a fall in their wages relative to U.S. workers, with a roughly equal fall in trade protection of the two groups. Alternatively, the declining Mexico-U.S. differential might not reflect diminished union power per se, but simply indicate that increased competition reduced the monopoly rents for which unions previously were able to bargain for both groups of workers (Revenga 1997). Either would provide an alternative to failed predictions of the Stolper-Samuelson theorem, but neither is particularly helpful in explaining the increasing skill gap. ${ }^{64}$

Given the fact that the rising skill premium has appeared in countries with a wide variety of labor market structures, it may not be surprising that changing minimum wages and union power seem unlikely to be driving the evolution of the wage distribution. Overall, the very weak linkages through trade in Mexico and elsewhere in the region and in Europe and the United States suggests that the liberalization process in general (through FDI and greater contacts with firms abroad) may have led to greater rates of transfer of skill-biased technology.

To the degree that the mechanism through which this is conveyed to the labor market is the creation of more demanding jobs that will be 
Table 5.7 Evolution of Household Inequality

\begin{tabular}{ccc}
\hline Year & $\begin{array}{c}\text { Gini Coefficient } \\
\text { (World Bank) }\end{array}$ & $\begin{array}{c}\text { Gini Coefficient } \\
\text { (Mexican Government) }\end{array}$ \\
\hline 1992 & 55.9 & 47.5 \\
1996 & 54.4 & 45.6 \\
2000 & 54.6 & 48.1 \\
2002 & n.a. & 45.4 \\
\hline
\end{tabular}

n.a. Not applicable.

Source: De Ferranti et al. (2004) for the World Bank and the Mexican Statistical Institute (INEGI) Web site for the Mexican government.

more satisfying to workers over the longer term, the rising skill premium is preferable to the alternative. The challenge is to ensure that the educational system is able to generate workers with the necessary skills.

A final observation: neither the increasing wage dispersion nor other liberalization factors appear to have translated into worsening household income distribution. Table 5.7 reports two sets of Gini statistics measuring household inequality, the first from a recent World Bank report titled Inequality in Latin America: Breaking with History? (De Ferranti et al. 2004) and the second from the official Mexican statistics. There are definitional differences so the absolute levels are not necessarily comparable. But the trends are similar. In both series there appears to be a decrease in inequality in the period of increasing trade liberalization to just after the Tequila crisis, followed by a slight increase during the post-crisis recovery. But taking the 1992 numbers as pre-NAFTA and comparing them to either the 2000 or 2002 numbers, there appears to be a decrease over the period overall. Again, with the noise from the Tequila crisis and without controlling for other factors it would be difficult to confidently attribute the improving income distribution to trade reforms.

\section{Other Measures of Labor Market Performance}

Although the rising wages and historically low unemployment figures cast some doubt on the argument that NAFTA has reduced overall employment, some observers have argued that trade liberalization, and NAFTA more specifically, have led to decreases in certain types of employment and more generally to an erosion in the quality of work. One preoccupation is that trade liberalization has contributed to the rising number of "informal" workers-those unprotected by social security and health benefits. ${ }^{65}$ A second preoccupation is Rodrik's (1997) concern that the increased competition leads to a greater product demand elasticity that, through Marshall's iron law of factor demand, translates 
into greater own wage elasticities of demand. This, in turn, means shocks are more directly translated to the labor market than previously, thereby leaving workers to face more aggregate risk.

Emerging and Declining Sectors. Trade liberalization leads to a better allocation of workers from sectors with little future in the global economy to sectors more in line with a country's comparative advantage. The actual effects are not always so easy to measure and we examine only two that have received special attention. For a more complete treatment of issues of job quality, see De Ferranti et al. (2002).

Export Processing Work Figure 5.9 plots the level of employment in export-oriented maquilas and a measure of rural employment over the last 20 years. Export processing sectors have generated high rates of employment growth, rising from under 0.5 percent of employment just before the 1987 liberalization to just over 3.0 percent at their peak in 2000. The graph suggests that there may have been an increase in the rate of job creation in the sector after 1995 although this is partially because of the substantial depreciation of the peso. The overall impression from the

Figure 5.9 Jobs in the Maquila and Registered Rural Sector (thousands)

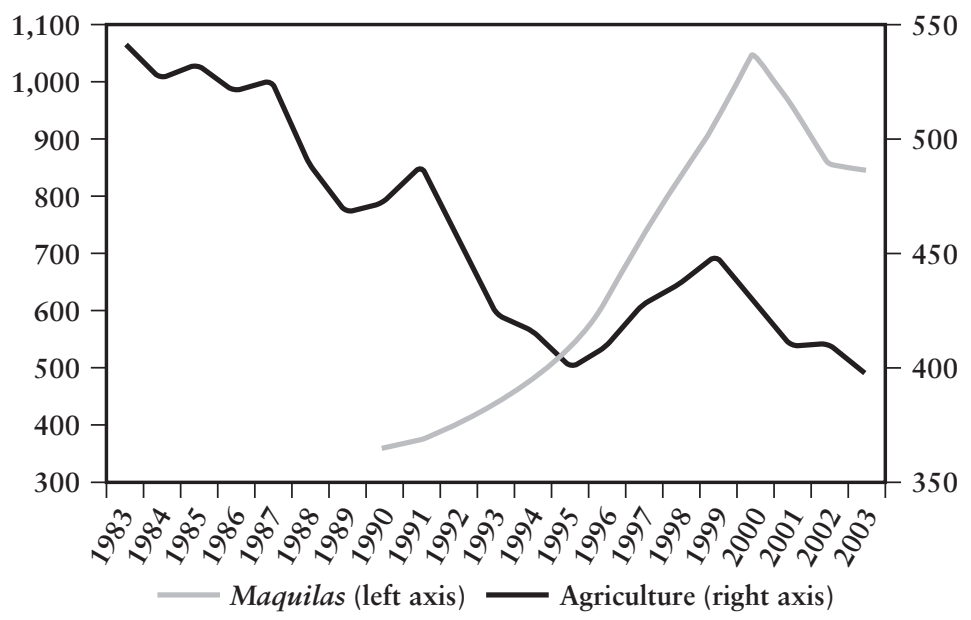

Source: Mexican Government, INEGI, and the Mexican Social Security Institute. 
limited data is that these are considered good jobs for modestly educated people, a view supported by admittedly small surveys (Sargent and Mathews 1999) and there is rising alarm within Mexico that the jobs are being lost to lower wage Asian locales. Recent studies suggest that pay is higher than comparable sectors and the jobs are desirable, and among women's groups the concern is that men are crowding women out of these jobs. ${ }^{66}$ The literature suggests that a combination of job security, low skill demand, flexibility in managing home and child responsibilities, and a rapid route to financial autonomy is attractive to the overwhelming majority of the workforce that is female (Chant 1991, Fussell 2000, Sargent and Mathews 1999, and UNIFEM 2000).

The high degree of homogeneity of product and the strong competition with Asia mean that Marshall's fundamental law of labor demand holds ferociously in this industry. A very high elasticity of product demand means there is relatively little latitude for raising wages without corresponding increases in productivity. Electronics producers in Guadalajara report a very slim margin (3 percent including transportation) over Malaysia in electronics assembly, and the source of their comparative advantage lies in the ability to respond quickly to customize machines within days, which the Asian manufacturers cannot do. The loss of some of these jobs may be welcome. The now established Asian newly industrialized countries went through a process of graduation from low-wage/low-skill industries to those requiring more highly skilled and higher quality workforces. However, to the degree that it reflects, for example, new, reasonably educated, and very low-cost Chinese capacity coming on line with the increasing global integration of that country, it represents a major challenge for the Mexican labor market.

Rural Employment Concerns about the impact of trade and in particular NAFTA on the rural areas has focused both on the potential adverse effects on rural employment and on the quality of new jobs created. Unfortunately, Mexico's surveys do not permit trustworthy evaluation of the impact of NAFTA on the sector. The National Employment Survey (Encuesta Nacional de Empleo) is available only since just before NAFTA and has a significant change in methodology that makes comparisons before and after 1994 suspect. As an alternative although imperfect measure, figure 5.9 graphs the employment of workers registered with the social security administration. Although this measure almost certainly misses subsistence farmers, what it suggests is that employment in the rural sectors has been falling steadily across the 1980s and that, if anything, the rate of job destruction slowed with the devaluation and recovery of the post-NAFTA period.

Furthermore, the limited available evidence at a microeconomic level suggests that subsistence farmers were substantially less affected by 
NAFTA than was expected. For example, NAFTA calls for a gradual (15-year) phase-out of price supports for corn staples. Taylor (2001) undertook some simulations of the impact this phase-out would have and then compared it with detailed surveys at the village level in Michoacan. When perfect integration of the small farmer economy with the national and international market is analyzed in a village-level computable general equilibrium model, the 18 percent real drop in the support price for white corn between 1994 and 1997 was predicted to lead to a 26 percent fall in output and a 4 percent increase in migration to the United States. In fact, corn output declined only slightly, from 18.13 to 18.02 million metric tons, and neither rural incomes nor migration to the United States were greatly affected (see chapter 4). Taylor argued that the reason for these results is that rural campesino communities are much more diversified than was thought and they face very high transaction costs getting their crops to market, which prompts local rather than international price determination (Taylor 2001). ${ }^{67}$ Simulating in the model this relative isolation from the market by allowing prices to be determined locally, production actually increased because of the effects on consumption of the transfer from PROCAMPO.

Some of the factors that isolate rural communities from the heat of international competition, however, have also kept those farmers among the poorest Mexicans and prevented them from taking advantage of what new opportunities are offered by trade reform. Subsistence farming is very low-productivity agriculture that does not offer long-term potential for exit from poverty. The limited evidence suggests that earnings in emerging nontraditional agricultural sectors (e.g., flowers in Ecuador and fruits in Chile) tend to be higher than other wages in rural areas (see De Ferranti et al. 2001). However, this more optimistic picture seems hard to square with, for instance, the situation of indigenous migrant workers in Sayula, Jalisco, roughly an hour from Mexico's Silicon Valley in Guadalajara, where working conditions are indeed harsh and have been subject to human rights investigations. As is true of maquila workers, the available evidence suggests that workers do consider these jobs to be better than their next-best alternative. ${ }^{68}$ However, Mexicans might reasonably hope for something better. Unfortunately, the migrants to Jalisco are very poorly equipped for more sophisticated jobs and, more generally, for competition in the global marketplace. At the most basic level, only 55 percent of workers speak Castilian, which makes coordination difficult even in the tomato business. As with other indigenous groups, these workers have among the lowest levels of literacy, and the need to put their children in the fields perpetuates low educational attainment.

This also partly explains why little of the arriving FDI has gone to the states with the highest indigenous populations. There is a statistically negative relationship between the percent of the population that speaks 
an indigenous tongue and FDI, although the effect appears completely the result of the correlation with being distant from the United States and with low levels of education. That said, Quintana, Roo, and Yucatán, which have ready access by sea to U.S. markets, have higher than predicted FDI and that suggests that indigenous language or culture need not be a barrier to participating in emerging industries.

The overall picture that emerges is that the poor infrastructure, geographical distance, and even cultural norms that often isolate indigenous communities prevent ready access to the new opportunities offered by the global marketplace, but those same factors also have given workers time to adjust to the inevitable long-run competition on the import side. This time can be used both to raise the quality of education and to think through appropriate strategies for growth that maintain cultural integrity to whatever degree possible.

Unemployment and Informality. Looking again at figure 5.4, it is difficult to infer any trend toward increased unemployment following NAFTA. In fact, following the crisis, unemployment reached its lowest level in decades. This is consistent with global comparisons that suggest there is no long-term relationship between openness and unemployment (see De Ferranti et al. 2001; Marquez and Pagés 1998). Nonetheless, it may be argued that the low unemployment figures disguise a persistent and increasing level of underemployment or unprotected employment of poor quality. One view sees the "informalization" of employment occurring as global manufacturing networks seek to control costs by reducing worker benefits: large and medium-size firms facing international competition, or multinationals themselves, outsource production to informal small firms, including home-based and self-employed microentrepreneurs (see, e.g., Castells, Portes, and Benton 1989).

The evidence to date is less pessimistic. To begin, repeated microenterprise surveys suggest that 65 percent of informal firm owners report entering the sector voluntarily for higher earnings or more flexibility, and the vast majority (90 percent) remain oriented toward the domestic market. ${ }^{69}$ In fact, a U-shaped relationship similar to that in figure 5.7 appears between the degree of industry exposure to external competition and the share of formal workers in the industry: more-exposed sectors show fewer informal workers. This is broadly consistent with the evidence from Brazil and Ecuador (Goldberg and Pavcnik 2003 and Martinez and Pagés 2004), which also found that increased trade does not lead to lower rates of social security affiliation. Furthermore, in Mexico the number of microenterprises reporting linkages with large firms that might be international has actually fallen from 2.0 percent in 1992 to 1.5 percent in 1996 and those connecting with larger firms appear to do relatively better (Sanchez, Yoo, and Zappala 2001). Micro firms whose 
Figure 5.10 Relative Formal/Informal Sector Sizes and Incomes and the Real Exchange Rate
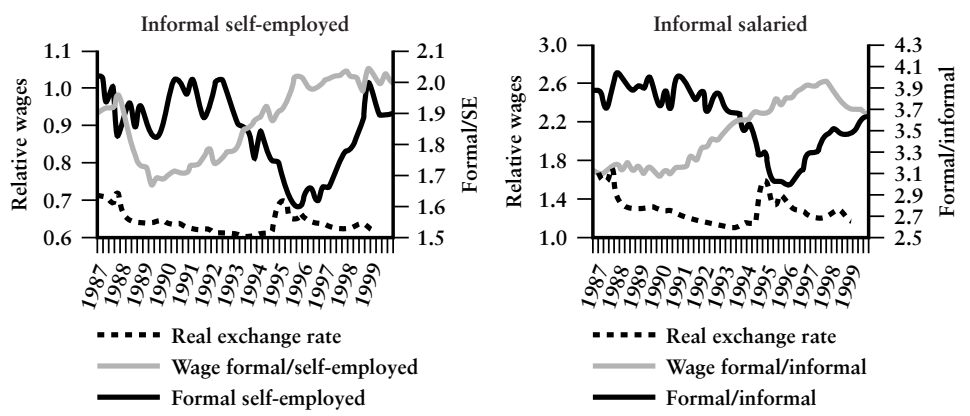

Source: Fiess, Fugazza, and Maloney 2000.

clients are large firms and those located in areas with high FDI earned roughly 25 percent more than their comparable counterparts, and those with large suppliers do roughly 10 percent better than comparable firms. ${ }^{70}$ Arguably it is the isolation from markets more generally and from public institutions that is the larger problem.

The largely voluntary and nontradable nature of the sector suggests that movements in the sector size over the last decade may be better described as outcomes of the macro evolution over the last decade in the spirit of standard tradable/nontradable small economy. ${ }^{71}$ Figure 5.10 plots the ratio of the number of formal sector workers relative to the number of informal workers, their relative incomes, and the real exchange rate. In a traditional dualistic or segmented view of the informal sector we would expect to see the two labor market variables move against each other: a rise in the formal sector wage, perhaps resulting from an increase in minimum wages or increased competitive pressures, would force workers into the informal sector and drive down the informal wage relative to the formal. But what is striking is that in Mexico these series moved together in the beginning of the 1990s and at the same time the exchange rate was appreciating. This suggests that the dramatic rise in informality during this period was driven by increased opportunities in the nontradables sectors that expanded across this time. In the period of the strengthening peso, there does seem to be evidence of an increase in informality concomitant with a decline in relative informal 
income in Mexico from 1992 to 1994 that suggests segmentation arising from nominal rigidities presenting difficulties in adjusting to further shocks. This tendency is sharply reversed after 1995 as the share of the workforce in formal employment increases sharply again, rising toward traditional levels. In the same way that it is unreasonable to attribute the sharp crisis-induced wage declines to trade liberalization, so it is probably unreasonable to attribute to NAFTA much of any increasing informalization of the workforce in the post-NAFTA period. Preliminary study suggests that there is a secular increase in female employment in the informal sector across a similar period, but it appears to be largely driven by the striking increase in female labor force participation.

Increased Labor Market Risk? A final concern is that more competitive product markets are likely to lead to a greater sensitivity of the labor market to shocks: NAFTA would make life riskier for Mexican workers. For ongoing firms Marshall's iron law of factor demand suggests that a higher product elasticity will translate into greater own wage demand elasticities. However, the theoretical case is not clear-cut and there is little evidence of the effect from liberalization experiences in Chile, Colombia, or Turkey and only weak evidence from Mexico after the first wave of reforms in $1987 .{ }^{72}$ The literature is very ambiguous about what the impact on firm entry and exit should be with the changes in competition, uncertainty, and barriers to entry surrounding trade liberalization, although existing studies from Chile and Colombia do not suggest large effects. Looking at labor force data directly, after extracting transitory shocks that workers can hedge against and looking only at permanent shocks, worker risk does appear to increase with changes in the trade regime, but not by level of protection (Krebs, Krishna, and Maloney 2004).

\section{Challenge of Labor Policy in a Free Trade World: Raising Labor Productivity}

At the time of NAFTA's signing, the Mexican labor market was not excessively rigid or distorted: minimum wages were weakly binding and unions seemed primarily concerned with maintaining employment rather than fixing wages. ${ }^{73}$ Arguably the fact that unemployment has remained so low in Mexico, even in times of crisis, reflects the relative ease of adjusting real wages. The very large informal sector, accounting for close to 50 percent of the workforce, probably reflects the low opportunity costs of self-employment arising from low formal sector productivity and the weak linkages between contributions and benefits in the formal sector rather than segmentation as customarily imagined. There is a very high degree of turnover, much of it voluntary, and there are substantial flows of workers in each direction between both formal and informal sectors. 


\section{Figure 5.11 Estimated Flexibility/Distortion in Selected Labor Markets}

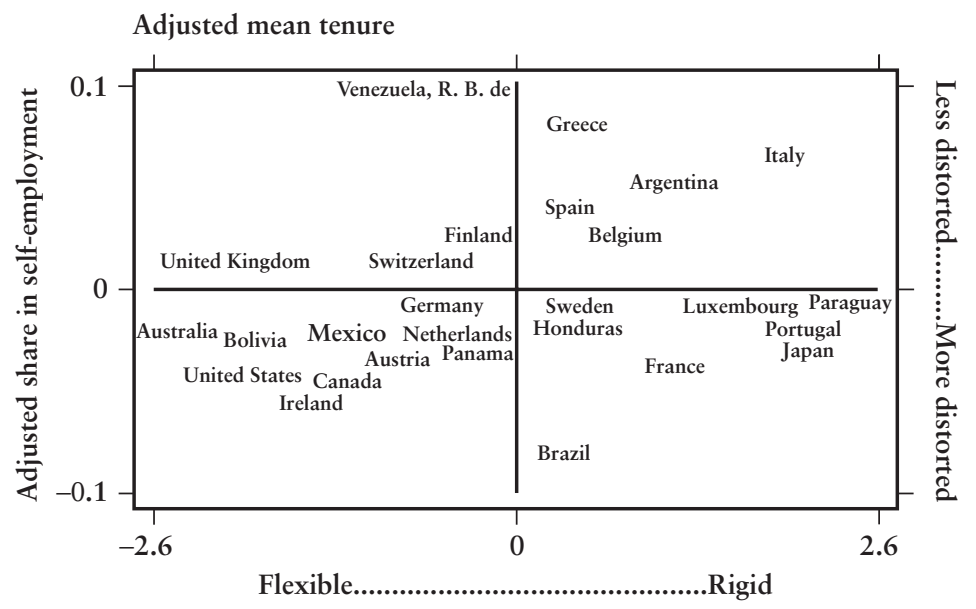

Source: Maloney 2001.

Figure 5.11 suggests that when adjusted for demographic and other variables, Mexico shows neither a high degree of informality (a possible measure of segmentation) or low turnover (a common measure of flexibility).

A full examination of labor market reform priorities is beyond the scope of this chapter, but conventional concerns with reducing wage rigidities should probably not be the primary focus of a NAFTA-compatible labor policy, although care is needed to see that rigidities do not become a problem over the medium term: the fall in inflation, greater openness to trade, and the weakening of labor unions may lead to more frequent labor market adjustments through unemployment.

Two issues do merit attention. The first is ensuring that the Mexican labor code is consistent with an overall strategy of moving toward a dynamic innovation-driven economy. The many ways in which Mexico is sorely lacking in this respect, and how critical this is to the long-run benefits of NAFTA are discussed at length in chapter 6. Second, it is essential that institutions evolve in such a way that workers are protected in a more open and dynamic economy (see De Ferranti et al. 2000). It is important to highlight the fact that in many areas of potential change, there are net gains to be made by both workers and firms in overhauling 
an inefficient system: both would benefit from restructuring the severance pay system and improving and expanding worker training. Reform of the industrial relations and collective bargaining framework involves altering some legal structures dating from 1917. But if placed in the context of modernizing the workplace and enhancing the technical proficiency and productivity of the worker and, in the medium term, improving compensation, common ground is more likely to be found for a coherent package of reforms.

\section{Enhancing Labor Productivity}

Over the long term the only way to raise Mexicans' standard of living is to increase labor productivity. This requires both flexibility in introducing new techniques into existing industries and facilitating the flow of labor from industries adversely affected by NAFTA into new industries that benefit from it. There is a lesson to be learned from the Scandinavian labor unions, which have consistently embraced a policy of open trade regimes, encouragement of technological adoption, and outsourcing of low-productivity jobs despite their short-run costs in worker dislocation (Hjalmarson 1991).

Mexican labor productivity has grown below the regional average for the last two decades and many of its existing characteristics and institutions are likely to continue to impede turning this around. Human capital levels remain below those customary for a country of its income level and below those of countries that have engaged in "take-offs" in innovative activity, such as Finland, Israel, Korea, and Taiwan (China). This is critical for several reasons. First, raising the level of human capital is key to redressing the worsening distribution of wages discussed earlier. Greater exposure to trade, investment, and outward orientation have increased the returns to skills and hence the incentive to acquire them. Institutions need to be responsive to this increased demand. Second, the increasing flight of jobs out of Mexico to cheaper venues dictates that Mexico upgrade its workforce so as to occupy higher rungs of the international production ladder. The experience of Costa Rica suggests the potential for deepening and moving into more sophisticated technologies. The fact that Costa Rica has the highest software exports per capita in the region and the fact that Intel is establishing a center to develop software there suggest that the technological sector may have "roots" in a way that previous assembly did not.

But there are also ongoing barriers to productivity growth built into the labor code. Firms must face incentives not only to upgrade their production practices through a coherent innovation policy described in chapter 6; they must also be able to make the accompanying changes on the shop floor. In Mexico this is often cumbersome. As an example, in a 
labor code designed in the context of a closed economy, the workeremployer relationship is conceived of as a contract for life and legally a firm cannot adjust its workforce to adopt new technologies or, more broadly, adjust for economic reasons including downturns. On paper this provides far greater protection than that enjoyed by comparable workers in the neighboring NAFTA countries. Heckman and Pagés-Serra's (2000) Job Security Index found the discounted cost of dismissing a worker to be far higher in Mexico than in even the most regulated European labor markets-and there is a logic for it in the absence of any system of unemployment insurance and the lack of portability in many pension funds (particularly in the public sector). But the result has been an excessive emphasis on job stability, very costly adjustments to the workforce, and a system prone to involved litigation, leading to reduced labor mobility and impaired resource reallocation and slower job creation. ${ }^{74}$

Furthermore, recent simulations by Parente and Prescott (2000) suggest that the dynamic costs of such barriers in terms of productivity growth forgone can be very high. Garcia Verdú (2003), for example, offered several examples of how the extant labor legislation and union power interacted to impede the adoption of new technologies in the airline industry in recent years. NAFTA may have removed one set of barriers to technological adoption in the form of barriers to competition and the technology embodied in foreign goods, but there are still substantial barriers within firms.

Worker Protections. The necessary complement to the Scandinavian openness to trade and technological advances is their well-known safety net protecting workers, especially those moving between jobs. Unfortunately, the present Mexican system protects workers poorly. A comprehensive treatment of issues of social protection can be found in De Ferranti et al. (2001) but a couple of points merit mention here.

The system of job protection and severance pay discussed above is perhaps the least effective system imaginable in protecting workers against the inevitable shocks to the labor market. Effectively, risk is pooled not over the national workforce but over the worker's firm. Severance payments are often demanded exactly at the moment when a firm is least able to honor its obligations, leading to increased stress on weak firms and uncertainty for the worker about the firm's ability to pay. In practice, most severance packages are renegotiated (or, if not, legal fees may amount to 40 percent) and the worker gets substantially less than the amount mandated by law (Davila 1994). Furthermore, workers are reluctant to investigate more productive employment opportunities because of the loss of seniority-related benefits, and if they choose to leave they are more likely to seek to be fired than to quit. ${ }^{75}$ Other options, such as individual accounts or even unemployment insurance 
plans, ensure greater security and do so with fewer distortions of the firms' incentives to hire and innovate. ${ }^{76}$

NAFTA had as a specific side agreement, the North American Agreement on Labor Cooperation (NAALC) to ensure enforcement of existing labor protections and there are pressures to include even stronger measures in the Central America-United States Free Trade Agreement (CAFTA) and future agreements. More generally, the issue of labor protections and working toward making them uniform across trading partners is a complicated one (see Elliot and Freeman 2003), and the literature is ambiguous on protections' net impact on Mexican workers even from a conceptual point of view (see Brown, Deardorff, and Stern 1996). Although they found important synergies between globalization, development, and labor standards, Elliot and Freeman pointed out that even seemingly innocuous "enforce-your-own-laws" provisions, such as were the focus of NAALC, can lead to greater use of irregular contracts and can undermine improvements in core labor standards in countries with overly rigid labor laws. This is certainly relevant in Mexico where, as noted above, the labor laws' preclusion of firing workers for economic reasons and very high de facto firing costs make the country far more "protective" of workers than is true in Canada or the United States. A move toward greater flexibility in worker separations combined with greater protections for the unemployed, which are argued in this chapter to be important to productivity growth, may be impeded.

Of practical concern on both sides of the Rio Grande is that labor standards will not reflect local worker or national preferences, but may be abused as trade barriers by the advanced country partners. Stern's (2003) argument - that in the virtual absence of compelling evidence that multinationals or exporting sectors offer worse pay or working conditions than does alternative employment, and actually in the presence of the very large body of evidence to the contrary, the movement should be toward strengthening the International Labour Organization as a general watchdog over core labor standards rather than toward building labor standards into particular trade agreements-may therefore have merit. ${ }^{77}$ The potential for protectionist abuse would be reduced and pressure would be put not only on foreign trade but on all sectors of the economy.

In any case, history suggests that the only way to raise living standards in a sustained fashion is through increasing labor productivityworkers can be paid more if they produce more. As this report has argued, the challenge of raising productivity is a multidimensional one involving measures to accelerate capital formation, innovation, and the adoption of foreign technologies and those to increase the human capital of the workforce. The process of raising job quality is thus fundamentally the process of development to which trade agreements make 
only a contribution and that to be effective require complementary reforms in factor markets.

\section{Notes}

1. Studies of capital mobility often focus on covered short-term interest differentials. In this regard, Kumhof (2001) showed that covered differentials between the Mexican peso and the U.S. dollar have been negligible since 1996. Whether this is evidence of financial integration is debatable, however (see Dooley and Chinn 1995).

2. As noted in chapter 2 , trade liberalization had already advanced considerably since the 1986 entry of Mexico into the General Agreement on Tariffs and Trade.

3. This view is stated, for example, in Lustig (2001).

4. Much of the material in these sections is based on the background paper by Cuevas, Messmacher, and Werner (2002).

5. In contrast, public sector flows, which had been positive in the early 1990s, have remained negative (and relatively small in magnitude) after 1995, and as a consequence the capital account has been dominated by private flows. See Cuevas, Messmacher, and Werner (2002) for further details.

6. This residual item comprises loans to nonbank private agents, some of which are obtained on the basis of an official quasi-guarantee in the form of a supporting contract of the borrower with the government. In this sense they may not strictly represent loans to private agents.

7. These global trends are explored at length in World Bank (2001).

8. See Cuevas, Messmacher, and Werner (2002) for a comparison of trends in portfolio equity flows across emerging markets.

9. To keep things in perspective it is important to note that FDI to industrialized countries grew even faster in the 1990s.

10. The privatizations were those of the telephone company and the banking system.

11. This is still far below the corresponding figures for industrialized countries where M\&A transactions account for more than 80 percent of total FDI inflows. Of the M\&A flows to developing countries, privatization accounted for about half of the M\&A transactions. These figures are presented in Calderón, Loayza, and Servén (2002), who also examined possible differences in the economic impact of M\&A and greenfield FDI.

12. The jump in 2001 reflects one specific transaction (the sale of Banamex to U.S. investors) and therefore represents a one-time event rather than a change in trend.

13. The liberalization measures included privatization of commercial banks and the elimination of mandatory reserve requirements and directed credit.

14. The measures adopted by the authorities to confront the crisis are thoroughly described in Banco de Mexico (1996).

15. At first sight the pre-NAFTA boom in portfolio equity investment might appear as another result of the anticipation of the treaty, to the extent that foreign investors sought to buy into Mexican firms to take advantage of the upcoming strengthening of the relationship with the United States. If this anticipation had been an important force, however, one might have expected share prices of firms in tradable (manufacturing) industries to exhibit above-average growth. In reality, manufacturing share prices were the least dynamic of all sectors, which casts doubt on this interpretation.

16. The various effects that would fall under "credibility" are spelled out in Fernández and Portes (1998) and Whalley (1996). See also Schiff and Winters (1998). 
17. Note that even though FTAs do not necessarily preclude the imposition of antidumping duties, they nevertheless do offer formal mechanisms for dispute resolution. In this sense they provide a guarantee of uninterrupted market access. See Fernández and Portes (1998).

18. This locking-in is emphasized by Kehoe and Kehoe (1994).

19. In chapter 8 we complement this analysis with another empirical assessment focusing on the FDI performance of NAFTA's neighboring countries.

20. This is in contrast with other recent articles focusing instead on bilateral FDI flows or stocks, which often use empirical models based on gravity variables. See for example Levy-Yeyati, Stein, and Daude (2002).

21. Specifically, the Association of Southeast Asian Nations, the European Free Trade Association (which today is the EU), NAFTA, the Group of Three (Colombia, Mexico, and the República Bolivariana de Venezuela), the Andean Group in its recent revival, MERCOSUR (Common Market of the South), and the Common Market for Eastern and Southern Africa (which in the analysis is included only as an expected FTA).

22. Specifically, EXPFTA is a dummy that takes on the value 1 for a specified number of years preceding the FTA and equals 0 from the time the FTA comes into effect onward. The results below correspond to the case when FTA membership is anticipated two years ahead of its occurrence. Alternative time horizons were used too, without any substantial changes in results.

23. Thus, an increase in INTEGRATION holding FTAGDP constant would imply a reduced FDI appeal for the host country in question. Note that this variable has only time-series variation.

24. The dependent variable is net FDI inflow. All variables with a monetary dimension are measured in constant dollars and expressed in logs. Country fixed effects were added in all the regressions. Endogeneity is potentially an issue, especially in the case of GDP growth. However, specification tests could not reject its exogeneity. Additional experiments are reported in Cuevas, Messmacher, and Werner (2002).

25. The fact that the coefficient on global FDI is less than unity likely reflects the fact that increasingly important FDI recipients are excluded from the sample because of the lack of complete data. Our measure of total FDI inflows is not the sum of the inflows into the sample countries, which are obtained from a World Bank database, but a worldwide total reported by the World Investment Report from the United Nations Conference on Trade and Development.

26. Although this result is consistent with expectations and previous results concerning the role of openness, simultaneity is a potential concern because FDI may target traded sectors and lead to stronger export performance. However, there is likely a long gestation period between new investment and exports, which reduces the risk of simultaneity.

27. Albuquerque, Loayza, and Servén (2003) reported this result using direct measures of real wages for a reduced country sample.

28. It is important to note that the systematic overprediction found in Mexico in the final years is not encountered in other countries. Mexico's prediction errors are statistically significant in 1998 and 1999 (in the latter year only in the specification including institutional variables).

29. The details of this calculation are offered in appendix 4 of Cuevas, Messmacher, and Werner (2002).

30. However, Waldkirch argued that NAFTA did not bring about a significant increase in FDI from outside North America.

31. This is documented in Cuevas, Messmacher, and Werner (2002).

32. Blomström and Kokko (1997) reviewed some arguments in support of this view. The multi-FTA study by Levy-Yeyati, Stein, and Daude (2002) found some 
evidence that NAFTA's FDI effects are more modest than those of the other FTAs considered.

33. The data set is an unbalanced panel of 367 firms sampled between 1989 and 2000. Of these firms, only 64 are present for the whole sample period. Relative to the universe of Mexican private firms, the firms in the sample are relatively large and modern. Over 1994-2000 they accounted for some 4.5 percent of the formal private sector labor force, their sales amounted to 6.0 percent of GDP, and their total assets equaled 36.0 percent of GDP.

34. Strictly speaking, the data indicate the currency in which liabilities are denominated. We are equating dollar-denominated liabilities with liabilities to foreigners.

35. It is important to note that the real peso depreciation in 1995 cannot be claimed as an explanation for the continued high proportion of foreign debt after 1995, let alone in 2000 (when the real exchange rate was appreciating).

36. It is also likely that the relative stability of bank debt ratios shown in table 5.4 , notwithstanding the banking crisis and its adverse effects on bank credit volumes, conceals an increasing patronage of foreign banks by the firms in the sample. Unfortunately, the data do not permit verification of this conjecture.

37. This section draws extensively from López-de-Silanes (2002).

38. The state of Mexican financial markets is documented by González-Anaya and Marrufo (2001). See also De Ferranti et al. (2000) for a comparative perspective.

39. This has been amply documented by a large number of studies. See, for example, Beck, Levine, and Loayza (2000).

40. Of course this is not the only factor at work. Mexico's history of macroeconomic instability has also hampered financial development. However, restoring macroeconomic stability will not lead automatically to financial development without accompanying regulatory changes.

41. Details on the specific components and data underlying each index are given in López-de-Silanes (2002).

42. The exact definition of each variable is given in the background paper by López-de-Silanes (2002).

43. Recent studies have concluded that resort to the issuance of ADRs in foreign markets negatively affects the liquidity and investability of domestic capital markets and their ability to foster growth-although it has a positive effect on accounting standards and disclosure-related openness. See Moel (2001).

44. Similar calculations were done using purchasing power parity-adjusted series. Predictably, they fall between the two measures plotted here. The problem with the dollar-based measure is that if the exchange rate appreciates for reasons not directly related to the labor market in the short run (e.g., a burst in foreign investment) in dollar terms Mexican wages will rise, but they may not move significantly at all in terms of domestic purchasing power. The series were taken from the Mexican statistical agency (INEGI) for the Mexican hourly production worker and CPI series and from the U.S. Bureau of Labor Statistics.

45. Robertson took mean wages by age, education level, region of residence, and time period to construct a panel of synthetic cohorts. The data used to estimate his (1) and its variants are the same log wage means for matched U.S.-Mexican age-education cells. The data are quarterly and run from 1987 to 2001 . The maximum number of observations possible is 14,400 (48 age-education groups, 15 years, 4 quarters per year, and 5 Mexican regions). Not all cells can be matched because of demographic differences between the countries and following age groups over time so that the actual number of observations used in estimation is 13,145 .

46. Hanson (2002) found the very rapid rates of convergence (the equilibrium U.S.-Mexico wage differential being reached within one to two quarters) to be 
inconsistent with rising levels of trade, investment, and migration between the two countries, which in themselves suggest incomplete integration and hence less rapid adjustment. The rapid rate of convergence that Robertson estimated may be influenced by the high frequency of his data (quarterly) and the relatively short span of years they cover. If, in fact, we are observing a gradual transition to a new steady state, then his data would not be able to pick this up.

47. The sign of the interaction coefficients on the shock terms are often negative and are generally positive on the convergence coefficients. With the NAFTA effects there is some evidence of a small increase in convergence in electric machinery in the center, and faster convergence only in Tijuana and Matamoros, again suggesting migration.

48. Furthermore, Robertson and Dutkowsky (2002) found that labor market adjustment costs at the two-digit level of Mexican manufacturing are small-about an order of magnitude smaller than in industrialized countries, so persistent differentials should be eroded. On the other hand, the phenomenon of inter-industry wage differentials has spawned a very large body of literature, and significant differences in industry wages persist in Latin America. These differentials are also highly correlated across industrialized countries.

49. A large body of literature documents how particular Mexican states are more likely than others to send migrants to the United States and have been for many decades (see Woodruff and Zenteno 2001). These states are mostly in an agricultural region in western Mexico. They are neither the poorest states in the country nor the states that are closest to the United States. Most research attributes these migration patterns to longstanding regional networks that help Mexican workers find jobs in the United States. The persistence of these migration networks suggests that historical migration flows are a good indicator of current regional opportunities for migration abroad. For recent work on the impact of natural resources on growth, see Lederman and Maloney (2003) and Martin and Mitra (2001).

50 . When unemployment and wages are included in the migration equation, the impact of all of the "globalization"-related variables is sharply reduced and, in some cases, eliminated (Aroca and Maloney 2004).

51. As Hanson $(1996,1997)$ discussed, models of interregional trade based on increasing returns to scale (e.g., Krugman and Livas 1996) imply that economic activity will tend to agglomerate in a small number of industry centers and that regional wages will decrease with transportation costs to these centers. This latter result arises from a combination of congestion in industry centers, which drives up local housing prices relative to housing prices in outlying locations, and labor migration between regions, which requires that nominal wages in industry centers be sufficiently high that real wages are equalized across locations. Krugman and Livas (1996) showed that two types of industry centers emerge: a principal center (e.g., in Mexico City), in which firms produce for the domestic market, and a smaller center (e.g., at the northern border), in which firms produce for the foreign market (e.g., United States). If these two centers are in different parts of the country, then trade reform will shift activity away from the industry center oriented toward the domestic market and toward the industry center oriented toward foreign markets. See Hanson 1998 and Chiquiar 2001.

52. It is worth noting that Reyes, Johnson, and Van Swearingen (2002) found no impact of this increased enforcement on actual migration rates.

53. Robertson (2001) found that the returns to education for urban workers rose from 0.035 in 1987 to 0.050 in 1994 and to 0.070 in 1998. For Mexico also see Feliciano (2001). See, for Argentina, Galiani and others (2000); Chile, Robbins (1994); Colombia, Santamaria (2000); Costa Rica, Robbins and Gindling (1999); Mexico, Cragg and Epelbaum (1996) and Montes-Rojas (2001); and Uruguay, Sanguinetti, Pantano, and Posadas (2001). Sánchez-Páramo and Schady (2003) 
found similar increasing skill premiums for several liberalizing countries of Latin America.

54. Esquivel and Rodriguez-Lopez concluded that during the period 1994 2000 , the effect of trade liberalization on the wage gap was nil, suggesting that the very slight increase in wage inequality that occurred in this period was driven by technological progress.

55. Most studies employ the methodology of Katz and Murphy (1992) to separate the two possible causes. See, for Mexico, Cragg and Epelbaum (1996), LopezAcevedo and Salinas (2000), and Sánchez-Páramo and Schady (2003). There were similar findings by Robbins (1994) for Colombia and by Meller and Tokman (1998) for Chile. A now substantial body of European and U.S. literature has found similar phenomena there. Also see Jun, Murphy, and Pierce (1993).

56. See Abrego and Whalley (2002) for a review. Sanguinetti, Pantano, and Posadas (2001) found that import penetration increases inequality in Argentina, although Galiani and others (2000) found that this can account for only a small share of the increase. Santamaria (2000) found a similarly small effect for Colombia. Blom et al. (2003) showed that in Brazil, after controlling for workers' personal characteristics, wages rose in the industries where tariffs experienced larger reductions, but they did not find any correlation with inequality. Similarly, Sanguinetti, Pantano, and Posadas (2001) found no connection in Uruguay. Most recently, Behrman, Szekely, and Birdsall (2001) found for 18 Latin American countries during 1977-98, that technological progress rather than trade flows appears to be a channel through which reforms affect wages.

57. See Brown, Deardorff, and Stern (2002) for an extensive review of the literature. For firms that exported more than 80 percent of their product, wages were 58 percent to 67 percent higher. Maloney and Ribeiro (2001), using manufacturing firm-level data, found a premium for exporting but it disappeared when controls were made for higher levels of technology and training in export-oriented firms.

58. Aitken, Harrison, and Lipsey (1996), controlling for plant, industry, and region characteristics, found that, manufacturing plants that are foreign owned pay their skilled workers 21.5 percent more and their unskilled workers 3.30 percent more than do plants that are domestically owned. On the other hand, using firm-level surveys, Maloney and Ribeiro (2001) found the reverse-that skilled workers are paid 2-5 percent more and unskilled 2-17 percent more for union and nonunion firms, respectively.

59. For surveys, see Smith and Edmonston (1997), Borjas, (1999), and Borjas, Freeman, and Katz (1997). There also has been research on the performance of Mexican immigrants in the United States. See Cornelius and Marselli (2001) and Durand, Massey, and Zenteno (2001) on the changing characteristics of Mexican immigrants in the United States.

60. Chiquiar and Hanson (2002) reached this conclusion by constructing counterfactual wage densities for Mexican immigrants, which show the distribution of wages that would exist were Mexican immigrants in the United States paid according to the wage structure of Mexico. Comparing this counterfactual wage distribution with the actual wage distribution for residents of Mexico, it appears that male Mexican immigrants in the United States would tend to fall disproportionately in the upper middle of Mexico's wage distribution.

61. On wages in the informal sector in Mexico see Marcouiller, Ruiz de Castilla, and Woodruff (1997) and Maloney (1999). Bell (1997) found evidence of substantial noncompliance with minimum-wage laws in workplaces in the informal sector, although figure 5.8 speaks for itself. She also found no impact on firm hiring.

62. The informal sector is defined in each country either by whether a salaried worker is unaffiliated with social security systems or works in a very small firm (approximately six or fewer employees). 
63. Revenga and Montenegro (1998) regressed the log ratio of average wages in Mexican plants to average wages in the corresponding U.S. industry on average industry tariffs in Mexico, average industry import license requirements (a measure of quota coverage) in Mexico, value added per worker in the Mexican plant, capital per worker in the Mexican plant, and dummy variables for the industry and for the year. A 50.0 percent reduction in tariffs would be associated with a 3.7 percent reduction in relative Mexico-U.S. wages for production workers and a 4.3 percent reduction in relative Mexico-U.S. wages for nonproduction workers (where the difference in the estimates for the two samples is not statistically significant).

64. Maloney and Ribeiro (2001) found some impact at the 20th regression quartile. This suggests that unions ensure a minimum pay level for each skill class, but no obvious bias in favor of those workers with less skill. Also see Pencavel (1997) for a discussion of efficient bargaining in developing countries.

65. Conceptual and statistical definitions of the informal sector are not as clearcut as one might expect because of the sector's characteristically diverse and complex nature. In this section the informal sector includes three groups of workers: (1) employers who hire at most 15 or in most cases fewer than 5 paid workers, with or without apprentices; (2) self-employed workers who own and operate one-person businesses alone or with the help of unpaid workers, generally family members, and apprentices; and (3) employees in these microfirms, regardless of their degree of protection. Alternative definitions of the informal sector focus on the issue of "protectionism" and thus include owners or workers in firms of fewer than $15 \mathrm{em}$ ployees who do not have social security or medical benefits.

66. Fleck (2001) found that in 1998 maquila hourly earnings were 2.6 percent lower than Mexican wage workers in other sectors, but benefits averaged 8.0 percent more, leaving maquila workers ahead. More recently, Brown (2001) found that women and men who work in maquilas earn 38.0 percent and 31.0 percent, respectively, more than their counterparts in non-maquila manufacturing.

67. In a sample of 196 households in the central Mexican state of Michoacan, a number of surplus-producing farmers sold their excess production locally rather than selling to the government at the higher guaranteed price. When asked why, most responded that it was too costly to transport their harvest to the nearest government (CONASUPO) purchase point, approximately 40 miles away. Others cited cases in which neighbors had paid to transport their maize only to have it rejected on the grounds that the quality was not sufficiently high or the silo was already full. This added marketing uncertainty discouraged farmers from selling unless there was a sufficient price spread to cover transportation and an implicit marketing risk premium. Some farmers complained that, lacking their own vehicles, they would have had to sell to intermediaries at a price below the guaranteed price (reflecting the high transaction costs and marketing risks in this region).

68. The System for the Integral Development of the Family (Sistema Integral de Desarrollo de la Familia 2000) jointly with the National Autonomous University of Mexico interviewed 728 migrant families in the Sayula area about their reasons for leaving their home areas in Guerrero, Oaxaca, and Veracruz, three of the poorest states in Mexico. Fifty-three percent said they lacked good work; 27 percent reported that they needed money; 15 percent wanted to travel to other places; and 3 percent had no, bad, or contested land. But it is important to note that only 1 percent said they were deceived by the contractor who brought them to Jalisco. This, combined with the recurrent seasonal nature of the jobs and well-developed information networks, suggests that migrants knew about the conditions they would find and were so poor as to chose to take the jobs anyway.

69. To say voluntary is not to say well-off or even happy; it is to say only that in a market without segmentation this option was deemed better than alternative 
jobs in the formal sector. For a review of thinking on the role of the informal sector see Maloney (2004) and Cunningham and Maloney (2001).

70. The very small fraction of these who are home based do tend to earn about 20 percent less. This is likely to represent the cost of more flexible work arrangements for the overwhelming number of workers who are female with families (Cunningham and Ramos 2001).

71. Fiess, Fugazza, and Maloney (2000) explored cointegration relationships in relative earnings, relative sector size. and the real exchange rate and they formulated hypotheses to identify the degree of segmentation in the labor market in Brazil, Colombia, and Mexico. Positive co-movements between relative wages and sector sizes are attributed to segmentation, whereas negative co-movements of relative wages and sector sizes are classified as integration. Different labor market regimes are empirically identified with the Likelihood Ratio on the coefficients of the cointegration vectors, 1987Q1 to 1999Q1 for Mexico. The test of integrated markets in Mexico cannot be rejected prior to 1995 . Tests of the stability of the cointegration space suggest the possibility of different relationships in different subperiods. This finding is consistent with the argument that rigidities in the formal sector may bind in some periods and not in others, depending on the macroeconomic environment.

72. See Rodrik (1997), Fajnzylber and Maloney (2004), and Krishna, Mitra, and Chinoy (2001) for Turkey. Beginning from the standard neoclassical model of the firm with linear costs in a competitive context in 1894, Alfred Marshall derived a simple "fundamental law of factor demand" that describes the relationship between employment and the cost of labor:

$$
\Delta L=\alpha \Delta w+\eta \frac{w^{*} L}{P} \Delta w .
$$

The first term on the right-hand side simply measured the ease of substitution with other factors-machinery, for example. But the second term measured how much a rise in the wage translated into a rise in the cost of the finished product through labor's share in the price of the good. Then $N$, the product elasticity of demand, would tell by what percent output would fall with a 1 percent rise in product price and, hence, proportionally how much demand for labor would fall. When a firm sells a very common object that many people sell-tomatoes, nondescript textiles, or even basic computers, for example-it faces perhaps an almost infinite $N$. This means even very small rises in labor costs cause a very large fall in employment. But more generally, any increase in product elasticity through trade liberalization will be translated into the own wage elasticity. This implies that any product market shock is communicated more directly to labor markets, thus increasing the risk workers face. As Fajnzylber and Maloney (2004) noted, this "iron law" is in fact less rigid when the assumption of linearity of costs and perfect competition are relaxed and the actual impact of liberalization on demand elasticities may be indeterminate.

73. See Maloney, Revenga, and López-Acevedo (2001) for a more thorough treatment.

74. The rise in the number of wrongful dismissal cases that have challenged the "fire at will system" in the United States has led to a 2-5 percent decrease in employment despite payments that amount only to US\$10 per employee. The subsidiary effects on costs thus appear to be very large, on the order of 10 percent of labor costs at a labor demand elasticity of 0.3 (Dertouzos and Karoly 1993).

75. Dismissal can imply up to 122 days of salary per year of service in severance compensation; quitting entitles the employee to payment of only 12 days of salary per year of service.

76. See the Mexico Labor Policy Note in Giugale, Lafourcade, and Nguyen (2001). 
77. See Brown, Deardorff, and Stern (2001) for an extensive review of the global evidence on the effects of multinational production on wages and working conditions in developing countries.

\section{References}

The word "processed" describes informally produced works that may not be commonly available through libraries.

Abrego, Lisandro, and John Whalley. 2002. Decomposing Wage Inequality Change Using General Equilibrium Models. Working Paper 9184, National Bureau of Economic Research. Cambridge, MA.

Aitken, B., A. Harrison, and R. E. Lipsey. 1996. Wages and Foreign Ownership: A Comparative Study of Mexico, Venezuela, and the United States. Journal of International Economics 40 (3/4): 345-71.

Albuquerque, R., N. Loayza, and L. Servén. 2003. World Market Integration Through the Lens of Foreign Direct Investors. Policy Research Working Paper 3060, World Bank, Washington, DC.

Aroca, Patricio, Mariano Bosch, and William Maloney. 2002. Is NAFTA Polarizing México? or Existe También el Sur? Spatial Dimensions of Mexico's PostLiberalization Growth. World Bank, Washington, DC. Processed.

Aroca, P., and William F. Maloney. 2004. Migration, Trade and FDI in Mexico. World Bank, Washington, DC. Processed.

Baldwin, R., J. François, and R. Portes. 1997. The Cost and Benefits of Eastern Enlargement: The Impact on the EU and Central Europe. Economic Policy: A European Forum 24: 125-76.

Baldwin, R., and E. Seghezza. 1998. Regional Integration and Growth in Developing Nations. Journal of Economic Integration 13 (3): 367-99.

Banco de Mexico, 1996. "The Mexican Economy, 1996: Economic and Financial Developments in 1995, Policies For 1996.” Mexico DF: Banco de Mexico.

Beck, T., R. Levine, and N. Loayza. 2000. Finance and the Sources of Growth. Journal of Financial Economics 58 (1/2): 261-300.

Behrman, Jere, Miguel Szekely, and Nancy Birdsall. 2001. Economic Reforms and Wage Differentials in Latin America. Paper presented at the World Bank Poverty and Applied Micro Seminar Series, Washington, DC.

Bekaert, G., and Campbell R. Harvey. 1998. Capital Markets: An Engine for Economic Growth. Brown Journal of World Affairs Winter/Spring: 33-53.

Bell, Linda. 1997. The Impact of Minimum Wages in Mexico and Colombia. Journal of Labor Economics 15 (3): S102-S135.

Berzosa, C. 2000. México y España ante Dos Procesos de Integración. Comercio Exterior 50 (8): 718-23.

Blom, Andreas, Penélope Goldberg, Nina Pavcnik, and Norbert Schady. 2003. Trade Liberalization and Labor Market Adjustment in Brazil. Working Paper 2982, World Bank, Washington, DC.

Blomström, M., and A. Kokko. 1997. Regional Integration and Foreign Direct Investment. Working Paper 6019, National Bureau of Economic Research, Cambridge, MA.

Borrus, Michael, and John Zysman 1997. You Don't Have to Be Giant: How the Changing Terms of Competition in Global Markets Are Creating New Possibilities 
for Danish Companies. Working Paper 97-5. Danish Research Units for Industrial Dynamics, Copenhagen.

Brown, Cynthia J. 2001. Gender in Mexico's Maquila Industry. World Bank, Washington, DC. Processed.

Brown, Drusilla K., Alan V. Deardorff, and Robert M. Stern. 1996. Some Economic Effects of the Free Trade Agreement Between Tunisia and the European Union. Working Paper 385. Research Forum on International Economics, Cairo, Egypt.

2002. The Effects of Multinational Production on Wages and Working Conditions in Developing Countries. Discussion Paper 483, Research Seminar in International Economics, University of Michigan, Ann Arbor.

Calderón, C., N. Loayza, and L. Servén. 2002. Greenfield FDI vs. Mergers and Acquisitions: Does the Distinction Matter? World Bank, Washington, DC. Processed.

Castellanos, Sara 6., Rodrigo Garcia-Verdu, and David Kaplan. 2004. "Nominal Wage Rigidities in Mexico: Evidence From Social Security Records.” NBER Working Paper No. W10383.

Castells, Manuel, Alejandro Portes, and Lauren Benton. 1989. The Informal Economy. Baltimore: Johns Hopkins University Press.

Chant, Sylvia. 1991. Women and Survival in Mexican Cities. Manchester: Manchester University Press.

Chiquiar, D. 2001. Regional Implications of Mexico's Trade Liberalization. University of California, San Diego. Processed.

Chiquiar, D., and G. H. Hanson. 2002. International Migration, Self-Selection, and the Distribution of Wages: Evidence from Mexico and the United States. University of California, San Diego. Processed.

Claessens, S., D. Klingebiel, and S. Schmukler. 2002. The Future of Stock Exchanges in Emerging Economies: Evolution and Prospects. Brookings-Wharton Papers on Financial Services February: 167-202.

Cornelius, Wayne A., and Enrico A. Marselli. 2001. The Changing Profile of Mexican Migrants to the United States: New Evidence from California and Mexico. Latin American Research Review 36 (3): 105-31.

Cragg, M. I., and M. Epelbaum. 1996. Why Has Wage Dispersion Grown in Mexico? Is It the Incidence of Reforms or the Growing for Skills? Journal of Development Economics 51 (1): 99-116.

Cuevas, A., M. Messmacher, and A. Werner. 2002. Macroeconomic Synchronization Between Mexico and Its NAFTA Partners. Banco de México, Mexico City. Processed.

Cunningham, Wendy V., and William F. Maloney. 2001. Heterogeneity in the Small Firm Sector in Mexico. Economic Development and Cultural Change 50 (1): 131-56.

Cunningham, Wendy, and Carlos Ramos. 2001. The Home as a Factory Floor. Draft. World Bank, Washington, DC.

Davila, E. 1994. Regulaciones Laborales y Mercado de Trabajo en Mexico. In Regulacion del Mercado de Trabajo en America Latina, ed. Gustavo Marquez. San Francisco: International Center for Economic Research.

De Ferranti, David, Guillermo Perry, Francisco H. G. Ferreira, and Michael Walton. 2004. Inequality in Latin America: Breaking with History? Washington, DC: World Bank. 
De Ferranti, David, Guillermo Perry, Indermit S. Gill, and Luis Servén, with Francisco H. G. Ferreira, Nadeem Ilahi, William F. Maloney, and Martín Rama. 2000. Securing Our Future in a Global Economy. Washington, DC: World Bank.

De Ferranti, David, Guillermo Perry, Daniel Lederman, and William F. Maloney. 2002. From Natural Resources to the Knowledge Economy. Washington, DC: World Bank.

Dertouzos, James N., and Lynn A. Karoly. 1993. Employment Effects of Worker Protection: Evidence from the United States. Cornell International Industrial and Labor Relations Report 23. Ithaca, NY: ILR Press.

Dooley, M., and M. Chinn. 1995. Financial Repression and Capital Mobility: Why Covered Interest Rate Differentials Fail to Measure Capital Market Integration. Working Paper 5347, National Bureau of Economic Research, Cambridge, MA.

Durand, Jorge, Douglas S. Massey, Rene M. Zenteno. 2001. Mexican Immigration in the United States. Latin American Research Review 36 (1): 107-27.

Elliot, Kimberly Ann, and Richard B. Freeman, 2003. Can Labor Standards Improve Under Globalization? Institute for International Economics, Washington.

Esquivel, Gerardo, and Jose Antonio Rodríguez-Lopez. 2003, Technology, Trade and Wage Inequality in México Before and After NAFTA. Journal of Development Economics 72 (2): 543-65.

Fairris, D. 2003. Unions and Wage Inequality in Mexico. Industrial and Labor Relations Review 56 (3): 481-97.

Fajnzylber, Pablo, and William Maloney. 2004. Labor Demand and Trade Reform in Latin America. World Bank, Washington, DC. Processed.

Feenstra, R. C., and G. H. Hanson. 1996. Foreign Investment, Outsourcing and Relative Wages. In Political Economy of Trade Policy: Essays in Honor of Jagdish Bhagwati, eds. R. C. Feenstra, G. M. Grossman, and D. A. Irwin, 89-127. Cambridge: MIT Press.

1997. Foreign Direct Investment and Relative Wages: Evidence from Mexico's Maquiladoras. Journal of International Economics 42 (3/4): 371-94.

Feliciano, Zadia. 2001. Workers and Trade Liberalization: The Impact of Trade Reforms in Mexico on Wages and Employment. Industrial and Labor Relations Review 55 (1): 95-115.

Fernández, R., and J. Portes. 1998. Returns to Regionalism: An Analysis of Nontraditional Gains from Regional Trade Agreements. World Bank Economic Review 12 (2): 197-220.

Fiess, Norbert, Marco Fugazza, and William F. Maloney. 2000. Informality, Real Exchange Rates, and Labor Market Segmentation. World Bank, Washington, DC. Processed.

Fleck, Susan. 2001. A Gender Perspective on Maquila Employment and Wages in Mexico. In The Economics of Gender in Mexico, eds. Maria Correia and Elizabeth Kartz. Washington DC: World Bank.

Frankel, J. A., and S. Wei. 1998. Regionalization of World Trade and Currencies: Economics and Politics. In The Regionalization of the World Economy, ed. J. A. Frankel, 189-219. Chicago: University of Chicago Press.

Fussell, Elizabeth. 2000. Making Labor Flexible: The Recomposition of Tijuana's Maquiladora female labor force. Feminist Economics 6 (3): 59-79.

Galiani, S., and P. Sanguinetti. 2000. Wage Inequality and Trade liberalization: Evidence from Argentina. Journal of Development Economics 72 (2): 497-513. 
Garcia Verdú, Rodrigo 2003. Barrera a la adopcion de mejoras practices y tecnologia en la industria de la aviacion: Un estudio de Caso. Mexico City: Banco de México.

Giugale, Marcelo, Oliver Lafourcade, and Vinh H. Nguyen, 2001. Mexico. A Comprehensive Development Agenda for the New Era. Washington, D.C.: World Bank.

Goldberg, Penélope, and Nina Pavcnik. 2003. The Response of the Informal Sector to Trade Liberalization. Working Paper 9443, National Bureau of Economic Research, Cambridge, MA.

González-Anaya, J. A., and G. Marrufo. 2001. Financial Market Performance in Mexico. Paper prepared for the Mexican Credit Conference, Center for Research on Economic Development and Policy Reform, Stanford University, October.

Hallberg, Kristin, Hong Tan, and Leonid Koryukin. 2000. Export Dynamics and Productivity: Analysis of Mexican Manufacturing in the 1990's. World Bank, Washington, DC. Processed.

Hanson, G. 1996. Localization Economies, Vertical Organization, and Trade. American Economic Review 86 (5): 1266-278.

- 1997. Increasing Returns, Trade, and the Regional Structure of Wages. Economic Journal 107 (440): 113-33.

1998. Regional Adjustment to Trade Liberalization. Regional Science and Urban Economics 28 (4): 419-44.

- 2002. What Has Happened to Wages in Mexico Since NAFTA? World Bank, Washington, DC. Processed.

Hanson, G., and A. Harrison. 1999. Trade, Technology, and Wage Inequality in Mexico. Industrial and Labor Relations Review 52 (2): 271-88.

Heckman, James, and Carmen Pagés-Serra. 2000. The Cost of Job Security Regulation: Evidence from Latin American Labor Markets. Journal of the Latin American and the Caribbean Economic Association 1 (1): 109-54.

Hjalmarsson, Lennart. 1991. The Scandinavian Model of Industrial Policy. In Diverting Paths: Comparing a Century of Scandinavian and Latin American Development, eds. Magnus Blomström and Patricio Meller, 246-65. Washington, DC: Inter-American Development Bank.

Jun, C., K. M. Murphy, and B. Pierce. 1993. Wage Inequality and the Rise in Returns to Skill. Journal of Political Economy 101: 410-42.

Jones, Ronald W. 2000. Globalization and the Theory of Input Trade. Cambridge: MIT Press.

Kaminsky, G., and S. Schmukler. 2001. Short-Lived or Long-Lasting? A New Look at the Effects of Capital Controls. In Susan M. Collins and Dani Rodrik, eds. Brookings Trade Forum: 2000. Washington, D.C.: Brookings Institution Press.

Katz, L., and K. M. Murphy. 1992. Changes in Relative Wages, 1963-1987: Supply and Demand Factors. Quarterly Journal of Economics 107 (1): 35-78.

Kehoe, P., and T. Kehoe. 1994a. Capturing NAFTA's Impact with Applied General Equilibrium Models. Federal Reserve Bank of Minneapolis Quarterly Review 18 (1): 17-34.

Krebs, Tom, Pravin Krishna, and William F. Maloney. 2004. Trade Policy, Income Risk and Welfare. World Bank, Washington, DC. Processed.

Krishna, Pravin, Devashish Mitra, and Sajji Chinoy. 2001. Trade Liberalization and Labor Demand Elasticities: Evidence from Turkey Journal of International Economics 55 (2): 391-409. 
Krugman, Paul, and R. Livas. 1996. Trade Policy and the Third World Metropolis. Journal of Development Economics 49:137-50.

Kumhof, M. 2001. International Capital Mobility in Emerging Markets: New Tests from Daily Data. Review of International Economics 9 (1): 626-40.

Leamer, E., A. Guerra, M. Kaufman, and B. Segura. 1995. How Does the North American Free Trade Agreement Affect Central America? Policy Research Working Paper 1464, World Bank, Washington, DC.

Lederman, Daniel, and William F. Maloney. 2003. Trade Structure and Growth. Working Paper 3025, World Bank, Washington, DC.

Levy-Yeyati, E., E. Stein, and C. Daude. 2002. Regional Integration and the Location of FDI. Inter-American Development Bank, Washington, DC. Processed.

Lopez-Acevedo, Gladys. 2001. Technology and Firm Performance in Mexico. World Bank, Washington, DC. Processed.

Lopez-Acevedo, Gladys, and Angel Salinas. 2000. The Distribution of Mexico's Public Spending on Education Working Paper 2404, World Bank, Washington, DC.

López-de-Silanes, F. 2002. NAFTA and Mexico's Reforms on Investor Protection. World Bank, Washington, DC. Processed.

Lustig, N. 2001. Life Is Not Easy: Mexico's Quest for Stability and Growth. Journal of Economic Perspectives 15 (1): 85-106.

Maloney, W. F. 1999. Does Informality Imply Segmentation in Urban Labor Markets? Evidence from Sectoral Transitions in Mexico. World Bank Economic Review 13 (2): 275-302.

- 2001. Self Employment and Labor Turnover in Developing Countries: Cross Country Evidence. In World Bank Economists' Forum, eds. Shantayanan Devarajan, F. Halsey Rogers, and Lyn Squire, 137-68. Washington, DC: World Bank.

2004. Informality Revisited. World Bank Economic Review 32 (7): 1159-178.

Maloney, W. F., and J. Nuñez. Forthcoming. Measuring the Impact of Minimum Wages: Evidence from Latin America. In Law and Employment: Lessons from Latin America and the Caribbean, eds. Carmen Pagés and James Heckman. Cambridge, MA: National Bureau of Economic Research.

Maloney, William F., with Ana Revenga, and Gladys Lopez-Acevedo. 2001. Labor Markets. In Mexico: A Comprehensive Development Agenda for The New Era, eds. Marcelo Giugale, Olivier Lafourcade, and Vinh H. Nguyen, 511-36. Washington, DC: World Bank.

Maloney, W. F., and E. P. Ribeiro. 2001. Employment and Wage Effects of Mexican Unions: A Case of Extreme Efficient Bargaining. Policy Research Working Paper 2131, World Bank, Washington, DC.

Marcouiller, D., V. Ruiz de Castilla, and C. Woodruff. 1997. Formal Measures of the Informal Sector Wage Gap in Mexico, El Salvador and Peru. Economic Development and Cultural Change 45 (January): 367-92.

Marquez, Gustavo, and Carmen Pagés. 1998. “Trade and Employment: Evidence from Latin America and the Caribbean. Research Department Working Paper 366. Inter-American Development Bank, Washington, DC.

Martin, Will, and Devashish Mitra. 2001. Productivity Growth and Convergence in Agriculture and Manufacturing. Economic Development and Cultural Change 49 (2): 403-22. 
Martinez, Hermes, and Carmen Pagés. 2004. Trade Liberalization and the Quality of Jobs. Inter-American Development Bank, Washington, DC. Processed.

Meller, Patricio, and Andrea Tokman. 1998. Chile: Apertura Comercial, Empleo y Salarios. Santiago, Chile: Organización Internacional del Trabajo-Equipo Técnico Multidisciplinario.

Moel, Alberto. 2001. The Role of American Depositary Receipts in the Development of Emerging Markets. Economia 2 (Fall): 209-73.

Montes-Rojas, Gabriel V. 2001. Trade Reform, Technical Change and Inequality: The Case of México and Argentina in the 90's. Washington, DC: World Bank.

Oyarzún de la Iglesia, J. 2000. México en el TLCAN, España en la Unión Europea: Balance de la Integración. Comercio Exterior 50 (8): 688-710.

Parente, Stephen L., and Edward C. Prescott. 2000. Barriers to Riches Cambridge, MA: MIT Press.

Pencavel, J. 1997. The Legal Framework for Collective Bargaining in Developing Countries. Working Paper 008-1997, Department of Economics, Stanford University, California.

Revenga, A. 1997. Employment and Wage Effects of Trade Liberalization: The Case of Mexican Manufacturing. Journal of Labor Economics 15 (3, pt. 2): S20-43.

Revenga, A., and C. Montenegro. 1998. North American Integration and Factor Price Equalization: Is There Evidence of Wage Convergence between Mexico and the United States? In Imports, Exports, and the American Worker, ed. S. Collins, 305-34. Washington, DC: Brookings Institution Press.

Reyes, Belinda, Hans P. Johnson, and Richard Van Swearingen 2002. Holding the Line? The Effect of the Recent Border Build-up on Unauthorized Immigration. http:// www.ppic.org/publications/PPIC162.

Robbins, Donald J. 1994. Relative Wage Structure in Chile, 1957-1992: Changes in the Structure of Demand for Schooling. Estudios de Economía 21: 49-78.

Robbins, Donald J., and T. H. Gindling. 1999. Trade Liberalization and the Relative Wages for More Skilled Workers in Costa Rica. Review of Development Economics 3 (2): 140-54.

Robertson, R. 2000a. Trade Liberalization and Wage Inequality: Lessons from the Mexican Experience. World Economy 23 (6): 827-49.

- 2000b. Wage Shocks and North American Labor Market Integration. American Economic Review 90 (4): 742-64.

—_. 2001. Relative Prices and Wage Inequality: Evidence from Mexico. Macalester College, St. Paul, MN. Processed.

- 2002. Did NAFTA Increase Labor Market Integration Between the United States and Mexico?” World Bank, Washington, DC. Processed.

Robertson, R., and Donald H. Dutkowsky. 2002. Labor Adjustment Costs in a Destination Country: The Case of Mexico. Journal of Development Economics 67 (1): 29-54.

Rodrik, Dani. 1997. Has Globalization Gone Too Far? Washington, DC: Institute for International Economics.

Sanchez, Susana M., Anna Yoo, and Cara Zappala. 2001. Constrained Global Integration: A Note on Micro-enterprises in Latin America. World Bank, Washington, DC. Processed. 
Sánchez-Páramo, C., and N. Schady. 2003. Off and Running? Technology, Trade, and the Rising Demand for Skilled Workers in Latin America. Policy Research Working Paper 3015, World Bank, Washington, DC.

Sanguinetti, P., J. Pantano, and J. Posadas. 2001. Trade Liberalization and the Dynamics of the Trade Structure in Argentina and Uruguay. World Bank, Washington, DC. Processed.

Santamaria, Mauricio. 2000. External Trade, Skill, Technology and the Recent Increase of Income Inequality in Colombia. PhD diss., Georgetown University.

Sargent, John, and Linda Mathews. 1999. Exploitation or Choice? Exploring the Relative Attractiveness of Employment in the Maquiladoras. Journal of Business Ethics 18: 213-27.

Schiff, M., and A. Winters. 1998. Dynamics and Politics in Regional Integration Arrangements: An Introduction. World Bank Economic Review 12 (2): 177-95.

Serrano, C. 2001. The Role of Commercial Banks in the Provision of Credit to Small and Medium Enterprises in Mexico. Paper prepared for the Mexican Credit Conference organized by the Center for Research on Economic Development and Policy Reform, Stanford University, October.

Serra Puche, J. J. 1992. Conclusión de la Negociación del Tratado de Libre Comercio entre México, Canadá y Estados Unidos. Mexico City: Secretaria de Comercio y Fomento Industrial (SECOFI).

Sistema para el Desarrollo Integral de la Familia. 2000. Perfil Socioeconómico de Jornaleros Migrantes en Sayula. Jalisco, México. Processed.

Smith, James P., and Barry Edmonston, eds. 1997. The New Americans: Economic, Demographic, and Fiscal Effects of Immigration. Washington, DC: National Academy Press.

Stern, Robert M. 2003. Labor Standards and Trade Agreements. Discussion paper 496 presented at the Research Seminar in International Economics, University of Michigan, August 18.

Tan, H., and G. Batra. 1997. Technology and Firm Size-Wage Differentials in Colombia, Mexico, and Taiwan (China). World Bank Economic Review 11 (1): 59-83.

Taylor, J. Edward. 2001. Microeconomics of Globalization: Evidence from Mexico, China, El Salvador, and the Galapagos Islands. World Bank, Washington, DC. Processed.

UNIFEM (United Nations Development Fund for Women). 2000. El Impacto del TLC en la Mano de Obra Femenina en México. New York: United Nations.

Venables, A., and L. Winters 2002. Economic Integration in the Americas: European Perspectives. Unpublished manuscript.

Waldkirch, A. 2001. The New Regionalism and Foreign Direct Investment: The Case of Mexico. Oregon State University, Corvallis. Processed.

Whalley, J. 1996. Why Do Countries Seek Regional Trade Agreements? Working Paper 5552, National Bureau of Economic Research, Cambridge, MA.

Woodruff, C., and R. Zenteno. 2001. Remittances and Micro-enterprises in Mexico. University of California at San Diego. Processed.

World Bank. 2001. Global Development Finance. Washington, D.C.: World Bank. 


\section{6 \\ Innovation in Mexico: NAFTA Is Not Enough}

THIS CHAPTER EXAMINES THE evolution OF Mexican technological progress in the past few decades, with special attention given to the role of trade, foreign direct investment (FDI), and the national innovation system (NIS). ${ }^{1}$ The main message is that trade liberalization and the North American Free Trade Agreement (NAFTA) are helpful but they are not enough to help Mexico catch up to the level of technological progress observed in its North American partners, especially the United States. In fact, the evidence reviewed here suggests that, given its level of development, Mexico suffers from low levels of innovation effort, and it severely underperforms when compared with successful comparator economies, such as the Republic of Korea. In addition, its national innovation system (i.e., how the private sector, universities, and public policies interact to produce economically meaningful innovation) is inefficient. Without addressing these deficiencies it is unlikely that NAFTA alone will be sufficient for Mexico to catch up with the pace of innovation in North America.

The literature suggests that roughly half of cross-country differences in per capita income and growth are driven by differences in total factor productivity (TFP), generally associated with technological progress (see Dollar and Wolf 1997, and Hall and Jones 1999). Furthermore, much of the widening gap between rich and poor countries results not from differences in capital investment but from differences in technological progress. This fact moves to center stage an abiding question in economic development: why do developing countries, with great potential gains to be realized in adopting technologies from the industrialized economies, fail to do so? In fact, perversely, the countries generating new technologies at the frontier appear to have faster TFP growth in manufacturing and agriculture than do poor countries that could, in theory, adopt existing technologies invented in the advanced economies (Martin and Mitra 2001). 
Recent work in innovation stresses that adopting existing technology has its cost. Firms and countries need to develop an "absorptive" or "national learning" capacity, which is hypothesized to be a function of spending on research and development (R\&D). ${ }^{2}$ Although learning is often considered relevant only for basic science dedicated to expanding the knowledge frontier, Cohen and Levinthal (1989) among others stressed that learning (i.e., knowing where the frontier is and figuring out what adaptations are necessary) is the "second face" of R\&D. In fact, Pavitt (2001) argued that investment in pure research is also important for developing countries. First, those countries that are most familiar with the frontiers of basic science will best train the applied problem solvers in the private sector. Second, even basic research does not flow easily or without cost across borders, so developing countries cannot simply rely on what is being generated in the advanced countries. Finally, Lederman and Sáenz (2003) presented econometric evidence suggesting that innovation outcomes, namely patents per capita, are an important explanation of the levels of development observed around the world.

In this chapter we review indicators of Mexico's technological progress and innovation efforts since the 1960s and then ask what the global and Mexican experiences suggest about how greater openness to trade and FDI should affect growth. We then argue that Mexico is missing a critical complement to liberalization in its weak national learning capacity. This is partly a result of weak efforts in education and innovation, and partly in how these efforts are coordinated through a largely dysfunctional NIS. The principal conclusion is that exploiting the opportunities offered by greater integration with Canada and the United States requires Mexico to make substantial policy improvements in both the level and efficiency of innovation efforts. NAFTA is not enough.

\section{Mexican Innovation and Technological Progress Since the 1960s}

One of the most heavily used indicators of progress in innovation is the level and growth rate of TFP. This is generally understood to be the part of the growth of gross domestic product (GDP) that is not explained by the accumulation of raw labor, physical capital, and perhaps human capital ideally after controlling for capacity utilization. Since the pioneering work of Solow $(1956,1957)$ this indicator has been thought to be a good proxy for technological progress.

Figure 6.1 shows the average annual growth rates of TFP for Mexico since the 1960s to the end of the 20th century, compared with the rates of Chile, Costa Rica, Latin America as a whole, the high-income countries of 


\section{Figure 6.1 Growth Rates of Total Factor Productivity, 1960-99}

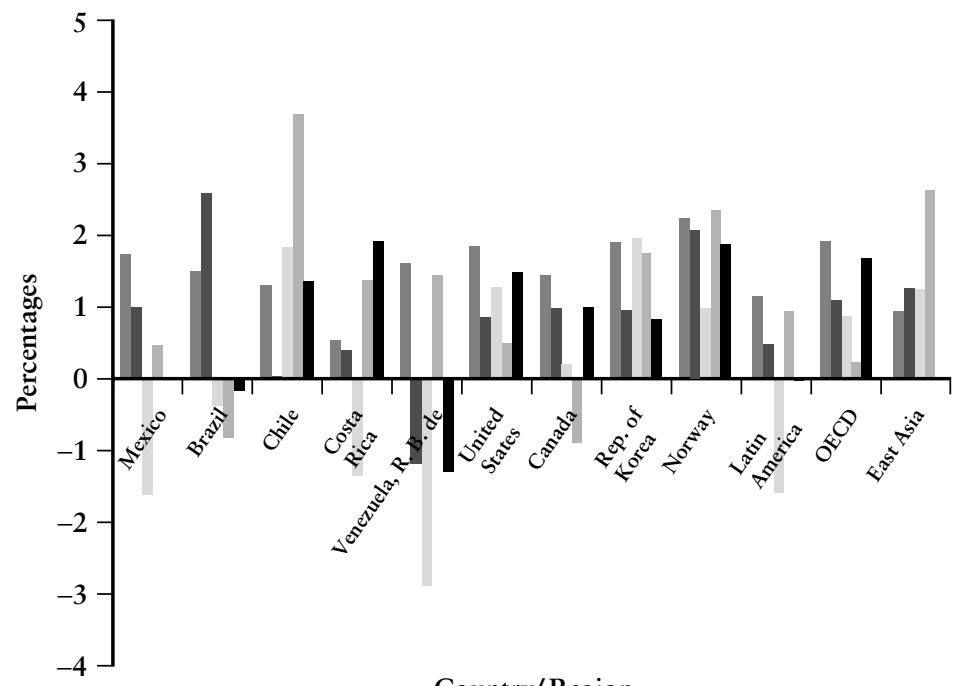

Country/Region

$$
\begin{aligned}
& \square 1960-69=1970-79 \square 1980-89 \\
& \square 1990-94 \quad \square 1995-99
\end{aligned}
$$

Source: Loayza, Fajnzylber, and Calderón 2002.

the Organisation for Economic Co-operation and Development (OECD), and the East Asia and Pacific region. ${ }^{3}$ Mexico's TFP performance was highest in the 1960s and, as in most of the other economies except Brazil and the East Asia region as a whole, it declined in the 1970s and declined with the rest of Latin America in the 1980s (largely as a result of the debt crisis). ${ }^{4}$ The slight recovery in the 1990s may have resulted from economic reforms implemented in the late 1980s and early 1990s in most Latin American and Caribbean countries, although recent econometric estimates suggest that, on average in the region, these effects are modest. ${ }^{5}$ On the other hand, figure 6.1 suggests that Chile, the most advanced reformer, has performed far above both the Latin American and Asian regional averages for the past two decades. Given the overall similarity in policy packages, there would seem to be nothing in 
the economic model adopted that intrinsically dictated lower rates of TFP growth.

An explanation for the patterns above was put forward by Acemoglu, Aghion, and Zilibotti (2002) who argued that there are two stages of technology adoption. The first is based on fomenting the accumulation of technology embodied in capital formation, even if this requires some static efficiency losses through interventionist policies, arguably including the period of import-substituting industrialization (ISI) in Latin America. The following stage, centered on innovation, requires a greater structural flexibility and fewer distortions. In their view, Brazil, the Republic of Korea, Mexico, Peru, and Taiwan (China) all successfully pursued the first stage, but the Asian economies were able to make the transition to efficient innovative economies whereas Latin America was not. The Chilean case, which leads Mexico in liberalization by roughly 10 years, supports this diagnosis and offers some reason to suppose that Mexico will experience a similar rebound in TFP in the coming years if all other things are equal. In light of the successful growth experiences of the relatively open Finland, Ireland, Israel, and Spain across a similar period, it is difficult to argue that the extreme "closedness" of the region was necessary or desirable, especially given the difficult political economy problems of moving to a more "innovative" structure later. ${ }^{6}$

Finally, it is worth noting that productivity growth in Norway, another petroleum exporter, was quite fast by international standards throughout this period, which suggests that net exporters of natural resources do not necessarily have lower potential for productivity growth. On the contrary, Lederman and Maloney (2002) found that countries rich in natural resources tend to experience faster economic growth, even after controlling for the contributions of human and physical capital accumulation.

Another commonly used innovation proxy is the number of patents granted to scientists in the country (figure 6.2). It is generally believed that patent statistics broadly reflect the flow of innovations covering either adaptations of existing patents or brand-new inventions (Griliches 1990; Patel and Pavitt 1995). Measures of the number of patents granted to researchers from around the globe, however, are not without flaws. One particularly important consideration is that costs of applying for patents, the level of intellectual property protection, the pecuniary benefits from patents, and other institutional features vary greatly among countries. Thus patents granted by agencies from one country are not strictly comparable to those granted by others. In what follows we also use the number of patents granted to Mexican residents by the United States Patent and Trademark Office (USPTO) as a proxy for the flow of innovation. ${ }^{7}$ The data from the USPTO are attractive because of their 
Figure 6.2 Patents per Million Workers, 1960-2000

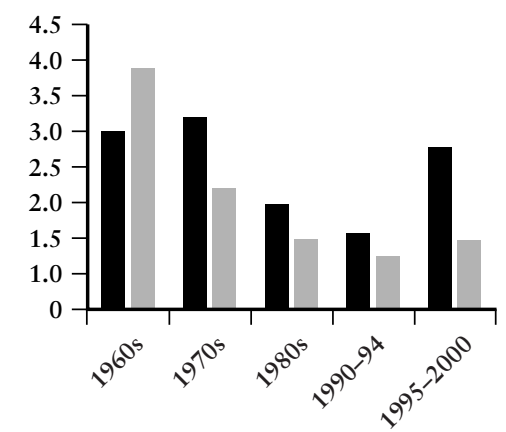

- Latin America and the Caribbean Mexico

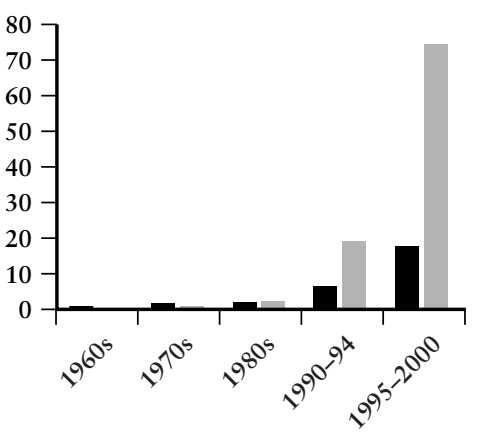

- East Asia Republic of Korea
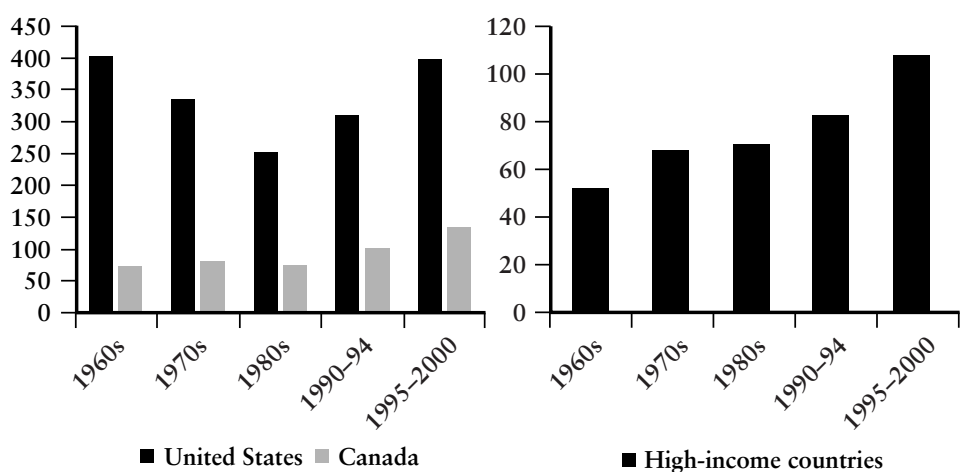

Source: U.S. Office of Patents and Trademarks.

global and long time coverage, and especially because it is commonly understood that the United States offers perhaps the most advanced levels of intellectual property protection in the world (Maskus 2000). Although the costs of the application process are likely to be higher in the United States than in most other countries, the benefits are also likely to be higher.

The evidence suggests that Mexico's patenting activity follows a similar pattern over time as does its TFP growth rate discussed above. Patent counts for Mexican innovators were highest in the 1960s, declined continuously until the first half of the 1990s, and finally picked up again after the implementation of NAFTA in the second half of the 
1990s. This resurgence was quite modest by historical standards, however, and was insufficient to make a significant dent in the observed gap with respect to Canada and the United States. Compared with other emerging countries, Mexico is also far behind East Asia (especially the Republic of Korea) and, within its own region, lags Costa Rica and the República Bolivariana de Venezuela.

This pattern remains even when we account for differences in level of development. Figure 6.3 benchmarks performance by researchers residing in Mexico in each dimension, comparing them with the average of those in countries with the same levels of GDP, the same size labor force, and the same value of merchandise exports as the United States since the 1960s. ${ }^{8}$ The graph shows how far Mexico is from the average of similar economies (the zero line), and Mexico's average absolute levels by decades. A negative number on the vertical axis is evidence of underperformance. Mexico's performance in patents has fallen from more than twice the average in the 1960s to substantially below the average in the 1980 s just prior to the debt crisis and the structural reforms.

Figure 6.3 Innovation Outputs in Mexico

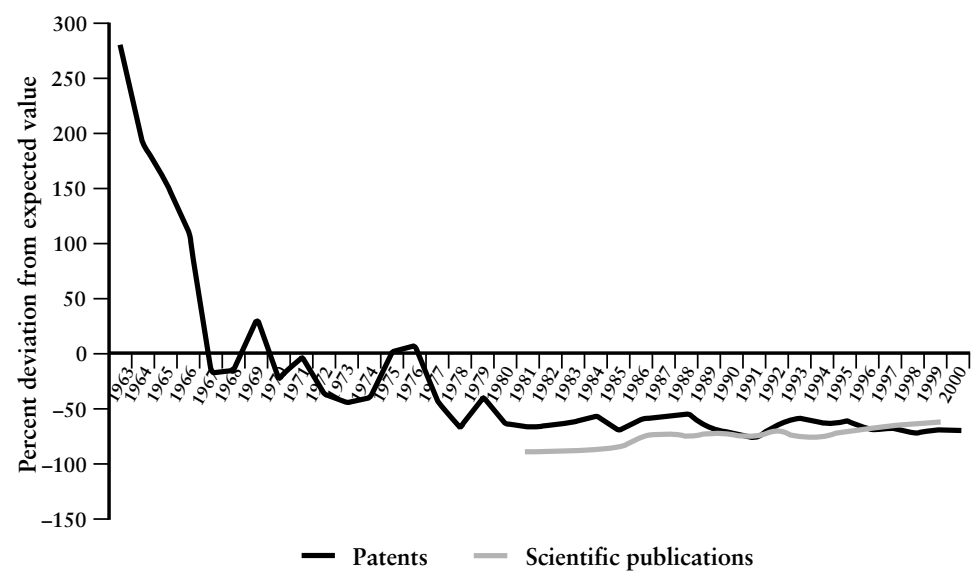

\begin{tabular}{|lcc|}
\hline Decade & Patents & $\begin{array}{c}\text { Scientific } \\
\text { Publications }\end{array}$ \\
\hline $1990 s$ & 47 & 1557 \\
$1980 s$ & 39 & 847 \\
$1970 s$ & 49 & - \\
$1960 s$ & 72 & - \\
\hline
\end{tabular}


A final indicator of innovation is the number of scientific publications, which can be interpreted as a measure of outcome of basic rather than applied research. Mexico shows some upward progress from the 1980s to roughly half of its expected value.

In summary, looking at TFP growth, patenting activity, and scientific publications, Mexico lags behind many countries of its level of development and sorely behind the Asian newly industrialized countries that were once its comparators.

\section{How Trade and FDI Affect Innovation and Technological Progress}

What does the international evidence say about how the increased trade and FDI encouraged by NAFTA might affect growth through the transmission or generation of technology?

The bulk of the literature relating trade to growth suggests modest effects working primarily through physical capital accumulation. ${ }^{9}$ Loayza, Fajnzylber, and Calderón (2002), using a panel of countries since 1960, found that a 1 percent increase in the portion of the trade-to-GDP ratio that is related to trade policies leads to an increase in the growth rate of GDP per capita that ranges between 0.025 and 0.010 percentage points per year. ${ }^{10}$ Consistent with the findings of Baldwin and Seghezza (1996) and Levine and Renelt (1992), Wacziarg (2001) ${ }^{11}$ found that the most statistically robust channel through which trade positively affects economic growth is via investment, with domestic investment growth accounting for more than 60 percent of the positive effect of trade on growth. He speculated that these results are consistent with theories that focus on the pro-competitive effects of trade because the survival of existing firms and the entry of new ones after trade liberalization probably require large fixed capital costs.

Yet an emerging body of literature also finds an impact of trade and investment variables on TFP growth, although the exact channel remains ambiguous. In Mexico the overall impact of NAFTA on productivity was positive. Chapter 2 of this volume showed that the agreement was associated with convergence in rates of TFP growth among the manufacturing sectors in Mexico and the United States. López-Córdova (2002) offered estimates of the whole package of NAFTA-related phenomena (namely, lower Mexican tariffs, the preferential tariff margin in the United States, higher import-to-output ratio, and participation of foreign producers) to have increased TFP by 10 percent. Schiff and Wang (2002) offered a similar estimate of 5.6-7.5 percent. These estimates are broadly consistent with estimates of a very large impact of the free trade agreement in Canada. Trefler (1998) argued that, overall, 
manufacturing TFP rose by 0.2 percent per year, or 1 percent for the firms most affected by trade, primarily as a result of plant turnover and rising technical efficiency within plants. Hence it is likely that TFP growth in Canada and Mexico would have been even lower than those shown in figure 6.1 if NAFTA and its predecessor, the Canada-U.S. Free Trade Agreement, had not been implemented.

Imports of capital or intermediate goods, which are thought to embody or transmit knowledge of new production techniques or skills, appear associated with a positive effect on the levels of TFP. ${ }^{12}$ Coe, Helpman, and Hoffmaister (1997) found that the overall level of imports is important for international technology diffusion for 77 developing countries. Keller (2002), looking at industry-level data from eight OECD countries, found that roughly 50 percent of TFP growth in manufacturing industries results from their own R\&D spending, 30 percent results from other domestic industries, and a remaining 20 percent results from R\&D expenditures in foreign industries, some of which is communicated by trade. He speculates that the latter share may be much higher in developing countries where local R\&D effort is substantially lower than in the high-income countries. For Latin America, Schiff and Wang (2004) found modestly positive effects of the technology embodied in intermediate inputs on TFP for certain high-R\&D industries in Latin America. ${ }^{13}$ And looking specifically at NAFTA, Schiff and Wang (2002) found that the roughly 14-18 percent increase in total imports from the NAFTA partners to Mexico led to an increase in TFP levels in manufacturing industries of between 5.1 and 7.0 percent. The 3 percent diversion of imports from other OECD countries, whose imports have no impact on TFP, led to another 0.47 percent. ${ }^{14}$

However, the interpretation of these results is not necessarily straightforward. Seemingly in contradiction to the above studies, Eaton and Kortum (1996) found that bilateral imports do not help predict bilateral patenting activity, their indicator of international technology diffusion. Based on firm-level data from Mexico, López-Córdova (2002), like Muendler (2002) for Brazil, found a negative impact of imported inputs on manufacturing TFP. ${ }^{15}$ Furthermore, Schiff and Wang (2002) expressed doubt about the meaning of their own estimates in the CoeHelpman-Hoffmaister tradition. The fact that input trade with the United States is a good vehicle for technology transfer to Mexico, but apparently trade with other high-income OECD countries has no effect on TFP, is counterintuitive. The result is strikingly consistent with Keller (2002) who found that the impact of trade in intermediate goods decreases with geographic distance between trade partners. In fact, employing Keller's elasticity, the U.S. impact on Mexico should be, and is, roughly 10 times as large as that with respect to the OECD. However, space-dependent depreciation of technology embodied in inputs seems 
unlikely and, as Schiff and Wang (2002) suggested, these results might be picking up greater collaborative and subcontracting relationships across the border rather than an effortless transfer of production knowledge embodied in the intermediate inputs themselves. This in no way undermines the benefits of an open trade stance with respect to the United States, but it does suggest that the incredibly large TFP-enhancing effects of trade with the United States reflect nontrade channels of influence, which might be related to personal and business interactions among businesspeople, firms, and researchers.

Firms may also learn by exporting in the sense that participation in foreign markets might help firms identify the latest production, management, and even marketing techniques. Thus exporters in Mexico could have enhanced their learning capacity during the post-NAFTA and trade liberalization period. Numerous cross-sectional studies have shown that Mexican exporters tend to be more technically efficient, presumably because of technological development related to the import of technologies from abroad (see recent work by Alvarez and Robertson [2001] and by Meza González and Yaguë [2002]). However, using the only micro-level panel data spanning the NAFTA period that allow for the determination of causality-whether exports make a firm more efficient or whether more efficient firms export-López-Córdova (2002) found no impact of exporting on TFP growth and actually a negative correlation with productivity levels. In a study published in 2000 the World Bank found that the number of years of experience in exporting does seem to be associated with rising TFP levels, although these estimates did not control for unobserved firm-specific characteristics and the act of beginning to export itself did not appear to stimulate productivity growth.

The absence of a positive finding is consistent with the panel regressions done by Clerides, Lach, and Tybout (1998) for Mexico's early period of liberalization as well as for Colombia and Morocco. The researchers found little evidence in any country for firms' cost structures changing after breaking into the export market and they argue that the higher productivity is likely to be the result of a selection of the better firms into exporting - that is, the Schumpeterian reallocation effect. ${ }^{16}$ These results also are consistent with Kraay, Soloaga, and Tybout's (2002) analysis of firms in the chemical industry in Mexico and Colombia. The researchers were unable to establish Granger causality between engaging in international activities-be it imports or exports-and indicators of productivity gains. ${ }^{17}$ It is worth noting that the disappointing results regarding the lack of a robust positive effect of exporting on TFP growth are found elsewhere in both emerging and advanced economies. ${ }^{18}$

There can be little doubt that FDI increases the host-country capital stock and contributes the technology embodied in that capital. It also 
may have reallocation effects to the degree that it displaces inefficient firms. However, the macroeconomic evidence does not suggest strong causality between FDI and TFP growth ${ }^{19}$ and the microeconomic evidence for technological spillovers to other firms is thin and pessimistic. López-Córdova (2002) discovered a negative direct effect of FDI on the same industry's TFP. This is consistent with numerous other panel studies of other developing and industrialized countries. ${ }^{20}$ Other literature on Mexico is sparse. Blomström and Wolff (1994) found that both the rate of local firms' labor productivity growth and their catch-up rate to the multinationals were positively related to the industry's degree of foreign ownership. Furthermore, the rate of convergence of industry labor productivity with the U.S. rate of growth is higher in industries with a higher share of multinationals. They pointed out, however, that it is difficult to distinguish a rise in within-firm productivity from simply increased competition forcing out less efficient firms and thus raising the average rate of growth.

In summary, our reading of the existing international evidence is that NAFTA might have helped spur trade, FDI, and economic growth. But the trade channel's benefits were mainly driven by factor accumulation effects and displacement of inefficient firms by more efficient firms. FDI stimulated by NAFTA aided Mexico's economic recovery, but it did not necessarily augment the technological progress component of TFP. The evidence for direct knowledge spillovers through these mechanisms seems generally weak.

\section{National Learning Capacity: The Missing Complement}

Those findings seem somewhat counterintuitive, given how important trade and to a lesser extent FDI appear to have been in the "Asian miracles," which did experience rapid rates of TFP growth. However, the lackluster productivity growth of Mexico's other partner, Canada, offers important insights. Daniel Trefler (1999a,b) has argued that the free trade agreement was associated with closing the gap with respect to the United States in some manufacturing activities, but in exacerbating it in others, such as computers and industrial machinery. He argued that a critical explanation is low levels of Canadian R\&D and deficient basic science, and that the presumption that the country can simply rely on basic science from the United States is misguided. By the time a seminal innovation is transferred from the United States, its most valuable applications have already been exploited by U.S. companies. To support this point Trefler cited evidence showing that a 5 percent increase in U.S. $\mathrm{R} \& \mathrm{D}$ is associated with a rise of 6.7 percent in U.S. productivity, but only with a 2.4 percent increase in Canadian productivity. 
Both partners' experiences suggest that, although they are helpful, trade and FDI are not enough to put Mexico on a rapid growth path and that important complementary efforts in innovation are necessary. An emerging strand of the growth literature stresses the importance of "national learning" or "innovative" capacity to adopting new technologies and implicitly taking advantage of the new trade opportunities for convergence. Acemoglu and Zilibotti (2001) argued that most technologies developed in advanced countries are not as productive in developing countries because the host countries' low human capital is not appropriate for using innovative production processes. Lloyd-Ellis and Roberts (2002) similarly argued that education and technological progress are not only complements but dynamic complements, with the return to each determined by the growth of the other. Technology transfer from the United States to Mexico, for example, will not lead to the equalization of productivity levels between these countries as long as Mexico's human capital is deficient compared with that in the United States.

Howitt and Mayer-Foulkes (2002) offered a "convergence club" theory that explains why human capital-and innovative effort more generally-are essential for convergence among countries. They traced three possible productivity-growth paths for countries exposed to identical technological progress. Countries with high human capital relative to that at the technological frontier will experience the fastest rates of TFP growth. ${ }^{21}$ That is, the most dynamic economies will tend to be those that have the necessary human capital and the required learning capacity for pushing the technological frontier forward. Countries with lower learning capacity will tend to rely on the adoption of technologies previously invented in the most dynamic countries (as Trefler suggested is the case in Canada) and they will appear to show slower levels of TFP growth than the leading countries. Those economies that have inadequate human capital or learning capacity to adopt technologies stagnate. ${ }^{22}$ Microeconomic evidence from Mexico suggests, in fact, that firms that spend more on R\&D, use highly skilled workers, and train them have greater probabilities of adopting new technologies (López-Acevedo (2002). But the question remains whether, in the aggregate, Mexico is making the necessary complementary effort in innovation that theory suggests would be necessary for it to converge with U.S. levels or whether an excessive reliance on passive transfers through trade and FDI will leave the country stuck in a low-growth trap.

\section{Where Does Mexico Stand in Innovation Effort?}

As a way of quantifying Mexico's innovation effort, we benchmarked two common indicators of innovation inputs: expenditures on R\&D 
Figure 6.4 Mexico's Research and Development Effort Is Below the Median

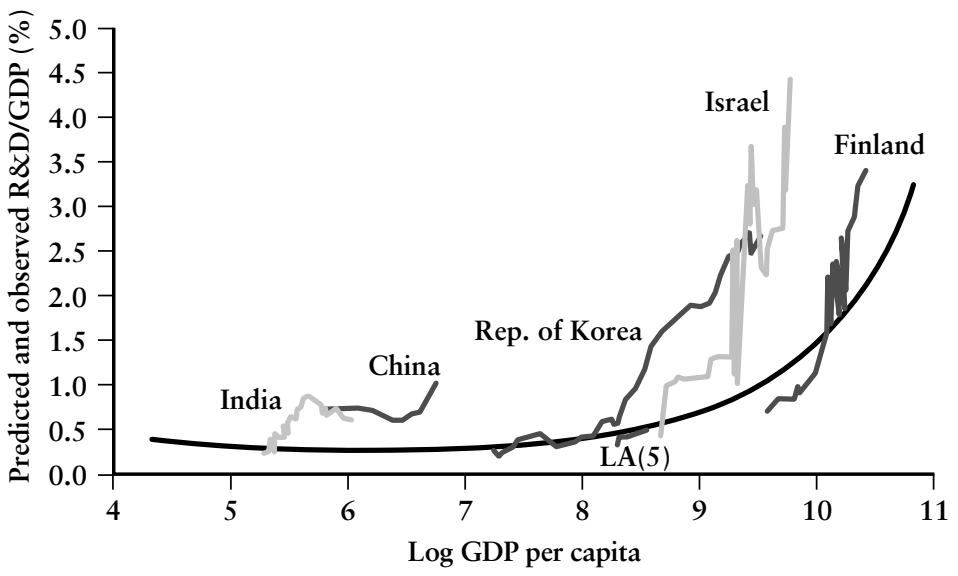

Note: LA $(5)=$ Argentina, Brazil, Chile, Costa Rica, and Mexico. Source: Lederman and Maloney 2003.

and payments for licensing of new foreign technologies, again with respect to GDP and labor force. ${ }^{23}$ The former extends beyond investment in cutting-edge technologies to many expenditures on adoption and adaptation of technologies, and it is a variable that shows substantial variance across country growth trajectories. Figure 6.4 suggests that not only does the share of GDP dedicated to R\&D in the average country increase with income per capita, but several high-growth comparator countries-Finland, the Republic of Korea, and Israelhad dramatic takeoffs relative to this benchmark, a path that China and India appear to be attempting to follow. It is disappointing that the average effort of five middle-income Latin American countries (Argentina, Brazil, Chile, Costa Rica, and Mexico) is substantially below trend.

Figure 6.5, employing the same benchmarking approach as used above, ${ }^{24}$ suggests that since the late 1960s Mexico's R\&D effort has been below the level of the countries at the same level of development, whereas licensing expenditures since the late 1970s have exceeded or met the predicted level. Figure 6.5 shows that the debt crisis of the 
Figure 6.5 Innovation Inputs in Mexico

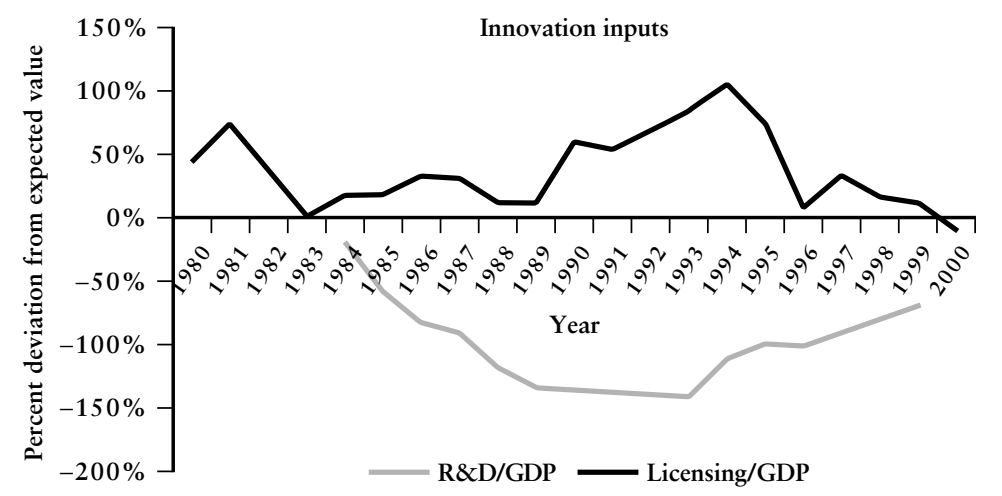

\begin{tabular}{|lcc|}
\hline Decade & R\&D/GDP & Licensing/GDP \\
\hline $1990 \mathrm{~s}$ & $0.33 \%$ & $0.15 \%$ \\
$1980 \mathrm{~s}$ & $0.33 \%$ & $0.08 \%$ \\
$1970 \mathrm{~s}$ & $0.19 \%$ & $0.16 \%$ \\
$1960 \mathrm{~s}$ & $0.17 \%$ & - \\
\hline
\end{tabular}

1980s was associated with a rapid decline in R\&D effort. It is therefore possible that one of the channels through which the process of adjustment during the 1980s hampered productivity growth might have been through the reduction of R\&D investments. During the NAFTA period, R\&D spending rose again, although not to the average. From this viewpoint Mexico needs to do more to stimulate innovative activity and address impediments to it. This becomes even more obvious when we look, again, at the high-innovation countries discussed in the section on patents. Of those countries only Canada did not experience either a boom or a continuously high level of R\&D effort, a result consistent with Trefler's (1999a,b) argument that his country risks falling into a lower growth equilibrium if it does not push up its R\&D effort. The cases of Finland and the Republic of Korea are remarkable in that they went through a period of very rapid improvements in their relative R\&D effort, and by the early 1980 s they were both well above the median. 
Table 6.1 Estimates of the Rates of Return to R\&D in the United States

\begin{tabular}{lcccr}
\hline Source & $\begin{array}{c}\text { Return } \\
\text { (own) }\end{array}$ & Spillovers & $\begin{array}{c}\text { Social } \\
\text { return }\end{array}$ & S*/S \\
\hline Sveikauskas (1981) & 0.17 & - & - & 2.4 \\
Griliches (1994) & 0.30 & - & - & 4.3 \\
Griliches and Lichtenberg (1984a) & 0.34 & - & - & 4.9 \\
Terleckyj (1980) & 0.25 & 0.82 & 1.07 & 11.7 \\
Scherer (1982) & 0.29 & 0.74 & 1.03 & 10.6 \\
Griliches and Lichtenberg (1984b) & 0.30 & 0.41 & 0.71 & 5.9 \\
Jones and Williams (1998) & 0.35 & - & - & 5.0 \\
\hline
\end{tabular}

-Not available.

Note: $S * / S=$ Optimal investment in R\&D divided by actual investment (see box 6.1).

Source: Jones and Williams 1998.

\section{How Much Should Mexico Spend on Innovation?}

It is legitimate, however, to ask if the Republic of Korea's and Finland's rapid increases in innovation expenditures were key elements in their rapid catch-ups or perhaps evidence of a wasteful high-tech "white elephant"? Another way of phrasing the question is whether the returns to $R \& D$ can justify these dramatic increases in R\&D expenditures. Most estimates of the impact of R\&D spending on TFP in selected U.S. firms and industries are very high, ranging from 30 to 120 percent, which, when compared with a 7 percent return on capital, implies the United States should invest several times more in R\&D than it currently does (see table 6.1 and box 6.1). ${ }^{25}$ Lederman and Maloney (2003) found estimates of social rates of return to the R\&D for a global sample including poorer countries in this range as well.

They also found that not only do natural resource-abundant economies such as Mexico (captured by the ratio of net exports of natural resources) appear to grow faster than others, ${ }^{26}$ but the interaction with R\&D spending is significantly positive. That is, consistent with the previous discussion, we may be able to explain the better performance of Australia or Scandinavia in their exploitation of natural resources (compared with Mexico and other Latin American economies) by their much higher commitment to innovation.

\section{Why Is Innovation Effort So Low in Mexico?}

High social returns may not translate into high private returns and, hence, innovative effort because unattended market imperfections tend 
Box 6.1 Some Algebra: How Much Should Be Spent on $\mathrm{R} \& \mathrm{D}$ ?

Beginning with a simple production function,

$$
Y=K^{\alpha} L^{1-\alpha} S^{\lambda}
$$

where $S$ is the stock of accumulated R\&D. This can be rewritten as

$$
\begin{aligned}
& \Delta \ln Y=r_{k}\left(\frac{I}{Y}\right)+r_{s}\left(\frac{\dot{S}}{Y}\right)+(1-\alpha) \Delta \ln L \text { using the fact that } \\
& \beta_{x} \Delta \ln (X)=r_{x}\left(\frac{\dot{X}}{Y}\right)=r_{x}(x)
\end{aligned}
$$

where $r_{x}$ is the rate of return on factor $X, x$ is the share of investment in $X$ over $Y$, and $\beta_{x}$ is the output elasticity of this factor. If we remove the influence of physical factors to get TFP, then the social rate of return to $\mathrm{R} \& \mathrm{D}$ is

$$
r_{s}=\Delta \ln T F P / s
$$

where $s$ is the share of R\&D spending in income. Following Jones and Williams (1998), the optimal level of R\&D expenditure occurs where $r_{s}=r$, the real interest rate. So, the ratio of the optimal level of R\&D investment to actual level along a balanced growth path can be expressed as the ratio of the social rate of return to $R \& D$ to the real interest rate:

$$
\frac{S^{*}}{S}=\frac{r_{\mathrm{s}}}{r}
$$

Jones and Williams argued that for a very conservative estimate of 28 percent return to R\&D in the United States, a long-run 7 percent rate of return on the stock market over the last century suggests that the United States should be investing perhaps four times the present level.

to reduce the equilibrium marginal private returns to R\&D. ${ }^{27}$ Knowledge is especially susceptible to market failures that lead to an under-investment in R\&D and other innovation-related activities.

Non-Appropriability. Most commonly cited is the inability of innovators to exclude others from using their ideas. This is implicit in the finding that rates of return to $R \& D$ tend to be roughly four times the private rate in the studies cited above. In fact, recognition of this failure has led to an emphasis on public interventions necessary to ensure the socially 
optimal level of innovation: temporary monopoly rights are granted through patents and other intellectual property regime (IPR) instruments, $R \& D$ subsidies are awarded, and so forth. The same problem slows the transmission of existing ideas. A firm that incurs the costs of tapping into the global stock of knowledge will soon find its discoveries adopted by other firms that free-ride on the investment. Historically this has given rise to institutions ranging from agricultural extension services to technology parks to institutions designed to act as "antennae" for new ideas at the sectoral and national levels.

Lumpiness and Scale Economies Dictate Specialization. R\&D and innovation are characterized by economies of scale and lumpiness. To be effective, resources often need to be concentrated in a manner beyond the capacity of the individual firm. Combined with the fact that even patents are not effective in resolving the non-appropriability problem in "pure science," that provides a rationale for institutions dedicated to R\&D and innovation efforts, such as research centers and universities, in their research role. Innovation and knowledge developed by those institutions tend to be nonexclusive and are made available to all interested parties.

Innovation, Diffusion, and Application Require Collaboration Among Many Institutions and Firms. Although innovation is sometimes the product of one firm alone, the more common pattern is one of joint efforts among various firms, among firms and R\&D-related institutions, or among various R\&D-related institutions. Furthermore, progress does not proceed linearly from pure science to applied technologies, but moves in both directions; and feedback from frontline users of technology to researchers is essential for the refinement of products and production processes (Nelson and Rosenberg 1993). Finally, as a result of specialization the full supply chain of knowledge is not totally integrated, either vertically or horizontally. Technological advance is not necessarily evenly diffused throughout the supply chains. In each example, success may require cooperation across all necessary actors that is subject to coordination failures and transaction costs. In many industrialized countries these issues have given rise to national institutions devoted to fomenting collaboration or eliminating impediments to technological collaboration among different institutions.

The development and necessary interaction and coordination of these market and nonmarket institutions have led to the concept of NISs and the emergence of an extensive body of relevant literature that we can only touch on here (Nelson and Rosenberg 1993; OECD 1999, 2001a). It is the networks of public and private firms interacting in a concerted 
way to generate and adopt technologies through which nations can be said to learn. Again, this "national learning capacity" is what permits nations to adopt and innovate in their initial areas of comparative advantage and helps create new areas (see Furman, Porter, and Stern 2002; Nelson 1993; Romer 1990; and Wright 1999). In the broader concept of an NIS we can include other supporting institutions, such as credit and labor markets, and even the degree of market friendliness of the economy (i.e., if it is difficult to take an idea to market, there is no incentive to develop it in the first place).

Mexico has numerous innovation-related public institutions to address particular market failures, which are associated with the education ministry, the National Council for Science and Technology (CONACYT), and the national petroleum company (PEMEX). As is generally the case, however, by their nature as nonmarket institutions, market forces will not guarantee that the various components will function coherently in a fashion that remedies the market failures they were intended to address. Finland, consistently ranked among the first two most-competitive economies in the world, is extraordinarily mindful of the need to ensure the smooth collaboration of elements of its NIS in a way that Mexico, today, is not. The challenge for public policy is thus not only to help establish research and educational agencies, but to see that market and extra-market incentives ensure that these are adequately integrated with each other and with the productive sector.

The overall weak functionality of the Mexican NIS may contribute to impeding the innovation effort. As a suggestive beginning, table 6.2 presents some estimates of the determinants of R\&D. The core specification includes the previous quinquennium's $R \& D$, the level of income per capita, GDP growth as a measure of volatility, and a measure of fixed investment. Because it proved difficult to estimate the elements of the NIS as a group, we first include them serially, fully cognizant that their often high degree of correlation implies that a significant correlation on one may be picking up the influence of others. Intellectual property right protection, access to credit, the level of educational attainment, the ability of the government to mobilize resources, the overall openness or market friendliness of the economy, and the quality of research institutions and the degree of their collaboration with the productive sector all enter significantly and of predicted sign. In column 9 of the table we combine the intellectual property index, credit market depth, and the ability of government to mobilize resources and find they all enter significantly. In column 10 the quality of research institutions is just below the 10 percent significance line. What is also important is that the variables in these last two regressions eliminate the impact of 


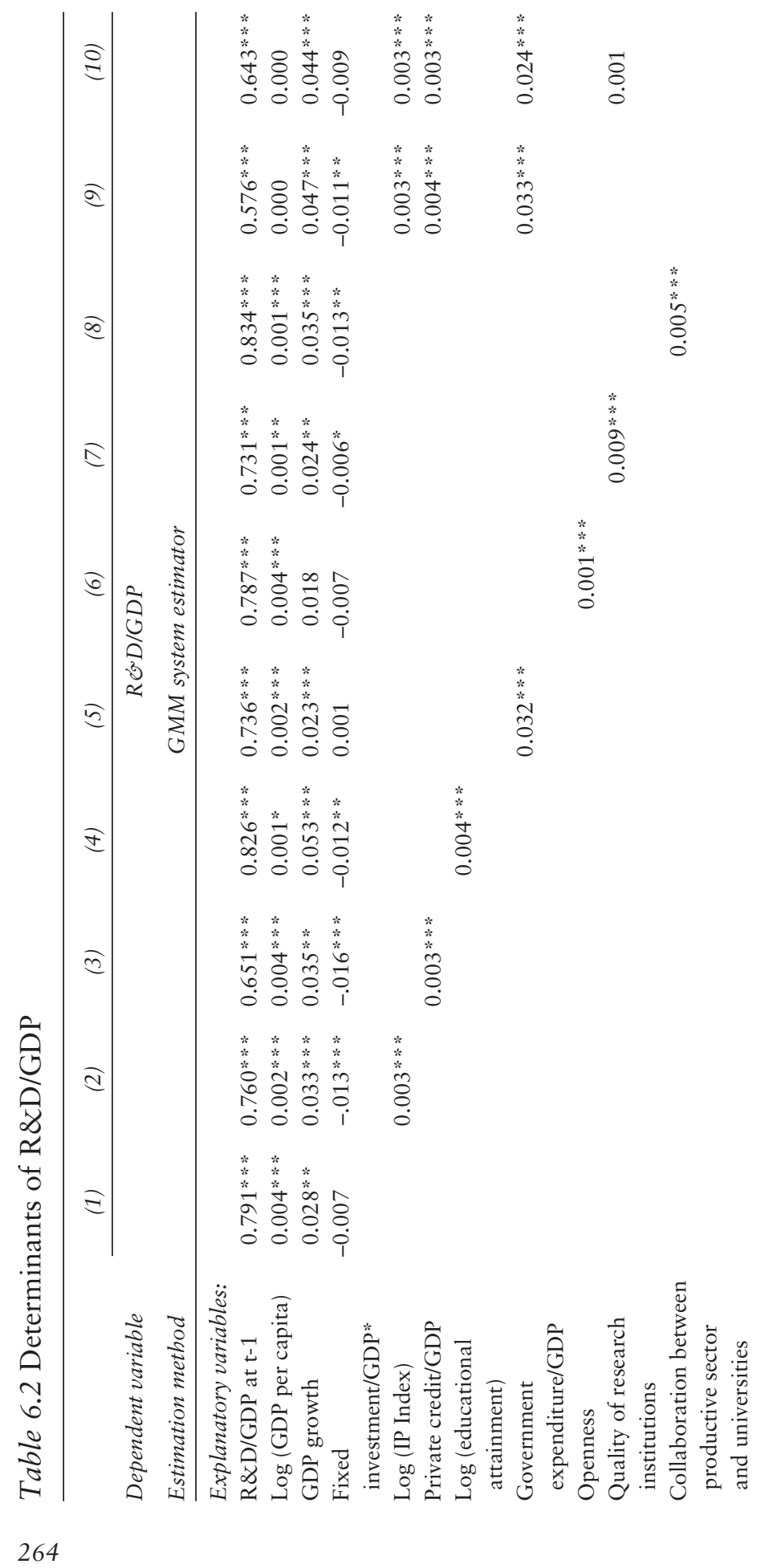




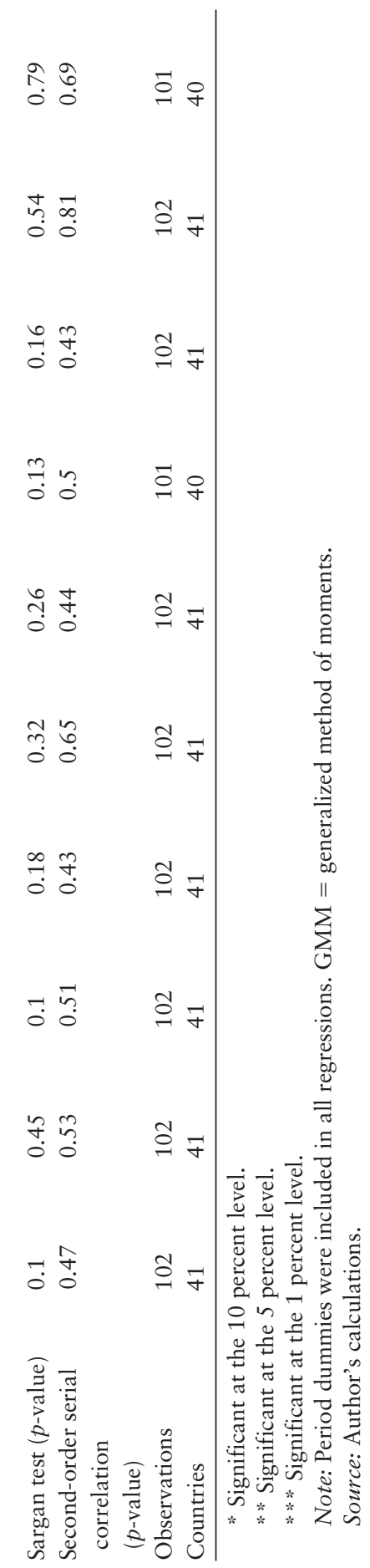




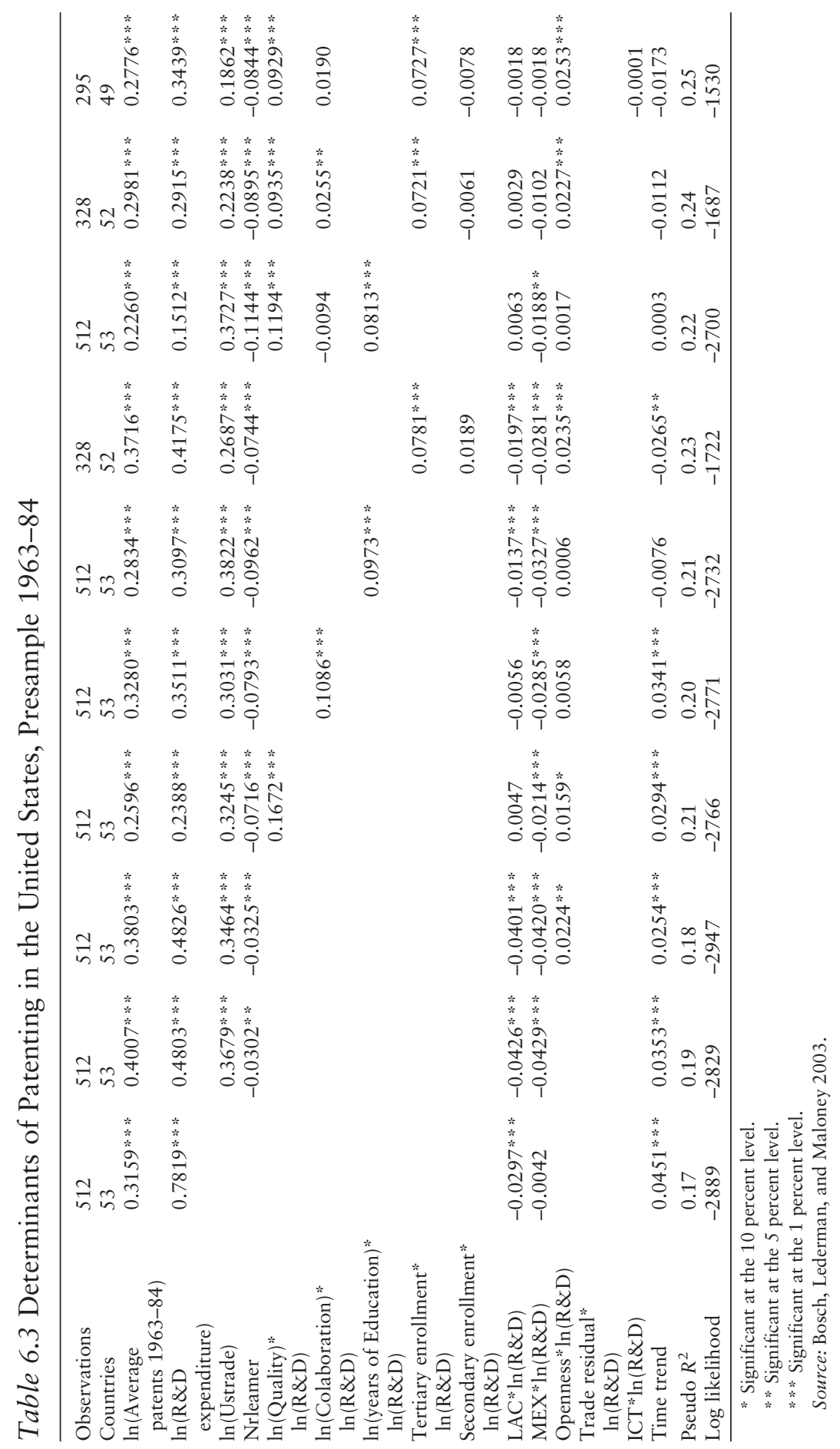


level of development, which suggests that it is partly the evolution of these variables across the development process that explains higher levels of R\&D expenditure. These findings suggest that deficient elements of the NIS may be important explanations for the low levels of innovative activity found in Mexico.

\section{How Much Bang for the Buck? The Patenting Efficiency of Mexican R\&D}

These same factors appear to influence a second characteristic of Mexico, the apparent low efficiency in the use of innovation investment measured as how well it converts R\&D financing into patenting. Table 6.3 presents econometric estimates of country-specific patenting elasticities with respect to total R\&D investment. ${ }^{28}$ Also included in the regression to standardize by trade and endowment patterns are the log of exports to the United States, net exports of natural resources, and the log of the presample mean of patents (1963-85). In every regression are a dummy for Latin America and a dummy for Mexico that are interacted with the $\mathrm{R} \& \mathrm{D}$ terms as a measure of whether the transformation rates are higher than the mean for those countries. The first three columns suggest that there is a strong and statistically significant relationship between R\&D expenditures and patents. However, the Latin American dummy with R\&D generates a strongly negative coefficient, which suggests both that the region performs substantially more poorly than the norm in converting $R \& D$ expenditures into innovation and that Mexico is even worse. Figure 6.6 expands this exercise and plots the interactive dummies for a number of other regions and countries, leaving the OECD as reference. Again, Finland, the Republic of Korea, and Taiwan (China), to mention a few, suggest above-average efficiency compared with Latin America and Mexico.

Returning to table 6.3 we find that the negative Latin American effect disappears altogether when the quality of scientific and research organizations (i.e., universities and public research institutes) and the quality of collaboration between the productive sector and universities are introduced. When tertiary enrollment rates are added, Mexico's dummy also disappears. It is noteworthy that secondary enrollment and the level of development of information and communications technology (ICT) do not explain the region's innovation inefficiency so a focus on computer and communication infrastructure to the detriment of the more traditional institutions of learning seems inadvisable. ${ }^{29}$

In summary, Mexico's inefficiency results from a combination of low enrollment rates in universities and poor quality research and linkages between the universities and the productive sector. 
Figure 6.6 Research and Development Efficiency, 1985-2000

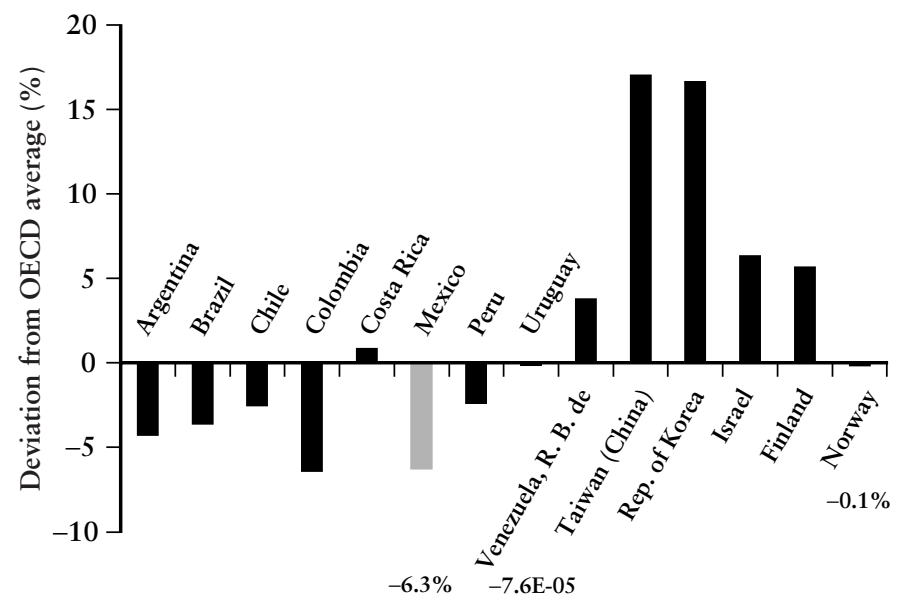

Source: Bosch Lederman and Maloney 2003.

\section{Structural Change in Trade But Not in Innovation}

As a further measure of how well the NIS is working, we can ask how well Mexico's innovation effort corresponds with the emerging areas of comparative advantage-how much the NIS is "supporting" the emerging sectors with potential dynamism. NAFTA stimulated a structural change whereby Mexico became a net exporter of machinery, including telecommunications equipment, road vehicles and parts, and office and data processing equipment (i.e., computers) (see De Ferranti et al. 2002, chapter 5). In addition, the incidence of intra-industry trade rose remarkably fast after 1994. What is not clear is whether these are simply upscale maquila operations or whether they have the potential to become knowledge clusters that both provide employment opportunities and drive future growth.

Figure 6.7a-d shows an index of Innovative Revealed Comparative Advantage (IRCA; see Patel and Pavitt 1995) that captures how patenting in various sectors in Mexico, Brazil, the Republic of Korea, and Taiwan (China), relative to each country's total patenting, compares with the world's share of total patenting in that sector. A value 
Figure 6.7a-d Mexico's Comparative Advantage in Innovation: Not in the "New" Sectors

a. Mexico: IRCA in selected industries

b. Mexico: Brazil and Mexico: IRCA in aircraft and computing equipment
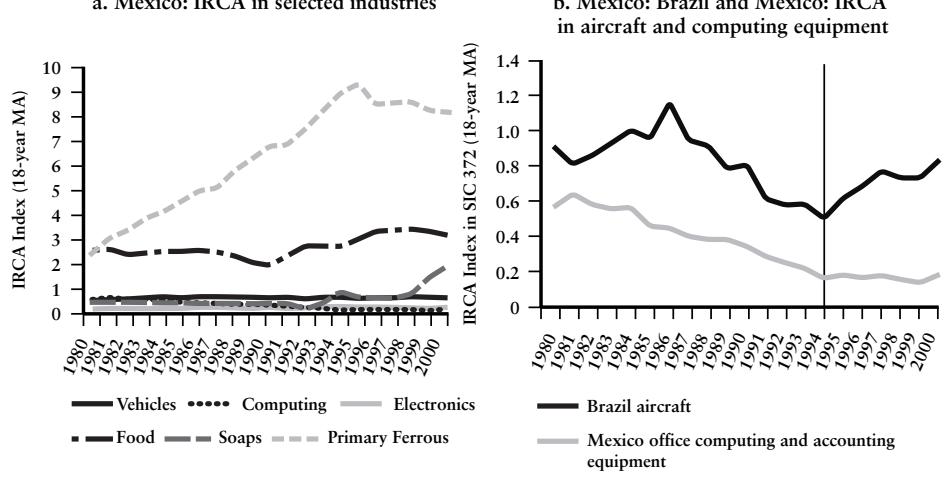

c. Republic of Korea: IRCA in selected electronics industries

d. Taiwan (China): IRCA in selected electronics and transportation industries
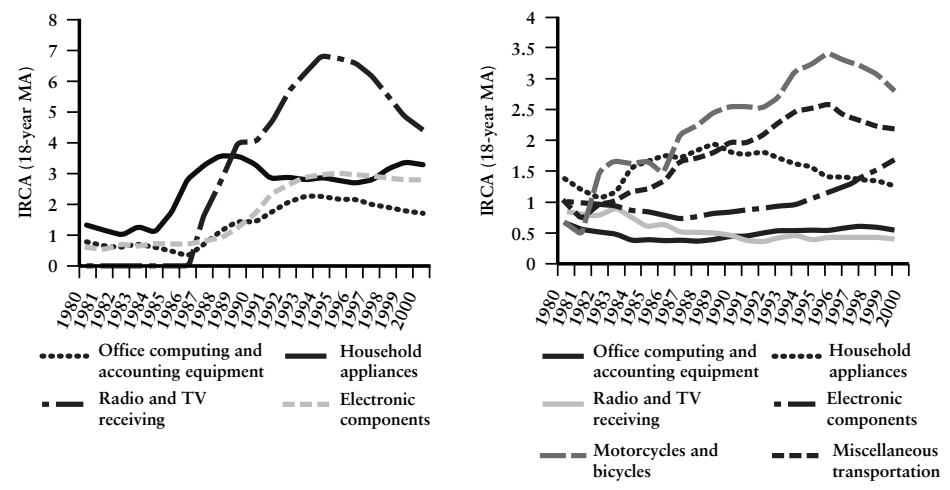

Note: $\mathrm{MA}=$ moving average; $\mathrm{SIC}=$ Standard Industrial Classification. Source: Author's calculations.

above unity suggests that a country has an innovative comparative advantage in that sector. It is striking that the principal sectors where Mexico (figure 6.7a) shows an IRCA are in more traditional processed foods, soaps and paints, and primary ferrous products; not remotely in computers and automobiles. In contrast, figure $6.7 \mathrm{~b}$ suggests that Brazil's aircraft index has been rising since the privatization of EMBRAER (Brazil's small airplane and parts producer) in 1994. More 
dramatically, the Republic of Korea shows a notable increase in the index for electronic equipment and by 2000 had achieved a clear IRCA in the sector (figure 6.7c). Taiwan (China) (figure 6.7d) also experienced substantial changes in its innovative structure, and now has a clear IRCA in transportation industries (motorcycles and bicycles, miscellaneous transportation equipment) and various electronics products (radio and TV receiving equipment, household appliances). Mexico's inability to generate an IRCA in the areas where it appears to be exporting heavily suggests that the NIS is not supporting the productive sector. To the degree that Mexico is simply relying on temporarily low labor costs to assemble computers rather than developing depth in supporting a knowledge base, these sectors may lose steam in the near future.

\section{The NIS: A Closer Look}

The previous sections have suggested that both the level and the efficiency of the national R\&D effort depend on elements of the NIS- the quality of the nonmarket-based institutions developed to resolve market failure and how well they are linked. At present the Mexican NIS appears to be characterized by a lack of coordination among its components. As a first cut, we may "follow the money" and look at levels of cross-support among components. Table 6.4 shows that all of the government's R\&D is self-financed, and less than 8 percent of the R\&D performed by universities is financed by the productive sector. In turn, neither the government nor universities contribute significant amounts to the productive sector's efforts. The three sectors function more or less independently - a recipe that is unlikely to produce economically meaningful innovation in the future.

This pattern appears in sharp contrast to some of the Asian newly industrialized countries (NICs) and Scandinavian countries that, while making a massive effort to create an educated scientific community, recognized the importance of a well-coordinated NIS to support the private sector in the context of an export-oriented trade policy (De Ferranti et al. 2003). Again, even a cursory review of Finland's technology policy reveals a virtual obsession with coordination among various elements of the NIS: between firms and among firms, universities, and think tanks. The emphasis is not only on having the right human capital but on ensuring that it faces the correct incentives to interact and generate networks that serve as collectors, creators, and disseminators of knowledge that enhances competitiveness. 
Table 6.4 R\&D in Mexico: Who Does It and Who Pays for It? Expenditures in 1999 (millions of US\$)

\begin{tabular}{|c|c|c|c|}
\hline & Performed & Financed & $\begin{array}{c}\text { Share of } \\
\text { financing } \\
(\%)\end{array}$ \\
\hline $\begin{array}{l}\text { 1. Productive sector } \\
\text { Financed bv: }\end{array}$ & $\$ 588.70$ & & \\
\hline \multicolumn{4}{|l|}{ Financed by: } \\
\hline Government & & $\$ 7.30$ & $*$ \\
\hline Other & & $*$ & $*$ \\
\hline External & & 109.2 & 18.5 \\
\hline 2. Government & $\$ 1,037.30$ & & \\
\hline \multicolumn{4}{|l|}{ Financed by: } \\
\hline Productive sector & & - & \\
\hline Government & & $\$ 1,037.30$ & 100 \\
\hline Other & & - & \\
\hline External & & - & \\
\hline 3. Universities & $\$ 607.30$ & & \\
\hline \multicolumn{4}{|l|}{ Financed by: } \\
\hline Productive sector & & $\$ 47.30$ & 7.8 \\
\hline Government & & $\$ 332.20$ & 54.7 \\
\hline Higher education & & $\$ 223.50$ & 36.8 \\
\hline $\begin{array}{l}\text { Higher education } \\
\text { and government }\end{array}$ & & $\$ 555.70$ & 91.5 \\
\hline 4. Private/nonprofit & $\$ 71.90$ & & \\
\hline Total & $\$ 2,304.20$ & & \\
\hline
\end{tabular}

- Not available.

Source: Carlos Bazdresch, CIDE, based on data from CONACYT.

Firm-Firm Linkages, Public Research Centers, and State-Owned Enterprises

Firms can internalize many of the externalities of non-appropriability, lumpiness, and risk discussed above by banding together to form industrylevel associations and research centers. One of the most famous policy initiatives to promote inter-firm linkages in the United States is SEMATECH, a research consortium of semiconductor manufacturers set up in 1987 by 14 U.S. semiconductor firms with the financial assistance of the U.S. government, which has been given credit for reviving the industry in the face of Japanese competition (Irwin and Klenow 1996). As one Mexican example, the Unión Nacional Avicola partly 
concerns itself with raising the quality of technological inputs into the production process-again, with interest in importing foreign technologies (Mayer 2002). In both cases, the dominant private sector presence ensures relevance of R\&D. But these efforts have developed without the involvement of the public sector, and have arisen out of the firms' own concerns about their competitiveness.

Theory suggests that market forces alone often do not lead to the establishment of strong knowledge-sharing and technology diffusion agreements among private firms, primarily because firms are naturally concerned about allowing potential competitors to profit from their own R\&D investments and know-how. Mexico, like many other countries, established many public research centers (PRCs) to fill the gap. Rosenberg (2000) argued that such institutions generally have poor track records because government researchers have relatively little understanding of the specific needs of the productive sector and face few incentives to address them. This critique appears writ large in Mexico. Many of the present 150 PRCs emerged in the ISI period, largely under the logic that fledgling industries lacked in-house capability to undertake the necessary research, and they have come to enjoy a disproportionate share of the national research budgets. However, they are dependent on the secretariat to which they belong and frequently oppose any efforts of the secretariat to contract with firms or outside universities that might be more qualified to investigate a particular question. ${ }^{30}$ Furthermore, the lack of competition has had the usual depressing effects on quality and has created obvious disincentives to work with other institutions that might be potential rivals. Proposed reform laws foresee greater autonomy for the centers and they further offer the possibility that research funds will be allocated competitively rather than automatically to the particular center of investigation. Inducing a greater degree of competition for scarce research funding would move Mexico close to the funding allocation systems of high performers like Finland. In addition, Finland moved to unify its PRCs under one roof. This ensures the same marginal return to the research peso across sectors and permits greater transparency and ease of monitoring.

Box 6.2 presents three cases of generally fruitful PRC-led technology transfer to the private sector in Mexico. In all three cases these have been in areas where Mexico has an ICCA: ferrous metals and foot items. In both of the cases related to CIATEQ, however, the successful experiences date prior to the privatization of the industries involved, which suggests the long gestation period needed to establish effective technology transfer relationships. Furthermore, the case of CINVESTAV-Irapuato suggests the importance of establishing international linkages and of promoting the domestic NIS as part of the global stock of knowledge. What also emerges is how low levels of human capital in the private sector itself, related to low tertiary and secondary schooling especially in 


\section{Box 6.2 Knowledge Flows from Public Research Centers to the Productive Sector in Mexico}

\section{Case 1}

Since its establishment in the 1970s, the Center of Research and Technical Assistance based in Querétaro (CIATEQ) has interacted with industry. One of its first projects in metallurgy involved long-term collaboration with the Altos Hornos de México company in Coahuila. CIATEQ's early specialization in metal-mechanics led to another long-term collaborative project mechanizing agriculture, first with industries producing capital goods for agriculture in general and later with the sugar mills. The latter effort has been maintained without interruption and has involved multidisciplinary projects in several areas, including materials technology. At first, this collaboration was with the sugar cane producers' association from Veracruz, but after privatization, collaboration now exists directly with sugar cane enterprises from other regions and countries, such as Guatemala. These efforts contributed to the development of material sciences, leading innovations in metal pieces and metal casts, and the design, development, and operation of industrial plants and services.

\section{Case 2}

In Mexico's Bajío region, farmers' associations ${ }^{1}$ are becoming aware of the value of knowledge to solve their crop problems. This is the case of the strawberry, which is one of the main regional crops and has huge potential for national and export markets. The Center for Research and Advanced Studies based in Irapuato (CINVESTAV-Irapuato) has tried to help farmers acquire technology to make virus-resistant strawberries by applying a 20 -year-old technology called in vitro micropropagation. Beginning in 1983, CINVESTAV worked unsuccessfully to establish contacts with peasants. In 1995 new contacts were made through state and municipal governments to establish a laboratory to teach farmers who then enjoyed government financial support how to micropropagate the plants. Despite CINVESTAV's on-site laboratory and extensive training, deficient education and interest in the particular strawberry species has led, again, to limited success.

\section{Case 3}

In 1991, CINVESTAV-Irapuato began collaborative interactions with a foreign company-Monsanto. This company developed technology for the genetic modification of potatoes to make them virus resistant. CINVESTAV-Irapuato sought to apply this technology to Mexican potato varieties from different regions. The transfer of technology involved several knowledge flows and diverse knowledge networks, including transfer of 


\section{Box 6.2 (continued)}

genes modified by Monsanto; training of researchers in the Monsanto Research Centre on the Science of Life located in St. Louis, MO; field tests of the genetically modified Alpha potato, performed in the state of Washington by Monsanto; acquisition of equipment by the center; and the rapid advancement in scientific capacities for developing new modified varieties. In this bilateral collaboration other actors have participated as intermediaries or financing agencies. ${ }^{2}$ This networking allowed CINVESTAVIrapuato to make a breakthrough in applying modified genes to local agriculture, creating a knowledge capability that could lead to further innovation in the near future.

\section{Notes}

1. These organizations are crop-specific, have close ties to government agencies (particularly the Ministry of Agriculture), and play an important role in diffusing official policies related to technical aspects of crops. They participate in public-private organizations representing the interests of middle-man farmers. However, they also take independent positions with regard to government policies.

2. On the international side, the project has been mediated by (a) the International Service for Acquisition of Agri-Biotech Applications, which is a nonprofit organization that has the role of easing the acquisition of technology from industrial countries for developing countries; (b) the Rockefeller Foundation, which has financed the collaboration (mainly the salaries and travel expenses) of researchers going to the United States, and the purchase of reagents and equipment for CINVESTAV; and (c) the National Institute for Forestry, Agriculture, and Livestock Research, in charge of carrying out large-scale field tests on the modified potato variety throughout Mexico.

Source: Casas, de Gortari, and Santos (2000), pp. 230-32.

rural areas, have also become obstacles to successful PRC-intermediated technology transfers.

Finally, it is clear that one of the most straightforward ways of ensuring linkages between productive activities and R\&D efforts is through public management of important economic sectors. This is the case in countries like Brazil (EMBRAER, prior to 1994), Chile (CODELCO), Costa Rica (telecommunications, utilities), Mexico (PEMEX), Taiwan (China) (telecommunications), and Venezuela (PEDEVESA). The evidence on the efficiency of total R\&D expenditures in several of these countries is quite strong, thus indicating that public firm management is not necessarily misguided, although that seems not to be the case in Mexico. Furthermore, the initial linkages of the PRCs in box 6.2 were to public sector firms. 


\section{Universities}

There are several channels through which universities enrich the innovation network. First, they produce tertiary educated workers who are the lifeblood of the NIS. The importance of this function cannot be overstated. Interviews with high-tech companies in Costa Rica highlight the issue of the generation of quality human capital in a country as an order of magnitude more important than other factors, including R\&D incentives, R\&D suppliers, and so forth (see De Ferranti et. al. 2002). Second, universities are well suited for large, long-term, basic research. Third, they are likely to maintain contacts with research centers in industrialized countries and hence perform an important role as a link to worldwide scientific and technological know-how. In all cases the degree to which they remedy the underlying market failures depends on the linkages to the productive sector.

Higher education plays a dominant role in Mexican and Latin American R\&D, as shown in table $6.5,{ }^{31}$ and this often translates into a bias toward doing basic as opposed to applied research (Hansen et al. 2002). This bias is not necessarily a weakness, provided that the incentives academics face ensure that the work is of high quality and is linked to the

Table 6.5 Structure of R\&D Effort in Selected Countries, 1995-2000 (percent of total R\&D expenditures, annual averages)

\begin{tabular}{|c|c|c|c|c|c|}
\hline Economy & $\begin{array}{l}\text { Financed } \\
\text { by the } \\
\text { productive } \\
\text { sector }\end{array}$ & $\begin{array}{c}\text { Financed } \\
\text { from } \\
\text { abroad }\end{array}$ & $\begin{array}{l}\text { Performed } \\
\text { by the } \\
\text { productive } \\
\text { sector }\end{array}$ & $\begin{array}{l}\text { Performed } \\
\text { by higher } \\
\text { education }\end{array}$ & $\begin{array}{c}\text { Performed } \\
\text { by the } \\
\text { nonproductive } \\
\text { public sector }\end{array}$ \\
\hline Brazil & 39.14 & 0.00 & 44.04 & 44.27 & 11.69 \\
\hline Canada & 44.56 & 12.69 & 57.69 & 28.67 & 13.64 \\
\hline Chile & 19.37 & 5.75 & 9.62 & 47.11 & 43.27 \\
\hline Costa Rica & - & - & 32.58 & 48.72 & 18.70 \\
\hline Finland & 62.72 & 4.12 & 66.95 & 19.12 & 13.93 \\
\hline Ireland & 66.46 & 8.79 & 71.58 & 20.46 & 7.96 \\
\hline $\begin{array}{c}\text { Rep. of } \\
\text { Korea }\end{array}$ & 73.02 & 0.08 & 72.53 & 10.42 & 17.05 \\
\hline Mexico & 19.06 & 5.22 & 22.66 & 39.82 & 37.52 \\
\hline Sweden & 64.37 & 3.47 & 75.73 & 21.57 & 2.70 \\
\hline $\begin{array}{l}\text { Taiwan } \\
\text { (China) }\end{array}$ & 60.03 & 0.10 & 61.00 & 12.20 & 26.80 \\
\hline United States & es 62.98 & 0.00 & 73.88 & 14.33 & 11.78 \\
\hline $\begin{array}{l}\text { Venezuela, } \\
\text { R. B. de }\end{array}$ & 38.13 & 0.00 & - & - & - \\
\hline
\end{tabular}

- Not available.

Source: Authors' calculations, based on annual data collected by Lederman and Sáenz (2003). 
productive sector. For example, in Finland 40 percent of firms have collaborative arrangements with universities (Brunner 2001); and as Blomström and Kokko (2001) documented, these interactions have been vital to the continued dynamism of both the high-tech and more traditional forest industries. Comparable numbers are not available for Mexico. However, figure 6.8 reports survey results published in the latest issues of the World Economic Forum's (2002) Global Competitiveness Report (GCR) of business perceptions of university-private sector interactions (labeled "collaboration" in figure 6.8). Like many Latin American countries, Mexico appears with a very low ranking.

This is consistent with case studies by Mayer (2002) of Avimex, a veterinary pharmaceutical company in Mexico, who noted that despite a high 10-15 percent of sales spent on R\&D and world-class innovations in joint projects with U.S. research institutes, the major disadvantage Avimex and Mexican firms in general face is the lack of research part-

Figure 6.8 Global Competitiveness Report Survey Results: Private Sector Perceptions of Innovation-Related Factors, 1996-2001

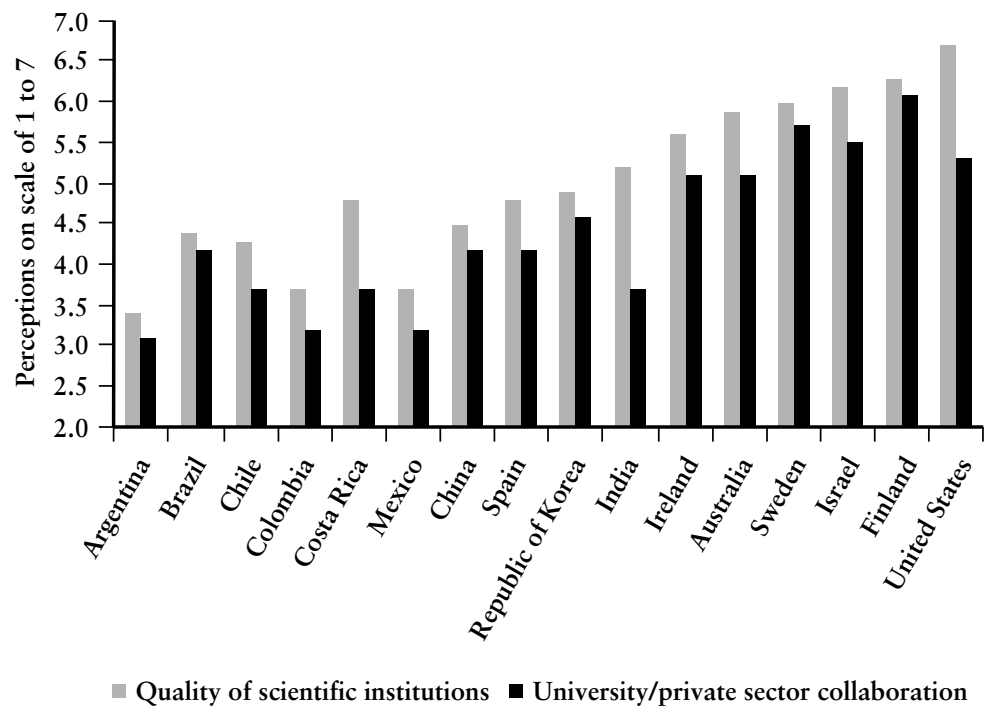

Source: World Economic Forum 2002. 
ners within the country. That lack has forced them to look for partners in the United States. In her study of 13 high-tech firms in Jalisco, Mexico's Silicon Valley, that employed roughly 249 Mexican engineers involved in research and design, Rivera Vargas (2002) found that there was limited contact between them and their academic counterparts. In particular, no joint research projects in electronics or related areas were being carried out (cited in Hanson 2004). Hanson argued that although there are cases in which multinational corporations and universities collaborate on curriculum development, there appear to be no systematic plans to use these relationships as means of technological transfer and there appears to be little active learning. More generally, the government, when encouraging manufacturing investment such as the maquilas, never looked beyond job creation to active programs of technology transfer.

The isolation of the Mexican university arises from both demand and supply sides. There are a number of factors-among them poorly designed incentives-responsible for the dearth of effective linkages and collaboration between scientific institutions and the private sector in Latin America and the Caribbean region. But there is also a lack of incentives for universities to link and address private sector knowledge needs. Arguably there is a more "liberal arts" as opposed to "technical" culture, with deep historical roots that resonate with Lazonik's analysis of the inadequate U.K. system a few decades ago. ${ }^{32}$ But there are also more concrete disincentives. Because researchers cannot appropriate the benefits of innovation, they have little incentive to undertake innovations and link with the private sector. Various industrialized countries allow ownership rights to governmentfunded R\&D—often on a case-by-case basis and in some instances, such as in Japan and the United States, explicitly in the national patent laws. In the United States the Bayh-Dole Act of 1980 allows industry contractors of the government, national laboratories, and academic institutions to automatically retain title to the inventions that come out of their research work, even if it is funded by the government. In return, the government receives from the university or industry a royalty-free license for governmental purposes. There is convincing evidence that these laws have in fact helped speed the rate of patenting by research conducted in the U.S. public laboratories (Jaffe and Lerner 2001), and thus the lessons regarding incentives for patenting by researchers apply also to the Mexican PRCs as well as universities.

Goldfarb, Henrekson, and Rosenberg (2001) cited differences in academic structures and their influence on researcher involvement with the commercialization of research ideas as an important reason for the much lower spillovers from academia to industry in Sweden than in the United States. Competition for researchers and scientists in the United States has reinforced the need for policies that are attractive to them. Universities have established technology transfer offices and have liberal policies on faculty leave of absence and consulting privileges that 
allow faculty to pursue commercial opportunities while keeping their positions on the faculty intact. In Sweden, however, universities do not gain from the commercialization, and hence they resist faculty involvement with industry. For instance, it is difficult for Swedish professors to take temporary leave to organize firms, as is done in the United States. What matters is that property rights are allocated to the university or the researcher, and thus the innovation can be commercialized. However, how they are allocated also has a significant impact. If researchers get the property rights, they are likely to remain at the university; otherwise they likely will move to the productive sector.

At a more mundane level, Mayer (2002) argued that bureaucratic rigidities in Mexico make it difficult to write contracts with and get access to the use of laboratories and equipment from the university. The approval process is very centralized and bureaucratic and so is a disincentive to firms attempting interactions with the universities.

\section{Supporting Capital and Labor Markets and IPRs}

Credit markets and labor markets are critical supporting elements of the NIS, and here too Mexico may be facing important barriers to raising the innovation effort. Both topics have been dealt with at greater length in chapter 5 of this volume and we can only briefly sketch some additional elements here. By nature, innovation has long gestation periods and high levels of risk, and the absence of accommodating long-term credit markets can inhibit long-run innovation-related risk taking, as table 6.2 suggests. The shallowness of Mexican markets is documented in chapter 5, but we know less about the specialized capital market institutions required across the innovation cycle: pre-commercialization financing where new ideas get seed money as well as subsequent stages of venture capital infusion needed to bring ideas to market. In India, besides ample fiscal incentives for R\&D, a development financial institution (namely, the Industrial Credit and Investment Corporation of India and its subsidiaries) initiated venture capital in 1988 and subsequently private venture capital firms emerged, albeit on a smaller scale. In Israel Trajtenberg (2001) reported, innovation policy is essentially credit policy. In Mexico there is presently no recognition of the venture capital firm as a legal entity. There are holding companies or "SIMCAS" that hold other firms' assets, but the legal structure does not encourage the association of several entrepreneurs to share risk, and the profits of the SIMCAs enjoy unfavorable fiscal treatment.

That said, other countries of the region that have established venture capital-type institutions, such as Chile, have suffered for a lack of "deal flow"-the ideas are not there or if they are there, they are unable to escape the institution in which they were generated. Hence, a government program to resolve the capital problem may be "pushing on a 
string" if it does not also address the fundamental dysfunction of the NIS discussed above.

Parente and Prescott (2000) have placed heavy emphasis on barriers to the adoption of new technologies embodied in the labor codes or other workplace restrictions as explanations for differing levels of development. Whether their largely anecdotal evidence can establish such impediments as primary, it is clear as chapter 5 discusses that the labor code is not friendly to the introduction of new technologies or processes. It is likely that the dynamic concerns about TFP growth should assume a larger profile in the national debates over labor reform. (See also OECD 2001b.)

Finally, although the literature on intellectual property rights is somewhat ambiguous, the strengthening of IPRs seems important to the innovation effort (e.g., see Park 2001). The index of IPRs in table 6.2 is a significant determinant of $\mathrm{R} \& \mathrm{D}$, and in the Mexican case the rise in the index can account for all of the rebound in $\mathrm{R} \& \mathrm{D}$ and is the only determining variable among increased credit intermediation, lower risk, and greater ability to mobilize public resources whose value moved in the direction that could have been responsible (see Lederman and Maloney 2003).

\section{Conclusion}

The countries to which Mexico often compares itself, most particularly the Asian NICs, have followed growth strategies characterized by a very active approach to innovation policy. This often included an active engagement in world markets, particularly on the export side. Thus, NAFTA, and more generally economic integration with Canada and the United States, is a step in the right direction. Import competition has been associated with improvements in manufacturing TFP, and it may have helped indirectly by improving the efficiency of R\&D. Improvements in intellectual property rights and increased credit availability (see chapter 4 of this volume) were probably associated with the moderate yet insufficient increase in R\&D expenditures in the late 1990s. Nevertheless, the main conclusion of this chapter is that NAFTA is not enough to ensure technological convergence in North America.

On basic indicators of investment in innovation and innovation outcomes, Mexico lags significantly behind comparator countries. The low levels of both innovation effort and efficiency suggest that the country needs to address issues related to the inefficiency of its national innovation system. In particular, it needs to improve the quality of its research institutions by changing both internal promotion/advancement criteria and incentives to interact with the private sector. Besides regulatory changes affecting IPRs for university and PRC researchers, it is likely that public subsidies will be needed to provide additional incentives for 
firms to establish such linkages, especially when there is little previous collaborative experience and thus little mutual trust. The careful design of such mechanisms is essential and simply increasing the financing to existing programs and institutions should emphatically not be an option. Reform of supporting institutions such as credit and labor markets along the lines discussed in chapter 5 of this volume should also be considered. Finally, more effort needs to be dedicated to collecting statistics and methods to monitor the functioning of the NIS and the success of government interventions. It might be useful to build an information-based monitoring facility that would play a role similar to that of Spain's National Commission for the Evaluation of Research Activity (CNEAI). ${ }^{33}$

Clearly, Mexico's location next to one of the most dynamic sources of innovation in the world today offers opportunities for collaboration with northern universities and firms. Within the NAFTA context, Mexico might negotiate the co-financing of joint research or exchange programs. However, such efforts will lead to little if human capital and institutions are not brought up to speed to enable Mexico to participate as a full partner in innovation.

\section{Notes}

1. Pastor (2002) used the title "NAFTA Is Not Enough." We, however, do not address issues related to innovation policies.

2. At the firm level, see Cohen and Levinthal (1989); Forbes and Wield (2000); Griffith, Redding and Van Reenen (2003); and Pavitt (2001). At the national level see, for example, Baumol, Nelson, and Wolff (1994).

3. Most of the analyses presented in this chapter are quantitative, relying on internationally comparable indicators of various aspects of innovative activity and technological progress provided by Lederman and Sáenz (2003).

4. Although the fall in productivity growth in the United States and other high-income countries in the 1970s has been attributed to the oil shock of 1973 and its macroeconomic repercussions (Griliches 1988), it is difficult to blame the fall in productivity in Mexico and other oil exporters on this factor. The East Asia region, for example, did not experience such a slowdown, perhaps because some East Asian and Pacific countries such as Indonesia are oil exporters, but the Republic of Korea did experience it.

5. In assessing the impact of various factors on TFP growth in the region, Loayza, Fajnzylber, and Calderón (2002) found that for all 20 Latin American countries in the sample, the impact of structural reform policies was positive, and for 15 countries in the sample, stabilization policies were positive as well. They noted, however, that the estimated growth-combined contribution of the two ranged between 2.5 percent and 3.0 percent-not insignificant but not likely to transform the region into Asian or Scandinavian growth miracles.

6. Many resource-rich countries-Australia, Canada, Finland, and Swedenalso closed somewhat after the Great Depression, but none to the degree of Latin America (Maloney 2002).

7. The USPTO demands that the invention be "novel and nontrivial, and has to have commercial application" (Jaffe and Trajtenberg 2002, pp. 3-4). 
8. The patent residuals are derived from a negative binomal regression on GDP, population, and their squares plus a term for trade with the United States, which is known to be correlated with patenting. Median regression on the same regressors less the U.S. trade variable give the publications residuals. See Bosch, Lederman, and Maloney (2003) for technical details about the methodologies and data.

9. Interested readers can also consult other literature reviews on these issues, including Navaretti and Tarr (2000) and Saggi (2002).

10. The corresponding result from a 30-year cross-section of countries was below this range, falling to 0.005 percent.

11. For a strong critique of cross-country studies that examines the linkage between trade and economic growth, see Rodríguez and Rodrik (2000).

12. For a more expansive review of the literature, see Keller (2001).

13. The high-R\&D industries are those that have relatively high shares of $R \& D$ expenditures over sales in the high-income countries.

14. There was no difference between high $R \& D$-intensive industries and low $\mathrm{R} \& \mathrm{D}$-intensive ones, which suggests that industrial composition is not critical to the benefits of NAFTA.

15. Muendler (2002) argued that this may be explained by the failure among manufacturers to adjust production practices to the increased availability of imported inputs.

16. They do find, however, that the presence of exporters may make it easier for nonexporters to break into foreign markets; in Colombia, nonexporters appear to experience cost reductions when export activity increases.

17. Intermediate inputs increased marginal costs and quality among rubber producers and fertilizer/pesticide producers. Pharmaceutical producers, imported intermediates, combined with exports or imported capital goods, reduce marginal costs and tend to increase product quality. But these are exceptions to a fairly ambiguous record.

18. The same inconclusiveness appears in the U.S. microeconomic data (Bernard and Jensen 1999). Likewise, a study of a panel of Spanish firms concluded that there is only evidence in favor of the (Schumpeterian) firm-selection channel, but the evidence concerning the learning-by-exporting hypothesis is very weak (Delgado, Fariñas, and Ruamo 2001). Similar results were reported for Korean and Taiwanese firms by Aw, Chung, and Roberts (2000).

19. For less-developed countries, see, for example, Calderón, Loayza, and Servén 2002; Carkovic and Levine 2002; and Loayza, Fajnzylber, and Calderón 2002.

20. Lipsey (2002), in a comprehensive review of the literature, argued that the evidence is vast that foreign firms tend to be at least as productive as domestic firms and hence their presence pushes up average productivity. However, the evidence that the presence of foreign firms has positive productivity spillovers is extremely ambiguous. The great majority of the papers that find strong effects employ crosssectional data, which cannot control for unobserved country characteristics. Those using firm-level panels frequently find insignificant or even negative effects (e.g., Aitken and Harrison [1999] for Venezuela). Van Pottelsberghe de la Potterie and Lichtenberg (2001) found that investing in a relatively more technologically advanced country and hence adding foreign production to domestic production increases productivity in the home country. But the reverse case of investment in a technologically less advanced country has insignificant or negative results for the host developing country. Baldwin, Braconier, and Forslid (2000) found mixed results for seven OECD countries. Using panel firm-level data from Sweden, Braconier, Ekholm, and Midelfart Knarvik (2000) discovered no spillovers from incoming FDI on productivity, and the only variable in their sample affecting TFP was own-country R\&D. Xu (2000), using panel data on technological transfer from the United States found a technology transfer effect by U.S. multinational 
corporations only for advanced countries, although a competition effect does appear to increase productivity. Kinoshita (2000) found at the firm level, for example, little evidence of positive effects of FDI in the Czech Republic from 1995 to 1998. Smarzynska (2004) reported no direct impact of FDI in Lithuania on firms in the same industry, although there was an impact on affiliated upstream suppliers.

21. For these authors, "innovative-effective" human capital is a combination of the level of education and the effort invested by the economy to develop new technologies based on the existing technological frontier.

22. Similar results were previously suggested by Grossman and Helpman (1991, chapter 8), among others. They proposed a model with multiple growth equilibria resulting from intra-national R\&D externalities. Maloney (2002) argued that this partly explains why Latin America nearly disappeared from some industries where it once dominated globally.

23. To derive the relationship between the rate of R\&D investment and GDP, we estimated a median regression where the dependent variable was the log of R\&D expenditures over GDP from the early 1960s to 2000, and the arguments were the log of GDP per capita and log of GDP per capita squared.

24. These are residuals from more general median regressions for both $R \& D$ and licensing, which included log GDP, log GDP squared, log labor, log labor squared, and time dummies as arguments.

25. Griliches (1992) estimated social returns to R\&D in the United States of between 20 percent and 60 percent. In fact, for the United States Jones and Williams (1998) confirmed that rates of return are at least 30 percent and calculated that the optimal resources that should be devoted to R\&D could be four times the present level in the United States.

26. See also Lederman and Maloney (2002) who investigated the impact of trade structure on growth and found natural resources to be positively related to growth.

27. For an intuitive discussion of the determinants of the equilibrium private marginal rate of return, see David, Hall, and Toole (2000). Briefly, the equilibrium return is determined by the marginal costs of and returns to R\&D. Some of the market failures affect the costs (i.e., capital markets might be incomplete) and others affect the returns (i.e., the non-appropriability problem).

28. These estimates were obtained using a pooled regression of 52 countries over a 15-year period (1985-2000) in a negative binomial regression application of Blundell, Griffith, and Windmeijer's (2002) pre-sample mean estimator, which aims to control unobserved country-specific characteristics and the likely endogeneity of some of the explanatory variables.

29. The ICT index used in this analysis is the one provided by Lederman and $\mathrm{Xu}$ (2001), which is the result of the first principal component from factor analysis using four indicators of ICT: telephone lines per capita, cellular phones per capita, personal computers per capita, and Internet hosts per capita.

30. Discussions (various dates in 2001 and 2002) with and presentations by Carlos Bazdresch, Centro de Investigacion y Docencia Economicas (CIDE), a former head of CONACYT in Mexico.

31. The data in table 6.4 for Mexico differs from those in table 6.5 because of the different sources of information and different time periods. The data in table 6.5 are internationally comparable.

32. This appears to be the case throughout the region. Agapitova and HolmNielsen (2002) argued that, overall, the university mentality in Chile is not geared to solving problems on a business time scale, and Mullin (2001) argued that overall academic interests tend to be narrow and unapplied. Observers of Costa Rica's two-star technical school stress not so much incentives, but the "foundational impulse"- a desire to be patterned more on the Massachusetts Institute of Technology or other technical schools of excellence than on those with a liberal arts bias. 
33. This commission has improved the quality and quantity of basic research output in Spain, even in a period of time when public funding of research declined (Jiménez-Contreras, de Moya Anegón, and López-Cózar 2003). The main monitoring variable used by the CNEAI is the number of publications of government- and university-funded research, which are made public once or twice a year. Indeed, given the reputational rewards sought by researchers, it is likely that the mere publication of the performance index can by itself improve the quality of research. This principle could be used to improve the quality of applied research by, for example, maintaining an accurate count of patents granted by the Canadian, Mexican, and U.S. governments to researchers residing in Mexico and financed by public funds, either via the PRCs or the universities. Other important variables to monitor are discussed in De Ferranti et al. (2003, chapter 8).

\section{References}

The word "processed" describes informally produced works that may not be commonly available through libraries.

Acemoglu, Daron, Philippe Aghion, and Fabrizio Zilibotti. 2002. Distance to Frontier, Selection, and Economic Growth. Working Paper 9066, National Bureau of Economic Research, Cambridge, MA.

Acemoglu, Daron, and Fabrizio Zilibotti. 2001. Productivity Differences. Quarterly Journal of Economics 116 (2): 563-606.

Agapitova, Natalia, and Lauritz Holm-Nielsen. 2002. Chile-Science, Technology, and Innovation. Human Development Department LCSHD Paper 79, World Bank, Latin America and the Caribbean Region, Washington, DC.

Aitken, Brian J., and Ann E. Harrison. 1999. Do Domestic Firms Benefit from Direct Foreign Investment? Evidence from Venezuela. American Economic Review 89 (3): 605-18.

Alvarez, Roberto, and Raymond Robertson. 2001. Exposure to Foreign Markets and Firm-level Innovation: Evidence from Chile and Mexico. University of Chile, Santiago, and Macalester College, St. Paul, MN. Processed.

Aw, Bee Yan, Sukkyun Chung, and Mark J. Roberts. 2000. Productivity and Turnover in the Export Market: Micro-level Evidence from the Republic of Korea and Taiwan (China). World Bank Economic Review 14 (1): 65-90.

Baldwin, Richard, Henrick Braconier, and Rikard Forslid. 2000. Multinationals, Endogenous Growth and Technological Spillovers: Theory and Evidence. Discussion Paper 2155, Centre for Economic Policy Research, London.

Baldwin, Richard E., and Elena Seghezza. 1996. Testing for Trade-induced Investment-led Growth. Working Paper 5416, National Bureau of Economic Research, Cambridge, MA.

Barro, Robert J. 1991. Economic Growth in a Cross Section of Countries. Quarterly Journal of Economics 106: 407-44.

Baumol, William J., Richard R. Nelson, and Edward N. Wolff, eds. 1994. The Convergence of Productivity, Its Significance and Its Varied Connotations. Oxford, UK: Oxford University Press.

Bernard, Andrew B., and J. Bradford Jensen. 1999. Exporting and Productivity. Working Paper 7135, National Bureau of Economic Research, Cambridge, MA. 
Blomström, Magnus, and Ari Kokko. 2001. From Natural Resources to High-Tech Production: The Evolution of Industrial Competitiveness in Sweden and Finland. Stockholm School of Economics. Processed.

Blomström, Magnus, and Edward N. Wolff. 1994. Multinational Corporations and Productivity Convergence in Mexico. In Convergence Of Productivity: Cross-National Studies and Historical Evidence, eds. W. J. Baumol, R. R. Nelson, and E. N. Wolff. Oxford, UK: Oxford University Press.

Blundell, Richard, Rachel Griffith, and Frank Windmeijer. 2002. Individual Effects and Dynamics in Count Data Models. Journal of Econometrics 108: 113-31.

Bosch, Mariano, Daniel Lederman, and William F. Maloney. 2003. Patenting and Efficiency: A Global View. Office of the Chief Economist for Latin America and the Caribbean Region, World Bank, Washington, DC. Processed.

Braconier, Henrik, Karolina Ekholm, and Karen Helene Midelfart Knarvik. 2000. Does FDI Work as a Channel for R\&D spillovers? Evidence Based on Swedish Data. Discussion Paper 2469, Centre for Economic Policy Research, London.

Brunner, José Joaquín. 2001. Chile: Informe e Indice Sobre Capacidad Tecnológica. Universidad Adolfo Ibáñez, Santiago de Chile. Processed.

Calderón, César, Norman Loayza, and Luis Servén. 2002. Greenfield FDI vs. Mergers and Acquisitions: Does the Distinction Matter?. Office of the Chief Economist for Latin America and the Caribbean Regino, World Bank, Washington, DC. Processed.

Carkovic, Maria, and Ross Levine. 2002. Does Foreign Direct Investment Accelerate Economic Growth?. University of Minnesota, Minneapolis. Processed.

Casas, Rosalba, Rebeca de Gortari, and M. Josefa Santos. 2000. The Building of Knowledge Spaces in Mexico: A Regional Approach to Networking. Research Policy 29: 225-41.

Clerides, Sofronis K., Saul Lach, and James R. Tybout. 1998. Is Learning by Exporting Important? Micro-Dynamic Evidence from Colombia, Mexico and Morocco. Quarterly Journal Of Economics 113 (3): 903-47.

Coe, David T., Elhanan Helpman, and Alexander W. Hoffmaister. 1997. North-South R\&D Spillovers. Economic Journal 107: 134-49.

Cohen, Wesley M., and Daniel A. Levinthal. 1989. Innovation and Learning: The Two Faces of R\&D. Economic Journal 99: 569-96.

David, Paul A., Bronwyn H. Hall, and Andrew A. Toole. 2000. Is Public R\&D a Complement or Substitute for Private R\&D? A Review of the Econometric Evidence. Research Policy 29: 497-529.

De Ferranti, David, Daniel Lederman, William F. Maloney, and Guillermo E. Perry. 2002. From Natural Resources to the Knowledge Economy: Trade and Job Quality. World Bank, Latin American and Caribbean Studies Department, Washington, DC.

De Ferranti, David, Guillermo E. Perry, Indermit Gill, J. Luis Guasch, William F. Maloney, Carolina Sanchez-Paramo, and Norbert Schady. 2003. Closing the Gap in Education and Technology. World Bank Latin American and Caribbean Studies Department, Washington, DC.

Delgado, Miguel, Jose Fariñas, and Sonia Ruano. 2001. Firm Productivity and Export Markets: A Non-Parametric Approach. Journal of International Economics 57: 397-422.

Dollar, David, and Edward N. Wolf. 1997. Convergence of Industry Labor Productivity among Advanced Economies, 1963-1982. In The Economics of Productivity, ed. Edward N. Wolff. London: Elgar. 
Eaton, Jonathan, and Samuel Kortum. 1996. Trade in Ideas: Patenting and Productivity in the OECD. Journal of International Economics 40 (3): 251-78.

Forbes, Naushad, and David Wield. 2000. Managing R\&D in TechnologyFollowers. Research Policy 29: 1095-109.

Furman, Jeffrey L., Michael Porter, and Scott Stern. 2002.The Determinants of National Innovative Capacity. Research Policy 31: 899-933.

Goldfarb, Brent, Magnus Henrekson, and Nathan Rosenberg. 2001. Demand vs. Supply Driven Innovations: U.S. and Swedish Experiences in Academic Entrepreneurship. Working Paper in Economics and Finance 0436, Stockholm School of Economics.

Griffith, Rachel, Stephen Redding, and John Van Reenen. 2003. R\&D and Absorptive Capacity: From Theory to Data. Working Paper 01/03, Institute for Fiscal Studies, London.

Griliches, Zvi. 1988. Productivity Puzzles and R\&D: Another Nonexplanation. Journal of Economic Perspectives 2 (4): 9-21.

- 1990. Patent Statistics as Economic Indicators: A Survey. Journal of Economic Literature 28 (4): 1661-707.

1992. The Search for R\&D Spillovers. Scandinavian Journal of Economics 94: 29-47.

- 1994. Productivity, R\&D and the Data Constraint. American Economic Review 84: 1-23.

Griliches, Zvi, and Frank Lichtenberg. 1984a. Interindustry Technology Flows and Productivity Growth: A Reexamination. Review of Economics and Statistics 66: 324-29.

1984b. R\&D and Productivity Growth at the Industry Level: Is There Still a Relationship? In $R \mho D$, Patents and Productivity, ed. Zvi Griliches. Chicago: University of Chicago Press.

Grossman, Gene M., and Elhanan Helpman.1991. Innovation and Growth in the Global Economy. Cambridge: MIT Press.

Hall, Robert, and Charles I. Jones. 1999. Why Do Some Countries Produce So Much More Output Per Worker Than Others? Quarterly Journal of Economics 114 (1): 83-116.

Hansen, Thomas Nokolaj, Natalia Agapitova, Lauritz Holm-Nielsen, and Ognjenka Goga Vukmirovic. 2002. The Evolution of Science and Technology: Latin America and the Caribbean in Comparative Perspective. World Bank, Washington, DC. Processed.

Hanson, Mark. 2004. Transnational Corporations, Knowledge Transfer, and National Development: The Case of Mexico. University of California, Riverside. Processed.

Howitt, Peter, and David Mayer-Foulkes. 2002. R\&D, Implementation and Stagnation: A Schumpeterian Theory of Convergence Clubs. Working Paper 9104, National Bureau of Economic Research, Cambridge, MA.

Irwin, Douglas A., and Peter J. Klenow. 1996. High-Tech R\&D Subsidies Estimating the Effects of Sematech. Journal of International Economics, 40 (3/4): 323-44.

Jaffe, Adam B., and Josh Lerner. 2001. Reinventing Public R\&D: Patent Policy and the Commercialization of National Laboratory Technologies. Rand Journal of Economics 32 (1):167-98.

Jaffe, Adam B., and Manuel Trajtenberg. 2002. Patents, Citations and Innovations: A Window on the Knowledge Economy. Cambridge: MIT Press. 
Jiménez-Contreras, Evaristo, Félix de Moya Anegón, and Emilio Delgado LópezCózar. 2003. The Evolution of Research Activity in Spain: The Impact of the National Commission for the Evaluation of Research Activity (CNEAI). Research Policy 32 (1): 123-42.

Jones, Charles I., and John C. Williams. 1998. Measuring the Social Return to R\&D. Quarterly Journal of Economics 113: 1119-135.

Keller, Wolfgang. 2001. International Technology Diffusion. Working Paper 8573, National Bureau of Economic Research, Cambridge, MA.

- 2002. Trade and the Transmission of Technology. Working Paper 6113, National Bureau of Economic Research, Cambridge, MA.

Kinoshita, Yuko. 2000. R\&D and Technology Spillovers Via FDI: Innovation and Absorptive Capacity. Working Paper 349, William Davidson Institute, Ann Arbor, MI.

Kraay, Aart, Isidro Soloaga, and James Tybout. 2002. Product Quality, Productive Efficiency, and International Technology Diffusion: Evidence from Plant-Level Panel Data. Working Paper 2759, World Bank, Washington, DC.

Lederman, Daniel, and William F. Maloney. 2002. Trade Structure and Growth. Office of the Chief Economist for Latin America and the Caribbean Region, World Bank, Washington, DC. Processed.

- 2003. R\&D and Development. Office of the Chief Economist for Latin America and the Caribbean Region, World Bank, Washington, DC. Processed.

Lederman, Daniel, and Laura Sáenz. 2003. Innovation Around the World: A Cross-Country Data Base of Innovation Indicators. Office of the Chief Economist for Latin America and the Caribbean Region, World Bank, Washington, DC. Processed.

Lederman, Daniel, and Lixin Colin Xu. 2001. Comparative Advantage and Trade Intensity: Are Traditional Endowments Destiny?. Office of the Chief Economist for Latin America and the Caribbean Region, World Bank, Washington, DC. Processed.

Levine, Ross, and David Renelt. 1992. A Sensitivity Analysis of Cross-Country Growth Regressions. American Economic Review 82 (4): 942-63.

Lipsey, Robert E. 2002. Home and Host Country Effects of FDI. Working Paper 9293, National Bureau of Economic Research, Cambridge, MA.

Loayza, Norman, Pablo Fajnzylber, and César Calderón. 2002. Economic Growth in Latin America and the Caribbean: Stylized Facts, Explanations, and Forecasts. Office of the Chief Economist for Latin America and the Caribbean Region, Regional Studies Program, World Bank, Washington, DC.

López-Acevedo, Gladys. 2002. Determinants of Technology Adoption in Mexico. World Bank, Washington, DC. Processed.

López-Córdova, J. Ernesto. 2002. NAFTA and Mexico's Manufacturing Productivity: An Empirical Investigation Using Micro-level Data. Paper presented at the Latin American and Caribbean Economic Association Meeting, Madrid.

Lloyd-Ellis, Huw, and Joanne Roberts. 2002. Twin Engines of Growth: Skills and Technology as Equal Partners in Balanced Growth. Journal of Economic Growth 7 (2): 87-115.

Maloney, William F. 2002. Missed Opportunities: Innovation, Natural Resources, and Growth in Latin America. Economia 3 (1): 111-50.

Martin, William, and Devashish Mitra. 2001. Productivity Growth and Convergence in Agriculture and Manufacturing. Economic Development and Cultural Change 49 (2): 403-22. 
Maskus, Keith E. 2000. Intellectual Property Rights in the Global Economy. Washington, DC: Institute for International Economics.

Mayer, David. 2002. Liberalization, Knowledge, and Technology: Lessons from Veterinary Pharmaceutics and Poultry in Mexico. Centro de Investigacion y Docencia Economicas. Processed.

Meza González, Liliana, and Ana Belen Mora Yagüe. 2002. Why Do Mexican Manufacturing Firms Invest in R\&D? Universidad Iberamericana, D.F. Mexico, and Georgetown University, Washington, DC. Processed.

Muendler, Marcus. 2002. Openness and Growth: A Study of Brazilian Manufacturers, 1986-1998. University of California at Berkeley. Processed.

Mullin, James. 2001. Science, Technology, and Innovation in Chile. International Development Research Centre, Ottawa.

Navaretti, Giorgio Barba, and David G. Tarr. 2000. International Knowledge Flows and Economic Performance: A Review of the Evidence. World Bank Economic Review 14 (1): 1-15.

Nelson, Richard R. 1993. A Retrospective. In National Innovation Systems: A Comparative Analysis. New York: Oxford University Press.

Nelson, Richard, and Nathan Rosenberg. 1993. Technical Innovation and National Systems. In National Innovation Systems: A Comparative Analysis. New York: Oxford University Press.

OECD (Organisation for Economic Co-operation and Development). 1999. Managing National Innovation Systems. Paris.

- 2001a. Innovative Clusters: Drivers of National Innovation Systems. Paris.

. 2001b. The Cross-Market Effects of Product and Labour Market Policies. Science and Technology Outlook 2001. Paris.

Parente, Stephen L., and Edward C. Prescott. 2000. Barriers to Riches. Cambridge: MIT Press.

Park, Walter G. 2001. Intellectual Property and Patent Regimes. In Economic Freedom of the World, 2001 Annual Report. Fraser Institute, Vancouver, BC.

Pastor, Robert A. 2002. NAFTA Is Not Enough: Steps Toward a North American Community. In The Future of North American Integration Beyond NAFTA, eds. Peter Hakim and Robert E. Litan. Washington, D C: Brookings Institution Press.

Patel, Pari, and Keith Pavitt. 1995. Patterns of Technological Activity: Their Measurement and Interpretation. In Handbook of the Economics of Innovation and Technological Change, ed. Paul Stoneman. Padstow, UK: T. J. Press Ltd.

Pavitt, Keith. 2001. Public Policies to Support Basic Research: What Can the Rest of the World Learn from U.S. Theory and Practice? (And What They Should Not Learn). Industrial and Corporate Change 10 (3): 761-79.

Rivera Vargas, Maria Isabel. 2002. Technology Transfer Via University-Industry Relationship: The Case of the Foreign High-Technology Electronics Industry in Mexico's Silicon Valley. New York: Routledge-Falmer.

Rodriguez, Francisco, and Dani Rodrik. 2000. Trade Policy and Economic Growth: A Skeptic's Guide to the Cross-National Evidence. In NBER Macroeconomics Annual 2000. Cambridge: MIT Press.

Romer, Paul. 1990. Endogenous Technological Change. Journal of Political Economy 98 (5): 71-102.

Rosenberg, Nathan. 2000. Why Do Firms Do Basic Research (With Their Own Money)? Economics of Science and Innovation 2: 197-206. 
Saggi, Kamal. 2002. Trade, Foreign Direct Investment, and International Technology Transfer: A Survey. World Bank Research Observer 17 (2): 191-235.

Scherer, Fredric M. 1982. Inter-Industry Technology Flows and Productivity Growth. Review of Economics and Statistics 64: 627-34.

Schiff, Maurice, and Yanling Wang. 2002. Regional Integration and Technology Diffusion: The Case of NAFTA. Working Paper 3132, World Bank, Washington, DC.

- 2004. Education, Governance and Trade-Related Technology Spillovers in Latin America. Discussion Paper 1028, Institute for the Study of Labor (IZA), Bonn, Germany.

Smarzynska, Beata K. 2004. Does Foreign Investment Increase the Productivity of Domestic Firms? In Search of Spillovers Through Backward Linkages. American Economic Review 94 (3): 605-27.

Solow, Robert. 1956. A Contribution to the Theory of Economic Growth. Quarterly Journal of Economics 50: 65-94.

- 1957.Technical Change and the Aggregate Production Function. Review of Economics and Statistics 39: 312-20.

Sveikauskas, Leo. 1981. Technological Inputs and Multifactor Productivity Growth. Review of Economics and Statistics 63: 275-82.

Terleckyj, Nestor E. 1980. Direct and Indirect Effects of Industrial Research and Development on the Productivity Growth of Industries. New Developments in Productivity Measurement and Analysis, eds. John W. Kendrick and Beatrice N. Vaccara. Chicago: University of Chicago Press.

Trajtenberg, Manuel. 2001. Innovation in Israel 1968-1997: A Comparative Analysis Using Patent Data. Research Policy 30 (3): 363-89.

Trefler, Daniel. 1998. The Long and Short of the Canada-U.S. Free Trade Agreement. University of Toronto, Canadian Institute for Advanced Research, and National Bureau of Economic Research, Cambridge, MA.

- 1999a. Does Canada Need a Productivity Budget? Policy Options JulyAugust: 66-71.

- 1999b. My Brains and Your Looks: Canada in an Innovative World (A Business Agenda with Heart). Paper presented at the Canadian Deputy Minister's Retreat, Toronto, Ont., January 27.

Van Pottelsberghe de la Potterie, Bruno, and Frank Lichtenberg. 2001. Does Foreign Direct Investment Transfer Technology Across Borders? Review of Economics and Statistics 83 (3): 490-97.

Wacziarg, Romain. 2001. Measuring the Dynamic Gains from Trade. World Bank Economic Review 15 (3): 393-429.

World Bank. 2000. Mexico Export Dynamics and Productivity Analysis of Mexican Manufacturing in the 1990s. Report 19864-ME, Washington, DC.

World Economic Forum. 2002. The Global Competitiveness Report 2001-2002. Harvard University Center for International Development. Geneva: World Economic Forum.

Wright, Gavin. 1999. Can a Nation Learn? American Technology as a Network Phenomenon. NBER Conference Report series. Chicago: University of Chicago Press,

Xu, Bin. 2000. Multinational Enterprises, Technology Diffusion, and Host Country Productivity Growth. Journal of Development Economics 62: 47793. 


\section{7 \\ NAFTA and the Trade Flows of Nonmember Countries}

HAS MEXICO BENEFITED FROM NAFTA at the expense of other countries? The North American Free Trade Agreement's (NAFTA's) potential welfare-reducing effect through trade diversion has long been a major concern for nonmember countries, and particularly for Central America and the Caribbean, whose geographical location and pattern of specialization are relatively similar to Mexico's. As a result, preventing the presumed damage from NAFTA has been a major driving force in the efforts of some neighboring countries to achieve "NAFTA parity."

Conceptually, in contrast with welfare-enhancing trade creation (which reflects the removal of distortions in the relative price of goods between two members of a preferential trading arrangement) trade diversion results from the introduction of distortions in the relative prices of goods between member and nonmember countries. ${ }^{1}$ Trade creation involves replacing high-cost suppliers in a member country with lowercost producers from another member country. Trade diversion instead replaces low-cost suppliers from nonmember countries with higher-cost producers from member countries.

Trade diversion can result from the formation of both customs unions and free trade agreements (FTAs) such as NAFTA. In the latter case, however, there is an additional reason why trade diversion is more likely to result from FTAs than are customs unions (see Krueger 1995). Because external barriers generally differ among FTA members, rules of origin (ROOs) are usually imposed to prevent "trade deflection"-that is, goods from nonmember countries being imported by the member with the lowest external tariff for re-export to other members (see chapter 4 of this volume). In the case of NAFTA, ROOs provide incentives for producers in Mexico, for example, to purchase higher-cost inputs from another partner country (e.g., the United States), despite the existence of lower-cost suppliers from nonmember countries, to satisfy 
ROO requirements allowing export of the final product to the United States free of duty. In this sense ROOs export protection from one partner country to the rest, even if the external tariff structure of the FTA members remains unaltered. From a welfare perspective, the trade diversion induced by ROOs makes FTAs inferior to customs unions.

The purpose of this chapter is to assess if NAFTA has had significant trade-diverting effects on third countries, especially the neighboring countries of Central America and the Caribbean. ${ }^{2}$ A number of recent studies have been similarly concerned with the trade-creating and -diverting effects of other FTAs. As preferential trading arrangements have proliferated around the world over the last decades, so have empirical analyses of their consequences. A considerable part of this body of literature has focused on the European Economic Community/European Union (EEC/EU; see box 7.1), but some studies have examined also the trade creation and diversion of various other preferential trade agreements (PTAs), including the European Free Trade Association (EFTA), the Association of Southeast Asian Nations (ASEAN), the Canada-U.S. Free Trade Agreement (CUSFTA), and Latin American PTAs other than NAFTA. Most studies have found significant trade creation effects of these regional integration agreements (RIAs). Some studies also found trade diversion. ${ }^{3}$

These studies have used various approaches to assess the effects of FTAs on the welfare of excluded countries. In theory, a direct indication of the effects of an FTA on nonmembers would be given by the resulting change in their terms of trade. ${ }^{4}$ The presumption is that the change in trade preferences against nonmember countries could lead to a decline in demand for their exports and thus require a fall in their relative price to restore equilibrium, leading to an unambiguous welfare deterioration (Corden 1984).

In practice, however, changes in aggregate export and import prices reflect many factors, including the changing composition of each country's imports and exports, and proper analysis of the terms of trade effects of an FTA requires disaggregate price data, which are seldom available. ${ }^{5}$ As a consequence, to date few studies of the effects of FTAs on nonmember countries have followed this approach, and most studies have focused instead on the observed evolution of trade flows as a more tractable proxy for welfare changes. ${ }^{6}$ The analysis below follows this methodology.

Its simplest version is based on the intuitive observation that if the FTA's trade flows with the rest of the world are no smaller than they were prior to FTA formation, then the rest of the world cannot have suffered a welfare loss, whereas FTA members must have experienced a gain. ${ }^{7}$ This condition may seem easy enough to check in a static world, but in a world where trade is expanding, FTA imports and exports of 


\section{Box 7.1 Trade Creation and Diversion in the Process of Enlarging the EU}

Right after the Treaty of Rome in 1957, trade within the EU started rising more rapidly than with non-EU countries. Imports from EFTA6 countries-Denmark, Finland, Norway, Sweden, Switzerland, and the United Kingdom-remained somewhat stable over the period whereas those from other regions fell noticeably. ${ }^{1}$ Later accession by new members further increased intra-EEC trade. With the accession of Greece, Portugal, and Spain, intra-EU trade increased by more than 20 percent.

The overwhelming part of this growth has been identified as trade creation, and available estimates vary between US\$8 billion and US $\$ 17$ billion. On the other hand, trade diversion over this period is usually found to be small (less than US $\$ 2$ billion) relative to trade creation (see Ohly 1993).

Bayoumi and Eichengreen (1997) concluded from a gravity-based analysis that some trade diversion did occur between the initial period of the EU (EEC) and the late 1960s, but less so thereafter. Their figures indicate that around half of the increase in the intra-EEC trade that was observed over the 1956-70 period was matched by a decrease in trade with other partners, largely developing countries. Later on, accession by Denmark, Ireland, and the United Kingdom (all in 1972) also generated some trade diversion. Between 60 and 90 percent of their new trade with the EEC corresponded to trade creation. As to Greece's entry (1981), between 65 and 75 percent was trade creation. In contrast, no evidence of trade diversion was found after the accessions of Portugal and Spain.

Sapir (1998) also found that EU-EFTA trade was penalized by EEC formation and enlargement, although in later years he found no significant evidence of trade diversion. In turn, Soloaga and Winters (2001), using a larger country and RIA sample, concluded that the EU's trade with nonmember countries declined significantly with the RIA's southern enlargement

Note: For membership in Preferential Trade Agreements like EFTA, see appendix table 7.11.

most commodities will tend to rise along with overall trade so that the condition will be automatically satisfied. Thus, it is common to restate the condition in terms of shares, and examine the extent to which increases in intra-FTA trade are achieved at the expense of the trade shares of nonmember countries.

However, there is no obvious reason to presume that, in the absence of the FTA under consideration, trade shares would have remained constant, and a more rigorous approach requires carefully specifying the counterfactual scenario to characterize what trade flows would have 
been had the FTA not been created. This amounts to identifying the determinants of members and nonmembers' trade flows and then analyzing the extent to which flows were affected by the preferential trading arrangement, holding all other determinants constant. Such analysis typically looks for declines in member imports from nonmember countries-for given values of all non-FTA-related trade determinants-as evidence of trade diversion. ${ }^{8}$

In spite of its popularity, however, this focus on nonmembers' exports to FTA member countries may be misleading. The reason is that the link between exports and welfare of nonmember countries is conceptually tenuous. Instead, under certain conditions it can be shown that the welfare of nonmember countries is more closely related to their imports from member countries. The intuitive reason is that welfare should be more tightly linked to what the country in question purchases, and consumes-provided it does so within its intertemporal budget constraint-than to what it sells in the post-FTA environment. ${ }^{9}$

The analysis in this chapter combines these various ingredients. First it looks at the broad trends in aggregate trade and market shares of NAFTA member and nonmember countries in Latin America. Next it reassesses those trends, controlling for the observed changes in trade determinants other than preferential trading arrangements. In view of the above considerations, the analysis departs from the conventional emphasis on FTA imports alone and examines the changes in trade between NAFTA members and nonmembers in both directions.

Assessing the effects of NAFTA on the trade flows of nonmember countries poses major challenges. Only a short time has elapsed since the passage of NAFTA for its full effects to unfold. In addition, the late 1990s also saw changes in other key trade determinants, such as the devaluation of the Mexican peso in 1994-95 and the global trend toward trade liberalization. Subject to these limitations, we find little evidence of any adverse impact of NAFTA on the aggregate trade flows of neighboring countries-a result in line with the majority of previous studies.

Some earlier assessments of the impact of NAFTA on third countries have identified in particular the textile and apparel sector as a prime suspect for trade diversion. Given the prominent role of this sector in the total exports of several Central American and Caribbean countries, we examine it in some detail to complement the aggregate analysis. Consistent with the evidence from aggregate trade flows, the sector-specific data do not yield any compelling evidence that neighboring countries lost apparel market share from trade diversion caused by NAFTA.

Finally, trade diversion is not the only channel through which preferential trading arrangements may harm excluded countries. Trade preferences can distort also the international allocation of investment in 
favor of member countries, especially when the preferences are accompanied by ROOs. They encourage suppliers located outside the FTA to relocate to a member country in order to benefit from the preference and meet $\mathrm{ROO}$ requirements. We will explore these potential foreign direct investment (FDI) diversion effects of NAFTA in the next chapter.

\section{Trends in Trade Flows Before and After NAFTA}

Assessing the trade effects of NAFTA is no easy matter because many other factors relevant for the trade flows of member and nonmember countries were also changing around the time of NAFTA's inception. ${ }^{10}$ First, total world trade grew considerably through the 1980s and 1990s. Second, many countries undertook significant trade liberalization measures, including Mexico in the late 1980s, so that trade flows in the 1990s partly reflected the continuing effects of those reforms. Likewise, the phasing out of tariffs under NAFTA extends over a 15 -year period initiated in 1994, so its effects on trade flows should appear gradually rather than abruptly. Finally, Mexico's real exchange rate experienced a large appreciation over 1987-94, followed by a big depreciation at the end of 1994.

In this section we review the main trends in trade flows between 1980 and 2000. To place NAFTA in a broader perspective, the analysis includes also eight other RIAs- the Andean Group, the Central American Common Market (CACM), the Caribbean Community and Common Market (CARICOM), MERCOSUR (all in Latin America and the Caribbean); and EFTA, the EU, ASEAN, and the Gulf Cooperation Council (GCC). Table 7.11 in the appendix to this chapter provides summary information on the origins and membership of each of these blocs.

Figure 7.1 documents the upward trend in world openness to trade (measured by nonfuel exports plus imports divided by gross domestic product $[\mathrm{GDP}])$. It also shows the comparative trends in total trade for countries that belong to a RIA and those that do not, and for Latin American and Caribbean countries that belong to RIAs (Andean Group, CACM, CARICOM, and MERCOSUR) as well as RIAs integrated only by industrialized countries. It is apparent from the figure that total world nonfuel trade has grown faster than world GDP: after rising steadily over the past two decades, world openness was 4.3 percent higher in 1996-2000 than in 1980-85. ${ }^{11}$ For countries included in the nine RIAs considered, openness also has increased since the late 1980sby 5.2 percent of GDP by the end of the sample period. In turn, countries not included in these nine RIAs also increased their openness over the same time period, but to a lesser extent (2.8 percent). Looking separately 


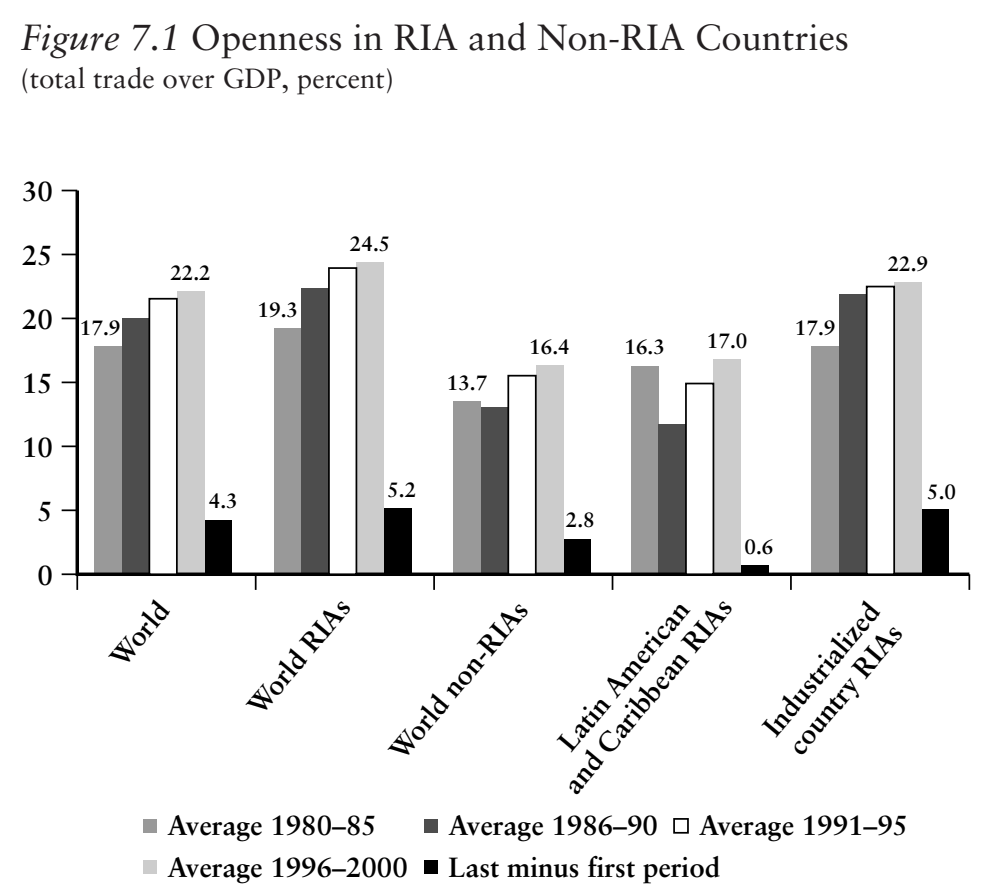

Source: Montenegro and Soloaga 2002.

at RIA countries in Latin America and the Caribbean and in the industrialized world, it can be seen that the latter increased their openness considerably more than the former $(5$ percent vs. 0.6 percent, respectively) between the early 1980s and the late 1990s.

Over the same period, and particularly since the late 1980s, trade barriers declined in most developing countries. For a sample of 129 developing countries, the mean unweighted tariff declined from an average of 27.2 percent in 1985 to 11.3 percent in 1999. For Mexico the decline was very similar: the mean tariff fell from 25.2 percent to 10.1 percent over the same period. ${ }^{12}$ In addition, nontariff barriers also were lowered in most countries, although the extent of their decline is difficult to quantify.

Against this background of trade expansion and liberalization, figure 7.2 shows the trends in NAFTA members' imports (measured in 1995 U.S. dollars) over the past two decades. Total bloc imports from all sources more than doubled, and intra-bloc imports were 2.5 times 
Figure 7.2 NAFTA: Total Imports by Source (billions of 1995 US\$)

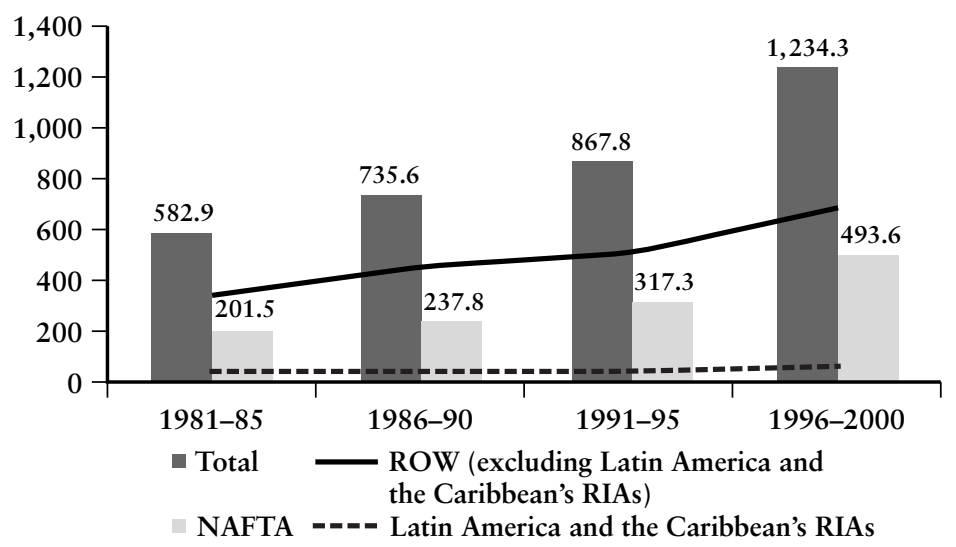

Source: Montenegro and Soloaga 2002.

higher in 1996-2000 than in 1981-85. In contrast, NAFTA imports from Latin American and Caribbean RIAs increased only 1.4 times, whereas imports from the rest of the world (i.e., excluding Latin American and Caribbean RIA countries) doubled over the same period. As a result of these trends, in 1996-2000 the share of intra-bloc imports in NAFTA members' total imports had risen to 40 percent, more than 5 percentage points above the level at the beginning of the 1980s. In contrast, the share of Latin American and Caribbean RIAs in NAFTA markets declined to 4.6 percent-from 7.1 percent in the early 1980s-whereas the share of other countries decreased by 4 percent (from 58.8 to 54.8). Thus, over the period there was a substantial intensification in intra-bloc trade within NAFTA, and a loss of market share by nonmember countries.

Figure 7.3 shows the evolution of total trade (imports plus exports) in real terms for countries belonging to Latin American and Caribbean RIAs. Aggregate trade rose in all cases over the period of analysis, but to very different degrees. MERCOSUR countries increased their total trade by 177 percent between the first and last five-year periods of our sample; however, CACM countries' total trade increased by 125 percent. Countries belonging to the Andean Group and to CARICOM showed 


\section{Figure 7.3 Total Trade in Latin America and the Caribbean's RIAs \\ (billions of 1995 US\$)}

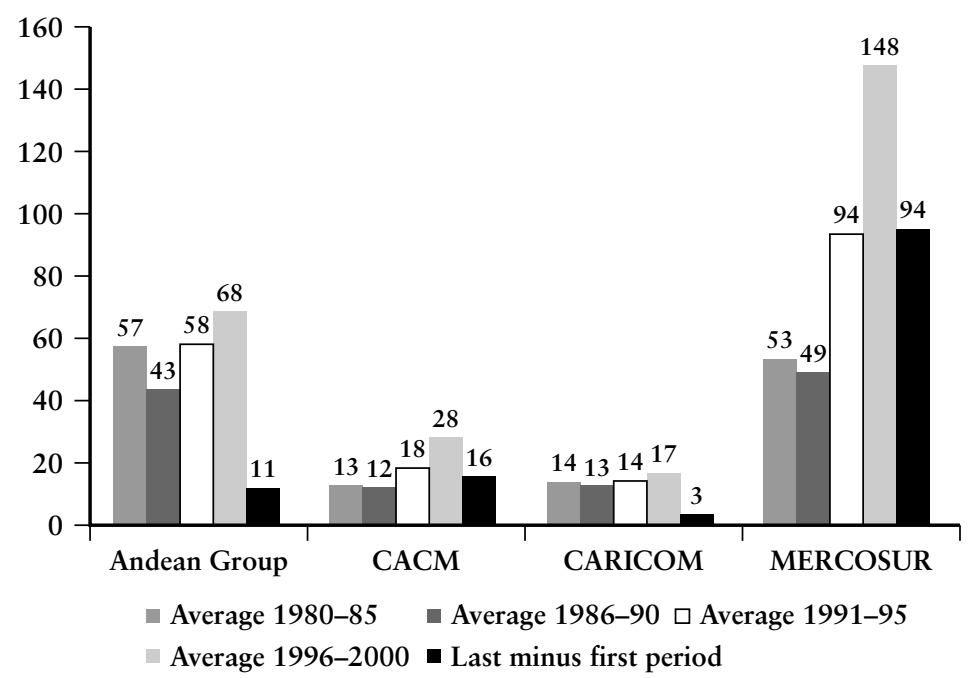

Source: Montenegro and Soloaga 2002.

considerably less dynamism. Their overall nonfuel trade rose by only 20 percent during the same period. ${ }^{13}$

Table 7.1 offers a comparative perspective on intra-bloc trade across Latin American and Caribbean RIAs since the early 1980s. Two main facts emerge. First, intra-bloc trade is particularly significant for NAFTA countries: it accounts for a higher fraction of total bloc trade than in any of the other blocs shown. Second, all RIAs in Latin America and the Caribbean region have exhibited an upward trend in the share of intra-bloc imports, although to varying degrees. The increase was most pronounced in MERCOSUR and least pronounced in CACM and CARICOM countries.

Table 7.2 shows that the increasing trend in the share of intra-bloc imports in total NAFTA imports affected almost all industries at the one-digit Standard International Trade Classification (SITC) level. When comparing the average shares of 1996-2000 with those of 1981-85 (column "e" in the table), the share of intra-bloc imports shows a decrease only in two sectors (chemicals-SITC 5, and paperSITC 6.4). For all the other aggregates the shares have gone up, and in 
Table 7.1 Intra-Bloc Imports

(percent of total imports)

\begin{tabular}{lccccc}
\hline Period & $\begin{array}{c}\text { Andean } \\
\text { Group }\end{array}$ & CACM & CARICOM & MERCOSUR & NAFTA \\
\hline 1981 & 5.8 & 16.5 & 8.4 & 7.0 & 34.2 \\
$1982-83$ & 5.5 & 17.3 & 8.2 & 7.7 & 34.7 \\
$1984-85$ & 5.8 & 5.9 & 7.9 & 11.1 & 34.0 \\
$1986-87$ & 4.4 & 11.7 & 7.7 & 12.2 & 31.4 \\
$1988-89$ & 5.1 & 10.8 & 6.9 & 15.3 & 33.2 \\
$1990-91$ & 7.9 & 11.0 & 8.3 & 16.0 & 34.4 \\
$1992-93$ & 9.4 & 12.2 & 8.8 & 20.2 & 37.1 \\
$1994-95$ & 13.0 & 13.5 & 10.4 & 19.6 & 38.1 \\
$1996-97$ & 14.4 & 13.7 & 9.9 & 20.9 & 40.2 \\
$1998-2000$ & 13.1 & 14.3 & 11.1 & 20.7 & 40.7 \\
Averages & & & & & \\
$1981-89$ & 5.3 & 12.4 & 7.8 & 10.7 & 33.5 \\
1990-95 & 10.1 & 12.2 & 9.2 & 18.6 & 36.5 \\
1996-2000 & 13.7 & 14.0 & 10.5 & 20.8 & 40.5 \\
\hline
\end{tabular}

Source: Montenegro and Soloaga 2002.

some cases they have done so by a substantial amount: more than 10 percent in food (SITC 0), animal fats (SITC 4), and in most of the manufactured goods subsectors (SITC 6 components). The last columns of the table show that most of the gains in the share of intra-bloc trade happened in the late 1980s and early 1990s, prior to the passage of NAFTA. Share increases during the late 1990s were generally more modest (even negative in some cases), although still significant for sectors such as leather and textiles.

In contrast with the increasing share of intra-bloc imports in NAFTA trade, the shares of other Latin American and Caribbean RIAs in total NAFTA imports declined. The only exception was CACM, whose share rose from 0.4 percent in the 1980 s to 0.7 percent in the late 1990s. In turn, the biggest loss in market share was that of MERCOSUR, whose share of NAFTA imports fell from 2.3 percent in the 1980s to 1.4 percent in the late 1990s. CARICOM and Andean Group countries also lost market share, but to a lesser extent (table 7.3). It is also important to note that Mexico's market share started rising in the late 1980s, around the time of its unilateral trade liberalization.

Figures 7.4 and 7.5 depict the main trends in Mexico's exports. Figure 7.4 tracks Mexico's market share of overall NAFTA and nonNAFTA non-oil imports. The sharp increase in Mexico's presence in NAFTA markets is apparent from the figure. However, it is worth 


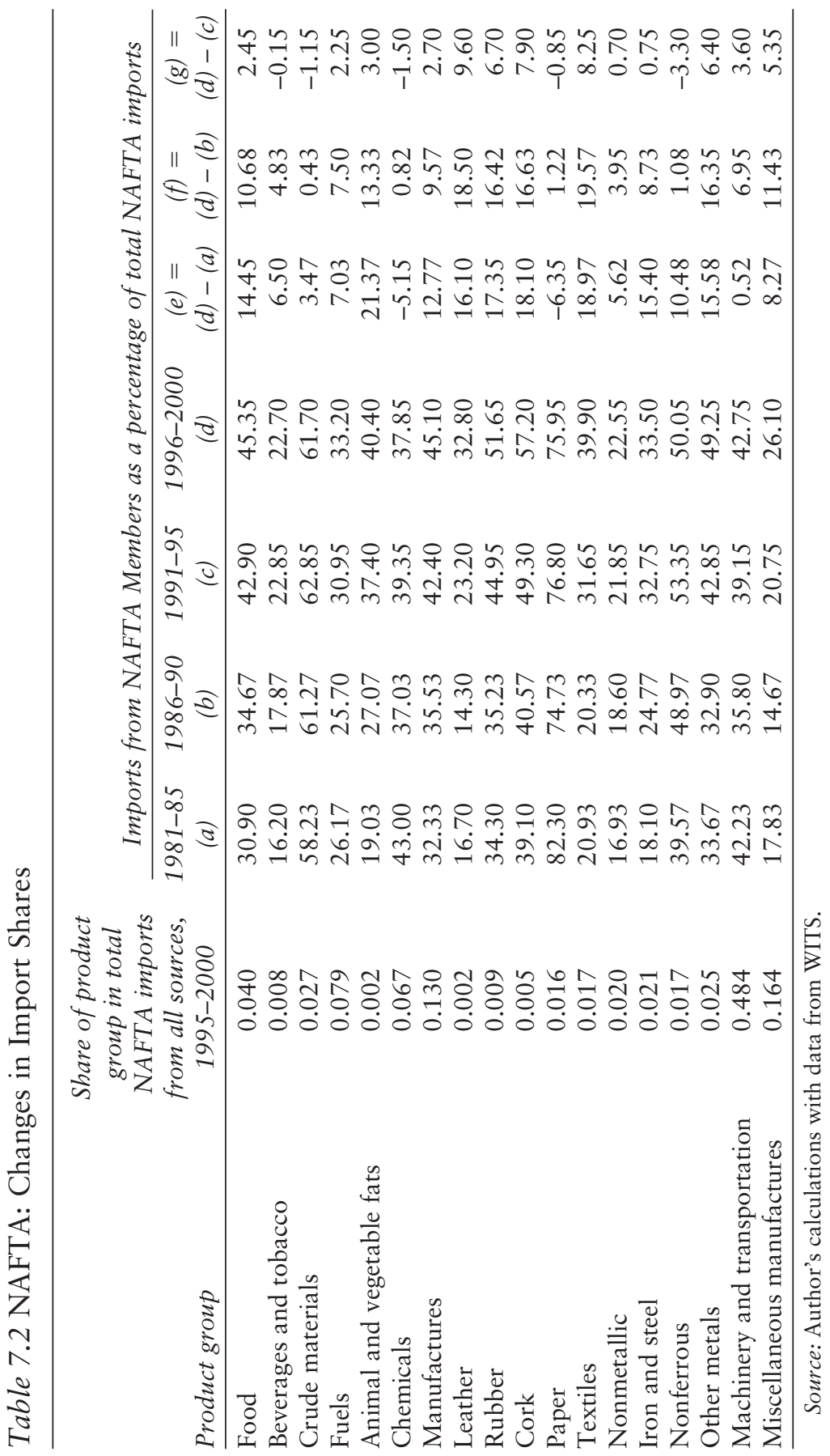




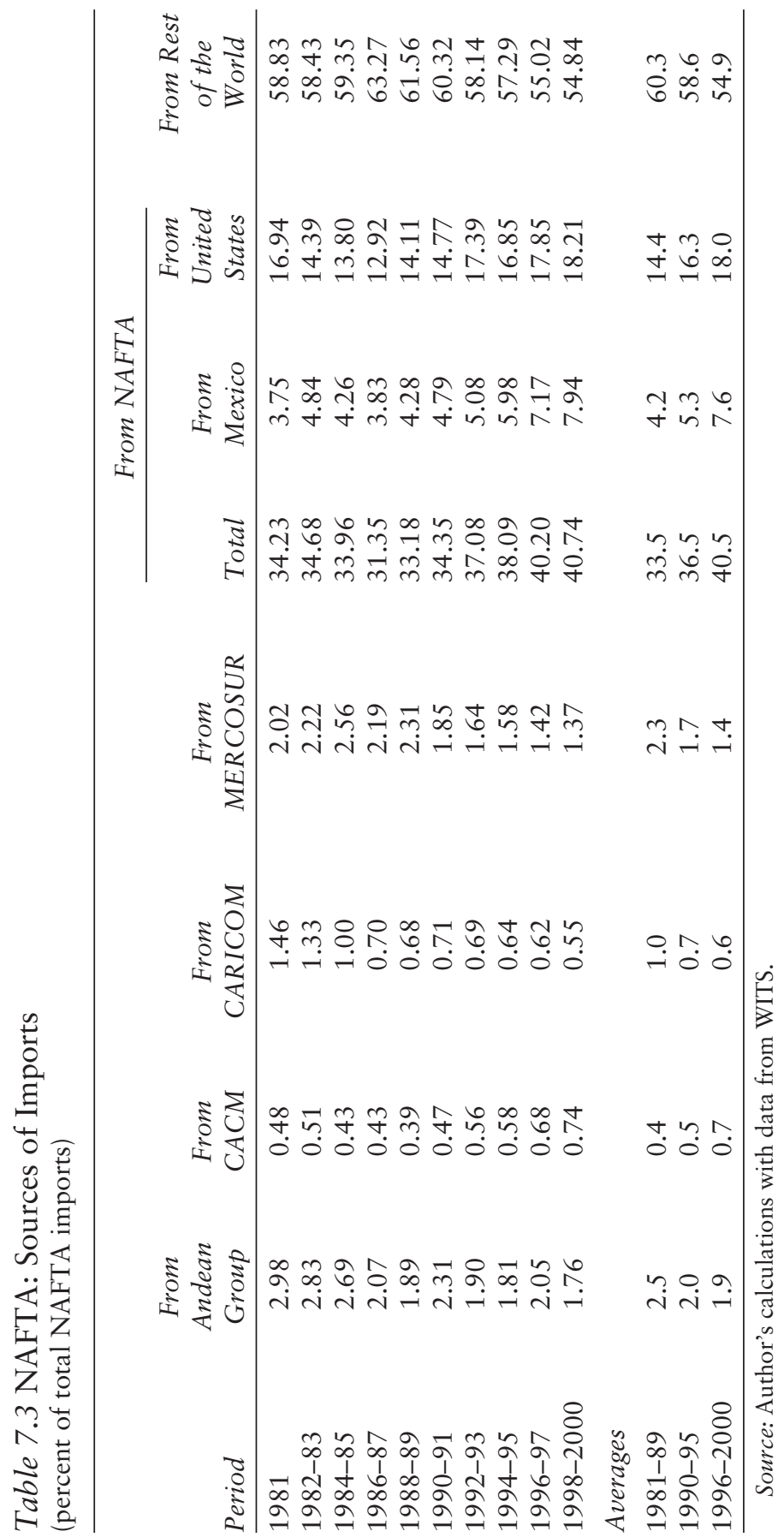


Figure 7.4 Share of Mexico's Nonfuel Exports in NAFTA and Non-NAFTA Markets

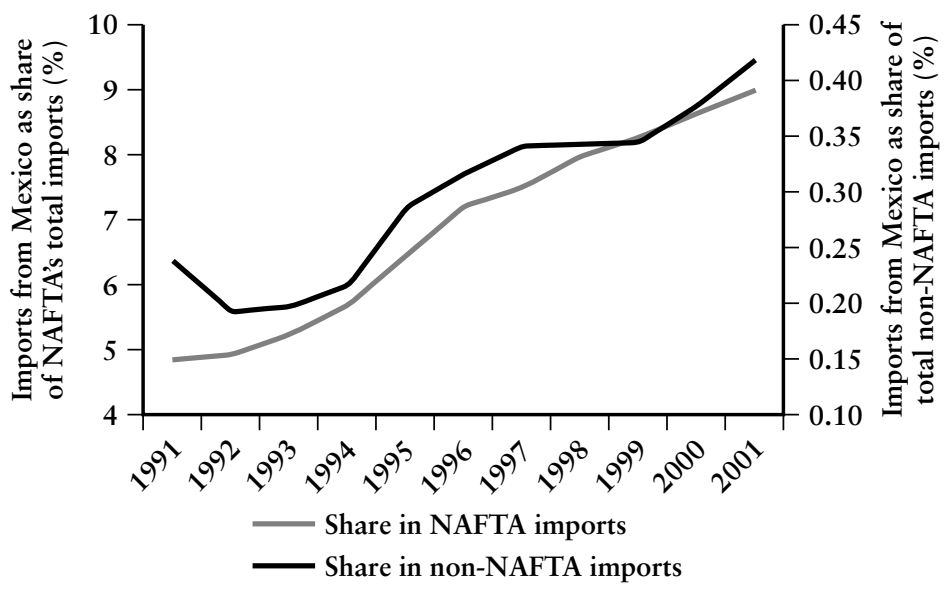

Source: Authors' elaboration from World Bank data.

noting that the upward trend was already present in the pre-NAFTA years. But, most important, the figure shows that Mexico also has gained share in non-NAFTA markets. Its share of world imports (excluding those of NAFTA countries) more than doubled in the post-NAFTA years, rising from 0.20 percent in 1993-94 to 0.40 percent in 2000-01. Thus, Mexico's steady gain in NAFTA market share mirrors its rising share in non-NAFTA markets, where it enjoys no preferential treatment. This suggests that, to a significant extent, Mexico's increased presence in NAFTA markets results from factors other than preferential tariff treatment.

In turn, figure 7.5 clearly shows that NAFTA and the United States in particular have become increasingly important for Mexico's exports since the early 1990s. By the end of the decade close to 90 percent of Mexico's exports were directed to the United States. In contrast, none of the other Latin American and Caribbean RIAs that are considered accounted for much more than 1 percent of Mexico's total exports.

What happened to exports from other Latin American and Caribbean RIAs? Figures 7.6 through 7.9 highlight their destinations. Figure 7.6 shows that NAFTA is the main destination of Andean Group exports, and increasingly so since the mid-1990s. The figure also shows that the increasing intra-bloc trade within the Andean Group in the 1990s came 
Figure 7.5 Destinations of Mexico’s Exports

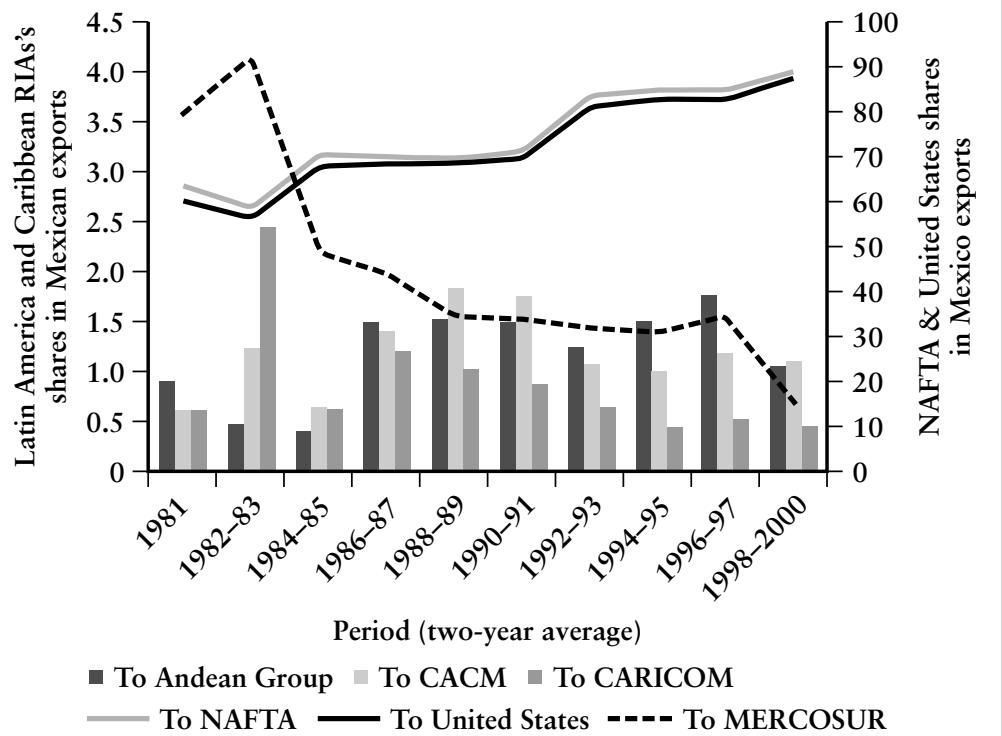

Source: Montenegro and Soloaga 2002.

along with a modest increase in exports to other Latin American and Caribbean RIAs and with a decline in the share of exports to the rest of the world (defined here as those countries not included in NAFTA or the other Latin American and Caribbean RIAs under analysis).

Likewise, figure 7.7 shows that NAFTA is also the main export destination for CACM countries, accounting for more than 40 percent of total bloc exports. In this case, however, the share of NAFTA does not show any clear trend in recent years. Trade among bloc members has been on the rise to account for about a quarter of total bloc exports by the end of the nineties.

In the case of CARICOM countries (figure 7.8), the pattern is rather different. NAFTA's share in total bloc exports decreased sharply in the late 1990s, from more than 50 percent in the 1980s and mid-1990s to around 30 percent in 1998-2000. In addition, the intra-bloc trade share does not display any clear trend. As already noted, total exports of these countries did not expand at the same pace as those of the rest of the blocs analyzed here. 
Figure 7.6 Destinations of Andean Group Exports

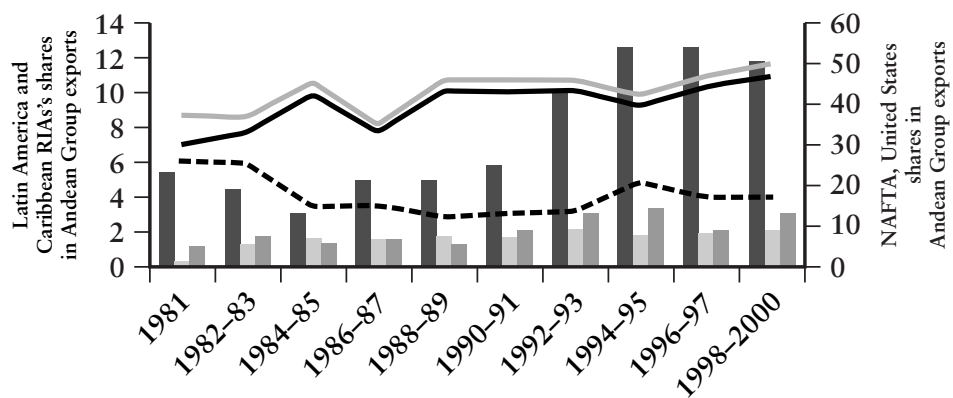

Period (two-year average)

- To Andean Group To CACM To CARICOM

To NAFTA — To United States - - - To MERCOSUR

Source: Montenegro and Soloaga 2002.

Figure 7.7 Destinations of CACM Exports

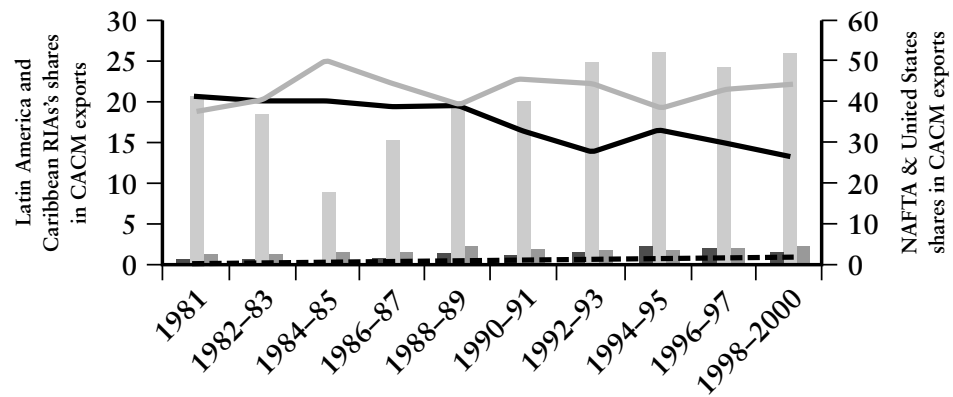

Period (two-year average)

- To Andean Group $\square$ To CACM $\square$ To CARICOM To NAFTA To ROW - - - To MERCOSUR 


\section{Figure 7.8 Destinations of CARICOM Exports}

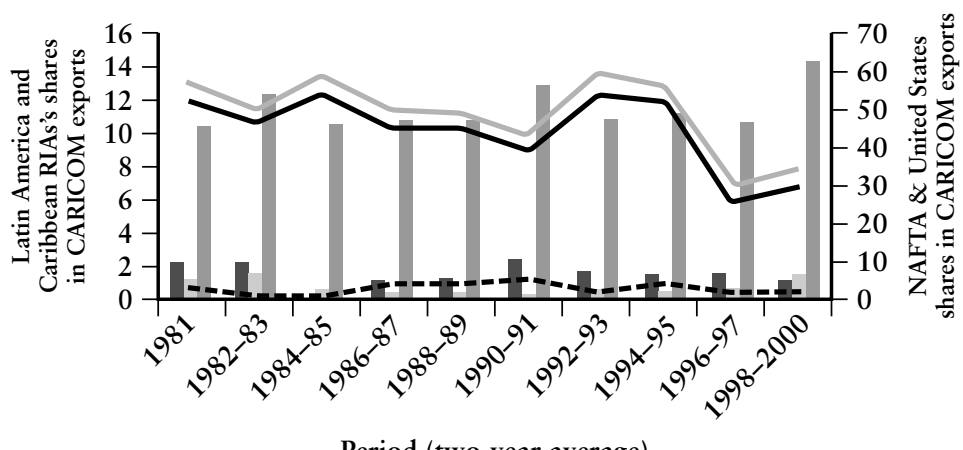

Period (two-year average)

- To Andean Group $\square$ To CACM $\backsim$ To CARICOM

To NAFTA — To United States --.- To MERCOSUR

Source: Montenegro and Soloaga 2002.

Finally, figure 7.9 shows the sharp increase in MERCOSUR intrabloc trade since the mid-1980s, along with a slight decrease in the share of NAFTA countries in the bloc's exports. By 1999-2000, MERCOSUR's trade with non-NAFTA, non-Latin American and Caribbean RIA countries represented about 50 percent of its total trade, a drop of 14 percentage points from the 64 percent average share in 1981-90.

In summary, the share of intra-bloc trade has been on the rise in all Latin American and Caribbean RIAs, perhaps with the exception of CARICOM countries. Furthermore, NAFTA has become a more important export destination for most of the other RIAs, with CARICOM and, to a lesser extent, MERCOSUR, as the main exceptions.

Which Latin American and Caribbean countries have been the winners and losers in U.S. markets? Table 7.4 shows the evolution of shares in U.S. imports of most countries in the region. The last three columns rank them in terms of the share loss over different periods (i.e., a " 1 " denotes the country or RIA with the biggest loss in the U.S. import market, " 2 " the second-largest loss, and so on). Columns (g) and (h) would most closely identify the post-NAFTA changes in market shares.

Mexico emerges as the clear winner. Central American countries (excluding Panama), Chile, and Colombia also fared well. At the other end, Brazil appears as the biggest loser among Latin American and 
Figure 7.9 Destinations of MERCOSUR Exports

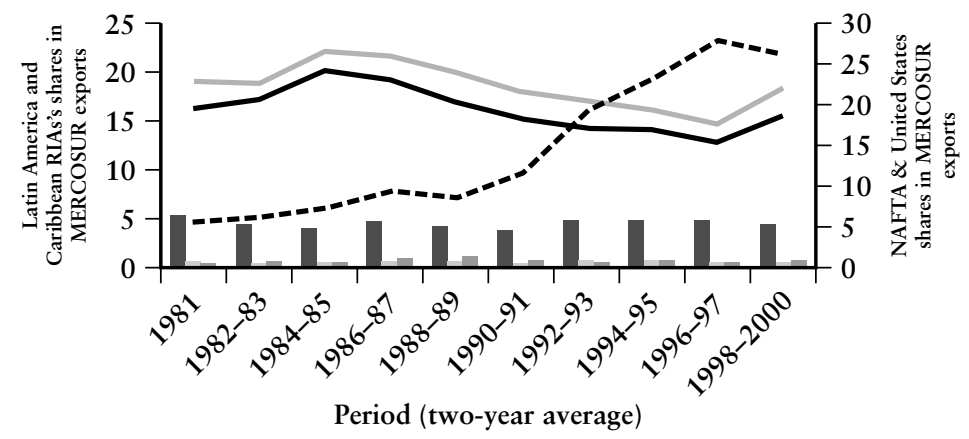

- To Andean Group $\approx$ To CACM $\approx$ To CARICOM

- To NAFTA — To United States ---- To MERCOSUR

Source: Montenegro and Soloaga 2002.

Caribbean countries, along with Ecuador and Venezuela. In terms of Latin American and Caribbean blocs, CARICOM and MERCOSUR were the biggest losers. In both cases, however, the erosion in market share began well ahead of the creation of NAFTA. For MERCOSUR the decline is mainly due to Brazil. For CARICOM the losses are concentrated in the Bahamas and in Trinidad and Tobago. ${ }^{14}$

To summarize this section, the information reviewed so far does not point to any definite conclusions regarding the effects of NAFTA on trade with nonmember LAC countries. CARICOM countries perhaps provide the exception, although in this case their declining participation in NAFTA imports is associated with an overall underperformance in export growth relative to other countries. But on the whole we have not observed any obvious turning points in trade trends around the time NAFTA was signed.

From the demand side (i.e., NAFTA imports), it is clear that total imports from bloc members increased more than imports from nonmember LAC countries. However, imports from the latter rose as well. Furthermore, Table 7.4 shows that CACM countries-clear candidates for trade diversion-either maintained or increased market shares in NAFTA's import markets. From the supply side (i.e., LAC RIA exports), intra-bloc trade increased markedly, and the share of total RIA exports to NAFTA countries behaved differently for the various LAC RIAs: it 


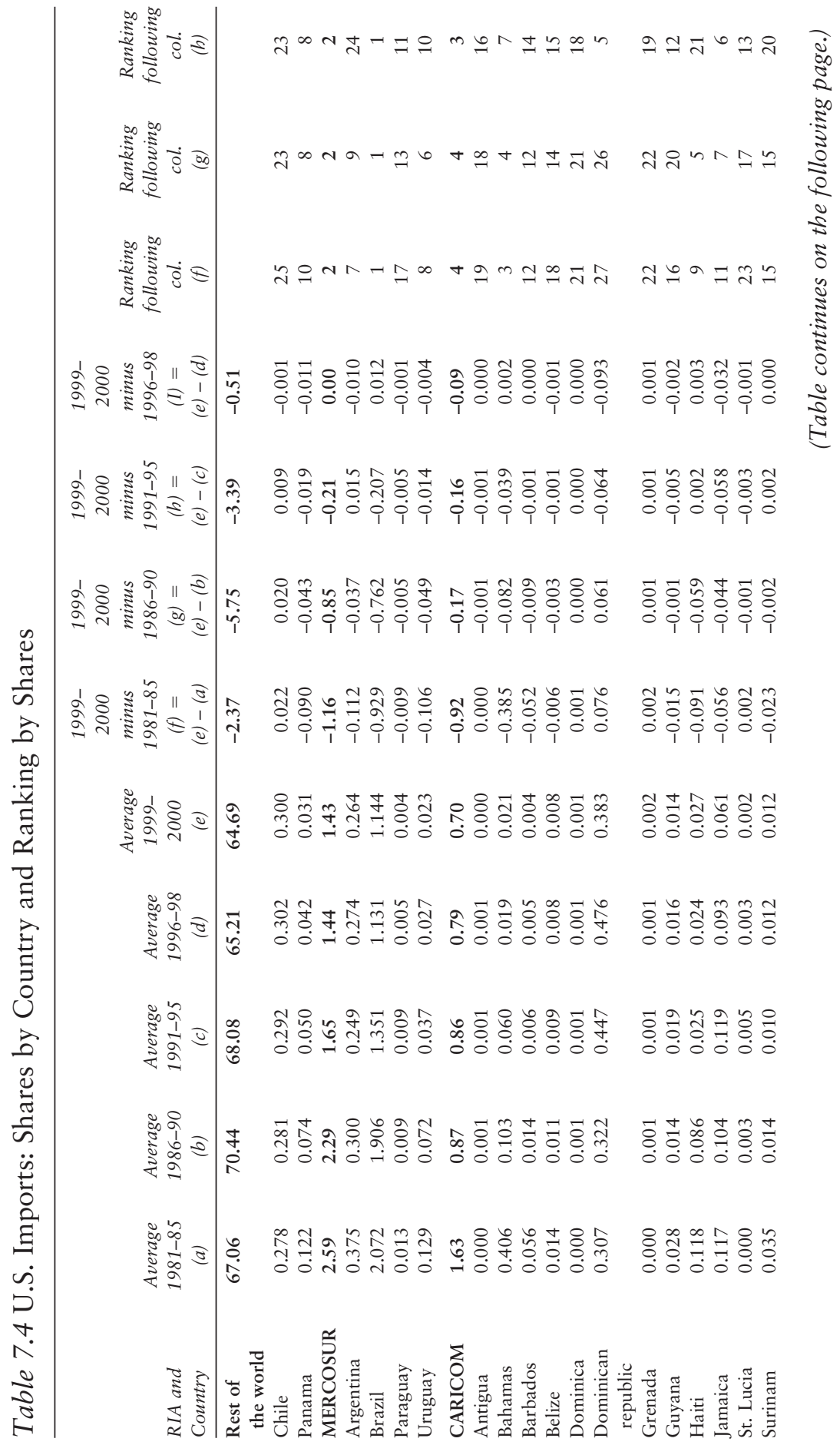




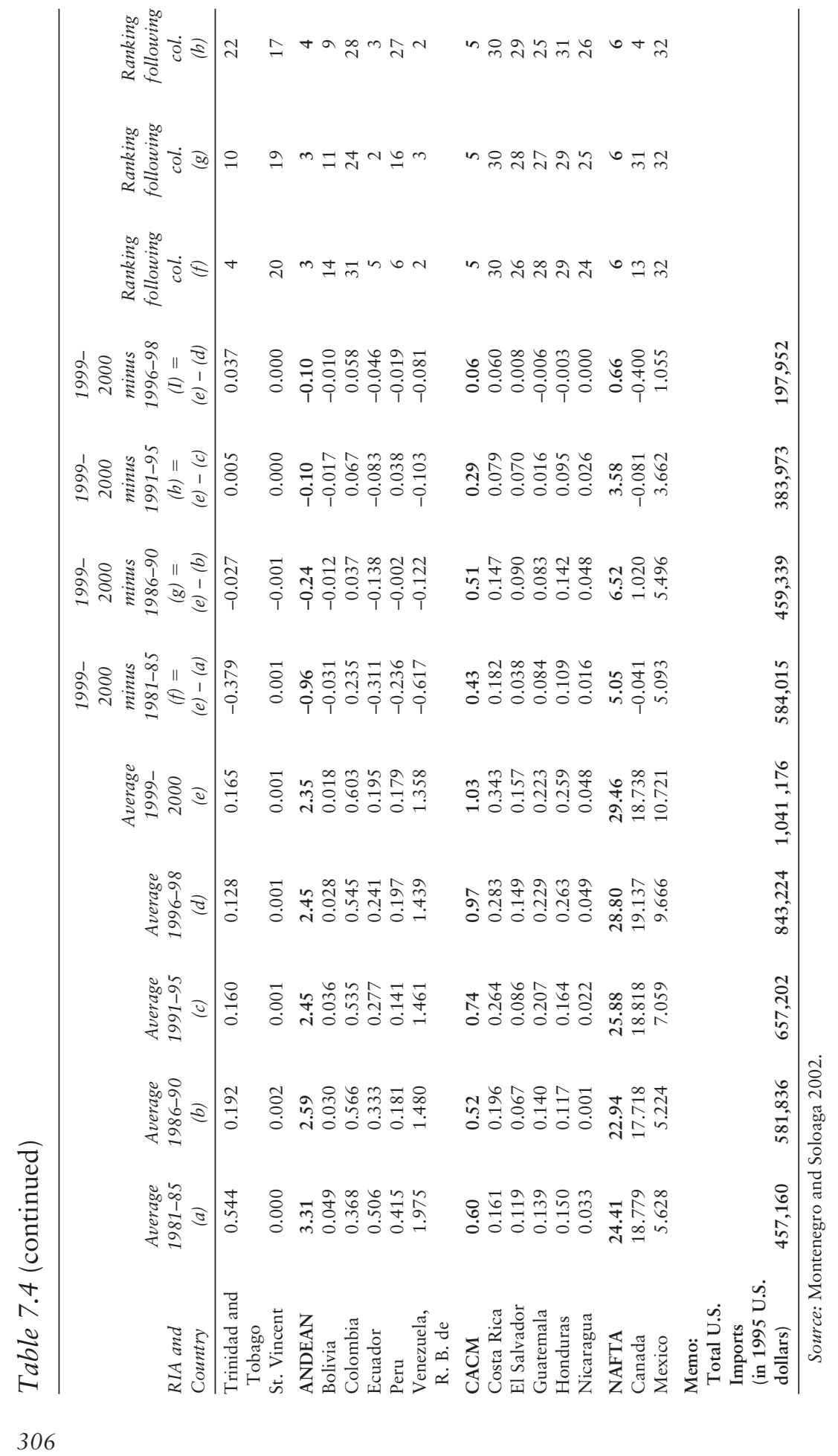


increased for CACM and Andean Group countries, and decreased for MERCOSUR and CARICOM.

\section{Assessment of NAFTA's Impact on Aggregate Trade Flows}

In a world of increasing global trade and with trade reforms taking place simultaneously in a number of countries and regional blocs, the trends just reviewed may reflect a variety of factors in addition to the creation of NAFTA. Thus, they have to be taken as indicative rather than conclusive regarding the effects of NAFTA on members' and nonmembers' trade. For example, the fact that Central American countries increased their presence in NAFTA markets after 1994 does not automatically imply that they were unaffected by trade diversion: their share of member countries' total imports might have been even higher in the absence of NAFTA. In other words, to identify the impact of NAFTA we need to control for other factors affecting trade flows.

\section{Background}

A number of recent empirical studies have examined the effects of NAFTA on trade flows taking into account major trade determinants. To date, no published study has attempted to explore the impact of the agreement on members' and/or nonmembers' terms of trade. ${ }^{15}$ Most studies have examined aggregate imports and exports, but there are also some studies that focus on disaggregated trade data. A comparative summary is given in table 7.5.

Studies focusing on aggregate trade flows most often adopt a gravity approach. Among them, Krueger $(1999,2000)$, who used data up to 1997, found that events other than NAFTA, such as Mexico's real exchange rate and its trade liberalization process, appear to have dominated whatever effects NAFTA may have had on trade patterns. According to this analysis, Mexico's unilateral trade liberalization since the late 1980s was the main factor behind the observed increase in its trade-to-GDP ratio. In this context, the increase in Mexico's trade with the United States is not surprising, given that prior to liberalization the United States already accounted for two thirds of Mexican trade.

Gould (1998) also adopted the gravity framework to analyze the impact of NAFTA on North American trade. Using aggregate quarterly data he concluded that NAFTA may have stimulated U.S. exports to, but not imports from, Mexico. He found no evidence of trade diversion. In another gravity-based study using a multi-RIA perspective, Soloaga and 
Table 7.5 Econometric Studies of the Trade Impact of NAFTA

\begin{tabular}{|c|c|c|c|}
\hline $\begin{array}{l}\text { Study } \\
\text { reference }\end{array}$ & $\begin{array}{c}\text { Trade } \\
\text { disaggregation }\end{array}$ & Framework & $\begin{array}{l}\text { Evidence of } \\
\text { trade diversion }\end{array}$ \\
\hline Gould 1998 & Aggregate & Gravity model & No \\
\hline $\begin{array}{l}\text { Krueger } 1999, \\
2000\end{array}$ & Aggregate & Gravity model & No \\
\hline $\begin{array}{l}\text { Soloaga and } \\
\text { Winters } 2001\end{array}$ & Aggregate & Gravity model & No \\
\hline $\begin{array}{l}\text { Garces-Diaz } \\
2002\end{array}$ & Aggregate & $\begin{array}{l}\text { Import and } \\
\text { export } \\
\text { equations }\end{array}$ & Not explored \\
\hline CBO 2003 & Aggregate & $\begin{array}{l}\text { Import and } \\
\text { export } \\
\text { equations }\end{array}$ & Not explored \\
\hline $\begin{array}{l}\text { U.S. International } \\
\text { Trade } \\
\text { Commission } \\
1997\end{array}$ & 68 sectors & $\begin{array}{l}\text { Import and } \\
\text { export } \\
\text { equations }\end{array}$ & $\begin{array}{l}\text { In textiles and } \\
\text { apparel }\end{array}$ \\
\hline Romalis 2004 & $\begin{array}{l}\text { 5,000 } \\
\text { commodities }\end{array}$ & $\begin{array}{l}\text { Commodity } \\
\text { demand } \\
\text { equations }\end{array}$ & Yes \\
\hline $\begin{array}{l}\text { Fukao, Okubo, } \\
\text { and Stern } 2003\end{array}$ & $\begin{array}{l}\text { Two-digit level } \\
\text { manufacturing }\end{array}$ & $\begin{array}{l}\text { Share (in U.S. } \\
\text { market) } \\
\text { equations }\end{array}$ & $\begin{array}{l}\text { In textiles and } \\
\text { apparel }\end{array}$ \\
\hline
\end{tabular}

Source: Author's compilation.

Winters (2001) found no discernible impact of NAFTA on the intra- or extra-bloc trade of NAFTA members.

Two relatively recent studies use a time-series approach to analyze aggregate trade flows. The study of Mexican imports and exports by Garces-Díaz (2002) concluded that the U.S. economic expansion is the main reason for the outstanding performance of Mexican exports in the 1990s. Income effects and real depreciation, rather than NAFTA, account for the bulk of the expansion in Mexican exports since 1994. These results, which agree with those reported by Gould (1998), hold at both aggregate and disaggregated levels. Likewise, the recent assessment of U.S.-Mexico trade by the U.S. Congressional Budget Office (CBO 2003) concluded that NAFTA had a very modest effect on bilateral trade flows, and attributed the growth in Mexico's exports to the United States after 1994 to the real depreciation of the peso and the sustained expansion of the U.S. economy. Although neither of these studies tackled directly the issue of trade diversion, both of them concluded that the behavior of Mexican exports did not experience any significant structural changes 
over the 1990s. This, combined with the relatively modest impact on aggregate trade flows that both studies attributed to NAFTA, suggests that significant trade diversion is unlikely to have occurred.

All of these studies focus on aggregate trade flows. It is conceivable that NAFTA (or any similar RIA) could cause sharp variations in patterns of trade at the commodity level. From the perspective of third countries, aggregate models might be unable to capture trade diversion effects if the share in total exports of those sectors adversely affected is small or, even if it is large, if changes in those sectors are compensated for by changes of opposite sign in exports of other commodities.

Disaggregated analyses attempt to capture these composition effects. Among such studies, the sector-by-sector study of NAFTA developed by the U.S. International Trade Commission (1997) found evidence of trade diversion in 1 sector (apparel products) out of 68 sectors analyzed. In apparel, the study concluded that U.S. imports from NAFTA partners rose at the expense of Asian and Caribbean Basin countries. ${ }^{16}$

Using a highly disaggregated approach based on the estimation of import share equations, Romalis (2004) found that NAFTA and CUSFTA had a substantial impact on North American trade. His study identified the impact of NAFTA by exploiting the variation across commodities and time in the U.S. tariff preference given to goods produced in Canada and Mexico. Romalis' study found that some 30 percent of the rise in Mexican exports to the United States since 1993 result from Mexico's improved preferential treatment, which implied substantial trade diversion. ${ }^{17}$ Moreover, the trade diversion effect is concentrated primarily in textiles, apparel, and footwear.

Finally, Fukao, Okubo, and Stern (2003) examined the behavior of Mexico's share in the U.S. import market by estimating import share equations at the two-digit level. Of the 60 sectors examined, they found evidence of trade diversion in the textile and apparel sector, where Mexican exports would have replaced lower-cost Asian exports. This is in agreement with the results of the U.S. International Trade Commission (1997) study mentioned earlier.

On the whole, therefore, studies based on aggregate data found no evidence of trade diversion as a result of NAFTA. They also tended to conclude that the contribution of NAFTA to the expansion of Mexico's trade with its partners was modest. In contrast, studies using disaggregate data did find indications of trade diversion, particularly in the textile and apparel sector. Next we revisit these issues in more detail.

\section{Methodological Approach}

To examine the effects of NAFTA on aggregate trade flows we adopted a gravity approach. The empirical robustness of the gravity model has 
made it the workhorse for investigations of the geographical patterns of trade. ${ }^{18}$ In this framework, trade between two countries depends on their economic and physical size (GDP, population, land area) and on transaction costs (distance, adjacency, cultural similarities).

In addition to these standard determinants, the empirical model used here allows countries' membership in RIAs to affect their trade flows. We departed from previous analyses by allowing RIAs to affect both members' imports from and exports to nonmember countries. Furthermore, we allowed for both "anticipation effects" (e.g., the level of trade between RIA members rising above "normal" levels before the RIA is formally commenced; see Freund and McLaren 1999) and for the effects of non-RIA relationships on trade flows between RIA members, reflecting the fact that RIAs are not usually formed between randomly selected countries but between countries with long-standing economic ties.

In this framework, country i's imports from country $j$ can be expressed in the following way:

$$
\begin{aligned}
\operatorname{LnX} X_{i j}= & \alpha+\beta 1 \operatorname{Ln} Y_{i}+\beta 2 \operatorname{Ln} N_{i}+\beta 3 \operatorname{Ln} Y_{j}+\beta 4 \operatorname{Ln} N_{j}+\beta 5 \operatorname{Ln} \bar{D}_{i} \\
& +\beta 6 \operatorname{Ln} D_{i j}+\beta 7 \operatorname{Ln} T_{i}+\beta 8 \operatorname{Ln} T_{j}+\beta 9 C_{i j}+\beta 10 I_{i}+\beta 11 I_{j} \\
& +\beta 12 L_{i j}+\sum_{k} b_{k} P_{k i} P_{k j}+\sum_{k} m_{k} P_{k i}+\sum_{k} n_{k} P_{k j}+\varepsilon_{i j}
\end{aligned}
$$

where $X_{i j}$ is the value of imports of country $i$ from country $j$ (i.e., exports from $j$ to $i$ ); $Y_{i}, Y_{j}$ is the gross domestic product of country $i$ (or $j$ ); $N_{i}$, $N_{j}$ is the population of country $i$ (or $j$ ); $\overline{D_{i}}$ is the average distance of country $i$ to exporter partners, weighted by exporters' GDP share in world GDP ("remoteness" of country $i$ ); $D_{i j}$ is the distance between the economic center of gravity of the respective countries; $T_{i}, T_{j}$ is the land area of country $i$ (or j); $C_{i j}$ is a dummy that takes value 1 if countries $i$ and $j$ share a land border and 0 otherwise; $I_{i}, I_{j}$ is a dummy that takes value 1 when country $i$ (or $j$ ) is an island, and 0 otherwise; $L_{i j}$ is a dummy for cultural affinities, proxied by the use of the same language in countries $i$ and $j ; P_{k m}$ is a dummy taking value 1 if $m$ is a member of bloc $k$ and 0 otherwise; and $\varepsilon_{i j}$ is a white noise error term.

The first two lines of equation 7.1 characterize exports from $j$ to $i$ if neither is a member of a RIA. Thus they represent the volume of trade that would be considered "normal" between two countries in the absence of any RIAs.

Our main interest is the third line of equation 7.1, which captures the effects of regional arrangements on members' trade flows. Here $b_{k}$ is a coefficient measuring the extent to which trade is higher than normal if both $i$ and $j$ are members of the bloc (intra-bloc trade), $m_{k}$ is a coefficient measuring the extent to which members' imports from all countries are 
higher than expected, and $n_{k}$ is a coefficient measuring the extent to which members' exports to all countries are higher than expected. In other words, flow $i j$ is raised by $m_{k}$ if $i$ is in a given RIA, whether or not $j$ is also a member; by $n_{k}$ if $j$ is in a given RIA, whether or not $i$ is a member; and by $\left(\mathrm{m}_{k}+\mathrm{n}_{k}+\mathrm{b}_{k}\right)$ if both are members of the same RIA.

For many of the blocs considered here, regionalism was accompanied by a strong, nondiscriminatory (most-favored-nation) trade liberalization. We took $m_{k}$ and $n_{k}$ as combining the effects of the general liberalization and trade diversion, whereas $b_{k}$ captures the increase in intrabloc trade beyond the general effect. In this context the traditional estimate of so-called (gross) intra-trade effects is equal to $\left(m_{k}+n_{k}+b_{k}\right)$.

A negative coefficient on the dummy for a given RIA's imports from nonmembers $\left(m_{k}\right)$ indicates that, all things being equal, the RIA has traditional import diversion effects. In turn, a negative coefficient on the dummy for a given RIA's exports to nonmembers $\left(n_{k}\right)$ - which, for want of a better term, we labeled "export diversion"-may be taken to mean that the RIA hurts the welfare of nonmember countries, along the lines of the argument mentioned above.

We estimated the gravity model over the largest available set of countries and a long time period to describe "non-RIA" years adequately. Hence, we used data on nonfuel visible imports for 130 countries over 1980-2000 from the World Integrated Trade Solution (World Bank UNCTAD trade database). This set of countries represents around 95 percent of total world imports in the period covered. The distance variable is the great circle distance between economic centers and was based on distances calculated by the authors. All the other variables are from the World Bank Economic and Social Database (BESD).

To place NAFTA in perspective, we considered the same nine RIAs as in the preceding section: the Andean Group, ASEAN, CACM, CARICOM, the EEC/EU, EFTA, the Gulf Cooperation Council (GCC), MERCOSUR, and NAFTA. Because our focus is on the impact of regionalism in the Americas, and in particular on NAFTA, the inclusion of non-Latin American and Caribbean RIAs in our analysis is mainly to control for their effects on the trade of countries in that region. The last column in table 7.11 in the appendix identifies specific dates in which major developments could be expected to affect trade patterns in the nine RIAs analyzed.

We defined the trade bloc dummies $\left(P_{k m}\right)$ by bloc membership in 1996. In this setting it is important to note that "abnormal" levels of trade captured by the bloc-related dummy variables could reflect either RIA effects or the action of unobservable characteristics of country members that affect their levels of trade. However, here we were interested in whether RIAs change the intensity with which particular countries trade with each other. Thus we allowed the coefficients on the bloc 
dummies to change over time, and we measured the effects of trade blocs not by the values of the dummy coefficients per se but by their movements over time. The rationale is that pairs of countries may have "abnormal" trade relationships for a variety of reasons other than RIA membership, but if those reasons do not change significantly over time the coefficients on the RIA dummies should not change either. This approach also allowed us to assess the "anticipation effects" mentioned earlier.

Because trade values are bounded from below by zero, the appropriate estimation procedure is that of a Tobit model. ${ }^{19}$ We computed three different sets of Tobit estimates. ${ }^{20}$ The first is a set of 21 separate regressions (one for each year) for the annual data 1980-2000. From these we sought to identify not only the "level" effect on trade of RIA but also the variation of this effect through time, in particular around the years marked in the last column of Table 7.11, to assess whether any observed "abnormalities" in trade are directly associated with preference effects.

Second, we averaged the data over non-overlapping three-year periods (to smooth out transitory shocks and cyclical changes) and estimated a single pooled regression with time dummies allowing all coefficients to change across periods. We used these estimates to test for significant differences in coefficients across periods. ${ }^{21}$

Finally, in the third approach we extended the basic equation with ad hoc dummies to track the evolution of trade of CACM and CARICOM countries with Mexico and the United States. In this way we tailored the gravity model to test the impact of NAFTA on trade among this subset of countries. Pooling all NAFTA nonmember countries as the previous exercises implicitly do could make it difficult to detect the trade-diverting effects of the treaty on this specific group of countries that had been feared by numerous observers.

\section{Results}

The detailed results are described in Montenegro and Soloaga (2002); here we just summarize the main findings. In the estimations, the gravity variables-GDP, area, absolute distance-generally had the expected sign and were highly significant: trade increases slightly more than proportionately with the GDP of the importer and exporter countries and decreases with size and distance. The coefficients reflecting population effects (of importer and exporter) were negative and not always significant. The degree of "remoteness" of an importer country from its suppliers had the expected positive sign, although in the annual estimation it was not always significant whereas the estimated parameters for common land borders were always positive and significant. The coefficients for the exporter being an island were positive and significant, but those for the 
importer were imprecise in the annual estimates and significantly negative in the pooled estimates. The proxy for "cultural similarities" (common language) was always statistically significant, with the expected sign (positive). Furthermore, most of these effects were stable over time.

As for the estimates of the RIA dummies, they are quite heterogeneous. The intra-bloc trade coefficients were positive for all Latin American and Caribbean RIAs in all periods, but in the case of NAFTA they were not significant. Thus, Latin American countries in RIAs involving only Latin American and Caribbean countries-the Andean Group, CACM, CARICOM, and MERCOSUR - trade significantly more heavily with each other than predicted by standard trade determinants. For non-Latin American and Caribbean RIAs, positive but insignificant bloc-trading effects were found for ASEAN and EFTA economies, and a negative and significant effect was found for the EU.

In turn, the coefficients for NAFTA's overall bloc imports appear to have become significantly positive in the late 1990s. Earlier estimates are generally imprecise. For the other Latin American and Caribbean RIAs, the estimates are generally negative and significant, although for CACM and CARICOM many of the estimates are rather imprecise. Among the non-Latin American and Caribbean RIAs, the estimates are negative for EFTA and positive in the other cases (ASEAN. EU, and GCC).

As for bloc exports, the coefficient estimates for NAFTA are negative and generally significant since the late 1980s. Results for the other RIAs were fairly heterogeneous: negative and significant for the Andean Group and CARICOM, positive and significant for CACM (outside Latin America and the Caribbean, the same result for ASEAN and the EU), and insignificant for MERCOSUR (as well as EFTA).

Figure 7.10 depicts the annual estimation results for NAFTA: positive but insignificant bloc effect dummies and increasing openness to imports since 1997 coupled with a decrease in total bloc propensity to export since 1998.

To draw inferences on the impact of NAFTA we need to look for significant changes in the coefficients of the RIA's intra-bloc, import and export dummies around NAFTA's date of creation. For this we turn to the pooled estimates on three-year averages. The results for NAFTA are summarized in table 7.6, and are fairly consistent with those from the annual estimation. The coefficients of intra-bloc trade dummies show a positive trend, but are not statistically significant. It appears that the observed changes in intra-bloc trade are not significantly associated with events such as CUSFTA in 1988 and NAFTA itself when we take into account the "normal" variation in trade levels dictated by the gravity variables. In turn, overall bloc imports display a positive trend, whereas the bloc coefficient for exports remains roughly constant in the last part of the sample (although it declines from the levels of the early 1980s). 
Figure 7.10 NAFTA: Annual Estimates of Bloc Dummy Coefficients

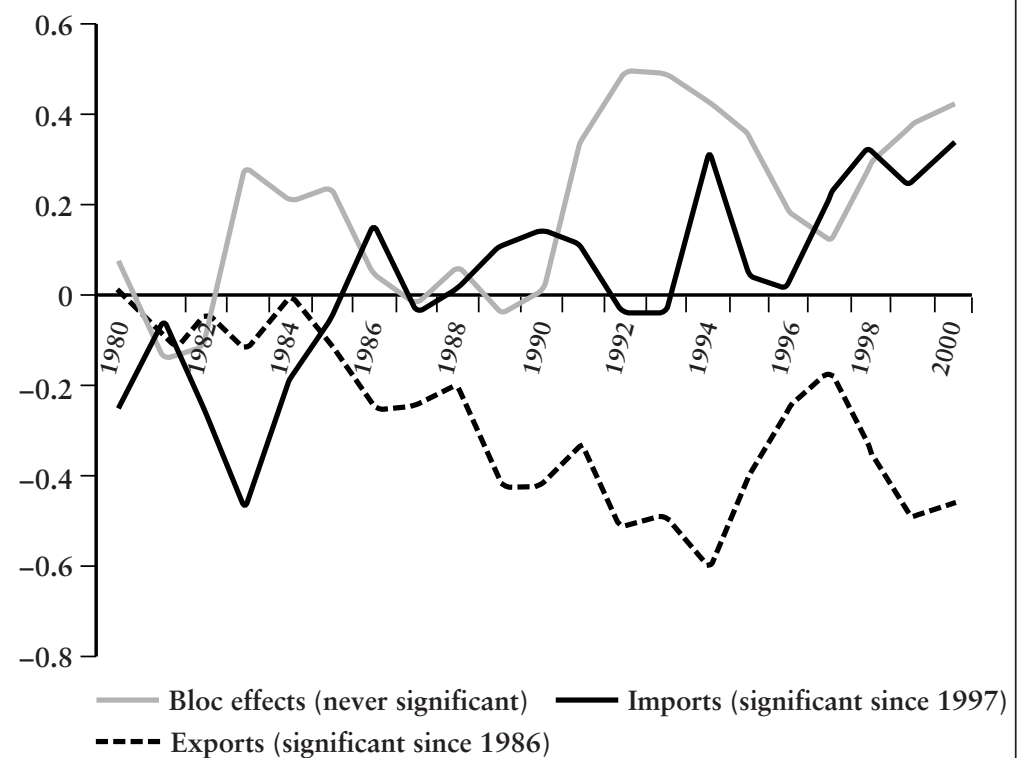

Source: Montenegro and Soloaga 2002.

For other Latin American and Caribbean RIAs, when we control for the impact of the gravity variables, the revamping (Andean Group, CACM, and CARICOM) or launching (MERCOSUR) of RIAs in Latin America does not seem to have been accompanied by a larger-than-expected increase in intra-bloc trade propensities. The positive trend in the estimated coefficients for bloc members' imports, which is significant in the cases of CACM, CARICOM, and MERCOSUR, presumably reflects the drive to unilateral trade liberalization that swept Latin America in the late 1980s and early 1990s.

So far we have found no clear evidence of any effects of NAFTA on third countries. Perhaps this is because we are lumping all nonmember countries together and not considering separately the neighboring countries of Central America and the Caribbean, which on a priori grounds should be expected to have been most affected by Mexico's preferential access to the U.S. market. Thus, in the final experiment we expanded the gravity framework to try to capture any particular effects of NAFTA on those countries. 
Table 7.6 NAFTA Dummy Estimates with Pooled Data (dependent variable: log imports)

\begin{tabular}{|c|c|c|c|c|c|c|c|c|c|}
\hline Dummy & Period & $\begin{array}{c}\text { Coeffi- } \\
\text { cient } \\
\text { (gravity } \\
\text { estimates) }\end{array}$ & $\begin{array}{l}\text { Statis- } \\
\text { tical } \\
\text { signi- } \\
\text { ficance }\end{array}$ & \multicolumn{6}{|c|}{$\begin{array}{l}\text { Test of equality of coefficients: } \\
\text { periods in rows vs. periods in columns }{ }^{a}\end{array}$} \\
\hline Bloc trade & 1980-82 & -0.074 & & & & & & & \\
\hline Bloc trade & $1983-85$ & 0.221 & & & & & & & \\
\hline Bloc trade & 1986-88 & 0.018 & & & & & & & \\
\hline Bloc trade & 1989-91 & 0.102 & & & & & & & \\
\hline Bloc trade & 1992-94 & 0.478 & & & & & & & \\
\hline Bloc trade & 1995-97 & 0.222 & & & & & & & \\
\hline Bloc trade & 1998-00 & 0.391 & & & & & & & \\
\hline Imports & 1980-82 & -0.249 & $* * *$ & & $* * *$ & $* * *$ & $* * *$ & $* * *$ & $* * *$ \\
\hline Imports & 1983-85 & -0.285 & $* * *$ & & $* * *$ & $* * *$ & $* * *$ & $* * *$ & $* * *$ \\
\hline Imports & 1986-88 & 0.060 & & & & & & & $* * *$ \\
\hline Imports & 1989-91 & 0.150 & $* *$ & & & & & & $* *$ \\
\hline Imports & 1992-94 & 0.122 & $\#$ & & & & & & $* * *$ \\
\hline Imports & 1995-97 & 0.120 & \# & & & & & & $* * *$ \\
\hline Imports & 1998-00 & 0.397 & $* * *$ & & & & & & \\
\hline Exports & 1980-82 & -0.132 & $*$ & & $*$ & $* * *$ & $* * *$ & & $* * *$ \\
\hline Exports & 1983-85 & -0.205 & $* * *$ & & & $* * *$ & $* * *$ & & $* * *$ \\
\hline Exports & 1986-88 & -0.338 & $* * *$ & & & & $* *$ & & \\
\hline Exports & 1989-91 & -0.479 & $* * *$ & & & & & $* *$ & \\
\hline Exports & 1992-94 & -0.564 & $* * *$ & & & & & $* * *$ & \\
\hline Exports & 1995-97 & -0.267 & $* * *$ & & & & & & $* *$ \\
\hline Exports & 1998-00 & -0.486 & $* * *$ & & & & & & \\
\hline
\end{tabular}

* Significant at the 10 percent level.

* Significant at the 5 percent level.

\# Significant at the 15 percent level.

$* * *$ Significant at the 1 percent level.

a. F-test of equality of coefficients. For instance, for the period 1980-82 the coefficient of -0.249 for NAFTA imports is not statistically different from the coefficient for 1983-85 $(-0.285)$, but is statistically different from those corresponding to 1986-88 (0.060), 1989-91 (0.150), 1992-94 (0.122), 1995-97 (0.120), and 1998-2000 (0.397). Significance is indicated within columns 5 through 10 .

Source: Montenegro and Soloaga 2002.

To perform this experiment, the empirical model was left unchanged for all the RIAs except CACM, CARICOM, and NAFTA. For those blocs we amended the model as follows: (a) we replaced the dummy for NAFTA and separately modeled trade between the United States and Canada, between the United States and Mexico, and between Canada and Mexico. The purpose is to isolate the evolution of 
U.S. imports from (exports to) Mexico; (b) we did the same for CACM and CARICOM countries with two dummies per RIA capturing imports from the United States and exports to the United States; and (c) we created dummies for trade between CACM and Mexico and between CARICOM and Mexico to capture changes in the patterns of trade that could statistically be associated with NAFTA (i.e., a "stopover effect").

As with the preceding exercise, the estimation was performed using pooled data averaged over subperiods allowing all coefficients to change over time and then testing for parameter constancy. Various experiments with different period lengths were performed, but the qualitative results were similar in all cases.

Table 7.7 reports the resulting coefficient estimates on the variables of interest and the F-tests of coefficient equality across periods. Rows 1 to 14 show results for Mexico's overall openness to exports (rows 1 to 7) and imports (rows 8 to 14). There is a clear positive trend in both since 1986-88. ${ }^{22}$ As before, these trends seem to originate in Mexico's unilateral trade liberalization since the late 1980s. For both variables, however, levels in 1995-97 and 1998-2000 are statistically higher than in most of the previous periods in the sample. For the case of Mexico's global exports (to the world, including its NAFTA partners), these results suggest that the anti-export bias declined from an average of -1.16 in 1989-91 to -0.74 in 1998-2000. To the extent that this change may be viewed as reflecting the consequences of NAFTA, it suggests that Mexican exports would have been about 50 percent lower in the latter period if NAFTA had not been implemented. The corresponding number for Mexico's global imports is close to 100 percent.

Rows 15 to 28 in figure 7.7 show results for Mexico's imports from the United States (rows 15 to 21) and exports to the United States (rows 22 to 28). The positive point estimates on the dummies are evidence that the level of trade between the United States and Mexico is above what could be expected for similar countries in the sample, although the difference is significant only in the case of U.S. imports from Mexico. In any case, there is little evidence of any significant changes in the coefficients over time. Recall that we controlled for trends in other (non-NAFTA) determinants of Mexico's trade with the United States, so the conclusion is that when those trends are taken into account there is little left to be captured by changes in the Mexico-U.S. dummies.

Were there significant changes in trade between CACM or CARICOM and the United States? The next two blocks in the table address this question. Trade between CACM countries and the United States has been consistently above what could be considered "normal" between 


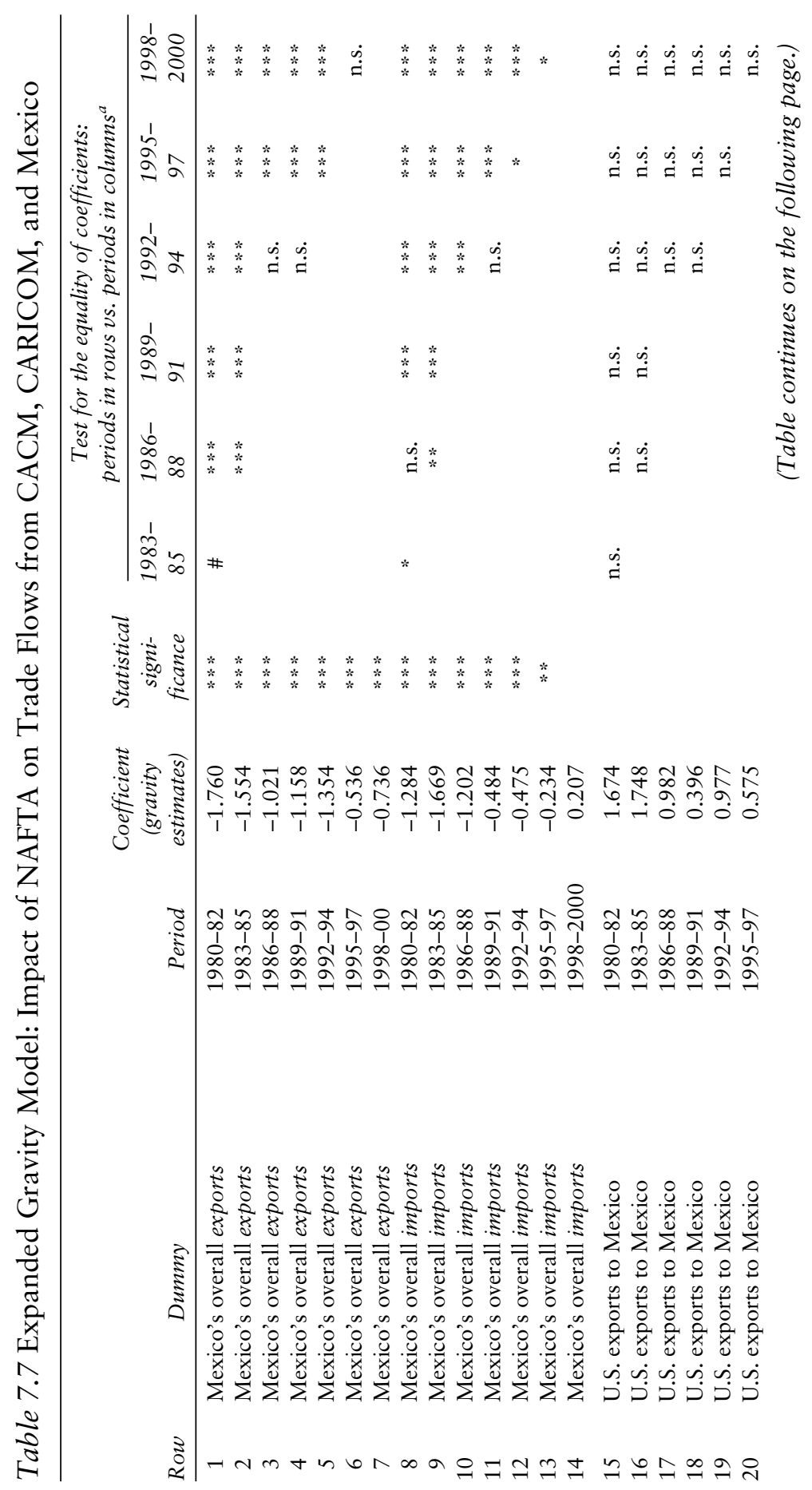




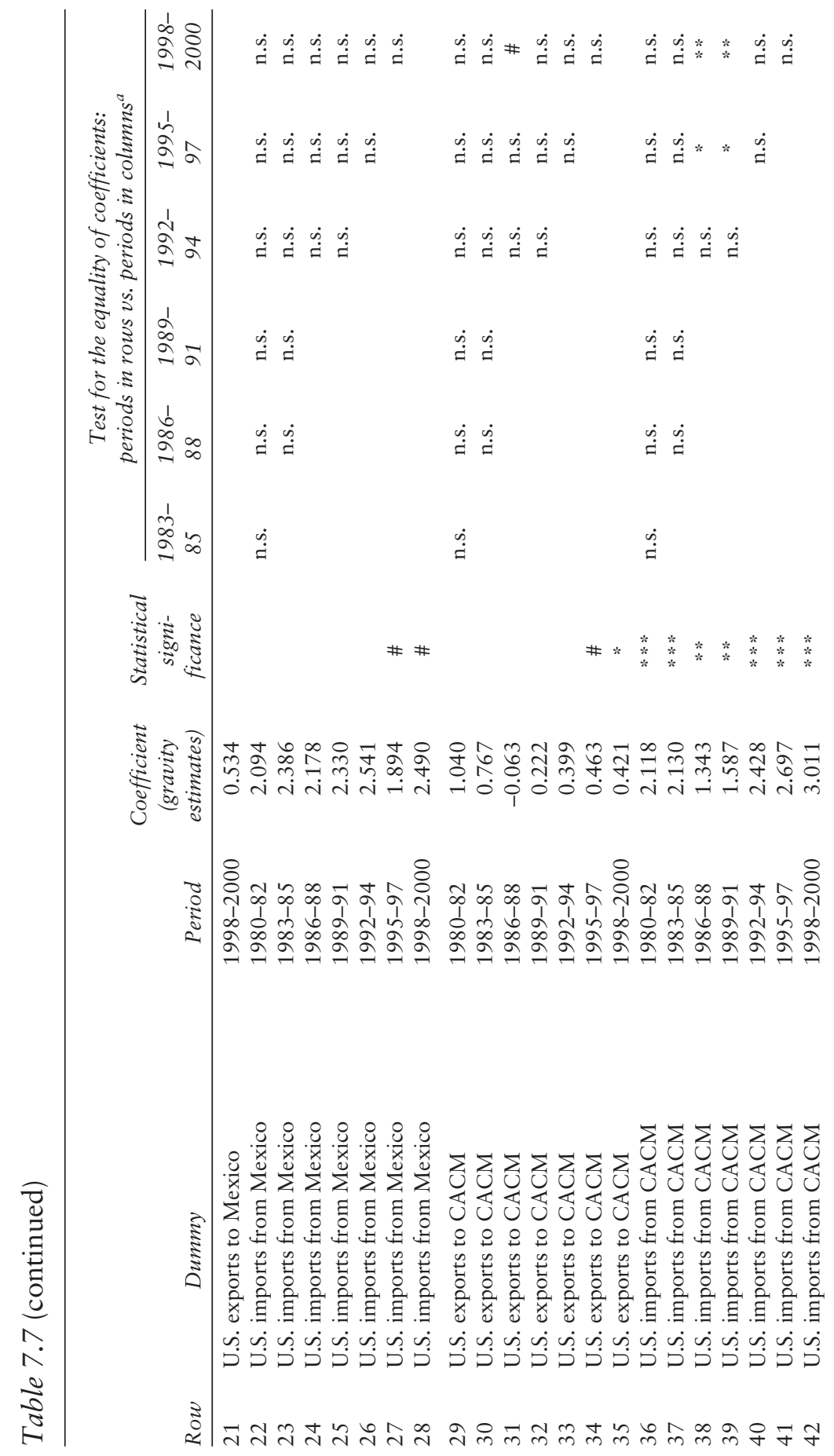




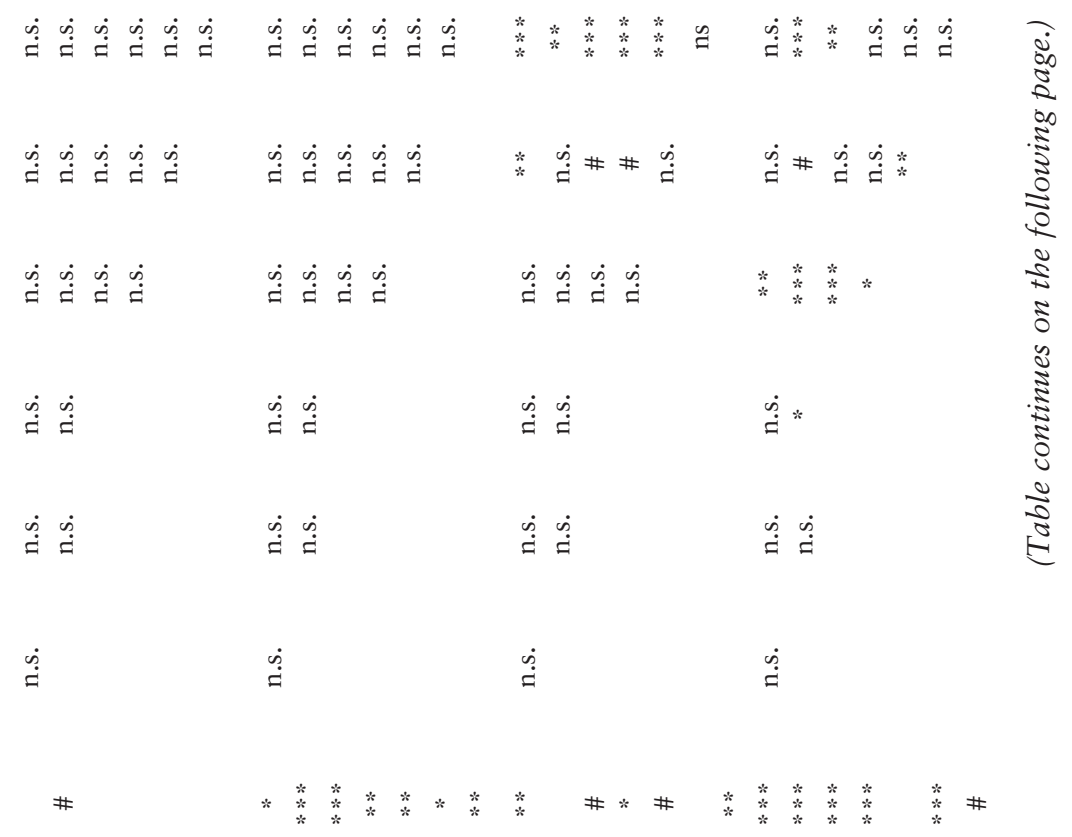

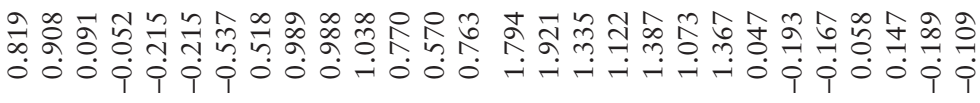

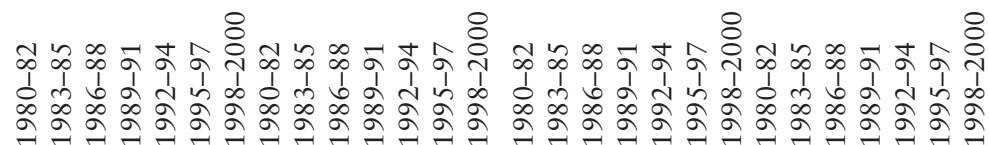

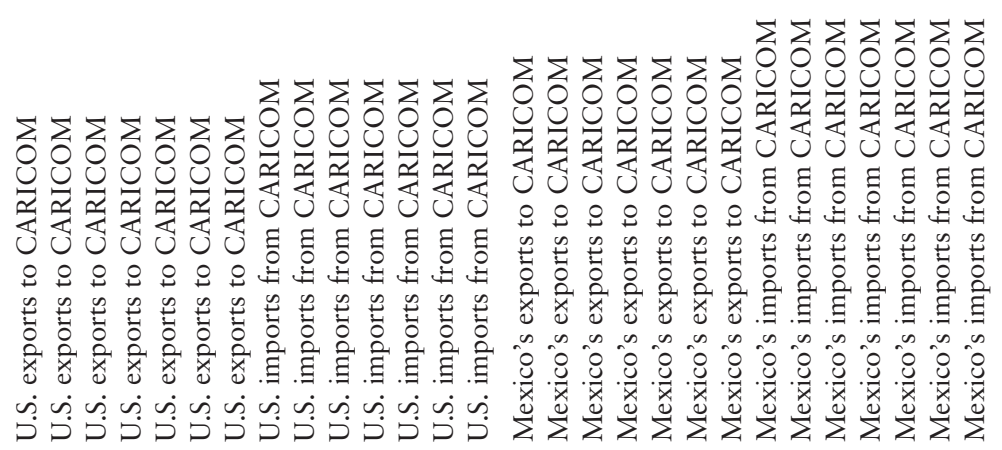

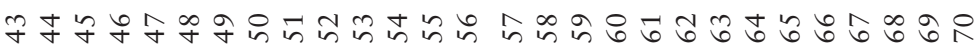




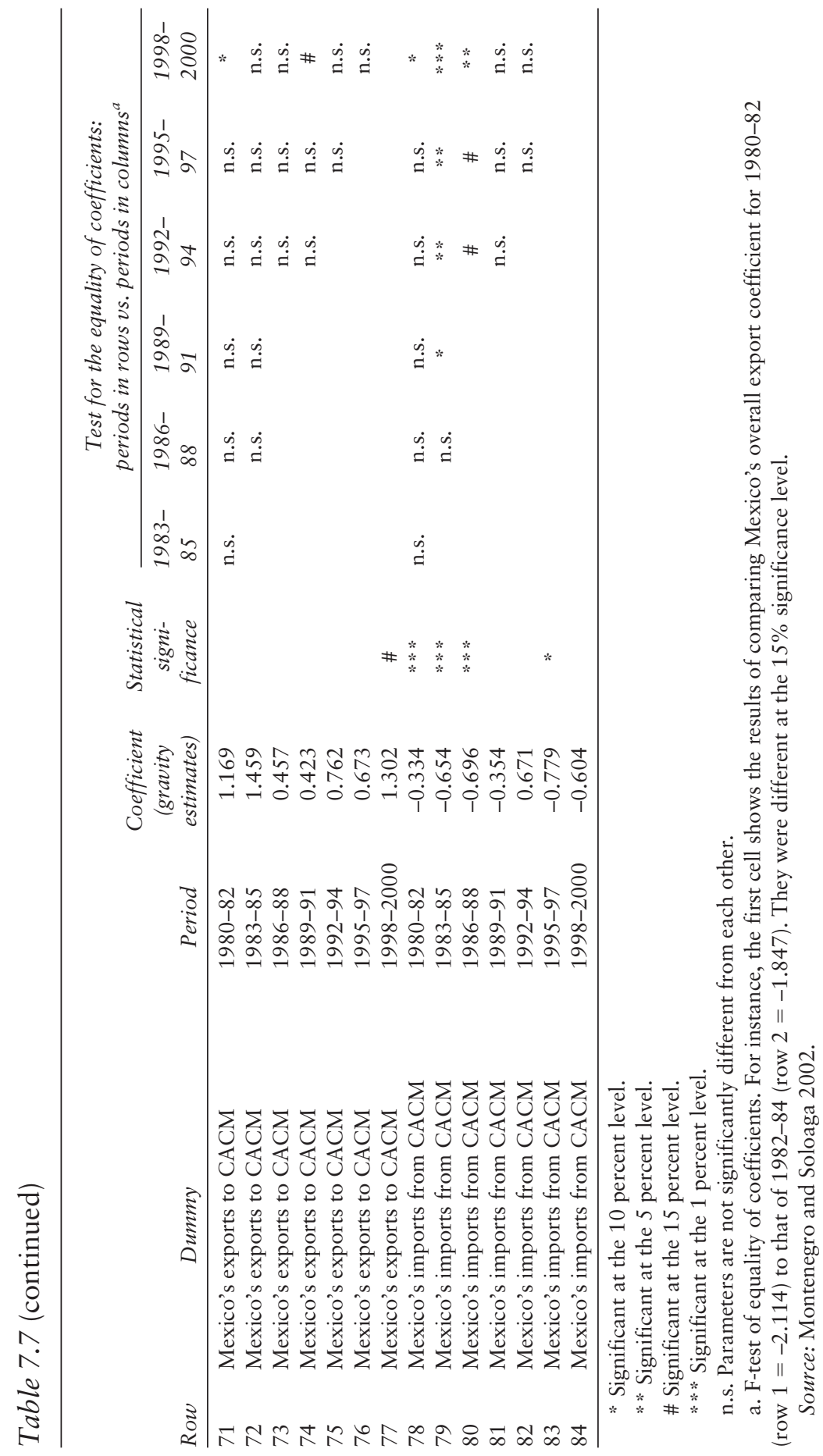


countries of similar size and distance (except for CACM imports in 1986-88). The coefficient for "abnormal" exports from CACM to the United States was always statistically significant, although that of "abnormal" imports from the United States was not. If anything, the estimates suggest a positive trend in exports from CACM to the United States since 1986-88, which points against any negative impact of NAFTA on CACM exports.

In the case of CARICOM-U.S. trade, most of the coefficients for CARICOM exports (but only the early ones in the case of imports) are statistically significant. Both suggest a negative trend after 1989-91 (until 1995-97 only in the case of exports). Statistically, however, the changes in the coefficients after that date are not significant.

As for the stopover effect, results from the expanded gravity model show that CACM and CARICOM exports to Mexico generally remained below "normal" levels throughout the sample, although virtually none of the coefficients is significant. It is hard to conclude much from this pattern, but in any case a positive trend with changes that could be associated to NAFTA is certainly not evident; if anything, the opposite seems to happen.

\section{Summary}

On the whole the empirical results in the preceding section agree with those of most previous studies using aggregate trade flow data. When other trade determinants are taken into account, NAFTA appears to have had only a modest effect on the volume of Mexico's trade with the United States and Canada. In fact, Mexico's anti-trade bias with the whole world declined, but intra-NAFTA trade did not change significantly. This prompts the immediate question of what, if not NAFTA, is the main factor behind the upward trend in Mexico's trade with the United States? The clearest answer is given by the time-series studies cited earlier, which attribute the bulk of the rise in trade to income effects-most notably, the expansion of the U.S. economy ${ }^{23}-$ and the real exchange rate of the peso. The gravity model gives a similar verdict as its estimates show that bilateral trade rises more than proportionately with the GDP of the importer and exporter. ${ }^{24}$ When account is taken of these factors there is not much left for NAFTA itself to explain. ${ }^{25}$ Nor is there much evidence of any significant adverse effect of NAFTA on the aggregate trade flows of neighboring countries.

These conclusions, however, stand in contrast with the findings from the more disaggregated studies cited earlier that suggest trade diversion in the textile and apparel sector specifically. For this reason we explore it in greater detail below. 


\section{Trade Diversion at the Sector Level in Central America and the Caribbean}

There are two facts that make this contrast between aggregate and microeconomic studies puzzling. First, apparel products account for a considerable fraction of NAFTA's imports from Central American and Caribbean countries. Second, apparel is the sector in which NAFTA introduced the largest gap in U.S. trade preferences between those countries and Mexico.

\section{Trade Preferences and the Performance of Apparel Exports}

The first of those facts is documented by Table 7.8, which highlights the importance of apparel in overall NAFTA imports from Central American and Caribbean countries, as well as Mexico. ${ }^{26}$ It is clear from the table that apparel plays a major role in the region's trade with NAFTA, and increasingly so for most countries in the table (the only exception being Costa Rica in the late 1990s).

Access by Central America and the Caribbean to the U.S. market has been governed since 1983 by the Caribbean Basin Initiative (CBI), which granted free access-with no tariffs or quotas-to most goods produced by those countries, but with a number of major exceptions (the most relevant being the textile and apparel sector). Imports from the excluded sectors received no preferential treatment and were subject to maximum tariffs (those applicable to third countries).

Table 7.8 Apparel Exports to NAFTA (percent of total exports to NAFTA)

\begin{tabular}{lcc}
\hline & $1991-94(\%)$ & $1995-2001(\%)$ \\
\hline Mexico & 2.98 & 5.77 \\
Costa Rica & 35.95 & 27.39 \\
Guatemala & 37.72 & 47.79 \\
Honduras & 45.59 & 71.43 \\
Nicaragua & 6.69 & 45.18 \\
EI Salvador & 43.85 & 76.04 \\
Central America & 38.52 & 51.51 \\
Dominican Republic & 47.86 & 50.97 \\
Jamaica & 41.71 & 42.23 \\
CARICOM & 31.24 & 34.78 \\
\hline
\end{tabular}

Source: UN-COMTRADE Apparel HS 61, 62. 
Prior to NAFTA, Mexican apparel exports to the United States were subject to the same tariff treatment as those from CBI countries. But the passage of NAFTA created a bias in favor of Mexican goods. In the postNAFTA years, effective tariffs barely declined for CBI countries (they hovered in the 15-18 percent range), whereas they basically vanished for Mexico. More recently, enhancements to the original CBI terms have brought them closer to "NAFTA parity" in terms of preferences in the textile and apparel sector, although the bias was not completely eliminated until the passage of a new U.S. law in 2000 (and even after that some differences remain; see box 7.2).

The change against CBI countries in relative preferences in the textile and apparel sector imposed by NAFTA had long been regarded as one of its major threats for the neighboring countries (e.g., Jorge and Salazar-Carrillo 1997; Leamer et al. 1995). Has it been borne out by the facts? Table 7.9 shows the shares of CBI countries and Mexico in NAFTA's total apparel imports. It is clear that Mexico has experienced a spectacular increase in market share in the post-NAFTA years. ${ }^{27} \mathrm{By}$ 1999 Mexico had caught up with CBI exporters as a group (figure 7.11). But CBI countries did not lose market share. Instead they expanded considerably their combined presence in the NAFTA market, although at a slower pace than did Mexico. Of the region's countries shown in the table, only Costa Rica and Jamaica-two higher-wage countries-saw their market share decline in the post-NAFTA period. As the table shows, these CBI gains were achieved at the expense of Asian exporters (China, Hong Kong [China], the Republic of Korea, and Taiwan [China]), whose combined share of the NAFTA market was drastically cut over the past decade. These latter countries, rather than those of the $\mathrm{CBI}$ area, appear to be prime candidates for trade diversion in apparel.

In principle, the fact that most CBI countries (and the group as a whole) gained market share in the post-NAFTA period seems to provide evidence that they were not affected by trade diversion. ${ }^{28}$ Because the entire region faced the same relative preferences vis-à-vis Mexico, the contrast between the shrinking market shares of some individual countries and the rising shares of others should instead reflect country-specific factors, such as the relocation of exporters across countries within the region in view of their relative production cost (Chacón 2001). Regarding Asian exporters, figure 7.11 clearly suggests they might have been affected by trade diversion, but it should be noted that the decline in their market share had already started well ahead of NAFTA.

Of course these before-and-after comparisons are only suggestive. The proper experiment should compare the observed export pattern with the one that would have prevailed in the absence of NAFTA. It is important to recall that the changing export patterns also reflect the influence of other factors as important as NAFTA or even more so-most 


\section{Box 7.2 The Caribbean Basin Initiative}

The 1983 Caribbean Basin Economic Recovery Act (CBERA), commonly referred to as the Caribbean Basin Initiative or CBI, is a unilateral, nonreciprocal, grant of duty-free or reduced-duty access for certain exports to the U.S. market. Most textiles and apparel, certain footwear, canned tuna, petroleum and its derivatives, and certain watches are not eligible for any preferential treatment. The CBERA was amended by the Caribbean Basin Economic Recovery Act of 1990, which made the trade benefits permanent.

Currently, 24 Caribbean, and Central and South American countries enjoy these trade preferences. ${ }^{1}$ Benefits under CBI are dependent on various mandatory and discretionary conditions, including intellectual property rights protection, investment protection, improved market access for U.S. exports, and workers' rights. Over the late 1990s, about one fifth of overall U.S. imports from CBERA countries entered the United States under CBERA preferential provisions.

Ever since NAFTA was proposed in the early 1990s, Caribbean Basin countries expressed concern that Mexico's more preferential trading status would erode their own preferential access to the U.S. market. This led to demands for modifying the CBI to achieve "NAFTA parity" to prevent a diversion of exports and investment from the CBERA region, particularly in the textile and apparel sector.

In May 2000 the United States enacted the Caribbean Basin Trade Partnership Act (CBTPA), which focuses primarily on the preferential treatment of textile and apparel products and adds several eligibility criteria. Articles accorded duty-free and quota-free treatment include apparel assembled in a beneficiary country from fabric wholly formed and cut in the United States from U.S.-made yarn, or from a fabric made in the United States from U.S.-made yarn, cut in a beneficiary country and sewn together there with U.S.-made yarn. Duty-free access for apparel knit in the region is subject to an annual cap, with separate limits for knit apparel and t-shirts. The Trade Act of 2002 further expanded the benefits under CBERA through a substantial increase in the quota ceilings for knit-to-shape apparel and exclusion of the cost of trimmings and findings from the cost of U.S. fabric components.

CBTPA requirements for duty-free import of textiles and apparel remain more stringent than those imposed by NAFTA, in that the latter allows the use of yarn from any NAFTA member country, not only the United States. Nevertheless, the available information shows that since enactment of CBTPA a considerable fraction of the region's apparel exports have entered the United States under the new preferential regime, approaching the utilization rate of NAFTA by Mexican exporters (see the table included here).

\section{Note}

1. The following 20 countries were designated on January 1, 1984: Antigua and Barbuda, Barbados, Belize, British Virgin Islands, Costa Rica, Dominica, 


\section{Box 7.2 (continued)}

Dominican Republic, El Salvador, Grenada, Guatemala, Haiti, Honduras, Jamaica, Montserrat, Netherlands Antilles, Panama, St. Kitts and Nevis, Saint Lucia, Saint Vincent and the Grenadines, and Trinidad and Tobago. The Bahamas was designated on March 14, 1985. On April 11, 1986, Aruba was designated, retroactive to January 1, 1986, upon becoming independent of the Netherlands Antilles. Guyana was designated effective November 24, 1988, and Nicaragua was designated effective November 13, 1990.

Source: Ahearn 2002 and Gitli and Arce 2000.

Apparel Exports to the United States Under CBI/CBTPA and NAFTA Preferences (percent of apparel exports to the U.S.)

\begin{tabular}{lccccc}
\hline & $1990(\%)$ & $1995(\%)$ & $2000(\%)$ & $2001(\%)$ & $2002^{a}(\%)$ \\
\hline $\begin{array}{l}\text { Caribbean Basin } \\
\begin{array}{l}\text { countries } \\
\text { Mexico }\end{array}\end{array}$ & 0 & 0 & 2 & 54 & 65 \\
\hline
\end{tabular}

a. January through November.

Source: U.S. International Trade Commission.

notably the Mexican devaluation of 1994 that resulted in a huge increase in the wages of neighboring countries relative to those in Mexico. Over 1994-99 the change in relative wages was two or three times larger than the change in relative tariff preferences granted by NAFTA, and this is particularly relevant for textile and apparel plants in the region and elsewhere, given that wages reportedly account for a large share of total production cost (Gitli and Arce 2000). Information on wage levels comparable across countries is scarce, but for those economies with available data, figure 7.12 shows that between 1994 and 1998 U.S. dollar wages almost doubled relative to Mexico's, with El Salvador as the exception.

\section{The Role of Export Processing Zones}

Trade-promoting actions in Central American and Caribbean countries were probably instrumental in preventing their NAFTA market sharesboth in apparel and more generally-from declining in the post-NAFTA years. Most of the countries in the area are very open to trade. Since the late 1980s they have pursued active trade liberalization policies on several fronts-unilateral, bilateral, multilateral, and regional—and by the 
Table 7.9 Shares in NAFTA's Total Apparel Imports (percent of total imports by NAFTA)

\begin{tabular}{lcc}
\hline Economy & 1991-94 (\%) & 1995-2001 (\%) \\
\hline Mexico & 3.74 & 10.76 \\
Costa Rica & 1.79 & 1.50 \\
Guatemala & 1.48 & 2.04 \\
Honduras & 1.27 & 3.28 \\
Nicaragua & 0.03 & 0.41 \\
EI Salvador & 0.67 & 2.06 \\
Central America & 5.24 & 9.29 \\
Dominican Republic & 3.76 & 3.91 \\
Jamaica & 1.05 & 0.77 \\
CARICOM & 5.00 & 4.78 \\
Bangladesh & 2.21 & 2.88 \\
China & 15.44 & 11.71 \\
Hong Kong (China) & 14.54 & 8.82 \\
Indonesia & 2.82 & 3.31 \\
India & 3.24 & 3.29 \\
Republic of Korea & 6.67 & 3.81 \\
Thailand & 2.48 & 2.82 \\
Taiwan (China) & 7.48 & 3.84 \\
Asia & 54.89 & 40.47 \\
\hline
\end{tabular}

Source: UN-COMTRADE, Apparel HS 61,62.

end of the 1990s those policies had led to fairly low levels of tariff and nontariff barriers. ${ }^{29}$

In most countries in the region the process of trade liberalization has been accompanied by significant export-oriented incentives, which usually are articulated around export processing zones (EPZs). These zones have grown substantially in recent years, and in several countries they account at present for half or more of total exports (table 7.10).

EPZ incentives are relatively homogeneous across the region. All countries offer similar exemptions from taxes on intermediate inputs, taxes on exports, and remittances of goods and profits (see RoblesCordero and Rodríguez-Clare 2003). The bulk of firms and jobs in Central America's EPZs are found in the textile and apparel industry, especially in the cases of El Salvador, Honduras, and Nicaragua. In these countries the textile and apparel sector accounts for more than 90 percent of EPZ employment. ${ }^{30}$ Although the limited data available on EPZs do not allow a formal analysis, they likely played an important role in the steady expansion of apparel exports from CBI countries to the NAFTA bloc despite Mexico's preference advantage. 
Figure 7.11 Shares in NAFTA's Total Apparel Imports (percent)

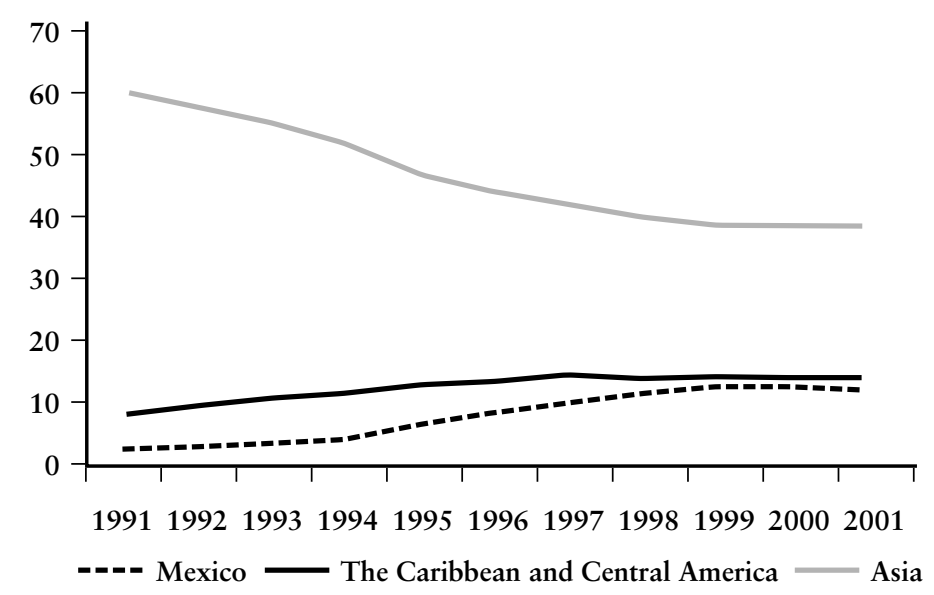

Source: Authors' elaboration from World Bank data.

In summary, although we cannot rule out the possibility that some degree of trade diversion against neighboring countries in the apparel sector may have occurred as a result of NAFTA, the impact of the trade agreement in this regard is likely dwarfed by the effects of the Mexican devaluation on relative wages across the region. In addition, the rising trend in apparel exports from Central American and Caribbean countries to the NAFTA area runs against the possibility of significant trade diversion. However, diversion could also be concealed in the trade flow data because of the offsetting incentives offered by EPZs in the affected countries. Trade diversion masked by those incentives would show up instead in a loss of fiscal revenues and welfare costs from other hard-toquantify distortions imposed by the EPZs to sustain trade flows.

\section{The Road Ahead}

The success of NAFTA's neighbors at maintaining their market share following Mexico's acquisition of preferential status in the United States and 
Figure 7.12 U.S. Dollar Wages Relative to Mexico

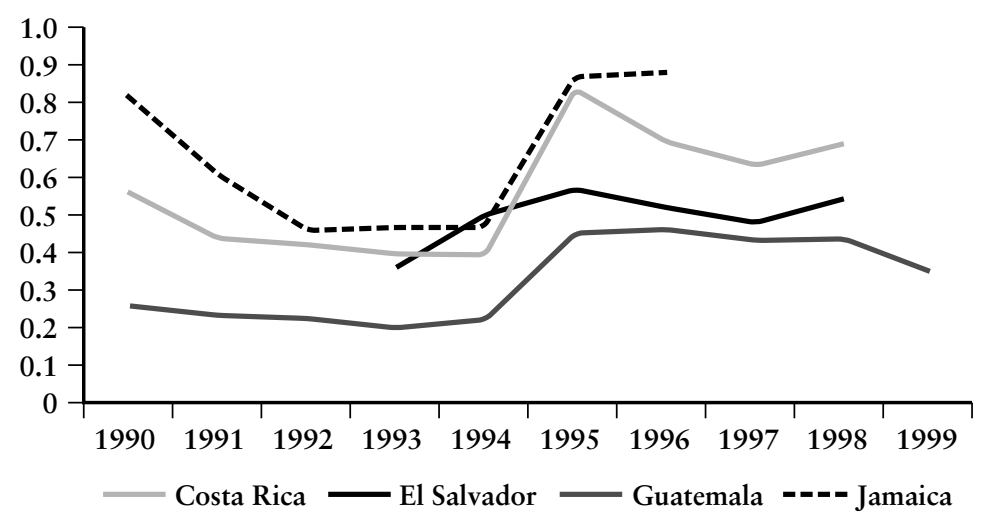

Source: Authors' elaboration from World Bank data.

Canada likely reflects their continuing efforts at trade liberalization, the generous export incentives granted by the EPZs, and the (limited) preferential access to the U.S. market offered by CBI and related provisions.

Looking to the future, in the apparel sector the upcoming elimination (by 2005) of import quotas derived from the Multi-fiber Arrangement

Table 7.10 Exports from EPZs

(gross exports of EPZs/total gross exports)

\begin{tabular}{lccc}
\hline & 1990 & 1995 & 2001 \\
\hline Costa Rica & 6.5 & 12.5 & 47.5 \\
Dominican Republic & 81.2 & 77.4 & 83.3 \\
EI Salvador & 12.2 & 39.1 & 57.7 \\
Honduras & 1.7 & 11.8 & 29.3 \\
Mexico & 42.1 & 38.5 & 46.8 \\
Nicaragua & $0.9^{\mathrm{a}}$ & 22.6 & 54.3 \\
\hline
\end{tabular}

a. 1992.

Source: Larraín B (2001), except for Mexico and Dominican Republic data, which came from the Mexican National Central Bank and the Dominican Republic National Central Bank. 
will cast the issue of NAFTA and United States preferences in a new light. Increased competition from low-cost Asian exporters is likely to follow. More generally, the levels of U.S. protection are likely to continue declining over the medium term as the economic (and political) dimension of the sector gradually shrinks. Thus the magnitude and relevance of apparel tariff preferences are likely to decline in the future.

From a broader perspective, however, Central American and Caribbean countries still stand to gain from joining the Free Trade Agreement of the Americas (FTAA) for two main reasons. First, EPZs do not represent a final stage on the road to trade integration. In most countries in the area EPZs have specialized heavily in relatively lowskill production processes and remain largely delinked from their respective local economies, which have drawn correspondingly little benefit in terms of technological advancement (Robles-Cordero and Rodríguez-Clare 2003). Even more important, EPZ incentives are typically granted on the basis of export performance ${ }^{31}$ and therefore conflict with World Trade Organization (WTO) rules outlawing export subsidies, which are scheduled to come into effect in the near future. This means that over the medium term those countries in Central America and the Caribbean whose trade promotion and FDI attraction efforts-as well as the avoidance of market share losses in the postNAFTA period-have been primarily based on EPZs will need to develop a new framework. The FTAA offers these countries an opportunity to do so in a coordinated manner.

Second, despite the progress made toward NAFTA-like tariff preferences after the Caribbean Basin Trade Partnership Act (CBTPA), and the fact that a major fraction of Central American and Caribbean exports to the United States already enjoy preferences comparable to those of NAFTA, these unilateral U.S. concessions do not amount to "NAFTA parity" in two fundamental respects. ${ }^{32}$ On the one hand, unilateral concessions do not offer a firm guarantee of U.S. market access. Unlike those granted by NAFTA, such preferences are often granted on a temporary basis ${ }^{33}$ and are subject to unilateral revocation by the United States at any time. Furthermore, the resolution of trade disputes is likewise left to the discretion of U.S. authorities. It is important to note that these considerations apply not only to Central American and Caribbean countries but also more broadly to all Latin American economies except Mexico and, more recently, Chile.

On the other hand, an FTA with the United States and Canada can help lock in the progress made on unilateral trade liberalization, making it immune to potential protectionist pressures that might arise in the future. This would offer domestic and foreign investors a more predictable framework without the possibility of backtracking in the rules governing international trade and perhaps in the reforms on other fronts. As we 
argue in chapter 8 , this positive impact on credibility would likely encourage investment in the new FTAA member countries.

The importance of this lock-in effect, however, may vary considerably among prospective FTAA members. It is likely to be most important for countries at an early stage of trade opening whose reforms still suffer from poor credibility. In contrast, a number of Central American and Caribbean economies already possess low barriers to trade and a strong constituency in favor of trade openness. For such countries the credibility dividend will largely depend on the extent to which FTAA accession prompts improvement and strengthening of policies and institutions.

An FTA also entails costs. Some of these are explicit, as in the case of negotiation costs that may be substantial for small economies. Even more important from the macroeconomic perspective is the cost of eliminating tariffs against other FTA members, which for some countries will imply a fiscal shock that is particularly significant for countries whose public revenues are highly dependent on tariff collection and whose imports largely originate in the NAFTA area. Within Central America, the fiscal loss from removing tariffs against NAFTA members could exceed 8 percent of total current revenues in Honduras, and would be almost as large in El Salvador and Guatemala (Perry, Lederman, and Suescún 2002). This underscores the need for fiscal reform in preparation for the FTAA.

Other costs are less directly visible but no less significant, as in the case of the distortions imposed by ROOs under NAFTA (see chapter 4 of this volume). If not properly tackled in the negotiation process, they can detract substantially from FTAA benefits by generating more trade and investment diversion than creation.

More broadly, the advent of an FTA makes it all the more important for prospective members to take the necessary policy steps to ensure that the agreement's potential benefits can be reaped. Such steps will vary across countries, depending on their respective initial conditions and policy and institutional frameworks, but some steps are likely to apply to a broad range of countries. For example, in addition to the fiscal strengthening already mentioned, we argued in chapter 3 that macroeconomic and, especially, real exchange rate stability are important preconditions for the expansion of trade and investment flows that will allow FTAA benefits to materialize.

Regarding trade policies, the anticipated gains from an FTA do not reduce the need for continued progress in unilateral trade reforms and multilateral negotiations under the WTO. Major trade issues, such as those surrounding agricultural trade, are unlikely to be resolved in the context of an FTA and will require multilateral action. For some countries, especially in South America, the Doha Trade Round discussions are likely to be as important for market access, or even more so, than the 
proposed FTAA. Success of the WTO round in providing incentives for all countries to delink their subsidies from production decisions-as previously attempted by the EU and implemented by the United States and Mexico-would be a significant improvement over the current situation for these countries, as we noted in chapter 4 .

The FTAA should not preclude simultaneous pursuit of other free trade agreements. Indeed, for some countries in Latin America and the Caribbean (notably those in MERCOSUR) trade with the EU is quantitatively more significant than trade with the United States, and thus the gains from an FTA with the EU could be even larger than those stemming from the FTAA. Furthermore, even for other countries, complementing the FTAA with trade agreements with other partners (e.g., with the EU as Chile has done) might help reduce the scope for trade diversion.

Finally, the above analysis suggests that much of the gain in export market share achieved by Mexico in recent years reflects its unilateral trade liberalization since the late 1980s. The implication for other Latin American and Caribbean countries is that trade-friendly policies, even if unilateral, can yield large dividends in terms of market expansion.

\section{Conclusion}

There are many difficulties in assessing the effects of NAFTA on the trade flows of nonmember countries. First, too little time has elapsed since the passage of NAFTA for its full effects to unfold, especially given the gradual tariff reduction envisaged by the treaty. Second, other major trade determinants have not remained constant. Among these determinants, the overvaluation of the Mexican peso up to 1994 and its subsequent collapse, the global trend toward trade liberalization, and the emergence or revamping of other trading blocs must all have had major effects on the trade flows of NAFTA members and nonmembers. This means that the conclusions from any empirical evaluation of NAFTA's impact on trade have to be taken with considerable caution.

With that major caveat, the results in this chapter are in broad agreement with the majority of previous studies. On the whole, both casual inspection of the data and econometric estimates yield little evidence of any adverse impact of NAFTA on the aggregate trade flows of neighboring countries.

Inspection of trends in trade flows reveals that Mexico has expanded substantially its share in U.S. overall imports. However, Mexico has also raised its export share in the non-NAFTA market, ${ }^{34}$ and thus the fact that it emerges as the top winner in the U.S. market does not constitute evidence of trade diversion. Furthermore, Central American countries, which would have been prime candidates for trade diversion, 
actually have increased their presence in U.S. markets. From the perspective of U.S. imports, the big losers appear to be Brazil, Ecuador, and the República Bolivariana de Venezuela, which on a priori grounds should have been less affected by NAFTA than the neighboring countries of Central America and the Caribbean.

Econometric analysis of aggregate trade flows using a gravity approach likewise fails to find any significant trade diversion effects from NAFTA. In fact, there is no clear evidence that NAFTA members' propensity to trade exclusively among themselves has risen significantly in recent years, when conventional trade determinants are taken into account. Much of the increase in trade among members, and especially the substantial increase in Mexico's exports to the United States, may reflect factors other than NAFTA, such as the sustained expansion of the U.S. economy. On the other hand, Mexico's global trade patterns after 1994 mimic the behavior of trade under unilateral liberalization. A more detailed analysis of the trade flows of Central American and Caribbean countries with NAFTA members does not change these conclusions. Overall, our estimates suggest that Mexico's global exports would have been roughly 50 percent lower without NAFTA, whereas global imports would have been almost 100 percent lower.

Aggregate flows could conceal significant trade diversion at the microeconomic level, and several studies have pointed to the textile and apparel sector as a likely candidate. This is particularly relevant for Central America and the Caribbean region because apparel accounts for the bulk of the region's exports to the NAFTA bloc, and given the fact that after 1994 Mexico has enjoyed a significant preference advantage vis-àvis the other countries-although the preference has recently been almost completely eliminated.

A thorough evaluation of the impact of NAFTA on the patterns of apparel trade between member and nonmember countries is still lacking, but the available information does not show strong evidence that neighboring countries lost market share from apparel trade diversion caused by NAFTA preferences. On the one hand, observed changes in trade patterns across the region-most notably, the rapid increase in Mexico's share of the U.S. market-likely reflect the effects of the Mexican devaluation as much as (or even more than) the effects of NAFTA. On the other hand, although all Central American and Caribbean countries faced the same change in U.S. preferences relative to those enjoyed by Mexico, their post-NAFTA performances showed considerable diversity. Most Central American countries managed to raise their export share in NAFTA markets, although Caribbean economies did not fare as well. In contrast, Asian countries suffered a sharp decline in their NAFTA market share, which suggests that they may have been the actual losers from apparel trade diversion. 
This suggests that factors other than NAFTA preferences are responsible for much of the diversity in post-NAFTA performance of neighboring countries. Among such factors, export incentives granted by a number of countries in the context of EPZs may have played an important role. It is thus possible-although hard to verify-that the upward trend in the region's apparel export shares might have been achieved at significant costs derived from EPZ concessions, such as foregone fiscal revenues and other potential distortions. In this regard WTO rules imply that most EPZ incentives in their current form will have to be phased out over the medium term; therefore a new export- and investmentfriendly framework will have to be developed.

Although NAFTA's neighboring countries have fared relatively well, they would still derive benefits from an FTAA. First, it would offer the opportunity to phase out the EPZ regime in an orderly manner and avoid potentially large adverse effects on exports. Second, in addition to tariff preferences the FTAA would provide a guarantee of market access and a locking-in effect of unilateral reforms, thereby boosting credibility and investor confidence in those countries where they are still low. However, an FTAA also entails potentially significant costs and raises new policy challenges, including the need for fiscal reform in countries that stand to lose badly needed tariff revenues, and the achievement of macroeconomic and real exchange rate stability for the FTA benefits to materialize.

Finally, the potential benefits from an FTAA do not detract from the need for continued progress in unilateral and multilateral trade reform. Major trade issues, such as those surrounding agricultural trade, are unlikely to be resolved in the context of an FTAA and will continue to depend on the progress of multilateral negotiations. Regarding unilateral liberalization, our analysis in this chapter suggests that much of the gain in export market share achieved by Mexico in recent years reflects its unilateral trade liberalization since the late 1980s. The implication for third countries is that trade-friendly policies, even if unilateral, can yield large dividends in terms of export market expansion. 


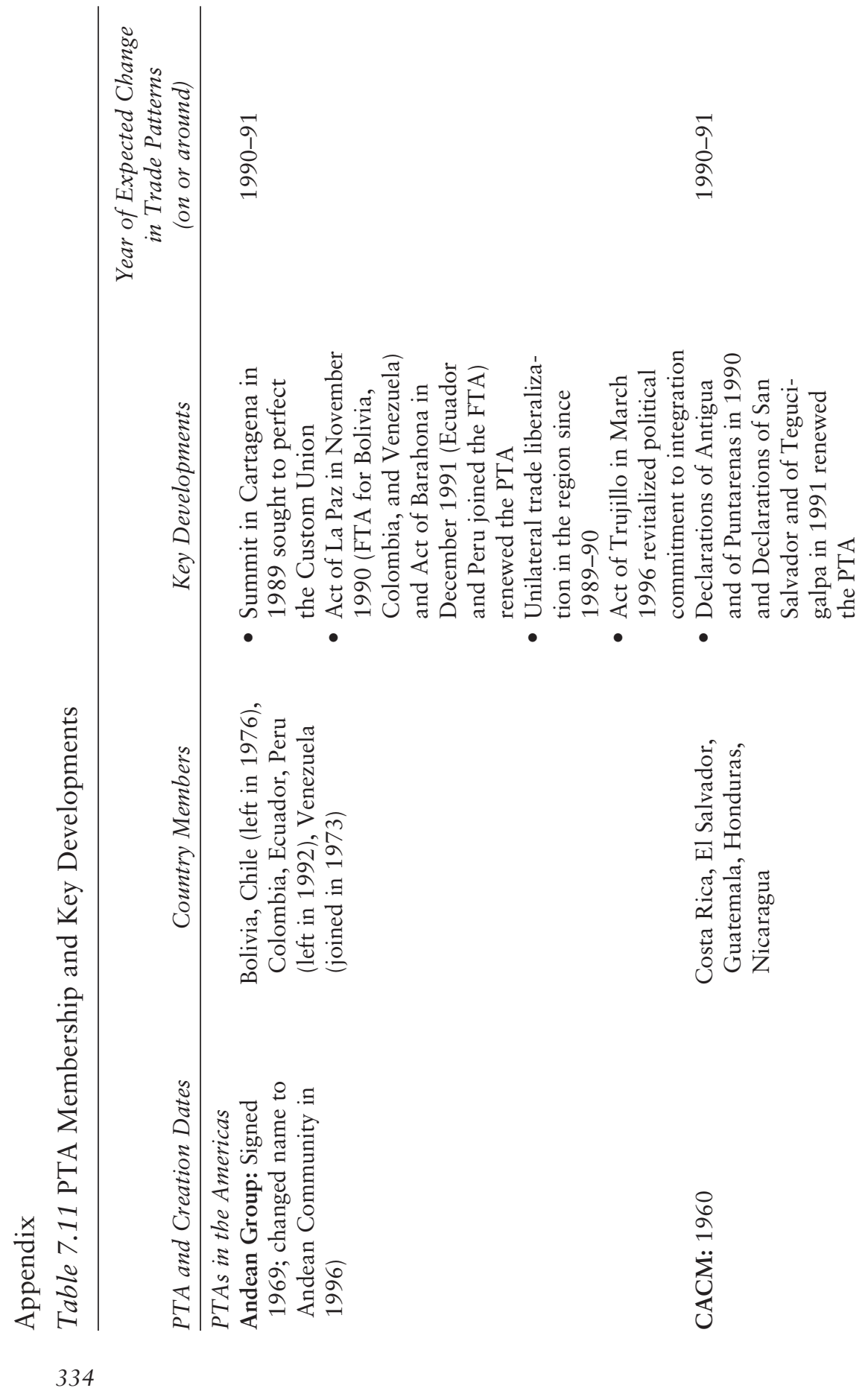




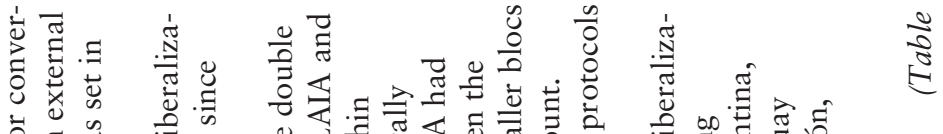

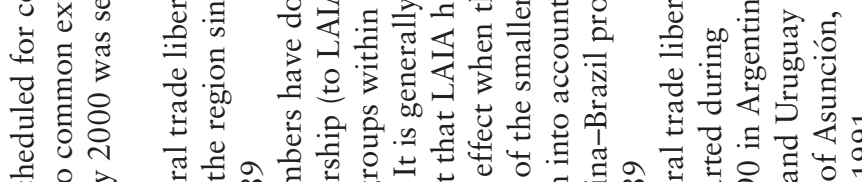

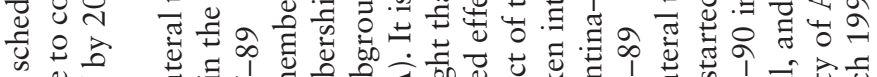

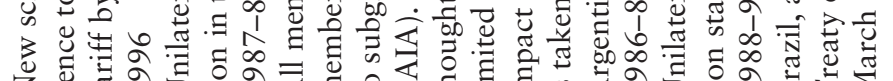

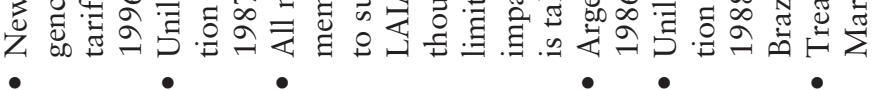
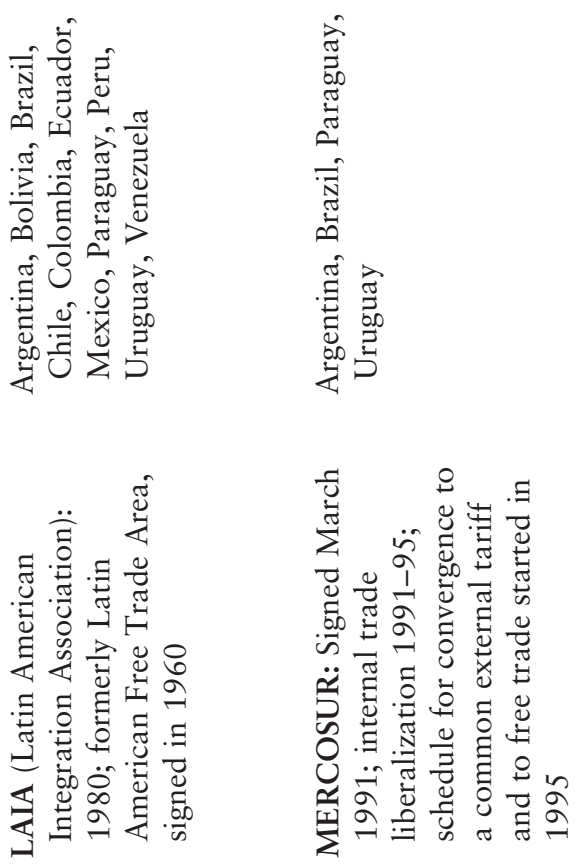


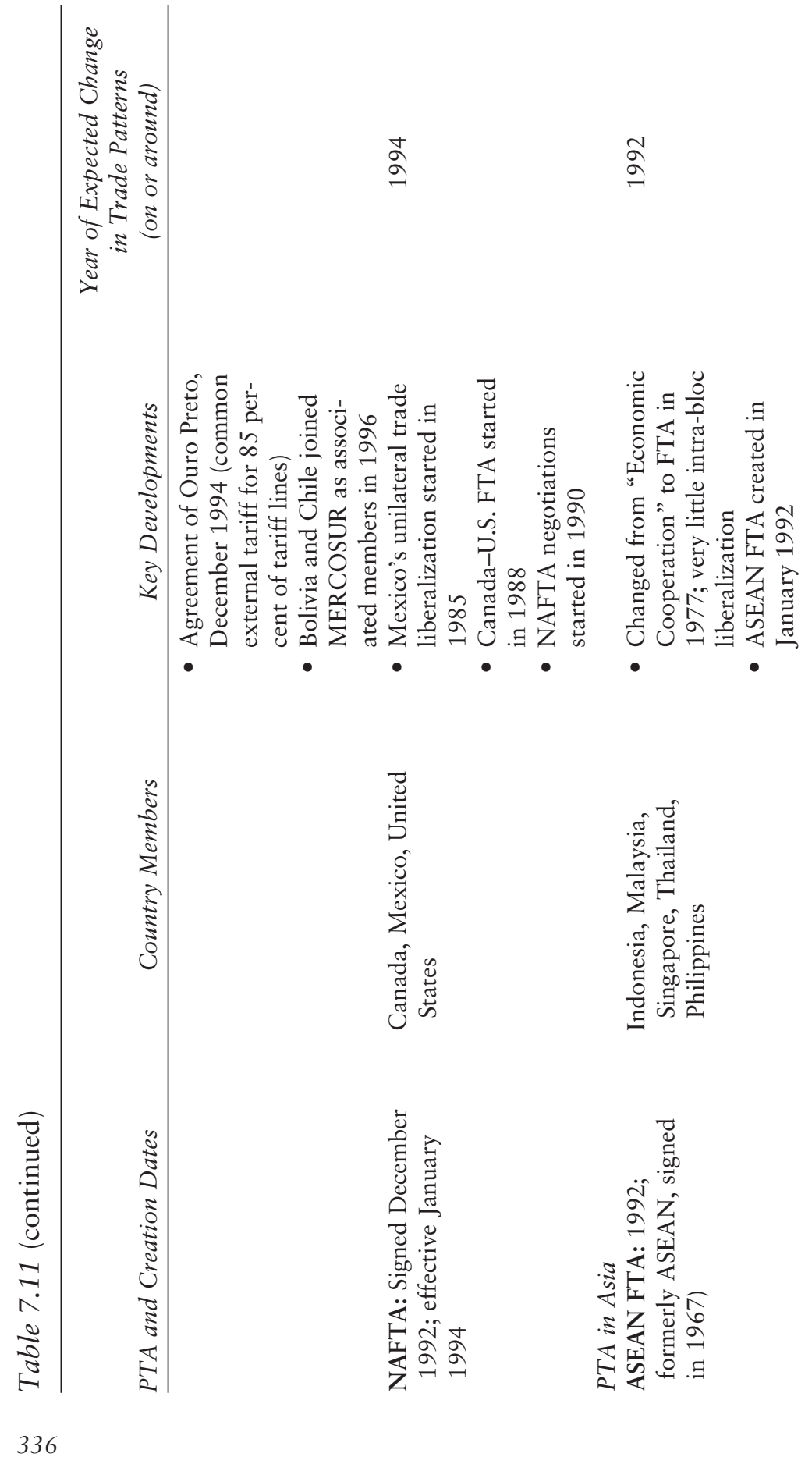




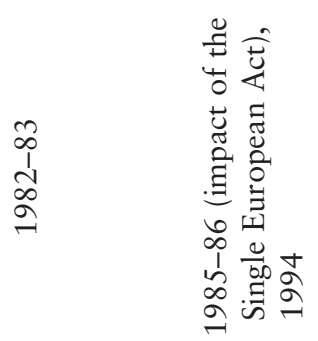

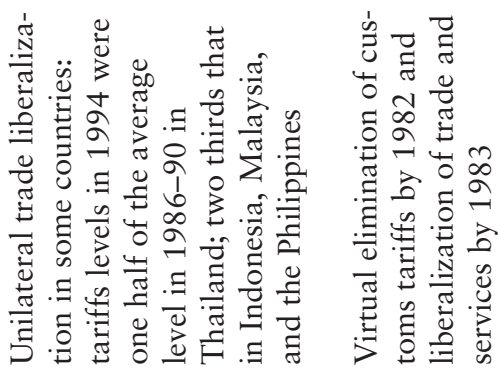

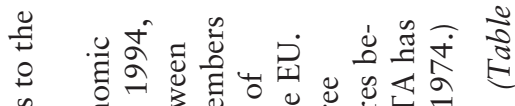

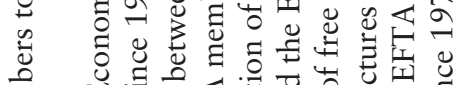
है

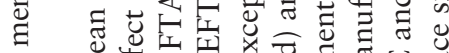

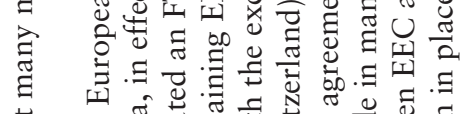

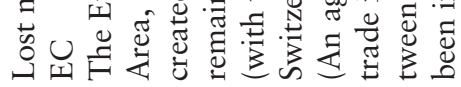




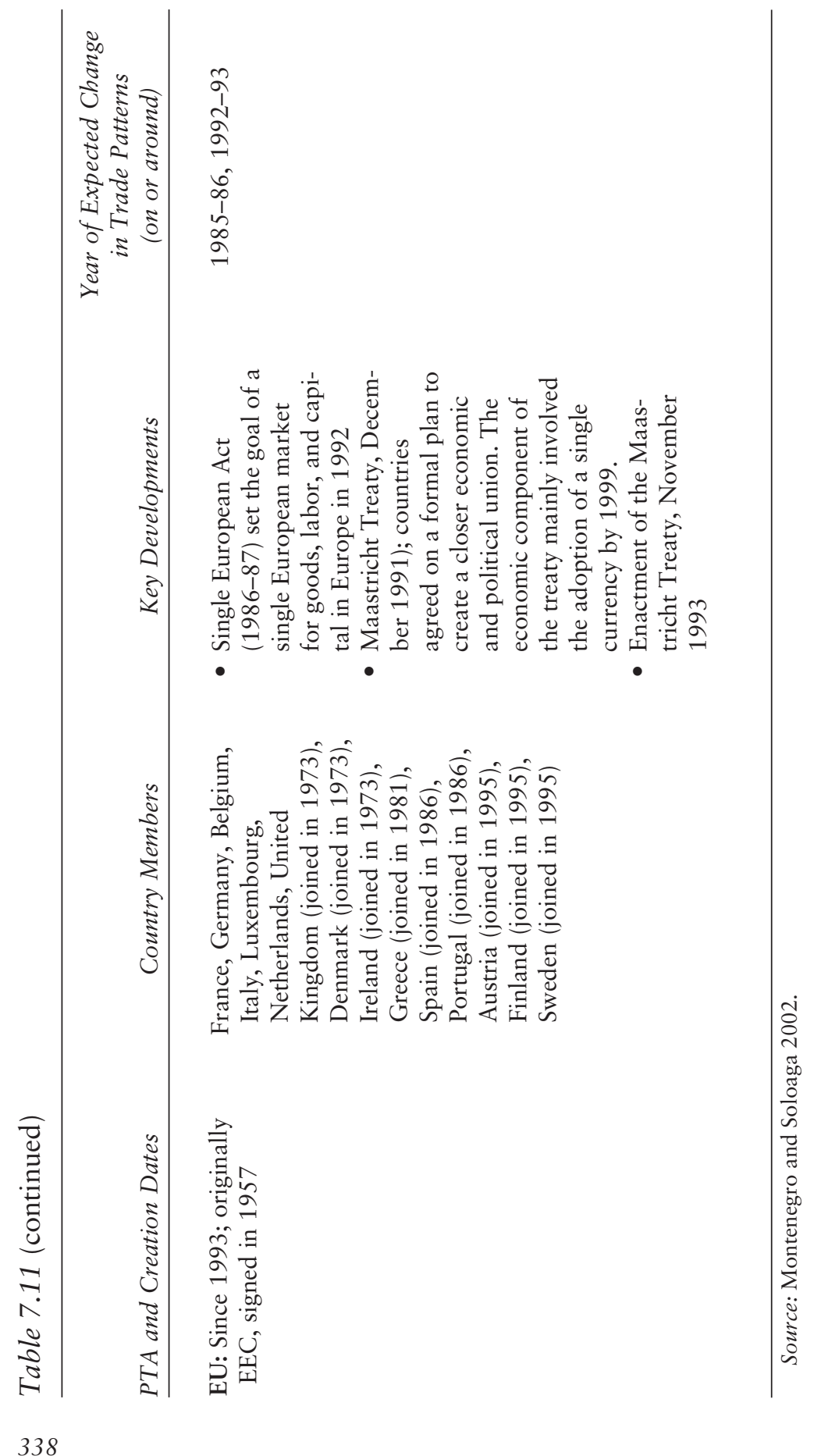




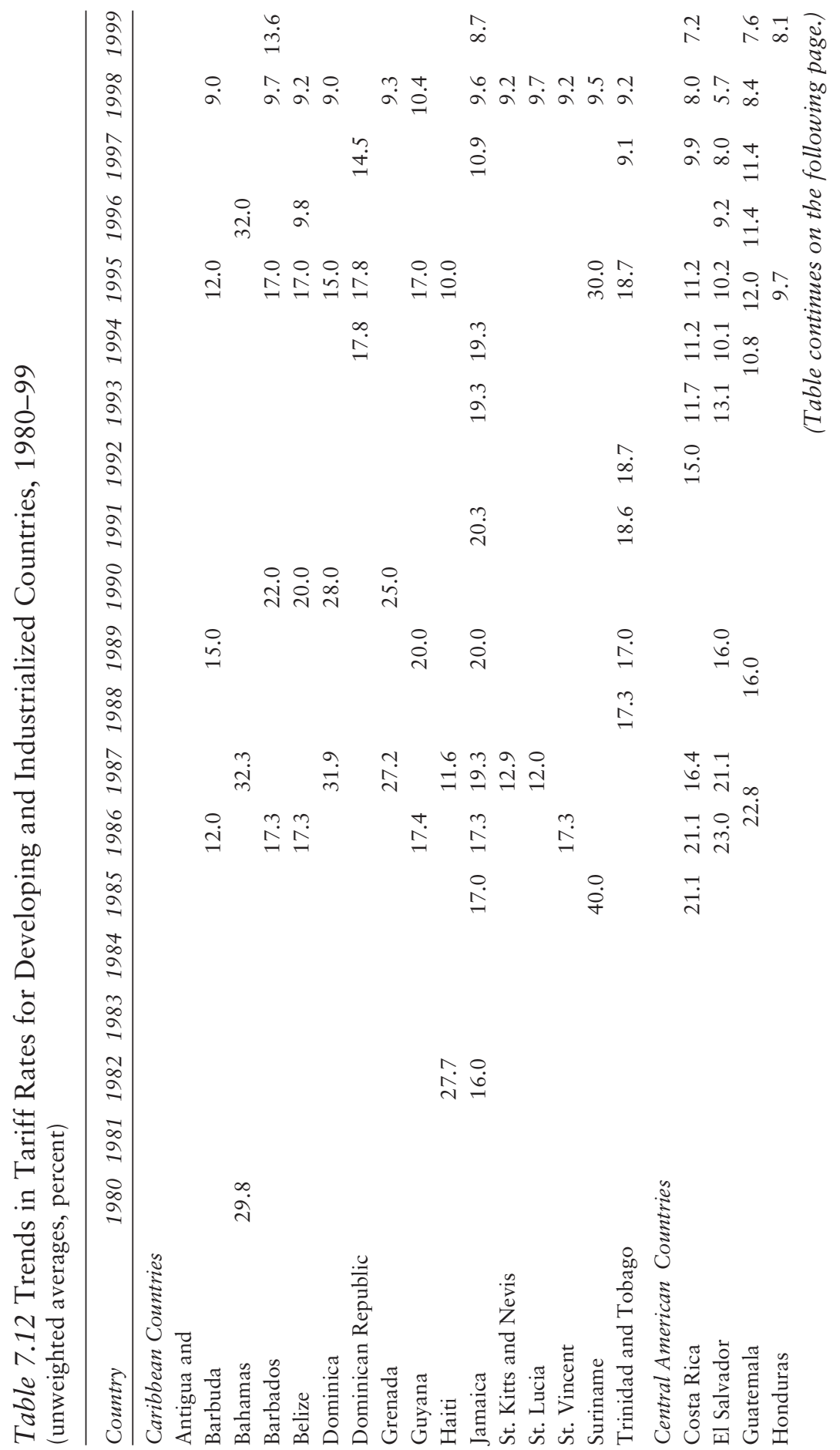




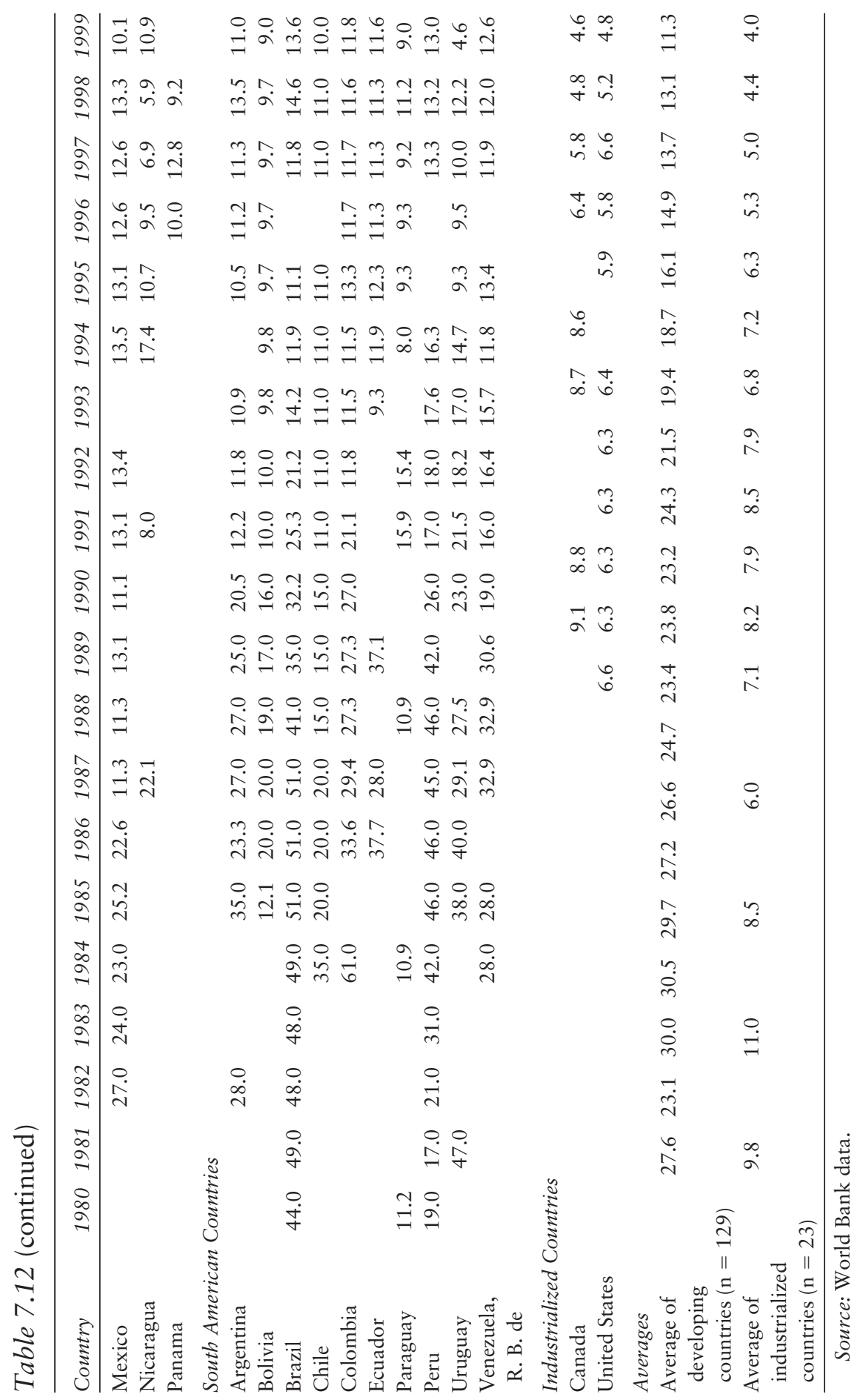




\section{Notes}

1. The concept of trade diversion dates back to Viner (1950).

2. Concern with the potentially harmful effects of NAFTA on these countries has been expressed by a number of observers. See, for example, Jorge and SalazarCarrillo (1997).

3. See, for example, Bayoumi and Eichengreen (1997), Frankel (1997), Frankel and Wei (1998), and Soloaga and Winters (2001). The last source reported clear indication of trade diversion in EFTA and the EEC.

4. This presumes that the FTA is "large" relative to nonmember countries, in the specific sense that its creation can affect their terms of trade.

5. In the case of NAFTA, the observed changes in both aggregate terms of trade and the relative export prices of specific commodities (in particular, apparel exports), fail to yield any evidence of diversion against neighboring Central America and the Caribbean countries.

6. A relatively recent study that looks at price changes was conducted by Winters and Chang (2002). They found large terms of trade losses for third countries in the case of the Common Market of the South (MERCOSUR).

7. This is the so-called Kemp-Wan theorem (Kemp and Wan 1976). In the context of a customs union, the underlying notion is that there exists an ideal "compensating common tariff" that leaves nonmembers' trade with members exactly at pre-union levels, thus offsetting the trade diversion loss and leaving union members with the trade creation gain. (See Winters [1997] for a discussion of this argument.)

8. Empirical implementations of this approach have been most commonly, although not exclusively, based on the econometric estimation of gravity models of international trade. However, computable general equilibrium models have also been popular for this kind of exercise (see Baldwin and Venables 1995).

9. See Winters (1997) for the detailed argument.

10. This section and the next summarize results in the background paper by Montenegro and Soloaga (2002).

11. Comparing the first and last periods in figure 7.1 we see that total trade grew by 108 percent in real terms, whereas total GDP grew by 68 percent.

12. See appendix table 7.12 for detailed data on average tariff levels across countries over the past two decades.

13. Of course the figures are considerably bigger if we compare average levels for 1996-2000 with those for 1986-90. The resulting change was 203 percent for MERCOSUR, 137 percent for CACM, 57 percent for the Andean Group, and 33 percent for CARICOM countries.

14. Disaggregated data show that CARICOM's declining share in NAFTA's import markets is not confined to one or two export industries, but affects instead a variety of export sectors.

15. A quick look at the evolution of aggregate export prices of nonmember countries in Central America and the Caribbean relative to those of Mexico yields no evidence that nonmembers lost out to Mexico in the post-NAFTA years. Indeed, those countries' export prices rose faster than Mexico's during 1994-2001. The same result is obtained when looking at relative prices of apparel exports from Mexico and neighboring countries to the United States.

16. The study also found that in 59 of the 68 sectors NAFTA had a negligible effect on U.S. trade, resulting in part from the low level of pre-NAFTA tradeweighted duties. Imports from Mexico already received preferences under the generalized system of preferences (GSP; also available for other countries) and from 
duty-free treatment for U.S. inputs; those from Canada were substantially liberalized by the previously agreed (1988) Canada-U.S. FTA. The remaining eight sectors experienced a "significant" effect from NAFTA, but no trade diversion (U.S. International Trade Commission 1997, pp. 5-12).

17. Romalis found that Mexico's share of U.S. imports has increased most rapidly in those commodities for which NAFTA gave the greatest increase in tariff preferences. For those commodities with at least a 10 percent increase in relative tariff preference for Mexican goods, the simple average of Mexico's share in U.S. imports has risen by 224 percent since 1993. This is an order of magnitude higher than the more modest 23 percent rise in the rest of the goods (i.e., those without increase in relative tariff preferences for Mexican goods). It is important to note that 70 percent of the commodities with preferences greater than 20 percent (where trade diversion therefore would have been strongest) are textiles, clothing, and footwear. Unlike gravity models, however, Romalis' empirical framework imposes some restrictive assumptions, such as unit income elasticity of demand for all commodities from all suppliers.

18. Linneman (1966), Pöyhönen (1963), and Tinbergen (1962) provided initial specifications and estimates of the determinants of trade flows; Aitken (1973) applied the gravity model to RIAs. More recently, Anderson (1979), Anderson and Mercouiller (1999), Bergstrand (1985), and Deardorff (1998) provided partial theoretical foundations for the gravity equation, although none of the models generate exactly the equation generally used in empirical work.

19. In truth, however, this refinement does not add much relative to standard ordinary least squares estimation because with the logarithmic transform the truncation of the sample occurs at the logarithm of the minimum recorded value of trade (\$0.001 million), and only about 2 percent of observations are recorded at that level.

20. The first two basically update the analysis in Soloaga and Winters (2001).

21. Other experiments used four-, five-, and seven-year periods. Qualitative results were similar to those reported in the text.

22. Note that the dummies for overall exports and imports (rows 1-14 in the table) capture all of Mexico's trade-including trade with the United States. A separate set of dummies (rows 15-28) captures any differential trends in Mexico-U.S. trade, relative to those of overall trade.

23. Both Garces-Díaz (2002) and CBO (2003) found U.S. income elasticities of Mexico's exports around 3. Furthermore, the estimated value is virtually the same in the pre- and post-NAFTA periods.

24. In contrast, some studies (e.g., Anderson and van Wincoop 2003; Romalis 2004) often impose unit scale elasticities.

25. For example, CBO (2003) concluded that NAFTA might account for an increase of about 10 percent in Mexico's exports to the United States.

26. Apparel is defined here as chapters 61 and 62 of the Harmonic System.

27. Mexico's share of the non-NAFTA apparel market also rose in the postNAFTA period, from 0.03 percent in 1991-94 to 0.07 percent in 1995-2001.

28. Rather than showing up in trade flows, diversion might have resulted in a decline in the price of U.S. apparel imports from CBI countries relative to those from Mexico. However, an analysis of apparel price data from the U.S. Customs Service (as reported on the data Web page maintained by the U.S. International Trade Commission, http://dataweb.usitc.gov) at various levels of disaggregation fails to yield evidence of any such decline in CBI countries' relative export prices.

29. The process of liberalization is documented in detail in CIEN (2002). Tariffs declined more markedly in Central American than in Caribbean countries, however. See table 7.12 and Perry, Lederman, and Suescún (2002). 
30. This is shown by the data reported in Robles-Cordero and Rodríguez-Clare (2003).

31. Among the countries considered here, El Salvador is the only one where EPZ tax concessions are not related to export performance. Some specific concessions are still allowed under World Trade Organization rules. This is the case of duty drawback schemes and of concessions related to trade in services.

32. Bake and Spross (2003) outlined the key differences between the current situation and an FTAA.

33. In the case of CBTPA they run until 2008.

34. This holds not only at the aggregate level but also for most of the sectors in which Mexico's share of U.S. imports has risen see Krueger (1999, 2000).

\section{References}

The word "processed" describes informally produced works that may not be commonly available through libraries.

Ahearn, Raymond. 2002. Trade and the Americas. Issue Brief for U.S. Congress, September 20, 2002. Washington, DC: Congressional Research Service.

Aitken, Norman D. 1973. The Effect of the EEC and EFTA on European Trade: A Temporal Cross-section Analysis. American Economic Review 63: 881-92.

Anderson, James. 1979. A Theoretical Foundation of the Gravity Model. American Economic Review 69 (1): 106-16.

Anderson, James E., and Douglas Mercouiller. 1999. Trade Insecurity, and Home Bias: An Empirical Investigation. Working Paper 7000, National Bureau of Economic Research, Cambridge, MA.

Anderson, James E., and Eric van Wincoop. 2003. Gravity with Gravitas: A Solution to the Border Puzzle. American Economic Review 93 (1): 170-92.

Baldwin, Richard, and Anthony Venables. 1995. Regional Integration. In Handbook of International Economics, Vol. 3, eds. G. Grossman and K. Rogoff, 1597-644. Amsterdam: North-Holland.

Bake, Remy, and Fernando Spross. 2003. El tratado de Libre Comercio con los Estados Unidos: Temas Sensitivos para Centroamérica y Recomendaciones para Optimizar la Negociación. Background paper for the Centroamérica en el Siglo XXI Project.

Bayoumi, Tamim, and Barry Eichengreen. 1997. Is Regionalism Simply a Diversion? Evidence from the Evolution of the EC and EFTA. In Regionalism Versus Multilateral Trade Arrangements, eds. Takatoshi Ito and Anne O. Krueger. Chicago: University of Chicago Press.

Bergstrand, Jeffrey. 1985. The Gravity Equation in International Trade: Some Microeconomic Foundations and Empirical Evidence. Review of Economics and Statistics 20: 474-81.

Chacón, Francisco. 2001. Comercio Internacional de los Textiles y el Vestido. In Impacto del TLCAN en las Exportaciones de Prendas de Vestir de los Países de América Central y República Dominicana, eds. R. Buitelar and E. Rodriguez. Mexico DF: Instituto para la Integración de América Latina y el Caribe.

CIEN (Centro de Investigaciones Económicas Nacionales). 2002. Ventajas y Desventajas para Centroamérica de la Liberalización Comercial Unilateral, 
Bilateral, Regional y Multilateral. Unpublished manuscript. Guatemala City, Guatemala. Processed.

CBO (Congressional Budget Office). 2003. The Effects of NAFTA on U.S.-Mexican Trade and GDP. Washington, DC: CBO.

Corden, W. Max. 1984. The Normative Theory of International Trade. In Handbook of International Economics, Vol. 1, eds. G. Grossman and K. Rogoff, 63-130. Amsterdam: North-Holland.

Deardorff, Alan. 1998. Determinants of Bilateral Trade: Does Gravity Work in a Classical World? In The Regionalization of the World Economy, ed. Jeffrey Frankel. Chicago: University of Chicago Press.

Frankel, Jeffrey A. 1997. Regional Trading Blocs in the World Economic System. Washington, DC: Institute for International Economics.

Frankel, Jeffrey A. and Shang-Jin Wei. 1998. Regionalization of World Trade and Currencies: Economics and Politics. In The Regionalization in the World Economy, ed. Jeffrey Frankel. Chicago: University of Chicago Press.

Freund, Caroline, and John McLaren. 1999. On the Dynamics of Trade Diversion: Evidence from Four Trade Blocs. Discussion Paper 637, Federal Reserve Board, Washington, DC.

Fukao, Kioji, Toshihiro Okubo, and Robert Stern. 2003. An Econometric Analysis of Trade Diversion Under NAFTA. North American Journal of Economics and Finance 14: 3-24.

Garces-Díaz, Daniel. 2002. Was NAFTA Behind the Mexican Export Boom (1994-2000)? Banco de Mexico, Mexico City. Processed.

Gitli, Eduardo, and Randall Arce. 2000. Los Desbalances de los Países de la Cuenca del Caribe frente al TLCAN: La Industria de la Confección. In Impacto del TLCAN en las Exportaciones de Prendas de Vestir de los Países de América Central y República Dominicana, eds. R. Buitelar and E. Rodriguez. México DF: Instituto para la Integración de América Latina y el Caribe.

Gould, David M. 1998. Has NAFTA Changed North American Trade? Federal Reserve Bank of Dallas Economic Review Q1: 12-23.

Jorge, Antonio, and Jorge Salazar-Carrillo. 1997. The Economics of the Caribbean: Present Problems and Future Trends. Stockholm: Institute for Latin American Studies.

Kemp, Murray, and Henry Wan. 1976. The Gains from Free Trade, International Economic Review 13: 509-22.

Krueger, Anne. 1995. Free Trade Agreements Versus Customs Unions. Working Paper 5084, National Bureau of Economic Research, Cambridge, MA.

— 1999. Trade Creation and Trade Diversion Under NAFTA. Working Paper 7429, National Bureau of Economic Research, Cambridge, MA.

- 2000. NAFTA's Effects: A Preliminary Assessment World Economy 23 (6): 761-75.

Larraín B, Felipe. 2001. Economic Development in Central America, Volume 2, Structural Reforms. Cambridge: Harvard University Press.

Leamer, Eduard, Alfonso Guerra, Martin Kaufman, andBoris Segura. 1995. How Does the North American Free Trade Agreement Affect Central America? Policy Research Working Paper 1464, World Bank, Washington, DC.

Linneman, Hans. 1966. An Econometric Study of International Trade Flows. Amsterdam: North-Holland. 
Montenegro, C., and I. Soloaga. 2002. NAFTA's Impact on Third Countries: Recent Evidence with a Gravity Model Approach. Universidad de los Americas, Puebla, Mexico. Processed.

Ohly, Claudia. 1993. What Have We Learned About the Economic Effects of EC Integration? A Survey of the Literature. Economic Paper 103, European Commission, Brussels.

Perry, Guillermo, Daniel Lederman, and Rodrigo Suescún. 2002. Trade Structure, Trade Policy and Economic Policy Options in Central America. Unpublished manuscript. Washington, DC.

Pöyhönen, Pentti. 1963. A Tentative Model for the Flows of Trade Between Countries. Weltwirtschatftliches Archiv 90 (1): 93-99.

Robles-Cordero, Edgar, and Andrés Rodríguez-Clare. 2003. Inversión nacional y extranjera en Centroamérica. Cómo fomentarla en el marco de la OMC?. Academia de Centroamérica. San José, Costa Rica. Processed.

Romalis, John. 2004. NAFTA's and CUSFTA's Impact on North American Trade. University of Chicago. Processed.

Sapir, A. 1998. The Political Economy of EC Regionalism. European Economic Review 42: 717-32.

Soloaga, Isidro, and L. Alan Winters. 2001. Regionalism in the Nineties: What Effect on Trade? North American Journal of Finance and Economics 12 (1): 1-29.

Tinbergen, Jan. 1962. Shaping the World Economy: Suggestions for an International Economic Policy. New York: Twentieth Century Fund.

U.S. International Trade Commission. 1997. The Impact of the North American Free Trade Agreement on the U.S. Economy and Industries: A Three-Year Review. Publication 3045, Washington, DC.

Viner, Jacob. 1950. The Custom Union Issue. New York: Carnegie Endowment for International Peace.

Winters L. Alan, and Won Chang. 2000. Regional Integration and Import Prices: An Empirical Investigation. Journal of International Economics 51 (2): 363-77.

2002. How Regional Blocs Affect Excluded Countries: The Price Effects of MERCOSUR, American Economic Review 92 (4): 890-904. 



\section{8 \\ The Impact of NAFTA on Foreign Investment in Third Countries}

IN CHAPTER 5 WE EXAMINED THE effects of free trade agreements (FTAs) on foreign investment in member countries, focusing on the case of Mexico under the North American Free Trade Agreement (NAFTA). As discussed in that chapter, an FTA may both raise the profitability and reduce the risk from investing in FTA member countries, thereby prompting an increase in their investment inflows. Some evidence of this effect was found in the case of Mexico.

However, this also means that an FTA makes nonmember countries relatively less attractive investment destinations, all other things being equal. From the perspective of international investors, this may prompt a portfolio reallocation away from these countries and thus a significant change in the allocation of investment across countries-an "investment diversion" effect analogous to the trade diversion effect analyzed in chapter $7 .^{1}$

Has the rise in foreign direct investment (FDI) in Mexico implied a reduction in FDI to other Latin American countries? If so, which countries and why? And what can they do to remedy this situation? Although the investment creation effect of FTAs has attracted increased attention in recent years, few studies have examined the impact on investment flows to nonmember countries. On a priori grounds, the redirection of FDI inflows is likely to be more marked for those host countries that are most "similar" to (i.e., closer substitutes for) the FTA members in terms of location, endowments, and overall investment environment. Thus, as with trade diversion, in the case of NAFTA the neighboring countries of Central America and the Caribbean would be among the prime candidates for investment diversion because from the location perspective they are relatively close substitutes for Mexico as FDI destinations. ${ }^{2}$

As with FDI to FTA member countries, the impact on FDI to nonmembers depends to a large extent on whether investment flows are 
horizontally or vertically motivated. As we explained in chapter 5 , horizontal FDI is aimed at serving the local market of the host country and usually is motivated by trade costs, such as transportation and tariffs. Vertical FDI is typically aimed at exporting the production to third countries or back to the source country, and it aims to exploit a cost advantage of the host country. Obviously, many intermediate forms of FDI are possible.

If FDI into nonmember countries is mainly horizontal, it is unlikely to be strongly affected by the creation or enlargement of an FTA. ${ }^{3}$ If FDI is vertically motivated instead, then flows to host countries excluded from the FTA are likely to decline as source countries substitute investment within the FTA for investment outside it. This applies to all investors, both from within and outside the FTA, who export back from their host to the FTA, because it will be cheaper to do so from member countries than from nonmember countries.

Although foreign investment in industrialized countries is primarily of the horizontal variety, in developing countries vertical investments account for a significant share of FDI (see Shatz and Venables 2001). Historically, both forms of FDI have been present in Central and South America. The early waves of FDI were directed to the most traditional sectors of the region (agricultural and mineral goods), which constituted the main exports of the host countries. Copper, bananas, oil, and so forth were originally produced across Latin America by foreign companies. During the import substitution era, Central and South America significantly raised tariffs, which attracted significant flows of horizontal FDI. ${ }^{4}$

In recent years, however, much of the FDI flowing to Central America and the Caribbean has been of a vertical nature. During the 1980s the debt crisis along with political instability in El Salvador and Nicaragua practically shut down the Central American Common Market. In response, most countries in the area adopted a strategy of promoting exports to alternative markets, first with direct fiscal subsidies and later with tax exemptions in the framework of the export processing zones (EPZs) discussed in the previous chapter. These incentives, which spread across the region, exempt domestic and foreign producers from import, export, and income taxes, and typically require that most of the production be targeted to exports.

As a result of those incentives, much of FDI in Central America (aside from that in tourism and the privatizations recently observed in El Salvador, Guatemala, and Panama) is closely linked to the EPZs. These flows are vertically motivated and, therefore, highly sensitive to relative cost considerations. This is so particularly in the case of textiles and apparel, which use easily movable equipment and constitute a major fraction of the region's exports to NAFTA countries. As already noted in chapter 7, in this sector NAFTA introduced, at least temporarily, a preference advantage for Mexico over the excluded Central American and 
Caribbean countries that might have encouraged redirection of their FDI inflows toward Mexico in the years following FTA implementation. ${ }^{5}$

In contrast, FDI flows to South America appear less closely linked to exports. The average market size of host countries in South America is considerably larger than the size of markets in Central American countries, and that provides a strong incentive for horizontal FDI. Moreover, during the 1990s most South American economies, especially Argentina and Brazil, received considerable FDI inflows from privatization of public utilities and concessions of public works. These flows should be relatively insensitive to whatever free trade agreements exist in the region because they target the local market for nontraded goods. ${ }^{6}$ On a priori grounds, therefore, if NAFTA did have an effect on FDI flows to excluded countries, its magnitude should have been smaller for South America than for NAFTA's Central American neighbors. ${ }^{7}$

As already noted in chapter 7, however, FTAs are only a subset of the broad array of determinants of FDI inflows identified in the analytical and empirical literature. Much of the variation in FDI inflows across countries can be explained quite apart from their preferential trading arrangements. ${ }^{8}$ Thus, the above discussion of FDI creation and diversion has to be put in context. The FDI impact of an FTA may be dwarfed by the effects of changes in other FDI fundamentals.

In this chapter we assess the impact of NAFTA on FDI flows to nonmember countries. ${ }^{9}$ We first review the changing trends in FDI flows across Latin America and the Caribbean before and after NAFTA. Because FDI displays a generalized upward trend in most countries, in the third section of the chapter we examine in more detail the relative postNAFTA performance of each host country—relative to the other hosts and to its own history as an FDI destination-paying particular attention to the neighboring countries of Central America and the Caribbean. In the fourth section we take a broader view of the determinants of FDI in Latin America beyond NAFTA and review their evolution in the countries under analysis. The final section provides some concluding remarks and policy lessons.

On the whole, this analysis does not find much evidence that the FTA led to a slowdown in investment flows to other Latin American countries, nor specifically to the neighboring countries of Central America and the Caribbean. Instead, country-specific features and policies, aside from (or in addition to) NAFTA, likely played a major role in the changing pattern of FDI across the region through their impact on its fundamental determinants-the anticipated return and perceived risk from investing in different host countries. Ultimately, FTAs are neither necessary nor sufficient for countries to attract increased investment inflows. FTA membership does not make up for bad policies. It is a complement to, rather than a substitute for, an investment-friendly policy and institutional environment. 


\section{Trends in FDI to Latin America and the Caribbean Before and After NAFTA}

The first step to assess the impact of NAFTA on FDI in nonmember countries is to examine their FDI performance relative to that of Mexico. Figure 8.1 offers a comparative perspective on net FDI inflows to the Caribbean, Central America, Mexico, and South America since 1980. Here and in the rest of the chapter, we consider six major Central American and Caribbean countries-Costa Rica, the Dominican Republic, El Salvador, Guatemala, Honduras, and Jamaica ${ }^{10}$-and nine South American economies-Argentina, Bolivia, Brazil, Chile, Colombia, Ecuador, Paraguay, Peru, and the República Bolivariana de Venezuela.

The upward trend in FDI relative to gross domestic product (GDP) since the early 1990s is clearly apparent in the figure in all three regions. Closer inspection reveals three distinct stages. First, until 1993 there was little difference in FDI performance across the three host regions presented in the graph. Annual flows to each one of them hovered around 1-2 percent of the respective GDP. Until that year South America consistently received lower flows than the rest, whereas Central America became the top FDI destination in 1987. Second, in 1994 FDI to Mexico experienced a

Figure 8.1 Net FDI Inflows as a Percentage of GDP

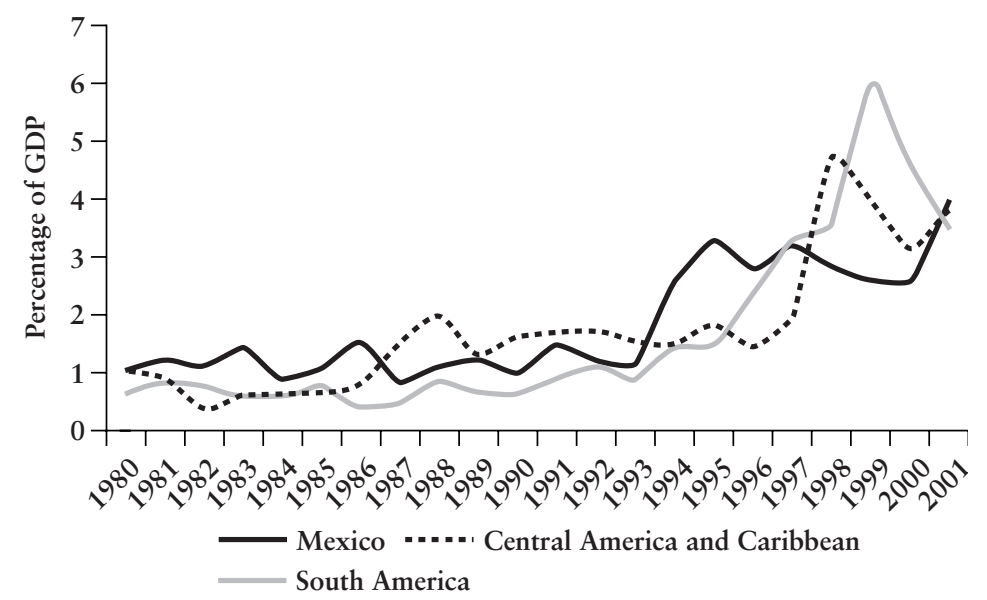

Source: UNCTAD, World Investment Report. 
steep increase, coinciding with the inception of NAFTA. As a result Mexico surged ahead of the other two regions, becoming the prime FDI host over the period 1994-96. Third, after 1997 FDI flows to Central and South America caught up with and even exceeded flows to Mexico. ${ }^{11}$

The individual country performances underlying figure 8.1 are summarized in table 8.1, which presents two alternative measures of FDI: (a) per capita inflows in 1995 U.S. dollars and (b) the ratio of inflows to current GDP. The former measure is shown because, unlike the latter, it is unaffected by gyrations in real exchange rates (such as the devaluation of the Mexican peso during the Tequila crisis), and therefore it may offer a superior yardstick when assessing changes in FDI performance over short time periods. In contrast, the latter measure provides a more accurate picture of the economic dimension of FDI, especially over longer periods of time. The table shows the mean and standard deviation of FDI from U.S. and non-U.S. sources to the countries under analysis for the years 1980-93 (before NAFTA) and 1994-2001 (after NAFTA). ${ }^{12}$

The amounts in table 8.1 confirm that, by either measure of FDI inflows, the rising trend affected virtually all countries in Latin America and the Caribbean. The lone exception is Guatemala, whose FDI inflows declined between the two periods shown when measured relative to GDP, and showed the smallest increase among countries presented in the table when measured in per capita terms.

Beyond the common rising trend, some interesting facts emerge from the data. First, by either measure shown Mexico was not the top FDI destination in Latin America during the post-NAFTA period. Instead, Argentina and Chile (as well as Bolivia, if we look at ratios of FDI to GDP) were the main recipients of FDI. Nor is Mexico the top recipient of U.S. FDI. It places behind Chile and Jamaica (and behind Costa Rica in terms of ratio to GDP).

Second, Mexico was not the country experiencing the largest increases in FDI inflows between the pre- and post-NAFTA periods. Chile and Jamaica had bigger rises in FDI by both measures shown in the table, and other countries also outperformed Mexico in terms of rises in FDI per capita (e.g., Venezuela) or in terms of FDI relative to GDP (e.g., Bolivia and Costa Rica). Central America and the Caribbean region combined experienced an increase in FDI relative to GDP that was very similar to that of Mexico-from an average of 1.1 percent of GDP in 1980-93 to an average of 3.0 percent of GDP in 1994-2001. In Mexico the rise was from 1.2 to 3.0 percent of GDP over the same periods.

Third, both U.S.- and non-U.S.-based investors have increased their flows to the region. In a number of major countries, including Argentina, Brazil, and Chile, investment from non-U.S.-based sources rose faster than did U.S. investment. In terms of regionwide averages, nonU.S.-based investment exceeded its U.S. counterpart over both periods 


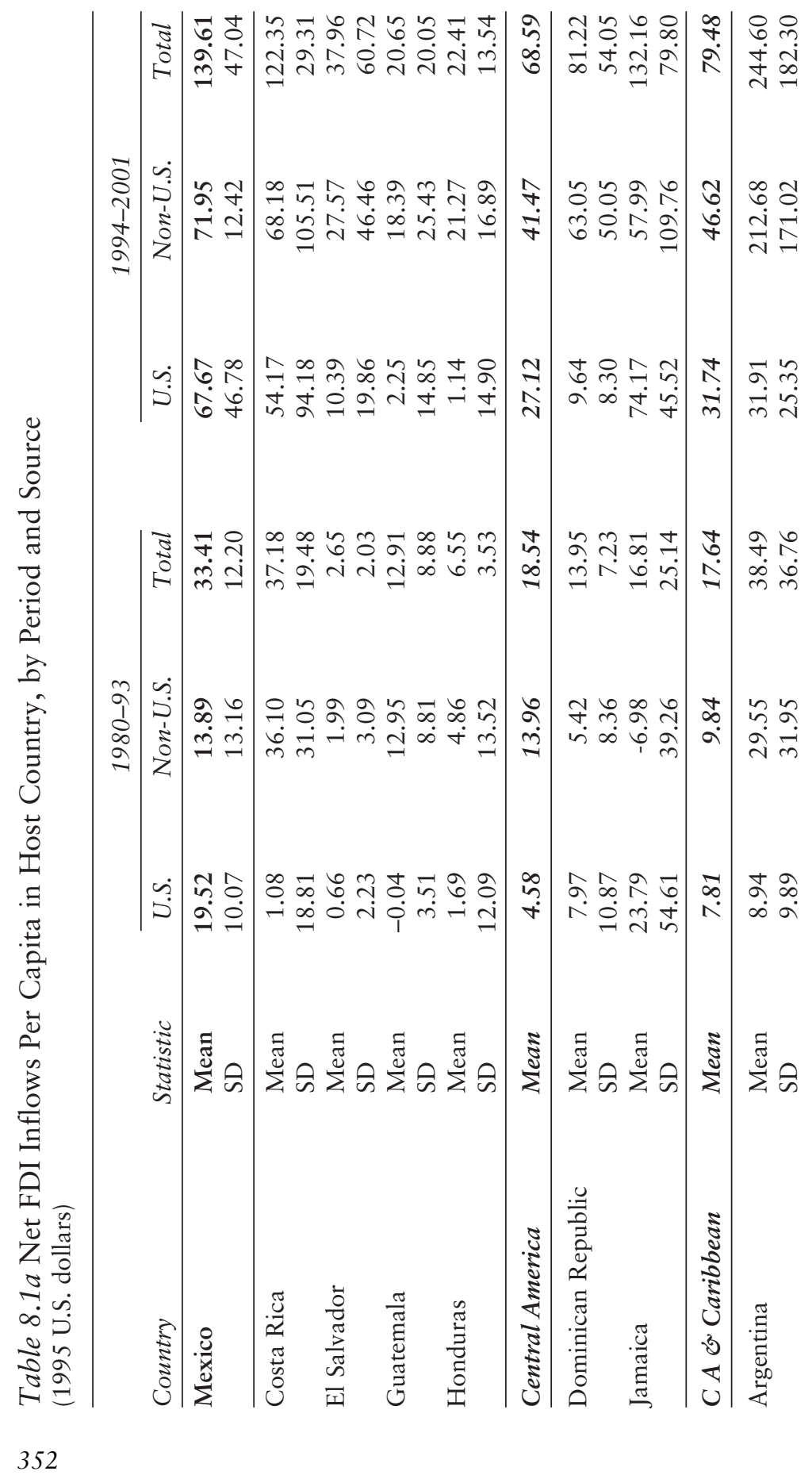




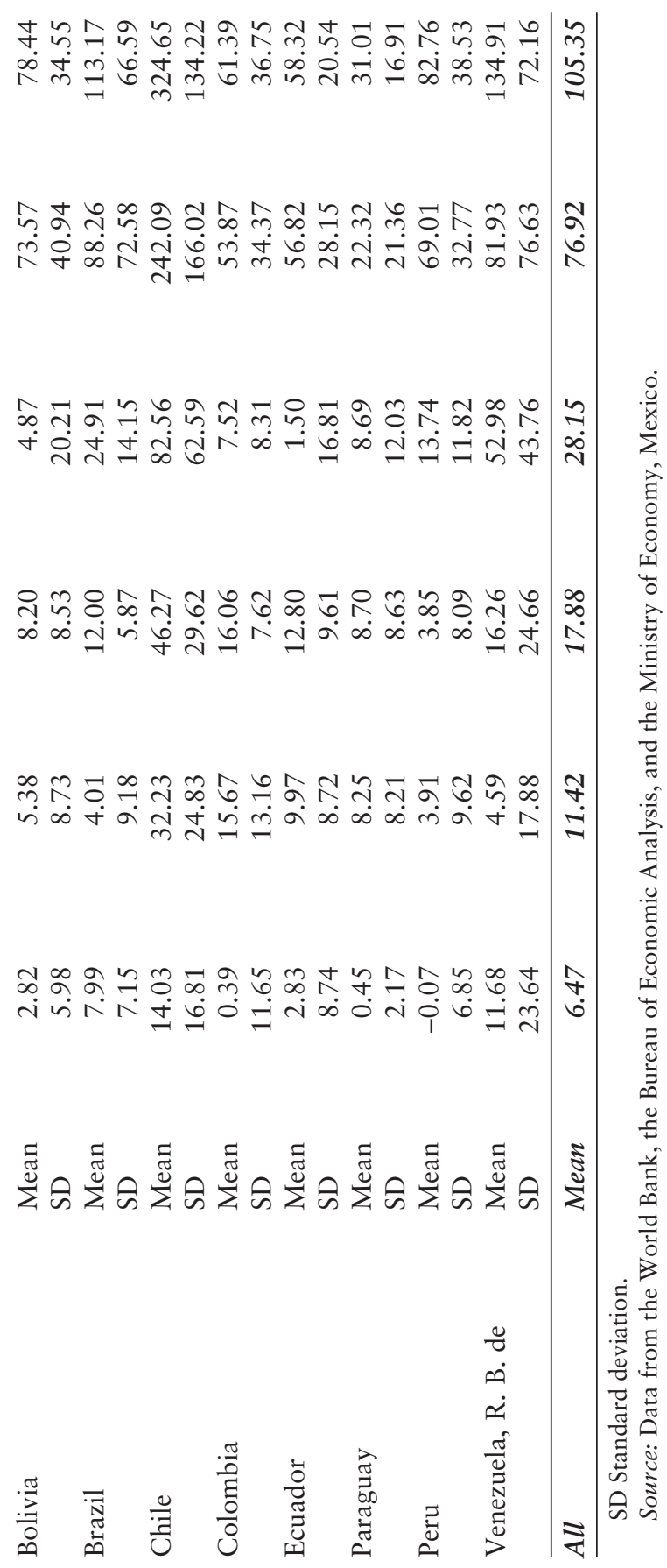




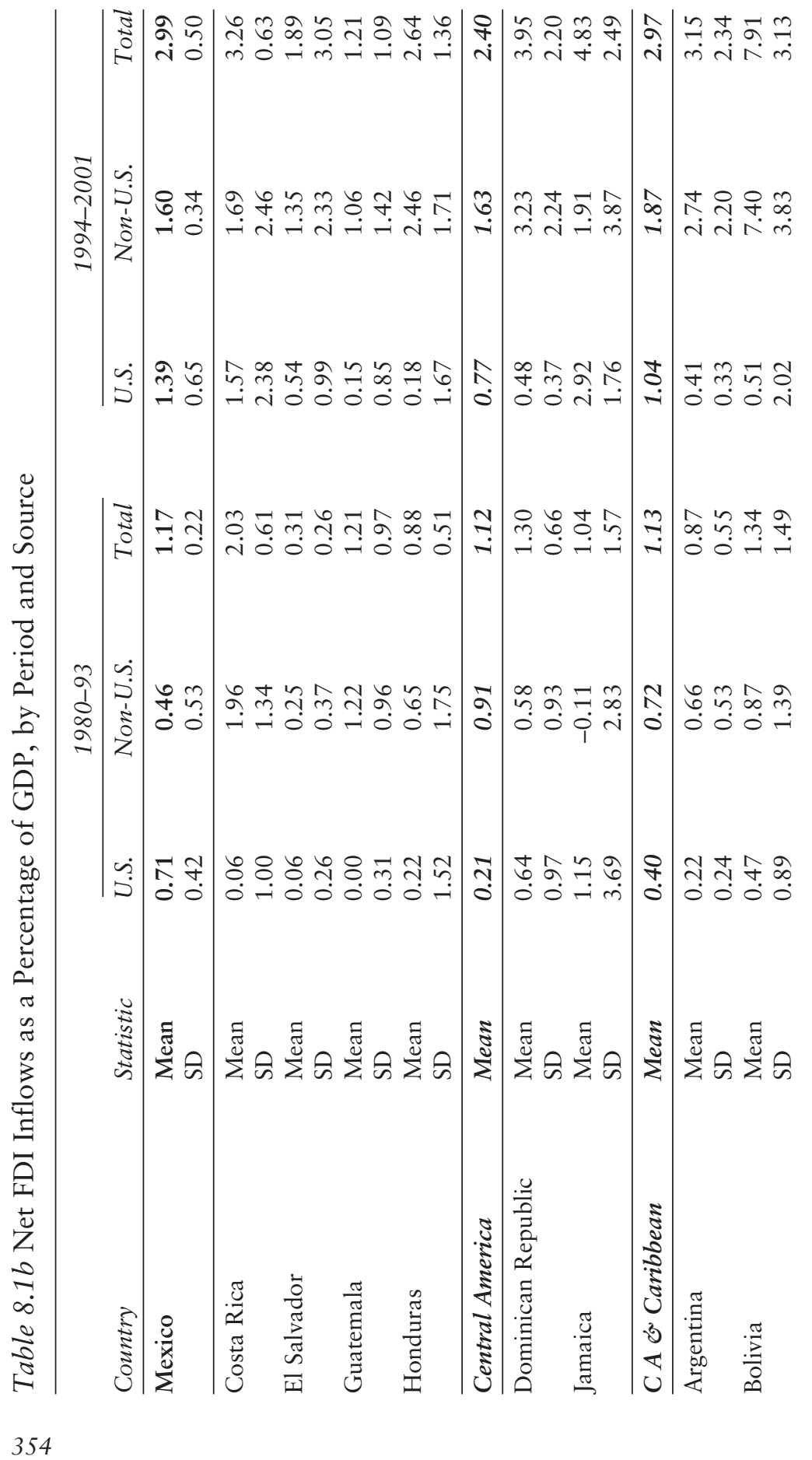




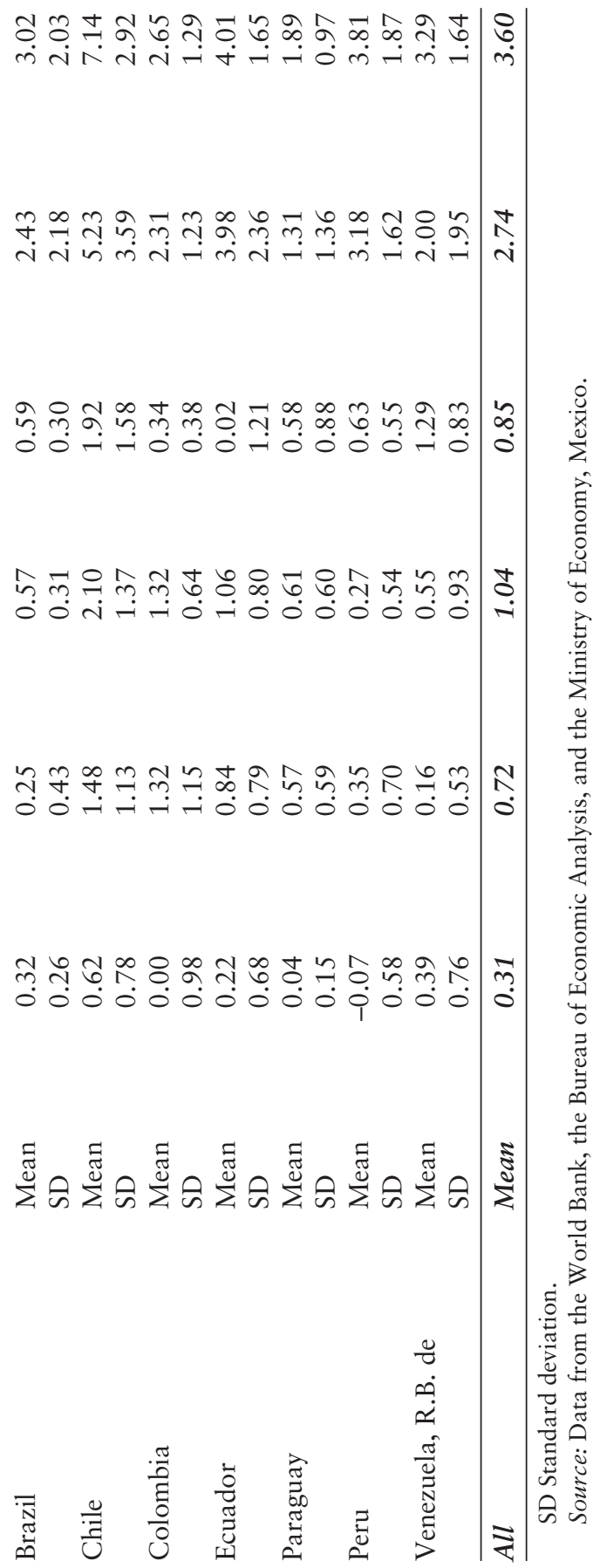


shown, and across periods the rise in the former exceeded the rise in the latter. Within Central America there was considerable diversity in the relative performances of FDI flows from U.S. and non-U.S. sources. Costa Rica and Jamaica saw a substantial expansion of the former, whereas the Dominican Republic and Honduras experienced a significant increase in the latter.

Fourth, there is nevertheless considerable heterogeneity across host countries in terms of the level and growth of total FDI. Within Central America, growth was spectacular in Costa Rica, but modest in El Salvador and Honduras and, especially, in Guatemala. The two Caribbean countries shown also had large increases in FDI inflows.

Fifth, heterogeneity also extends to the volatility of FDI. Measured by the coefficient of variation of per capita inflows, volatility declined in some countries (e.g., Costa Rica, Ecuador, Jamaica) and increased for others (El Salvador and Guatemala).

In summary, although FDI inflows to most Latin American economies showed a common upward trend, there is also a considerable degree of cross-country diversity. Even within Central America some countries have attracted much more FDI than others. But a preliminary inspection of observed FDI trends does not provide much evidence of a generally negative change in FDI inflows to the neighboring countries of Central America and the Caribbean following NAFTA implementation. Of course, a more rigorous analysis might find otherwise. It is developed below in two stages. In the first stage we examine in detail the trends in FDI to Mexico and other countries, looking for significant divergences between them. Second, we assess the ability of standard FDI determinants to account for the observed pattern of FDI allocation across Latin American countries in the pre- and post-NAFTA periods.

\section{Assessing FDI Diversion from NAFTA}

There are no formal studies of the impact of NAFTA on FDI flows to nonmember countries, and few assessments of the effects of other regional integration agreements (RIAs) on the international allocation of FDI flows. This stands in sharp contrast to the growing body of empirical literature assessing the effects of RIAs on FDI flows to member countries.

The case of the European Economic Community/European Union (EEC/EU) has attracted a few empirical studies focusing specifically on investment diversion at various stages of the FTA-from its creation to the accession of Iberian countries in 1985, the Single Common Market of 1992, and the upcoming expansion of the EU to Eastern European countries (see box 8.1 for a selective summary). On the whole, they do not find compelling evidence of investment diversion. 


\section{Box 8.1 FDI Diversion in Europe}

The creation of the European Economic Community (1952); the EU accession of Portugal and Spain (agreed in 1986 and fully implemented in 1992); the creation of the Single Market (1992); and the ongoing EU eastern enlargement offer some insights on the changing pattern of FDI across Europe caused by economic integration. Although there is evidence that European integration led to substantial investment creation for EU member countries, particularly in the late 1980s (see chapter 5), empirical evidence of investment diversion away from non-EU-member countries is limited and less than conclusive. First, the surge of FDI in Europe coincided with a worldwide increase in FDI flows, making it hard to disentangle the impact of global trends from the impact of European integration. Second, as Brenton, DiMauro, and Luecke (1999) pointed out, the existing analytical literature on FDI provides few if any testable propositions on the effect of simultaneous trade and investment liberalization.

\section{EEC Creation}

Earlier studies of FDI patterns focused more on the determinants of FDI to Europe than on potential FDI diversion effects (Aristotelous and Fountas 1996). An exception is Scarperlanda (1967), who tested for a change in international investment patterns following the creation of the European Common Market and found no evidence of any shift in U.S. investment into the EU and away from non-EU nations.

\section{Single Market and EU accession of Portugal and Spain}

Baldwin, Forslid, and Haaland suggested that the creation of the Single Market in the EU "probably led to investment diversion in the economies of the European Free Trade Association (EFTA) and investment creation in the EU economies"-in particular, Portugal and Spain (1995). Some EFTA firms reportedly adjusted by becoming EU-based firms, which resulted in an outflow of FDI from EFTA countries to EU countries (Oxelheim 1994). However, using a gravity model of FDI flows, Brenton, DiMauro, and Luecke (1999) found no evidence that increased investment in Portugal and Spain during the 1980s came at the expense of reduced investment flows to other European countries (see first figure). In the same vein, Agarwal (1996) documented that growth rates of FDI inflows to Iberian countries and the rest of the EU (Box continues on the following page.) 


\section{Box 8.1 (continued)}

during 1986-90 were comparable to observed levels in 1980-95, and concluded that it is much more likely that Portugal and Spain benefited from the creation of additional FDI resulting from strong economic growth in the EU rather than from an investment diversion effect away from non-EU countries.

\section{EU Eastern Enlargement}

Central and Eastern European economies have become an increasingly important destination for FDI in recent years, raising the concern that investment previously destined for the relatively cheap labor markets of Southern Europe may have been diverted to Central and Eastern Europe as the preferential status of Iberian countries is diluted (see second figure). However, existing empirical studies do not find clear evidence in favor of this view (e.g., Brenton, DiMauro, and Luecke (1999). In fact, the stagnation

FDI Inflows to Portugal and Spain from EU Sources and Total FDI Outflows from the EU (Excluding Portugal and Spain)

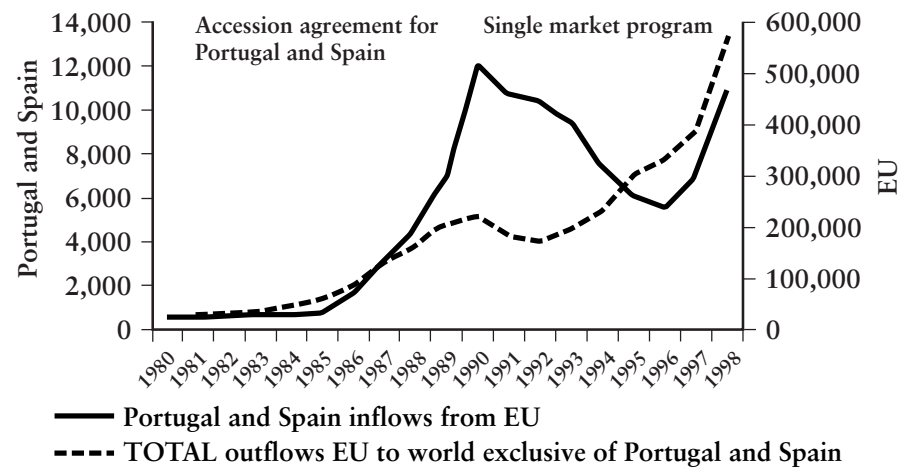

Note: Figures in US\$ million.

Source: Organisation for Economic Co-operation and Development. 
Box 8.1 (continued)

Share of World FDI Inflows by Host Region (percent)

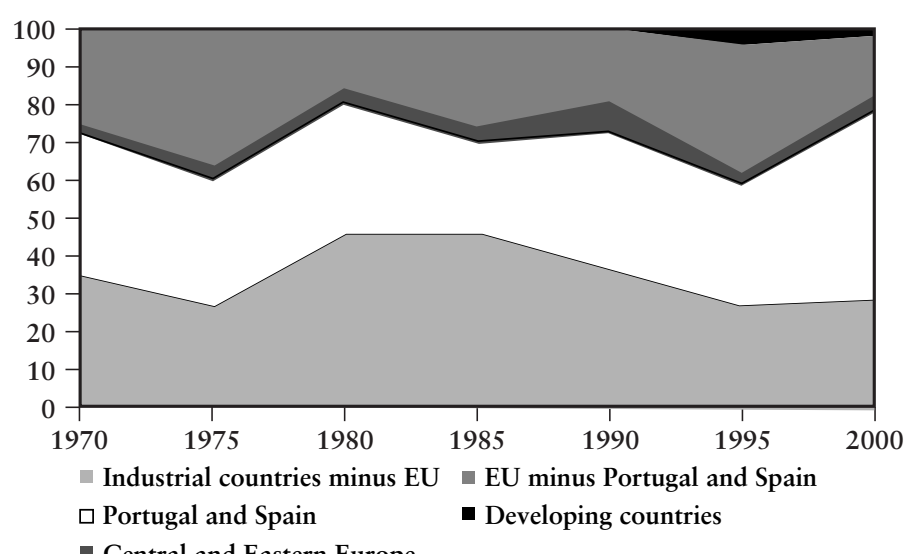

- Central and Eastern Europe

Source: United Nations Conference on Trade and Development.

or decline in FDI to Portugal and Spain in the late 1990s could just reflect the fact that FDI stocks in these countries have reached the equilibrium level (Buch, Kokta, and Piazolo (2001). Moreover, their FDI may be largely location-specific and thus unlikely to be strongly affected by Eastern enlargement (Martin and Gual 1994). The same argument has been offered to support the view that Eastern enlargement should have minimal effects on FDI to other developing regions. ${ }^{1}$ Furthermore, the expected positive impact on growth in Eastern Europe as a result of economic transformation and integration is likely to translate eventually into higher demand for products from developing countries, leading to an increase in FDI in these countries and to an overall investment creation (Agarwal 1996).

\section{Note}

1. The potential for FDI diversion is greatest in footloose labor and pollutionintensive segments of international production, which is internationally mobile. This part of FDI, however is generally considered relatively small. 
In a multi-RIA framework, an empirical study, Levy-Yeyati, Stein, and Daude (2002) found that RIAs divert investment originating in member countries from nonmember hosts. It is important to note that the possible diversion of FDI flows from nonmember source countries is not taken into account. This is a potential issue because, as table 8.1 showed, non-U.S. sources account for the majority of FDI across Latin America as well as for the majority of the increase in investment flows in recent years. ${ }^{13}$ Another caveat is that NAFTA is the only NorthSouth trade agreement in the study and, unlike the framework in chapter 7 that allows each FTA to be different, the basic framework of the study in question forces all FTAs to have the same effects on FDI allocation. There is some evidence to suggest that the investment impact of FTAs may be different, depending on whether they involve only North countries, only South countries, or both (see Blomström and Kokko 1997). ${ }^{14}$

In our analysis of the impact of FTAs on FDI in chapter 5 we attempted to identify the diversion of investment flows from both member and nonmember source countries, but found no significant effects. Like the preceding study, however, the implicit assumption was that NAFTA is not different from other RIAs. Also, both approaches share another restrictive feature, namely, the simplifying assumption that RIA-induced FDI diversion effects must be the same for all nonmember countries. As already argued, analytical considerations strongly suggest that FDI diversion should be more substantial for nonmember host countries that are closer substitutes for hosts belonging to the RIA under consideration. Admittedly, however, it is not easy to build an empirical framework that allows for varying degrees of substitutability among FDI hosts.

In view of these considerations, the analysis below follows a twostage approach. The objective is to assess if flows to Latin American and Caribbean countries excluded from NAFTA, and especially Central America and the Caribbean, show a different behavior than flows to Mexico before and after implementation of the agreement. To do this we first examined carefully the observed trends in FDI across the region. As shown in the previous section, most countries in the region experienced large increases in FDI inflows in the second part of the 1990s. Thus we used a simple descriptive procedure to isolate any differential behavior of nonmember countries vis-à-vis Mexico across the pre- and postNAFTA periods. The second stage of the analysis, presented in the next section, goes one step farther to explore the role of fundamental FDI determinants in the performance of FDI flows across the region. That step assesses the extent to which they can account for the changing foreign investment patterns across countries and over time. 


\section{Disentangling Common and Country-Specific FDI Trends Before and After NAFTA}

To disentangle country-specific FDI trends from common ones, we decomposed observed FDI flows from source country $i$ to host country $j$ in year $t$ as follows:

$\operatorname{FDI}(i, j, t)=$ source fixed effect $(i)+$ source/host pair fixed effect $(i, j)$ + common time effect $(t)+$ source time effect $(i, t)+$ host time effect $(j$, $t)+$ residual.

Such decomposition can be computed from a panel regression of FDI on sets of dummy variables, with each set defined so as to capture one of the components listed above. To identify the parameters of such regression, the conventional practice is to select a "base" country and year, dropping the corresponding dummies, in which case the coefficients on the remaining dummies can be interpreted as deviations from the omitted category. Therefore, they depend on the particular base chosen. Furthermore, the sets of dummies normalized in this manner are not mutually orthogonal, and so they cannot be strictly identified with the components in the above expression. For these reasons it is more convenient to normalize the sets of dummies by expressing each one in terms of deviations from their respective means (see box 8.2).

The decomposition can be implemented through a simple panel regression of FDI inflows including as explanatory variables several full sets of dummies, with each set capturing one of the components above, and with the coefficients on each set of dummies constrained to add up to zero. In this way, for example, the (normalized) common year effect estimates then capture annual deviations from the average flow of FDI during the sample period. This poses a restricted least-squares problem in which inference can be performed along the lines of Greene (1991).

Of particular interest in this context are the source/host fixed effects and the host time effects. The former measure represents the difference between the average annual FDI flow received by a given host from a given source relative to the average flow from the same host to the average country in the sample. This can be viewed as reflecting the relative geographic, historic, and political proximity of each host country to the source country under consideration. ${ }^{15}$

In turn, the host time effects represent for each host the deviation of its FDI inflow in each year from the common trend (i.e., the cross-country average for the year), as well as the deviation from the host country's typical performance (i.e., the average annual inflow it received over the sample). In effect, this removes from the host's annual inflow both the common trend and the unobservable factors that may make that host systematically more or less appealing than others to foreign investors. 


\section{Box 8.2 Disentangling Common and Idiosyncratic FDI Trends}

Assume we have observations on FDI flows from $i=1,2, \ldots, I$ source countries to a sample of $n=1,2, \ldots, N$ host countries over periods $t=$ $1, \ldots, T$. Let $f(i, n, t)$ denote FDI flows from country $i$ to country $n$ in year $t$. We can decompose $f(i, n, t)$ into

$$
f(i, n, t)=h(i)+b(t)+m(i, n)+f(i, t)+g(n, t)+u(i, n, t)
$$

where $h(i)$ is a fixed source country effect, $b(t)$ is a year effect that affects all source and host countries, $m(i, n)$ is a fixed source/host country effect, $f(i, t)$ is a fixed effect specific to source country $i$, and $g(n, t)$ is a year effect specific to a host country $n$. The term $u(i, n, t)$ is simply the residual of the series when these effects have been accounted for.

This model is still unidentified, and the conventional solution is to use a country/year as the base. The main problem with this strategy is that the right-hand side variables are not mutually orthogonal. Moreover, the numerical results depend on the choice of base country/year. It is therefore preferable to use a different set of identification assumptions, namely ones expressing the various effects as deviations from their respective means. This amounts to imposing the following six conditions:

$$
\begin{gathered}
\sum_{n=1}^{N} m(i, n)=0, i=1, \ldots, I ; \quad \sum_{t=1}^{T} b(t)=0, t=1, \ldots, T ; \\
\sum_{i=1}^{I} f(i, t)=0, t=1, \ldots, T \\
\sum_{t=1}^{T} f(i, t)=0, i=1, \ldots, I ; \quad \sum_{t=1}^{T} g(n, t)=0, n=1, \ldots, N ; \\
\sum_{n=1}^{N} g(n, t)=0, t=1, \ldots, T .
\end{gathered}
$$

These conditions make the right-hand side variables in the above equation mutually orthogonal. It is convenient to discuss their interpretation further. First, $h(i)$ indicates the relative importance of source country $i$ for the average host country in the sample during the sample period. For example, these estimates can be useful to assess the relevance of the U.S. economy as a source of FDI to the region. In turn, the estimates of $m(i, n)$ represent the permanent deviation of country $n$ with respect to the flows of FDI from country $i$ to the average country in the group. This controls for permanent differences across countries and can capture the ef- 


\section{Box 8.2 (continued)}

fects of geographic, historical, and political proximity of each of the $n$ countries to the particular source country $i{ }^{1}$

The second condition redefines the year effects $b(t)$ as deviations from the average flow of FDI to the average country in the group during the sample period. This normalization plays an important role below, as FDI shows a rising trend in most countries. By including these year effects we are able to separate the common factors behind the generalized increase in FDI flows to all the host countries in the region from those specific factors that favored a subset of countries with respect to others, which is our main interest.

The third and fourth equations normalize the source/year effects $f(i, t)$ in such a way that for each year they represent deviations across source countries with respect to the mean time effect $(b(t))$, and for each source country represent year deviations from its average $h(i)$. Finally, the fifth and sixth equations have a very similar interpretation. Thus, $g(n, t)$ are host country year effects that represent, for each year $t$, the deviation of host country $n$ with respect to the mean year effect $(b(t))$. For each host country $n$, they represent year deviations from its average flow.

This simple statistical decomposition can be very useful to ascertain which countries have done best and worst under NAFTA. Specifically, to examine whether under NAFTA Mexico has outperformed the other countries in the region, we can compare the estimated year effects for Mexico $g($ Mexico, $t)$ with those of other countries $g($ excluded, $t)$. These host/year effects indicate positive or negative deviations of the respective host country with regard to the rest of the group in the year in question, as well as deviations of the host country with regard to its average over time. If NAFTA has implied a relative advantage for Mexico, its time effects should be negative prior to NAFTA and positive afterward. Furthermore, the pattern of these time effects tells us whether such advantage narrows or widens over time. Likewise, the sum over time of the year effects of a given host provides an indication of the cumulative post-NAFTA performance of FDI flows to that host. As an example, for Mexico we would compute

$$
\sum_{t \geq 1994} g(\text { Mexico, } t)
$$

Note

1. Note that this represents a more general way of controlling for distance and other time-invariant characteristics of countries than do the parametric measures commonly employed in gravity models. Indeed, in our context finding informative measures of "closeness" to trading partners for individual Central American countries could be problematic, given their geographic proximity and small size. 
To examine if under NAFTA Mexico has outperformed the other countries in the region, one can compare the estimated host year effects for Mexico with those of other excluded countries. If NAFTA has implied a relevant advantage for Mexico, we must find that its time effects are negative prior to NAFTA and positive afterward. Furthermore, the pattern of these time effects tells us whether such advantage narrows or widens over time. Likewise, the sum over the post-NAFTA years of the time effects of a given host provides an indication of the cumulative post-NAFTA performance of FDI flows to that host, which can help detect stock adjustments triggered by NAFTA. ${ }^{16}$

Finally, the estimated host/year effects of the excluded countries, especially in Central America, are also of direct interest. They provide a measure of how much each respective country deviated from the average FDI performance of the overall sample in the year in question, as well as how much the year in question deviated from the average FDI performance of the country under consideration. If FDI to excluded countries was diverted by NAFTA, they should show negative host/year effects after 1993 .

\section{Empirical Results}

This framework is used to compare Mexico with two different groups of countries. The first group includes only the Central American and Caribbean countries listed earlier. The second group adds the main South American economies. As before, the exercise is performed for two different measures of FDI: annual net inflows of FDI in 1995 U.S. dollars per inhabitant of the host country (FDI pc), and net inflows of FDI relative to the GDP of the host economy (FDI/GDP). ${ }^{17}$

Table 8.2 reports the estimated fixed effects for source countries and source-host country pairs for both country groups and both measures of FDI. There are several salient results in the table. The first concerns the relative importance of U.S. and non-U.S. FDI sources. For the sample considered here, the latter are on average more important than the former. Second, U.S.-based investors play a more prominent role in Central America than in South America. Finally, there is a large degree of heterogeneity across countries, even within Central and South American groups. We next discuss each of these points in more detail.

The estimated source country fixed effects at the top of the table show that over the sample period as a whole the United States was, on average, a less important source of FDI than all other source countries combined. On average the United States invested US\$15 (in 1995 dollars) per person in each country in the group studied. This is less than half the US\$35 invested by all other sources combined. However, the difference narrows if we look only at Central American and Caribbean countries, where the respective figures are US\$17 and US\$24. The same 


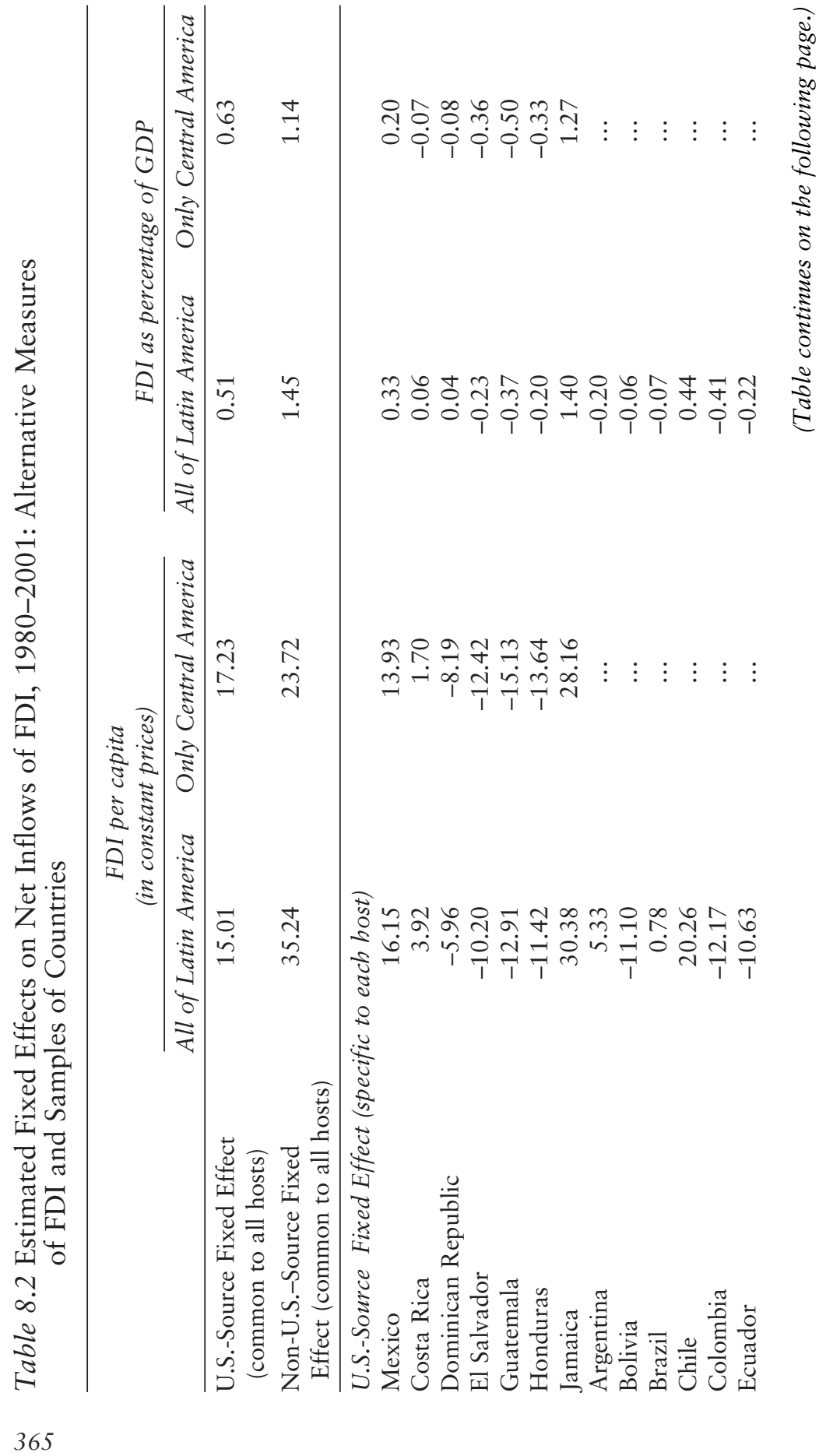




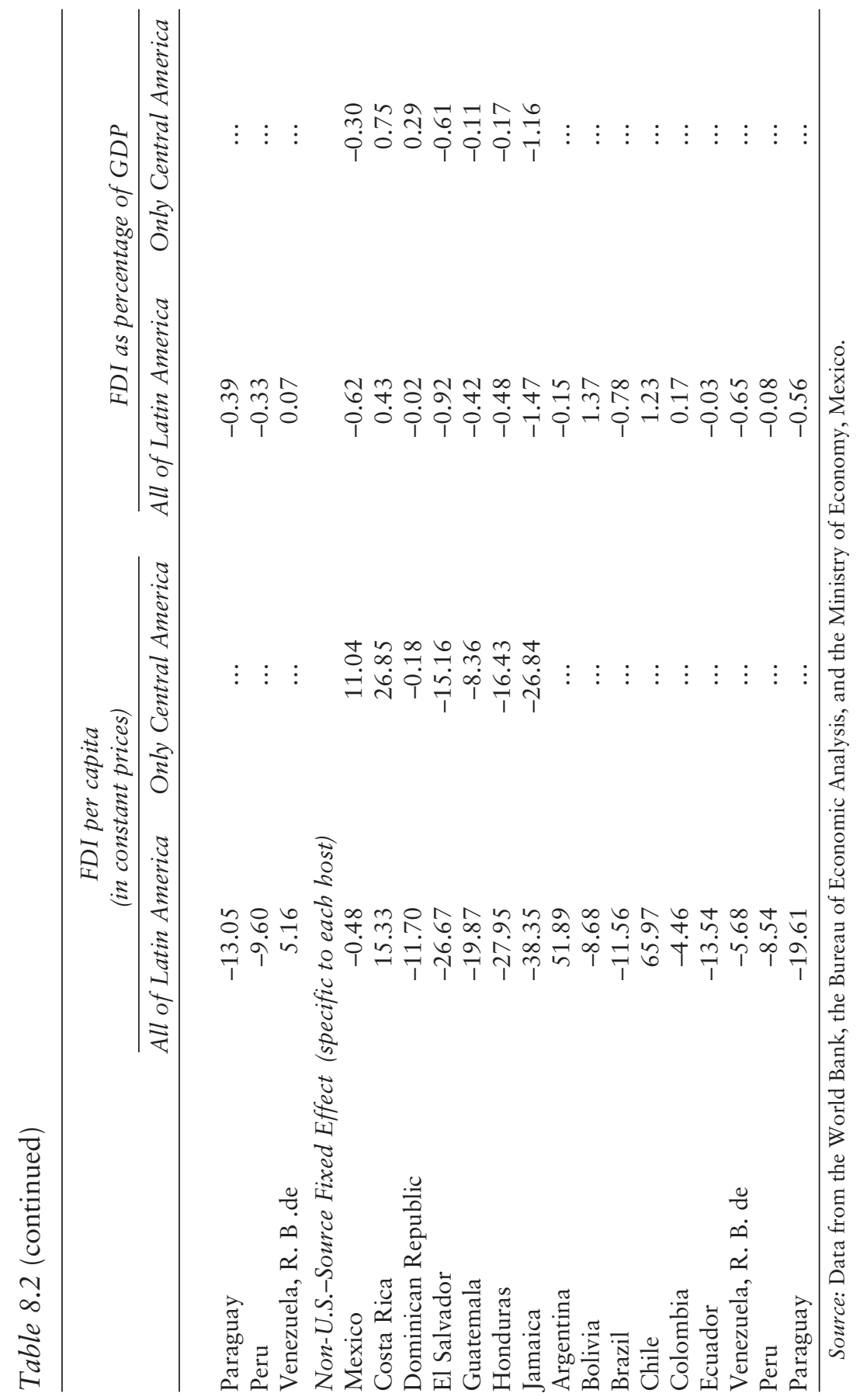


qualitative results hold for FDI-to-GDP ratios from the United States and other sources.

There is a great degree of heterogeneity across host countries, not only in terms of their total attraction of FDI but also in terms of the importance of the two sources. This is captured by the U.S.-host country and non-U.S.-host country pair effects reported in the table. All these effects must add up to zero and indicate how the host countries are ranked in terms of attracting FDI from each source. For example, Chile and Jamaica receive much more FDI from the United States than the other countries-specifically, US\$30 and US\$20 more per capita (in 1995 dollars) than the average of all Latin American countries. Mexico lags Jamaica and is on par with Chile in terms of U.S. inflows. In contrast, Colombia, Guatemala, and Paraguay received around \$12-13 less per capita than the average. Finally, countries receiving above-average FDI from the United States also received more often than not above-average FDI from other sources- that is, the two source/host effects of each host tend to have the same sign. There are exceptions, however, such as Jamaica, which is well above the average for U.S. investors but well below the average for the rest.

These fixed effects reflect each country's average FDI patterns over the whole sample period before and after NAFTA. To assess the changes in FDI trends over time for the various host countries in Latin America and the Caribbean region, we can inspect the estimated host/year-specific effects that capture the extent to which each host deviates from its average behavior and from the average behavior of the sample as a whole in a given year. Thus, to see if Mexico behaves differently from the rest of the sample in the post-NAFTA period it is sufficient to inspect the estimated host/year effects of Mexico. They are shown in table 8.3 for both country groups and both measures of FDI.

A permanent, positive impact of NAFTA on Mexico's ability to attract FDI should be reflected in positive estimates from 1994 onward. Given the normalizations imposed, looking at those estimates suffices to compare Mexico before and after NAFTA, and Mexico vs. the countries excluded from NAFTA. ${ }^{18}$ The table shows that for the first few years after NAFTA Mexico does perform above its own past as well as the rest of the sample. This result holds for all measures and country samples. In all those cases, when the sample of all Latin American countries is used, Mexico exhibits a positive effect in the first two years, 1994 and 1995. When only Central American countries are used, the positive effect holds for the first four years.

Furthermore, when using FDI per capita, the largest effect occurs initially (1994) and then declines. The estimates indicate that in the first year Mexico received US\$41 per capita in FDI above the Latin American average, or US $\$ 47$ relative to Central America and the Caribbean. The 
Table 8.3 Estimated Mexico/Year Effects on Net Inflows of FDI (Including FDI from Privatization): Alternative Measures of FDI and Samples of Countries

\begin{tabular}{|c|c|c|c|c|}
\hline \multirow[b]{2}{*}{ Year } & \multicolumn{2}{|c|}{$\begin{array}{l}\text { FDI per capita } \\
\text { (in U.S. dollars) }\end{array}$} & \multicolumn{2}{|c|}{$\begin{array}{c}F D I / G D P \\
(\%)\end{array}$} \\
\hline & $\begin{array}{c}\text { All of Latin } \\
\text { America }\end{array}$ & $\begin{array}{c}\text { Only Central } \\
\text { America }\end{array}$ & $\begin{array}{c}\text { All of Latin } \\
\text { America }\end{array}$ & $\begin{array}{c}\text { Only Central } \\
\text { America }\end{array}$ \\
\hline 1980 & 7.75 & -4.32 & 0.33 & 0.13 \\
\hline 1981 & 22.51 & 16.53 & 0.34 & 0.38 \\
\hline 1982 & 0.31 & -2.35 & 0.58 & 0.63 \\
\hline 1983 & 7.65 & -3.77 & 0.99 & 0.67 \\
\hline 1984 & -6.15 & -18.88 & 0.48 & 0.14 \\
\hline 1985 & -3.33 & -11.74 & 0.50 & 0.36 \\
\hline 1986 & -2.31 & -12.64 & 0.99 & 0.71 \\
\hline 1987 & -24.28 & -35.46 & -0.14 & -0.53 \\
\hline 1988 & -16.60 & -26.34 & 0.03 & -0.53 \\
\hline 1989 & -7.79 & -15.51 & 0.22 & -0.05 \\
\hline 1990 & -16.11 & -27.90 & -0.15 & -0.64 \\
\hline 1991 & 1.66 & -6.01 & 0.11 & -0.29 \\
\hline 1992 & -7.88 & -14.36 & -0.21 & -0.59 \\
\hline 1993 & -7.15 & -12.75 & -0.28 & -0.30 \\
\hline 1994 & 41.51 & 46.86 & 0.50 & 0.91 \\
\hline 1995 & 15.93 & 21.73 & 1.12 & 1.23 \\
\hline 1996 & -11.73 & 16.37 & 0.03 & 0.92 \\
\hline 1997 & -2.79 & 38.05 & -0.25 & 0.94 \\
\hline 1998 & -28.21 & -22.02 & -1.64 & -1.65 \\
\hline 1999 & -57.64 & -13.40 & -2.33 & -1.47 \\
\hline 2000 & 7.75 & 17.23 & -1.12 & -0.83 \\
\hline 2001 & 86.90 & 70.68 & -0.11 & -0.15 \\
\hline sum 1994-2001 & $1 \quad 51.72$ & 175.50 & -3.80 & -0.09 \\
\hline
\end{tabular}

Note: Figures shown in bold are statistically significant at the 10 percent level or better. Source: Authors' calculations.

differences fall to US\$16 and US\$22, respectively, in the following year. In contrast, when we look at FDI/GDP the response is hump-shaped, with the positive effect peaking in the second year. The different time pattern very likely results from the impact of the 1995 Mexican devaluation and recession, which artificially raises the FDI/GDP ratio in that year. In either case, the Mexico/year effects eventually decline, becoming negative by 1996 or 1998 depending on the specific measure and sample used. Finally, in 2000 and, especially, 2001 the effects turn positive again.

The fact that the Mexico/year effects rise at first and then turn negative is in agreement with the results reported in chapter 5, where we found that in 1994-95 FDI to Mexico exceeded the values predicted by 
an econometric model of FDI estimated on a large sample of countries. After 1995, FDI inflows fell increasingly short of the model's predictions. In turn, the jump in the estimated Mexico effect in 2001 is dominated by one single transaction (the sale of Banamex), which amounted to US\$108 per capita (or more than 2 percent of GDP).

Did Mexico acquire a permanent advantage as FDI host in the postNAFTA years? The bottom of table 8.3 shows the cumulative effects for Mexico over the entire post-NAFTA period. They are positive when performance is measured by per capita FDI inflows, although the estimate is significant only when using the Central American sample and is largely dominated by the spike observed in 2001. Indeed, if we stopped the econometric exercise in 2000 rather than 2001, the cumulative effect vis-à-vis Latin America would turn negative and that against Central America would remain positive but insignificant. Admittedly it is not clear that the large one-time Banamex sale in 2001 that is largely responsible for this result can be viewed as a result of NAFTA. In contrast, when using FDI as a percentage of GDP as the preferred indicator, the cumulative effect is negative but insignificant, even taking into account the Banamex transaction.

Are these results distorted by the differential timing and volume of privatization-related FDI in Mexico and elsewhere? Over the 1990s the sale of public enterprise assets attracted large volumes of FDI in a number of South American economies (Argentina, Brazil, Bolivia) and, more recently, Central American economies (most notably El Salvador). As already pointed out in chapter 5, Mexico's privatization program was, in comparison, fairly modest. Because privatization-related transactions are included in total FDI flows, the differential effects of NAFTA on FDI to Mexico and other Latin American countries could be masked by the large volume of those transactions in other countries in the region vis-àvis those received by Mexico.

Table 8.4 reports the Mexico/year effects that result from re-estimating the model using FDI net of privatization-related inflows as the dependent variable. The exercise only covers the period up to 1999 , given the lack of comprehensive privatization data after that date. ${ }^{19}$ Qualitatively, the pattern of the estimates is not very different from the previous one. ${ }^{20}$ They are positive in the initial years of the post-NAFTA period, peaking in 1994 when measuring FDI in per capita terms and in 1995 when measuring it as a ratio to GDP. Thereafter, they follow a declining pattern and turn negative at the end of the sample. However, these negative values are smaller in magnitude than those shown in table 8.3. As a result, the cumulative effect over 1994-99 vis-à-vis the Central American sample becomes positive also when measuring FDI as a percentage of GDP. As in the previous table, however, the effect is significant only when measuring FDI in per capita terms. 
Table 8.4 Estimated Mexico/Year Effects on Net Inflows of FDI (Excluding Privatization): Alternative Measures of FDI and Samples of Countries

\begin{tabular}{|c|c|c|c|c|}
\hline \multirow[b]{2}{*}{ Year } & \multicolumn{2}{|c|}{$\begin{array}{l}\text { FDI per capita } \\
\text { (in U.S. dollars) }\end{array}$} & \multicolumn{2}{|c|}{$\begin{array}{l}F D I / G D P \\
(\%)\end{array}$} \\
\hline & $\begin{array}{c}\text { All of Latin } \\
\text { America }\end{array}$ & $\begin{array}{c}\text { Only Central } \\
\text { America }\end{array}$ & $\begin{array}{c}\text { All of Latin } \\
\text { America }\end{array}$ & $\begin{array}{c}\text { Only Central } \\
\text { America }\end{array}$ \\
\hline 1980 & 8.55 & 0.55 & 0.10 & 0.04 \\
\hline 1981 & 23.31 & 21.41 & 0.10 & 0.29 \\
\hline 1982 & 1.11 & 2.53 & 0.34 & 0.54 \\
\hline 1983 & 8.45 & 1.10 & 0.75 & 0.58 \\
\hline 1984 & -5.36 & -14.00 & 0.25 & 0.05 \\
\hline 1985 & -2.53 & -6.87 & 0.27 & 0.27 \\
\hline 1986 & -1.51 & -7.77 & 0.75 & 0.62 \\
\hline 1987 & -23.48 & -30.58 & -0.38 & -0.62 \\
\hline 1988 & -15.75 & -21.46 & -0.21 & -0.62 \\
\hline 1989 & -6.40 & -10.64 & 0.00 & -0.14 \\
\hline 1990 & -36.99 & -44.64 & -0.96 & -1.31 \\
\hline 1991 & 9.68 & -1.14 & 0.11 & -0.38 \\
\hline 1992 & -7.23 & -12.72 & -0.44 & -0.75 \\
\hline 1993 & -3.53 & -7.87 & -0.47 & -0.39 \\
\hline 1994 & 54.64 & 51.73 & 0.78 & 0.82 \\
\hline 1995 & 26.91 & 26.61 & 1.66 & 1.14 \\
\hline 1996 & -4.81 & 20.35 & -0.01 & 0.81 \\
\hline 1997 & -6.17 & 24.73 & 0.00 & 0.41 \\
\hline 1998 & 5.69 & 8.96 & -0.83 & -0.30 \\
\hline 1999 & -24.59 & -0.27 & -1.82 & -1.04 \\
\hline sum 1994-1999 & $9 \quad 51.67$ & 132.10 & -0.21 & 1.83 \\
\hline
\end{tabular}

Note: Figures shown in italics are statistically significant at the 10 percent level or better. Source: Authors' calculations.

Thus, ignoring privatization-related FDI does not alter the previous conclusions. The data continue to point toward an initial boom in FDI inflows to Mexico in 1994-95 (or 1994-97, depending on the country sample used) relative to the inflows to the other countries, followed by a slump at the end of the 1990s.

So far we have focused on the estimated year effects for Mexico. However, they only capture differences between Mexico and the (average of) the entire group of countries considered. To assess the performance of other countries of specific interest-namely, those in Central America and the Caribbean-we can compare their respective year effects with those of Mexico. Such comparison yields interesting information on how those countries have fared relative to Mexico (as well as their own past) after NAFTA. 


\section{Figure 8.2 Real FDI Per Capita and FDI/GDP Estimated Country/Year Effects, 1980-2001}
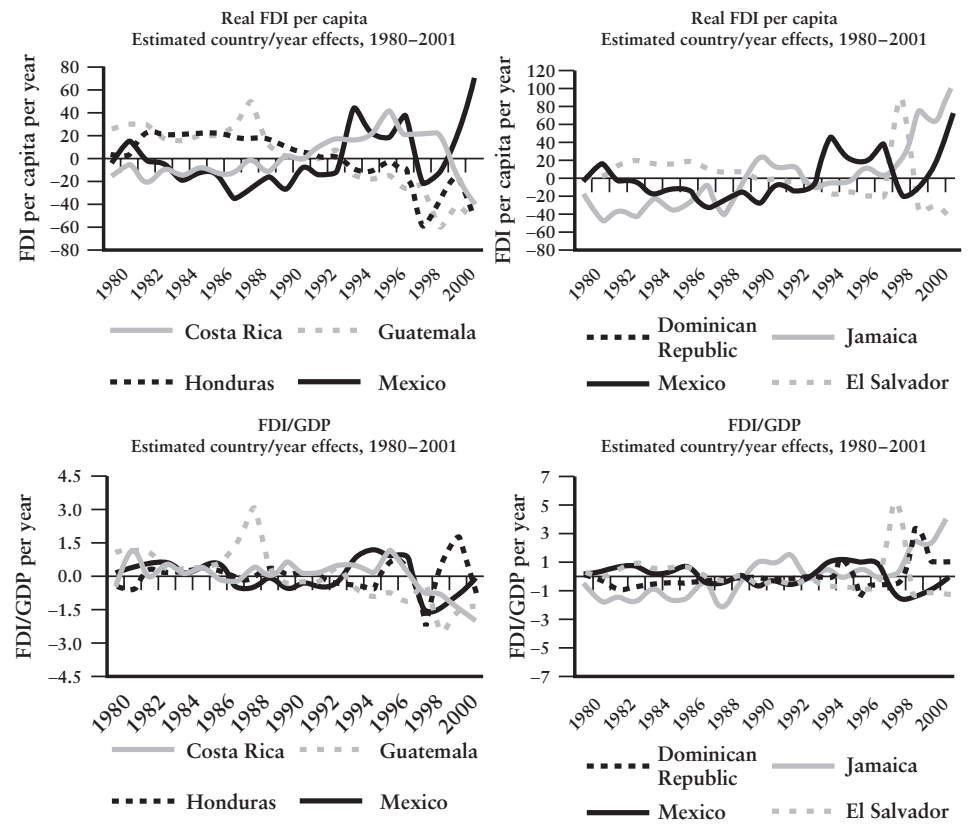

Source: Authors' calculations.

Figures 8.2 and 8.3 depict the country/year effects of Mexico, the Caribbean region, and Central America, along with their 10 percent significance bands, for the two measures of FDI employed. Figure 8.2 corresponds to the estimates based on total FDI inflows, and figure 8.3 reflects those based on FDI inflows net of privatization. In both cases, the estimates correspond to the sample excluding South America.

The top half of figure 8.2 presents the results using real per capita FDI. Between 1994 and 1997 Mexico's year effects consistently exceed those of all other countries, with Costa Rica the only exception. Over the rest of the 1990s, however, Costa Rica and Jamaica outperform Mexico in most years. These two countries exhibit positive time effects virtually throughout the 1990s. The graphs also show a clear spike in FDI to El Salvador in 1998, which reflects large privatization-related inflows in that year, and in Mexico in 2001 when using FDI per capita as the preferred measure. The bottom performers appear to be Guatemala and Honduras, with 


\section{Figure 8.3 Real FDI Per Capita and FDI/GDP Estimated Country/Year Effects, Net of Privatizations, 1980-99}
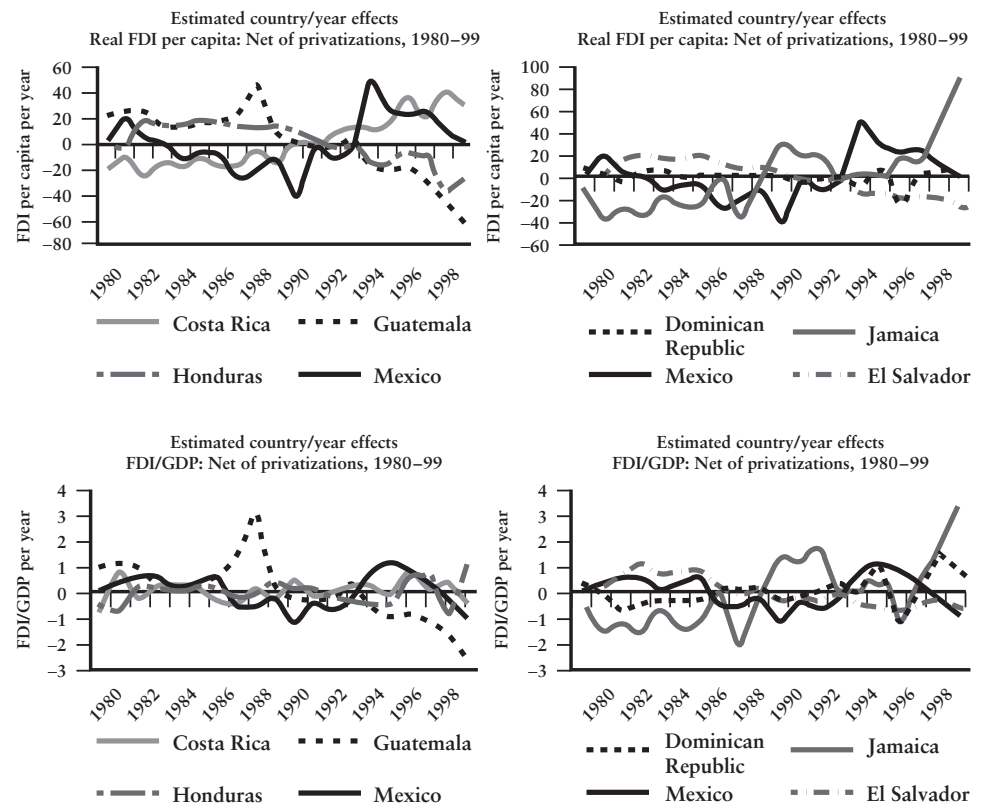

Source: Authors' calculations.

negative country-year effects during most of the 1990s when using per capita FDI. The information in terms of ratios to GDP, shown in the bottom half of the table, is qualitatively similar, although with this measure the performance of Honduras appears considerably stronger.

Figure 8.3 turns to the data net of privatization FDI. The sample period now ends in 1999 and the main difference is the removal of the outlying observation for El Salvador mentioned earlier. Costa Rica and Jamaica appear to emerge as performers on par with Mexico in the postNAFTA period, whereas Guatemala remains the principal underperformer over the 1990s.

We can also inspect the country/year effects in search of co-movement among countries' idiosyncratic FDI trends, as given by the correlation between their respective year effects. Specifically, a negative correlation between the effects of Mexico and those of another country-implying 
that years of unusually high FDI into the former are also years of unusually low FDI into the latter-could provide a hint that they are substitutes as FDI hosts. However, it is important to recall that the effects are constrained to sum to zero across all countries for any given year, and hence their correlation is by construction biased toward -1 . To minimize this distortion it is convenient to work with the broader sample (covering all of Latin America and the Caribbean). Furthermore, we use the per capita information to prevent the correlations from being distorted by movements in real exchange rates and output, which likely are highly correlated across countries.

With those caveats, table 8.5 presents the correlation matrix of the country/year effects. Because the large spike in privatization-related FDI to El Salvador noted earlier tends to distort the correlations, we focus on the lower part of the matrix, which corresponds to the data net of privatization FDI. Even with the short time span of data available (which places the standard error of each correlation at 0.22) several significant correlations emerge. Most notably, El Salvador, Guatemala, Honduras, and, to a lesser extent, the Dominican Republic show significant positive pairwise correlations, of 0.80 or higher in each case. In contrast, the effects of the first three of these countries are negatively correlated with those of Costa Rica and, to a lesser extent, Jamaica. The latter two countries also show a positive correlation. As for Mexico, its effects are not significantly correlated with those of any other country in the table.

What can we infer from these results? They suggest the existence of a block of Central American countries sharing similar FDI trends-El Salvador, Guatemala, and Honduras. This may reflect a common pattern of specialization, FDI incentives, or both. There is also some evidence of a second bloc, consisting of Costa Rica and Jamaica. Finally, there is very little suggestion of FDI reallocation from any of the countries shown toward Mexico, given the lack of any significant correlation between the time effects of Mexico and those of the other countries.

Which countries overperformed and which underperformed-relative to the rest as well as to their own history-in terms of FDI inflows in the post-NAFTA years? Figure 8.4 addresses this question. For each country it shows the cumulative country/year effects derived from the Latin America and Caribbean regionwide sample, for both measures of FDI employed, along with the corresponding 10 percent significance bands. Panel (a) uses total FDI over 1980-2001, and panel (b) uses FDI net of privatization transactions over 1980-99.

On the whole, Chile was the clear FDI leader in the post-NAFTA period. The main underperformer was Guatemala, regardless of whether privatization transactions are included. For the other countries, the rankings depend on the specific measure of FDI chosen. If we take per capita FDI as the preferred measure, Argentina fared significantly better 


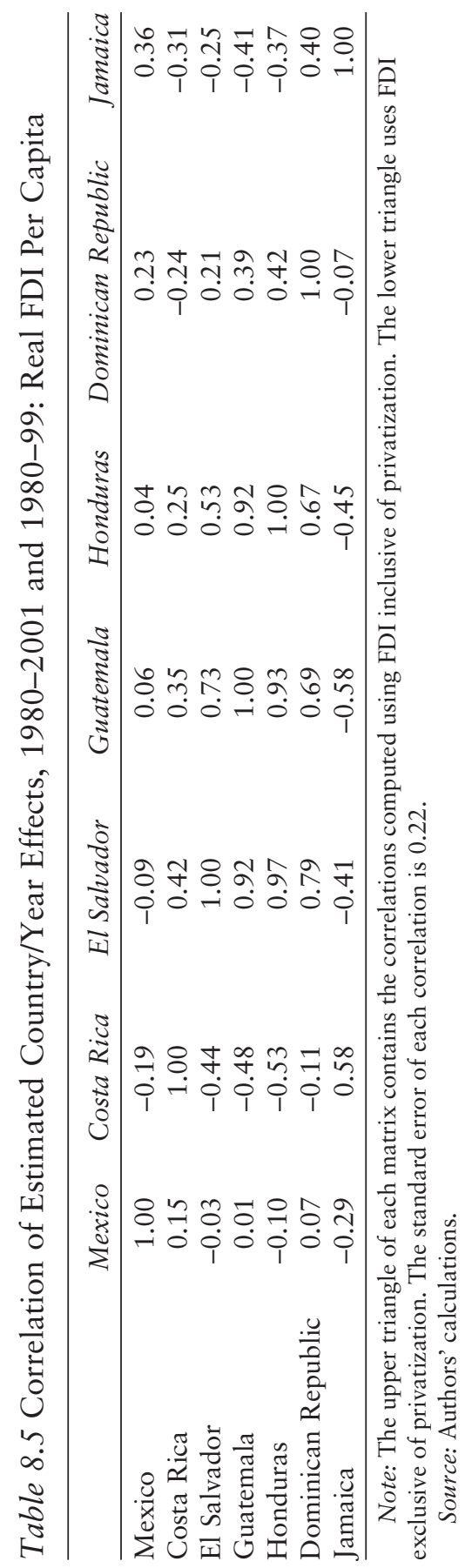


Figure 8.4 Cumulative Country/Year Effects and Their 10 Percent Significance Bands

(a) FDI inflows including privatization, 1994-2001

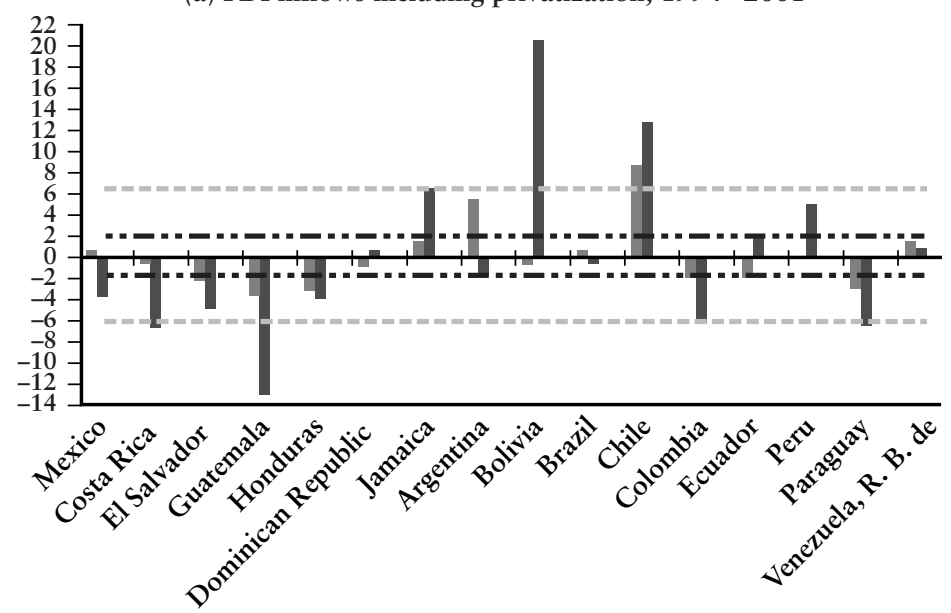

- Real FDI per capita $\times 10$ E-2

- FDI/GDP

.. - 10 percent bands

$=-=-10$ percent bands

(b) FDI inflows excluding privatization, 1994-1999

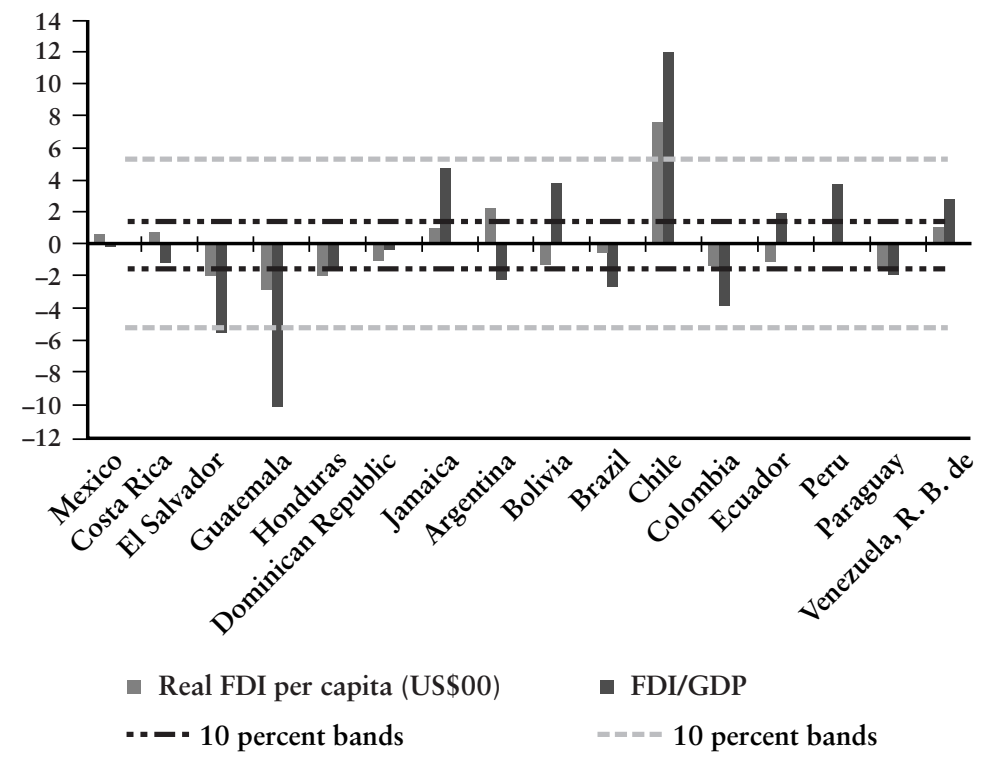

Source: Authors' calculations. 
than average, whereas Bolivia and Peru did quite well in terms of FDI relative to GDP. As for Mexico, its performance was roughly on par with the average, especially if privatization transactions are excluded. Relative to NAFTA's neighbors, Mexico did better than El Salvador and Guatemala, worse than Jamaica, and roughly on par with Costa Rica and the Dominican Republic.

To conclude this section we note that on the whole FDI trends do not provide strong indication that flows were diverted from other Latin American countries toward Mexico in the post-NAFTA years. Regarding Mexico, the evidence reviewed here is in broad agreement with that shown in chapter 5 . We found an increase in FDI inflows to Mexico in the early years of NAFTA, after controlling for common trends and the country's past FDI record. The rise tapers off at the end of the 1990s, which would be consistent with an FDI stock adjustment, a pattern similar to that encountered in Southern Europe at the time of EU enlargement. Over the post-NAFTA period as a whole, we also found that Mexico's FDI performance was not much different from the Latin American norm. Other Latin American countries experienced comparable or larger FDI rises, even if privatization-related flows are ignored.

As for NAFTA's neighboring countries, on average they did less well than Mexico in the post-NAFTA years, although the difference is only significant when measuring FDI in real per capita terms. However, their individual FDI trends were quite diverse. If we take the privatization-exclusive FDI measures as our preferred yardstick, El Salvador and Guatemala performed significantly worse than the Latin American norm according to the measures reported, whereas Costa Rica did no differently from the average, and the Dominican Republic and Jamaica actually did better. This diversity in FDI performance among NAFTA's neighboring countries-even though they all faced a common "NAFTA shock" - suggests that country-specific factors other than (or in addition to) FDI diversion from the FTA were at work. This issue is explored next.

\section{A Broader View of FDI Determinants in Central America and the Caribbean}

We now move beyond the descriptive analysis, first reviewing some nonFTA determinants of foreign investment of particular relevance for NAFTA's neighbors, and then placing the impact of NAFTA in a broader context of FDI determination.

\section{Trade Patterns and FDI Incentives in Central America}

One potential factor behind the dissimilar FDI trends across Central American countries is the divergence in their respective patterns of 
specialization over the past decade. As already noted in the preceding chapter, Guatemala, along with El Salvador and Honduras, increasingly tilted the composition of exports toward apparel, whereas Costa Rica did the opposite and Jamaica experienced no significant change in this regard. NAFTA granted Mexico a substantial tariff advantage in the apparel sector over the rest of the region, although the advantage was largely temporary, as the recent realignment of U.S. import preferences in the Caribbean Basin Trade Partnership Act (CBTPA) moved Caribbean Basin countries closer to tariff parity with Mexico.

Did this preferential treatment of Mexico's apparel sector significantly discourage FDI inflows to the neighboring countries, as argued by some observers? There are numerous indications but little hard data that the apparel industry has been a major recipient of FDI in these economies (e.g., ECLAC 2000). ${ }^{21}$ Thus, it is possible that the passage of NAFTA might have encouraged the redirection of further investment in the apparel sector to Mexico. However, it is very difficult to establish the order of magnitude of such an effect, given the lack of adequate data. ${ }^{22}$ Furthermore, it is hard to disentangle the effects that NAFTA might have had in this regard from those of the Mexican devaluation of 1994, which resulted in a sharp increase in the wages of neighboring countries relative to those in Mexico. Relative wage costs have been found to play a major role in the location decisions of export-oriented multinational firms across Central America and the Caribbean (Woodward and Rolfe 1993), and they are particularly relevant for textile and apparel firms, given the large weight of wages in total production cost. In any case, the fact (shown in chapter 7) that the share of exports from these countries in NAFTA's apparel market actually rose in the post-NAFTA years suggests either that FDI diversion effects associated with the apparel sector were relatively minor or that they were offset by other investment-attracting measures, such as those related to the EPZs discussed below.

In contrast with the pattern followed by El Salvador, Guatemala, and Honduras, Costa Rica actively pursued the strategy of diversifying FDI away from traditional sectors. Large volumes of FDI into Costa Rica went to the production of electric and electronic equipment, including computer components and software. ${ }^{23}$ In recent years significant amounts of investment have gone also to services, tourism, and medical supplies (Robles-Cordero and Rodríguez-Clare 2003). The most celebrated case is that of Intel, which is reviewed in detail in box 8.3. Costa Rica's ability to attract significant FDI into these nontraditional sectors has probably been a major factor in its solid aggregate FDI performance during the post-NAFTA years.

Aside from the sector destination of FDI, Central American and Caribbean countries have made extensive use of tax incentives to attract foreign investors. Such incentives are linked to the EPZs instituted by most countries. ${ }^{24}$ There is remarkable homogeneity in incentives across 


\section{Box 8.3 Costa Rica vs. Mexico in the INTEL Race}

Intel's 1997 choice of Costa Rica to locate a large production plant400,000 square feet, employing up to 2,000 people to assemble and test the latest microprocessors-illustrates the factors that affect the quantity and composition of FDI. First, it shows the region's potential to attract foreign investment into sectors that previously had been beyond its reach. However, it also highlights barriers to foreign investment that need to be removed. Finally, it shows that membership in a RIA with the source country and target market may be a relevant factor but not a determinant one.

Costa Rica was included in Intel's preliminary list of potential investment sites largely because of the active efforts of the Coalición Costarricense de Iniciativas para el Desarrollo (CINDE), which since the late 1980s had switched its FDI-attracting strategy from generally promoting the country to targeting specific groups of potential investors. At first it (successfully) targeted textile producers but later, when the country's wages and labor benefits put it in no position to compete with cheap-labor economies, CINDE switched its sites to electronics, and among other large companies it approached Intel as early as 1993 (Spar 1998). Costa Rica's political stability, geographic advantage, and the quality of its labor force earned it a spot on Intel's initial list, which included Argentina, Brazil, Chile, China, India, Indonesia, the Republic of Korea, Mexico, Puerto Rico, Singapore, Taiwan (China), and Thailand.

Next in the selection procedure, countries were dropped from the list if they failed to offer workable conditions regarding wages, labor benefits, taxes, tariffs, and regulations for capital repatriation. As all output was intended for export, tariffs and customs fees were particularly important. On the basis of these criteria, the list was first narrowed to Brazil, Chile, Costa Rica, and Mexico. By mid-1996 the list had narrowed further to only two contenders, Costa Rica and Mexico. By the end of 1996 Intel announced its decision to build the plant in Costa Rica, and construction began in April 1997.

In retrospect, the studies by Spar (1998) and Larraín B, Lopez-Calva, and Rodríguez-Clare (2000) suggest that three main factors led to the selection of Costa Rica over Mexico. First, Costa Rican authorities responded promptly to Intel's concerns, which involved the inadequacies of the country's physical and educational infrastructures. Regarding education, although human capital indicators in Costa Rica outdid those of Mexico, they were not sufficient to support Intel's personnel needs. On infrastructure the main problem was in the transportation sector. The capacity and frequency of flights to and from the main airport were deemed inadequate, as was highway access from the plant's prospective location. Furthermore, the high cost of electricity was an additional concern. 


\section{Box 8.3 (continued)}

The Costa Rican authorities moved swiftly to address all these issues. A joint team of government officials and Intel personnel identified the gaps in Costa Rica's educational system and proposed specific actions for improving technical skills and language training. The authorities granted more licenses to foreign carriers, accelerated plans for a new cargo terminal, and agreed to help improve access to the highway. A two-tier industrial rate structure was established for power, giving larger users like Intel more favorable pricing. The active efforts of the authorities may have been encouraged by the great magnitude of the prospective investment relative to Costa Rica's economy, making the country's small size an asset rather than an obstacle to attracting FDI.

Second, Costa Rica's system of fiscal incentives was aggressive and credible. It had successfully attracted other foreign firms. Political stability and the authorities' firm strategy of inserting the country's economy into international markets convinced investors that the incentives would remain in place for the long term. In contrast, Mexico's incentives were less generous, and the credibility of its attempt to offer special tax breaks was undermined by their discretional nature.

A third factor was the requirement in Mexico that investors be subject to a system of mandatory union rules. Intel's plants are union-free so allowing an exception could have triggered unionization elsewhere. According to Spar (1998), Mexican authorities offered to exempt Intel from the rules, but the discretional nature of this very offer may have made Intel wary of the business environment in Mexico.

Three lessons can be extracted from the Intel episode. First, Costa Rica already had many of the conditions that Intel needed. It had enjoyed political stability for a long time and had made efforts to liberalize international trade and labor markets. ${ }^{1}$ It also possessed a fairly well-trained workforce and an incipient electronics sector.

Nevertheless, the second conclusion is that fiscal incentives were also important. In a world where many countries compete to attract FDI, one key factor in favor of Costa Rica was the credibility of its incentive regime, given by its generalized nature and automated process.

The third lesson is that active involvement of the authorities can be key in attracting a big investment project. They were prompt and effective in removing obstacles identified by the prospective investor. But an important fact, highlighted by Spar (1998), is that the Costa Rican government responded to Intel's concerns mostly by changing the general nature of the regulations and enhancing the education system, not by providing grants and subsidies specifically to Intel. ${ }^{2}$

(Box continues on the following page.) 


\section{Box 8.3 (continued)}

\section{Notes}

1. As discussed by Larraín B, Lopez-Calva, and Rodríguez-Clare (2000), a study carried out in 1999 confirmed that other foreign investors' perceptions of Costa Rica largely coincided with Intel's assessment. The 61 foreign investors interviewed ranked "political stability" and "well-educated labor force" as the top strengths of Costa Rica.

2. This section is based on Monge-Naranjo (2002), drawing from Spar (1998), and on Larraín B, Lopez-Calva, and Rodríguez-Clare (2000).

countries. One key difference lies in the taxation of profits. Mexico, like Chile, does not provide any exemption, and foreign investors are subject to the same 34 percent tax on profits as are local firms. In contrast, the other countries fully exempt foreign firms from the profit tax for long periods of time, and in fact the main difference lies in the duration of the exemption period (table 8.6). ${ }^{25}$ It is conceivable that these incentives might have contributed to offset potential FDI diversion effects from the treaty, although most of the EPZs' legal codes were enacted before 1994 and were not altered in response to NAFTA. Indeed, there was little margin for further profit tax concessions because tax rates were already at zero. $^{26}$

How effective are these incentives? The limited information available suggests that EPZs attract much of the FDI accruing to Central American countries (Robles-Cordero and Rodríguez-Clare 2003). There is some evidence that EPZs and the associated tax concessions have an impact on export-oriented FDI location decisions. Studies by Woodward and Rolfe

\section{Table 8.6 Fiscal Incentives to Foreign Investors}

\begin{tabular}{lll}
\hline Country & \multicolumn{1}{c}{ Income tax exemption } & Years of benefit \\
\hline Mexico & 0 percent (tax is 34 percent) & n.a. \\
Costa Rica & 100 percent first, then & 8 to 12 , then \\
& 50 percent & 4 to 6 \\
Guatemala & 100 percent & $12-15$ \\
El Salvador & 100 percent & 20 \\
Honduras & 100 percent & Indefinite \\
Dominican Republic & 100 percent & 15 to 20 \\
Brazil & 100 percent & 3 to 10 \\
Chile & 0 percent (tax is 34 percent) & n.a. \\
\hline
\end{tabular}

n.a. Not applicable.

Source: Borbón-Guevara 1999; Robles-Cordero and Rodríguez-Clare 2003. 
(1993), who examined location decisions in the Caribbean basin; Kumar (1994), who analyzed the location of U.S. multinational corporations across 40 countries; and Choi (1995), who examined the location of U.S.owned textile plants across 47 countries, all concluded that the existence of EPZs tends to attract FDI. The first of those studies also found that the length of tax holidays has a positive effect on location choices, although the second study found no conclusive evidence in this regard.

Tax and other concessions to FDI are not necessarily inefficient when foreign (as opposed to domestic) investment involves positive externalities through channels such as technological spillovers. However, they have major limitations. First, tax regulations in the home country may prevent multinational firms from taking advantage of tax concessions enjoyed by the subsidiaries in other countries. Second, competition in tax and other concessions among FDI hosts can lead to a "race to the bottom" whose outcome is an excessively low level of taxes in all countries without any stimulating effects on FDI. Incentives also involve potentially large costs in terms of foregone fiscal revenues, economic distortions, and enhanced scope for rent-seeking. Third, and most important, when the effectiveness of tax concessions in attracting FDI is examined in a broader empirical context that also includes "deep" FDI determinants, such as productivity, macroeconomic stability, governance, and institutional quality, available studies find that the latter factors have a larger and more robust impact than tax concessions on the cross-country distribution of FDI inflows. Incentives appear to make a difference only when the choice of location is made among competing jurisdictions for which those FDI fundamentals are roughly equivalent. ${ }^{27}$

From a practical perspective, a key issue is that income tax concessions to EPZs in Central America and the Caribbean, with the exception of El Salvador, are linked to export performance, and as such they represent export subsidies contrary to World Trade Organization (WTO) regulations-except when the concessions apply to firms producing services (such as call centers and "back-office" services). Such schemes were to be dismantled by January 1, 2003, although the deadline was later extended.

How should countries respond to this new situation? In principle they could replace existing EPZ incentives with broader tax concessions to all foreign investors, regardless of export performance, or even to all investors, both domestic and foreign. But the first option would still imply an asymmetric treatment of local and foreign firms for which there is no clear justification in view of the inconclusive evidence on the existence and significance of spillovers from foreign firms (see chapter 6). As for the latter option, it would entail unacceptably high fiscal costs.

In this regard the upcoming Free Trade Area of the Americas (FTAA) or Central America-U.S. Free Trade Agreement (CAFTA) may offer a 
unique opportunity for the joint phasing out of EPZ-based investment incentives that run counter to WTO rules in Central America and the Caribbean. This would help the countries involved switch to a more promising investment-promotion strategy based on uniform taxation of all firms, possibly supported by a regionwide agreement to prevent tax competition and focused on strengthening the FDI fundamentals mentioned earlier-macroeconomic stability, productivity growth, and the quality of the institutional and regulatory framework. The empirical role of these fundamentals in FDI flows is discussed next.

\section{The Relative Appeal of Alternative FDI Destinations}

Trade preferences and tax concessions are only two among many ingredients that determine the allocation of FDI across developing countries. Other factors also matter, or matter even more. ${ }^{28}$ Conceptually, foreign investment flows can be viewed as reflecting the portfolio decisions of international investors regarding the location of their assets. Broadly speaking, these depend on two types of factors. First, global factors affect the willingness of international investors to invest in developing countries. Thus they cause FDI to change across a broad range of countries. Second, local factors-that are country-specific_-affect primarily the decision to invest in each host country. Global factors relate to required rates of return and risk perceptions in world financial markets, as reflected by industrialized-country interest rates and term and risk premiums. In turn, local factors capture the anticipated return and risk associated with FDI in specific host countries. They measure such ingredients as host country productivity, economic volatility, and institutional quality. ${ }^{29}$

This framework provides a guide to the allocation of a worldwide pool of FDI resources across individual hosts. It is useful to recast it in terms of the relative attractiveness of each host country. In this context the latter can be summarized by two key variables: the anticipated return to FDI in each host country relative to the rest; and the perceived risk associated with FDI in each host, also relative to the rest. Other things being equal, a higher relative return attracts FDI into the country offering it, whereas a higher relative risk redirects inflows to other host countries. This serves to underscore the fact that, in addition to global factors impinging on worldwide FDI, what matters for the allocation of FDI inflows is not just the absolute appeal of each host, but also its position vis-à-vis other hosts in terms of both level and volatility of investment returns.

It is useful to examine the predictions of this framework regarding the allocation of FDI across Latin America. ${ }^{30}$ For this purpose we follow the approach adopted by Calderón, Loayza, and Servén (2003) in analyzing capital flow determinants. We constructed a synthetic index of return as 
a weighted average of (a) productivity growth, measured by per capita GDP growth ${ }^{31}$; (b) market size and scale economies, measured by total population; (c) openness, measured by the ratio of imports plus exports to GDP at constant prices; (d) market distortions, measured by the premium on foreign exchange in the black market; (e) governance and institutional quality, proxied by the Kaufmann governance index and the Gastil civil liberties index; and (f) overall tax burden, proxied by general government consumption as a ratio to GDP. (In chapter 5 we already saw that many of these variables are significant determinants of FDI inflows.)

Likewise, we constructed a synthetic risk index summarizing four main ingredients: (a) overall macroeconomic stability, measured by the standard deviation of the rate of GDP growth per capita; (b) monetary and price stability, captured by the inflation rate and its standard deviation; (c) external sector instability, measured by the standard deviation of real exchange rate changes, terms of trade shocks, and the openness measure above; and (d) lack of governance and overall institutional quality, measured by the inverse of the two variables in (e) above. ${ }^{32}$ (Again, we encountered some of these variables in chapter 5.)

To highlight the key role of relative return and risk, each country's index is expressed in terms of deviation from the (average) index of the other countries in the sample. Finally, to complete the empirical framework we added a scale measure of FDI (namely, worldwide FDI outflows relative to world GDP) and the global financial factors mentioned above, which for simplicity are represented by their first two principal components. ${ }^{33}$

The results from empirical implementation of this framework for a large sample of developing countries over the past three decades are shown in table 8.7. Given the size of the sample, this stylized approach accounts for a fairly respectable portion of the observed variation in FDI flows. Most important, the results show that higher relative returns attract FDI whereas higher relative risk deters it. Higher interest rates and risk premiums in world markets also deter FDI, as implied by the negative coefficients on the synthetic global factors. Last, the coefficient on the scale variable is highly significant and below one, reflecting the fact that not all FDI hosts are included in the sample (which in fact excludes industrialized countries) and that the excluded hosts taken together play a quantitatively significant role as FDI destinations. In addition, when privatization transactions are omitted, the fact that the coefficient is below one also reflects the significant role of excluded privatization-related flows in worldwide FDI flows.

It is instructive to examine how Latin American countries fare vis-àvis the rest of the developing countries in terms of return and risk. Figure 8.5 depicts differential risk and return for the entire country 
Table 8.7 Determinants of Net FDI Inflows to Developing Countries, 1970-99

(percent of GDP)

\begin{tabular}{lcc}
\hline Dependent variable & Total FDI/GDP & $\begin{array}{c}\text { FDI/GDP excluding } \\
\text { privatization }\end{array}$ \\
\hline Relative return & $0.005^{* *}$ & $0.004^{* *}$ \\
Relative risk & 0.001 & 0.001 \\
World FDI/GDP & $-0.007 * *$ & $-0.006^{* *}$ \\
Global factor 1 & 0.001 & 0.001 \\
& $0.647 * *$ & $0.535^{* *}$ \\
Global factor 2 & 0.161 & 0.153 \\
& $-0.001 * *$ & $-0.001 * *$ \\
$R^{2}$ & 0.001 & 0.001 \\
Number of observations & $-0.003 * *$ & $-0.003 * *$ \\
Number of countries & 0.001 & 0.001 \\
\hline
\end{tabular}

Note: Standard errors appear in italics under each coefficient. See the text for descriptions of the variables.

Source: Authors' calculations.

Figure 8.5 Relative Risk and Return, All Developing Countries, 1980-99

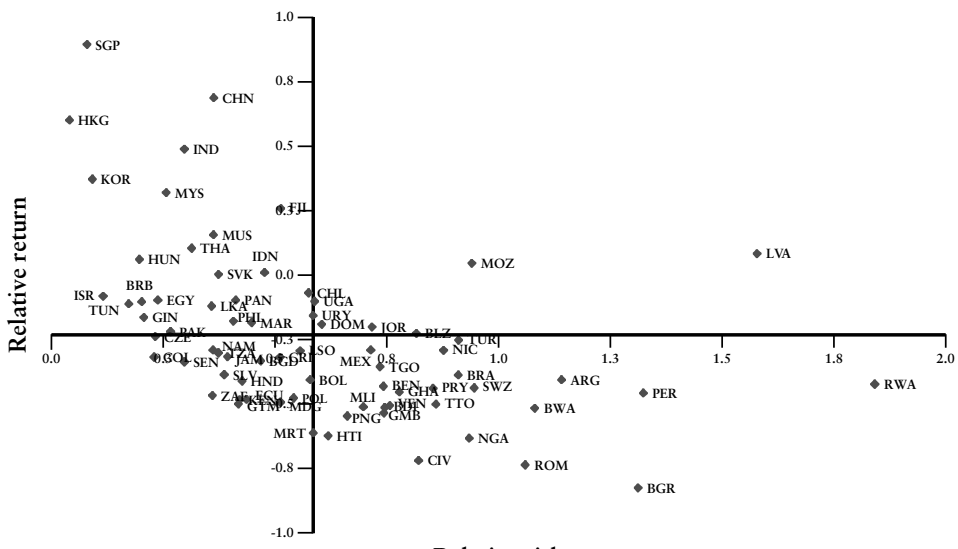

Relative risk

Source: Authors' calculations. 
Figure 8.5 (continued)

\begin{tabular}{|c|c|c|c|}
\hline Note: & & $\mathrm{COK}$ & Cook Islands \\
\hline ABW & Aruba & $\mathrm{COL}$ & Colombia \\
\hline AFG & Afghanistan & $\mathrm{COM}$ & Comoros \\
\hline AGO & Angola & $\mathrm{CPV}$ & Cape Verde \\
\hline AIA & Anguila & CRI & Costa Rica \\
\hline ALB & Albania & CSK & Czechoslovakia \\
\hline AND & Andorra & CUB & Cuba \\
\hline ANT & Netherlands Antilles & CXR & Christmas Island \\
\hline ARE & United Arab Emirates & CYM & Cayman Islands \\
\hline ARG & Argentina & CYP & Cyprus \\
\hline ARM & Armenia & $\mathrm{CZE}$ & Czech Republic \\
\hline ASM & American Samoa & DDR & German Democratic \\
\hline ATF & Fr. So. Ant. Tr & & Republic \\
\hline ATG & Antigua and Barbuda & DEU & Germany \\
\hline AUS & Australia & DJI & Djibouti \\
\hline AUT & Austria & DMA & Dominica \\
\hline AZE & Azerbaijan & DNK & Denmark \\
\hline BAT & Br. Antr. Terr & DOM & Dominican Republic \\
\hline BDI & Burundi & DZA & Algeria \\
\hline BEL & Belgium & ECU & Ecuador \\
\hline $\mathrm{BEN}$ & Benin & EGY & Egypt, Arab Rep. \\
\hline BFA & Burkina Faso & ERI & Eritrea \\
\hline BGD & Bangladesh & ESH & Western Sahara \\
\hline BGR & Bulgaria & ESP & Spain \\
\hline BHR & Bahrain & EST & Estonia \\
\hline BHS & Bahamas, The & ETF & Ethiopia (includes Eritrea) \\
\hline $\mathrm{BIH}$ & Bosnia and Herzegovina & ETH & Ethiopia (excludes Eritrea) \\
\hline BLR & Belarus & EUN & European Union \\
\hline BLX & Belgium-Luxembourg & FIN & Finland \\
\hline BLZ & Belize & FJI & Fiji \\
\hline $\mathrm{BMU}$ & Bermuda & FLK & Falkland Island \\
\hline BOL & Bolivia & FRA & France \\
\hline BRA & Brazil & FRE & Free Zones \\
\hline $\mathrm{BRB}$ & Barbados & FRO & Faeroe Islands \\
\hline BRN & Brunei & FSM & Micronesia, Fed. Sts. \\
\hline BTN & Bhutan & GAB & Gabon \\
\hline BWA & Botswana & GAZ & Gaza Strip \\
\hline CAF & Central African Republic & GBR & United Kingdom \\
\hline CAN & Canada & GEO & Georgia \\
\hline CCK & Cocos (Keeling) Islands & GHA & Ghana \\
\hline $\mathrm{CHE}$ & Switzerland & GIB & Gibraltar \\
\hline CHL & Chile & GIN & Guinea \\
\hline $\mathrm{CHN}$ & China & GLP & Guadeloupe \\
\hline CIV & Cote d'Ivoire & GMB & Gambia, The \\
\hline CMR & Cameroon & GNB & Guinea-Bissau \\
\hline $\mathrm{COG}$ & Congo, Rep. & GNQ & Equatorial Guinea \\
\hline
\end{tabular}


Figure 8.5 (continued)

\begin{tabular}{|c|c|c|c|}
\hline GRC & Greece & MAR & Morocco \\
\hline GRD & Grenada & $\mathrm{MCO}$ & Monaco \\
\hline GRL & Greenland & MDA & Moldova \\
\hline GTM & Guatemala & MDG & Madagascar \\
\hline GUF & French Guiana & MDV & Maldives \\
\hline GUM & Guam & MEX & Mexico \\
\hline GUY & Guyana & MHL & Marshall Islands \\
\hline HKG & Hong Kong, China & MID & Midway Islands \\
\hline HND & Honduras & MKD & Macedonia, FYR \\
\hline HRV & Croatia & MLI & Mali \\
\hline HTI & Haiti & MLT & Malta \\
\hline HUN & Hungary & MMR & Myanmar \\
\hline IDN & Indonesia & MNG & Mongolia \\
\hline IND & India & MNP & Northern Mariana Islands \\
\hline IOT & British Indian Ocean Ter. & MOZ & Mozambique \\
\hline IRL & Ireland & MRT & Mauritania \\
\hline IRN & Iran, Islamic Rep. & MSR & Montserrat \\
\hline IRQ & Iraq & MTQ & Martinique \\
\hline ISL & Iceland & MUS & Mauritius \\
\hline ISR & Israel & MWI & Malawi \\
\hline ITA & Italy & MYS & Malaysia \\
\hline JAM & Jamaica & NAM & Namibia \\
\hline JOR & Jordan & NCL & New Caledonia \\
\hline JPN & Japan & NER & Niger \\
\hline JTN & Jhonston Island & NFK & Norfolk Island \\
\hline KAZ & Kazakhstan & NGA & Nigeria \\
\hline KEN & Kenya & NIC & Nicaragua \\
\hline KGZ & Kyrgyz Republic & NIU & Niue \\
\hline KHM & Cambodia & NLD & Netherlands \\
\hline KIR & Kiribati & NOR & Norway \\
\hline KN1 & Saint Kitts-Nevis-Anguilla- & NPL & Nepal \\
\hline & Aru & NRU & Nauru \\
\hline KNA & St. Kitts and Nevis & NZE & Neutral Zone \\
\hline KOR & Korea, Rep. of & NZL & New Zealand \\
\hline KWT & Kuwait & $\mathrm{OMN}$ & Oman \\
\hline $\mathrm{LAO}$ & Lao PDR & PAK & Pakistan \\
\hline LBN & Lebanon & PAN & Panama \\
\hline LBR & Liberia & PCE & Pacific Islands \\
\hline LBY & Libya & PCN & Pitcairn \\
\hline LCA & St. Lucia & PCZ & Fm Panama Cz \\
\hline LIE & Liechtenstein & PER & Peru \\
\hline LKA & Sri Lanka & PHL & Philippines \\
\hline LSO & Lesotho & PLW & Palau \\
\hline LTU & Lithuania & PMY & Pen Malaysia \\
\hline LUX & Luxembourg & PNG & Papua New Guinea \\
\hline LVA & Latvia & POL & Poland \\
\hline MAC & Macao & PRI & Puerto Rico \\
\hline
\end{tabular}


Figure 8.5 (continued)

\begin{tabular}{|c|c|c|c|}
\hline PRK & Korea, Dem. Rep. & TJK & Tajikistan \\
\hline PRT & Portugal & TKL & Tokelau \\
\hline PRY & Paraguay & TKM & Turkmenistan \\
\hline PYF & French Polynesia & TMP & East Timor \\
\hline QAT & Qatar & TON & Tonga \\
\hline REU & Reunion & TTO & Trinidad and Tobago \\
\hline ROM & Romania & TUN & Tunisia \\
\hline RUS & Russian Federation & TUR & Turkey \\
\hline RWA & Rwanda & TUV & Tuvalu \\
\hline RYU & Ryukyu Is & TWN & Taiwan \\
\hline SAU & Saudi Arabia & $\mathrm{TZA}$ & Tanzania \\
\hline SBH & Sabah & UGA & Uganda \\
\hline SDN & Sudan & UKR & Ukraine \\
\hline SEN & Senegal & UNS & Unspecified \\
\hline SER & Yugoslavia & URY & Uruguay \\
\hline SGP & Singapore & USA & United States \\
\hline SHN & Saint Helena & USP & Us Msc.Pac.I \\
\hline SIK & SIKKIM & $\mathrm{UZB}$ & Uzbekistan \\
\hline SJM & Svalbard and Jan Mayen Is & VAT & Holy See \\
\hline SLB & Solomon Islands & VCT & St. Vincent and the \\
\hline SLE & Sierra Leone & & Grenadines \\
\hline SLV & El Salvador & VDR & Fm Vietnam Dr \\
\hline SMR & San Marino & VEN & Venezuela \\
\hline SOM & Somalia & VGB & British Virgin Islands \\
\hline SPE & Special Categories & VIR & Virgin Islands (U.S.) \\
\hline SPM & Saint Pierre and Miquelon & VNM & Vietnam \\
\hline STP & Sao Tome and Principe & VUT & Vanuatu \\
\hline SUR & Suriname & WAK & Wake Island \\
\hline SVK & Slovak Republic & WLD & World \\
\hline SVN & Slovenia & WLF & Wallis and Futura Isl. \\
\hline SVR & Fm Vietnam Rp & WSM & Samoa \\
\hline SVU & Soviet Union & YDR & Yemen Democratic \\
\hline SWE & Sweden & YEM & Yemen Rep. \\
\hline SWK & Sarawak & YUG & Yugoslavia, FR \\
\hline SWZ & Swaziland & & (Serbia/Montene \\
\hline SYC & Seychelles & ZAF & South Africa \\
\hline SYR & Syrian Arab Republic & ZAR & Congo, Dem. Rep. \\
\hline TAN & Fm Tanganyik & $\mathrm{ZMB}$ & Zambia \\
\hline TCA & Turks and Caicos Isl. & ZPM & Fm Zanz-Pemb \\
\hline TCD & Chad & ZW1 & Fm Rhod Nyas \\
\hline TGO & Togo & ZWE & Zimbabwe \\
\hline THA & Thailand & & \\
\hline
\end{tabular}


sample, averaged over the period 1980-99. The most attractive FDI host countries are those located in the upper-left corner of the graph, characterized by low risk and high return. It can be seen that the lowest relative risk and the highest returns are found among East Asian countries. The Latin American country coming closest to this top group is Chile. In the worldwide sample, however, Chile does not appear particularly distinguished. At the other extreme, Argentina and Peru stand out in the world sample for their high risk over the period considered.

Figure 8.6 plots the changes in Latin American countries' differential risk and return between 1980-93 and 1994-99-that is, before and after NAFTA. Virtually all of the region's economies managed to raise their

Figure 8.6 Change in Risk and Return in Latin America and the Caribbean, 1980-93 vs. 1994-99

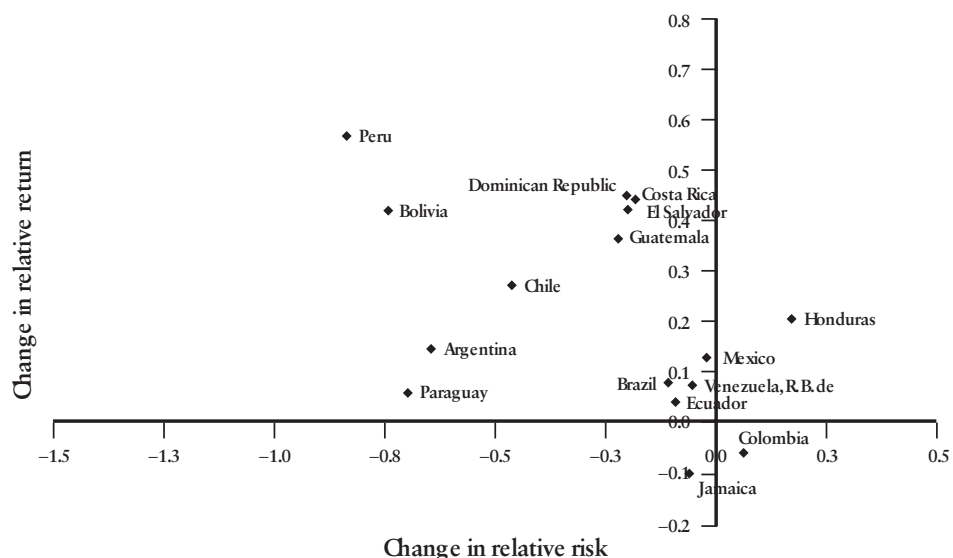

$\begin{array}{llll}\text { Note: } & & & \\ \text { ARG } & \text { Argentina } & \text { BOL } & \text { Bolivia } \\ \text { BRA } & \text { Brazil } & \text { CHL } & \text { Chile } \\ \text { COL } & \text { Colombia } & \text { CRI } & \text { Costa Rica } \\ \text { DOM } & \text { Dominican Republic } & \text { ECU } & \text { Ecuador } \\ \text { GTM } & \text { Guatemala } & \text { HND } & \text { Honduras } \\ \text { JAM } & \text { Jamaica } & \text { MEX } & \text { Mexico } \\ \text { PER } & \text { Peru } & \text { PRY } & \text { Paraguay } \\ \text { SLV } & \text { El Salvador } & \text { VEN } & \text { Venezuela }\end{array}$

Source: Authors' calculations. 
differential returns, lower their risks, or both. The most dramatic change was that of Peru, which experienced the largest improvement in both dimensions following its recovery from the period of high macroeconomic instability of the late 1990s. According to the synthetic indexes Mexico was among the countries whose relative return increased, although its relative risk did not change much. The latter fact results from the backward-looking nature of the risk index, which reflects primarily the instability associated with the Tequila crisis and which does not allow for any forward-looking effects of increased credibility that may have resulted from NAFTA.

This synthetic framework provides another way to gauge indirectly the impact of NAFTA on FDI flows. Because the empirical framework does not incorporate explicitly the passage of NAFTA as an investment determinant, comparison between the actual patterns of FDI across countries in the post-NAFTA period and the patterns predicted by the empirical model can serve to detect any major effects of NAFTA on the allocation of FDI across the region, beyond those captured by the FDI fundamentals embedded in the risk and return indexes.

Table 8.8 shows the actual change in FDI inflows to Latin American and Caribbean countries between 1980-93 and 1994-99, and compares it with the change predicted by the risk-return framework. The calculation is performed both using total FDI and excluding privatization-related FDI. In the case of Mexico the observed change in FDI between the two subperiods (around 1.7 percent of GDP) is in both cases somewhat above that predicted by the model, likely capturing a temporary positive impact of NAFTA. However, the difference relative to the model's predictions is fairly modest and statistically insignificant, implying that the changes in FDI fundamentals - some of which may reflect the impact of NAFTAaccount for most of the observed variation in FDI inflows to Mexico.

In South America, in turn, the observed change in FDI exceeds the model's predictions by a wide margin in the case of Chile and in Bolivia and Peru if privatization transactions are included. However, when privatization-related FDI is excluded from the picture, the actual and predicted FDI performances are fairly close for most countries, with Chile as the single exception.

For Central America the results are fairly diverse. The changes in relative risk and return account reasonably well for the observed FDI patterns, with the main exceptions of Guatemala, which did much worse than predicted, and Jamaica, which did much better. Thus, the pattern is similar to that found in Figure 8.4. Excluding privatization inflows does not alter the picture and, in fact, it makes the overprediction of Guatemala's performance statistically significant. In this latter case, El Salvador also exhibits a negative residual but it is not statistically significant. 


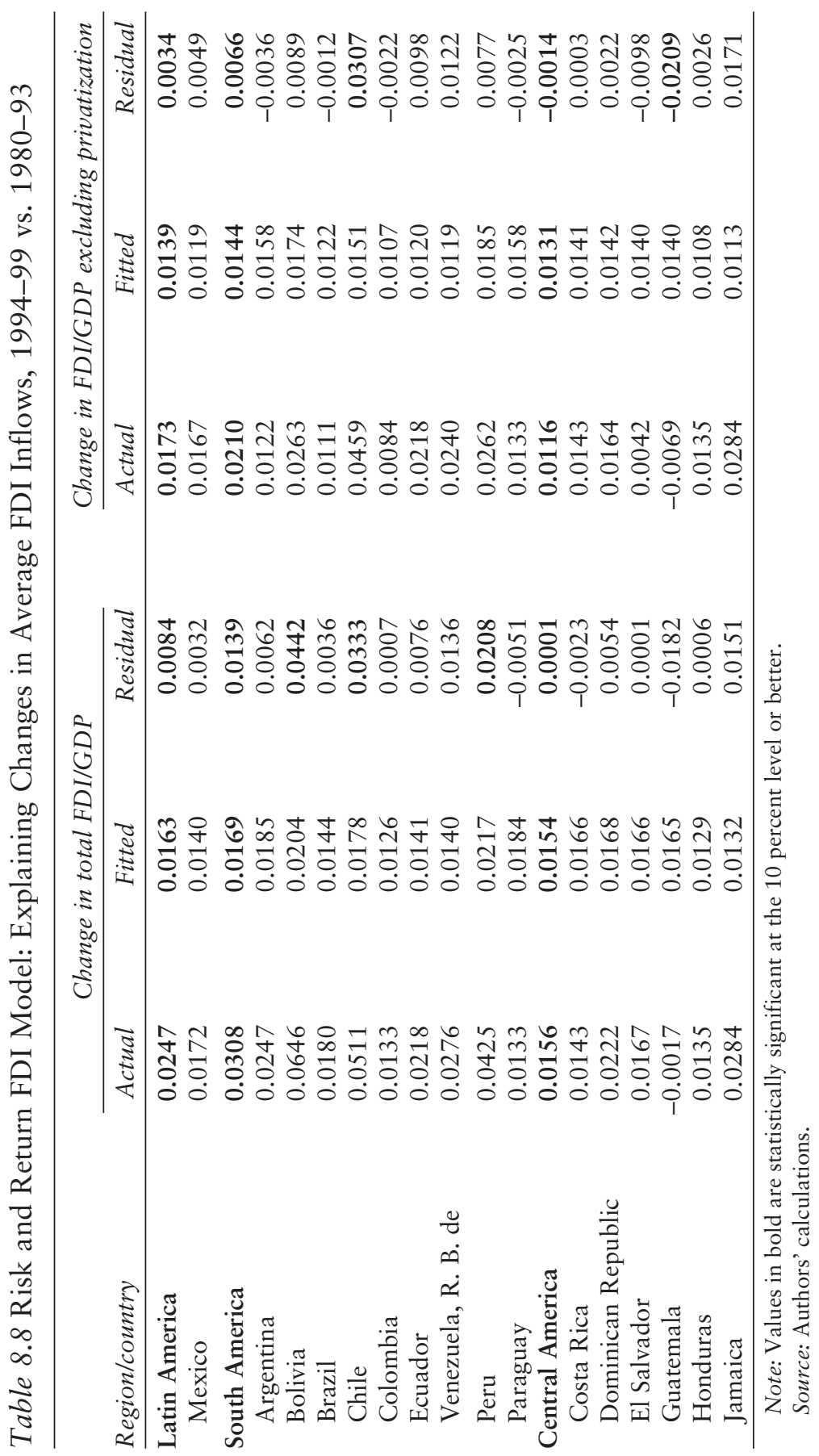


Thus, except for the extreme cases of Chile and Guatemala, the changes in risk and return FDI fundamentals account fairly well for the observed changes in the pattern of FDI flows to most Latin American and Caribbean countries after 1993. This of course does not mean that NAFTA had no independent effects on such patterns, but rather that the effects of the treaty are largely captured by those changing fundamentals. For example, most of the increase in Mexico's return index between the pre- and post-NAFTA periods noted earlier can be traced to the increase in the economy's openness over those years, when it practically doubled. Such an increase in openness was very likely helped by NAFTA, as argued in previous chapters. ${ }^{34}$ But for the rest of the countries the observed changes in FDI inflows generally reflect a number of different factors, both global and local. In particular, when we control for the risk and return determinants of FDI, no systematic pattern of FDI underperformance is visible in the data for the neighboring countries of Central America and the Caribbean region.

\section{Conclusion}

This chapter has examined trends in FDI inflows across Latin America before and after NAFTA in search for evidence of FDI diversion. On the whole, we do not find much evidence that the FTA led to a significant slowdown in investment flows to Latin American countries in general and to the neighboring countries of Central America and the Caribbean in particular. The generous investment incentives granted by most of these countries under the EPZ regime may have helped them retain their appeal as FDI hosts in the post-NAFTA environment. But the FDI performance of NAFTA's neighbors also shows a good deal of heterogeneity. Although some countries did experience a relative slowdown in FDI inflows in the post-NAFTA years, others performed on par with or even better than Mexico. This suggests that country-specific features and policies, aside from (or in addition to) NAFTA, have played a major role in the changing pattern of FDI inflows across the region. Indeed, a simple empirical framework encompassing fundamental FDI determinantsthe anticipated return and perceived risk from investing in different host countries-can account for much of the FDI variation before and after NAFTA.

The analysis in this chapter provides also a perspective on the potential effects on FDI inflows from a NAFTA expansion to other Latin American and Caribbean countries and a future FTAA. As in the cases of Mexico with NAFTA and Southern Europe with the EU, entry of other neighboring countries into an FTAA would likely cause an increase in their FDI inflows-although, as in those cases as well, the increase 
might be only temporary, reflecting a stock adjustment. The relatively low volume of FDI relative to trade in Latin America compared with the EU suggests that the FTAA offers the scope for a considerable increase in FDI to the region, both from within and outside the FTAA. It is also likely to encourage further concentration of investment in a few countries (Venables and Winters 2002).

The available evidence on RIAs and foreign investment also suggests that the likelihood and magnitude of an FDI increase to RIA newcomers rises with their attractiveness (Levy-Yeyati, Stein, and Daude 2002). Unstable countries with low productivity, distorted policies, and weak institutions are unlikely to draw much FDI benefit from joining a RIA. Countries with strong institutions protecting investors' rights, a stable macroeconomic environment, and open trade regimes are much more likely to reap large gains from FTAA membership.

Ultimately, FTAs are neither necessary nor sufficient for countries to attract increased FDI inflows. Some leading FDI hosts, such as Chile, did not need to enter into a RIA to become top investment destinations. At the other end, Greece's entry into the EU did not earn it the FDI dividends that Portugal and Spain collected. FTA membership does not make up for bad policies. It is a complement to rather than a substitute for an investment-friendly policy and institutional environment. Thus, for countries hoping to benefit from RIA-induced investment creation, the prospect of an upcoming RIA requires renewed effort on reforms aimed at improving investment fundamentals: economic and policy stability, productivity, institutions, and governance. Along some of these dimensions-the latter in particular-many Latin American and Caribbean countries still score quite poorly vis-à-vis other developing regions such as East Asia.

This strategy toward FDI stands in contrast with the alternative of engaging in an aggressive "incentive race," in which countries compete with each other in terms of tax and other concessions to attract FDI flows. Tax concessions do have an effect on FDI location decisions, and many countries tend to combine both strategies to some extent. FDI incentives are predicated on the basis of positive externalities from foreign investment, which are hard to identify and quantify, and as a result incentives are likely to be excessive in many cases. However, the empirical evidence also suggests that FDI-specific incentives are less effective in attracting investment than are investment-friendly policies and institutions, which should be the primary concern of the authorities. Any incentives offered on top of this should be rules-based and available on equal terms to all investors, irrespective of industry and nationality.

In the end, for host countries the key concern is not the volume of FDI they may receive but the benefits that it will bring to their economies. 
This means that reforms in anticipation of the FTAA have to focus also on the key determinants of those benefits, even if they do not directly affect the volume of FDI inflows. If, as commonly believed, FDI has beneficial effects in terms of technological and knowledge spillovers (although evidence of their existence is far from conclusive), sufficient levels of human capital and an adequate knowledge and innovation system need to be in place for the domestic economy to absorb them (see Blomström and Kokko 2003). This means that knowledge and innovation policies are a major item in the reform agenda.

\section{Notes}

1. The concepts of foreign investment creation and diversion in the context of trade integration date back to Kindleberger (1966).

2. See Leamer et al. (1995) for an ex ante assessment of the potential effects of NAFTA on investment in Central America, including an evaluation of the location similarities between Mexico and Central America.

3 . If the FTA does have an impact, it is likely to be negative because the relative size of the local market of nonmember countries decreases vis-à-vis the now enlarged local market of the FTA.

4. During this period major multinational companies (e.g., Colgate, Firestone, Pfizer, Sherwin-Williams, and many others) established production plants in Central America. Automakers established production units in Argentina, Brazil, and Mexico. Tariff jumping was one of the major motivations for those investments.

5. The analytical underpinnings of this FDI redirection are examined by Elkholm, Forslid, and Markusen (2003).

6. Strictly speaking, FTAs could have an indirect effect on this kind of FDI as well if they affect the growth prospects of the host country and thereby the anticipated profitability of the privatized firm and bidders' willingness to pay for it.

7. This hypothesis is consistent with the empirical evidence presented by Hanson, Mataloni, and Slaughter (2001) who found that vertical FDI is encouraged by low host-country trade barriers and discouraged by large host-country market size.

8. Of course, FTA membership may have an impact on other "deep" determinants of FDI flows, such as trade openness, and hence may affect FDI indirectly through channels other than the "credibility" effect discussed earlier.

9. Much of the material in this chapter is based on the background paper by Monge-Naranjo (2002).

10. We excluded Panama from the sample because its FDI inflows are very large and extremely erratic, likely reflecting its role as an international financial center; and Nicaragua because data for much of the period under analysis are unavailable. Data on net FDI inflows were obtained from the World Bank World Development Indicators and the United Nation's Conference on Trade and Development's (UNCTAD's) World Investment Report.

11. The sharp rise in FDI flows to South America in 1999 shown in figure 8.1 is largely the result of a surge in flows to Argentina related to the sale of YPF, the leading petroleum company. In turn, the rise in FDI flows to Central America and the Caribbean in 1998 reflects a generalized increase in flows to all countries in the area (except Honduras), a particularly abrupt increase in the case of El Salvador. Finally, the jump in FDI to Mexico in 2001 reflects the sale of Banamex, which 
amounted to more than 2 percent of GDP.

12. For Mexico the breakdown of inflows to U.S. and non-U.S. sources is based on data from the Secretariat of Economy. For the other countries, it is based on data from the U.S. Bureau of Economic Analysis so the comparisons have to be taken with some caution. Although further disaggregation of inflows from nonU.S. sources might be of interest, the necessary data are unavailable for most countries in Latin America and the Caribbean.

13. Despite neglecting this channel, the study's estimated diversion effect is extremely large: entry by a source country into an FTA would reduce its stock of FDI to nonmember countries by about 27 percent.

14. Indeed, experiments reported by Levy-Yeyati, Stein, and Daude (2002) do suggest that NAFTA may be different from the other FTAs in terms of its FDI impact.

15. Note that this represents a more general way of controlling for distance and other time-invariant characteristics of countries than do the parametric measures commonly employed in gravity models. Indeed, in our context finding informative measures of closeness for Central American countries could be problematic given their geographic proximity and small size.

16. Even if the effects of NAFTA on FDI flows to Mexico were purely transitory, they might amount to a permanent change in the stock of FDI to Mexico. The cumulative sum in the text helps assess this possibility.

17. The analysis was also performed measuring FDI by its ratio to fixed investment of the host country. The results were generally analogous to those obtained with FDI/GDP and thus are not reported.

18. Recall that for a given country the sum of those terms over the entire period is equal to zero, and that for each year its sum across all countries is equal to zero.

19. The information on privatization-related FDI was obtained from UNCTAD. It is not available after 1999 and, unfortunately, its coverage prior to 1987 is spotty at best. For these reasons the results in the text have to be taken with some caution.

20. Note that changing the definition of the dependent variable also changes the estimated source/host effects and the common time effects. To save space, they are not reported here.

21. The available evidence is only indirect, and is given by the fact that most textile exports originate in EPZs, where the majority of firms-most of which belong to the textile and apparel sector-are foreign-owned. The exception in this regard is Costa Rica. See Esquivel, Jenkins and Larraín B (1998).

22. One also has to recall that discussion of policy initiatives toward "NAFTA parity" started in the United States soon after passage of NAFTA (and even before), which suggests that the temporary nature of Mexico's preferential treatment was widely recognized. This anticipation of upcoming parity would have mitigated its impact on fixed investment decisions guided by longer-term prospects.

23. For all these goods, the Caribbean Basin Initiative (CBI) and NAFTA provide equal benefits, so that exports from CBI countries enter the U.S. market on the same footing as competing goods from Mexico. This is not always the case in third markets, however, where some of these exports are viewed as subsidized by EPZ benefits and thus subject to exclusion from preferential treatment. This is reported in a study by CINDE-PROCOMER (2001a) (the agencies promoting FDI and international trade in Costa Rica) that analyzed market access of goods produced in Costa Rica in the sectors listed in the text. The study found that such goods (and hence those produced in any other country under the CBI/CBTPA umbrella) enter the U.S. market in the same conditions as if they were produced in Mexico, but face more obstacles in markets in Europe, South America, and even Central America! 
24. Details on EPZ incentives are given in studies by CINDE-PROCOMER (2001b,c,d) and by Borbón-Guevara (1999) who compared the incentives provided by Costa Rica and other countries. See also Robles-Cordero and Rodríguez-Clare (2003).

25. In some cases (e.g., Costa Rica and Guatemala) the period of exemption depends on whether the plant locates in a low-development region. In general, however, by reinventing/renaming themselves right before expiration of the exemption, it is quite possible that firms may be able to extend the exemption beyond the letter of the law.

26. However, some anecdotal evidence indicates that governments might have resorted to other forms of incentives, such as worker training, co-financing of some investments, more generous infrastructure provision, power subsidies, and so forth.

27. See Morisset and Pirnia (2002) for an overview of the literature on the effectiveness of tax incentives, and Stein and Daude (2001) for some econometric evidence.

28. This is clearly illustrated by the results of a survey of Costa Rican textile firms reported by Monge-Naranjo (2002). Although some respondents did mention trade agreements and EPZs as important factors in their decision to locate in a specific country, a number of other factors-from wage costs to infrastructure and availability of skilled labor-were mentioned by a larger number of survey participants.

29. This framework and its empirical validation are spelled out in detail in Albuquerque, Loayza, and Servén (2003). They showed that although both global and local factors play significant roles in determining the worldwide allocation of FDI (each accounts for roughly half of the total explained variation), global factors have become increasingly important in recent years as a result of rising world financial integration.

30. The material that follows is a brief summary of Albuquerque, Loayza, and Servén (2003) and Calderón, Loayza, and Servén (2003).

31 . Using instead a measure of total factor productivity growth leads to analogous results.

32. Note that these institutional variables enter in both the return and risk indexes. The reason is that weak institutions affect both transaction costs (and hence anticipated returns) and the predictability of returns (and hence perceived risk). See Calderón, Loayza, and Servén (2003) for further discussion and the exact description of the variables involved as well as their weighting in the construction of the synthetic indexes.

33. The underlying global variables are world GDP growth, the U.S. real interest rate, the term premium on 10-year U.S. Treasury bonds, the U.S. credit spread, and the U.S. stock market return. The use of principal components is convenient because these variables are strongly mutually correlated. The first two components account for more than 60 percent of the overall variance of the underlying variables.

34. They key role of openness for Mexico's FDI performance was already identified in chapter 5 .

\section{References}

The word "processed" describes informally produced works that may not be commonly available through libraries.

Agarwal, Jamuna P. 1996. Impact of "Europe Agreements" on FDI in Developing Countries. International Journal of Social Economics 23 (10/11): 150-63. 
Albuquerque, Rui, Norman Loayza, and Luis Servén. 2003. World Market Integration Through the Lens of Foreign Direct Investors. Policy Research Working Paper 3060, World Bank, Washington, DC.

Aristotelous, Kyriacos, and Stilianos Fountas. 1996. An Empirical Analysis of Inward Foreign Direct Investment Flows in the EU with Emphasis on the Market Enlargement Hypothesis. Journal of Common Market Studies 34 (4): 571-83.

Baldwin, Richard E., Rikard Forslid, and Jan Haaland. 1995. Investment Creation and Investment Diversion: Simulation Analysis of the Single Market Programme. Working Paper 5364, National Bureau of Economic Research, Cambridge, MA.

Blomström, Magnus, and Ari Kokko. 1997. Regional Integration and Foreign Direct Investment. Working Paper 6019, National Bureau of Economic Research, Cambridge, MA.

2003. The Economics of Foreign Direct Investment Incentives. Working Paper 9489, National Bureau of Economic Research, Cambridge, MA.

Borbón-Guevara, J. 1999. Estudio Comparativo de los Principales Incentives Ofrecidos por los Países del Area Centraomericana dirigidos a la Atraccion de la Inversion Extranjera Directa. Master's thesis, University of Costa Rica, San Jose' de Costa Rica.

Brenton, Paul, Francesca DiMauro, and Matthias Luecke. 1999. Economic Integration and FDI: An Empirical Analysis of Foreign Direct Investment in the EU and in Central and Eastern Europe. Empirica 26: 95-121.

Buch, Claudia M., Robert M. Kokta, and Daniel Piazolo. 2001. Does the East Get What Should Otherwise Flow to the South: FDI Diversion in Europe. Working Paper 1061, Kiel Institute for World Economics, Kiel, Germany.

Calderón, Cesar, Norman Loayza, and Luis Servén. 2003. Do Capital Flows Respond to Risk and Return? Policy Research Working Paper 3059, World Bank, Washington, DC.

CINDE-PROCOMER (Coalición Costarricense de Iniciativas para el DesarrolloPromotora del Comercio Exterior de Costa Rica). 2001a. Inversión Extranjera en Alta Tecnología y Acceso a Mercado. San José de Costa Rica, Costa Rica.

2001b. Sector Textil Exportador en Costa Rica: Retos y Oportunidades ante la ampliación de los beneficios de la Iniciativa para la Cuenca del Caribe. San José de Costa Rica, Costa Rica.

- 2001c. Benchmarking de Incentivos a la Inversion Extranjera Directa. San José de Costa Rica, Costa Rica.

- 2001d. Inversión Extranjera Directa y Desarrollo. Análisis sobre las Estadísticas Actuales. San José de Costa Rica, Costa Rica.

Choi, I. 1995. Export-oriented Foreign Direct Investment in East Asia and Latin America: Determinants of Location. PhD diss., Department of Economics, University of South Carolina. Processed.

ECLAC (Economic Commission for Latin America and the Caribbean). 2000. Foreign Investment in Latin America and the Caribbean. 1999 Report. Santiago de Chile, Chile.

Elkholm, Karolina, Rikard Forslid, and James Markusen. 2003. Export-platform Foreign Direct Investment. Working Paper 9517, National Bureau of Economic Research, Cambridge, MA.

Esquivel, Gerardo, Mauricio Jenkins, and Felipe Larraín B. 1998. Export Processing Zones in Central America. Working Paper 646, Harvard Institute for International Development, Cambridge, MA. 
Greene, W. 1991. The Restricted Least-squares Estimator: A Pedagogical Note. Review of Economics and Statistics 73: 563-67.

Hanson, G., R. Mataloni, and M. Slaughter. 2001. Expansion Strategies of U.S. Multinational Firms. Brookings Trade Forum, 245-94.

Kindleberger, Charles. 1966. European Integration and the Industrial Corporation. Columbia Journal of World Business 1: 65-73.

Kumar, Nagesh. 1994. Determinants of Export Orientation of Foreign Production by U.S. Multinationals: An Inter-Country Analysis. Journal of International Business Studies 25 (1): 141-56.

Larraín B, F., L. Lopez-Calva, and A. Rodríguez-Clare. 2000. Intel: A Case Study of Foreign Direct Investment in Central America. Center for International Development, Harvard University, Cambridge, MA. Processed.

Leamer, Eduard, Alfonso Guerra, Martin Kaufman, and Boris Segura. 1995. How Does the North America Free Trade Agreement Affect Central America? Policy Research Working Paper 1464, World Bank, Washington, DC.

Levy-Yeyati, Eduardo, Ernesto Stein, and Christian Daude. 2002. Regional Integration and the Location of FDI. Inter American Development Bank, Washington, DC. Processed.

Martin, Carmela, and Jordi Gual. 1994. Trade and Foreign Direct Investment with Central and Eastern Europe: Its Impact on Spain Discussion Paper 1006, Centre for Economic Policy Research, London.

Monge-Naranjo, Alexander. 2002. Human Capital, Organizations and Foreign Direct Investment. Northwestern University, Chicago. Processed.

Morisset, J., and N. Pirnia. 2002. How Tax Policy and Incentives Affect Foreign Direct Investment. World Bank, Washington, DC. Processed.

Oxelheim, Lars. 1994. The Global Race for Foreign Direct Investment. Berlin: Springer-Verlag.

Robles-Cordero, Edgar, and Andrés Rodríguez-Clare. 2003. Inversión nacional y extranjera en Centroamérica. Cómo fomentarla en el marco de la OMC? Academy of Central America. Processed.

Scaperlanda, A. 1967. The EEC and U.S. Foreign Investment: Some Empirical Evidence. Economic Journal 77: 22-26.

Shatz, Howard, and Anthony Venables. 2001. The Geography of International Investment. World Bank, Washington, DC.

Spar, Debra. 1998. Attracting High Technology Investment: Intel's Costa Rican Plant. Foreign Investment Advisory Service Occasional Paper 11, World Bank, Washington, DC.

Stein, Ernesto, and Christian Daude. 2001. Institutions, Integration and the Location of Foreign Direct Investment. Inter-American Development Bank, Washington, DC. Processed.

UNCTAD. Various numbers. World International Report. Geneva.

Venables, Anthony, and L. Alan Winters. 2002. Economic Integration in the Americas: European Perspectives. University of Sussex, UK.

Woodward, Douglas, and Robert Rolfe. 1993. The Location of Export-oriented Foreign Direct Investment in the Caribbean Basin. Journal of International Business Studies 24 (1): 121-44. 



\section{Index}

A

AD/CVD. See antidumping and countervailing duties

ADRs (American Depositary Receipts), 198

Agrarian Capitalization Law (Ley de Capitalizacón del Campo), 140

Agricultural Marketing Board (ASERCA), 138, 139-40

agriculture in Mexico consequences from NAFTA, 13-14

experiences with delinking income subsidies, 150-51

market access granted by Mexico, 141-42

market access granted by U.S., 142-43

overall impact of NAFTA, 137

policy reforms without NAFTA, 137-40

resilience of, 146-49

trade and production outcomes, 143-46

transformation toward nontraditional crops, 149 , 151-52

Alliance for the Countryside, 139-40

American Depositary Receipts (ADRs), 198
Andean Groups. See also non-

NAFTA countries headings, 293

Andean Trade Promotion and Drug Eradication Act (ATPDEA), 12

antidumping and countervailing duties (AD/CVD), 2, 14-15

appeal mechanisms, 160-61

expiration rules, 159-60

historical description of relevant institutions, 156-57

impact of NAFTA's Chapter 19, 154-56

Mexican activity after NAFTA, 161-66

policy implications, 166-68

responsibilities of UPCI, 157-58

role of individual countries' laws, 152-54

size of the duties levied, 159

special procedures, 160

apparel exports

consequences from NAFTA, 15-16

economic challenge posed by rules of origin, 121 (See also rules of origin under NAFTA)

FDI diversion analysis, nonNAFTA countries, 377

rules of origin under NAFTA, 12-13, 121, 131-32 
apparel exports (continued)

textile-apparel ROOs affect on different countries, 132, 133-35t, 136

trade diversion at sector level, non-NAFTA countries, 322-25

Argentina. See also non-NAFTA countries headings, 17

ASEAN. See non-NAFTA countries headings, 293

ASERCA (Agricultural Marketing Board), 138, 139-40

ATPDEA (Andean Trade

Promotion and Drug Eradication Act), 12

B

bankruptcy law in Mexico, 205-6

BANRURAL, 140

Bolivia. See non-NAFTA countries headings

Brazil. See also non-NAFTA countries headings, 17

C

CACM (Central American

Common Market). See non-

NAFTA countries headings, 293

CAFTA (Central America-United

States Free Trade

Agreement), 131-32, 232

Cairns Group, 17

Canada. See economic convergence among NAFTA members

Canada-U.S. Free Trade Agreement (CUSFTA), 152, 153

CAP (Europe's Common Agricultural Policy), 17

capital. See factor markets; foreign direct investment

Caribbean Basin

Initiative/Caribbean Basin

Economic Recovery Act

(CBI/CBERA), 12, 131, 132, 322-25
Caribbean Basin

Initiative/Caribbean

Community and Common

Market (CARICOM). See

also non-NAFTA countries

headings, 293

Center for Research and Advanced

Studies (CINVESTAV),

273-74

Center of Research and Technical

Assistance (CIATEQ), 273

Central America

monetary unification, 9-10

trade patterns and FDI incentives

actual change compared to predicted framework, 389, $390 t, 391$

changes in differential risk and return, 388-89

divergence in specialization, 377

INTEL in Costa Rica, 378-80

relative return to FDI, 382-83

role of relative return and risk, $383,384-87 \mathrm{t}, 388$

taxation of profits, 380-82

Central American Common Market (CACM). See non-NAFTA countries headings, 293

Central America-United States Free Trade Agreement (CAFTA), 131-32, 232

Chapter 19 in NAFTA, 154-56

Chile. See non-NAFTA countries headings

CIATEQ (Center of Research and Technical Assistance), 273

CINVESTAV (Center for Research and Advanced Studies), 273-74

Coalición Costarricense de Iniciativas para el Desarrollo (CINDE), 378-80

Colombia. See also non-NAFTA countries headings, 136 
Compania Nacional de Subsistencia Populares (CONASPUO), 137-38, 140, 142

corporate law in Mexico, 205

Costa Rica. See also non-NAFTA countries headings, 378-80

countervailing duties. See antidumping and countervailing duties

CUSFTA (Canada-U.S. Free Trade Agreement), 152, 153

\section{D}

damage assessment criteria, 158-59

Doha trade round, 17

Dominican Republic. See nonNAFTA countries headings dumping. See also antidumping and countervailing duties, 158

\section{E}

economic convergence among

NAFTA members

data graphs and tables, 62-71t

expectations for, 28-29

geography and divergence, 30

income gaps related to institutional gaps, 44-46t

Mexico relative to other countries, 48-49

Mexico relative to U.S., 47-48

overview, 41-42

study data and methodology, 42-43

study results, 44, 47-48

initial GDP conditions and divergence

data and methodologies, 54-55

explanatory variables, 57

study results, 55-59

productivity gap measurements

data and estimates of TFP, 50-51

estimation strategy, 51-52

study results, 52-53

study methodology, 30-32 study summary and conclusions, 59-61

technology and income divergence, 29-30

time-series evidence of impact analysis of Mexico's performance, 39-41

cointegration analysis, 37-39

model results, 35-37, 39

structural time-series modeling, 32-37

Ecuador. See non-NAFTA countries headings

education level and economic success, 57

EFTA. See non-NAFTA countries headings, 293

El Salvador. See non-NAFTA countries headings, 132

\section{European Union}

assessment of FDI diversion from NAFTA, 357-59

FDI lessons learned, 177, 178-79

macroeconomic synchronization among members, 83-84

trade creation and diversion, 291

trade flow trends before and after NAFTA, 293 (See nonNAFTA countries' trade flows)

Europe's Common Agricultural Policy (CAP), 17

export processing zones (EPZs), 15, 325-26, 327f

F

factor markets

aggregate external financing trends

global, 182-83, 184-86t, 187-88

local factors, 188

relation to NAFTA, 188

capital vs. labor, 175-76

FDI impacted by NAFTA, econometric analysis 
factor markets (continued)

elements of perceived riskiness, 189

model applied to Mexico, 193-96

results, 191-92

role of global factors, 192-93

role of local factors, 193

time pattern of flows, 195-96

variables used, 190-91

financial integration due to

NAFTA

changes in Mexico's pattern of external financing, 179,

181-82

expectations of modifications in financing, 176-77

factors tempering the impact of NAFTA, 177, 179, 180-81

lessons learned from EU, 177, 178-79

institutional reforms required for development, 199-202

labor markets evolution (See labor markets evolution in Mexico)

private sector financing after NAFTA, 196-99

FDI. See foreign direct investment

Fideicomiso Institudo en Relación con la Agricultura (FIRA), 140

Finland, 258, 259, 260, 270

FIRA (Fideicomiso Institudo en Relación con la Agricultura), 140

foreign direct investment (FDI)

aggregate external financing trends

global, 182-83, 184-86t, 187-88

local factors, 188

relation to NAFTA, 188

capital markets in Mexico (See factor markets) degree of benefits from an FTA, $18-20$

direct trade/FDI effects on labor markets, 214-16

impact of NAFTA on nonmember countries (See non-NAFTA countries' FDI)

impact on innovation in Mexico, 253-56

skill premium due to FDI and outsourcing, 219

Foreign Direct Investment Laws (1973, 1993), 179, 180-81

Foreign Trade Law (LCE), 157

Free Trade Area of the Americas

$$
\text { (FTAA), 1, 8-10 }
$$

G

General Agreement on Tariffs and Trade (GATT), 10

Greece, 177

Guatemala. See non-NAFTA countries headings

Gulf Cooperation Council (GCC). See non-NAFTA countries headings, 293

$\mathrm{H}$

Honduras. See non-NAFTA countries headings

I

informal workers, 226-28

innovation in Mexico impact of trade and FDI, 253-56 lessons from NAFTA, 23-25

national innovation system concept of, 262-63, 264-66t, 267

financing, 270, 271t

firm-firm linkages, 271-72

intellectual property rights, 279

public management of sectors, 274-75

public research centers, 272-74 
supporting capital and labor markets, 278-79

universities and, 275-78

national learning capacity

amount spent on R\&D, 260, 261

barriers to innovation, 260-62

concept of a national innovation system, 262-63, 264-66t, 267

human capital's role, 257

importance to technology adoption, 256-57

lack of structural change, 268-70

patenting efficiency, 267, $268 \mathrm{f}$

quantification of innovation effort, 257-59, 260t

progress since 1960s

average annual growth rates of

TFP, 248-50

number of patents granted, 250-52

number of scientific publications, 253

stages of technology adoption, 250

institutional reforms, 7

INTEL in Costa Rica, 378-80

intellectual property rights, 279

International Country Risk Guide

(ICRG), 48

International Labour Organization, 232

International Trade Practices Unit (UPCI), 157-58

Ireland, 83-84

Israel, 258

$\mathrm{J}$

Jamaica. See non-NAFTA countries headings

L

labor

degree of benefits from an FTA, 20-23 markets evolution in Mexico (See labor markets evolution in Mexico)

worker protections, 231-33

labor markets evolution in Mexico convergence of wages, 207-9 direct trade/FDI effects, 214-16 estimating wage synchronization and convergence effects, 209-14

exports processing work, 223-24 factors complicating an analysis, 202, 206-7

geographic effects, 214-16

increased labor market risk question, 228

labor market institutions, 220-22

labor productivity enhancement challenges, 230-31

labor productivity rise challenges, 228-30

legal reforms, 204-6

migration effects, 214-16, 219-20

reform through market-based mechanisms, 203-4

rural employment, 224-26

skill premium, 216-17

skill premium due to FDI and outsourcing, 219

skill-based technical change, 217-19

unemployment and informal workers, 226-28

wage dispersion, 216-17

worker protections, 231-33

Latin America and Caribbean countries. See also nonNAFTA countries headings

export trends before and after NAFTA, 300-303

implications of NAFTA on future trade negotiations, 16-17

Mexican economic convergence under NAFTA, 39-41

policy coordination role of NAFTA applied to, 107-10 


\section{Latin America and Caribbean countries (continued) \\ policy implications of $\mathrm{AD} / \mathrm{CVD}$ activity under NAFTA, 166-68 \\ legal reforms in Mexican labor markets, 204-6 \\ Ley de Capitalizacón del Campo (Agrarian Capitalization Law), 140 \\ Ley de Comercio Exterior (LCE), 157}

literacy rates, 57

M

macroeconomic dynamics after NAFTA

financial integration linked to synchronization, 81-82, 84-85

output synchronization economic sector level, 95-96 industrial sector level, 96-98 regional level, 93-95

policy coordination applied to Latin America and the Caribbean, 107-10 applied to Mexico, 105-6 correlation between fiscal and monetary indicators, 102-3

expectations of enhanced stability, 101

indications of increased synchronization, 103 political considerations, 104 reasons to increase policy coordination, 103-4 post-NAFTA fluctuations in cycles, 8

summary and conclusions, 110-11

synchronization analysis

GDP growth/aggregate output, 87-93

importance of synchronization, 77-78 methodological approach, 85-87

trade integration achieved, 77 , $78 \mathrm{f}$

trade integration linked to synchronization

international evidence of an impact, 82-85

theory of impact, $80-82$ volatility

GDP analysis, 98-99

NAFTA's impact on, 100-101

need to reduce, 79

sources of, 99-100

MERCOSUR. See non-NAFTA

Mexico countries headings, 293

AD/CVD system (See antidumping and countervailing duties) agricultural impact of NAFTA (See agriculture in Mexico) capital and labor markets (See factor markets)

economic convergence study (See economic convergence among NAFTA members) economic performance since 1980, 4-6

export trends before and after NAFTA, 297, 300, 301f institutional gap's impact on GDP, 6-7

labor markets evolution (See labor markets evolution in Mexico)

NAFTA's effect on development, 2

post-NAFTA macroeconomic dynamics (See macroeconomic dynamics after NAFTA)

trade integration effects, 10-12

monetary unification, $8-10$, 103-4 
$\mathrm{N}$

$$
\begin{aligned}
& \text { NAALC (North American } \\
& \text { Agreement on Labor } \\
& \text { Cooperation), } 232
\end{aligned}
$$

\section{NAFTA}

analytical challenge of identifying the impact, 4-6

content of, 3-4

effect on development, 2

factor markets lessons

for capital and FDI, 18-20

for labor, 20-23

rigidity of Latin American

labor legislation, 22-23

impact on nonmember countries

(See non-NAFTA countries

headings)

innovation lessons, 23-25

remaining trade barriers (See trade barriers)

shortfalls in economic convergence, 6-7

synchronization of

macroeconomic cycles, 8-10

trade integration effects

on agriculture, 13-14

on antidumping and countervailing duties, 2 , 14-15

difficulties in isolating, 10-12

implications for other countries, 16-17

rules of origin for preferences, 12-13

trade diversion, 15-16

national innovation system (NIS).

See innovation in Mexico

non-NAFTA countries' FDI

assessment of FDI diversion from NAFTA

changes over time, 367-69

correlation matrix of country/year effects, 373-76

estimated fixed effects for source countries, 364 , 365-66t, 367

EU studies, 356-59 privatization-related inflows, 369-73

separation of common and country-specific trends, 361-64

conclusions, 391-93

horizontal vs. vertical, 347-49

trade patterns and FDI incentives, Central America

actual change compared to predicted framework, 389, 390t, 391

changes in countries' differential risk and return, 388-89

divergence in specialization, 377

INTEL in Costa Rica, 378-80 relative return to FDI, 382-83 role of relative return and risk, $383,384-87 \mathrm{t}, 388$

taxation of profits differences, 380-82

trends before and after NAFTA individual country performances, 351, 352-55t, 356

performance relative to Mexico, 350-51

non-NAFTA countries' trade flows analysis overview, 290-93

conclusions, 331-33

existing trade agreements, 334-38t

NAFTA's impact on aggregate trade flows

disaggregated analyses, 309 gravity model methodology, 309-12

gravity model results, 312-16, 317-20t, 321

recent empirical studies, 307-9

summary and conclusions, 321

results and implications of policies, 327-31

trade diversion at sector level 
non-NAFTA countries' trade flows (continued)

apparel exports, 322-25

export processing zones role, $325-26,327 f$

summary and conclusions, 327 trade diversion causes, 289-90

trends before and after NAFTA

evolution in share of U.S. imports, 303-4, 305-6t intra-bloc trade, 296-97, 298-99t

in Latin American exports, 300-303

in Mexico's exports, 297, 300, $301 \mathrm{f}$

NAFTA members' imports, 294-95

total trade evolution, 295-96

world openness to trade, 293-94

trends in tariff rates, 339-40t

North American Agreement on Labor Cooperation (NAALC), 232

$\mathrm{O}$

optimal currency areas (OCA), 78 Organisation for Economic

Co-operation and

Development (OECD), 17

P

Paraguay. See non-NAFTA countries headings

patents and innovation progress, 250-52

Peru. See non-NAFTA countries headings

Portugal, 83-84, 177, 357-59

PROCAMPO (Programa para el Campo), 14, 138-39, 149

public research centers (PRCs), 272-74

Puerto Rico, 42
$\mathbf{R}$

Republic of Korea, 258, 259, 260

República Bolivariana de Venezuela. See non-NAFTA countries headings

research and development (R\&D) spending. See also innovation in Mexico, 23-25

rules of origin (ROOs) under NAFTA, 12-13

analytical framework, 121-24

economic challenge posed by, 121

factors affecting apparel sector, 131-32

policy implications for Mexico, 136

preferences and utilization rates, conclusions, 131

preferences and utilization rates, empirical analysis, 124-28

preferences and utilization rates, results, 125, 127, 128, 129-30

textile and apparel trade features, 121,131

textile-apparel ROOs affect on different countries, 132, 133-35t, 136

rural employment, 224-26

$S$

Scandinavian countries, 230, 231, 270

securities regulation in Mexico, 204-6

SEMATCH, 271

softwood lumber case in Canada, 167

South America, 109-10

Spain, 83-84, 177, 357-59

$\mathrm{T}$

tariff rate quotas (TRQs), 141

telephone density, 57 
Tequila crisis, 1, 20, 27, 37, 39, 59, 99, 181, 206

textiles. See apparel exports

total factor productivity (TFP). See also innovation in Mexico, $50,247,248$

trade barriers

agriculture and NAFTA

experiences with delinking agricultural income subsidies, 150-51

market access granted by Mexico, 141-42

market access granted by U.S., 142-43

overall impact of NAFTA, 137

policy reforms in Mexico without NAFTA, 137-40

resilience of Mexican agriculture, 146-49

trade and production outcomes, 143-46

transformation toward nontraditional crops, 149 , 151-52

antidumping and countervailing duties

impact of NAFTA's Chapter 19, 154-56

Mexican activity after NAFTA, 161-66

Mexico's system before and after NAFTA (See Mexico, $\mathrm{AD} / \mathrm{CVD}$ system)

policy implications, 166-68

role of individual countries' laws, 152-54

overview, 119-21

rules of origin under NAFTA

analytical framework, 121-24 economic challenge posed by, 121

factors affecting apparel sector, 131-32

policy implications for Mexico, 136

preferences and utilization rates, conclusions, 131

preferences and utilization rates, empirical analysis, 124-28

preferences and utilization rates, results, $125,127,128$, 129-30

textile and apparel trade features, 121, 131

textile-apparel ROOs affect on different countries, 132, 133-35t, 136

trade in non-NAFTA countries. See non-NAFTA countries' trade flows

trade integration effects. See macroeconomic dynamics after NAFTA

TRQs (tariff rate quotas), 141

$\mathrm{U}$

Unidad de Practicas Comerciales

Internacionales (UPCI), 157-58

unions in Mexico, 220-21

universities and innovation in

Mexico, 275-78

Uruguay Round, 120, 136

W

worker protections in Mexico. See also labor markets evolution in Mexico, 231-33

WTO, 152, 153 




\section{LATIN AMERICAN DEVELOPMENT FORUM}

A

nalyzing the experience of Mexico under the North American Free Trade Agreement (NAFTA), the authors draw lessons for other countries considering free trade agreements with the United States. This book will be of interest to scholars and policymakers interested in international trade and development.

“The best quantitative evaluation of NAFTA - where it paid off, where it didn't, and where we don't know. Indispensable for every Latin American and Caribbean country considering a free trade pact with the United States."

— Gary Clyde Hufbauer, Reginald Jones Senior Fellow, Institute for International Economics

"Lessons from NAFTA is a well-articulated and insightful book that covers many of the relevant areas related to the Agreement. In a hemisphere with plenty of trade negotiations among Latin American countries and the United States, this report written by leading trade and development researchers will be a crucial reference to analyze the impact of these agreements. As the authors mention, to grasp the new opportunities requires countries to be aware that "improving macroeconomic performance and institutions and putting in place an education and innovation system" are areas that cannot be solved through FTAs. The onus remains on domestic policy."

- Jose Luis Machinea, Executive Secretary of the United Nations' Economic Commission for Latin America and the Caribbean, former Finance Minister of Argentina

"NAFTA has turned 10 years old, and the debate on its consequences is still raging. Proponents see free trade agreements as the ultimate development panacea; opponents claim these agreements make the world poorer and more unequal. The truth, as usual, is somewhere in-between. In this careful and thoughtful book, long on analysis and short on diatribe, Lederman, Maloney, and Servén show that NAFTA has helped Mexico get closer to the income levels of its richer neighbors. They also argue that a Free Trade Area of the Americas should go further than NAFTA, eliminating distortive rules of origin and antidumping and countervailing duties. These are key lessons-and not just for trade negotiators and policy wonks concerned with Latin America."

- Andrés Velasco, Sumitomo Professor of International Development, John F. Kennedy School of Government, Harvard University

"At last there is a rigorous study evaluating NAFTA in terms of its objectives, putting rhetoric aside."

— Jaime Serra, former Secretary of Commerce and Industry of Mexico 